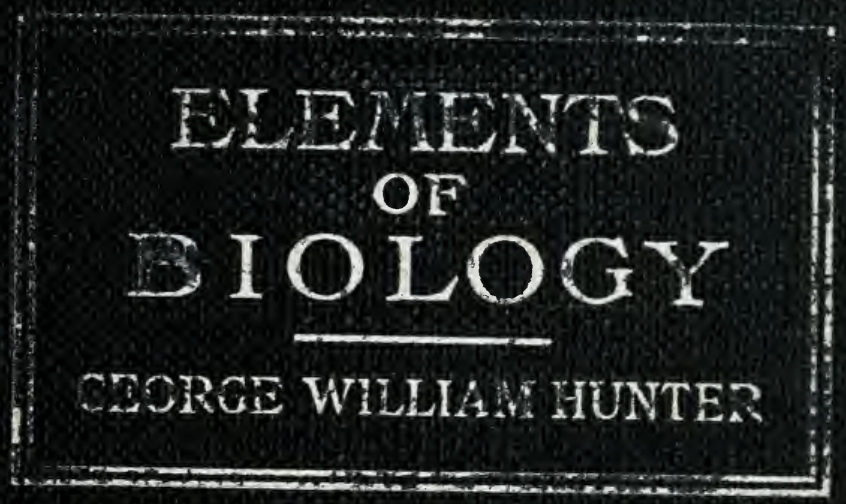




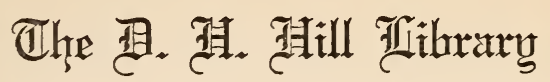

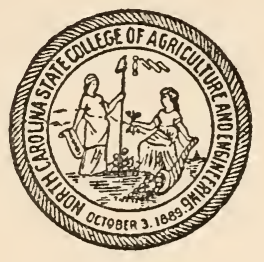

Ziorth Taralina State Uallege

$$
\text { QH308 }
$$
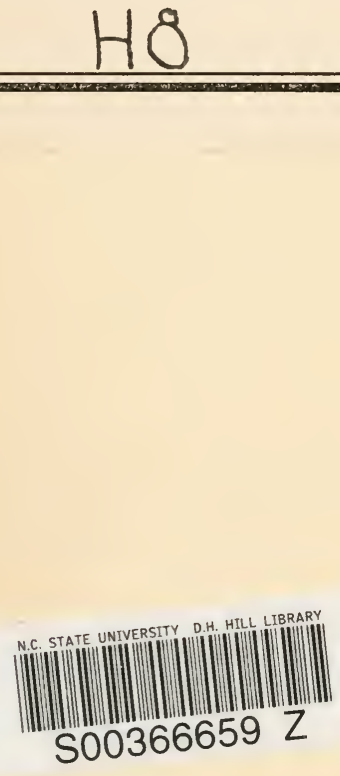
This book is due on the date indicated below and is subject to an overdue fine as posted at the circulation desk.

EXCEPTION: Date due will be earlier if this item is RECALLED. 
$\beta$ 





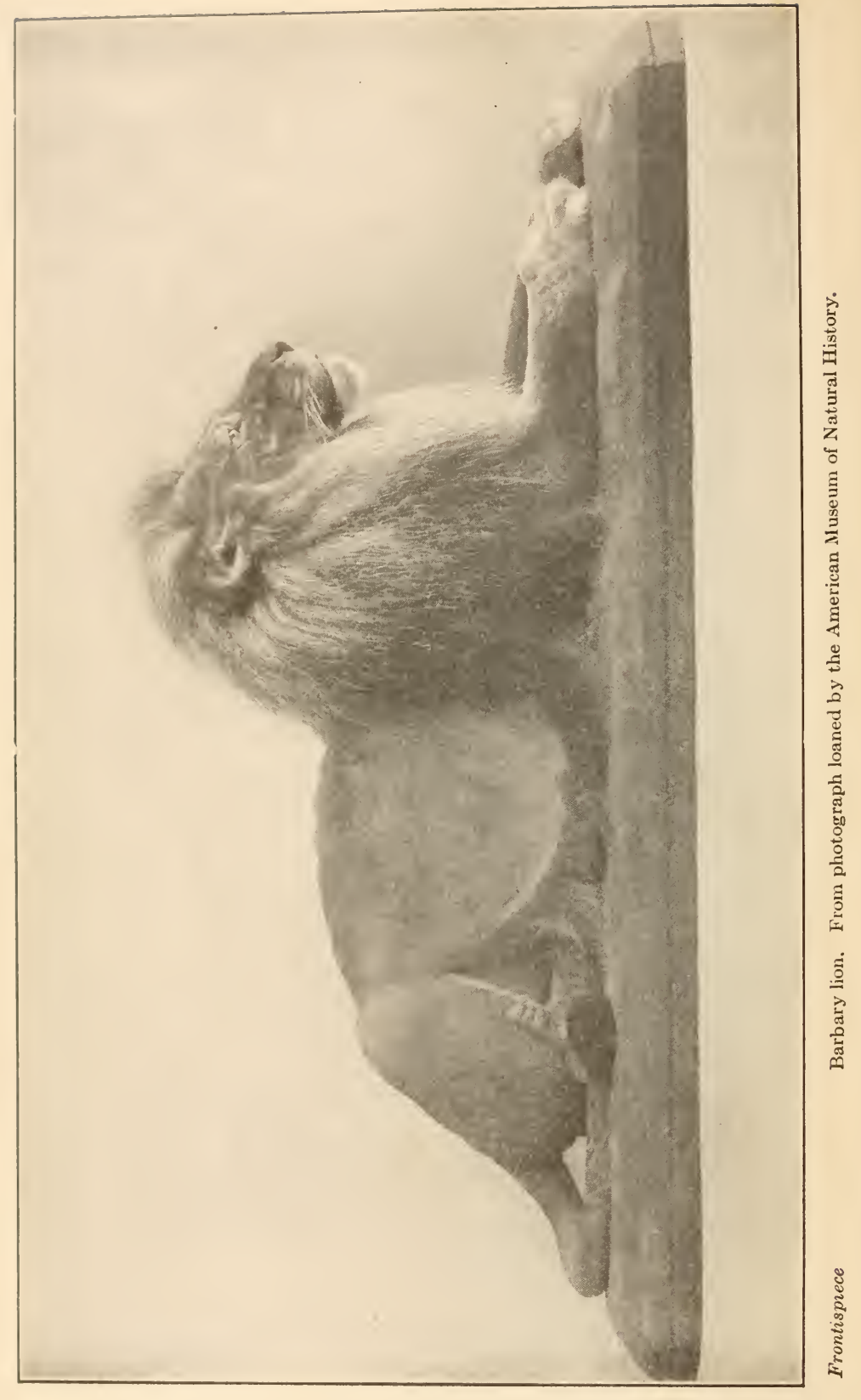




\section{ELENENTS OF BIOLOGY}

A PRACTICAL TEXT-BOOK CORRELATING BOTANY, ZOÖLOGY, AND HUMAN PHYSIOLOGY

BY

GEORGE WILLIAM HUNTER, A.M.

Head of the Department of Blology, De Witt Clintox High School, New YORK

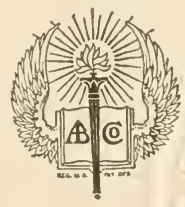

NEIV YORK .: CINCINNATI :: CHICAGO AMERICAN BOOK COMPANY 
Copyright, 1907, BY GEORGE WILLIAM HUNTEE.

HUNTER, BIOLOGY.

W. P. II 


\section{THE PURPOSE AND PLAN OF THIS BOOK}

THE aim of this book is to correlate the allied subjects of botany, zoölogy, and human physiology in a general course of biology for the first year of the high school. The foundation principles upon which this correlation is made are that the life processes of plants and of animals are similar, and in many respects, identical ; that the properties and activities of protoplasm are the same whether in the cell of a plant or of an animal; and that the human body is a delicate machine built out of that same mysterious living matter, protoplasm. With such a foundation correlation is not only possible, but natural.

The following pages are the results of my experience with large classes of young students in the first year of the high school. The average age of such pupils is about fourteen years. To such pupils the life activities of plants and animals have an appealing interest; simple experiments in plant physiology are performed with never failing zest. Laboratory and field work, so far as they relate to adaptations to functions, are readily comprehended.

For young students laboratory questions should be simple and few; they should apply to structures easily found, and deal with externals only. Minute directions are necessary in order to insure the successful working out of the given problem. The form of the laboratory questions must, after all, be left to the individual teacher. The paragraphs on laboratory work which follow are suggestions. For formal directions in botany and zoölogy according to the note and question method, the reader is referred to Hunter and Valentine, Laboratory Manual of Biology, Henry Holt and Company. For laboratory exercises in human anatomy and physiology, Eddy, Experi- 
mental Physiology and Anatomy, American Book Company, will be found useful.

The following chapters contain such material as has been found by most teachers of first-year biology to be sufficient for a wellrounded course in the first year of the high school. In selecting material, the syllabuses for elementary botany, zoölogy, and human physiology given by the New York State Education Department have been followed. It would not be wise to attempt all of the work outlined in this book. Work should be attempted only with such materials as are easily obtainable in a given locality. It is thought that each successive chapter, although related to that immediately preceding it, is yet distinctive enough to allow of the omission of a chapter or chapters without in any way interfering with the continuity of the work.

Two styles of type have been used. The larger type contains material which is believed to be of first importance, the smaller type the less important topics. Suggestions for laboratory exercises are set in the smaller sized type without leading.

The order of the chapters follows the order in which the topies are likely to be taken up when work is begun in the fall of the year. The introductory experiments in physics and chemistry may be omitted until the study of the seed and seedling, thus utilizing the early fall days for the work on the flower, insect pollination, and the fruit. The subject of protoplasm and the cell, necessarily somewhat vague to the pupil, must be taken up with the flower in order that the process of fertilization may be understood. The study of the root, stem, and leaf follow in order, emphasis being placed throughout on the function rather than structure. The chapter on plant ecology is so placed simply for convenience; the work may well come in connection with the physiological work already referred to.

Some portion of the work outlined on the cryptogams is not recommended to such schools as have no laboratory equipment, the use of the compound microscope being essential to such laboratory 
exercises. If work is attempted without the microscope, the mosses and ferns present the best points for attack; much work of an economic nature may also be done with the yeasts, molds, and bacteria. If the laboratory equipment permits, several days should be spent in the laboratory study of mucor and spirogyra, the latter being used to teach the concept of the cell.

In the second half year the so-called evolutionary order may be followed with the animal types studied. It is desirable, however, to take up the study of the frog in the early spring during the breeding season, thus leaving the study of insects until June, when insect life is more abundant. Human physiology may be begun with the study of the frog and continued for the rest of the term, certain lessons each week being devoted to this subject. The topics of foods, digestion, assimilation, blood making, and circulation may well be taken up in connection with the laboratory work outlined on the frog; breathing, oxidations in the body, muscular activity, and excretion come well with the treatment of the insects.

For general use every school ought to have at least one compound microscope for demonstration purposes. For low power demonstration work a portable microscope such as is manufactured by the Bausch and Lomb Optical Company is useful. A small stock of simple reagents, glassware, and other apparatus, as noted from time to time in the following pages, are also necessary parts of the school equipment. Excellent results may be obtained with little or no apparatus except that made by the pupils and teacher working together. Let no one feel that the work outlined in this book needs expensive apparatus.

Acknowledgments are due to Miss A. P. Hazen of the Wadleigh High School for many suggestions and for her careful reading of the entire manuscript. The manuscript has also been read in part by Miss M. D. Womack of the Wadleigh High School, H. G. Barber, C. F. Morse, and R. W. Sharpe of the De Witt Clinton High School, and Mr. C. W. Beebe, Curator of Birds, New York Zoölogical Park. 
Proof has been read critically by three of my former pupils, J. W. Tietz, F. T. Lacy, and J. W. Ingle. To all of the above my thanks are due.

Thanks are due, also, to Prof. E. B. Wilson, W. C. Stevens, and C. W. Beebe, Dr. Alvin Davison, Dr. Frank Overton, Mr. Spencer, of the New Tork Aquarium, the United States Department of Agriculture, and the American Museum of Natural History, for permission to copy and use certain cuts and photographs which have been found useful in teaching. Prof. G. N. Calkins of Columbia University kindly loaned the photograph of the Amœba reproduced on page 182. R. W. Coryell and J. W. Tietz made several of the photographs of experiments. The photograph of the humming bird was used by permission of the Folmer and Schwing Company, Rochester, N.Y. In particular I am under obligation to my former coworker, Dr. C. A. King, for his example of earnest and inspiring work, to Mr. W. P. Hay, Head of the Department of Biology and Chemistry, in the Washington, D.C., High Schools, for his helpful criticisms, and to Messrs. Sedgwick and Wilson, whose General Biology is a monumental work in elementary biological teaching. 


\section{CONTENTS}

\section{PART I. BOTANY}

CHAPTER

I. INTRODUCTIUN . . . . . . . . . . 11

II. Introdectoky Experiments in Chemistry and Pilysics . . 15

III. Protoplasm and the Cell o . . . . . 23

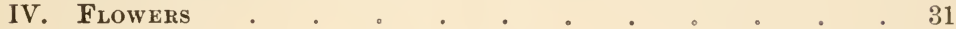

V. Fruits . . . . . . . . 50

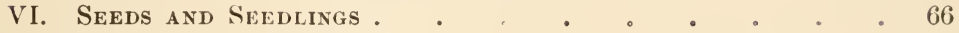

VII. Roots ANI THEIR WORK . • 。 . • . . . 82

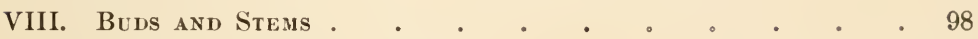

IX. Leaves and their Functions • • • 。 。 • . 123

X. EcologY . . . . . . • 。 。 。 142

XI. Flowerless Plants . • . • 。 • 。 . 150

\section{PART II. ZOÖLOGY}

XII. Protozon . . . . . . . 。 。 。 . 179

XIII. METAzOA . • . . . . . . 187

XIV. SPONGES . . . . . . . . 。 . . 191

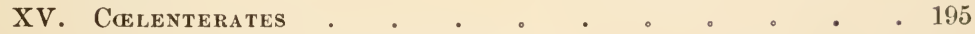

XVI. The Starfish and its Allies . • . 。 . . . 203

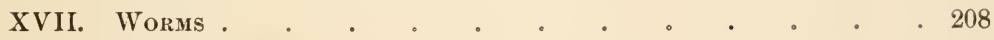

XVIII. Crustaceans . . . . . . . 。 215

XIX. Insects . . . . . . . . 。 227

XX. Splders and Mrriapods . • . 。 . 。 256

XXI. Mollusks • • . • . • . • • . . 259

XXII. Fishes . . 。 。 。 . . . 271

XXIII. Amphibians . • . . 。 。 . . 279

XXIV. REPTILES 。 . . . 。 . . . 286

XXV. Birds . . . . . . . . . 292

XXVI. Mammals . . . . . . 308 


\section{PART III. HUMAN PHYSIOLOGY}

CHAPTER

XXVII. Foods

XXVili. Digestion and Absorption

XXIX. The BLOOD

XXX. Circelation

XXXI. Muscles

XXXiI. The Skeleton .

XXXIII. Respiration • • • • • • • • . . 380

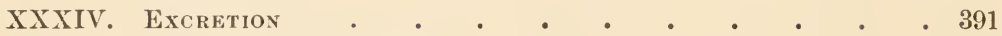

XXXV. The Nervous System . . . . . . . . 400

XXXVI. The Senses . . . . . . . . . . . 419

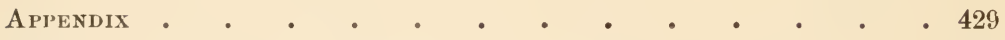

INDEX . $\quad$ • 


\section{ELEMENTS OF BIOLOGY}

\section{PAR' I. BOTANY}

\section{INTRODUCTION}

Science and Matter. - Science deals with that material which occupies all the space around us, - the air, the water, and the earth. This material is called matter. Matter is the building material of the world in which we live.

Matter exists in this world in two distinct states. It may be living, or may have been alive at some previous time, in which case we speak of it as organic matter; or it may never have been alive. The latter state of matter is called inorganic. Hence we find two groups of sciences which deal with matter: the biological sciences, which treat of living matter; and the chemical and physical sciences, which deal chiefly with inorganic matter.

Biology. - Biology is the science which treats of matter in a living state. The two subdivisions of biology, dealing with plant life and animal life respectively, are called botany and zoölogy.

Knowledge in Science gained by Observation. - Science has been defined as " knowledge gained by exact observation and correct thinking." First of all, science is a kind of knowledge. It is accurate knowledge. But it is possible to acquire a mass of knowledge not scientific with the sole aid of a text-book. Such knowledge, for example, might be that of the Latin or the German language. Scientific knowledge, according to our definition, must be gained through observation, from the accurate study of a specimen, something that we may see and touch. It is not enough to study a book alone; this may be an aid, but the specimen is, after all, the main thing. If we were to fit ourselves for the trade of a plumber or a carpenter or a mason, we certainly should not depend upon a book for our information regarding our particular 
trade. We should, instead, go to the shop and there learn to work with the tools of our trade. So, in the pursuit of scientific work, we must learn to use the tools with which nature has provided us, - our hands, our eyes, and the thinking mechanism, our brains. As Louis Agassiz, the famous naturalist said, "Study nature, not books."

Classification of Facts Observed. - The knowledge we gain by observation is worth very little to us or to any one else unless we use our brains to classify it and to apply it. We must find out what different facts mean as related to one another.

Single isolated facts about the color, coats, or markings found on the coats of a kidney bean mean but little to us if we cannot correlate these observations with others and relate them to scientific truths already learned. A great many men, working for long periods of time, have gathered together a large number of single isolated facts, have correlated these facts, and then have given to the world discoveries of world-wide importance. A careful boy or girl may, by his own painstaking work in science, find out some fact that is new, and in a small way make a discovery. It is one of the most interesting things about science work, that it has in it the spirit of discovery.

Morphology. - It is evident that, in order to understand the cause of the regular movements of a clock, it would be necessary to take the wheels apart and to find out the structure of the different pieces composing the works, so as to see how these parts are related to each other. In the study of biology it is usually found best to begin with the study of the form and structure of the parts of an organism; this study is called morphology.

Physiology. - After we have discovered in the clock the form and structure of the different wheels and cogs and the relation of one to the other, we are in a position to put them together again and to find out how they move and what causes the movement: to study the use or function of each part. The study of the uses or functions of the parts of an organism is called physiology.

The Experiment. - In order to study physiology, and indeed most sciences, we frequently have to make use of an experiment. There are always three steps in a complete experiment. Beginners 
in scientific study should always try to follow these steps exactly. First comes actually making the experiment. This includes collecting and putting together such materials as we may need, a statement of the work we perform, and most important of all, a definite statement of the problem that we are attempting to solve. The second step is to make observations on the experiment which we have set up. These observations may extend over a period of several days or even weeks. They must be noted in such form that we can use them in the third step of the experiment. This step, the hardest of all, consists in drawing conclusions from the observations we have previously made. Every experiment should be illustrated with drawings to show all the apparatus used at each stage of the process.

Use of Nотевоок. - Scientific work should be carefully and accurately performed, and the results should be recorded in some permanent form. For this purpose a notebook is used, in which the student makes a complete record, not only of experiments but also of all other work performed in the schoolroom, outdoors or at home. The notebook best adapted to this purpose is one in which the leaves may be added from time to time. For work done outdoors, field trips and the like, it is better to have a separate notebook. This may be used as a working book, in which observations are jotted down in a brief form and later copied in ink in the laboratory notebook. It is of advantage to have all your notes under one cover.

Drawing. - Drawing constitutes a very important part of your laboratory work. In scientific drawing, every line made should mean something; the lines should be firm and bold; sketchy work should not be allowed. A hard $(\mathrm{HHHHH})$ pencil should be used. If you are expert with the drawing pen, then make your drawings in ink. Do not attempt to shade your drawing. Every part of the drawing to which you wish to call attention must be carefully labeled. Place a neat index of the parts so labeled directly underneath the drawing, near the bottom of the page. Only one side of the paper should be used in any scientific work, whether written work or drawings.

The LABORATORY. - For convenience, science work is usually performed in a room called a laboratory. This room may be fitted up with certain appliances to make the work easier. But in biology the great out of doors makes a much more useful laboratory than any schoolroom. However, observations made at home or out of doors should, when possible, be verified in the laboratory under the supervision of a teacher.

Frequently the laboratory differs little if at all from an ordinary schoolroom. It should always be well lighted and, if possible, should have north 
light as well as some direct sunlight. A corner room is best if it can be obtained. If tables are used, they should be arranged so that each student may get as much light as possible without shading his neighbor.

INSTRUMENTS USED. - Every pupil ought to provide himself, in addition to the laboratory notebook and a hard pencil, with the following articles: a hand lens (a small brass-mounted tripod lens, one mounted in vulcanite, or the small lens known as a linen tester), two or three darning needles mounted in elder pith or in wooden handles, a good eraser, and a ruler marked with the metric system. A small pair of forceps, scissors, and a light, thinbladed knife or scalpel are useful, but not essential for most laboratory work.

Interest in Laboratory Work Essential. - It is not, however, the laboratory or the equipment that makes the laboratory work a success. It is rather the spirit of the pupils. Interest in the work is the first essential. When at work on what may seem to be only dry details, look ahead and think about what you are doing. Try to find a purpose in everything that you do. It is possible to make any piece of biological work interesting by keeping in mind that everything in nature is part of a great plan and has a purpose. It is your place to find out just how the given part that you may be studying is fitted or adapted to its work in the general plan.

At the end of each of the following chapters is a list of books which have proved their use either as reference reading for students or as aids to the teacher. Most of the books mentioned are within the means of the small school. Two sets are expensive: one, The Natural History of Plants, by Kerner, translated by Oliver, published by Henry Holt and Company, in two volumes, at $\$ 11$; the other, Plant Geography upon a Physiological Basis, by Schimper, published by the Clarendon Press, \$12; but both works are invaluable for reference.

Two books stand out from the pedagogical standpoint as by far the most helpful of their kind on the market. No teacher of botany or zoölogy can afford to be without them. They are: Lloyd and Bigelow, The Teaching of Biology, Longmans, Green, and Company, and C. F. Hodge, Nature Study and Life, Ginn and Company. Other books of great value from the teacher's standpoint are: Ganong, The Teaching Botanist, The Macmillan Company; L. H. Bailey, The Nature Study Idea, Doubleday, Page, and Company; and C. B. Scott, Nature Study and the Child, D. C. Heath and Company. 


\section{INTRODUCTORY EXPERIMENTS IN CHEMISTRY AND PHYSICS}

In the introductory chapter we learned that science concerns itself with matter, and that the science of biology is concerned with the study of this matter when it is in a living state. In order to understand this definition we must first get a conception of what matter really is.

Matter. - If you take a piece of ice in your hand, you are aware that it is cold, and that it has weight and a certain form. We call it a solid. A few minutes' exposure to the warmth of your hand will change this solid into a liquid. If the water thus formed be heated over a flame until it boils, it may be changed again, this time into a gas which passes off into the air and becomes invisible. The ice has successively changed from a solid to a liquid and then to a gas. In each state we could measure it and weigh it. In each form it occupies space. It must be considered matter, whether in the form of a solid, a liquid, or a gas.

Physics and Chemistry. - The sciences which treat chiefly of the properties and forces of inorganic or dead matter, and of the relations of the parts of the substances composing it, are known as the sciences of physics and chemistry.

Chemical Element. - All the building materials of this universe, both living and lifeless, are classified by chemists as either chemical elements or chemical compounds. A chemical element is so simple in its structure that it cannot be broken or decomposed into a simpler substance. Examples of such substances are oxygen, making up about one fifth of the atmosphere; nitrogen, composing nearly all the remainder of pure air; carbon, an element: that enters into the composition of all organic living things or those that once possessed life; and over sixty others of more or less importance to us in the study of biology. 
Preparation of Oxygen. - Oxygen may be easily prepared in the schoolroom or at home in the following manner.1 Heat half a teaspoonful of

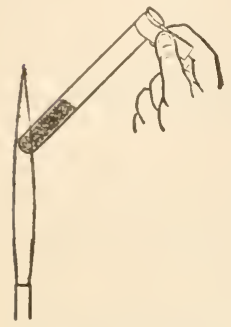

Preparing oxygen. black oxide of manganese with a little more than its bulk of chlorate of potash in a test tube over a bunsen flame or a spirit lamp. Vapors will be seen to arise as the mixture bccomes heated. After a moment insert a glowing match into the mouth of the test tube; it bursts into a bright flame. In what form does oxygen pass off from the two chemicals in the test tube? How could you determine the presence of oxygen in a substance? Is there oxygen in the air? How do you know?

Properties of Oxygen. - The physical properties of oxygen are those which we determine with our senses. Oxygen, when carefully prepared, is found to be a colorless, odorless, and tasteless gas. It is known to form nearly one half of the earth's surface, to form eight ninths of all water and over three fourths of the weight of the plants and animals inhabiting this world of ours. It has the very important chemical property of causing things placed in it to burn. If, for example, a piece of picture wire is heated red-hot, and then placed in a jar of oxygen, the metal will burn with a bright flame.

Oxidation. - Light carefully a small piece of magnesium wire and then place it in a test tube in which you have previously made oxygen. Notice the very brilliant flame. A light-colored ash remains. This is magnesium oxide. In the above experiment the oxygen in the test tube unites with the magnesium so rapidly as to form a flame. This process is known as a combustion.

The chemical union of oxygen with any other substance is called oxidation. Can you distinguish between combustion and oxidation? Oxidation takes place wherever oxygen is present. These facts, as we shall see later, have a far-reaching significance in the understanding of some of the most important problems of biology.

Oxidation in a Match. - The simple process of striking a sulphur match gives us another illustration of this process of oxidation. The head of the match is formed of a composition of phosphorus, sulphur, and some other materials. Phosphorus is a chemical element distinguished by its extreme inflammability. It unites with oxygen at a comparatively low temperature. Sulphur is another chemical element that combines somewhat easily with oxygen but at a much higher temperature. The rest of the match head is made up of red lead, niter or some other substance that will release oxygen, and some glue or gum to bind the materials together. The heat

1 For a concise statement of this and following experiments in the scientific form expected from the pupil, see Hunter and Valentine, Laboratory Manual of Biology, Henry Holt and Company, pages $213 \mathrm{ff}$. 
caused by the friction of the match head against the striking surface is enough to cause the phosphorus to ignite; this in turn ignites the sulphur and finally the wood of the match, composed largely of the element carbon, is lighted and oxidized. If we could take out the different chemical elements of which the match is formed and oxidize them separately we should find that the amount of heat needed to start the oxidation of the substances would vary greatly. The element phosphorus, for example, is kept under water in a glass jar because of the extreme readiness with which it unites with oxygen.

Experiment. - Oxidation may take place with very little heat present, although heat is always a result of oxidation.

Place an iron nail in a bottle of water, and cork and seal the bottle. Place another nail in a saucer in which is kept a little water. Note the formation of rust on the nail in the saucer and the absence of rust on the nail in the bottle. Rust is iron oxide and is formed by the union of iron and oxygen. This kind of oxidation is said to be a slow oxidation. Slow oxidations are constantly taking place in nature and result in the process of decay and breaking down of complex materials into simpler materials.

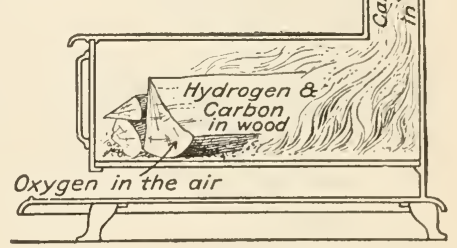

Diagram of combustion or rapid oxidation in a stove.

Heat given off as result of Oxidaticn. - One of the most important effects of oxidation lies in the fact that, when anything is oxidized, heat is produced. This heat may be of the greatest use. Coal, when oxidized, gives off heat; this heat boils the water in the tubes of a boiler; steam is generated, wheels of an engine turn, and work is performed. The energy released by the burning of coal may be transformed into any kind of work power. Energy is the ability to perform work.

Carbon. - Another chemical element of much importance to us is carbon. This element makes up an important part of all things that now have or at any time had life. Such matter we call organic. Carbon is found making up part of the bodies of plants and animals, of coal, and in a nearly pure state in the diamond. The presence of carbon can often be detected by the fact that the substance containing it turns black upon being heated in a flame.

Experiment. - Heat separately on a tin plate some leaves, sticks of wood, gravel, sand, and rich black earth. Place them over a hot flame for some minutes Which of the above materials contains carbon?

If some substance that contains carbon, as a piece of wood, is burned in a jar with a tight-fitting cover, the flame will be seen to go out after a short HUNTER'S BIOL. -2 
time. This will occur before all the wood is consumed. Another splinter of wood, placed in a jar with the cover off, will burn slowly but completely. A third piece of wood burned in the air will be quickly and completely consumed. If now a little limewater ${ }^{1}$ is poured into the jar which was closed, and the contents shaken up, the limewater will be found to turn a milky color. This milky appearance is due to the formation within the jar

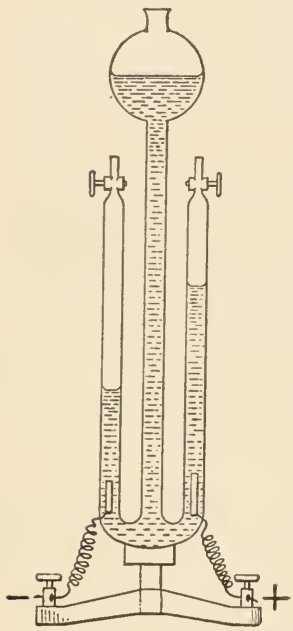

Apparatus for separating water into the two elements hydrogen and oxygen. of a material known as calcium carbonate. This is thrown down in the liquid as a result of the union of carbon with lime. Evidently some of the carbon from the wood has passed in the form of a gas into the limewater and there united with the calcium in the lime. Remembering what we know about oxidation, we see that the carbon of the wood has passed off and united with oxygen of the air in the jar. Thus, by the uniting of the two chemical elements, a chemical compound has been formed. The presence of carbon dioxide is known by the fact that it puts out a flame and that it turns limewater milky. This compound is known to chemists as carbon dioxide. ${ }^{2}$

Nitrogen. - There is another gaseous substance that will not support combustion; this is the element nitrogen. Its presence in the atmosphere is shown by the following experiment:-

Invert a bell jar in a large, deep dish of water, having previously placed within the jar on the surface of the water a piece of phosphorus supported on a flat bit of wood or cork. Leave the experiment for at least two days undisturbed (or, the phosphorus may be lighted and then the jar left for a few hours untouched). After that time the water will be found to have risen considerably in the jar. ${ }^{3}$ If you make a mark on the cover

${ }^{1}$ Limewater can be made by shaking up a piece of quicklime the size of your fist in about two quarts of water. Filter or strain the limewater into bottles and it is ready for use.

2 Chemists have shown that any given structure is made up of molecules. A molecule is the smallest bit of matter that can exist separately and still retain its composition and properties. A molecule is composed of still smaller particles called atoms. Carbon dioxide is so called because its molecule is made up of one atom of carbon and two atoms of oxygen. It is customary to use certain letters or symbols to designate certain chemical elements, as $\mathrm{C}$ for carbon, $\mathrm{H}$ for hydrogen, $\mathrm{N}$ for nitrogen. $\mathrm{P}$ for phosphorus, $\mathrm{Fe}$ (Latin ferrum) for iron. The molecule of carbon dioxide is made of one part of carbon and two of oxygen; it is written $\mathrm{CO}_{2}$. This is called the chemical formula. If an electric current is passed through a jar of water, the contents will be broken down into the elements hydrogen and oxygen. If now the gases are carefully collected, there will be found to be exactly twice as much of the hydrogen gas as there is of the oxygen. The chemical formula for water is $\mathrm{H}_{2} \mathrm{O}$. See figure.

${ }^{3}$ It would be well for the teacher at this place to bring up, the subject of atmospheric pressure. Air presses down on the earth's surface at sea level with a weight of fifteen pounds to every square inch of surface. 
to show where the water stood, you may measure the space occupied by the water in the jar. This space will be found to be almost exactly one fifth of the cubic contents of the jar. It was occupied by the oxygen of the air, this having been used up by the oxidation of the phosphorus. The remaining space at the completion of the experiment is occupied by the nitrogen, which makes the remaining four fifths of the atmosphere.

The physical properties of nitrogen are its lack of color, taste, and odor. Its chief chemical characteristics are its inability to support combustion and its slight affinity for other substances.

Mineral Matter in Living Things. We saw in the experiment for the detection

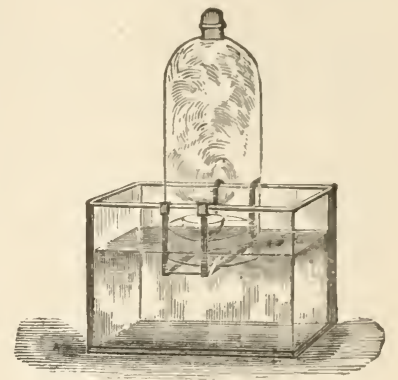

Experiment to show the amount of nitrogen present in the air.

of carbon by burning, that the sand or gravel contained no carbon. If a piece of wood is burned in a very hot fire, the carbon in it will all be consumed, and eventually nothing will be left except a grayish ash. This ash is well seen after a wood fire in the fireplace, or after a bonfire of dry leaves. This ash consists entirely of mineral matter which the plant has taken up from the soil, dissolved in water, and which has been stored in the wood or leaves.

If we were able by careful analysis to reduce a plant and an animal to the chemical compounds of which they were formed, we should discover that both contained mineral or inorganic material. We have just seen examples of this in plants. Mineral matter is found in bone, in the shells covering mollusks, and in many of the other parts of the bodies of animals.

Water in Living Things. - Water forms an important part of the substance of plants and animals. This can easily be proved by weighing a number of green leaves, placing them in a hot oven for a ferv moments, and then reweighing. How much weight of a given quantity of leaves is made up of water? Make the same experiment with some soft-bodied animal, as an oyster removed from the shell. Some jellyfish are composed of over 90 per cent water. The human body contains 60 per cent water.

Gases Present. - Some gases are found in a free state in the bodies of plants or animals. Oxygen is of course present wherever oxidation is taking place, as is carbon dioxide. Other gases may be present in minute quantities.

Classification of Organic Matter. - The organic or living part of a plant or animal is made up largely of the elements carbon, hydrogen, oxygen, and nitrogen, with a very minute amount of 
several other elements, which collectively we may call mineral matters. If we were to separate a plant or animal chemically into various organic compounds, we should find it composed of various groups of tissues, the chemical compositions of which are more or less alike. For example, the living part of a plant corresponds chemically with the living part of an animal. The starch found in grains or roots of plants has nearly the same chemical formula as the animal starch found in the liver of man; the oils of a nut or fruit are of composition closely allied to the fat in the body, or in a sheep or cow. These building materials of a plant or animal may be placed in one of the three following groups of organic substances: carbohydrates, materials containing a certain proportion of carbon, hydrogen, and oxygen; organic fats and oils, which contain chiefly hydrogen and carbon; and nitrogenous, or proteid substances, which contain nitrogen in addition to the above-mentioned elements. The above three kinds of organic materials also form the organic foods of all animals and plants.

Foods. - What is a food? We know that if we eat a certain amount of proper foods at regular times, we shall go on doing a certain amount of work, both manual and mental. We know, too, that day by day, if our general health is good, we are adding weight to our body, and that added weight comes as the result of taking food into the body. What is true of a boy or girl is equally true of plants. If food is supplied in proper quantity and proportion, they will live and grow; if the food supply is cut off, or even greatly reduced, they will suffer and may die. From this, the definition which follows is evident.

A food is a substance that forms the material for the growth or repair of the body of a plani or animal or that furnishes energy for it.

Nutrients. - Food substances may be classed into a number of groups, each of which may be detected by means of its chemical composition. Such food substances are known as nutrients. Let us now examine a few of the nutrients that we are likely to meet in our daily life, and see how we could test chemically for their presence. 
Carbohydrates. - Starch and sugar ${ }^{1}$ are common examples of this group of substances.

Starch Test. - If the substance to be tested is a solid, break or crush it and add water to it. Pour over it a few drops of iodine solution diluted with water. ${ }^{2}$ Notice the color of the iodine, a dark brown; after it has touched the material supposed to contain starch, note any change in color. If starch is present, it will turn dark blue.

Grape Sugar. - There are several forms of sugar commonly used as food; for example, cane sugar, beet sugar, and grape sugar, the latter commonly known as glucose. Glucose, or grape sugar, is manufactured commercially by pouring sulphuric acid over starch. It is used as an adulterant for many kinds of foods, especially in sirups, honey, and candy.

Test for Grape Sugar. - The presence of grape sugar is determined by the following test: Place in a test tube the substance to be tesied and heat it in a little water so as to dissolve the sugar. Add to the fluid twice its bulk of Fehling's solution, ${ }^{3}$ which has been previously prepared. Heat the mixture, which should now have a blue color, in the test tube. If grape sugar is present in considerable quantity, the contents of the tube will turn first a greenish, then yellow, and finally a brick-red color. Smaller amounts will show less decided red. This change also appears if Fehling's solution is boiled with cane sugar. A more accurate test is obtained by placing the substance believed to contain grape sugar in a test tube containing Fehling's solution and allowing the mixture to remain over night in a moderately warm room. If grape sugar is present, a red deposit or precipitate (copper axide) will be found in the tube the next morning.

Organic Fats and Oils. - T'ests for fats: Rub the material believed to contain oil several times on paper and hold the paper to the light. If oil is present, the paper will show a transiucent grease spot. Try this with several different nuts and decide which has the most oil.

A second test for oil is as follows: Heat the substance to be tested in an oven on a piece of paper. If oil is present, the paper will show a grease spot.

Third test: Reduce the substance to small pieces and pour benzine, ether, or other volatile oil over it. Allow the benzine or ether to evaporate; the oil that remains is the extracted oil from the substance tested.

1 The chemical formula for starch is $\mathrm{C}_{6} \mathrm{H}_{10} \mathrm{O}_{5}$; that of grape sugar, $\mathrm{C}_{6} \mathrm{H}_{12} \mathrm{O}_{6}$.

2 Iodine solution is made by simply adding a few crystals of the element iodine to 95 per cent alcohol; or, better, take by weight 1 gram of iodine crystals, $\frac{2}{3}$ gram of iodide of potassium, and dilute to a dark brown color in weak alcohol (35 per cent) or distilled water.

3 To make Fehling's solution (so called after its discovercr), add to 35 grams of copper sulphate (blue vitriol) 500 cubic centimeters of water. Put aside until it is completely dissolved. Call this solution No. 1.

To 160 grams of canstic soda and 173 grams of Rochelle salt add 500 cubic centimeters of water. Dilute to 1 liter. Call this solution No. 2.

For use mix equal parts of solution 1 and 2 .

The following formula is also convenient:-

I. Copper Sulphate: 9 grams in 250 c.c. water.

II. Sodium Hydroxide : 30 grams in 250 c.c. water.

III. Rochelle Salt : 43 grams in 250 c.c. water.

For use add to equal parts I, II, and III, two parts of water. 
Proteids. - Nitrogenous foods, or proteids, contain the element nitrogen in addition to carbon, hydrogen, and oxygen of the carbohydrates and hydrocarbons. They include some of the most complex substances known to the chemist, and as we shall see, have a chemical composition very near to that of living matter. Proteids occur in several different forms, but the following tests will cover most cases commonly met. White of egg, lean meat, beans, and peas are examples of substances composed in a large part of proteid.

Place in a test tube the substance to be tested; for example, a bit of hardboiled egg. Pour over it a little strong ( 80 per cent) nitric acid. Note the color that appears - a lemon yellow. Now wash the egg in water and add a little ammonium hydrate. The color now changes to a deep orange, showing that a proteid is present.

If the proteid is in a liquid state, its presence may be proved by heating; if it coagulates or thickens, as does the white of an egg, when boiled, then proteid in the form of an albumen is present.

Another characteristic proteid test easily made at home is by burning the substance. If it burns with the odor of burning feathers or leather, then proteid forms part of its composition.

\section{Books for Reference}

FOR THE PUPIL

Avery-Sinnott, First Lessons in Physical Science. American Book Company. Eddy, Experimental Physiology and Anatomy. American Book Company. Hunter and Valentine, Laboratory Manual of Biology. Henry Holt and Company. Peabody, Laboratory Exercises in Anatomy and Physiology. Henry Holt and Company

FOR THE TEACHER

Foster, A Text-book of Physiology. The Macmillan Company.

Green, Vegetable Physiology. J. and A. Churchill.

Sedgwick and Wilson, General Biology. Henry Holt and Company. 


\section{PROTOPLASM AND THE CELL}

A Living Plant. - If we walk out any afternoon in the fall of the year, we notice the many forms of plant life that fill the waste places along the waysides and make their way into the cultivated gardens and fields, driving out the rightful inhabitants. We call such plants weeds. Let us study some common weed such as the yellow-blossomed butter and eggs or the ubiquitous shepherd's purse, with the intention of finding out how such plants are so well fitted to live. If we think of the plant as a mass of living matter, we at once are struck with the evident fact that the living material has taken on very different forms in different parts of the plant. ${ }^{1}$ The root below the surface of the ground differs considerably in form

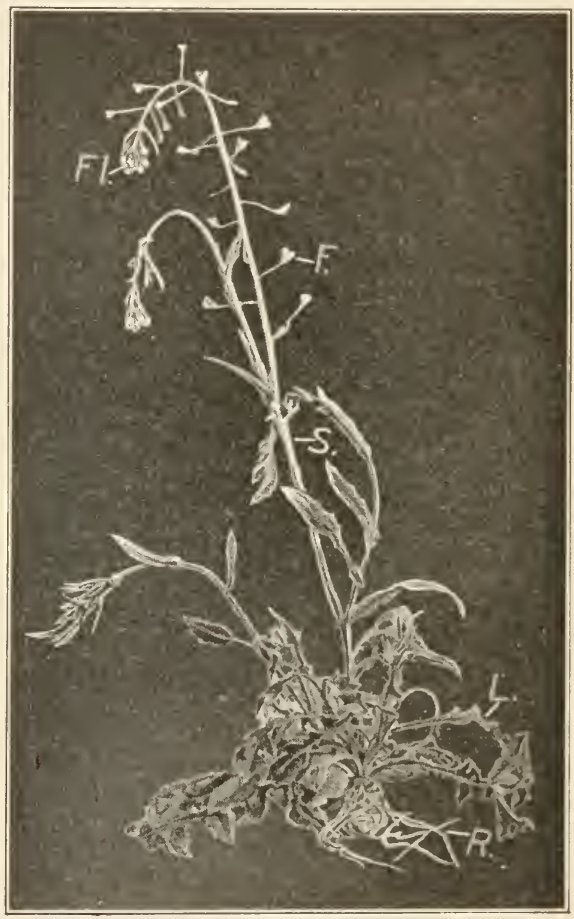

Shepherd's purse; $F l$, flowers; $F$, fruits; $S$, stem; $L$, leaves; $R$, roots. from the stem, which in turn differs in structure from the leaves.

1 The living matter of the plants is covered by dead organic matter formed by the activity of the live part. Thus the soft living mass within may be molded into various shapes, as stem, root, or leaves, with the help of the strong and rigid dead parts of the plant. 
Functions of the Parts of a Plant. - Still more prominent are the structures we call flowers and fruits. Each of these structures differs from each other part, and each has a different work or function to perform for the plant. The root holds the plant firmly in the ground and takes in water; the stem holds the leaves up to the light; the leaves, under certain conditions, manufacture food for the plant; the flowers form the fruits; the fruits hold the seeds, which in turn reproduce young plants of the same kind.

Organs.-Each part of a plant or animal, having a separate work or function, is known as an organ. Most plants and animals a re composed

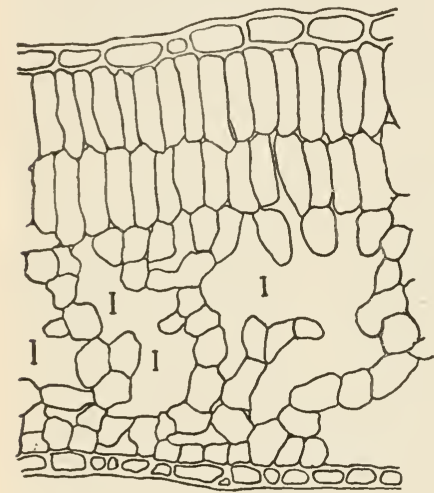

Section through the blade of a leaf, as seen under the compound microscope; $I$, air spaces, which communicate with the outside air. of organs; hence any living thing, even the simplest single living cell, has come to be called an organism.

If we look rather carefully from all sides at the organ called the leaf, we find that the materials of which it is composed do not appear to be everywhere the same. The leaf is much thinner and more delicate in some parts than in others. Holding the flat, expanded blade to the branch is a little stalk, the petiole, which extends into the blade of the leaf as a series of little veins which evidently form a framework for the flat blade somewhat as the sticks of a kite hold the paper in place. In the same manner the veins, if cut crosswise and mounted on a glass slide under the compound microscope, ${ }^{1}$ show that they are made up of building material which, although microscopic in size, yet differs considerably from other material in the same part of the vein. The smallest units of building material of the plant or animal disclosed by the compound microscope are called cells. The organs of a plant or animal are built of these tiny structures.

Tissues. - The cells which form certain parts of the veins, the flat blade, or other portions of the plant, are often found in groups

${ }^{1}$ For a study of the compound microscope, see Hunter and Valentine, Manual, page 3.

\section{FWPERTY LIBRARY}


or collections, the cells of which are alike in size and shapo Such a collection of cells is called a tissue. Examples of tissues are the cells covering the outside of the human body, the cells which collectively allow of movement, the so-called muscles; the material that forms the framework to which the muscles are attached, the bony tissues; and many others. ${ }^{1}$

Cells. - A cell may be defined as the smallest bit of living matter that can live alone. All plant and animal cells appear to be alike in the fact that every living cell possesses a structure known as the nucleus, which is found within the body of the cell. The nucleus is composed of living matter like the rest of the cell, although it seems to differ in some chemical way from that part of the cell surrounding it. This is seen when a plant or animal is placed in a liquid containing some dye such as logwood. Certain bodies in the nucleus take up the stain much more readily than the rest of the living matter of the cell, taking on a deep black color. They are thus called the chromosomes (color-bearing bodies). ${ }^{2}$

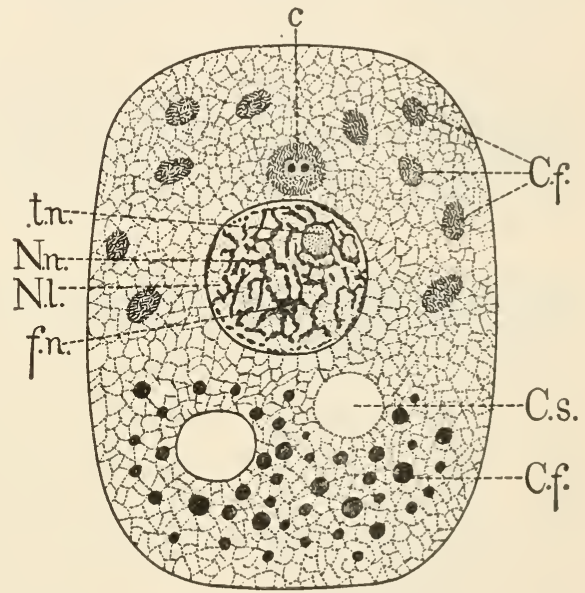

Diagram of a cell (after Wilson). The cell protoplasm contains cell food (C.f.); spaces contain liquid cell sap $(C . s$.$) ; just above the nucleus \left(N . I_{\text {. }}\right)$ is a structure called the centrosome $(c)$, which aids in cell division; within the nucleus are chromosomes $(N . n$.$) , which form a network; t.n., nucleolus.$

1 A very simple tissue that may be studied as an introductory study with the microscope is a thin section of elder or pith, mounted in water or glycerine (dilute) on a glass slide. (See Hunter and Valentine, Manual, page 7.) The study of ycast may be introduced at this point if microscopes are available; at any rate demonstration materis:l showing isolated cells and tissucs should here be shown.

2 . The chromosomes, which are believed to be always definite in number for every tissue cell, are of much interest to scientists. It is found that cach time a cell splits to form two new cells, the chromosomes split in half and an equal number of parts go into the nucleus of each new ccll thus formed. These chromosomes are supposed to be the bearers of the qualities which we believe can be handed down from plant to plant and from animal to animal; in other words, the inheritable qualities which make the offspring like its parents. 
Protoplasm. - The iiving matter of which all cells are formed is known as protoplasm (from two Greek words meaning first form).

The bulk of the nucleus is filled with a fluid; in some nuclei a body known as a nucleolus is found; it does not seem to be a constant structure. The protoplasm surrounding the nucleus is

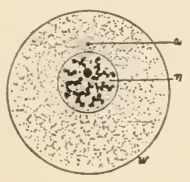

A

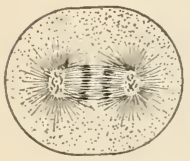

D

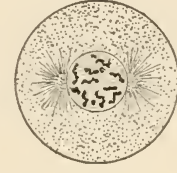

B

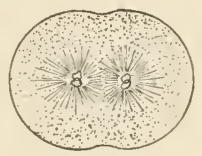

$\boldsymbol{E}$

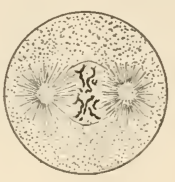

c

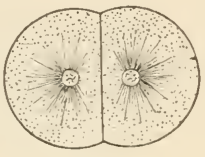

$\boldsymbol{r}$

Stages in the divisjon of one cell to form two cells. Note the separation of the chromosomes in the nucleus. Which part of the cell divides first? called cytoplasm because it makes up the body of the cell. The nucleus plays a very important part in the life of a cell. Cells grow to a certain size and then split into two new cells. In this process, which is of very great importance in the growth of both plants and animals, the nucleus divides first. The chromosomes also divide, each splitting lengthwise so that an equal number go to each of the two cells formed from the old cell. Lastly, the cytoplasm separates and two new cells are formed. This process is known as fission. It is the usual method of growth found in the tissues of plants and animals.

The protoplasm in some cells collects into little bodies called plastids. In plant cells the plastids are frequently colored green. This green coloring matter, which is found only in plant cells, is called chlorophyll and green plastids are called chlorophyll bodies. The cytoplasm of a cell contains spaces, which are usually filled with a fluid known as cell sap. These spaces in the cytoplasm are given the name of vacuoles. Frequently non-living materials are found within the cytoplasm of the cell.

The cell is surrounded by a very delicate living structure called the cell membrane. This is so thin that it is impossible to get a microscope of power enough to throw any light on its structure. Outside this membrane a wall is formed by the activity of the protoplasm in the cells of plants. In the cells of the pith it was the wall of cellulose or wood that you saw under the microscope. The wood used in building is made up of the dead walls of plant cells. 
Structure of Protoplasm. - Protoplasm, when viewed under a high magnification of a compound microscope, is a grayish, almost fluid mass, seemingly almost devoid of any structure. A careful observer will, however, find that the material seems to be made of a ground mass of fluid with innumerable granules of various size and form floating in the fluid portion. Other observers believe protoplasm to consist of a fluid groundwork with innumerable tiny threads scattered through it, each thread being more or less firmly united with other threads of the mass. Still other scientists hold that protoplasm has essentially the structure of an emulsion or froth or foam. To them the fine structure resolves itself into a collection of very minute bubbles. Doubtless all of the observers are right in part, for protoplasm doubtless assumes all of the above-mentioned forms in different plants and animals and under different conditions. But we must also bear in mind that when we make observations on protoplasm it may be already dead when we examine it - and therefore undoubtedly greatly changed in structure - or else we may view it under conditions which are far from the normal conditions under which it usually exists as living matter. Finally, the instrument we call the microscope, although seeming to be nearly perfect, may not always give to our eye an exact representation of what is under its lenses.

\section{Cells of Various Sizes and Shapes. -} Plant cells and animal cells are of very diverse shapes and sizes. There are cells so large that they can easily be seen with the unaided eye; for example, the root hairs of plants and eggs of some animals. On the other hand, cells may be so minute that in the case of the plant cells we call bacteria, several million could be placed on a dot of this letter $i$. The forms of cells may be extremely varied in different tissues; they may assume the form of cubes, columns, spheres, flat plates, or may be so irregular that description is impossible. One kind of tissue cell, found in man, has a body so small as to be quite invisible to the naked eye, although it has a prolongation several feet in length. Such are some of the cells of the ner-

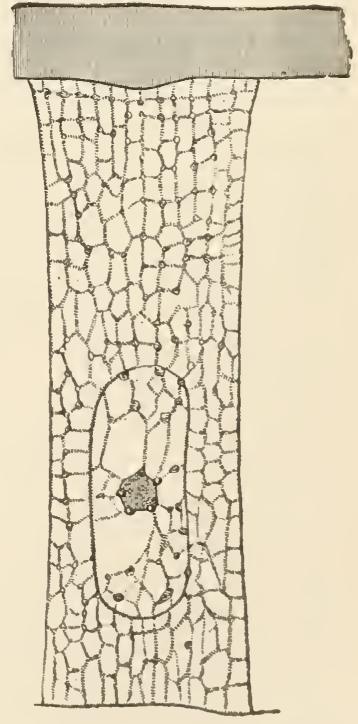

Animal cell, showing netlike structure of the protoplasm. (After Verworn.) 
vous system of man and other large animals, as the ox, elephant, and whale.

Varying Sizes of Living Things. - Plant cells and animal cells may live alone or they may form collections of cells as tissues. Some plants are so simple in structure as to be formed of only one kind of tissue cells. Usually living organisms are composed of several groups of such tissues. Examples have been given. It is only necessary to call attention to the fact that such collections of tissues may form organisms so tiny as to be barely visible to the eye; as, for instance, some water-loving flowerless plants or many of the tiny animals living in fresh water or salt water, such as the hydra, small worms, and tiny crustaceans. On the other hand, among animals the bulk of the elephant and whale, and among plants the big trees of California, stand out as notable examples.

Relation to Organic and Inorganic Matter. - The inorganic matter covering the earth, as air and water, and forming the great mass of its bulk, is made use of by plants and animals. The latter inake their homes in earth, air, or water; they breathe the oxygen of the atmosphere; they use the water for drinking; but in the main their food consists of organic matter. Plants, on the other hand, use the elements contained in the soil, air, and water, not only for food, but also to make the living matter of their own bodies. In some mysterious way, of which we shall later learn something, plants take up inorganic and organic substances from the soil and air and transform them into organic matter. This organic matter in turn becomes food for animals.

In the last chapter we found that the classes of substances in an animal or plant and the organic food substances have a similar composition. Let us now consider chemically the substance which forms the basis of all living things.

Protopiasm. - Living matter, when analyzed by chemists in the laboratory, seems to have a very complex chemical composition. It is somewhat like a proteid in that it always contains the element nitrogen. It also contains the elements carbon, hydrogen, oxygen, and a little sulphur, and perhaps phosphorus. Calcium, iron, silica, sodium, potassium, and other mineral matters are usually found in very minute quantities in its composition. We believe that the matter out of which plants and animals are formed, although a very complex building material and almost 
impossible of correct analysis, is nevertheless composed of certain chemical elements which are always present. To this living matter the name protoplasm has been given.

Protoplasm, then, is made up of certain chemical elements, combined in definite proportions. What is of far more importance to us is the fact that it is distinguished by certain properties which it possesses and which inorganic matter does not possess.

Properties of Protoplasm. - Plants and animals are largely made up of living matter. Let us study its properties:-

(1) It responds to influences or stimulation from without its own substance. Both plants and animals are sensitive to touch or stimulation by light, heat, or electricity. Leaves turn toward the source of light. Some animals are attracted to light and others repelled by it; the earthworm is an example of the latter. Many other instances might be given. Protoplasm is thus said to be irritable.

(2) Protoplasm has the power to move and to contract. Muscular movement is a familiar instance of this power. Plants move their leaves and other organs. One-celled animals change their form.

(3) Protoplasm has the power of taking up food materials, of selecting the materials which can be used by it, and of rejecting the substances that it cannot use. A commercial sponge, the dried skeleton of an animal, if placed in water, will swell up with the water absorbed by it, but the water thus taken in is not used by the dead skeleton. Protoplasm, however, in the tiny parts of the root of a plant called the root hairs, takes in only the material which will be of use in forming food or new protoplasm for the plant. An animal selects only such food as it wants, and refuses to eat material that it does not use as food.

(4) Protoplasm grows, not as inorganic objects grow, from the outside, ${ }^{1}$ but by a process of taking in food material and then changing it into living material. To do this it is evident that the same chemical elements must enter into the composition of the food substances as are found in living matter. The simplest plants

${ }_{1}^{1}$ Experiment. - Make a strong solution of alum (two spoonfuls of powdered alum to half a glass of water). Suspend in the glass a thread with a pebble attached to the lower end. Notice where and how crystals of alum grow. 
and animals have this wonderful power as well developed as the most complex forms of life.

(5) Protoplasm, be it in the body of a plant or an animal, uses oxygen. It breathes. Thus the food substances taken into the body are oxidized, and either release energy for growth, movement, etc., or form new protoplasm.

(6) Protoplasm has the power to rid itself of waste materials, especially those which might be harmful to it. A tree sheds its leaves partly to get rid of the accumulation of mineral matter in the leaves. Plants and animals alike pass off the carbon dioxide which results from the very processes of living, the oxidation of foods or parts of their own bodies. Animals eliminate wastes containing nitrogen through the skin and the kidneys.

(7) Protoplasm can reproduce, that is, form other matter like itself. New plants are constantly appearing to take the places of those that die. The supply of living things upon the earth is not decreasing; reproduction is constantly taking place. In a general way it is possible to say that plants and animals reproduce in a very similar manner. We shall study this more in detail later.

To sum up, then, we find that living protoplasm has the properties of sensibility, motion, growth, and reproduction alike in its simplest state as a one-celled plant or animal and when it enters into the composition of a highly complex organism such as a tree, a dog, or a man.

\section{BOOKS FOR REFERENCE}

FOR THE PUPIL

Leavitt. Outlines of Botany. American Book Company.

Atkinson. First Studies of Plant Life. Chap. XI. Ginn and Company.

\section{FOR THE TEACHER}

Goodale. Physiological Botany. American Book Company.

Green. Vegetable Physiology. J. and A. Churchill.

Huxley and Martin. Course of Elementary Instruction in Practical Biology. The

Macmillan Company.

Sedgwick and Wilson. General Biology. Henry Holt and Company.

Wilson. The Cell in Development and Inheritance. The Macmillan Company. 


\section{FLOWERS}

Structure of a Simple Flower. - For the following exercise, the buttercup and Sedum (stonecrop) are good. They may be obtained in the fall. ${ }^{1}$

The expanded portion of the flower stalk, which holds the parts of the flower, is called the receptacle. The green leaflike parts covering the unopened flower are called the sepals. Sometimes the sepals are all joined or united in one piece. Taken together, they are called the calyx. Notice that the sepals come out in a circle or whorl on the fiower stalk. How many sepals do you find? In what respect do they resemble leaves? Are there any evidences as to their use or function?

The more brightly colored structures are the petals. Taken together, they form the corolla. The corolla is of importance, as we shall see later, to make the flower conspicuous.

Compare the petals and sepals in this flower. Are sepals and petals in any respects like leaves?

A flower, however, could live without sepals or petals and still do the work for which it exists. The essential organs of the flower are within the so-called

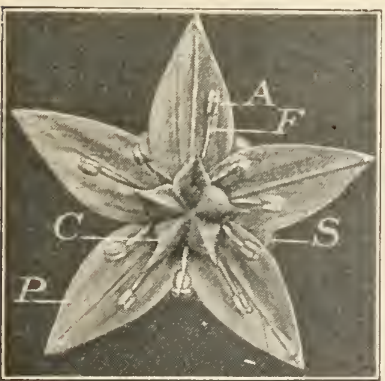

A flower of Sedum from above; $A$, anther; $C$, carpel; $F$, filament; $P$, petal; $S$, sepal.

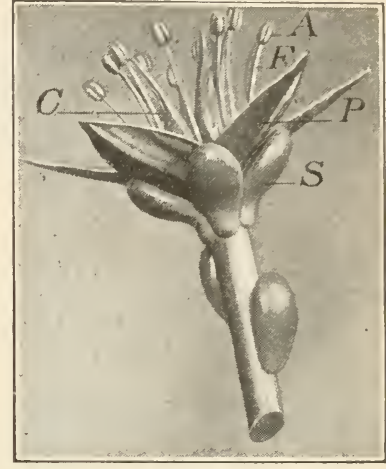

A flower of Sedum, from the side; $A$, anther of stamen; $C$, carpel; $F$, filament; $P$, petal; $S$, sepal. floral envelope. They consist of the stamens and carpels (or pistils). The latter are in the center of the flower. The structures with the knobbed ends are called stamens. How many stamens do you find, and what is their position?

In a single stamen the boxlike part at the end is the anther; the stalk is called the filament. The anther is in reality a hollow box in which a dustlike material called pollen is produced. It is necessary for the life of the plant that the pollen get out of the anther. Try to find how it gets out.

Pistil. - Each carpel or pistil is composed of a rather stout base called the ovary, and a more or less lengthened portion rising from the ovary called the siyle. The upper end of the style, which in some cases is somewhat broadened, is called the stigma. The stigmatic surface usually secretes a sweet fluid in which grains of pollen from flowers of the same kind can grow.

1 See Hunter and Valentine, Manual, page 54. 
Draw one of the flowers in your notebook. Show the flower stalk or peduncle and all the above-mentioned parts carefully labeled. Keep any notes that you may have made on the work on the flower. ${ }^{1}$

Pollen. - Pollen grains of various flowers, when seen under the microscope, differ greatly in form and appearance. Some are

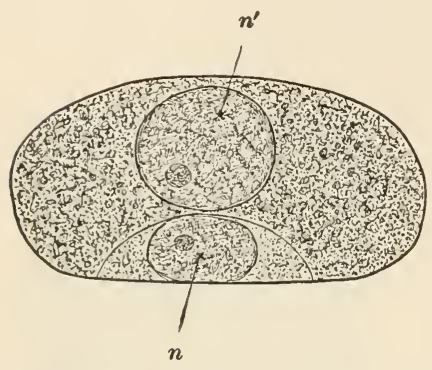

A pollen grain highly magnified. It contains two nuclei $\left(n, n^{\prime}\right)$ at the stage here represented. relatively large, some small, some rough, others smocth, some spherical, and others angular. They all agree, however, in having a thick wall, with a thin membrane under it, the whole inclosing a mass of protoplasm. At an early stage the pollen grain contains but a single cell. When we see it, however, we can distinguish two nuclei ir the protoplasm. Hence we know that at least two cells exist there.

Experiment. - Germination of the Pollen Grain. Make a solution of fifteen grams of granulated sugar in one hundred cubic centimeters of water. Place on each of several glass microscopic slides a few drops of the solution and sprinkle with pollen taken from well-opened flowers of sweet pea or a nasturtium. Place on the slides some very thin and small bits of cover glass, and with these prop up the cover slip which is placed over the sugar solution. Leave them for a few hours under a bell jar with a picee of moist sponge to keep the air in the jar moist. Examine the slides from time to time under the microscope. The grains of pollen will be found to germinate, a long threadlike mass of protoplasm growing from it into the sugar solution. The presence of this sugar solution was sufficient to induce growth.

Demonstration under Microscope.-Pollen tubes growing in dilute sirup. When the pollen

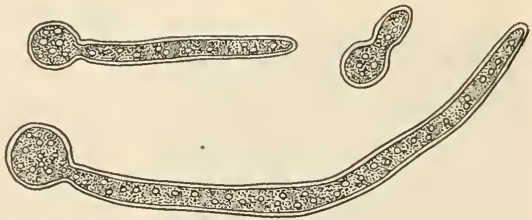

Three stages in the germination of the pollen grain in sugar solution. Drawn under the compound microscope. grain germinates, one of the nuclei enters the threadlike growth (this growth is called the pollen tube; see figure). The poll $n$ tube is therefore a long threadlike cell, which is artificially stimulated to growth by the sugar solution, but which in nature is brought into existence by the presence of the sweet liquid which exudes from the surface of the stigma. The cell which grows into the pollen tube is known as the sperm cell.

Structure of the Pistil. - Let us now examine the structure of the pistil more in detail. (Use for this purpose any large lily.) Cut the pistil length-

1 Laboratory directions for other work on flowers may be found in Hunter and Valentine. Manual, pages 51-63. 
wise; notice that the style appears to be composed of rather spongy material in the interior; the ovary is hollow and is seen to contain a number of rounded structures which appear to grow out from the wall of the ovary. These are the ovules. The compartments in which they grow are called the locules. How many locules do you find in a cross section of the lily ? ${ }^{1}$ That part of the ovary wall from which the ovules are outgrowths is called the placenta (plu. placent(e). How many placentæ do you find, and how would you locate them with reference to the outside of the ovary?

\section{Fertilization of the} Flower. - The ovules, under certain conditions, become seeds. An explanation of these condi. tions may be had if we examine, under the microscope, a very thin section of a pistil, on which pollen has begun to germinate. The central part of the style is found to be either hollow or composed of a soft tissue through which the pollen tube can easily grow. Upon germination, the pollen tube grows downward through the spongy center of the

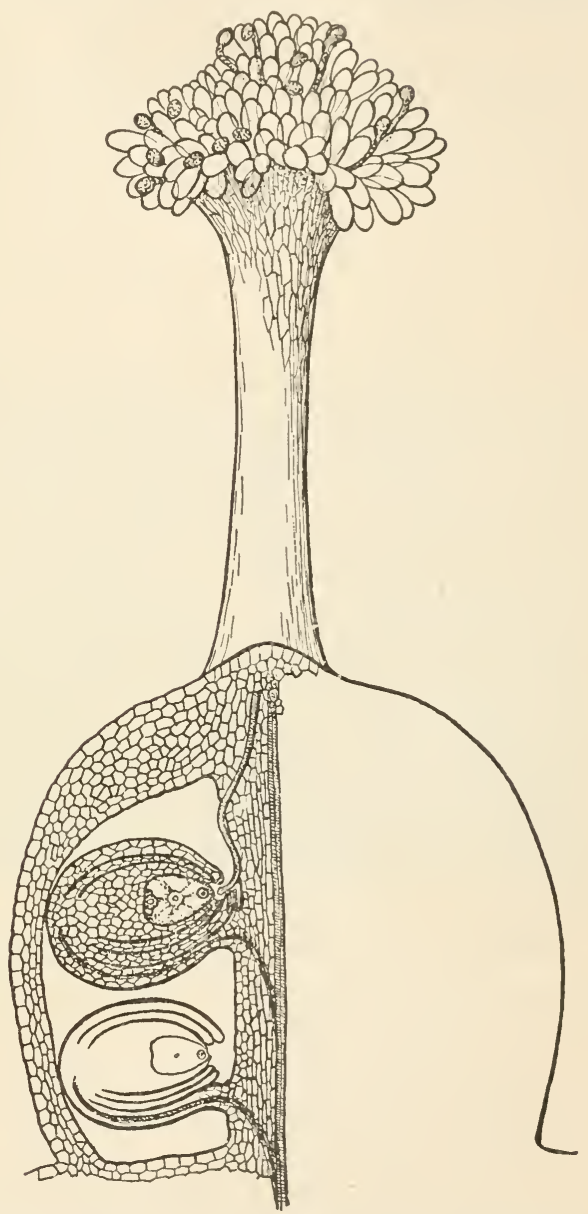

Fertilization of the ovule. The pollen tubes pass through the stigma and style. finally entering the cavity (locules) of the ovary. style, follows the path of least resistance to the locule of the ovary, and there grows into the ovule. It is believed that some

${ }^{1}$ The structural differences in the flower of a monocotyledon and dicotyledon may well be pointed out here. 
chemical influence thus attracts the pollen tube. In flowers in which the style is short, the tube reaches the ovule in the course of a few hours. In plants with a long style, from one to several days may elapse before the pollen tube reaches the locule of the ovary. Once it reaches the ovary, the tube penetrates an ovule by making its way through a little hole known as the micropyle. It then grows toward a clear area of protoplasm known as the embryo sac. The embryo sac is an ovoid area, microscopic in size, filled with semifluid protoplasm containing several nuclei. (See figure.) One of the nuclei, with the protoplasm immediately surrounding it, is called the egg cell. It is this cell that the sperm cell of the pollen tube grows toward; ultimately the sperm cell reaches the egg cell and unites with it. The two cells, after coming together, unite to form a single cell. This process is known as fertilization. This single cell formed by the union of the pollen tube cell or sperm and the egg cell is now called a fertilized egg.

Development of Ovule into Seed. - The primary reason for the existence of a flower is that it may produce seeds from which future plants will grow. The first beginning of the growth of the seed takes place at the moment of fertilization. From that time on there is a growth, within the ovule, of a little structure called the embryo. The embryo will give rise to the future plant. After fertilization the ovule is called a seed.

History of the Discoveries regarding Fertilization. - Although the ancient Greek and Roman naturalists had some vague ideas on the subject of fertilization, it was not until the latter part of the eighteenth century that it was demonstrated that pollen was necessary for the growth of the embryo within a seed. In the latter part of the eighteenth century a book appeared in which a German named Conrad Sprengel worked out the facts that the structure of certain flowers seemed to be adapted to the visits of insects. Certain facilities were offered to an insect in the way of easy foothold, sweet odor, and especially food in the shape of pollen and nectar, the latter a sweet-tasting substance manufactured by certain parts of the flower known as the nectar glands. Sprengel further discovered the fact that pollen could be and was 
carried by the insect visitors from the anthers of the flower to its stigma.

Pollination. - It was not until the middle of the nineteenth century, however, that an Englishman, Charles Darwin, discovered the true relation of insects to flowers by his investigations upon the cross-pollination of flowers. By pollination we mean the transfer of pollen from an anther to the stigma of a flower. Selfpollination is the transfer of pollen in one flower; cross-pollination is the transfer of pollen from the anthers of one flower to the stigma of another flower of the same kind. It was found by Charles Darwin

- and it has since been proved many times - that flowers which were self-pollinated did not produce so many seeds, or seeds with so much vitality, as those which were cross - pollinated. Microscopic examination of the stigma at the time of pollination also

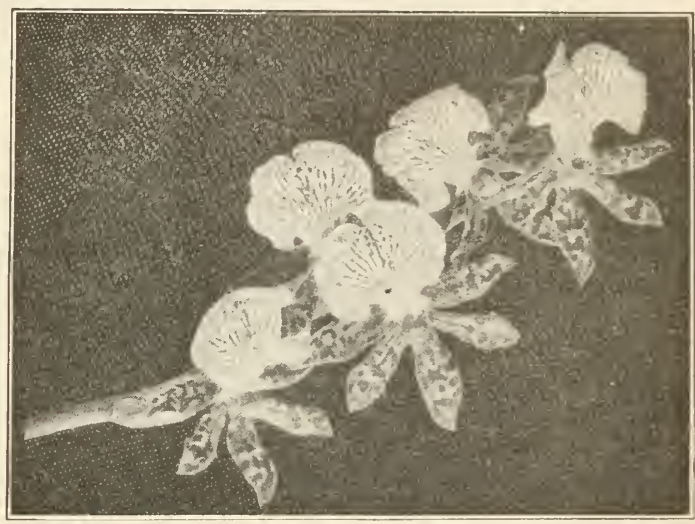

An orchid, a flower of the type from which Charles Darwin worked out his theory of cross-pollination by insects.

shows that the pollen from another flower germinates before the pollen which has fallen from the anthers of the same flower. This latter fact alone in most cases renders it impossible for a flower to produce seeds by its own pollen. Darwin worked for many years on the pollination of many insect-visited flowers, and discovered in almost every case that showy, sweet-scented, or otherwise attractive flowers were adapted or fitted to be crosspollinated by insects. He also found, in the case of flowers that were inconspicuous in appearance, often a compensation appeared in the odor which rendered them attractive to certain insects. The so-called carrion flowers, pollinated by flies, are examples, the odor in this case being like decayed flesh. Other flowers open 
at night, are white, and provided with a powerful scent so as to attract night-flying moths and other insects. We shall later take up some of the many cases of the adaptation of the parts of a flower to these insect callers. ${ }^{1}$ Flowers adapted to be crosspollinated by insects are almost invariably irregular in shape. Let us now consider rather in detail the structure of the sweet pea, an example of such a flower.

Sweet Pea. - The sepals are of almost the same size and shape; that is, regular. The petals, however, are quite different from each other in form. If you pull off the parts of the corolla you will find that they separate naturally into a large expanded petal at the top of the flower; this is called the vane or standard; two petals at the sides called the wings, and a curved part below called the keel, the latter being made of two petals joined along the edge.

A corolla of this kind is said to be papilionaceous from its fancied resemblance to a butterfly. What other plants do you know that have flowers of this shape?

If you press the point of a pencil down upon the keel of the flower, holding it in a natural position, you will soon find that the point has taken up some pollen. Evidently a bee might carry off pollen in the same manner.

Now remove the corolla from one side of the flower so as to show the stamens and pistil. Notice that the stamens are separated into two groups, those in one group united by their filaments to each other. How many are there in each group? This condition of stamens is said to be diadelphous. Draw the flower from the side, showing the above parts before you pull off the stamens. Look for the three parts of the pistil. Draw and label them. Notice the little hairs covering parts of the pistil; can you imagine their use? In old flowers you can see that the ovary is forming the characteristic pod of the pea family.

Insects as Pollinating Agents. - We have seen in a general way that insects assist in the cross-pollination of flowers. Let us now turn our attention to the insects to see how in their structure and habits they are adapted to play the important part that they fill in the cross-pollination of flowers. No one who sees a hive of bees with their wonderful communal life can fail to see that these insects play a great part in the life of the flowers near the hive. A famous observer named Sir John Lubbock tested bees and wasps to see how many trips, they made daily from the hive to the flowers, and found that the wasp went out on 116 visits during a working day of 16 hours, while the bee made but a few

${ }^{1}$ At this point, at least one field trip should be introduced for the purpose of studying under natural conditions the cross-pollination of flowers by insects. For suggestions for such a trip, see Hunter and Valentine, Manual, page 207. Many of the following exercises on fall flowers may profitably be taken in the field and reported on by the pupil as class exercises. Excellent suggestions for a field trip may be found in Andrews, Botany All the Year Round. 
less visits, and worked only a little less time than the wasp worked. It is evident that in the course of so many trips to the fields a bee must light on and cross-pollinate many hundreds of flowers.

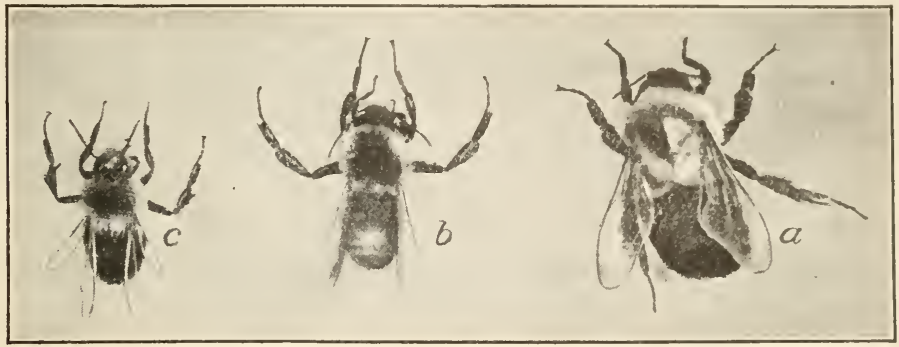

Bumblebees; $a$, queen ; $b$, worker ; $c$, dron $\epsilon$.

Laboratory Study of a Bumblebee. - The careful study of the bumblebee will give us some insight into the manner in which the bee transfers pollen. Living specimens may be chloroformed and then used dry, or material which has been preserved in formol or alcohol will answer the purpose. The body of an insect is divided into three regions; these may easily be found in the bee. The anterior or front part is the head, the middle is the thorax, and the posterior or hind part is the abdomen. The abdomen in the working bees is terminated in a sharp sting. Look carefully at the abdomen; you will find it is cut up into a series of little rings which taper off at the hind end of the body. These rings are called segments. Notice that the legs and wings are attached to the thorax. The wings are found on the dorsal or upper side of the body, the legs on the lower or ventral surface. Look at a leg with your hand lens. Is it all of one piece or jointed? When a plant or animal structure is fitted to do certain kind or kinds of work, we say that the structure is adapted to its functions. Can you determine how the leg is adapted for movement and for clinging to an object? Can you find any parts adapted to hold pollen? Notice the collection of stiff hairs on the joint next the body. In the honeybee these hairs are so arranged that they act as receptacles for pollen, which the bee stores there to carry home to the hive. Bees, wasps, and many other insects use pollen as food.

The body of the bee, as well as the head and legs, are more or less completely covered with tiny hairs. Are the hairs any better developed in certain parts of the body? If so, do you think they would be of use in carrying pollen, and why?

Pollination not intended by the Bee. - The cross-pollination of flowers is not planned by the bee; it is simply an incident in the course of the food gathering. The bee visits a large number of flowers of the same species during the course of a single visit from the hive, and it is then that cross-pollination takes place.

Field Work. - In any locality where flowers are abundant, try to answer the following questions: How many bees visit the locality in ten minutes? 
How many other insects alight on the flowers? Do bees visit flowers of the same kinds in succession, or fly from one flower on a given plant to another on a plant of a different kind? If the bee lights on a flower cluster, does it visit more than one flower in the same cluster?

Is Color or Odor in a Flower an Attraction to an Insect? - Try to decide whether color or odor has the most effect in attracting bees to flowers. Sir John Lubbock tried an experiment which it would pay a number of careful pupils to repeat. He placed a few drops of honey on glass slips and placed them over papers of various colors. In this way he found that the honeybee, for example, could evidently distinguish different colors. Bees seemed to prefer blue to any other color. Flowers of a yellow or flesh color are preferred by flies. It would be of considerable interest for some student to work out this problem with our native bees and with other insects. Test the keenness of sight in insects by placing a white object (a white golf ball will do) in the grass and see how many insects will alight on it. Try to work out some method by which you can decide whether a given insect is attracted to a flower by odor alone.

The Eyes of the Bumblebee. - Look carefully at the large eyes located on the sides of the head. They are made up of a large number of little units, each of which is considered to be a very simple eye. The large eyes are therefore called the compound eyes. All insects are provided with compound eyes, and in addition to these (in some cases) with simple eyes. The simple eyes of the bee may be found by a careful observer in front and above the compound eyes.

One would suppose that with so many eyes the sight of insects would be extremely keen, but such does not seem to be the case.

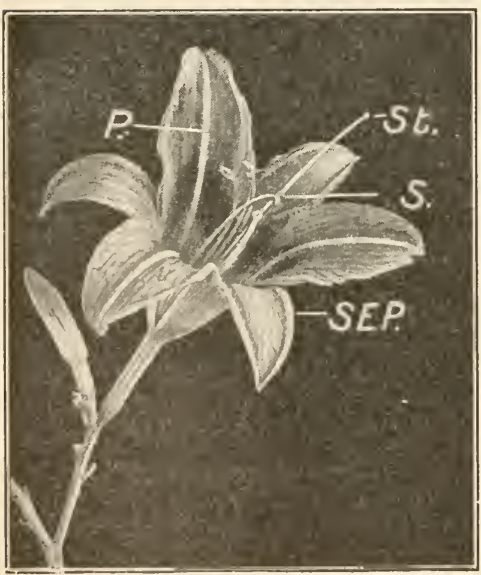

A lily; $P$, petal; $S$. , stamen (anther); SEP., sepal ; St., pistil (stigma).

Nectar and Nectar Glands. Insects can, as we have already learned, distinguish differences in color at some distance, but they do not seem to be able to make out form at any distance. To make up for this, they appear to have an extremely well-developed sense of smell. Insects can distinguish at a great distance odors which to the human nose are indistinguishable. Night-flying insects, especially, find the flowers by the odor rather than by color. The organ which perceives odors is located on the feelers on the head.

The bee is attracted to a flower for food. This food may consist of pollen and nectar. Nectar is a 
sugary solution that is formed in the flower by little collections of cells called the nectar glands. The nectar glands are usually so placed that to get to them the insect must first brush the stamens and pistil of the flower. Frequently the location of the nectaries (nectar glands) is made conspicuous by brightly colored markings on the corolla of the flower. The row of dots seen in the tiger lily is an example. You may easily find other instances of nectar guides, as they are called. Look for them in any of the common fall flowers.

Mouth Parts of the Bee. - The mouth of the bee is adapted to take in the foods we have mentioned, and is used for many other purposes for which a more highly developed animal, man, would use the hands and fingers. The honeybee laps or sucks nectar from flowers, it chews the pollen, and it uses part of the mouth as a trowel in making the honeycomb. A glance at the figure shows us that the mouth parts of the bee are complex. The parts con-

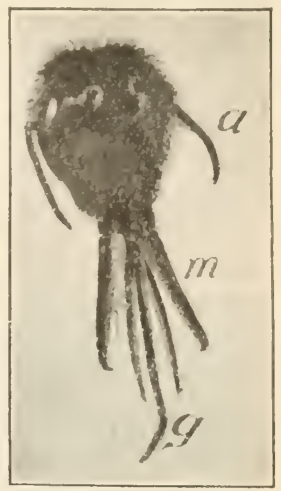

Head of the bumblebee; $a$, antenna; $g$, tongue used in licking the nectar from flowers; $m$, maxillæ. sist of a pair of very small jaws or mandibles, certain other structures, maxillæ, part of the lower lip called the labial palps, and a long tonguelike structure ealled the ligula. Watch a bee on a flower. Try to make out what parts of the mouth are used in taking nectar and in gathering pollen.

Make a drawing of the bumblebee, twice natural size, showing as many of the structures we have just described as possible. Label the parts carc-

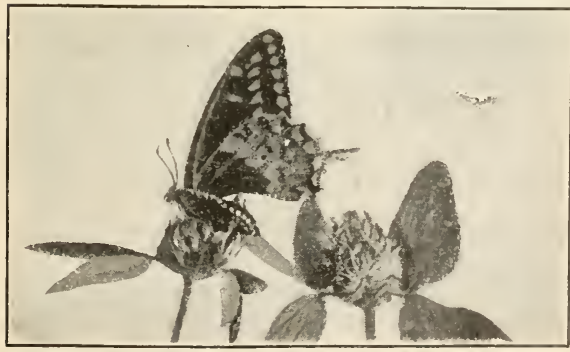

Swallowtail butterfly pollinating clover. Cross pollination of clover is usually effected by bumblebees.

Photograph by Davison. fully and put it in your notebook. It will be interesting to compare this drawing with the drawings you make later in the year when you study other insects. You will be surprised to find how much you improve in drawing.

\section{Other Insect Visitors. -}

Other insects besicles the bee are pollen carriers for flowers. Among the most useful are moths and butterflies. Both of these insects feed only on nectar, which they suck through a long tubelike proboscis. The heads and bodies of these insects are more 
or less thickly covered with hairs, and the wings are thatched with hairlike, tiny scales. All these structures are of use to the flower because they collect and carry pollen. On each side of the head of a butterfly is a long, fluffy structure, the palp. This collects and carries a large amount of pollen, which is deposited upon the stigmas of other flowers when the butterfly pushes its head down into the flower tube after nectar.

Flies and some other insects are agents in cross-pollination, as we shall see during some of our later studies. Humming birds

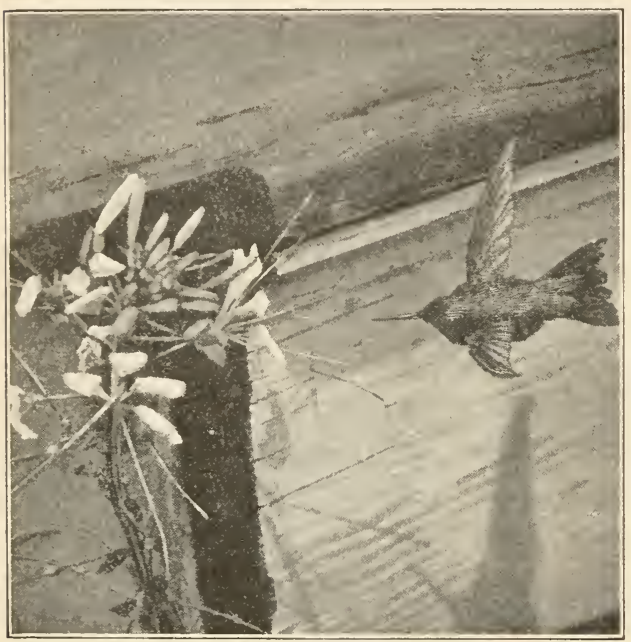

A humming bird just about to cross-pollinate a flower. are also active agents in some flowers. Snails are said in rare instances to carry pollen. Man and the domesticated animals undoubtedly frequently pollinate flowers by brushing past them through the fields.

Field Flowers. - Let us now take up some common wild flowers easily found in the fall of the year, and work out the relation of the parts of the flower to its insect visitors. Remember that the important part of these exercises is to find how and by what means the flower is adapted or fitted to receive the visits of insects. This work can be done best on field trips, but it can readily be modified so as to be useful as a schoolroom exercise.

The Evening Primrose (Onagra biennis). - The habitat preferred by this flower is dry fields, roadsides, or waste places. The yellow flowers are found in long, upright, densely crowded clusters. A flower cluster in which the individual flowers have no flower stalks or pedicles, with one main axis to the cluster, is called a spike. Notice that young and old flowers and fruits are all on the same cluster. Where are the youngest flowers located in the cluster? Is there any flower at the end of the main stalk? Could you determine in advance the length of the flower cluster? Such a cluster is said to be indeterminate. Why? Study a single open flower. Note the calyx and corolla; are the parts distinct? How many petals do you find? Notice that there are eight stamens and that the stigma is four-parted. Cut the ovary in cross section and see how many locules there are. 
When a flower has each circle of parts, as the sepals, petals. stamens, and pistils made up of a certain number of divisions, or wnen they appear in multiples of that number. the flower is said to be symmetrical. Here we see a very striking example of symmetry in a flower.

The chief attraction to insects is the nectar which is formed in nectar glands at the base inside the slender tubular corolla. Information is given to the insects of the contents by a faint, sweet odor. This flower is not visited by many day-flying insects. Can you determine the names of any that do come by day? At night the flower opens more widely and the scent becomes much more noticcable. Moths are its chief night visitors. The long proboseis is thrust into the flower and quickly withdrawn, but usually a little pollen is carried off on the palps, to be left on the next flower visited.

Try to determine what other insects, if any, visit the evening primrose at night.

Draw a single flower split open lengthwise to show the position of the parts, and especially any adaptations to insect pollination. Look for any special means for the prevention of self-pollination. Label all the parts.

Butter and Eggs (Linaria linaria). - From July to October this very abundant weed may be found especially along roadsides and in sunny fields. The flower cluster forms a tall and conspicuous spike. Can you sec any advantages to a plant in bearing its flowers in clusters?

Describe the general shape of the flowers. The corolla projects into a spur on the lower side; an upper two-parted lip shuts down upon a lower three-parted lip. The four stamens are in pairs. What is peculiar in their position and structure? Notice the position of the pistil. Could selfpollination easily occur? (The stamens of two lengths may allow selfpollination in stormy weather, when insects fail to reach the flower.)

Notice that certain parts of the corolla are more brightly colored than the rest of the flower. This color is a guide to insects. How might it help them in this flower?

Push a pencil between the two lips of the flower. Does the pencil touch the stamens? If a bee pushes aside the lips, would it be likely to take any pollen from the stamens? Do you think other insects than bees would be likely to aid the flower in pollination?

Draw the flower from the side, cut lengthwise to show the position of stamens and pistil. Make this drawing diagrammatic.

Moth Mullern (Verbascum blattaria). - The moth mullein is one of the most beautiful weeds, despite the fact that few blossoms are found at any given time. The plant flourishes on dry waste land, roadsides, and open fields. It was introduced into this country and has since become common here and in Canada.

The flowers are found in a long, loose raceme. A raceme is like a spike, except that each flower has its own flower stalk developed. Has this cluster yellow or white flowers? Into how many parts is the calyx divided? The corolla? Is the corolla perfectly regular? Notice the five stamens; is there anything peculiar about the filaments? Are they all of the same length? In spite of the fact that the flower is ealled moth mullein, it is not pollinated to any extent by moths. Bees and flies are the chief pollen bearers. Bees which alight on this flower do so for the purpose of collecting pollen. This they usually gather from the short stamens while they cling to the longer ones. As the bee lights on another flower, the pollen on the under side of the body is transferred to the stigma of this flower.

Draw the flower from above, twice natural size.

Jewel Weed (Impatiens biflora). - One of the most prevalent of all our 
brookside flowers is the jewel weed. It well deserves its name, a pendent flaming jewel of orange.

The flower is very irregular in shape. Are the flowers single or in clusters? The sepals as well as the petals are colored. The former are three in number, one of which is saclike in shape and contracted at one end into a spur. The petals are also three in number. Open the flower. Notice how short the filaments of the five stamens are. Make a note of their position with relation to the pistil. Would self-pollination be possible in this flower?

If it is possible to study jewel weed out of doors in its native habitat, it will be found that humming birds are the visitors which seem best adapted to cross-pollinate the flower. A careful series of observations by some girl or boy upon the cross-pollination of this flower might add much to our knowledge regarding it.

Jewel weed has the habit of producing (usually in the fall) inconspicuous flowers which never open but which produce seeds capable of germination and growth. Such flowers are said to be cleistogamous. In England, where the plant has been introduced, it is found to produce more clcistogamous flowers than showy ones, and the showy ones do not produce seed. There are no humming birds in England, and without this means of pollination the cleistogamous form prevails. Make a front view drawing of the flower of jewel weed twice natural size.

Many other examples of adaptations to secure cross-pollination by means of the visits of insects might be given. The moun-

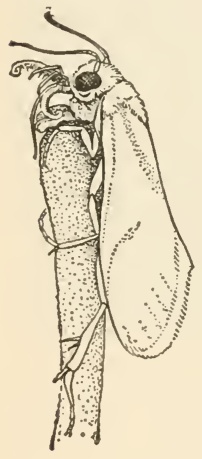

Pronuba pollinating pistil of yucca. tain laurel, which makes our hillsides so beautiful in late spring, shows a remarkable adaptation in having the stamens caught in little pockets of the corolla. The weight of the visiting insect on the corolla releases the anther of the stamen from the pocket in which it rests, and the body of the visitor is dusted with pollen. ${ }^{1}$

The milkweed or butterfly weed (Asclepias cornuti) is another example of a flower adapted to insect pollination. ${ }^{2}$

Still another example of cross-pollination is found in the yucca, a plant somewhat like the Spanish bayonet. In this flower the stigmatic surface is above the anther, and the pollen is sticky and could not be transferred except by insect aid. This is accomplished in a remarkable manner. A little moth called the Pronuba

1 See Hunter and Valentine, Manual, page 57.

2 For an excellent account of cross-pollination of this flower, the reader is referred to IV. C. Stevens, Introduction to Botany. Orchids are well known to botanists as showing some very wonderful adaptations. For simple reference reading, see Coulter, Plant Relations. A classic easily read by children is Darwin, On the Fertilization of Orchids. 
gathers pollen from an anther, flies away with this load to another flower, there deposits an egg in the ovary of the pistil, and then rubs its load of pollen over the stigma of the flower. The young hatch out and feed on the young seeds which have been fertilized by the pollen placed on the stigma by the mother. They eat some of the developing seeds and then bore out of the seed pod and escape to the ground, leaving the plant to develop the remaining seeds without molestation.

The fig insect (Blastophaga grossorum) is another member of the insect tribe that is of considerable economic importance. It is only in recent years that the fruit growers of California have discovered that the fertilization of the female flowers is brought about by a gall fly which bores into the young fruit. ${ }^{1}$

Pollination by the Wind. - Not all flowers

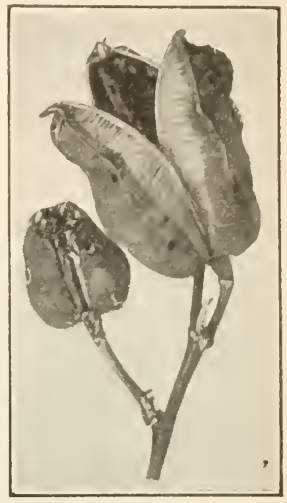

Pod of yucca pierced by the Pronuba. are dependent upon insects for cross-pollination. Many of the earliest of spring flowers appear almost before the insects do. These flowers, needing no conspicuous colors or showy corolla to attract insects, often lack this part altogether. In fact we are apt to entirely overlook the flowers which appear in the spring upon our common forest and shade trees. In many trees, as, for example, the willow, the flowers appear before the leaves come out. Such flowers are dependent upon the wind to carry pollen from the stamens of one flower to the pistil of another. Most of our common trees, oak, poplar, maple, and others, are cross-pollinated almost entirely by the wind.

Among the adaptations that a wind-pollinated flower shows are: (1) The development of very many pollen grains to each ovule. In one of the insect-pollinated flowers, that of the nightblooming cereus, the ratio of pollen grains to ovules is about eight to one. In flowers which are to be pollinated by the wind, a large number of the pollen grains never reach their destination and are

1 The teacher is referred to Year Book of the Department of Agriculture for 1900 for data on the insect which pollinates the Smyrna fig. 
wasted. Therefore in such plants several thousand, perhaps hundreds of thousands of pollen grains will be developed to every ovule produced. Such are the pines. In May and early June the ground under pine trees is often yellow with pollen, and the air may be filled with the dust for miles from the trees. Such, also, is the case with many of the grasses, the pollen being produced in such abundance that it causes a disease called hay fever.

(2) The pistil of the flower is peculiarly fitted to retain the pollen by having feathery projections along the sides which in-

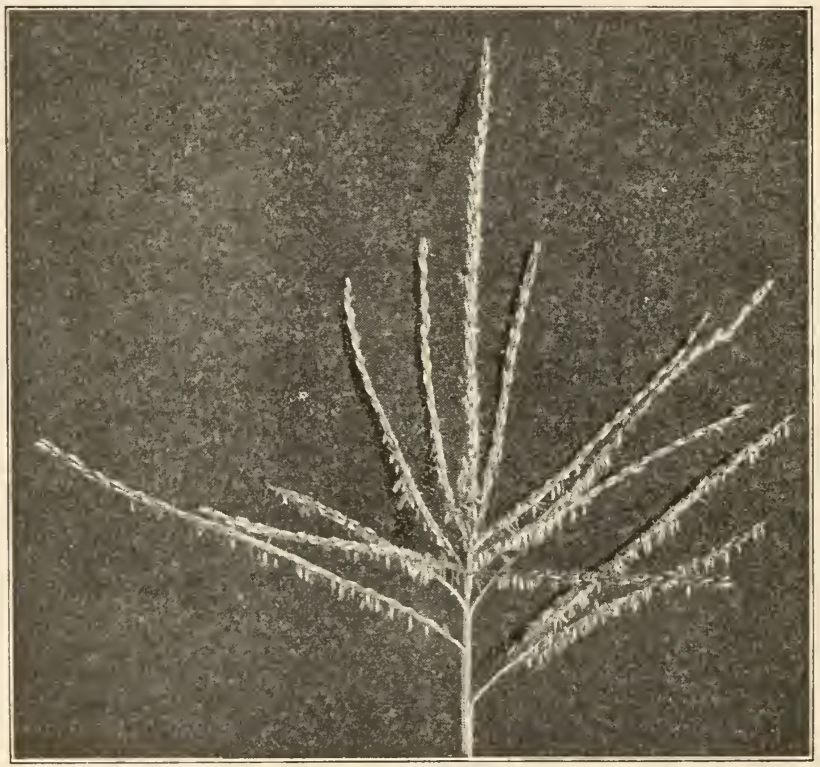

The staminate flower of the corn. Notice the hanging anthers full of pollen.

crease the stigmatic surface. This can be seen in the grass. In the Indian corn the stigmatic surface is the so-called silk which protrudes beyond the covering of modified leaves which form the husk of the ear of corn. All our grains, wheat, rye, oats, and others, have the typical feathery pistil of the wild grasses from which they descended. 
(3) The corolla is often entirely lacking. It would only be in the way in flowers that are dependent upon the wind to carry pollen.

Imperfect Flowers. - Some flowers, the wind-pollinated ones in particular, are imperfect. The plants bear flowers that lack either stamens or pistils. In such plants, cross-pollination must of necessity follow. If the staminate flowers (those which contain only stamens) are developed on one plant only, and the pistillate (those which bear only pistils) on another, as in the willow, we call the plant diocious. Try to make a list of all the trees and grasses in your neighborhood that are diœcious.

Other plants bear staminate and pistillate flowers on the same plant. In this case they are said to be monœcious. The oak, hickory, beech, birch, walnut, and chestnut are familiar examples.

The pine tree is another example

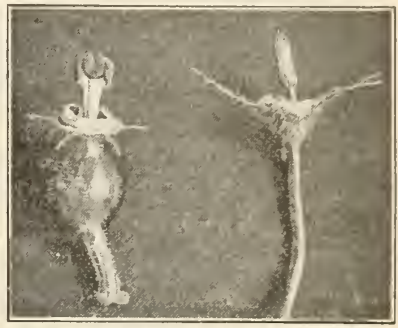

Imperfect flowers of the squash, the corolla removed. Pistillate flower at the left. of monœcious tree; the male or staminate flowers appear in tiny clusters called catkins, the female or pistillate flowers coming a little later as tiny cones, which in most species of pines take nearly two years to mature into seeds.

Water Pollination. - An unusual method of pollination is found in those plants which live almost entirely under the water. In eelgrass the pistillate flowers are attached to long slender stalks and float on the surface of the water. The staminate flowers, when ripe, break away from their submerged stems and float to the surface. If these float under a pistillate flower, the protruding ends of the pistils catch and retain some of the pollen from the staminate flower. Thus fertilization follows. After pollination, the stalk of the pistillate flower coils up in a spiral and draws the flower under the surface of the water, so that the seeds may ripen in security.

Summary. - If we now collect our observations upon flowers with a view to making a summary of the different devices flowers have assumed to secure cross-pollination, we find that they are as follows: - 


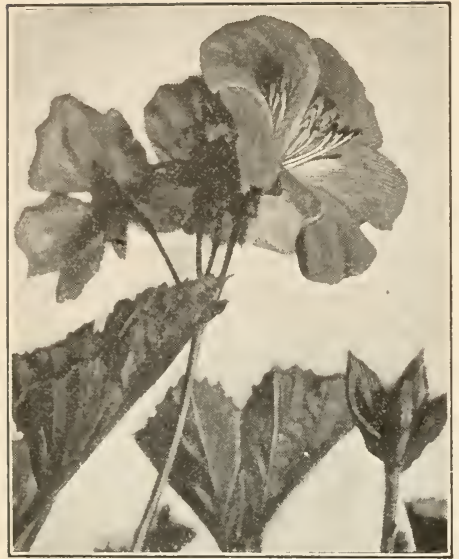

$A$

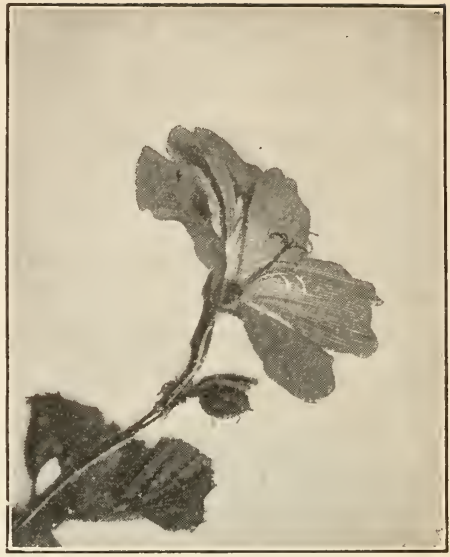

$B$

Flowers of the Lady Washington geranium showing the conditions of dichogamy; $A$, flower with stamens ripe, but with the stigma not ready to receive pollen; $B$, the same flower at a later stage; the stamens have withered, but the stigma is now ready to receive pollen.

(1) The stamens and pistils may be found in separate flowers, either on the same or on different plants.

(2) The stamens may produce pollen before the pistil is ready to receive it, or vice versa. This condition is called dichogamy. Examples may be found in several of the flowers recommended for study.

(3) The stamens and pistils may be so placed with reference to each other that pollination can be brought about only by outside assistance.

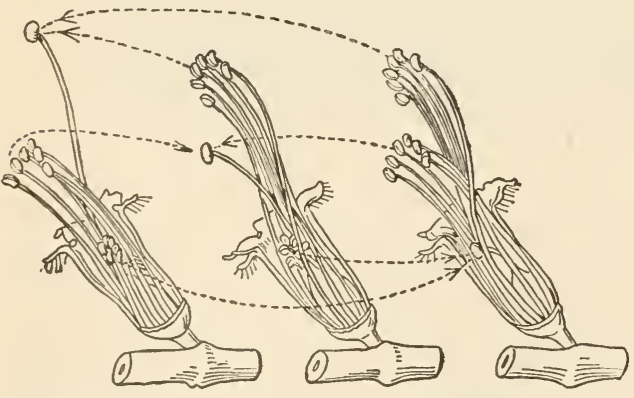

Condition of stamens and pistils in the spiked loosestrife (Lythrum salicaria).

In some flowers, as is shown by the primula of our hothouses, the stamens and pistils are each of two different lengths in different flowers. Short styles and long or highplaced filaments are found in one flower, and long styles with short or low-placed 
filaments in the other. Pollination will be effected only when some of the pollen from a low-placed anther reaches the stigma of a shortstyled flower, or when the pollen from a high anther is placed upon a long-styled pistil. This can be effected easily by flying insects. Flowers which have this peculiar condition are said to be dimorphic (Greek $=$ of two forms). There are, as in the case of the loosestrife, trimorphic flowers having pistils and stamens of three lengths.

Protection of Pollen. - Pollen, in order to be carried effectively by the wind, insects, or other agencies, must be dry. In some flowers the irregular form of the corolla protects the pollen from dampness. Other flowers close up at night, as the morning glory and four o'clock. Still others, as the bell flower, droop during a shower or at night.

Pollen is also protected from insect visitors which would carry off pollen but give the flower no return by cross-pollinating it. In some flowers access of ants, plant lice, or other small crawling insects, to the stamens is rendered difficult by hairs which are developed upon the filaments or on the corolla. Sometimes a ring of sticky material is found making a barrier around the peduncle underneath the flower. Many other adaptations of this sort might be mentioned.

INFLORESCENCE. - Inflorescence is a term given to a flower cluster. It refers to the position of the flowers on the flower stalk. Several types of inflorescence have already been noticed. In the Sedum the inflorescence is limited or the length determined because the flowers come out on the ends of the main flower stalk. Such a determinate inflorescence is named a cyme.

In most flower clusters the inflorescence is said to be indeterminate because the individual flowers come out on the sides of the main flower stalk. Hence the length of the inflorescence cannot be determined. There are several common forms of indeterminate inflorescence. Among forms we are likely to meet are:-

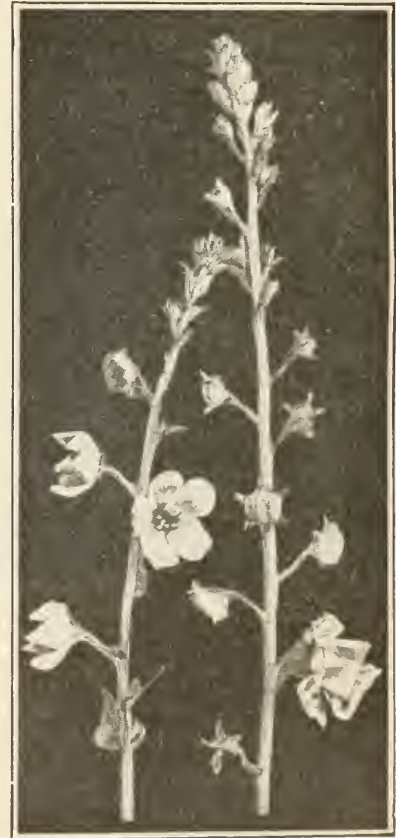

Raceme of moth mullein. 


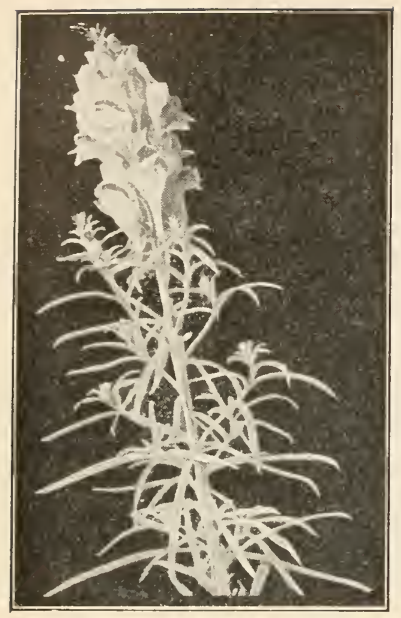

Spike of Linaria ("butter and eggs").

(1) The Raceme. - Moth mullein is an excellent example. The raceme is a tall flower cluster, bearing short pediceled flowers along the sides of its one main stalk. In such an inflorescence you will notice that the oldest flowers are at the base of the cluster. Notice another very important fact, that each flower comes out directly over a tiny green scale or leaf. This fact shows that a flower cluster is a branch which has become changed or modified to bear flowers instead of bearing only green leaves.

(2) The Spike. - A spike, as may be seen in figure, is simply a raceme in which the individual flowers have lost their pedicles, the flowers coming out on the main flower stalk. Examples are plantain, timothy grass, and "butter and eggs."

(3) The Umbel. - In this inflorescence the flower stalks spring from near the same point on the main flower stalk, like ribs in an umbrella; hence the name. A flat-topped cluster, as in wild carrot or the parsley, is the result.

(4) The Head.-In the head the long axis of the inflorescence is reduced, and the flower pedicles are also absent. A compact cluster, as in clover, results.

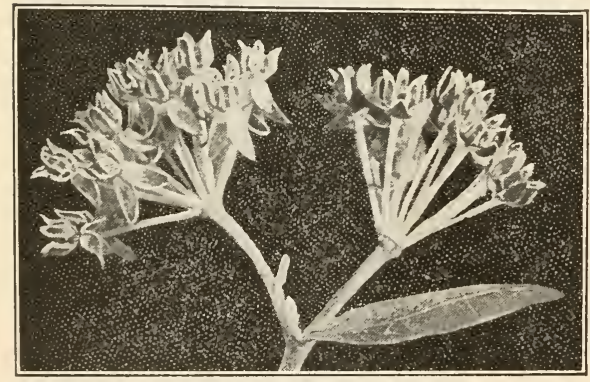

An umbel of milkweed.

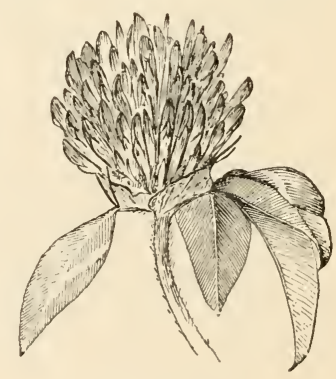

Head of clover.

(5) Composite Head. - This inflorescence, so often mistaken for a single flower, is found only in the great Composite family, to which so many of our commonest flowers and weeds belong. The daisy, aster, golden-rod, and sunflower are examples of the Compositæ.

The composite head is well seen in an aster or the sunflower. This head has an outer circle of green parts. These parts look like sepals, but in reality are a whorl of bracts. Taken together they form an involucre. 
Inside the bracts are the whorls of brightly colored, irregular flowers called the ray flowers. They appear to act, in some instances at least, as an attrac-

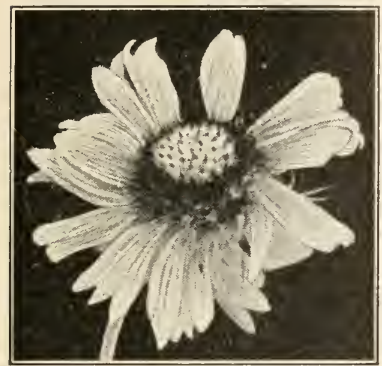

A composite head. tion to insects by showing a definite color (see the common dogwood, Cornus florida).

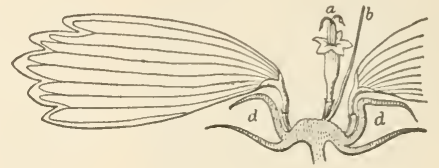

Section through composite head, showing a disk flower $(a)$, a ray flower $(c)$, and the involuere $(d)$.

In most cases the ray flowers are imperfect.

Decide this in the aster or cosmos. (The latter is easily obtained in the fall of the year.) Determine what parts of the ray flower are missing. The flowers occupying the center of the cluster are the disk flowers. Examine such a flower under the hand lens. Determine if the flower is perfect. A careful observer will find in cosmos that the anthers are united in a ring around the pistil. This is a typical condition in the Compositæ.

\section{Reference Books}

FOR THE PUPIL

Andrews, Botany all the Year Round, pages 222-236. Amerisan Book Company. Bailey, Lessons with Plants, Part III, pages 131-250. The Macmillan Company. Coulter, Plant Studies. Chapter VII. D. Appleton and Company.

Dana, Plants and Their Childien, pages 187-255. American Book Company. Hunter and Valentine, Laboratory Manual of Biology. H. Holt and Company. Leavitt, Outlines of Botany, pages 118-127. American Book Company.

Lubbock, Flowers, Fruits, and Leaves, Part I. The Macmillan Company.

Stevens, Introduction to Botany, pages 171-206. D. C. Heath and Company.

FOR THE TEACHER.

Darwin, Forms of Flowers. D. Appleton and Company.

Darwin, Orchids Fertilized by Insects. D. Appleton and Company.

Darwin, Fertilization in the Vegetable Kingdom. Chapters I. and II. D. Appletor and Company.

Campbell, Lectures on the Evolution of Plants. The Macmillan Company.

Gray, Structural Botany. American Book Company.

Lubbock, British Wild Flowers. The Macmillan Company.

Year Book, U.S. Department of Agriculture, 1896, 1897, 1898, 1899, 1900.

HUNTER'S BIOL. -4 


\section{FRUITS}

A Typical Fruit, - the Pea or Bean Pod. - In the study of the flower of the sweet pea it was seen that the pistil of the flower continues to grow after the rest of the flower withers. If we remove the pistil from such a flower and examine it carefully, we find that it is the ovary that has enlarged. The locule of the ovary has become almost filled with a number of almost spherical bodies, attached along one edge of the ovary. These we recognize as the young seeds.

Study of Bean or Pea Fruit. - The pod of the pea or string bean will show us these facts more clearly. Examine, and then draw, natural size, an un-

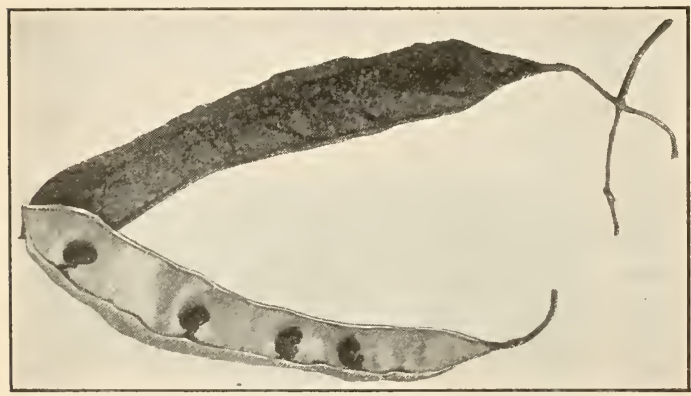

Fruit of the black locust; a legume, showing the attachment of the seeds. opened pod. Label the ovary, peduncle, remains of style, stigma and calyx if you can find them. Then split open the pod and make another drawing that will show the seeds. Label the stalk that attaches each seed to the wall of the pod. This is callcd the $f u$ niculus. That part of the ovary wall which bears the seeds is the placenta. The entire ovary wall is called the pericarp.

The walls of the pod are called valves. Show the above parts by labeling your drawing.

The pod, which is in reality a ripened ovary with other parts of the pistil attached to it, is considered as a fruit. By definition, a fruit is a ripened ovary together with any parts of the flower that may be attached to it. The chief use of the fruit to the flower is to hold, to protect, and ultimately to distribute the seeds where they can reproduce young plants.

Formation of Seeds. - Each seed has been formed as a direct result of the fertilization of the egg cell (contained in the embryo sac of the ovule) by a sperm cell of the pollen tube.

Foris of Fruits; the Achene, the Simplest Fruit. - The forms taken by fruits are very numerous. Naturally the simplest of all fruits would be 
one produced from a simple pistil or carpel containing only one seed. A collection of such fruits may be seen in the ripened flower of the buttercup, smartweed, or buckwheat. A single one of these fruits, that is, a single ripe ovary, is called an achene.

In the fruit of the strawberry the receptacle of the flower has grown up to form the fleshy mass that we call fruit, while the achenelike fruits are found growing on the outside of this. Such a collection of fruits is called an accessory fruit. Why?

Dry and Fleshy Fruits. - Fruits are easily grouped into two great classes, depending upon the amount of water they contain when ripe. They are hence called dry or fleshy.

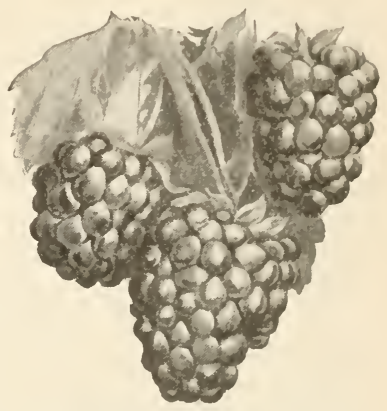

The blackberry; a fruit made up of many separate ripe carpels.

In the following list decide which are dry and which fleshy fruits. Bean, apple, acorn, orange, grain (wheat or corn), pumpkin. How would the seeds in fleshy fruit be able to get out of the fruit? What is the use of the fleshy part to the fruit?

Pome. - The botanist finds several kinds of fleshy fruits. One which we meet with most frequently is called the pome. An

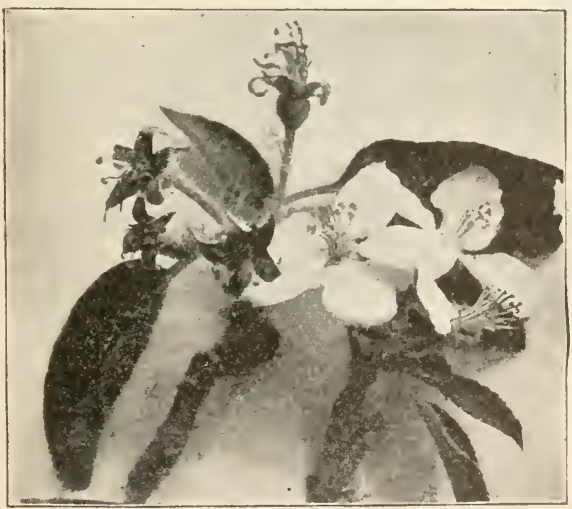

Young apples, and apple blossoms. apple is an excellent example.

Study of an Apple.-In order to understand the formation of the apple fruit it will be necessary to go back to the apple blossom. This gives us an explanation for the dried structures found at the opposite end from the apple stem. These are the dried ends of the sepals.

Notice the skin. Of what use is it to the fruit? Remove the skin from the apple. Leave the pared apple exposed to the air a few hours. What happens? The formation of the fruit can be understood better if we cut several sections through it at right angles to the stem. In a cross scction find the locules of the ovary; how many are there? The tough walls directly inclosing the seeds are the pericarp or ovary wall proper. The fleshy part of the 
apple, then, appears to be formed from some other parts of the flower. Botanists are undecided as to whether it is calyx tube, receptacle, or part

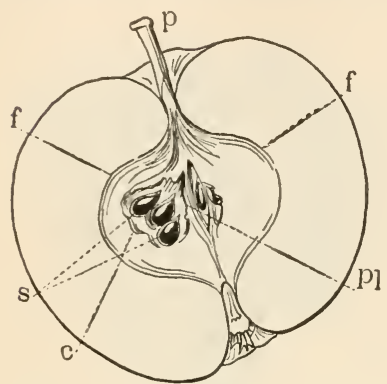

Longitudinal section of a pome; $p$, peduncle; $f$, fibrovascular bundles; $s$, seeds; $p l$, placenta; c, carpel. of both structures. ${ }^{1}$

Draw a cross section of an apple to show the above points. In a longitudinal section the relation of the fruit to the flower is better shown. The stem was the peduncle of the flower; the ovary wall, placenta, and seeds may easily be seen. In young specimens the funiculus, a thread attaching the seed to the placenta, may be found. A short distance outside the ovary wall is seen a faint line. This is composed of somewhat stringlike structures, the tubes such as we found in the strings of the string bean. These bundles of ducts are called the fibrovascular bundles. It is through these ducts that the apple has received most of the food material which was used to form the fruit. We shall learn more about the structure of the fibrovascular bundles in the study of the stems of different plants. Draw a longitudinal section of the apple, natural size.

Other fruits, built on the same plan of structure as the apple, are the pear, quince, and hip. These fruits are classed as pomes.

PePo. - Another fruit of somewhat similar structure as the pome is the pepo. The pumpkin, gourd, and squash are examples. Cut a squash open in cross sections. The ovary wall can be made out close to the numerous

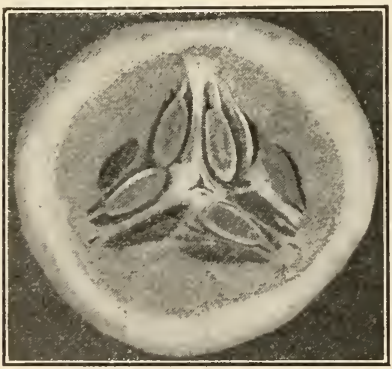

Cross section of a cucumber. Note the number of locules. How and where are the seeds attached?

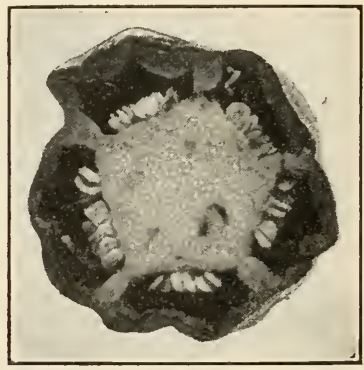

Cross section of a green pepper; a berry. How many locules has the ovary? Note the arrangement of the seeds.

seed which fill the locules of the ovary. How many locules are there in the squash? The outer fleshy part and the rind grow from the receptacle of the

${ }^{1}$ See Hunter and Valentine, Manual, page 73. In this and other suggestions for laboratory work it is expected that the teacher will select from the following pages only a portion of the given material. 
flowers. From what you have observed, make up a definition of a pepo fruit. Draw a cross section of the squash, natural size.

BerRy. - A gardener or vegetable vender rarely calls a tomato a berry. Tomatoes, however, are considered excellent examples of this type of fruit. ${ }^{1}$ In botanical language, a berry is any pulpy, juicy mass containing seeds, this mass inclosed in a rather tough but thin covering, as a rind or skin. In popular language, a berry is any small round edible fruit containing small seeds.

DRUPE. - Another fleshy fruit is the drupe or stone fruit. This is illustrated by the peach or cherry. In the drupe a juicy interior is surrounded by a skin; the center of the fruit is occupied by a stone which contains the seed. This stony covering is made up of the inner wall of the pericarp (ovary wall) which has separated from the part which forms the flesh of the fruit. The connection between these two layers is well seen in a clingstone peach or a very young cherry.

Classify as many of the following named fruits as you can : plum, apricot, egg plant, watermelon, lemon, pomegranate, cranberry, black haw, pear, date, olive. Make up your classification in tabular form.

Dry Fruits. - A dry fruit

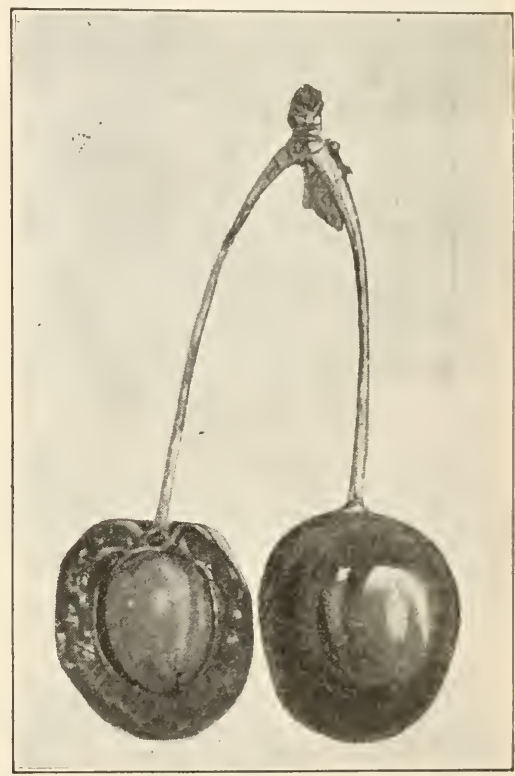

The cherry; a stone fruit or drupe. may split open to allow the escape of seeds. The pea is an example. Such a fruit is said to be dehiscent. ${ }^{2}$ Study an open pea pod. When it splits, it separates along both edges of the two sides or valves. Such a fruit is called a legume.

Follicle. - If the ovary splits along one edge of a valve only, the fruit is called a follicle. The milkweed pod is an example.

Capsule. - When the ovary forming the fruit is compound, the ovary having several locules, it is said to be a capsule.

1 For laboratory work on the tomato, see Hunter and Valentine, Manual, page 71.

2 For laboratory exercises on dry dehiscent fruits, see Hunter and Valentine, Manual, pages $66,67,68$. 
Examine a capsule of Jimson weed. Cut a cross section and decide how many locules there are. Where is the placenta? How many do you find? Open a green fruit to see the number of seeds produced. Draw the

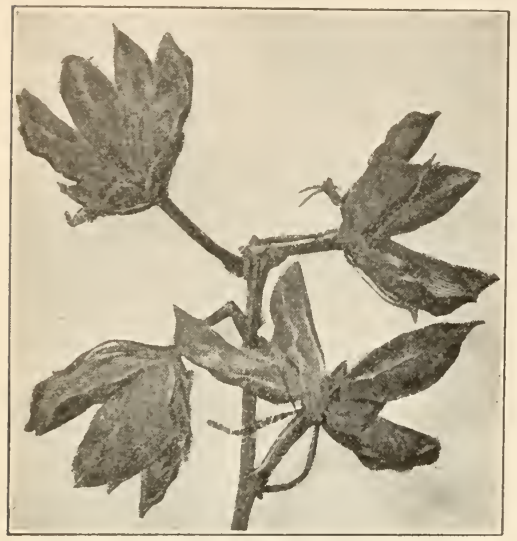

Capsules; each is made up of five carpels. cross section to show the attachment of the seeds. Show also the method of dehiscence (splitting of capsu!e). How does the fruit provide for scattering the seeds?

Silique. - Attention is called to the two or three odd types of capsule frequently seen. All flowers belonging to the mustard family form a silique. This differs from a legume in the presence of a false partition which divides the interior into two parts. Another common form is the purse-shaped capsule; it is known as silicle, best seen in the fruit of the peppergrass or of the shepherd's purse.

Indehiscent Fruits. - Among those of most importance to man economically are the dry indehiscent fruits. Such fruits do not open to allow the escape of seeds. Among them are found the grains, such as wheat, oats, and corn. Many of our most destructive weeds bear indehiscent dry fruits.

Achene. - The simplest and commonest of all indehiscent fruits is the achene. This we have seen before in the buttercup and on the outside of the strawberry. In many flowers, especially those of the great composite family (a group of plants containing many of the most noxious weeds, as the thistle, dandelion, sneezeweed, and others), hairlike projections are developed from the upper part of the fruit.

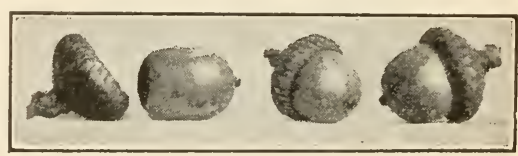

The acorn, a nut in which the involucre only partly covers the fruit.

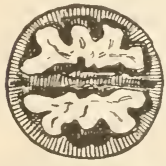

Cross section of a pecan nut.

These projections (collectively called the pappus) are of use to the fruit because they aid in carrying it to other localities at some distance from the parent plant.

Nut. - A nut can usually be recognized by the hard pericarp, or ovary wall, which fits tightly over the kernel. The latter, with its covering, is the true seed. The acorn and pecan are good examples of nuts. The Brazil nut is 
another example of a seed commonly called a nut. We have to bear in mind the distinction between true nuts and hard seeds. An example of the latter is the horse-chestnut. Here the whole capsulelike structure is the fruit and the "nuts" are hardcoated seeds. On the other hand, the acorn cup is made up of leaflike structures which together form what is called an involucre. The chestnut bur is another example of the involucre which has become prickly, the nuts being each a true fruit.

Grain. - The grain, as we shall see when we study the corn more carefully, is a fruit in which the seed occupies most of the space within the fruit, and the seed coat has become so closely attached to the ovary wall that the two coats cannot be separated.

Key Fruit or Samara. - A very common indehiscent fruit is found on the maple, ash, elm, and other trees. It is the key fruit or samara. In this

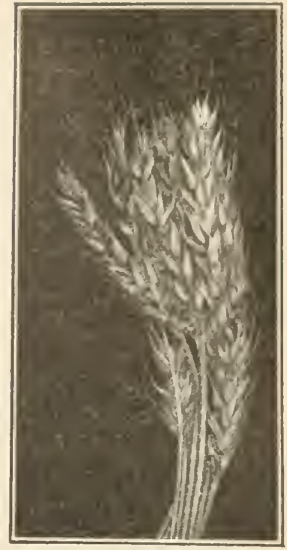

Grain; spikes of ripened flowers.

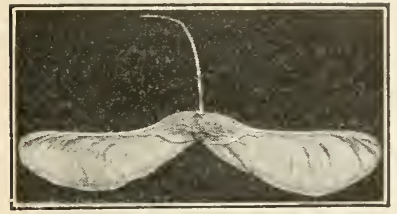

Key fruit of maple.

case the pericarp has lengthened into a long wing.

Hold a maple or ash fruit high above your head and allow it to fall to the ground. Does it fall directly under the point where it was held? When and how might the wings be of use to the fruit? ${ }^{1}$

Distinction between Seeds and Fruits. - We have seen that in the case of one-seeded fruits it is sometimes difficult to distinguish between the seed and the fruit. If we are able to examine the flower which forms a certain fruit, we ought to have no difficulty in making out all of its parts. A cross section through the ovary will show us that seeds are always surrounded not only by seed coverings, but also by the ovary wall, which later forms the pericarp. In

1 For laboratory exercises on dry indehiscent fruits, see Hunter and Valentine, Manual, pages 69, 70, 74, 75.

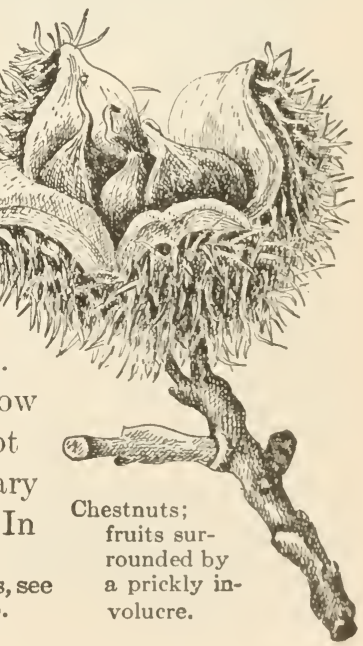


dehiscent fruits the distinction between seed and fruit is always easy. In the indehiscent fruits it is not always so plain, especially in the nuts, grains, and the achene fruits. In all of the above fruits it is necessary to remember that the pericarp, or ovary wall, adheres quite closely to the seed coat. In a grain of wheat the two have actually grown together. In a nut it is always possible to scrape off the seed coat, as a thin brownish covering around the kernel of the nut. Try this with a chestnut.

Homology of Parts in Flowers and Fruits. - In the acorn, chestnut, and hazelnut a number of leaflike structures come out on the branch just under the fruit and become the capsule of the acorn, the bur of the chestnut, and the husk of the hazelnut respectively. All these structures originate from the same place on the branch. Very early in their growth they appear to be leaflike. We have reason to believe that these structures are entirely similar to leaves in structure and position. Any part of a plant or animal that has the same position and structure as another similar part on another plant or animal is said to be homologous with it.

Homology of the Parts of a Flower. - It is believed by botanists that all parts of a flower (sepals, petals, stamens, and carpels) are homolo-

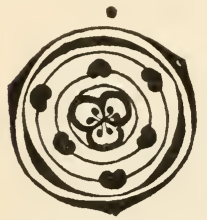

Horizontal diagram of a lily. The central area represents the ovary; the bean shaped structures, the stamens; and the two outer circles the petals and sepals, respectively. gous to each other and also to leaves. It would not take a great stretch of the imagination for you to see how like leaves are the sepals and even the petals of some flowers.

In roses and in the water lily the petals become thinner as we go inward and become tipped with yellow. On examination, this yellow tip is seen to be a pollen box. In short, the petal has become a stamen. A very good imitation of a pea pod could be made by folding a pea leaflet along the midrib. In the Sedum previously studied it will be sen that the carpels bear the same relation to the stamens as the stamens do to the petals. This holds true of petals and sepals. In other words, in a flower each part in each circle or whorl of parts alternates with the parts of the next succeeding whorl. A glance at the diagram will make this more clear. If each of the parts is homologous to leaves, then an opened bud ought to help make this plain. 
It becomes very evident after we have studied a number of flowers and have then taken up the fruits, that the same part of the flower almost invariably appears as a certain part of the fruit, although the part may serve a very different purpose in the different fruits. We have already referred to some examples of this. Take as another example the fate of the ovary wall or pericarp in such fruits as the peach, the apple, the pea, the nut, and a key fruit of maple. In all the above the pericarp of one

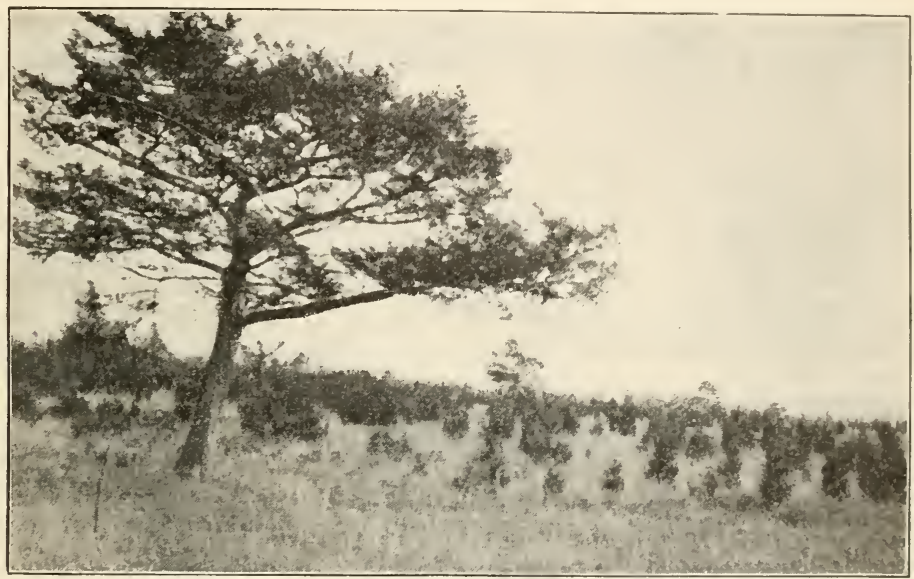

Young cedars around parent tree. Photographed by Overton.

is homologous with the pericarp in another. Yet what a contrast between the papery core of the apple and the hard shell of the nut, the partly fleshy and partly hard pericarp of the peach and the outgrowth we call the wing of the key fruit. ${ }^{1}$

Seed Dispersal. ${ }^{2}$ - If you will go out any fall afternoon into the fields, a city park, or even a vacant lot, you can hardly escape seeing how seeds are scattered by the parent plants and trees. If you count the young maple seedlings which

1 The teacher should point out other homologies in flowers and fruits. This field is one of the richest in this respect in all the field of botany and zoölogy.

${ }^{2}$ At this point a field trip may well be taken with a view to finding out how the common fall weeds scatter their seeds. Fruits and seeds obtained upon this trip will make a basis for laboratory work on the adaptations of seed and fruit for dispersal. 
are growing directly under the shade of the parent tree the number will surprise you. Sometimes several hundred will be found making a brave start in life. But nearly all these young trees are doomed to die, because of the overshading and crowding. Plants, like animals, are dependent upon their surroundings for food and air. They need light even more than animals need it. The soil directly under the shade of the old tree feeds the parent and there is no room for the young plants. This overcrowding is seen in the garden where young beets or lettuce are growing. The gardener assists nature by thinning out the young plants so that they may not be handicapped in their battle for life in the garden by an insufficient supply of air, light, and food.

It is evidently of considerable advantage to a plant to be able to place its progeny, which are to grow up from seeds, at a considerable distance from itself, in order that the young plant may be provided with a sufficient space to get nourishment and foothold. This is the problem which plants have to solve. Some solve the problem to a very much higher degree than others. They are the successful ones in the battle of life.

Adaptations for Seed Dispersal. - Plants are fitted to scatter their seeds either by having the adaptations in the fruit or in the seed. Various agents, as squirrels, birds, and other animals, make it possible for the seed to be taken away from the plant.

Fleshy Fruits with Hard Seeds. - Fleshy fruits, for example, are eaten by animals and the seeds passed off undigested. Most wild fleshy fruits have either small, hard, indigestible seeds, or else they have an unpleasant flavor.

Birds are responsible for much seed planting of berries or other small fruit. Bears and other berry-feeding animals aid in this as well.

Field Work. - Examine the fruit of huckleberry, blackberry, wild strawberry, wild cherry, black haw, wild grape, tomato, currant. Report how many of the above have seeds with hard coatings. Notice that in most, if not in all, edible fruits the fruit remains green, sour, and inedible until the seeds are ripe. In the state of nature, how might this be of use to a plant?

Hooks and Spines. - Some fruits possess hooks or spines which enable the whole fruit to be carried by animals or other moving objects away from the parent plant. Cattle are responsible for the 
spread of some of our worst weeds in this way. The burdock and clotbur are familiar examples. In both the mass of little hooks is all that remains of an involucre. Thus the whole fruit cluster may

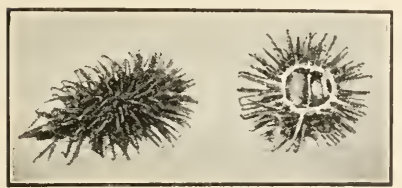

The cocklebur. be carried about and seeds scattered. In many other fruits of the composites, as in the cockleburs and beggar's ticks, the whole fruits are provided with strong curved projections which bear many smaller hooklike barbs.

Examine the front of a cocklebur or a beggar's tick with a low magnificatiou or even a hand lens. Draw such a fruit. Of what probable use are the many barbs?

Pappus. - Probably the most important adaptations for dispersal of seeds are those by which the fruit is fitted for dispersal by the wind. That much-loved and much-hated weed, the dandelion, gives us an example of a plant in which the whole fruit, an achene, is carried by the wind. The parachute, or pappus, is an outgrowth of the ovary wall. Many other fruits, notably that of the Canada thistle, are provided with the pappus as a means of getting away. If dandelions are available, notice the wonderful lightness and strength of the pappus. In the milkweed the seeds have developed a silky outgrowth which may carry the seeds for miles. In New York city the air is some-

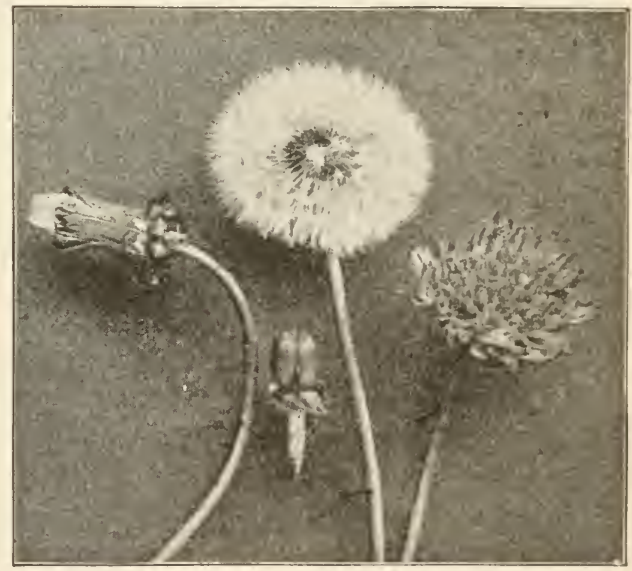

Dandelion heads; the middle one a mass of ripe fruits ready to be scattered by the wind. Photographed by Overton. times full of the down from these seeds which is brought from far over the meadows of New Jersey by the prevailing westerly wind. 
Winged Seeds. - The seeds of the pine, held underneath the scales of the cone, are prolonged into wings, which aid in their dispersal.

Tumble Weeds. - Sometimes whole plants are carried by the high winds of the fall. This is effected in the plants called tumble

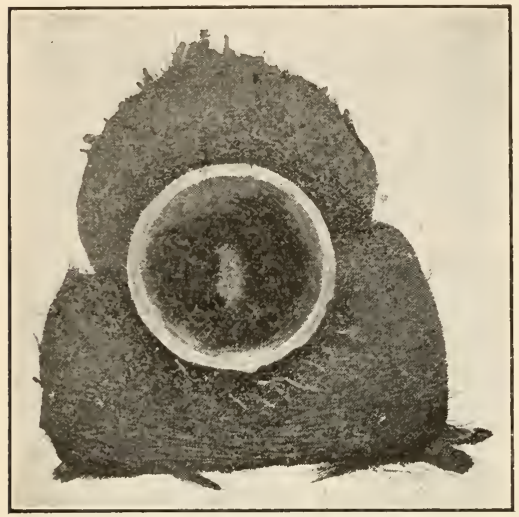

Cross section of a cocoanut in its fibrous husk. weeds, in which the plant body, as it dries, assumes a somewhat spherical shape. The main stalk breaks off and the plant may then be blown along the ground, scattering seeds as it goes, until it is ultimately stopped by a fence or bush. A single plant of Russian thistle may thus scatter over two hundred thousand seeds.

Seeds or fruits (for example, the cocoanut) may fall into the water and be carried thousands of miles to their new resting-place, the fibrous husk providing a boat in which the seed is carried. The great English naturalist, Charles Darwin, raised eighty-two plants from seeds carried in a ball of earth attached to the foot of a bird. It is probable that by means of birds and water most of the vegetation has come into existence on the newly formed coral islands of the Pacific. Ocean.

Some seeds have especial adaptations in the way of spines or projections. Insects make use of these projections in order to carry them away.

Ants plant seeds which they have carried to their nests for a food supply. Nuts are planted in much the same manner by squirrels.

Explosive Fruits. - Some fruits scatter their seeds through the explosion of the seed case. Such a fruit

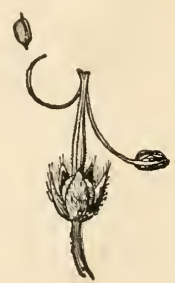

Pod of crane's bill discharging its seed. is the witch-hazel, which explodes with such force that the seeds are thrown several feet. The wild geranium, a five-loculed cap- 
sule, splits along the edge of each locule, snaps back, and throws the seed for some distance. Jewel weed fruits burst open in somewhat the same manner. Make observations on jewel weed to find out if possible how the explosion of the fruit is caused.

Large Numbers of Seeds. Plants which do not have especial means for scattering their seeds may make up for this by producing a large number of seeds and holding them in podlike fruits which are easily shaken by the wind. The poppy and jimson weed are familiar examples of such plants. Each capsule of jimson weed contains from four hundred to six hundred seeds, depending upon its size. If all of these seeds developed, the whole earth would

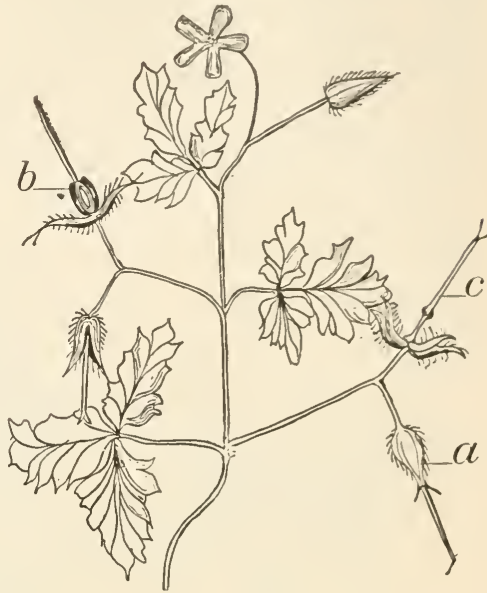

Wild geranium (crane's bill), showing method of seed dispersal; $a$, flower with seeds nearly ripe; $b$, flower with seeds ripe; $c$, flower after having thrown seeds. (After Lubbock.) soon be covered with jimson weed, to the exclusion of all other forms of plant life. That this is not the case is due to the fact that only those seeds which are advantageously placed can develop; the others will, for various reasons (lack of moisture to start the young seed on its way, poor soil, lack of air or sunlight, overcrowding), fail to germinate.

The Struggle for Existence. - Those plants which provide best for their young are usualiy the most successful in life's race. Plants which combine with the ability to scatter many seeds over a wide territory, the additional characteristics of rapid growth, resistance to dangers of extreme cold or heat, attacks of parasitic enemies, inedibility, and peculiar adaptations to cross-pollination or self-pollination, are usually spoken of as weeds. They flourish in the sterile soil of the roadside and in the fertile soil of the garden. By means of rapid growth they kill other plants of slower growth by usurping their territory. Slow-growing plants 
are thus actually exterminated. Many of our common weeds have been introduced from other countries and have, through their numerous adaptations, driven out other plants which stood in their way. It is evident that the plants which are best adapted to changes in their surroundings, those plants which have allowed themselves to be molded to fit into new conditions, are the successful ones. Such is the Russian thistle. First introduced from Russia in 1873 , it spread so rapidly that in twenty years it had appeared as a common weed over an area of some twenty-five thousand square miles. It is now one of the greatest pests in our Northwest.

Economic Value of Fruits. - Our grains are the cultivated progeny of wild grasses. Domestication of plants and animals mark epochs in the

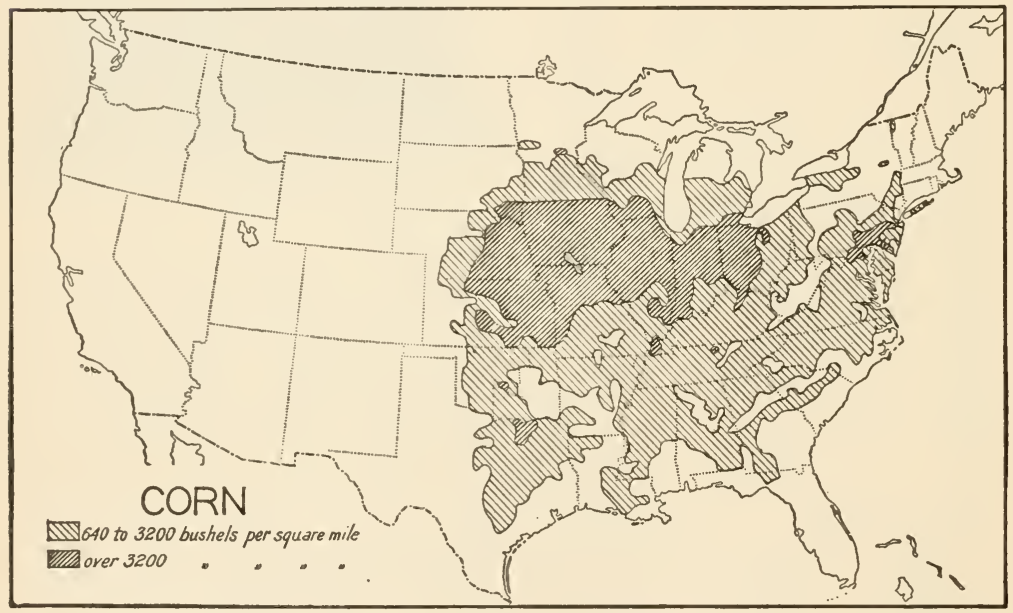

\begin{tabular}{|lllll}
\multicolumn{5}{c}{ Indian Corn Production-Percentage } \\
\hline Illinois & Lowa & Neb. Mo. Kan. Ohio Ind.Tex. Rest of United States \\
\hline
\end{tabular}

advance of civilization. The man of the stone age hunted wild beasts for food, and lived like one of them in a cave or wherever he happened to be; he was a nomad, a wanderer, with no fixed home. The tribes which first cultivated the soil made a great step in advance, for they had as a result a 
fixed place for habitation. The cultivation of grains and cereals gave them a store of food which could be used at times when other food was scarce. The word cereal (derived from Ceres, the Roman Goddess of Agriculture) shows the importance of this crop to Roman civilization. From earliest times the growing of grain and the progress of civilization have gone hand in hand. As nations have advanced in power, their dependence upon the cereal crops has been greater and greater.

"Indian corn," says John Fiske, in The Discovery of A merica, " has played a most important part in the discovery of the New World. It could be

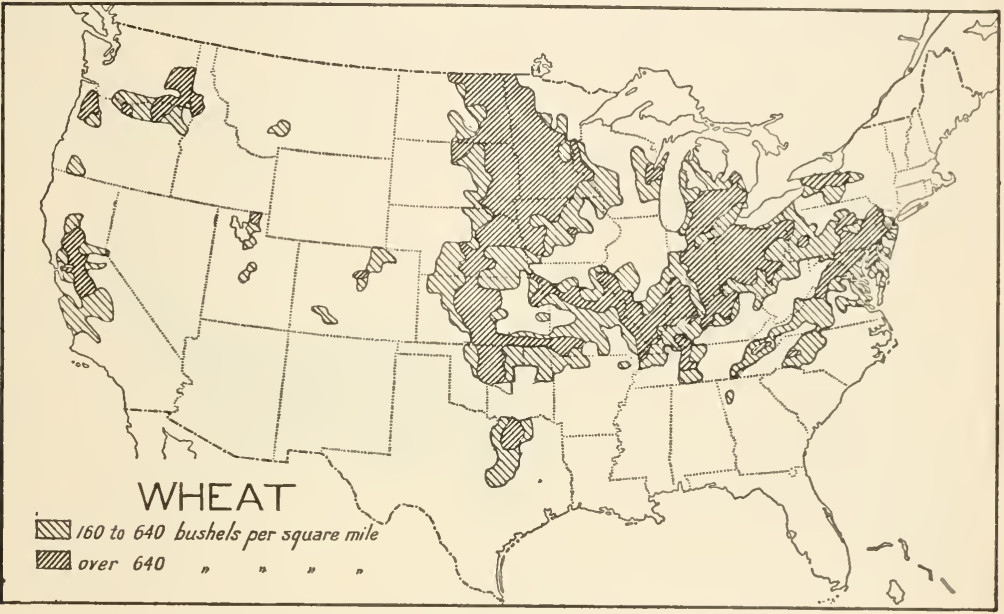

Wheat Crop in United States-Percentage Source

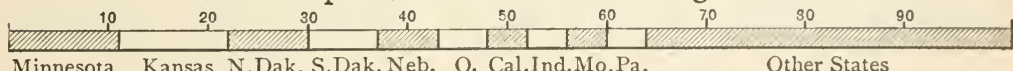

planted without clearing or plowing the soil. There was no neer of thresn. ing or winnowing. Sown in tilled land, it yields more than twice as much food per acre as any other kind of grain. This was of incalculable advantage to the English settlers in New England, who would have found it much harder to gain a secure foothold upon the soil if they had had to begin by preparing it for wheat or rye."

To-day, in spite of the great wealth which comes from our mineral resources, live stock, and manufactured products, the surest index of our country's prosperity is the size of the wheat and corn crop. According to the last census, the amount of capital invested in agriculture was over twenty billion dollars, while that invested in manufactures was less than one half that amount. 
ConN. - Two billion six hundred and sixty-six million four hundred forty thousand two hundred and seventy-nine bushels of corn were raised in the United States during the year 1900. This figure is so enormous that it has but little meaning to us. In the past half century our corn crop has increased over 350 per cent. Illinois and Iowa are the greatest corn-producing states, each having a yearly record of over four hundred million bushels. The figure on page 62 shows the principal corn-producing areas in the United States.

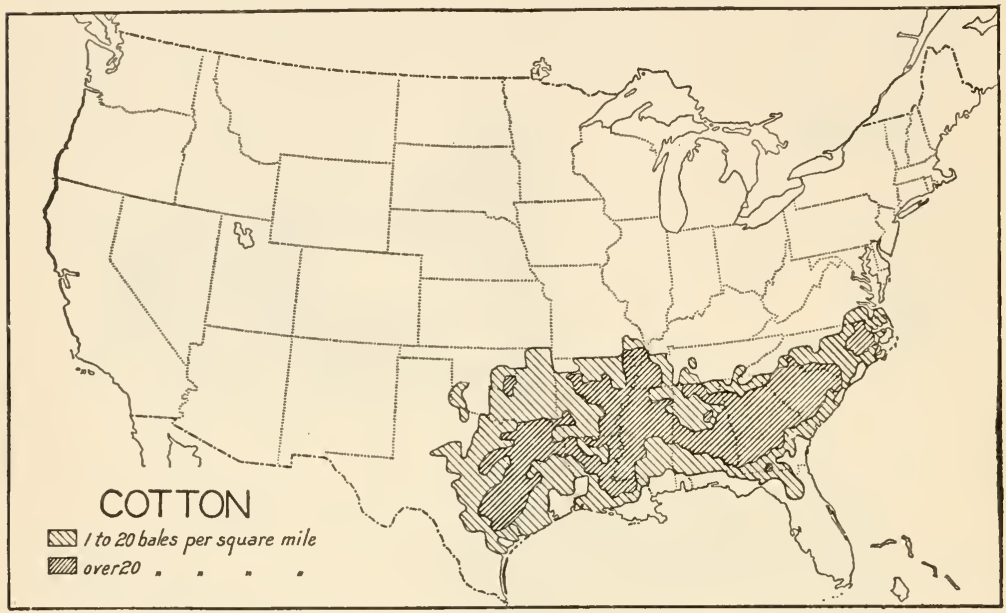

\section{Cotton Crop in United States-Percentage Source}

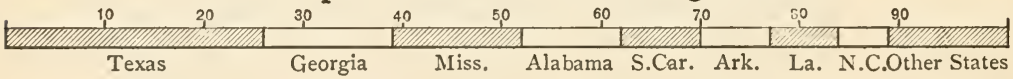

Percentage Consumption-United States Cotton Crop

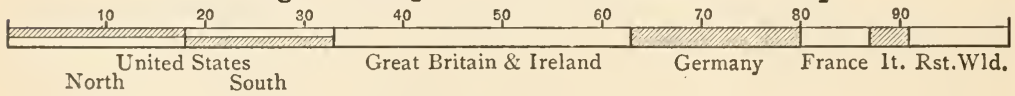

Indian corn is put to many uses. It is a valuable food. It contains a large proportion of starch, from which glucose and alcohol are made. Machine oil and soap are made from it. The leaves and stalk are an excellent fodder; they can be made into paper and packing material. Mattresses can be stuffed with the husks. The pith is used as a protective belt placed below the water line of our huge battle ships. Corn cobs are used for fuel, one hundred bushels having the fuel value of a ton of coal.

Whest. - Wheat is the crop of next greatest importance in size, and is 
of even greater money value to this country. Nearly six hundred and sixty million of bushels were raised in this country in 1900, representing a total money value of $\$ 500,000,000$. Seventy-two per cent of all the wheat raised comes from the North Central States and California. About three fourths of the wheat crop is exported, nearly one half of it to Great Britain. Wheat has its chief use in its manufacture into flour. This forms the chief industry of Minneapolis, Minnesota, and several other large and wealthy eities in this country. The germ, or young wheat plant, is sifted from the flour and made into breakfast foods.

OтнеR Fruits. - Of the other grain and cereals raised in this country, oats are the most important crop. Hay as a fodder crop is of great value next to that of corn, nearly $\$ 500,000,000$ worth being raised every year. Buckwheat, barley, and rye are also raised in considerable amounts, but are relatively unimportant commercially. Among our fruits cotton is probably that of the most importance to the outside world. Over ten million bales of five hundred pounds each are raised annually. Of this amount a large amount is exported, the United States producing over three fourths of the world's cotton supply. The relation of source and distribution of the cotton crop can be seen by a glance at the accompanying diagram.

Other important fruit crops might be mentioned. There are over one hundred and seventy-five million bushels of apples produced every year in the United States. Pears, peaches, plums, cherries, and grapes play an important part in the crop, especially in California, which produces yearly over seven hundred million pounds of grapes, over fifty per cent of the total yield in the United States.

\section{Reference Books}

FOR THE PUPIL

Dana, Plants and Their Children, pages 27-49. American Book Company. Goff and Mayne, First Principles of Agriculture. American Book Company. Atkinson, First Studies of Plant Life, Chap. XXIII. Ginn and Company. Bailey, Lessons with Plants, pages 251-314. The Macmillan Company. Bailey, Botany, Chaps. XXI, XXII. The Macmillan Company. Coulter, Plant Studies, Chap. VI. D. Appleton and Company. Beal, Seed Dispersal. Ginn and Company.

Newell, Reader in Botany, pages 97-137. Ginn and Company.

FOR THE TEACHER

Bailey, The Evolution of our Native Fruits. The Macmillan Company.

Bailey, Plant Breeding. The Macmillan Company.

Hodge, Nature Study and Life, Chaps. X, XI. Ginn and Company.

Sargent, Corn Plants. Houghton, Mifflin, and Company.

Kerner (translated by Oliver), Natural History of Plants. Henry IIolt and Company. 4 Vols. Vol. II, Part 2.

HUNTER'S BIOL. -5 


\section{SEEDS AND SEEDLINGS}

Relation of Flower to Fruit. - We have already found in our study of the fruit that the bean pod is a direct outgrowth from the flower. It is, in fact, the ovary of the flower, with the parts immediately surrounding it, which has grown larger to make a fruit.

Use of Fruit. - The fruit is the most important result of the flower. It holds and protects the seeds until the time comes that they are able to germinate and produce new plants like the original plant from which they grew.

Study of a Bean. - Let us now take up the careful study of a bean in order better to understand how the seed may produce a young plant. For this purpose we need some dry pods of the string bean and some kidney beans. ${ }^{1}$

If we have already studied the pod of the bean, it will now be easy for us to find and identify the parts of the pod which were style, stigma, and ovary in the flower. Opening the pod along one of the edges or sutures of the two valves, we find the seeds fastened to the placenta each by the little stalk or funiculus. If we pull a single bean from its attachment, we find the funiculus leaves a scar on the coat of the bean; this scar is called the hilum. Look near the hilum for a tiny hole called the micropyle. (Do not confuse it with a little knob called the strophiole.) Turn back to the figure showing the ovule in the ovary. Find there the little hole through which the pollen tube reached the embryo sac. This hole is called the micropyle, and is identical with the micropyle in the seed. Draw a single kidney bean from the edge bearing the hilum scar, and show exactly the location of the hilum, micropyle, and strophiole. Make the drawing twice natural size.

Home Experiment. - Divide ten kidney beans of nearly equal size into two lots. Cover the micropyles of one lot with wax or vaseline, weigh both lots of seeds exactly, then leave them in water over night. Weigh both lots in the morning. Note any differences in the appearance of the two lots of seeds. What is one use of the micropyle to the bean seed? This experiment may be made more instructive by covering a third lot of beans completely with wax and exposing them to the same conditions as you did the others. Does any water get in through the seed coats? Remove carefully the coat from a kidney bean which has been soaked over night in water. This coat, because of its toughness, is called the testa. Do you find another coat under it? You find the bean separates into two parts; these are called the cotyledons. If you separate the cotyledons very carefully, you find certain other structures between them. The rodlike part is called the hypocotyl (meaning under the cotyledons). This will later form the root (and part of the stem) of the young plant. Look for the first

- For extended laboratory study on the bean, see Hunter and Valentine, Manual, page 13. 
true leaves folded together between the cotyledons. How many leaves are there? That part of the plant above the cotyledons is known as the plumule or epicotyl (meaning above the cotyledons). Later we shall wish to know what part of the future plant the epicotyl forms.

All the parts of the seed within the seed coats together form the embryo or young plant.

Draw the bean to show all the above parts, twice natural size. Label every part carefully.

Food in the Cotyledons. - The problem now before us is to find out how the embryo of the bean is adapted to grow into an adult plant. Up to this stage of its existence it has had the advantage of food and protection from the parent plant. Now it must begin the battle of life alone. We shall find in all our work with plants and animals that the problem of food supply is always the most important problem to be solved by the growing organism. Let us see if the embryo is able to get a start in life (which many animals get in the egg) from food provided for it within its own body.

Experiment. - Mash up a little piece of a bean cotyledon which you have previously soaked in water. Test for starch with iodine solution What color appears? If you now mount a little of the stained material in water on a glass slide under the compound microscope, you will find that the starch is contained in the form of little ovoid bodies called starch grains. The starch grains and other food products are made use of by the growing plant in a manner which we shall later know more about.

Test the cotyledon of a bean, for proteid food, with nitric acid and ammonium hydrate. The change of the color of the surface shows us that considerable proteid is present. According to the compilations from the government reports, the kidney bean is one of the materials very rich in proteid food. It contains not less than 23 per cent of proteid, 57 per cent of carbohydrates, and about 2 per cent of fats.

Test a bean by heating it on a piece of paper in the oven to see if the small quantity of oil present can be detected by this means.

The above tests show us that the bean seed contains a large supply of food which, as we shall see, is used by the young plant in its germination.

Germination of the Bean, Pea, and Corn. - Soak the seeds at least eight hours in water before planting. In general, the larger the seed the longer the immersion in water before planting. For use in the laboratory secds may be planted in shallow boxes or trays. Use sawdust, clean white sand, or sphagnum moss to plant them in. Make holes in the bottom of the boxes for drainage. Plant beans about half an inch deep; smaller seeds 
may be planted from five to ten times their own depth. Keep the temperature as near $75^{\circ}$ Fahrenheit as possible. Protect at night from sudden drops in temperature by careful covering of the young plants. Water regularly and moderately. If the material for class work is ready at certain stages before time to use in the laboratory, the specimens may be placed in 4 per cent formol solution until needed. After the different plants have appeared above ground a daily record should be made of at least one of each kind of seed or grain planted. Note the length of time it took each to appear above the ground and make daily drawings until the young plants

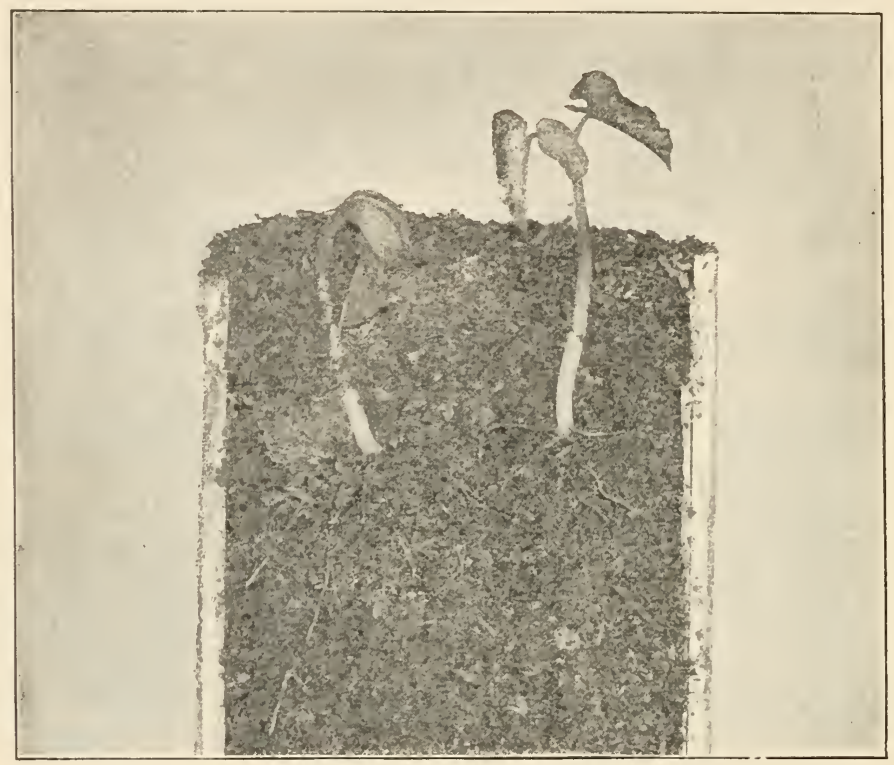

Sprouting beans. Note the arch in the hypocotyl. How is this of 'ise to the plant in its growth?

are at least two weeks old. At the end of that time an entire plant of kean, pea, and corn should be removed and drawn. You will thus accurately determine the fate of each part of the growing plant

Answer the following questions from bean seedlings grown at home or from material supplied you in the laboratory. Which part of the embryo breaks through the seed coats first and at what point does it appear? In what direction does the hypocotyl grow? Does it always take this direction? How does the seedling break through the ground? Which part appears first above ground? Why does it assume this position? Are the cotyledons pushed or pulled out of the ground? What color has the plant above ground? What becomes of the cotyledons in old specimens? Measure the cotyledons in a young specimen and then again when the plant has grown older. Do they grow in size? Make a table which shows the ultimate fate in a bean seedling of the following parts: cotyledons, hypocotyl, epicotyl. 
Make a series of at least three drawings of the developing seedling to show the growth of the various organs In this series draw a line across your paper to show the level of the ground.

Problems of Growth. ${ }^{1}$ - There are several interesting problems concerning the growth of the bean seedling. Most of these questions we can solve with the aid of simple experiments. These experiments may be allotted to different members of the class to perform at home and bring to school when the laboratory work of the bean seedling is finished and the pupils are ready for a discussicn of its growth. The following experiment should be started at once.

Experiment. - What is the function of the cotyledons of the bean? Plant six beans in sawdust. After they have grown so that the hypocotyls are above the surface, remove the cotyledons from three beans. Watch the growth of both lots very carefully, making sure that they are exposed to exactly the same conditions of heat, moisture, light, and air. After two weeks draw a bean from each lot. Of what use to the growing plant are the cotyledons? Why?

\section{Germination. - All the stages} passed through by the young plant, from the time the seed begins to sprout until it can

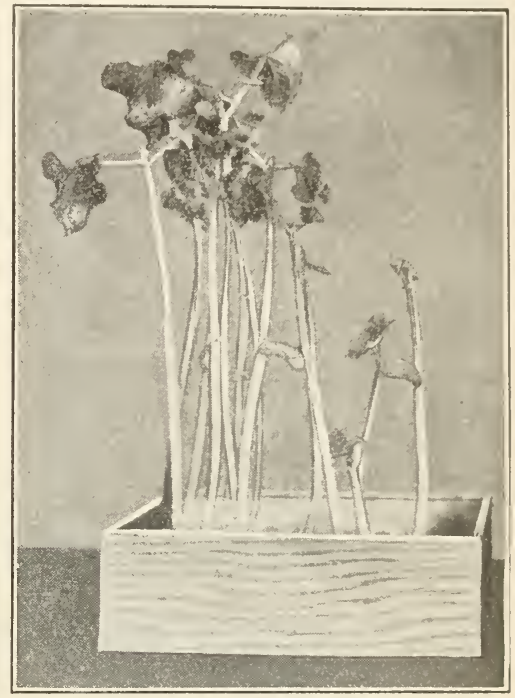

Bean seedlings. Note that in the older seedlings to the left the cotyledons have been almost entirely used up.

take care of itself by means of its roots and leaves, are known as the stages of germination. The young plant ceases to be a seedling after it has lost its seed leaves or cotyledons.

A comparison of the Pea and Bean. - Suggestions for laboratory work. Compare the markings on the outside of the pea with those you found on the bean. Make a diagram of the pea drawn from the hilum end. Show the following struetures neatly labeled: hilum, micropyle, strophiole.

Open a soaked seed. How many cotyledons do you find?

Plants having two cotyledons or seed leaves are ealled dicotyledons. Do you know any other plants having two eotyledons besides the pea and bean?

1 At this point, experiments may be introduced, showing the result of oxidation, of organic materials, the tests for carbon dioxide, the fact that oxidation of food substances takes place within the growing pea or bean (as shown by placing germinating seeds within a closed jar), and that air is necessary for germination.

${ }^{2}$ It must be remembered that this is not quite a fair test to the bean, because we take away from the young plant part of its own body. 
Most of our trees, and rery many of our common plants, belong to this great group of plants.

How many of the parts inside the cotyledons can you identify and compare with similar structures in the bean? Look for hypocotyl, epicotyl,

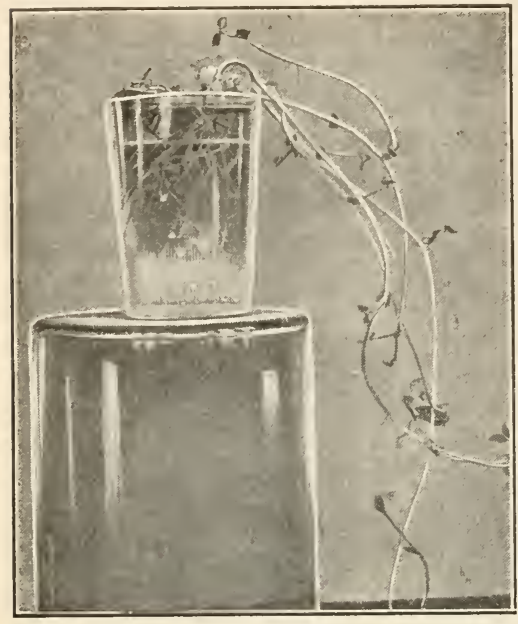

Experiment to show the function of the cotyledons of the pea, photographed at the end of two weeks. Note the size of the plants at the left, without cotyledons. and true leaves. Are the structures named homologous with the same structures in the bean? How do you know?

Draw the pea, showing all the above-named parts.

Compare the pea seedling and bean seedling with regard to the following points: (1) as to the method of getting out of the ground; (2) as to the part which appears first; (3) as to the parts that appear above ground; (4) the ultimate fate of each part.

This must be made the subject of an extended home experiment. Drawings should be made to illustrate each stage of growth, and each part should be carefully labeled. ${ }^{1}$

An experiment to prove the function of the cotyledons of the pea may be made in very much the same way as the experiment performed to find out the same thing for the bean. This experiment can be made at home and brought in at the same time as the bean experiment, and comparisons made.

Analogy. - A structure which has the same function or use as another structure is said to be analogous to it. Is the cotyledon of the pea analogous to the cotyledon of the bean? Is it also homologous?

Cotyledons as Foliage Leaves. - In the young plants which we have just been talking about, the cotyledons hold a reserve food supply, but do not serve at any time as true leaves for the plant In many dicotyledons, however, the seed leaves do act as true leaves. This may well be seen in the squash seedling. Here the young plant has little or no food stored in the cotyledons; it must be prepared to take care of itself quickly. It does this by means of the rapidly growing cotyledons, which soon unfold as true leaves to the sun. In the seeds of the pea and bean we have found that the embryo takes up all the space within the seed

${ }^{1}$ See Hunter and Valentine, Manual, page 18. 
coats. There are some dicotyledonous plants that have food stored outside of the embryo. Such a plant is the castor bean. ${ }^{1}$

Castor Bean. - A section cut vertically through the castor bean discloses a white oily mass directly under the seed coats. This mass is called the endosperm. If it is tested with iodine, it can be proved to contain starch; oil is also present in considerable quantity. Within the endosperm lies the embryo, a thin, whitish structure. If the embryo is carefully removed from the endosperm (see directions in preparation note, page 19, Hunter and Valentine, Manual), the structure of the embryo can easily be made out.

Open a number of soaked seeds of the following-named plants, and

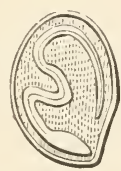

$a$

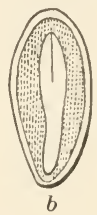

$b$

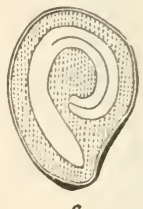

$c$

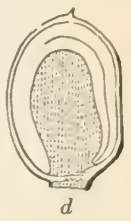

Arrangement of embryo in endosperm (GRAY); $a$, morning glory; $b$, barberry; $c$, potato; $d$, four o'clock.

locate, with the aid of the diagrams, the embryo and the endosperm in each: four o'clock, morning glory, castor bean, maple. Make diagrams for your notebook to show these facts.

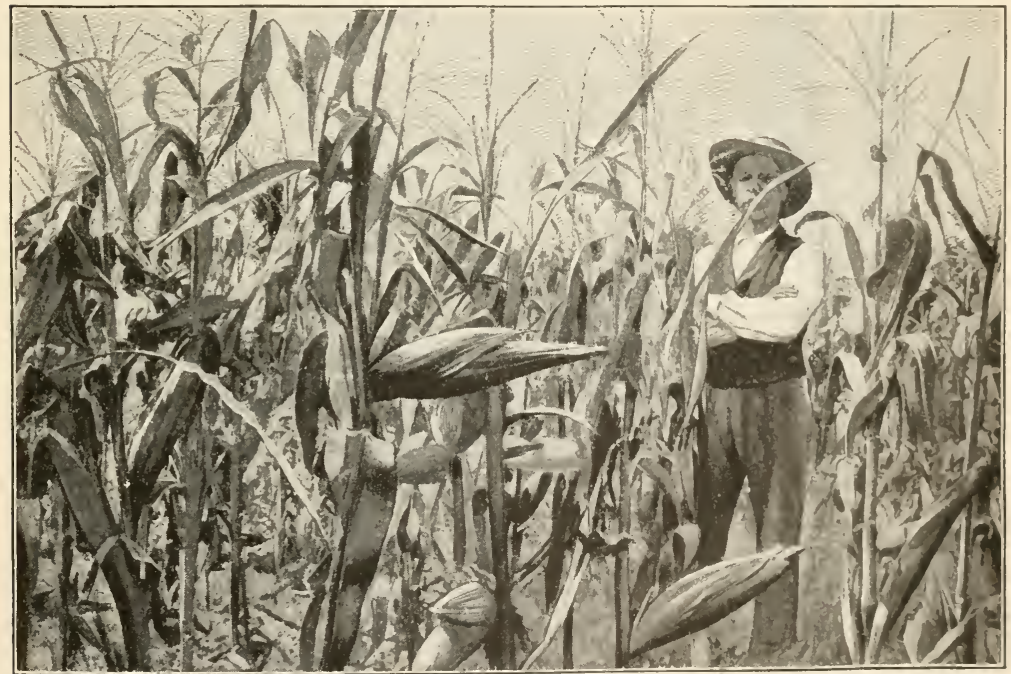

A cornfield, showing staminate and pistillate flowers.

The Corn. - The ear of corn is not a single fruit, but a large number of fruits in a cluster, like, for example, a bunch of bananas.

${ }^{1}$ For laboratory work on the castor bean, see Hunter and Valentine, Manual, page 19 . 
Push back the husk of a young ear of corn. The husk is simply a covering of leaflike parts which has grown over the young fruits for their better protection. We have already noticed such

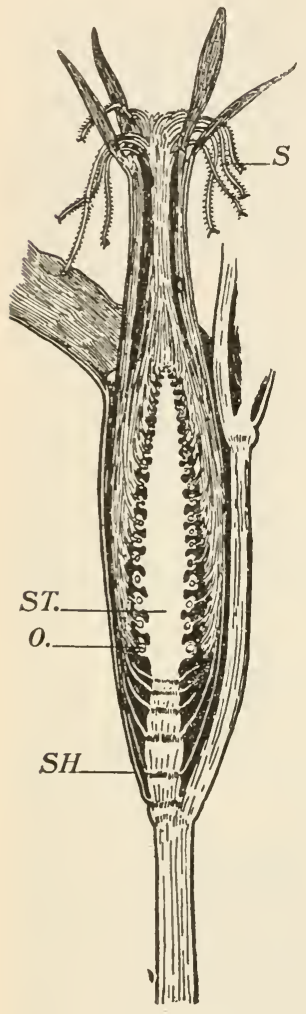

Longitudinal section of young ear of corn; $O$, the fruits; $S$, the stigmas; $S H$, sheathlike leaves; $S T$, the flower stalk or peduncle. (After Sargent.)

pointing toward the attached end and the plumule or the epicotyl pointing toward the unattached end.

Draw the longitudinal section of the corn grain as seen stained with iodine. Mark all the parts. Make your drawing at least twice natural size. and bur of chestnut. What did we call it? We uncover what was a short time before a bunch of very peculiar flowers. The corn cob is the much-thickened flower stalk on which the flowers were clustered. If you have removed the husk carefully you will see part of each flower remaining attached to each grain of corn. The so-called silk of corn is nothing more than a long central style and stigma. The corn grain itself was also part of the flower - the same part that formed the pod of the bean with its contained seeds. The corn grain, therefore, is a fruit and not a seed. Is the grain of corn homologous with the pea or bean?

Laboratory Suggestions for Work on Grain of Corn. ${ }^{1}$ - In a single grain of corn which has been soaked at least twenty-four hours, notice the differences between the attached and free ends of the grain. Look for the scar which marked the attachment of the silk. The light-colored area found on one surface marks the position of the embryo; the rest of the grain contains the endosperm. Cut a grain perpendicular to the flat side of the grain in a lengthwise direction. Find the embryo from its relation to the outside of the grain. Apply a drop of weak iodine solution. What material is found in the endosperm of corn?

The part of the grain that does not stain so deeply with iodine is the embryo. Find two parts, - a tiny elongated structure and an area lying between it and the endosperm. The latter is the single cotyledon.

Use a lens. Notice that the elongated structure in the embryo has two parts, the hypocotyl a structure forming the capsule of the acorn

'See Hunter and Valentine, Manual, page 16. 
Endosperm the Food Supply of Corn. - We do not find that the one cotyledon of the corn grain serves the same purpose to the young plant as did the two cotyledons of the bean. Although we find a little starch in the corn cotyledon, still it is evident from our tests that the endosperm is the chief source of food supply. The study of a thin section of the corn grain under the compound microscope shows us that the starch grains in the outer part of the endosperm are large and regular in size. Those near the edge of the cotyledon are much smaller and quite irregular, having large holes in them. We know that the germinating grain has a much sweeter taste than that which is not growing. This is noticed in sprouting barley or malt. We shall later prove that, in order to make use of starchy food, a plant or animal must in some manner change it over to sugar. That starch is being changed to grape sugar in the germinating corn grain can easily be shown by the following experiment:-

Cut lengthwise through the embryo half a dozen grains of corn that have just begun to germinate. Place them in a test tube with a little Fehling's solution and heat almost to the boiling point. On examination, the corn grains will be seen to give a slight reaction for the sugar test, especially along the edge of the cotyledon and between it and the endosperm.

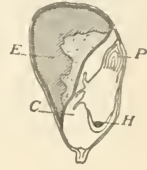

A grain of corn, cut lengthwise; $C$, cotyledon; $E$, endosperm ; $H$, hypocotyl; $P$, plumule.

Digestion. - This change of starch to grape sugar is a process of digestion. It is performed by means of a substance found in the cotyledon known as a digestive ferment or enzyme. The enzyme found in the cotyledon of the corn, which changes starch to grape sugar, is called diastase.

Demonstration. The action of diastase on starch. - Diastase can be separated from the cotyledon. It is here used in the form of a powder.

To 1 c.c. of starch in 100 c.c. of water, add a very little ( 1 gram) of diastase. Place the vessel containing the mixture in a warm place, where the temperature will remain nearly constant at about $98^{\circ}$ Fahrenhcit. Test part of the contents at the end of half an hour, and the remainder the next morning, for starch and grape sugar. The starch in the latter test will be found to be completely changed to grape sugar.

Experiment. - Select nine germinating grains of corn; remove the endosperm from six of them. Replace the endosperm in three of the grains by a little corn-starch paste. Place all nine grains on netting over a cup of water, so that the roots reach the water. Keep them moist. Watch from day to day to see which seedlings do the best. Explain the experiment. 


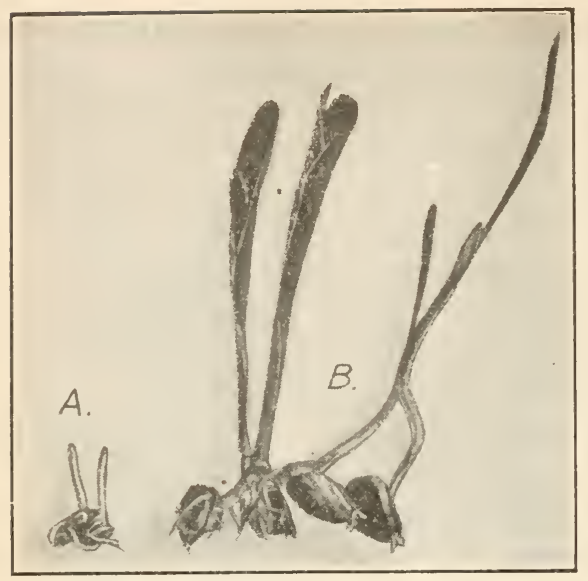

The use of the endosperm to the corn; $A$, seedlings without endosperm; $B$. seedlings with starch in place of endosperm; normal seedlings at the center.
Make drawings at the end of two weeks to explain your results. Of what use is the endosperm? Can the seedling make use of the food supply given it in the cornstarch paste?

\section{Other Foods in Corn} Grain. - Other foods besides starch and sugar are present in the corn grain. A test for proteid shows that a considerable amount of this food is present. Oil also is found. In the sweet corn that we eat water forms a very large percentage of its composition by weight. This is true of most plant and animal foods that are eaten in a fresh state.

Fate of the Parts of the Embryo of the Bean, the Pea, and the Corn. - If the above experiments with reference to the germination of peas, beans, and corn have been carefully observed, you have by this time reached very definite conclusions regarding the use of each part of the seed (or grain) to the young plant. In all specimens the hypocotyl is found to give rise to the root system of the young plant (and in the bean to part of the stem), while the part we call epicotyl forms the leafy shoot. The function of the cotyledons differed in all specimens. In the bean they were carried up above ground;

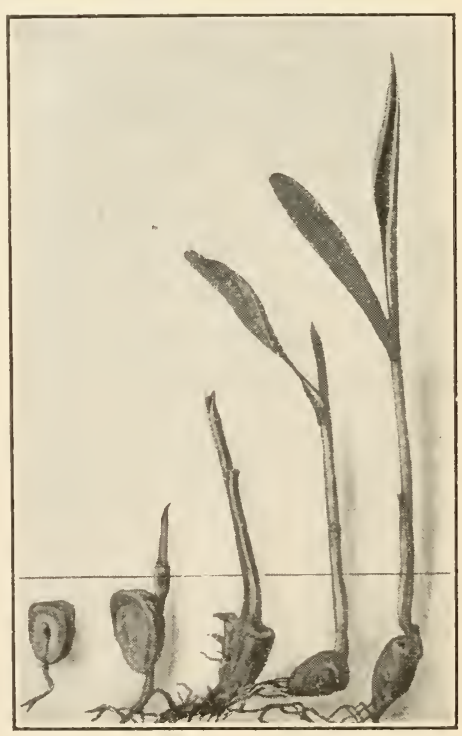

The germination of a grain of corn. 
at first they seemed to serve as leaves, later becoming absorbed as food by the growing seed. In the pea the cotyledons serve as food, but remain under ground. In the corn the single cotyledon serves as an organ for digesting and absorbing food from the storehouse of food known as the endosperm.

Monocotyledons and Dicotyledons. - Plants that bear seeds having but a single cotyledon are called monocotyledons. The corn is an example of such a plant. Although we find a good many monocotyledonous plants in this part of the world, this group is characteristic of the tropics, just as the dicotyledons are the type for the temperate climate. Sugar cane and many of the large trees, such as the date palm, palmetto, and banana, are examples. Among the common monocotyledons of the north temperate zone are corn, lily, hothouse smilax, and asparagus.

Polycotyledons. - A third type of plant, grouped according to the number of cotyledons, is the group represented by the pines and their kin.

Pine seedlings may be grown in damp moss or sawdust. They must be started at least three weeks before they are needed for use in the laboratory. ${ }^{1}$

The Pine Cone and its Seeds. - Material should be gathered in the fall and early summer. Get some very young cones and some of older growth that contain seeds. The pine tree bears inconspicuous flowers of two kinds, pollen-bearing and seed-forming. Pollination is accomplished by the wind, the cones growing as the result of fertilization. Notice the position of the cone on the branch. Compare a young cone with an old one. You will find in the young cones that the scales are green in color and are cemented together by the sticky resin or pitch. In the older cones the seeds are ready for dispersal. They usually take two summers to grow to maturity. Pull back one of the scales making up the cone and see what happens. How is the seed adapted to

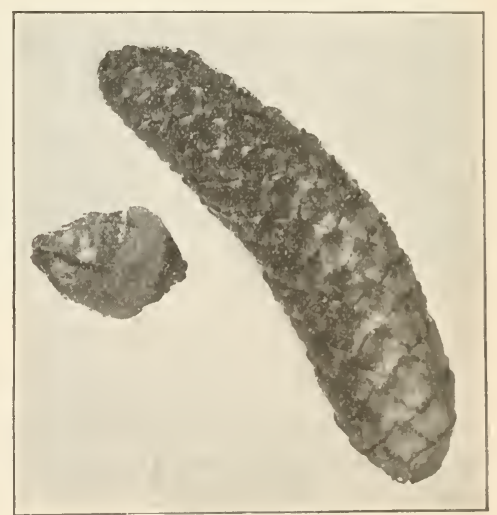

Spruce cone and scale containing winged seed. Photographed by Overton. be scattered? Draw one of the scales of the cone and a winged seed to show the position of the seed when in place.

If you cut open a seed lengthwise, after having split the hard outer coat, you will find the tiny embryo in the center of the seed, surrounded by its

${ }^{1}$ See Hunter and Valentine, Manual, page 75. 


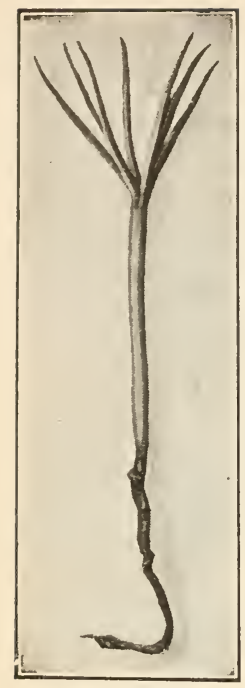

Pine seedling.

endosperm. If the student is a very careful observer, he may be able to make out the number of cotyledons in the young plant. There are fifteen seed leaves in one common species of pine. The number and position are better seen in a young seedling of three or four weeks' growth.

The Uses of Seeds. - Some of the uses of seeds to man have already been noted. A seed is a very young plant usually provided with a store of food to give it a start in life. Its use to the parent plant is incalculable, for it is by means of the seed that a plant reproduces its kind. This can be done, as we shall see later, to a limited degree by cuttings, grafting, and in other ways, but the usual way is by the production and planting of seeds. Not only does a seed serve to continue a species of plant in a certain locality, but it serves to give the plant a foothold in new places. Seeds may be blown by the wind or carried by animals, or by a hundred devices work their way to pastures new, there to establish outposts of their kind.

Immense numbers of seeds may be produced by a single plant. This may be of great economic importance. A single pea plant may produce twenty pods, each containing from six to eight seeds. This would mean the possibility of nearly twenty-five thousand plants produced from the original parent by the end of the second season. A plant of Indian corn may produce over fifteen hundred grains of corn. On the other hand, many weeds produce seed in still greater numbers. A single milkweed may set free over two thousand seeds. A single capsule of Jimson weed has been found to hold over six hundred seeds. The thistle is even more prolific.

Some seeds, especially those of weeds, are able to withstand great extremes of heat and cold and still to retain their ability to germinate. Some have been known to retain their vitality for over fifty years. In plants, the seeds of which show unusual hardiness, it is found that the food supply is often so placed as 
to protect the delicate parts of the embryo from injury. The food is in a form not easily dissolved by water or broken up by the action of frost, so that it is kept in a hard state until such a time as it can be softened by the process of digestion during the growtr of the plant. It can be seen that plants bearing seeds having some of the above characters have a great advantage over plants bearing seeds that are poorly protected.

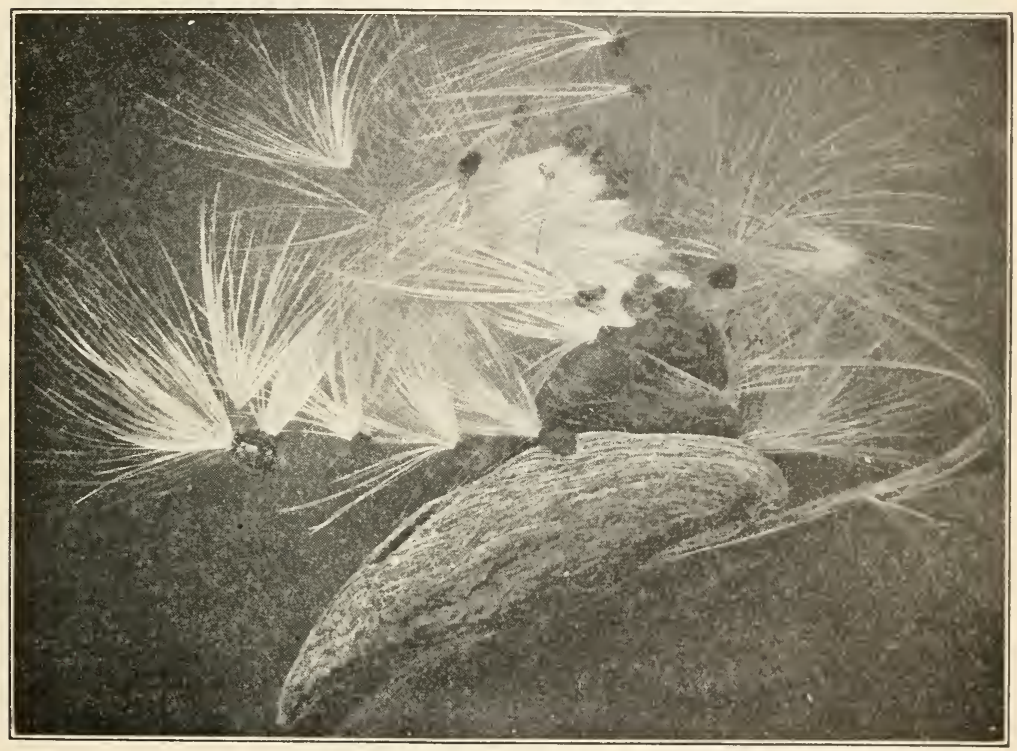

Milkweed fruit, showing method of seed dispersal.

External Factors which determine the Growth of Seeds. ${ }^{1}-$ We have spent some time in the consideration of seeds simply to learn a little about their structure. This has been done so that we may understand the work as we take up, by means of the following experiments, some of the factors which call the dormant seed to life. We know that a dry seed, after lying dormant and apparently dead for months and sometimes for years, will, when

1 In making experiments it is important to exclude, if possible, all other factors but the one you wish to determine. 
the proper stimuli are applied to it, start in its growth into a new plant. Let us see what these stimuli are.

Effect of Water on Dry Seeds. - Weigh ten dry navy beans; leave them in water over night; reweigh. How much have they increased in weight? We have already found that water gets into the seed through the micropyle. It can be proved that it gets in through the seed coat as well. If you cover five seeds entirely with paraffin, and in five others cover the hilum, micropyle, and half of the remainder of the coat, a difference in weight and size will be apparent the next morning.

Expansive Force of Germinating Seeds. - The expansive force of germinating seeds is considerable. You have noticed that the bean is considerably larger after soaking.

Fill a small bottle almost full of dry seeds (beans or peas), then fill the space left with water; wire in the cork tightly. Leave the bottle overnight

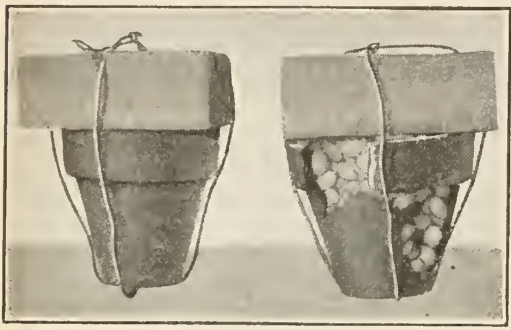

The expansive force of germinating seeds. The flower pot to the left was filled with dry beans, a block of wood wired on, and the whole apparatus placed in a pail of water over night. The right-hand figure shows the result. and note the results next morning. Would this force be of use in getting a start under the soil? Have you noticed that the soil is lifted in the garden by the rows of germinating peas and beans just before they come up? Is this due entirely to the expansive force of seeds? Watch future experiments before you attempt a definite answer.

Will a Dry Seed germinate?Place a layer of moist blotting paper or sawdust in bottom of each of three cups or three tin cans. Soak fifteen navy beans overnight. Place five in each dish. Water one dish so as to cover the seeds; water the second so as to keep sawdust rather moist; let the third remain unwatered. Cover the cups with loose-fitting covers. Make daily observations of the number germinating, and the condition of each for at least ten days. Put the results in tabular form. What amount of water is most favorable for germination of the navy bean?

Water a Factor in Germination. - A dry seec? will not germinate. Water is absolutely necessary to start the forces at work toward growth. But it is sometimes difficult to determine the amount of water that is most favorable to germination. Some seeds require a great deal of water, others require very little.

Will a Seed grow without Air? - We have already seen that in the germinating corn plant the starch stored in the endosperm was changed to grape sugar by the action of a digestive ferment called diastase. This sugar was then used by the plant as food.

\footnotetext{
'See Hunter and Valentine, Manual, page 222.
} 
In other words, the food furnished new material for the plant, and energy for it to push its way through the sawdust or soil. We have proved that energy is invariably released as a result of oxidation. It will be of interest, then, to see if the grain of corn or other seeds can grow without a supply of oxygen.

A simple method is as follows, although this is not an accurate experiment: Place 25 to 50 soaked beans or peas in each of two wide-mouth bottles, 6 oz. to $12 \mathrm{oz}$. Cork and seal one; leave the other uncorked, taking care to keep the seeds as moist as in the covered jar. Notice any differences in the seeds for at least one week. Make drawings showing your results. ${ }^{1}$

A more accurate method of determining this is to exclude air entirely from a glass jar or bottle in which germinating seeds had previously been placed.

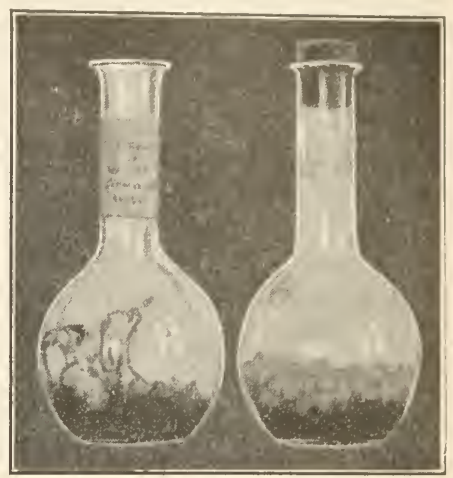

Experiment to show the effect of lack of air on germination.

Air may be exhausted by means of an air pump. If the tube is now sealed by heating under the flame of a burner, the seeds will be left in an air-tight jar. A jar with seeds in same condition, except for lack of air, should be kept as a control experiment.

Why did not the seeds in the covered jar germinate? We have seen that to release the energy contained in a piece of coal we must burn or oxidize it. To do this we must have a constant supply of fresh air containing oxygen. The seed, in order to release the energy contained in its food supply, must have oxygen, so that the oxidation of the food may take place. Hence a constant supply of fresh air is an important factor in germination. It is important that air should penetrate between the grains of soil around a seed. The frequent stirring of the soil enables the air to reach the seed. Air also breaks down some materials in the soil and puts them in a form that the germinating seed can use. What is at least one reason why the farmer plows and harrows a field? What is at least one important use of the earthworm?

1 See Hunter and Valentine. Manual. nя.ga 224 
Oxidation in the Human Body. - Exhale strongly through a straw or a glass tube into limewater. The limewater turns milky, showing that oxidation of organic matter has taken place within the body.

If now a glass cylinder in which has been placed some moist blotting paper on which a handful of soaked peas or beans are resting is left overnight in a moderately warm room, and if the air within the jar is tested the following morning, carbon dioxide will be found present. How shall we explain its presence, in view of the above test with the human breath?

Experiment. - Place sawdust in each of two small boxes (cigar boxes will do) and plant an equal number of bean, pea, and squash seeds in each. Place one box in a warm room (in the winter near a radiator or stove), the other in a room where the temperature will not exceed $70^{\circ}$ Fahrenheit. Be careful to give each box the same conditions of light and moisture. In which box do seeds first germinate? Which box shows the better growth after three weeks have elapsed?

Moderate Temperature Best. - Another factor influencing the germination of seeds is that of temperature. What is the most favorable temperature for the germination of the bean, pea, and squash ? ${ }^{1}$ From this experiment we find that although a high temperature may stimulate the seed to immediate activity, nevertheless, later, the seeds in moderate temperature do better than those in the heat. The temperature at which different seeds germinate varies greatly. Those of you who have a garden at home know that even some varieties of seeds germinate at lower temperatures than ochers of the same species; for example, early peas, lettuce, or radish seed. As a general rule, increase in temperature is favorable up to a certain point, beyond which it is injurious to the young plant. Can you determine this danger point from your experiments?

Light has a certain marked effect on young seedlings, which will be considered when we take up the growth of the stem in more detail.

Selective Planting. - Although it has been noticed for a long time that healthy seed usually produced healthy plants, it is only within recent years that farmers have begun to appreciate what can be done by selective planting. By selective planting we mean choosing the best plants and planting the seed from these plants with a view of increasing the yield. In doing this we must not necessarily select the most perfect fruits or grains, but must select seeds from the best plants. A wheat plant should be selected not from its yield alone, but from its ability to stand disease and unfavorable conditions. In 1862 a Mr. Fultz, of Pennsylvania, found three heads of beardless or bald

${ }^{1}$ See Hunter and Valentine, Manual, page 223. 
wheat while passing through a large field of bearded wheat. He picked them out, sowed them by themselves, and produced a quantity of wheat now known as the Fultz wheat (known favorably all over the world). By careful seed selection, some western farmers have increased their wheat production by 25 per cent. This, if kept up all over the United States, would mean over $\$ 100,000,000$ a year in the pockets of the farmers

Boys and girls who have gardens of their own can easily try experiments in selection with almost any garden vegetables. Corn is one of the best plants to experiment with. Gather for planting only the fullest ears and those with the largest kernels. You must also select from the plants those that produce the most ears. Plant such corn grains, carefully se-

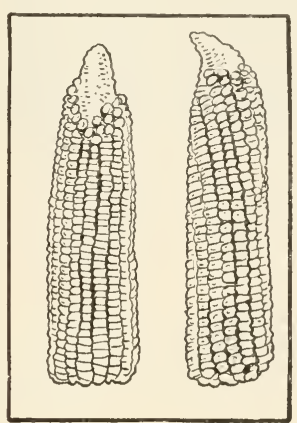

$a$

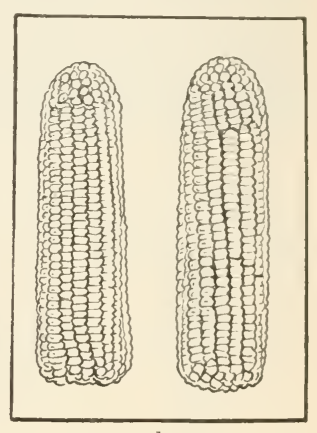

$b$

Improvement of corn by selection; $a$, original type; $b$, improved type developed from it. lected, in a plot by themselves in the garden, and compare their yield with that of the non-selected corn. The accompanying picture shows what can be done by selection. We find that, by what is known as a law of heredity, like produces like; hence the growth in the case of the selected grains. Not only does the corn produce ears with a greater number of grains, but it may improve upon the quality of the yield.

\section{Reference Books}

FOR THE PUPIL

Andrews, Botany All the Year Round, pages 103-119. American Book Company. Dana, Plants and Their Children, pages 50-98. American Book Company. Atkinson, First Studies of Plant Life. Chaps. I, II, III, XXV. Ginn and Company. Cornell Nature Study Leaflets. XXVIII, XLII, XLIV. N.Y. Dept. of Agriculture.

\section{FOR THE TEACHER}

Goodale, Physiological Botany. American Book Company. Gray, Structural Botany. American Book Company.

Leavitt, Outlines of Botany, prges 7-23. American Book Company.

De Candolle, Origin of Cultivated Plants. D. Appleton and Company.

MacDougal, Plant Physiology. Longmans, Green, and Company.

Year Book, U.S. Dept. of Agriculture, 1894, 1895, 1896, 1897, 1898, 1899, 1901. 


\section{ROOTS AND THEIR WORK}

THE development of a bean seedling has shown us that the root invariably grows first. One of the most important functions of the root

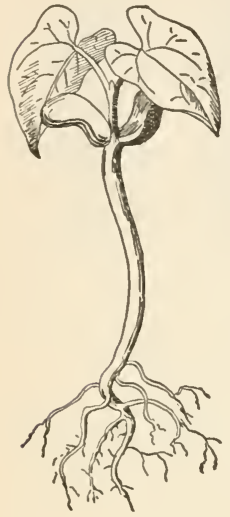

Young bean plant, showing primary and secondary roots. to a young plant is that of a holdfast, an anchor to fasten it in the place where it is to develop. This chapter will show us very many other uses of the root to the plant, the taking in of water, the storage of food, climbing, etc. All other functions than the first one stated arise after the young plant has begun to develop.

Root System. ${ }^{1}$ - If you dig up a young bean seedling and carefully wash off the roots, you will see that a long root is developed as a continuation of the hypocotyl. This root is called the primary root. Other smaller roots which grow from the primary root are called secondary, or tertiary, depending on their relation to the first root developed. In a young plant, notice the general direction taken by the roots. Can you give any reason for the spreading out of the roots in all directions?

Make a drawing of the root system of a seedling; label all its parts.

Downward Growth of Root. - Most of the roots examined take a more or less downward direction. We have already seen that factors outside of the seed call it into activity and cause what we call germination. Might external factors cause the root to grow downward, and if so, what are the factors?

The following apparatus and experiments will throw some light on this question.

The Pocket Garden. ${ }^{2}$ - A very convenient form of pocket germinator may be made in a few minutes in the following manner: Obtain two cleaned four by five negatives (window glass will do); place one flat on the table and place on the glass half a dozen pieces of colored blotting paper cut to a size a little less than the glass. Now cut four thin strips of wood so as to fit on the glass just outside of the paper. Next moisten the blotter,

1 See Hunter and Valentine, Manual, page 20.

2 Ibid., page 233. 
place on it some wellsoaked radish or mustard seeds or grains of barley, and cover it with the other glass. The whole box thus made should be bound together with bicycle tape. Seeds will germinate in this box, and with care may live for two weeks or more.

\section{Influence of Gravity.} - We are all familiar with the fact that the force we call gravity

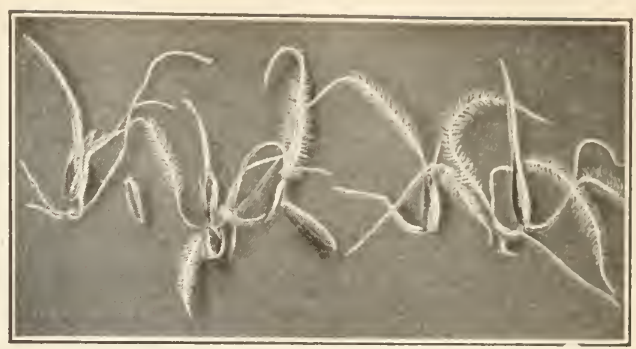

A pocket germinator, in which the roots of the barley seedlings show a turning in response to gravity. The germinator was originally turned $180^{\circ}$ from its presen $\hat{\imath}$ position. influences life upon this earth to a great degree. Might gravity act on the growing root? This question may be answered by the following simple experiment:

Place your pocket garden on one edge and allow the seeds to germinate until the root has grown to a length of about half an inch. Then turn the box at right angles to the first position. Allow it to remain for one day

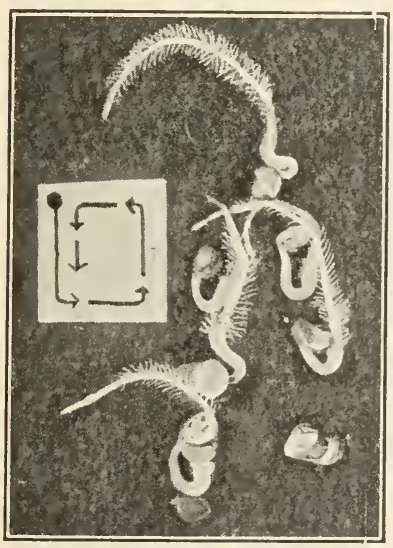

Revolve this figure in the direction of the arrows to see if the roots of the radish respond to gravity. undisturbed, and then examine it. The roots will be found to have turned in response to the change in position. In what part of the root does the change take place? What part of the growing root is most easily influenced by the force of gravity? Make a series of drawings to illustrate this experiment. This experiment seems to indicate that the roots are influenced to grow downward by the force we call gravity.

\section{Experiments to determine Influence} of Moisture on a Growing Root. The objection might well be interposed that the roots in the pocket garden grew downward after water. This is unlikely, however, as the air in the germinator is saturated with moisture. That moisture has an influence on the growing root is easily proved.

Plant bird seed or the seed of mustard or radish in the under side of a sponge, which should be kept wet, and may be suspended by a string under a bell jar in the schoolroom window. Note whether the roots leave the sponge to grow downward, or if the moisture in the sponge is sufficient to counterbalance the force of gravity. 
Another experiment is the following: Divide the interior of a shallow wooden box into two parts by an incomplete partition. Partly fill the box with sawdust and place the opening in the partition so that it is below the surface of the sawdust. Plant peas and beans in the sawdust on one side of the partition, water very slightly, but keep the other side of the box well soaked. After two weeks, take up some of the seedlings and note the effect on the roots.

Water a Factor which determines the Course taken by Roots. Water, as well as the force of gravity, has much to do with the direction

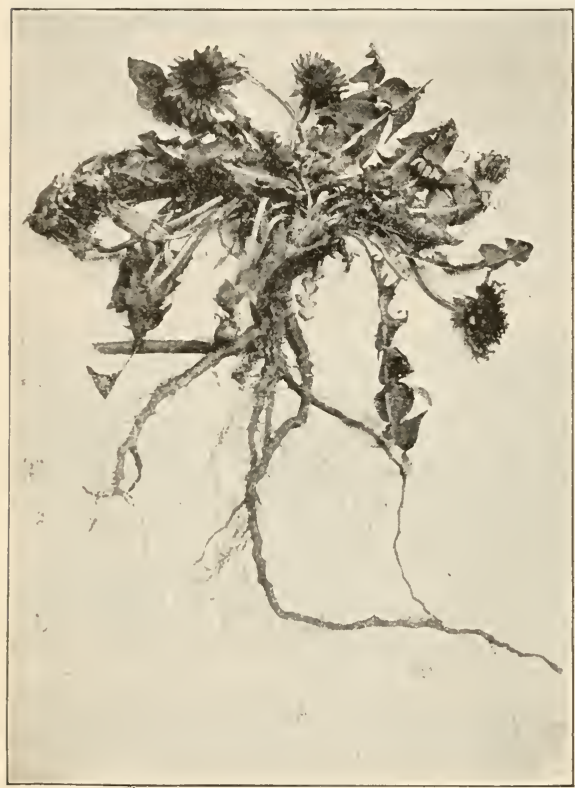

Dandelion plant. Photographed by Overton. taken by roots. The smaller roots, especially, are influenced by moisture. Moisturealso determines the kind and abundance of roots on a plant. Water is always found below the surface of the ground, but sometimes at a great depth. In order to obtain a supply of water, the roots of plants frequently spread out for very great distances. Most trees, and all grasses, have a greater area of surface exposed by the roots than by the branches. The mesquite bush, a low-growing tree of the American and Mexican deserts, often sends roots downwards for a distance of forty feet after water. The dandelion shown in the cut has a greater depth below the surface of the ground than appears above the surface. The roots of alfalfa, a common plant used for hay in the Western states, often penetrate the soil to a distance of ten to twenty feet below the surface of the ground.

The force of gravity is an exciting cause or stimulus to the growth of plants. The reaction of the plant (or any living thing) to this force is called geotropism. Roots are stimulated by 
gravity to grow downward; hence they are said to be positively geotropic.

The force with which roots grow downward is greater than the downward pull exerted by gravity on the growing root.

Windsor Bean Experiment. - Place a growing Windsor bean so that the plant is held by a pin through the cotyledons and the root directed downward into a dish of mercury. The root will push its way into this very dense substance.

Or a germinating bean may be so fastened that the root will point downward into a groove made in a little wooden or cork float which is placed on the surface of a dish of water directly under the bean. If the experiment is successful, the root will push the float either under water or out of the way. ${ }^{1}$

\section{Effect of Gravity on the Stem. - The} stem, on the other hand, seems to be affected in the opposite manner, and is therefore said to be negatively geotropic.

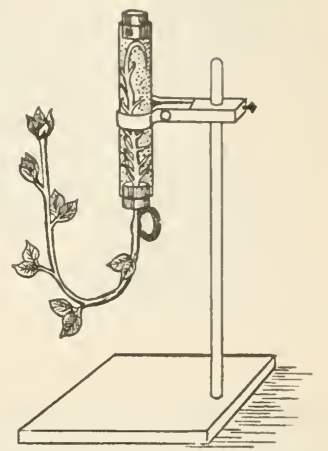

Experiment to show the effect of gravity upon the growth of stem and root. (After McDougall.)

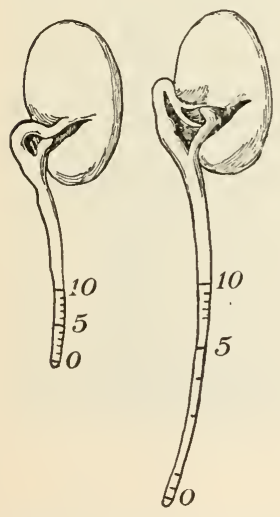

Figure to show the point of most rapid growth in the root of the bean. (After McDougall.)

The effect of gravity on the young stem may be shown by turning upside down a pocket garden in which are young barley or corn plants. The st $m$ at once turns upward again. The same thing may be proved by germinating radish or grass secds on the under side of a hanging sponge. After the ste $m$ has attaincd a length of one or two inches, turn the sponge so that the young plants are upside down.

Place where Root grows Most Rapidly. - Select three or four pea seedlings which have roots half an inch to an inch in length. Mark such roots on their outer surface at equal intervals (say one $\mathrm{mm}$. apart) by means of a thread dipped in India ink. Allow these marks to be continued on strips of paper which are placed next to the growing roots. Keep them in a moist germinator for several days Make drawings to show where increase in length took place.

The Root Cap and Most Rapid Point of Growth. - If we examine a longitudinal section of any dicotyledonous root under the microscope we find that at the very tip of the root can be seen a collection of cells arranged more or less loosely over the end of the root in the form of a cap. Most of these cells are dead, and this root cap is simply an adaptation to protect the

${ }^{1}$ See Hunter and Valentine, Manual, page 232. 
tender growing point of the root. Just beneath the root cap is a collection of tiny, thin-walled cells. At that point the cells are engaged in dividing

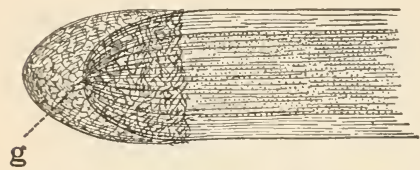

The end of a growing root, tipped and protected by the root cap; $g$, the growing point. (Considerably magnified.) tiny roots of barley or corn, and you will find that they are covered in places with what looks like a fuzzy growth. These hairlike structures are called root hairs. What is the color of the root hairs to the naked eye? Where

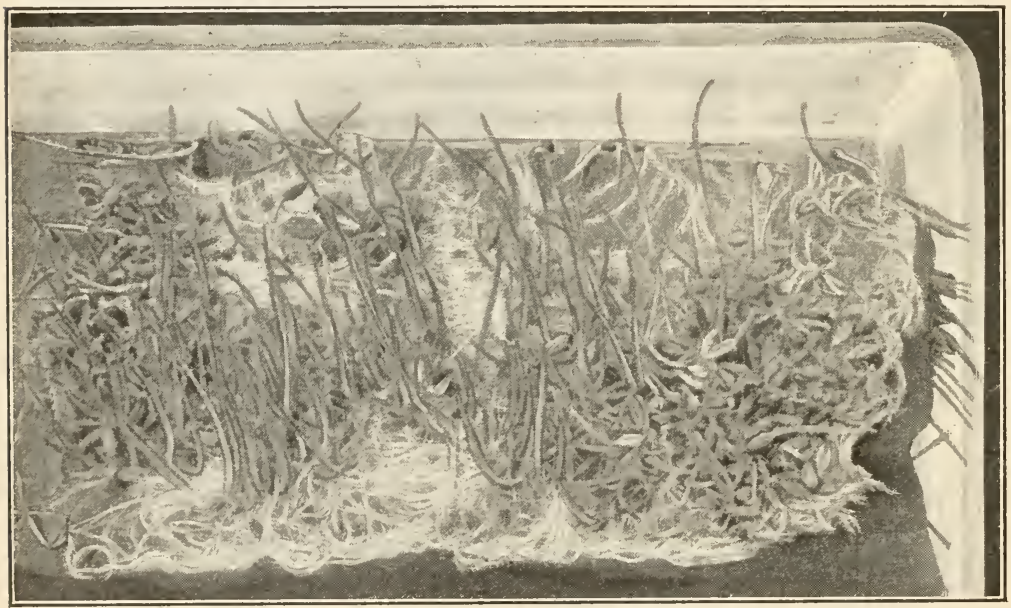

Root hairs of barley. The white appearance of the roots is due to these organs of absorption.

are the root hairs largest? Where are they longest? Where are they most abundant? Try giving your pocket garden more water; what is the effect on the root hairs? Can you get a similar result by cutting off the water supply of the roots? Do root hairs ever disappear after once coming out on the root?

Structure of a Taproot. - To understand fully the relation of the root hairs to the rest of the root, it will be necessary for us to examine some large, fleshy root (a taproot), so that we may get 
a little first-hand evidence as to its internal structure. If you cut open a parsnip or carrot so as to make a cross section of the root, you find two distinct areas, an outer portion, the cortex, and an inner part, the central cylinder. If you cut another parsnip in lengthwise section, these structures show still more plainly. An additional fact is seen; namely, that all the smaller roots leaving the main or primary root have a core of wood which bores its way out through the cortex wherever the small rootlets are given off. Make a drawing that will show these points.

Fine Structure of a Root. - If we could now examine a much smaller and more delicate root in thin longi-

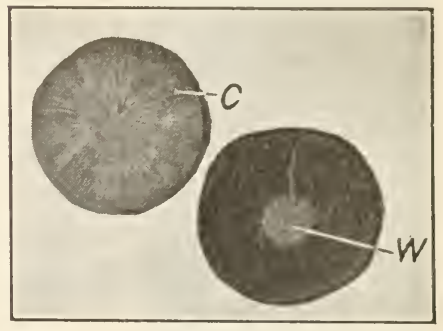

A cross section through a taproot (a parsnip); $C$, cortex; $W$, wood. Notice in the right-hand specimen, which has been dipped in iodine, that the core of wood continues out into the rootlets which leave the main root. Where is most starchy food stored in a parsnip? tudinal section under the compound microscope, we should find the following structure: (Cross sections and longitudinal sections of Tradescantia roots are excellent for demonstration of these structures.) The entire root is seen to be made up of cells, the walls of which are uniformly rather thin.

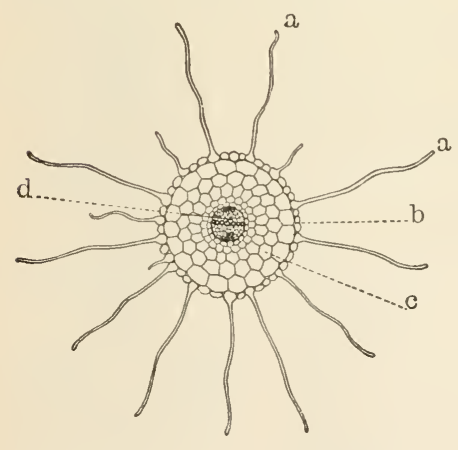

Cross section of a young taproot; $a, a$, root hairs; $b$, epidermis; $c$, cortical layer; $d$, fibrovascular cylinder.

The cells of this part of the root are more or less regular in size and shape. The central cylinder can easily be distinguished from the surrounding cortex. The cells of the former have somewhat thicker walls. In a longitudinal section a series of tubelike structures may be found within the central cylinder. These structures are, in fact, cells which have grown together at the small end, the long axis of the cells running the length of the main root. In their development the cells mentioned have grown together in such a manner as to lose their small ends, and now form continuous hollow tubes with rather strong walls. Other cells have come to develop greatly thickened walls; these cells give mechanical support to the tubelike cells. 
Fibrovascular Bundles. - Collections of such tubes and supporting woody cells together make up what is known as fibro-

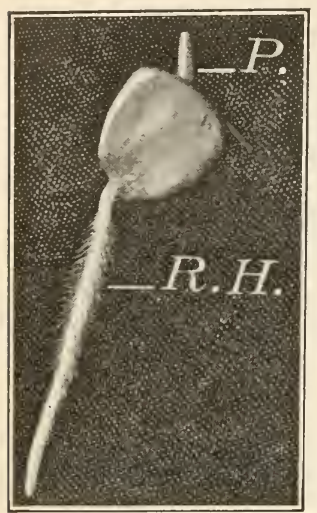

Young embryo of corn, showing root hairs (R.H.) and growing stem (P.). vascular bundles.

Structure of a Root Hair. - The cells of the cortex are almost uniform in character. The outmost layer, however, differs from the rest of the cortex. This layer is called the epidermis. It is the prolongations of the cells of the epidermis that form the structures we have already seen and know as root hairs.

Let us now take out one of the small radish seedlings from the pocket garden, mount it in water, and examine it under the low power of the microscope. A single root hair will be found to be a long round structure, almost colorless in appearance. The wall, which is very flexible and thin, is made up of cellulose, a substance somewhat like wood in chemical composition, through which fluids may easily pass. If we had a very high power of the microscope focused upon this cellulose wall, we should be able to find under it another structure, far more delicate than the cell wall. This is called the cell membrane. Clinging close to the cell membrane is the protoplasm of the cell, which in the root hair is found close to the membrane. The interior of the root hair is more or less filled with a fluid called cell sap. Forming a part of the living protoplasm of the root hair, sometimes in the hairlike prolongation and sometimes in that part of the cell which forms the epidermis, is found a nucleus. The protoplasm, nucleus, and cell membrane are alive; all the rest of the root hair is dead material, formed by the activity of the living substance of the cell. The root hair is a living plant cell with a wall

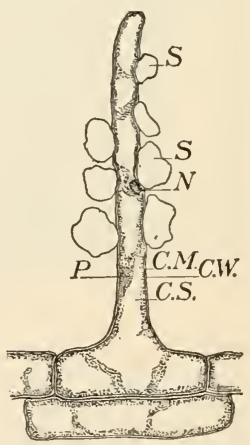

Diagram of a root hair: C.M., cell membrane; C.S., cell sap; $C . W$., cell wall; $P$, protoplasm; $N$, nucleus; $S$, soil particles. 
so delicate that water and mineral substances from the soil can pass through it into the interior of the root.

How the Root ABSorbS WATER. - This process can best be understood by means of the following experiment: ${ }^{1}$ Crack the shell of a fresh egg at one end and pick it, bit by bit, from the delicate membrane that lies underneath it until about one square inch of the membrane is exposed. Now break a small hole in the opposite end of the egg just large enough to admit a small glass tube. After putting the tube in place, cement it in with sealing wax or paraffin. Place the egg with the large end in a glass of water. Examine it after a few hours, and the contents of the egg will be found to have risen in the glass tube to a considerable distance. The membrane through which the water has passed has no holes in it. It allows the passage of certain fluids through it, and is hence called a permeable membrane. In the experiment just performed, a little of the contents of the egg passes into the glass, as can be proved by the proteid test applied to the contents of the glass. On the other hand, a considerable amount of water from the glass has passed into the egg through the membrane.

Osmosis. - The process by which two fluids, separated by a membrane, pass through the

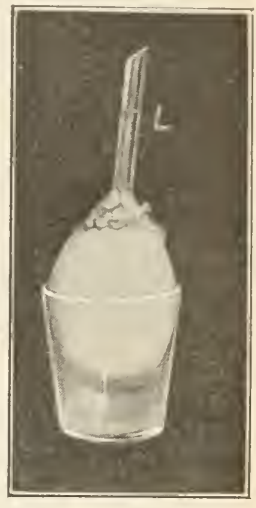

Experiment to show osmosis in an egg; $L$, level of the fluid in the tube.

membrane and mingle with each other is called osmosis. In this process the greater flow is always toward the more dense medium. The method by which the root hairs take up soil water is exactly the same process as we see in the egg. It is by osmosis. The white of the egg is the best possible substitute for living matter; it has, indeed, almost the same chemical formula as protoplasm. The animal membrane separating the egg from the water is much like the delicate membrane which separates the protoplasm of the root hair from the water in the soil surrounding it. The fluid in the root hair is more dense than the soil water; hence the greater flow is toward the interior of the root hair.

Passage of Soil Water within the Root. - We have already seen that in an exchange of fluids by osmosis the greater flow is always toward the denser fluid. Thus it is that the root hairs

1 This experiment, although not illustrating osmotic action in the strict sense, appeals to the pupil as does no other. 


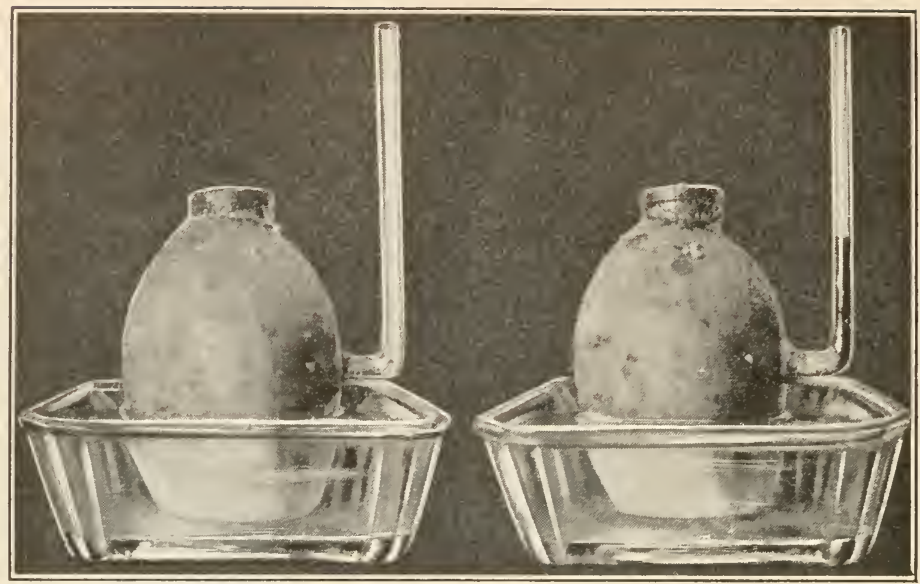

\& $x$ potato osmometer. The lower end of the potato was cut off and the remainder peeled for about one third of its length. A hole was bored to within three fourths of an inch of the cut end; a small hole was bored at the side of the potato. In the latter was inserted a small L-shaped tube, the lower end being vaselined to make it air tight. Sugar was then placed in the hole at the top and a cork inserted; water was poured into the dish below. Within two hours the water had risen in the tube as shown in the right-hand figure.

take in more fluid than they give up. The cell sap, which partly fills the interior of the root hair, is a fluid of greater density than the water outside in the soil. When the root hairs become filled with water, the density of the cell sap is lessened, and the cells of the epidermis are thus in a position to pass along their supply of water to the cells next to them and nearer to the center of the root. These cells, in turn, become less dense than their inside neighbors, and so the transfer of water goes on until the water at last reaches the central cylinder. Here (as we shall see later) it is passed over to the tubes of the fibrovascular bundles and started up the stem. The pressure created by this process of osmosis is sufficient to send water up the stem to a distance, in some plants, of twenty-five to thirty feet. Cases are on record of water having been raised in the birch a distance of eighty-five feet. How water gets to the summits of tall trees is a problem which we shall discuss in a later chapter.

Physiological Importance of Osmosis. - It is not an exaggeration to say that osmosis is a process not only of great importance 
to a plant, but to an animal as well. Foods are digested in the food tube of an animal; that is, they are changed into a soluble form so that they may pass through the walls of the food tube and become part of the blood. Without the process of osmosis we should be unable to use the food we eat.

Composition of Soil. - If we examine a mass of ordinary loam carefully, we find that it is composed of a number of particles of varying size and weight. Between these particles, if the soil is not caked and hard packed, we can find tiny spaces. In welltilled soil these spaces are constantly being formed and enlarged. They allow air and water to penetrate the soil. If we examine soil under the microscope, we find considerable water clinging to the soil particles and forming a delicate film around each particle. In this manner most of the water is held by the soil.

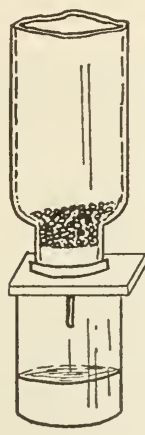

A

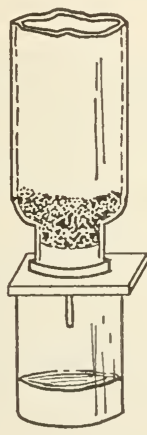

B

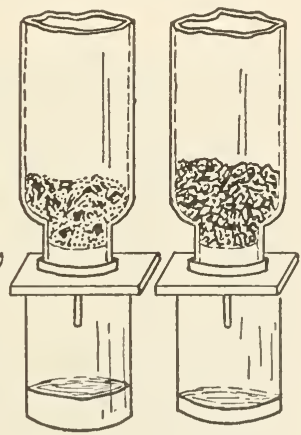

D

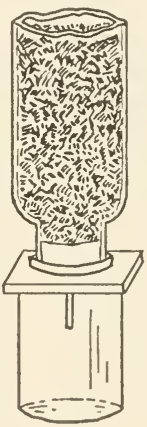

E

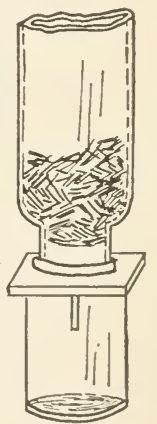

$F$

Experiment to illustrate the kind of soil which best retains water: $A$, gravel; $B$, sand; $C$, barren soil; $D$, rich soil; $E$, leaf mold; $F$, dry leaves.

Kind of Soll Favorable to Evaporation. - The picture shows an easily constructed apparatus to show which kind of soil can retain most water. Fill each of the vessels with a given weight (say 100 grams each) of gravel, sand, barren soil, rich loam, leaf mold, and 25 grams of dry pulverized leaves, then pour equal amounts of water (100 c.c.) on each. Measure all that runs through. The water that has been retained constitutes the water supply that plants could diaw on from such soil.

How WATER IS HELD IN SoIL. - To understand what comes in with the soil water, it will be necessary to find out a little more about soil. Scientists who have made the subject of the composition of the earth a study, tell us 


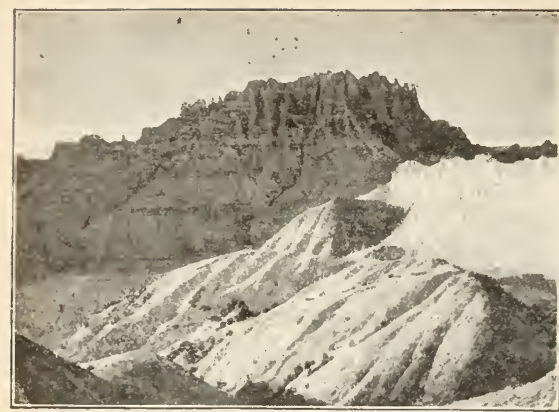

Inorganic soil is being formed by weathering.

that once upon a time at least a part of the earth was molten. Later, it cooled into solid rock. Soil-making began when the ice and frost, working with the heat, chipped off pieces of rock. These pieces in time became ground into fragments by action of ice, glaciers, or the atmosphere. This process is called weathering. Weathering is largely a process of oxidation. A glance at crumbling stone will convince you of this, because of the oxide of iron (rust) disclosed. So by slow degrees this earth became covered with a coating of what we call inorganic soil. Later, generation after generation of tiny plants and animals which lived in the soil died, and their remains formed the first organic materials of the soil.

You are all familiar with the difference between the so-called rich soil and poor soil. The dark soil simply contains more dead plant and animal life, which forms the portion called humus.

A simple experiment may be performed to show the amount of vegetable and mineral matter in different soils.

Amount of Organic Matter in Soil. - Gather about a pound of leaf mold from a forest, a like amount of the rich loam taken from beneath the leaf mold, and the same amount of soil taken from a barren roadside or field. Dry them carefully and then weigh equal amounts (say 100 grams) of each kind of soil. Place them on pieces of tin and heat them redhot over a coal fire or in

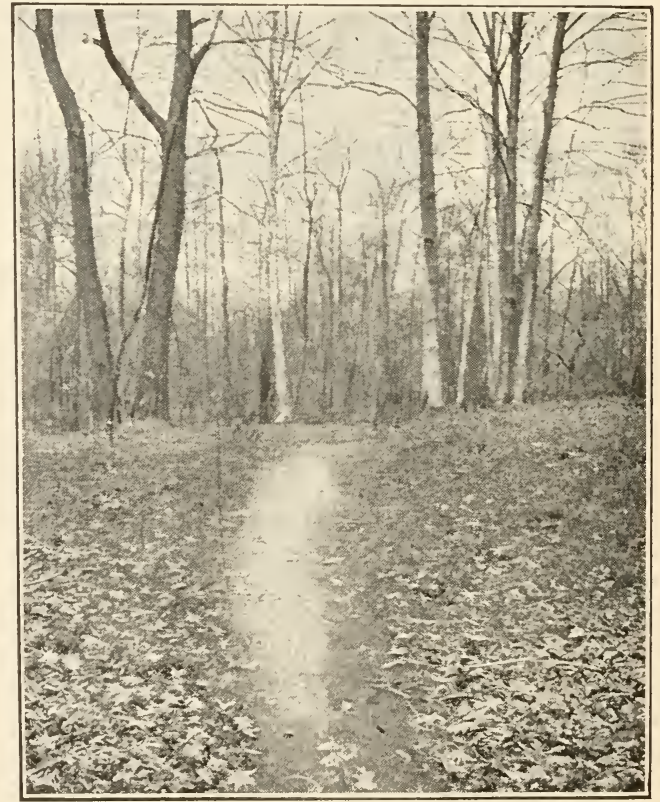

This picture shows how the forests help to cover the inorganic soil with an organic coating. 
a furnace until you feel sure that all organic matter is burned up. Then reweigh each and put the soil into three bottles, giving the weight before and after burning in each case. Professor Hodge (see Nature Study and Life, page 380 ) tried this experiment, and found that when each lot originally weighed 100 grams, the forest leaf mold in burning lost 78 grams, the forest loam lost 11 grams, while the barren soil lost only 1 gram. What results do you get from your experiment?

The Root Hairs take more than Water out of the Soil. - If a root containing a fringe of root hairs is washed off carefully, it will be found to have little particles of soil still clinging to it. Examined under the microscope, these particles of soil seem to be fastened to the root hair. The following experiment explains what the root hairs do to the soil surrounding them.

Grow a number of seedlings in a tumbler between blotting paper and the edge of the glass or in a pocket garden. Place a sheet of blue ${ }^{1}$ litmus paper so that the root will grow against it. Does a change of color take place near the root hairs?

Acid Reaction of Root Hairs. - The change of color of the litmus paper from a blue to red shows us that the growing root hairs have a decidedly acid reaction. Thus some mineral matters which otherwise could not be taken into the root hair are dissolved by the action of the acid. Lime (oxide of calcium), for instance, is such a mineral. The minerals that the root hairs take in with the soil water are calcium, potassium, iron, silicon, and other elements, in very small quantities. If radish or other seedlings be grown in moist, rich soil, and then removed when but an inch in height, the soil will be found to cling to the root hairs. In fact, the surface of the root hair often almost incloses tiny particles of soil, the acid given out literally eating away the soil particles thus inclosed.

The proportion of each of these mineral materials is very small compared with the water in which they are found. A very great amount of water must be taken up by the roots in order that the plant may get the needed amount of mineral matter with which to build its protoplasm. We also find that some mineral

1 The blue litmus paper contains a vegetable material which turns red in the presence of an acid. Red litmus paper changes back from red to blue when an alkaline medium is present. When a substance will not change either red or blue iitmus paper, it is said to be neutral. 
matters are taken in far in excess of the immediate needs of the plant. Such minerals are stored in the stem and leaves.

Need of Mineral Matter for Growth. - Plants will not grow well without certain of these mineral substances. This can be proved by the growth of seedlings in a so-called nutrient solution. Such a solution contains all the mineral matter that a plant uses for food. ${ }^{1}$

Mineral Matter necessary for Growth of Young Plants. - Obtain three jars; put distilled water in one, nutrient solution (without ferric chloride) in another, and nutrient solution plus ferric chloride in the third. Place germinating corn or bean seedlings in the jars so that roots extend down into the liquids. Observe the growth of the three lots of seedlings. Decide which of the three jars is most favorable to growth.

Nitrogen in a Usable Form necessary for Growth of Plants. - We learned that humus is made up of decayed plant and animal bodies. A chemical element needed by the plant to make protoplasm is nitrogen. This element cannot be taken from either soil

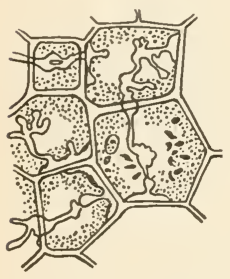

Bacteroids forming from filamentous structures in the cells of a root. water or air in a pure state, as is the case with the other chemical elements used by the plant in the manufacture of protoplasm. Nitrogen is usually obtained from the organic matter in the soil, where it exists with other substances in the form of nitrates. Nitrogen is found in such form in all decaying material; hence the use of fertilizers. ${ }^{2}$

Relation of Bacteria to Nitrogen. - It has been known for a long time that clover, peas, beans, and other legumes, cause the ground to become more favorable for growth of other plants. The reason for this has been discovered in late years. On the roots of the

${ }^{1}$ A nutrient solution may be prepared as follows :Distilled water $\left(\mathrm{H}_{2} \mathrm{O}\right)$

Potassium nitrate $\left(\mathrm{KNO}_{3}\right)$

Sodium chloride ( $\mathrm{NaCl})$

Calcium sulphate $\left(\mathrm{CaSO}_{4}\right)$

Magnesium sulphate $\left(\mathrm{MgSO}_{4}\right)$

Calcium phosphate $\left(\mathrm{Ca}_{3}\left[\mathrm{PO}_{4}\right]_{2}\right)$

Ferric chloride $\left(\mathrm{FeCl}_{3}\right)$

(Do not put the ferric chloride into the solution in the first place, but add a drop of it to each bottle when the seedlings are put in.)

2 Other important plant foods found in soil, but which are frequently used up by plants growing therein, are potash and phosphoric acid. Both of these substances are made soluble so as to be taken in by the root by the action of the carbon dioxide in the soil. 
plants mentioned are found little swellings or tubercles; in the tubercles exist millions of tiny plants called bacteria, which take out nitrogen from the atmosphere and fix it so that it can be used by the plant; that is, they form nitrates for the plants to use. These bacteria, alone of all the living plants, have the power to take the free nitrogen from the air and make it over into a form that can be used by the roots.

This fact is made use of by careful farmers who wish to make as much as possible from a given area of ground in a given time. Such plants as are hosts for the nitrogen-fixing bacteria are planted early in the season. Later these plants are plowed in and a second crop is planted. The latter grows quickly and luxuriantly because of the nitrates left in the soil by the bacteria which lived with the first crop.

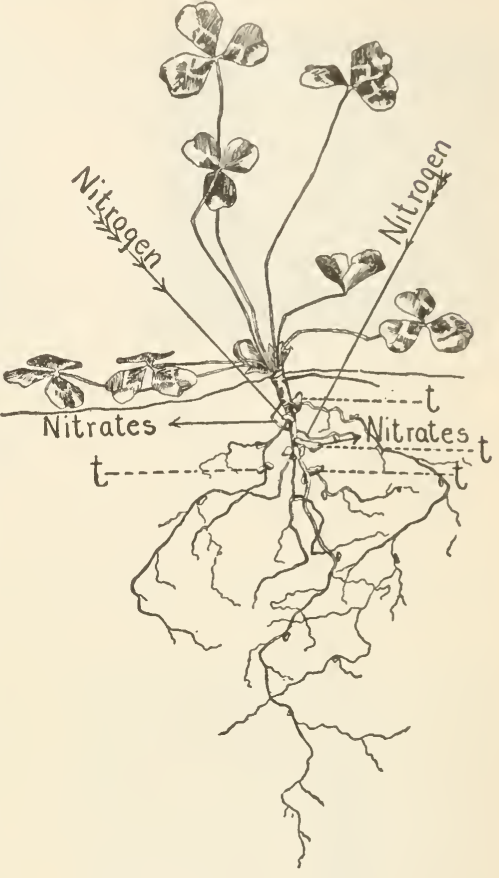

Tubercles on clover roots. For this reason, clover is often grown on land in which it is proposed to plant corn, the nitrogen left in the soil thus giving nourishment to the young corn plants. The annual yield of the average farm may be greatly increased by this means.

Forms of Roots and their Relation to the Life of the Plant. Roots assume various forms. The form or position of the root is usually dependent on the needs of the plant, the roots acting to help it succeed in certain localities.

Food Storage. - The use to the plant of the food stored in the taproot may be understood if we think of the life history of the parsnip. Such a plant produces no seed until near the end of the second year of its existence. After forming seeds it dies. The 
food stored in its root enables it to get an early start in the spring, so as to be better able to produce seeds when the time comes.

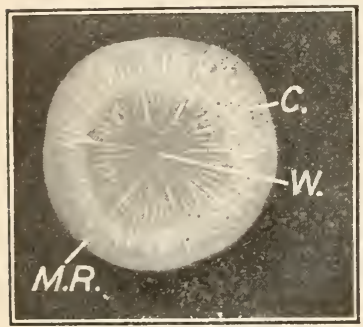

Cross section of parsnip. The cortex $(C$.$) is given up almost$ entirely to the storage of food. Note the medullary rays (M.R.) which radiate from the center of the wood (W.).

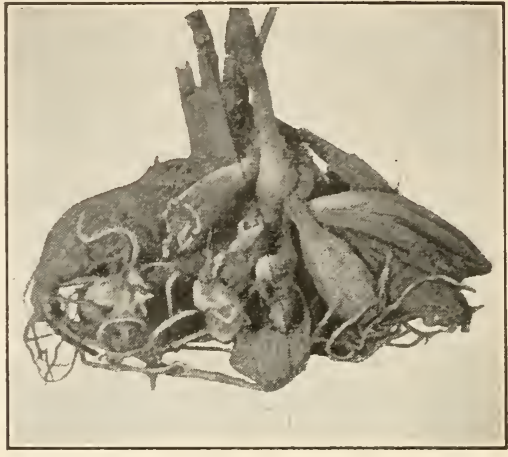

Fascicled roots (dahlia); fibrous roots which have become thickened with stored food.

Examples of other roots storing food are carrot, radish, yam, sweet potato, etc.

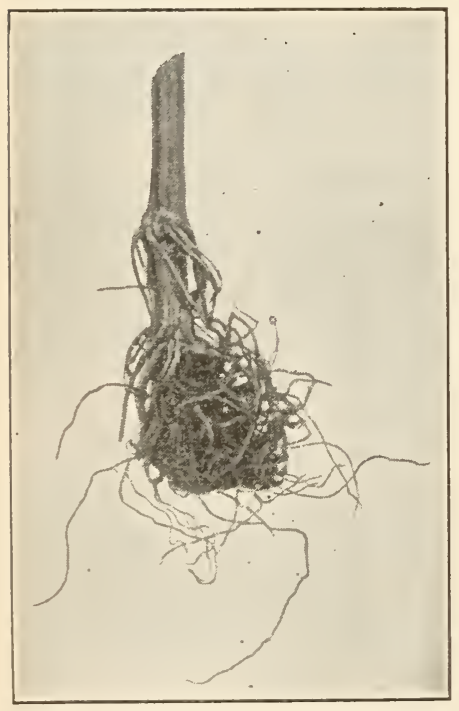

Corn roots, showing prop roots developed at first node above ground.
Demonstration. - Test a cross section of the parsnip root with iodine. In which part of the root is starch stored? Test another cross section with nitric acid and ammonia. Which part of the root contains stored food?

WATER Roots. - In the duckweed, a plant living in water, the roots are short and contain few root hairs. The water supply is so great that few root hairs have been called forth. The water hyacinth is another example of slight development of roots. The plant is buoyed up by the water and does not need strong roots to hold it firm.

Adventitious Roots. - Roots are often developed in unusual places. Roots coming out thus, as, for example, on the stem, are called adventitious. Such roots are developed along the stem of many climbing plants. Examine and draw the roots of English ivy. See how many other common wild climbers develop adventitious ronts. 
Some plants, as strawberry, couch grass, and many others, develop new plants by striking root at any point on the reclining stem where it touches the ground. This fact is made of use by practical gardeners in the layering of plants.

Examine the Indian corn for another kind of adventitious root. Here they serve as props for the tall stem. In the young seedlings of corn, notice how early these roots develop. Also notice the manner in which they arise on the stem.

Arr Roots. - In tropical forests, where the air is always warm and moist, some plants have come to live above the soil on the trunks of trees, or in other places where they can get a favorable foothold. Such plants are called epiphytes or air plants. The tropical orchid seen in our greenhouses is an example. Examine the roots of such a plant. Notice how thick they are. They are usually provided with a spongy tissue around the outside which has the function of absorbing water.

Parasitic Roots. - A few plants live on other living plants, and develop by the aid of nourishment taken at their expense. Such a plant or animal is called a parasite. The plant or animal on which the parasite lives is called the host. The mistletoe is an example of a parasitic plant. An examination of its roots shows that they have bored their way into the stem of the host. These roots not only penetrate the bark but push toward the center of the tree, taking nourishment from the cells there. The dodder is another seedbearing plant which has this habit. Dodder produces from seed, but is unable to live alone after it has passed the seedling stage, and will die if it cannot find a suitable host. It is found on many common weeds, as jewel weed and golden-rod. Many of the lower plants live as parasites, among them being mildew, rusts, and smuts found on roses, grain, and corn.

\section{Reference Books \\ FOR THE PUPIL}

Andrews, Botany All the Year Round. Chap. II. American Book Company. Goff and Mayne, First Principles of Agriculture. American Book Company. Atkinson, First Studies of Plant Life, Chaps. IX, XI, XII. Ginn and Company. Coulter, Plant Studies, Chap. V. D. Appleton and Company.

Stevens, Introduction to Botany, pages 31-44. D. C. Heath and Company.

FOR THE TEACHER

Goodale. Physiological Botany. American Book Company.

Gray, Structural Botany, pages 27-39, 56-64. American Book Company. Kerner-Oliver, Natural History of Plants. Henry Holt and Company.

Setmer-Moor, Practical Plant Physiology. The Macmillan Company.

Green, An Introduction to Vegetable Physiology, Chaps. V. VI. J. and A. Churchill. MacDougal, Plant Physiology. Longmans, Green, and Company.

HUNTER'S BIOL. -7 


\section{BUDS AND STEMS}

Structural Differences between the Stem and the Root. - Wash carefully the earth from the roots of a pea seedling that you have grown in the laboratory. Try to make out the following points: (1) note the differences in color between the stem and roots; (2) compare the manner in which the root and stem give off lateral branches. Notice that the leaves and lateral branches from a stem are more or less regular in position, while the small roots have no regular method of leaving the primary root. The places on the stem where leaves are given off are known as nodes, the part of the stem between being called an internode.

In a growing stem of any woody plant, notice the end of the stem; the bud at the termination is a future stem. It is well for us to remember that a stem is a developed bud, as we shall see when we take up the work on the bud more in detail.

One difference which is very noticeable between the stem and the root is the color, the young root being whitish or gray, and

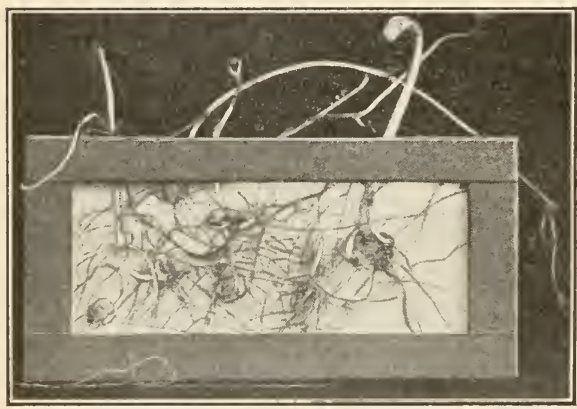

A pocket garden which has been kept in complete darkness for several weeks. Notice the condition of stems and leaves. the young stem being green. The following experiment will serve to explain this difference:-

Effect of Absence of Light on Young Plants. - Plant some peas in sawdust within a box, or wide-mouthed bottle which has been previously blackened so that no light is admitted to the interior. Grow some of the same seed in a box alongside the covered material, giving each the same amount of heat and moisture. After the young plants have grown, take one out, compare it with the ones grown in the light, and note the difference in color. Might the absence of light account for the color of the root?

The seedlings which have been grown in darkness show some other interesting conditions. The stems are long and more or less reclining on the sawdust. The leaves are hardly worthy of the name, being reduced to little scales. We know that they are 
modified leaves because they come out on the stem in the position taken by leaves. The stem of the plant grown in the darkness is much longer and thinner than the one grown in the light. Can you think of any reasons for these differences?

Effect of Light on Plants. - We can explain the changed condition of the seedling grown in the dark only by assuming that light has some effect on the protoplasm of the seedling and induces the growth of the green part of the plant. Numerous instances could be given in which plants grown in sunlight are healthier and better developed as to their green parts than those in the shady parts of a garden or field. On the other hand, some plants thrive in the shade. Such plants are the mosses and ferns. Still other plants, minute organisms hardly visible to the eye, do not thrive in the light, and may be killed by its influence. Such are molds, mildews, and some bacteria. It is to be noticed that such plants as do not need light are not green. As a matter of fact, the stem, which has but little chlorophyll, develops somewhat more rapidly under conditions where it receives no light.

Heliotropism.- We saw that the stems of the plants kept in the darkness did not always lift themselves erect as in the case of stems in the light. If your seedlings have been growing on a window sill, or where the light comes in from one side, you havedoubtless noticed that the stem and leaves

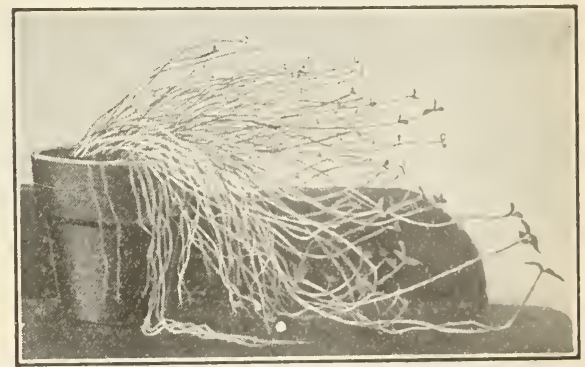

The growth of young stems and leaves of oxalis toward the light. of the seedlings incline in the direction from which the light comes. The tendency of young stems and leaves to grow toward sunlight is called positive heliotropism.

The experiment pictured on the following page shows this effect of light very plainly. A hole was cut in one end of a cigar box and barriers erected in the interior of the box so that the seeds planted in the sawdust received their light by an indirect course. 
The young seedling in this case responded to the influence of the stimulus of light so as to grow out finally through the hole in the box into the open air. Make this experiment, and see if you get the same result. Vary the apparatus in any manner you can, and plant some other seeds or grains.

This experiment shows that another factor besides gravity influences the stem to grow upward. This growth of the stem to the

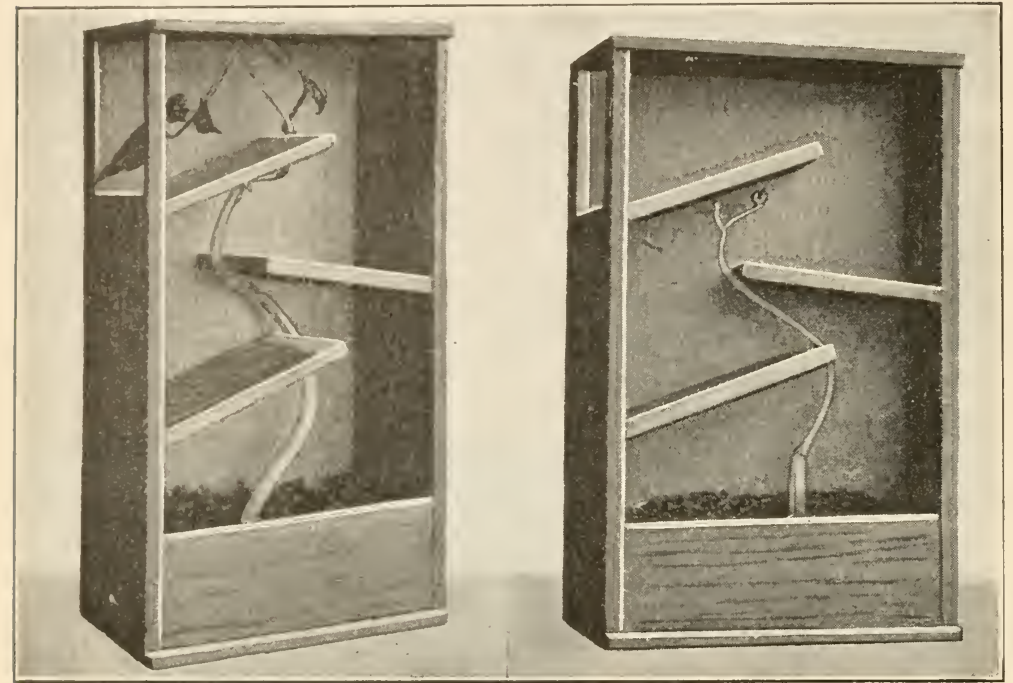

Two stages in an experiment to show that green plants grow toward the light.

light is of very great importance to a growing plant, because, as we shall see later, food-making depends largely on the amount of sunlight the leaves receive.

Structure of a Bud. - If we cut a head of cabbage so that the knife blade cuts through the long axis of the stem, we find that the stem is much shortened or dwarfed, and that the leaves are so placed as to cover it entirely. The cabbage is a big bud. If we carry out our definition of a bud, starting with what we have seen in the cabbage, we might say that a bud is a very much shortened branch, or in reality "the promise of a branch." 


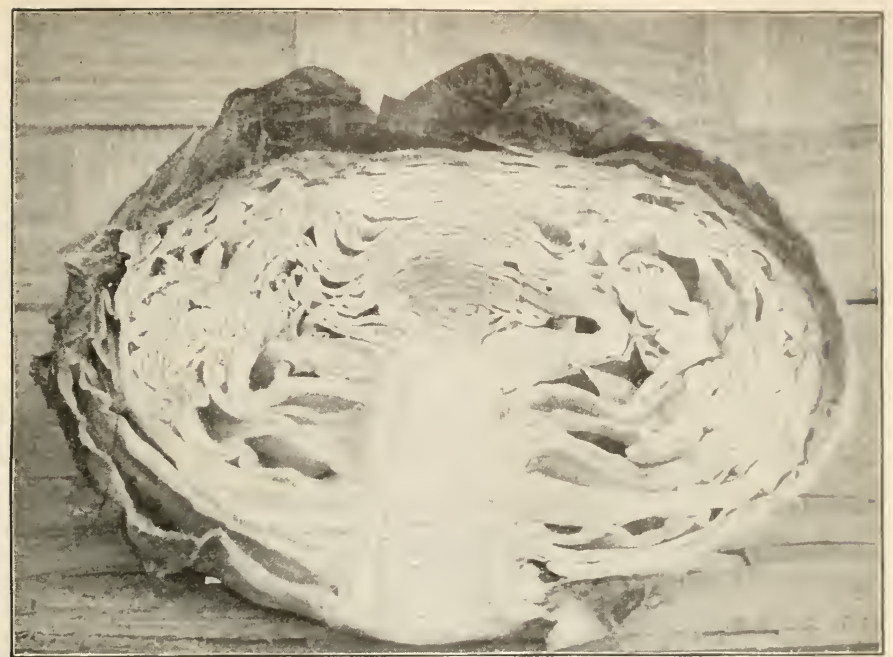

Cabbage head cut lengthwise to show stem and leaves. Photographed by Overton.

Factors which influence the Opening of a Bud. - A bud responds to the same stimuli that we have seen call a young plant into active life from the seed. If a branch containing unopened buds (such as horsechestnut or willow) is placed in water in a moderately warm room, it will respond to the factors without it and begin to open. The tips of branches, still attached to the tree outdoors, may be introduced into a warm room through a hole bored in the window sash. They will open to bear flowers and leaves during the

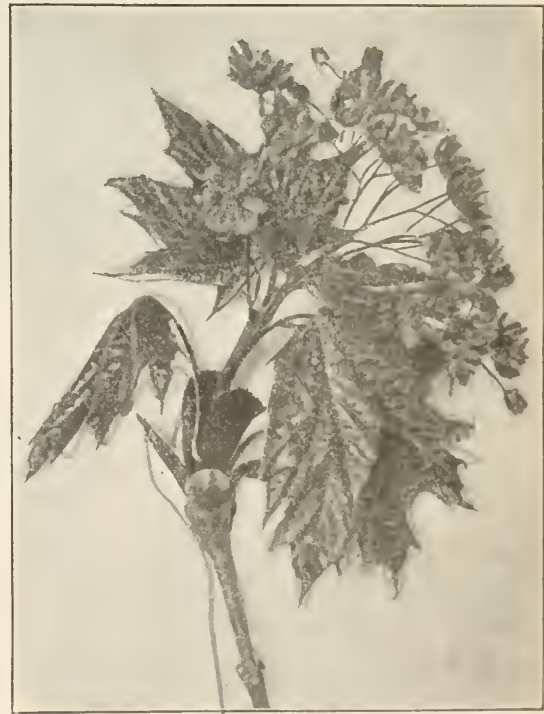

Blossom bud of Norway maple expanded, showing inconspicuous flowers. Photographed by Overton. 
coldest months of the year. The factors which influence the germination of seeds also act on the bud.

Position of the Bud on the Stem. - The growth of the stem from the bud can best be observed in a very young seedling. If, for example, we examine a pea seedling, it will be seen that the epicotyl is, in truth, the first bud of the plant. It produces the first stem and leaves. The position of the most active buds determines the form of the future tree. Buds come out at the ends of branches (terminal) and at the sides (lateral).

Deliquescent Tree. - If you examine a winter branch of the apple, elm, or oak tree, you will find that the lateral buds have

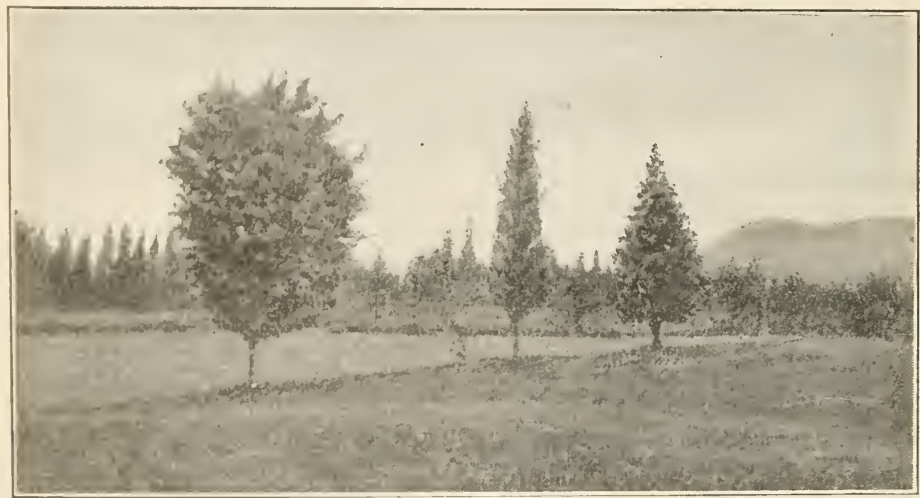

Excurrent trees (at right) and deliquescent tree (at left). In background a row of cedars which were planted by birds roosting on a fence along a roadside.

developed more strongly and more rapidly than the terminal bud. Thus the tree has come to assume during its growth a rounded shape. Such a tree, having a rather stout, short trunk, with many low, spreading, lateral branches, is said to be deliquescent.

Excurrent Tree. - If, on the other hand, the terminal buds of the tree get a better supply of light, food, or if other factors aid its growth, the tree will be tall and have but one main trunk, such as the Lombardy poplar, and pines and cedars. Such a tree is named excurrent. The picture shows trees of these two shapes.

Structure and Functions of the Parts of a Winter Twig. - The best way for us to understand the growth of a bud into a branch 
is to compare the structures we found in the bud with the markings that we find on the outside of a branch. Let us take for this work a winter branch of the horsechestnut tree. ${ }^{1}$ Place some branches in water in a warm room so that we may have some opened buds to look at later.

Laboratory Suggestions. - A twig in its winter condition shows the position of the buds very plainly. Notice that the terminal buds are larger than those on the sides of the branch. As the twig grew last year the scales covering the outside of the bud dropped off and the young shoot developed from the opened bud. The scales which dropped off left marks upon the surface of the twig, which run completely around the twig at a given point, forming a little ring. These rings tell the age of the branch. Estimate the age of the one you hold. Was the growth always the same each year? How might you account for the different rate of growth in different years?

Just above the lateral buds are marks, known as leaf traces, that show the points at which leaves were attached. A careful inspection of the leaf traces reveals certain tiny scars arranged more or less in the form of a horseshoe. These scars mark the former position of bundles of tubes which we have already studied in connection with roots. They are, in fact, continuations of the same fibrovascular bundles which pass from the root up through the stem and out into the leaves, where we see them as the veins which act as the support of the soft green tissues of the leaf. The most important use to the plant of the fibrovascular bundles $i$ s the conduction of fluids from the roots to the leaves and from the leaves to the stem and root. The position of the leaf traces on the branch give us a clew as to the appearance of the leafy tree. If we find the leaf traces oppositely placed, then we know that the leaves and buds, which

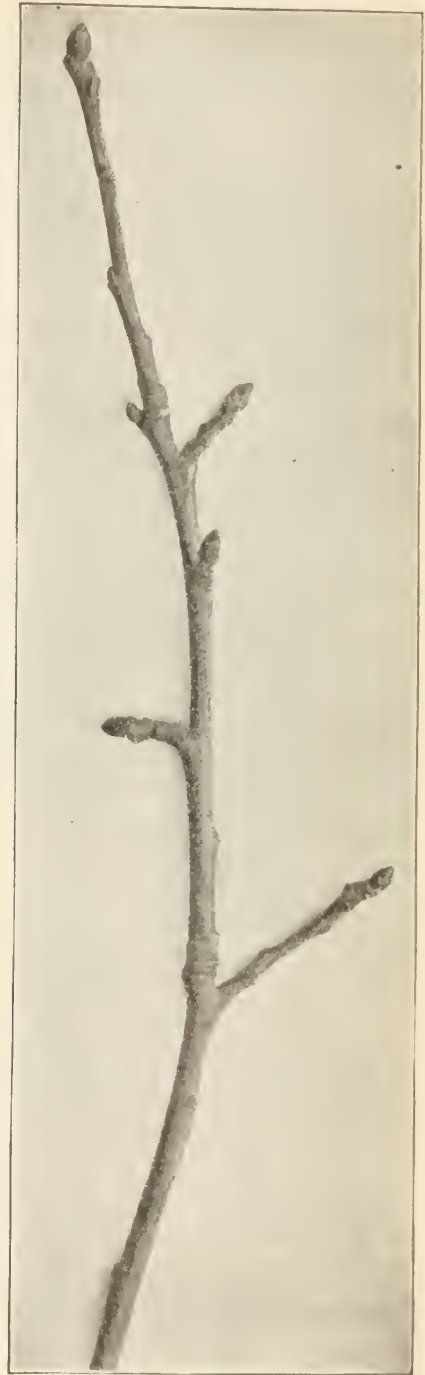

Three-year-old apple branch, showing terminal and lateral buds and bud scars.

1 See Hunter and Valentine, Manual, page 25. 
give risc to lateral branches, had a very definite arrangement in pairs at the nodes. Such are the maple or horse-chestnut. If, on the other hand, the leaf traces are placed alternate to each other, we can picture a tree with much less regularity in the position of leaves and lateral branches, as in the apple, beech, and elm.

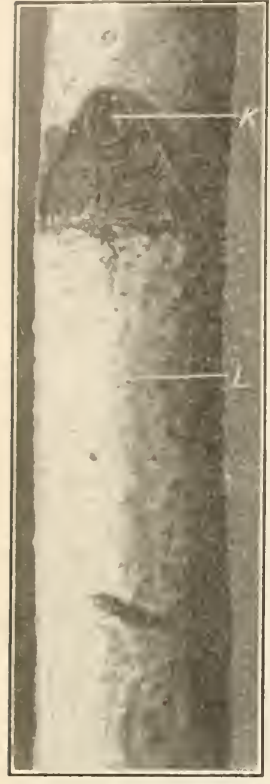

Twig, showing knot $(K)$ and lenticel $(L)$.

The very tiny scars, which look like little cracks in the bark, are very important organs, especially during the winter season, for they are the breathing holes of the tree. A tree is alive in winter, although it is much more active in the warm weather. Oxidation takes place much more rapidly in the summer because the plant is growing rapidly, and more fuel is consumed to release the energy needed for growth. We shall see later that the leaves are the chief breathing organs of the plant. But all the year round oxygen is taken in by means of the lenticels, as the breathing holes in the trunk and branches of a tree are called. Notice whether the distribution of the lenticels is regular over the surface of the branch. Notice also, that some of the lenticels have become split in the growth of the tree so as to appear as long cracks.

In the twig of the horse-chestnut another scar will be found at a point between two branches. This scar marks the place where a cluster of flowers was attached. It is called a flower scar.

Make a careful drawing of the branch, showing, if possible, all the parts we have discussed. Make careful labels for all the parts.

Adaptations in the Bud of Horse-chestnut. - If we now turn our attention to the horse-chestnut buds which have been previously plaeed in water to open, we shall be able to get some notion of the wonderful adaptations of the bud, which fit it for its work.

In the first place, a horse-chestnut bud is covered with a sticky material. Not only does this covering keep out unwelcome visitors which might bore into the bud and destroy the tender parts within, but it also serves as a waterproof covering agxinst the icy rains of the late fall and early spring. In the buds which have not begun to open, notice the overlapping position of the scales, like the shingles on a roof. Of what use might this be? In buds which have begun to open, notice that not only have the tiny green leaves been protected by the outer scales, but they have been additionally wrapped in soft, cottony substance. You can easily see that the lcaves have been folded together so that the flat surface has had a minimum of exposure. The young leaves are always folded or rolled up in the bud. Two purposes are thus served, protection from frost and from drying by little exposure of the delicate surface, and economy of space by means of the tight and compact stowing away of the parts thus folded. This ar- 
rangement of leaves within the bud is known as vernation. An interesting piece of field and laboratory work is the comparison of vernation in a number of different buds. Those of the wild cherry, birch, European walnut, snowball, lilac, and tulip tree are of interest for this purpose.

\section{Why buds are Covered. -} When we consider that most of our earliest green leaves come from opening buds in the early spring, the importance of a protective covering is well seen. Nevertheless buds are frozen time and again during the cold weather, only to thaw out again without injury to the plant. Sudden changes, however, do much harm. Some buds do not open during mild winter weather when temperature conditions are seemingly favorable; a definitelength of growth seems in that case to be necessary. During warm weather plants

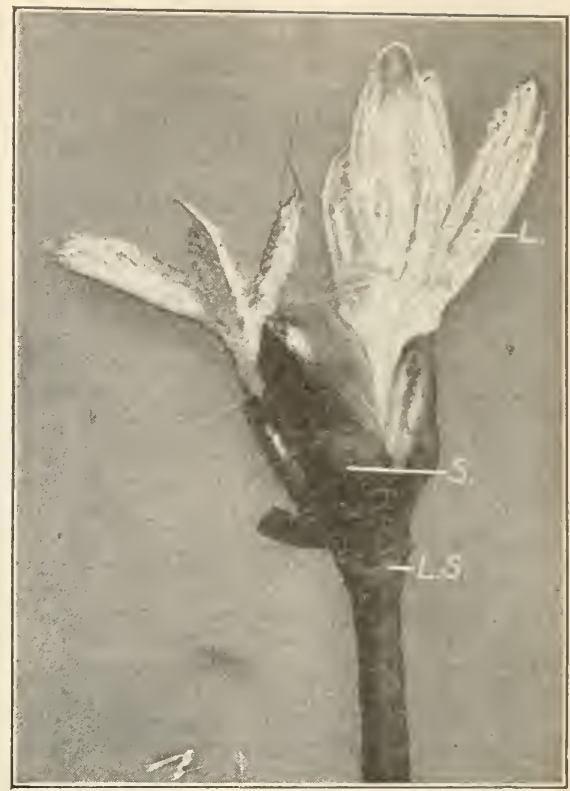

Opening bud of horse-chestnut; L., leaves; L.S., leaf scar; $S$. , scalelike leaves which cover bud. give rise to buds which are devoid of protective scale leaves. Such is also noticed in tropical forms, which are not called upon to meet rigorous cli-

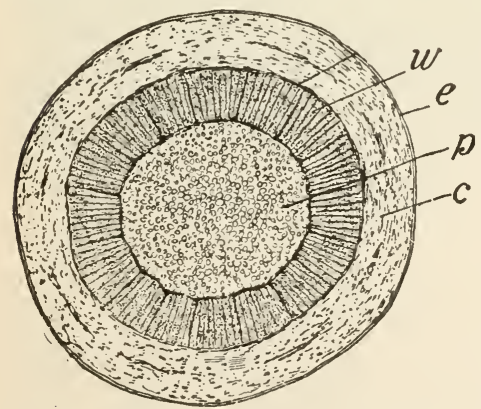

Section across a young twig of box elder, showing the four stem regions; $e$, epidermis, represented by the heavy bounding line; $c$, cortex; $w$, wood; $p$, pith. (From Coulter, Plant Relations.) matic conditions. We have now learned something about the outside markings of a branch. ${ }^{1}$

Let us turn our attention to the internal structure of the horse-chestnut stem to see how the parts within are adapted to perform the work which they do.

Study of a Dicotyledonous Stem.In the cross section of horse-chestnut twig, notice the innermost part, the pith. See if it is as tough as the wood of the stem. About what proportion of the cross section is oecupied by the wood? Everything outside of the wood is collectively known as the bark. It is made up of three layers. Pull off outer layer; notice its color.

${ }^{1}$ See Hunter and Valentine, Manual, page 32 . 
Compare it with the layer just under it as to color. How does the inner brown layer compare with the others in thickness? This inner layer is called the bast. It is made up largely of long, tough cells, somewhat like fibers in appearance.

Notice the lines which radiate from the pith to the bark or cortex. They are called medullary rays.

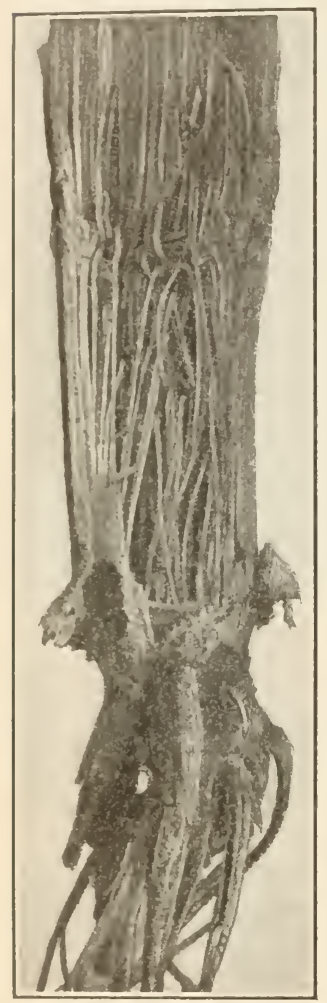

Longitudinal section of cornstalk, showing some of the fibrovascular bundles passing outward at the node just above the roots.

Compare a cross section of this stem with another made just above, where last year's bud was located. What differences do you find in the two cross sections? Show by means of a drawing the structure of a horse-chestnut stem. This may be taken as a type of dicotyledonous stem.

Study of a Monocotyledonous Stem. - Compare the above section with that of a monocotyledon, a piece of cornstalk, for example. Notice that in the corn the whole stalk is more or less pithy and that the wood is seattered through the pith in the form of structures which look like little dots. Cut a piece of dry cornstalk lengthwise, and you will find that these dots are the ends of long stringy threads. If the longitudinal section be made through a node of the cornstalk, some of these long structures will be found to curve outward at the node to enter the leaf, where they can be followed as veins. The threads are the same structures that we have seen as the little dots in the leaf scar of the horse-chestnut twig, the fibrovascular bundles. They are composed of bundles of very tiny tubes, supported by other thick-walled, tough, woody cells, which give mechanical support to the tubes. Notice that the exterior of the corn stem is composed of a great number of these bundles, which have grown close together and become harder and thicker. This outer covering of the cornstalk is called a rind. Of what use might the rind be to the stem?

Structure of Fibrovascular Bundle in a Monocotyledonous Stem. - The stem of a monocotyledon consists largely of pith, with, as we have seen, slender bundles of wood inclosing hollow cells placed end to end to form ducts. These are collected around the outer part of the stem, thus giving better support to the whole stem.

A single fibrovascular bundle in a cross section under the microscope shows the following arrangement. Around the outside of the bundle is a collection of thick-walled, woody cells. These cells serve to support the bundle. Inside of these cells are found a number of tubes of different diameters, some for conduction of water, others for air, and still others for liquid food material sent down from the leaves. All of these tubes were formed by the elongation of certain cells of the bundle which in their growth have divided so as to form a string of cells. The contents of some of these cells die; thus a hollow tube of cellulose remains, which admits the passage of material from one level of the stem to 
another through the open ends of the cells. We find the conducting tubes have quite different functions: Some carry soil water and air up the stem, while others take food material down toward the roots. As the bundles grow they elongate rapidly, but are limited in their growth outward by the hard-walled, woody cells. An old stem of a monocotyledon contains more bundles than does a young stem, the bundles growing out into the leaves.

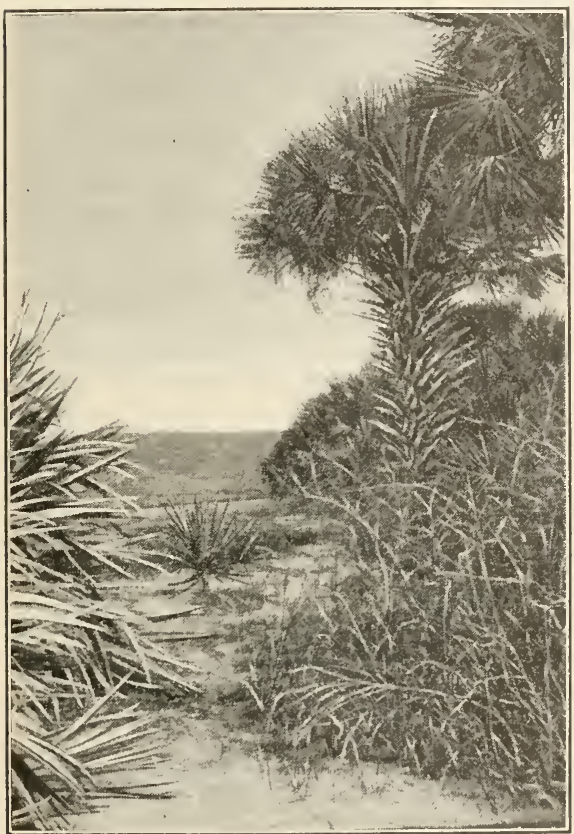

Palms and palmettos; typical monocotyledonous plants. Scene on Indian River, Florida.

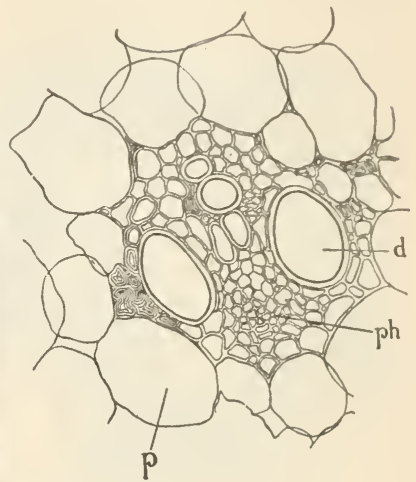

Monocotyledonous fibrovascular bundle; $p h$, region in which food passes down; $d$, woody portion or bundle ducts which carry air and water; $p$, pith cell.

Summary. - A stem of corn contains pith, dead tissue which is the original soft, spongy material out of which the stem is built, and a great mass of woody cells, many of them tough and fiberlike, serving to support the stem; others are long cells, hollow and end to end, forming tubes which connect the roots with the leaves, and through which fluids pass in both directions.

The stem of corn also contains a supply of stored food. Some of the cells of the pith store food, which is often being made faster than it can be used by the plant. Many monocotyledonous trees which live for long periods of time store food in large quantities in the trunk. The sago palm is an example. 
Young Monocotyledonous Stem. - Almost the entire stem of a rery young, green monocotyledon is composed of soft, thin-walled cells. These

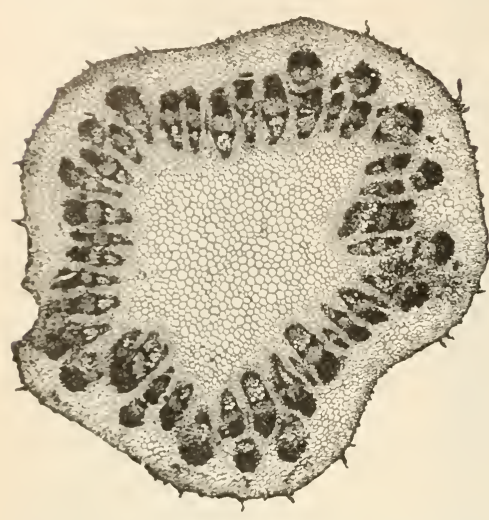

Transverse section of a stem of burdock, showing fibrovascular bundles not completely united into a ring.

the cross section) of the ends of supporting cells which occupy that area. If the section is several years old, we shall find a definite ring in the wood for each year's growth.

Medullary Rays. - Radiating from the center of the stem outward are found a number of tiny lines. These are more prominent in stems of older growth. The medullary rays, as they are called, are seen to begin at the pith and pass out to the bark. They are, indeed, formed of the pith. They are part of the original parenchyma which at first formed a large part of the whole stem. As the stem grew in size, fibrovascular bundles appeared. These bundles were not scattered through the stem, but were arranged more or less completely in a circle. Growth of these woody bundles took place along the outer edge. This caused the chyma (parent tissue.) Later in the life of the stem their contents are used up by the plant, and we find them empty and dry in the section of cornstalk. In some monocotyledonous stems their walls become hard, while in other cases, as in the bamboo, they entirely disappear.

Structure of a Young DicotyLedonous Stem. - In the stem of a young dicotyledon the pith is found to occupy relatively a small space in the middle of the section. This pith is composed of the parenchyma cells such as we found in the cornstalk. Surrounding the pith is the wood. The wood consists (in many tubes and the woody walls of

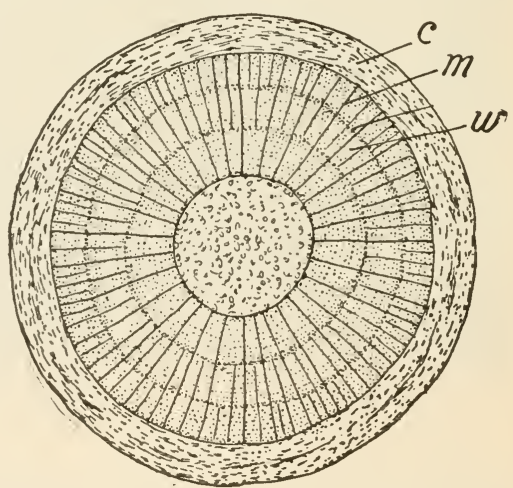

Section across a twig of box elder three years old, showing three annual growth rings, in the vascular cylinder. The radiating lines $(m)$, which cross the wood $(w)$, represent the pith rays, the principal ones extending from the pith to the cortex $(c)$. (From Coulter, Plant Relations.) are the cells making up the paren- 
bundles ultimately to unite along the outer edge because of more rapid growth in that region. This rapidly growing area, which extends completely around the stem under the bark as a hollow cylinder, is called the cambium layer. All growth takes place from that part of the stem. As the bundles squeezed together in their growth, the pith or parenchyma became compressed into thin plates, the edges of which are seen in the cross section. We call these plates the medullary rays.

Microscopic Structure of a Fibrovascular Bundle in the DicotyLEDonous STEM. - The structure of one of the young bundles in a young dicotyledonous stem is somewhat as seen in the illustration. The bundle is composed of two areas. The inner area, directed toward the middle of the stem, is made up of woody, thick-walled cells, which support and in some cases form part of the walls of the tubes which carry the soil water up the tree. These tubes differ considerably in size, the larger ones being formed during the more rapid spring growth of the bundle. The outer part of the bundle, which is separated from the inner part by the cambium layer, is quite different in structure from the inner part. It is, in fact, growing toward the outside and is forming the inner layer of the bark. The cells of the cambium layer are much softer and have thinner walls than those of the wood, because they are filled with protoplasmic material and are constantly dividing to form new cells.

Most of the cells of the inner bark are extremely tough and fibrous. Between the bast fibers, as the tough cells

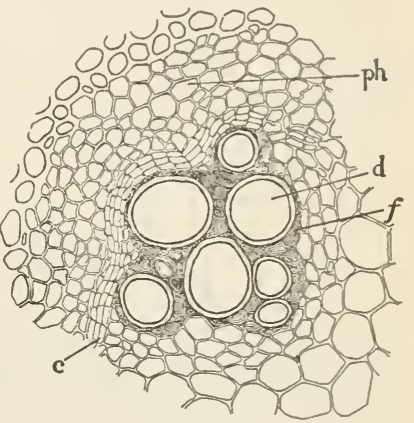

Fibrovascular bundle of a dicotyledon; $p h$, region of sieve tubes; $c$, cambium; $d$, duct; and $f$, fibers of the woody part of the bundle. are called, are found numerous elongated cells joined end to end, the ends of each cell being full of little holes. These are the sieve tubes (or soft bast cells); they serve as a channel for the sap or food materials which come down from the leaves toward the roots. This region of the stem also stores considerable food in a form suitable for the use of the stem.

As growth proceeds, the cambium layer constantly grows outward, and each new year new fibrovascular bundles are added to supply the new leaves and branches of that season. This accounts for the fact that in cross sections of small twigs some of the medullary rays appear to start from the pith, some from the outer edge of the first annual ring, and still more from each succeeding outer ring.

The outer bark of the tree is protective. The cells are nearly all dead, and the heavy woody skeletons keep out cold and dryness, as well as prevent the evaporation of the fluids within. Most trees are provided with a 
layer of corky cells, which serve this purpose. ${ }^{1}$ The experiment here illustrated shows this.

Select two potatoes of equal weight and peel the skin from one. Place the pared potato, with the parings, in one pan of the scales and the other potato in the other pan; it will be found that the pared potato loses weight very rapidly. A record of this loss of weight should be kept and the results noted in tabular order. Of what use is the epidermis to the potato ? ${ }^{2}$

Passage of Fluids up Monocotyledonous and Dicotyledonous Stems. - Use old seedlings of Indian corn for the monocotyledonous stem. Cut off the stem close to root and place it in a solution of eosin or red ink. Place some cut

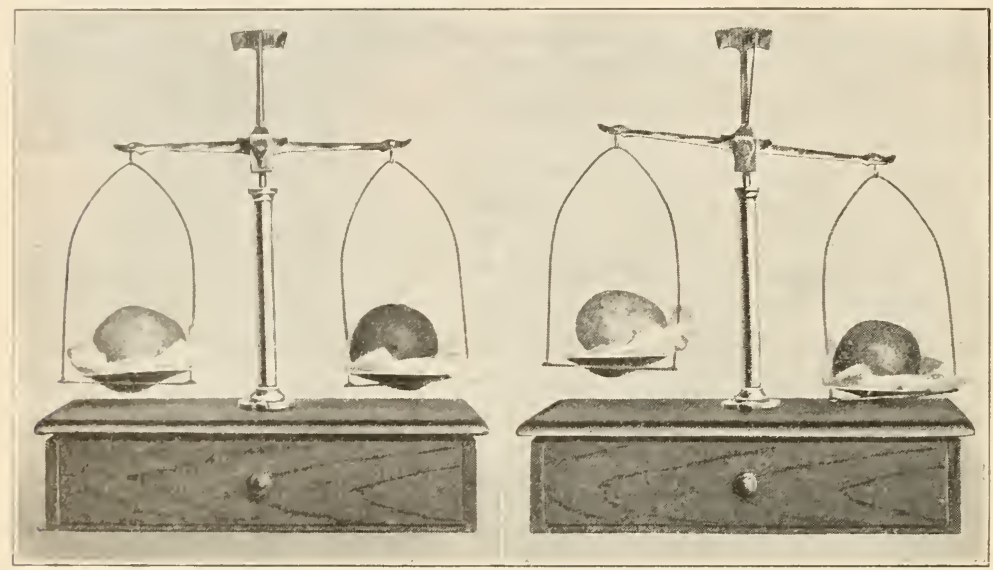

Experiment to show that the skin of the potato retards evaporation.

dicotyledonous stems in red ink. Garden balsam, which can be grown in the hothouse or laboratory, is the most transparent. Impatiens and sunflower are also good. Leave them in the solution in a sunny room for one day. In all the above cases the colored material is found to move up the stem and into the leaves and flowers. Cut some of the above stems and examine them closely to see where the most red ink is. Compare the distribution of bundles in stems with their distribution in the taproot.

Passage of Fluid up and down the Stem. - From the above experiments it is evident that the course taken by water in its course up the stem is confined to the collections of woody tubes which we call the fibrovascular bundles. In the stem of a mono-

1 The extreme outside layer of cells, as in the root, is known as the epidermis. It is often not seen in old stems.

${ }^{2}$ See Hunter and Valentine, Manual, page 239. 
cotyledon we see the cut ends of the bundles in a cross section scattered through the pith. In the dicotyledonous stem the pathway of the colored fluid is much more definite with reference to the outside of the stem. Try to follow the lines out into the leaves or buds, tracing the course exactly.

If the following experiment is made, it will be found that fluid passes not only up the stem but also down the stem.

N.B. This experiment should be started several (at least two) weeks in advance.

Place willow twigs in a glass of water. After a few days roots begin to grow. Where do the roots appear? After they have grown several days (until the roots are one inch in length) girdle a twig by removing the bark in a ring about one inch in width. After a time, roots appear above the cut area and grow down toward the water. The lower roots below the girdled area die.

This experiment shows us that the passage of food materials evidently takes place in a downward direction just outside the wood in the layer of bark which contains the bast fibers and sieve tubes. Food substances are also conducted to a much less extent in the wood itself, and food passes from the inner bark to the inside of the tree by way

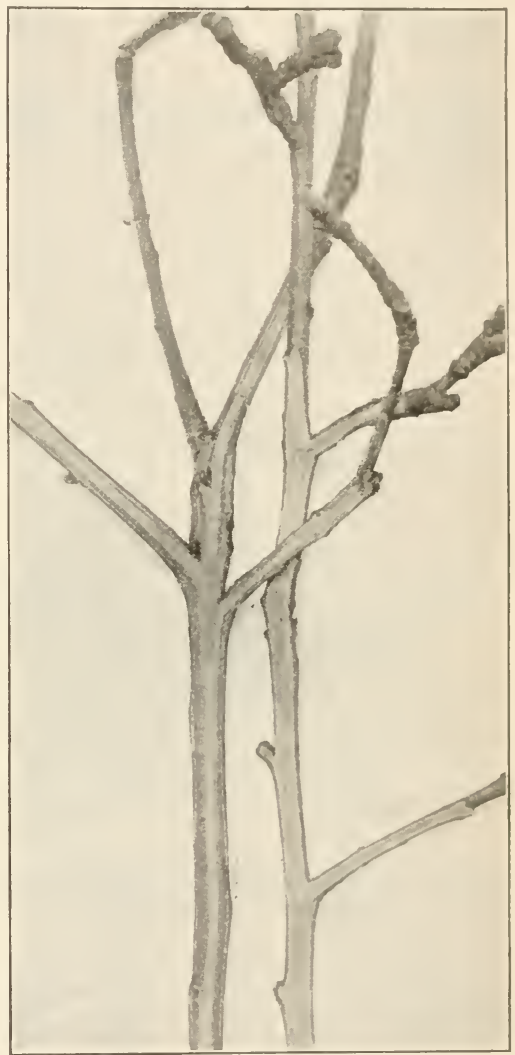

Apple twigs split to show the course of sap. of the pith plates or medullary rays. This can be proved by testing for starch in the medullary rays of young stems. It is found that much starch is stored in this part of the tree trunk. This experiment with the willow explains why it is that trees die, when girdled so as to cut the sieve tubes of the inner bark. The 
food supply is cut off from the protoplasm of the cells in the part of the tree below the cut area.

In what Form does Food pass through the Stem? - We have already seen that materials in solution (those substances which will dissolve in the water) will pass from cell to cell by the process of osmosis.

Experiment. - Partly fill one thistle tube with starch and water, and another with sugar and water. Tie over the end of each tube a piece of parchment paper. Place both test tubes under water in a dish. After twenty-four

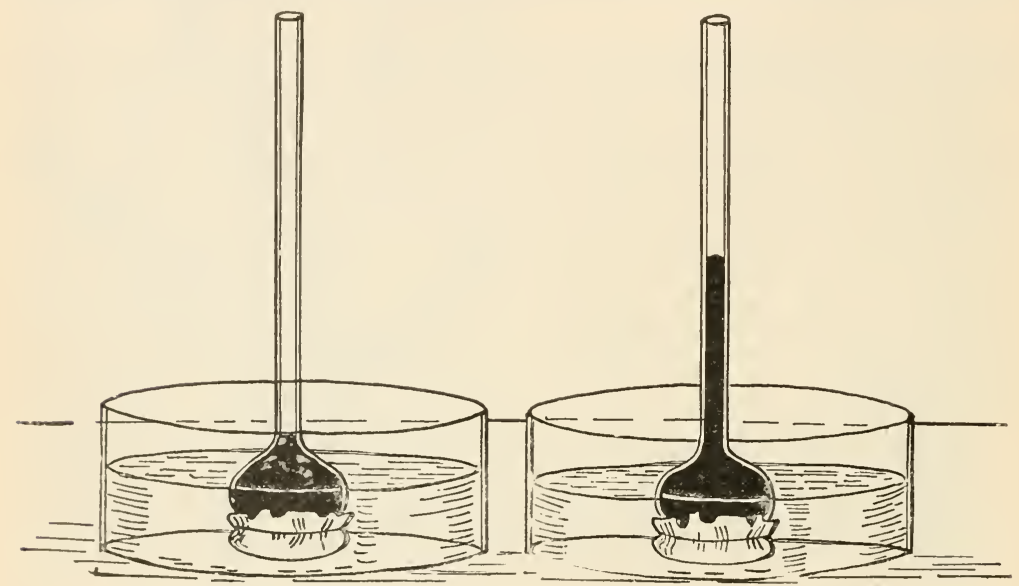

Experiment showing the osmosis of sugar (right-hand tube) and non-osmosis of starch (left-hand tube).

hours, test the water in the dish for starch, and then for sugar. We find only the sugar, which has been dissolved by the water, can pass through the membrane.

Digestion. - As we shall see later, the food for a plant is manufactured in the leaves. Much of this food is in the form of starch. But starch, being insoluble, cannot be passed from cell to cell in a plant. It must be changed to a soluble form. It is changed by a process known as digestion. We have already seen that starch was changed to grape sugar in the corn by the action of a substance (a digestive ferment) called diastase. This process of digestion seemingly may take place in all living parts of the plant, although most of it is done in the leaves. 
The food material may be passed in a soluble form until it comes to a place where food storage is to take place, then it can be transformed to an insoluble form (starch, for example); later, when needed by the plant in growth, it may again be transformed and sent in a soluble form through the stem to the place where it will be used. The processes by which starch is made soluble in the stem in the form of sugar and then changed back again to starch are but little understood.

Building of Proteids. - Another very important food substance stored in the stem is proteid. Of the building of proteid little is known. We know it is an extremely complex chemical substance which is made in plants from compounds containing nitrogen, the nitrates and compounds of ammonia received through the roots from the organic matter contained in the soil, in combination with sugars or starches of the plant body.

Some forms of proteid substance are soluble and others insoluble in water. White of egg, for example, is slightly soluble but can be rendered insoluble by heating it so that it coagulates. In a plant, soluble proteids pass down the sieve tubes in the bast and then may be stored in the bast or medullary rays of the wood in an insoluble form.

What forces Water up the Stem. - We have seen that the process of osmosis is responsible for taking in soil water, that the enormous absorbing surface exposed by the root hairs makes possible the absorption of a large amount of water. Frequently this is more than the weight of the plant in every twenty-four hours.

Experiments have been made which show that at certain times in the year this water is in some way forced up the tiny tubes of the fibrovascular bundles. It can be shown to rise a few inches in some stems by a laboratory experiment. This is best seen in the dahlia stem. During the spring season, in young and rapidly growing trees, water has been proved to rise to a height of nearly ninety

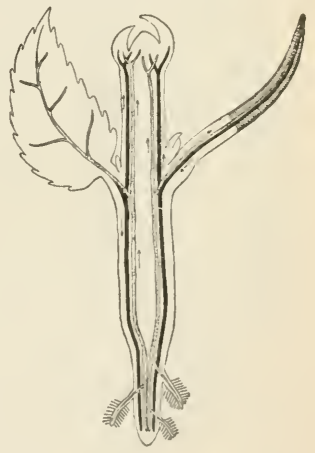

Diagram to show the areas in the stem through which raw food materials pass up the stem and food materials pass down (After Stevens.) feet. The force that causes this rise of water in stems is known as root pressure.

But root pressure alone cannot account for the rise of water (as in the stems of the big trees of California) to a height of several hundred feet. Other forces must play a part here. One way in which the rise of water can be partly accounted for is in the fact that capillary attraction may help in part. If you place in a glass containing red or other colored fluid three or HUNTER'S BIOL. -8 
four tubes of different inside diameter, the fluid will be found to rise very much higher in the tubes having a smaller diameter. This is caused by capillarity or capillary attraction. When we consider that the tubes of the fibrovascular bundles are very much smaller than any we can make out of glass, it ean be seen that water might rise in the stem to some height in tubes of microscopic diameter.

Another suggested method for the rise of water is given in the fact that air is found in some of the tubes in the form of bubbles, and these minute bubbles may help in the ascent of water.

The greatest factor, however, is one which will be more fully explained when we study the work of the leaf. Leaves pass off an immense quan-

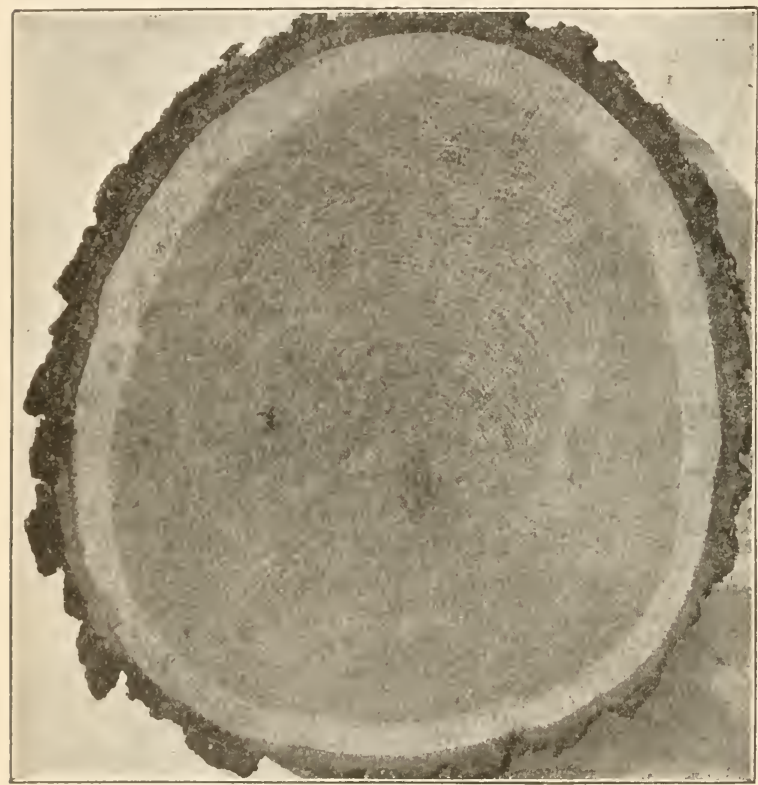

Cross section through a black oak showing heart wood and sap wood and medullary rays. (From Pinchot, U.S. Dept. of Agr.) tity of water by evaporating it in the form of vapor. This evaporation seems to result in a kind of suction on the column of water in the stem. In the fall, after the leaves have gone, much less water is taken in by roots, showing that an intimate relation exists between the leaves and the root.

Structure of Wood.Quite a difference in color and structure is often seen between the heart wood, composed of the dead walls of cells occupying the central part of the tree trunk, and the sap wood, the living part of the stem. In trees which are cut down for use as lumber and in the manufacture of various furniture, the markings and differences in color are not always easy to understand. 
Methods of cutting Timber. A glance at the diagram of the sections of timber show us that a tree may be cut radially through the middle of the trunk, or tangentially to the middle portion. Most lumber is cut tangentially. Hence the yearly rings take a more or less irregular course. The grain of wood is caused by the fibers not taking straight
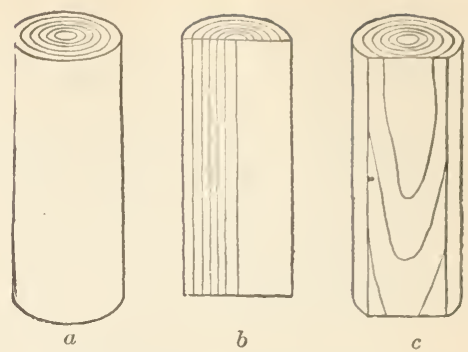

Diagrams of sections of timber: $a$, cross section; $b$, radial; $c$, tangential. (From Pinchot, U.S. Dept. of Agr.) lines in their course in the tree trunk. In many cases the fibers of the wood take a spiral course up the trunk, or they may wave

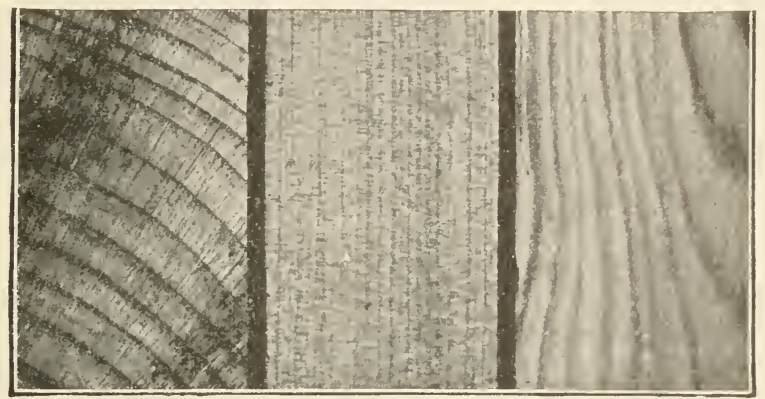

Sections of white pine wood. (From Pinchot, U.S. Dept. of Agr.)

outward to form little projections. Boards cut out of such a piece of wood will show the effect seen in many of the school

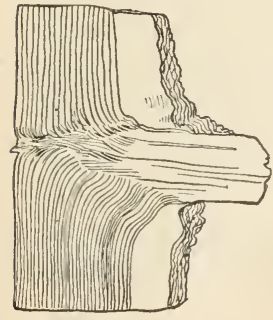

Section of tree trunk showing knot. desks, where the annual rings appear to form small elliptical markings.

Knots. - Knots, as can be seen from the diagram, are branches which at one time started in their outward growth and were for some reason killed. Later, the tree, continuing in its outward growth, surrounded them and covered them up. A dead limb should be pruned before such growth occurs. The markings in bird's-eye maple are caused by 
adventitious buds which have not developed, and have been overgrown with the wood of the tree.

BudDING. - We have said a bud is a promise of a branch; it may be more, the promise of a new tree. If the owner of an apple tree or peach tree wishes to vary the quality of fruit borne by the tree he may in the early fall cut a T-shaped incision in the bark and then insert a bud surrounded with a little bark from the tree bearing the desired fruit. ${ }^{1}$ The bud is bound in place and left over the winter. When a shoot from the imbedded bud grows

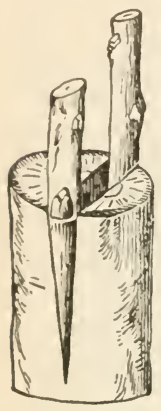

A cleft graft. out the following spring it is found to have all the characters of the tree from which it was taken. This process is known as budding.

Grafting. - Of much the same nature is grafting. Here, however, a small portion of the stem of the closely allied trce is fastened into the trunk of the growing tree in such a manner that the two cut cambium layers will coincide. This will allow of the passage of food into the grafted part and insure the ultimate growth of the twig. Grafting and budding are of considerable economic value to the fruit grower, as it enables him to produce at will trees bearing choice varietics of fruit. Over fifty methods of grafting are described in agricultural books. Those more successfully used are the cleft graft and the so-called whip graft. ${ }^{2}$

Forestry. - The American forests have long been our pride. Not only do they form the source of a very great industry, but what is still more vitsl to us, they protect the source of much of our water supply. They also serve as a protection against wind, floods, and moving sands. In Germany, especially, this relation of forest to water supply has been for a long time recognized, and the German forester or caretaker of the forests is well known. In some parts of central Europe the value of the forests was recognized as early as the year 1300 A.D., and many towns consequently bought up the surrounding forests. The city of Zurich has owned forests in its vicinity for at least 600 years. In this country only recently has the importance of preserving and caring for our forests been noted by our government. Now, however, we have a Division of Forestry of the Department of the Interior; and this and numerous state and university schools of forestry are rapidly teaching the people of this country the best methods for the preservation of our forests. The Federal Government has set aside a number of tracts of mountain forest in some of the Western states, some forty reserves in all, making a total area of almost twice the size of the state of Pennsylvania. New York has established for the same purpose the Adirondack

1 This bud should be taken from a tree of the same species.

2 For full directions for budding and grafting, see Hodge, Nature Studyand Life, pages 169-179, or Goff and Mayne, First Principles of Agriculture, Chap. XIX. 
Park, with over 1,000,000 acres of timber land, and other states are following her example.

Methods For KeEPING AND PRotecting the Forests. - Forests should be kept thinned. Too many trees are as bad as too few. They struggle with one another for foothold and light, which only a few can enjoy. Several methods of renewing the forest are in use in this country. (1) Trees may be cut down and young ones allowed to sprout from cut stumps. This is called coppice growth. This growth is well seen in parts of New Jersey. (2) Areas or strips may be cut out so that seeds from neighboring trees are carried there to start new growth. (3) Forests may be artificially planted. Two seedings planted for every tree cut is a rule followed in Europe. The greatest dangers are from fire, which often devastates large areas, and from careless cutting.

The Economic Value of Trees. - Trees form a protective covering for the earth's surface. They prevent soil from being washed away and they hold moisture in the ground. This they do because the evaporation of moisture through the stomata of the leaves cools the atmosphere, thus tending to precipitate the moisture in the air. Without trees many of our rivers might go dry in summer, while in the rainy season sudden floods would result. This has occurred in parts of Switzerland, France, and in Pennsylvania, where the forest covering has been removed. In some localities forests are used as wind-breaks and to protect mountain towns against avalanches. Thus in winter they moderate the cold, and in summer reduce the heat and lessen the danger from storms. The nesting of birds in woods protects many plants valuable to man which otherwise might be destroyed by insects.

Wood has great commercial importance as well. Even in this day of coal, wood is still by far the most-used fuel. It is useful in building. It outlasts iron under water, in addition to being durable and light. It is cheap and, with care of the forests, inexhaustible, while our mineral wealth will some day be used up. Hard woods are chiefly used in house building and furniture manufacture; the soft woods, reduced to pulp, are made into paper. Distilled wood gives alcohol. Partially burned wood is charcoal. Vinegar and other acids are obtained from trees, as are tar, creosote, resin, turpentine, and other useful oils.

Modified Stems. - Stems, as well as roots, may be modified or changed to adapt these parts of the body to their surroundings. As we have learned 
by experiments, external forces act on the organs of a plant so as to change its appearance and often its form and habit. A stem grown in complete darkness is white instead of green. The bleaching of the celery stems by covering them is a familiar example of this. Thus, in nature, forces which we know of as light, gravity, heat, moisture, wind, and many other factors, influence the plant in its growth. Let us now examine some of the examples of modified stems.

Stems Modified for Water or Food Storage. - Many stems store large quantities of food. The sago palm is an example of such a stem. In most woody stems food is stored during some parts of the year and is used as the plant comes to need it. In other stems the conditions of life are such that the plant has come to store water in the stem. The cactus, which we shall examine more in detail later, is a plant that has developed the stem for the storage of water, and is so adapted to desert conditions as to prevent the evaporation of water from the plant.

Underground Stems; the Rootstock. - Other stems not only contain stored food but run underground for the protection of the plant. Such

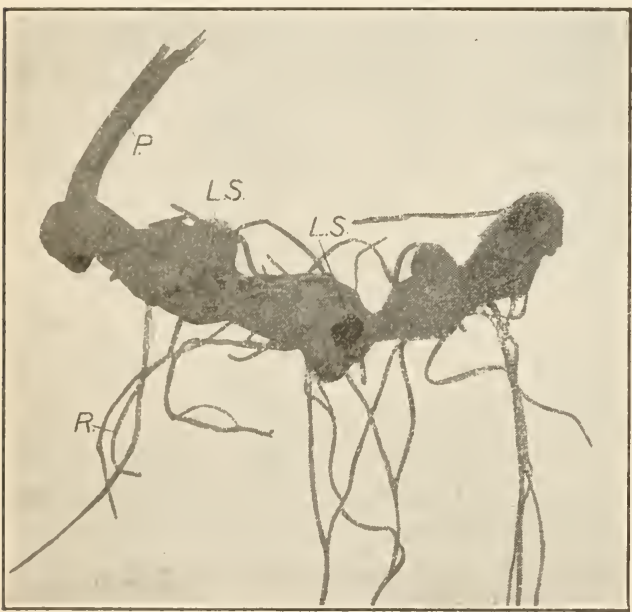

A rootstock, an underground stem. Note the leaf scars $(L . S$.$) , the roots (R$.$) , and the leaf stalk (P.).$ a stem is the rootstock of the iris. The rootstock in many respects resembles a root, but can be distinguished from this part of the plant because the leaves come out from definite points or nodes and because true roots leave the under surface. Some underground stems do not store food, but grow with considerable rapidity, thus covering ground and starting new outposts of the plant at a distance from the original plants. The pest called quick grass or couch grass, found in almost every lawn, has such a stem. It may be cut in pieces, but each piece may strike root, thus multiplying the plant.

The TUBer. - If the underground stem becomes thickened at its end and there forms an enlargement for the storage of food, we call such an enlargement a tuber. Its use to the plant is evident when a potato is planted. 
Examine a fresh potato. ${ }^{1} \quad$ Notice the marks or eyes on its surface. Find a little projection within each eye. This is a bud. Immediately under it you will find a tiny scale which represents a leaf. Later we shall see that a bud on a stem always has the same relation to a leaf as does this bud to the tiny scale. In other words, the position is the same in each case, and the structure may be said to be homologous to that of the bud and leaf of an ordinary stem.

Try to find out the arrangement of the leaves on the potato; they may be either opposite or alternately placed on the stem. See, also, if you can find the point at which the stem was attached to the parent plant.

If a potato is cut in cross section it will be possible to find all the parts of a stem. The pith occupies the central

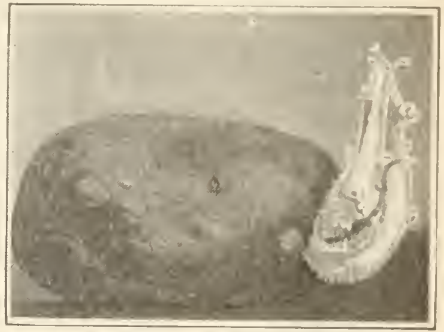

A tuber. Note the stems growing from the eyes at one end. portion; around this is the wood, which here looks like a dark band. Outside the wood we find the cortex, the potato being protected by the rather

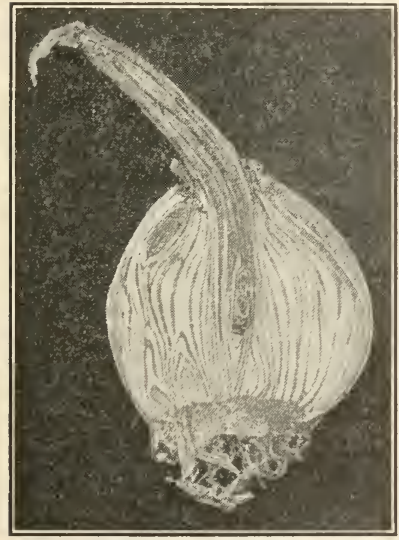

Longitudinal section of a lily bulb. Note the much thickened leaves, and the flower cluster at the center. Photographed by Overton. delicate epidermis.

Cut a potato and a sweet potato in cross section; place each in red ink overnight. It will then be easy to compare the course taken by fluids in passing up a root and a stem.

Cut out several eyes from healthy potatoes. From one or two remove all of the flesh of the potato, and in the other specimens leave food supply intact. Does the stored food help the young plant in its growth? Test for food stuffs in the potato. What foods are present?

Reduced Stems. - In some plants the stem is so reduced as to be almost lost. This may be of a distinct advantage to the plant in enabling it to escape destruction from enemies. Such a plant is the common dandelion, which, because of its short stem, escapes grazing animals and the knives of lawn mowers. Many other low-lying weeds are partly immune from dangers which beset taller plants.

BulBs. - In bulbs the stem is covered with thickened leaves, the whole making a compact and reduced plant which, becausc of its stored food, enables the plant to make an early start in the spring.

Cut an onion in longitudinal sections; draw, showing the scalelike, thickened leaves, the greatly reduced stem, and the roots. Test for food stuffs. What foods do you find present in the onion? 
Climbing Stems. Field Work. - A field excursion may be made for the purpose of obtaining as many kinds of climbing stems as possible. Place them in one of the following classes:-

(1) Stems which twist or twine.

(2) Stems having roots as holdfasts.

(3) Stems having parts of leaves or branches as holdfasts.

Stems may twist around an object in order to climb. Such a plant is the morning glory. Here the stimulus which draws the plant upward is

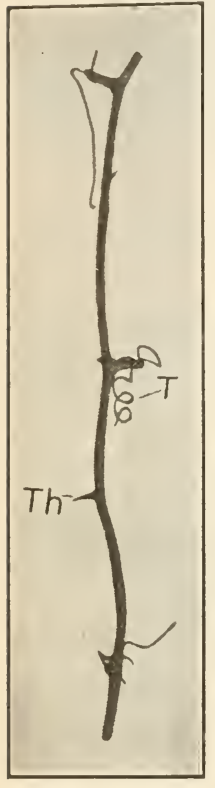

Catbrier; the tendrils ( $T$ ) are modified stipules (parts of leaves); $T h$, thorn. evidently the sun. In stems which make use of this method of climbing, it is noticed that each stem twines around the support in a given direction, some revolving with the course of the sun, others in the opposite direction. When such a stem touches an object curing its first growth, it is immediately stimulated to turn toward the object and coil around it.

Leaves and Stems modified as Holdfasts. - In the common nasturtium (Tropaolum) the leaves revolve in much the same manner as do the stems mentioned above. This movement results in some of the leafstalks fastening around supports, thus drawing the stem up.

TENDRILS. - In some plants definite climbing organs, known as tendrils, are developed. A tendril, which has the appearance of a much-twisted stem, may be modified from part of a leaf, as an entire leaf or as part of a branch. Tendrils have the habit of at first stretching out as far from the main stem as possible, then slowly revolving. After a support is touched they immediately coil around it and then begin to curl up somewhat after the manner of a watch spring. This draws up the stem of which they are a part.

Examine the tendrils of wild grape, pea, Virginia creeper, catbrier, white bryony, or any others you may find. Notice the position of the tendril on the main stem and try to decide of what part of the plant it is a modification. Noticc the suckers or disks at the ends of the tendrils of the Virginia creeper. Can you discover their use?

Stems modified As Thorns. - Leaves and parts of leaves may be changed into thorns for the protection of the plant. In some instances the stem becomes a spine or thorn. Such is the case in the honey locust.

Compare it with the black locust, in which a part of the leaf, the stipule, becomes the thorn. All such modifications seem to result in the better protection of tender parts which might otherwise suffer from the attack of animals. 
Leaflike Stems. - An examination of the hothouse smilax (Myrsiphyllum) shows us that the structures which at first sight appear to be leaves are really green, leaflike branches. This we know, because immediately below each cladophyll, as the leaflike branch is called, we find a tiny scale, evidently the leaf. The cladophyll occupies the same position with relation to the leaf that a bud which develops into a lateral branch would occupy. Thus we see it is homologous to a branch.

Roots and Stems as Food. Unclerground stems and roots form some of the most important sources of man's food supply. Our commonest foods, as the potato, sweet potato, carrot, parsnip, turnip, and beet, are well-known examples. Onions contain considerable proteid material. The sago palm is the chief support of many of the natives of Africa. Each adult tree will furnish 700 pounds of sago meal, $2 \frac{1}{2}$ pounds being enough to support a man one day. The cassava root, from which tapioca is made, is one of the main supports of African natives. Sugar, obtained from the stem

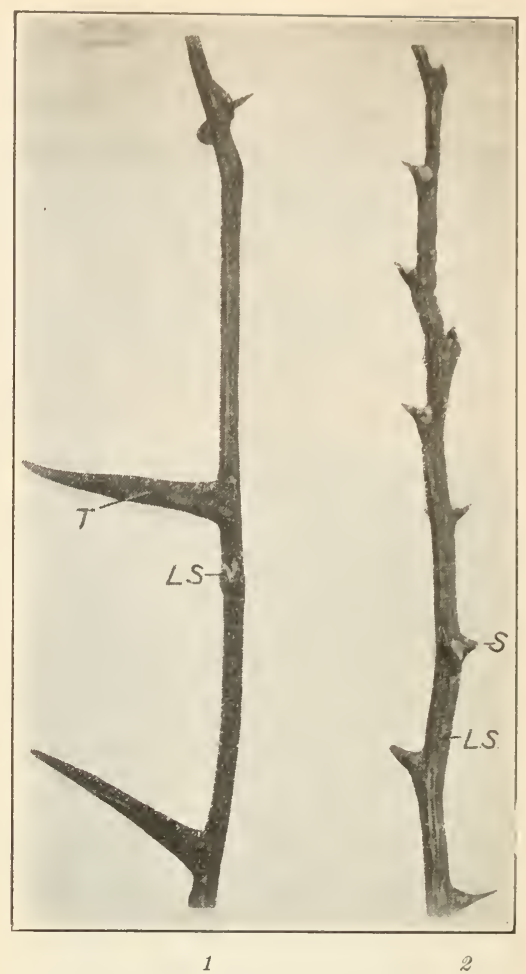

Stems of honey locust (1) and black locust (2); $L S$, leaf scars; the thorns $(S)$ on the honey locust are modified stipules (parts of leaves); the thorns $(T)$ on the black locust are modified branches.

of the sugar cane and from the beet root, is a world-known commodity.

The following table shows the proportion of foods in some of the commoner roots and stems:-

\begin{tabular}{|c|c|c|c|c|c|c|c|c|c|c|}
\hline & & & & & & Water & Proteids & CARBOHYDRATE & FATS & AsH \\
\hline Potato. & . & . & . & . & . & . $\quad 75.0$ & 1.2 & 18.0 & 0.3 & 1.0 \\
\hline Carrot. & & . & & . & . & 89.0 & 0.5 & 5.0 & 0.2 & 1.0 \\
\hline Parsnip & . & . & & . & 。 & 81.0 & 1.2 & 8.7 & 1.5 & 1.0 \\
\hline Turnip . & . & . & & - & . & 92.8 & 0.5 & 4.0 & 0.1 & \\
\hline Onion & & . & . & . & 。 & 91.0 & 1.5 & 4.8 & 0.2 & 0 \\
\hline Sweet Potato & & . & & 。 & . & 74.0 & 1.5 & 20.2 & 0.1 & 4 \\
\hline Beet . . & & . & & . & . & 82.2 & 0.4 & 13.4 & 0.1 & 0.9 \\
\hline
\end{tabular}




\section{REFERENCE Books}

FOR THE PUPIL

Andrews, Botany, All the Year Round, Chaps. VI, VII. Amerisan Book Company. Dana, Plants and Their Children, pages 99-129. American Book Company. Goff and Mayne, First Principles of Agriculture. American Book Company. Atkinson, First Studies of Plant Life, Chaps. IV, V, VI, VIII, XXI. Ginn and Company.

Hunter and Valentine, Laboratory Manual of Biology. Henry Holt and Company. MacDougal, The Nature and Work of Plants. The Macmillan Company.

\section{FOR THE TEACHER}

Apgar, Trees of the United States, Chaps. II, V, VI. American Book Company Goodale, Physiological Botany. American Book Company.

Gray, Structural Botany, Chap. V. American Book Company.

Leavitt, Outlines of Botany. American Book Company.

Goebel, Organography of Plants, Part V. Clarendon Press.

Ganong, The Tcaching Botanist. The Macmillan Company.

Lubbock, Buds and Stipules. D. Appleton and Company.

Pinchot, A Primer of Forestry. Bul. No. 24, Division of Forestry, U.S. Department of Agriculture.

Strasburger, Noll, Schenck, and Schimper, A Text-book of Botany. The Macmillan Company.

Ward, The Oak. D. Appleton and Company.

Year Book, U.S. Department of Agriculture, 1894, 1895, 1898. 


\section{LEAVES AND THEIR FUNCTIONS}

In the horse-chestnut bud previously studied the brown scales which cover the green scales of the bud can be shown to be like in structure to a leaf (homologous to a leaf). This is seen better in a near relative of the horse-chestnut, the buckeye, in which a series of changes in form from brown scales to green leaves may be followed.

Stipules. - The bud of the tulip tree (Liriodendron tulipifera) is an admirable source of information as to the structure of a leaf. ${ }^{1}$ In the buds of a tulip tree, however, the scales seem to act as wrappers around the little leaves and not to correspond to the blade of the leaf, but to an outgrowth of the leafstalk or petiole below it. The outgrowths at the base of a leaf are known as

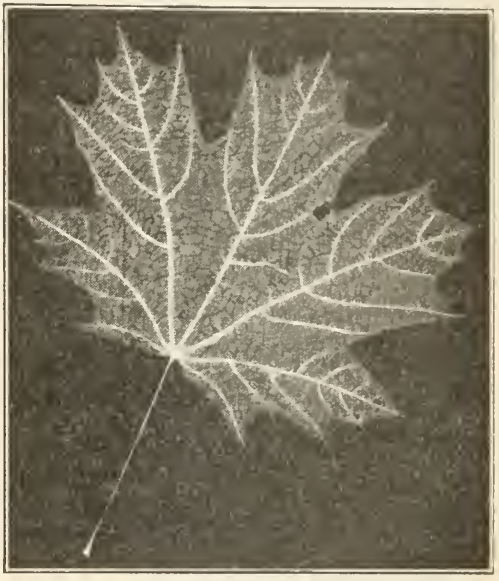

Palmately-veined leaf of the maple. stipules. The scales in this case are stipules which have come to protect the bud at a time when the delicate parts need protection most. These stipules are present as scales in many other buds. Frequently, when the leaf becomes able to care for itself, the stipules fall off and disappear. Such a bud is the elm, as can be seen by a careful dissection. Stipules usually are paired. Notice the notched appearance of the scales as you go inward. Most leaves do not show the stipules well, although a complete leaf is supposed to be supplied with them. They are well developed in the rose leaf.

See Hunter and Valentine, Manual, page 37. 
Leaf of a Dicotyledon. - If we now take up the study of a simple leaf such as the elm, we find that the parts seen in buds of the tulip tree are not always readily found. The petiole or leafstalk

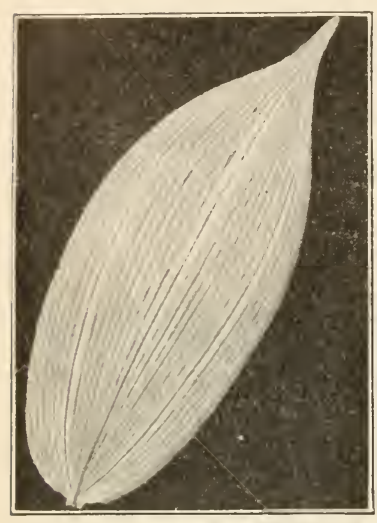

Parallel-veined leaf of false Solomon Seal. runs into the blade of the leaf as the midrib. Here it divides to form the network of veins found in the leaves of the dicotyledonous plants. ${ }^{1}$

Leaf of a Monocotyledon. - In the monocotyledons, as in Tradescantia, or in the leaves of a grass, there is no midrib, the leaf being traversed by a number of veins which run lengthwise of the blade and give it the name of parallel-veined leaf. ${ }^{2}$

Drawings should be made to show the parts of a typical simple netted-veined leaf and that of a leaf parallel veined. Both drawings should be natural size and should have all parts labeled.

Modification of Blade. - The blade of a leaf may undergo many modifications in different species of plants. It may have almost any shape, from a thin line to an almost circular outline. It may have an almost smooth margin, as in the ieaf of the rubber plant (Ficus elastica), or the margin may be more or less deeply indented, as in the tulip, sassafras, and the oak.

Compound Leaf. - If the margin is so deeply indented that the blade is cut down to the midrib, then each part of

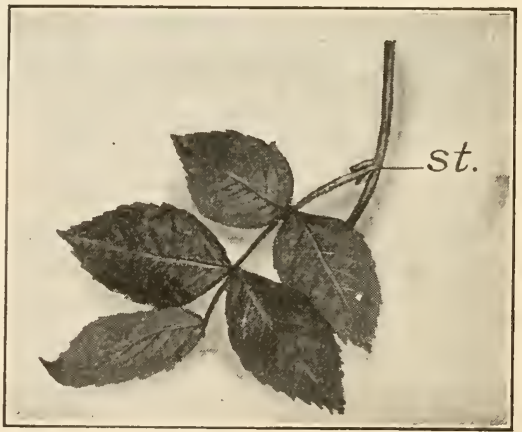

Pinnately-compound leaf of rose, showing stipules (st.). the blade is said to be a leaflet, and the whole leaf is compound. In most cases it is easy to distinguish a compound leaf: (1) by

${ }^{1}$ See Hunter and Valentine, Manual, pages 39-42. $\quad{ }^{2}$ Ibid., page 45. 
the bud in the axil of the leaf, that is, between the leafstalk and the branch; (2) by the presence of stipules (this is well seen in the rose leaf); (3) by the fact that the arrangement of veins in the leaflet frequently does not follow the same system of branching as would be found in a simple leaf of the same form.

Arrangement of Veins. - The shape of the blade of leaves of dicotyledons depends somewhat upon the arrangement of the veins. If the blade is long and thin, the veins will be found to go out from the midrib somewhat like the side parts of a feather; hence the leaf is said to be feather veined (or pinnate). If the blade is nearly circular in outline, the veins will leave the petiole to radiate somewhat like fingers from the palm of the hand. Such venation is said to be palmate.

The same general arrangement of veins holds true for compound leaves. The pea and locust are examples of pinnately compound leaves, the horse-chestnut of a palmately compound leaf. ${ }^{1}$

Leaves turn toward the Light. - It is a matter of common knowledge that green leaves turn toward the light. Place growing pea seedlings, oxalis, or any other plants of rapid growth near a window which receives full sunlight. Within a short time the leaves are found to be in positions to receive the most sunlight possible.

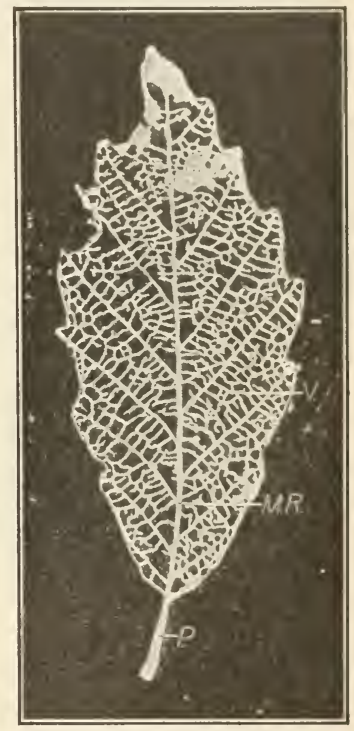

The skeleton of a pinnately veined leaf; $M . R$. ., midrib; $P$., the leafstalk or petiole; $V$, the veins.

Home Experiment. - Turn such plants after two or three days so that the leaves are away from the sun. Make observations every hour during some Saturday morning and try to find out just what part of the leaf turns to the light.

Effect of Light. - We have already found that seedlings grown in total darkness are almost yellow-white in color, that the leaves

' For laboratory work on leaves, see Hunter and Valentine, Manual, pages 39-47. 
are but slightly develcped, and that the stem has developed far more than the leaves. We have also seen (page 99) that a green

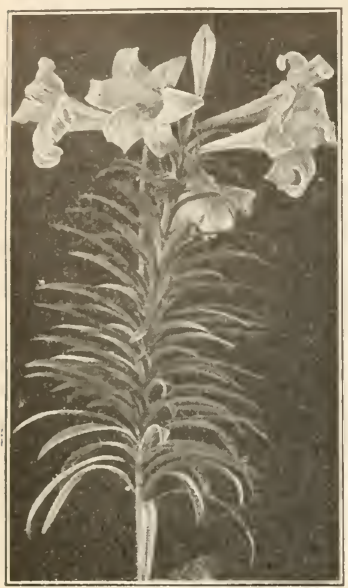

A lily, showing long, narrow leaves. plant will grow toward the source of light, even against great odds. This effect of light is seen as well in older plants. Any field trip will reveal the fact that in low-lying plants the leaves which are shaded are often yellow and dwarfed. Plants kept in poorly lighted rooms at home show this.

Arrangement of Leaves. - A careful study of trees in any park, or in the woods, shows that the stems of trees in thick forests are usually tall and straight and that the leaves come out in clusters near the top of the tree. The leaves lower down are often smaller and less numerous than those near the top of the tree. Careful observation of any plant growing outdoors shows us that in almost every case the leaves are so disposed as to get much sunlight. The ivy climbing up the wall, the morning glory, the dandelion, and the burdock all show different arrangements of leaves, each presenting a large surface to the light. Leaves are usually definitely arranged, fitting in between each other so as to present their upper surface to the sun. Such an arrangement is known as a leaf mosaic. Good examples of such mosaics, or leaf patterns, are seen in the alter-

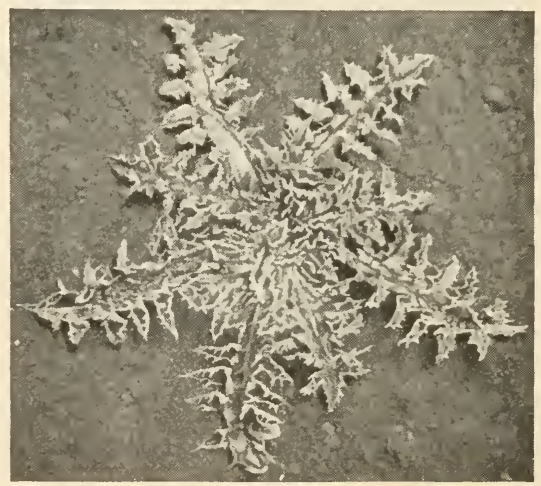

The dandelion, showing a whorled arrangement of long, narrow leaves. nate-leaved trees. Here the leaves turn, by the twisting of the petioles, so that all the leaves present their upper surface to the 
sun. In the case of the dandelion a rosette or whorled cluster of leaves is found. In the horse-chestnut, where the leaves come out opposite each other, the older leaves have longer petioles than. the young ones. In the mullein the entire plant forms a cone. The old leaves near the bottom have long petioles, and the little ones near the apex come out clcse to the main stalk. In every case each leaf receives a large amount of light. Other modifica-

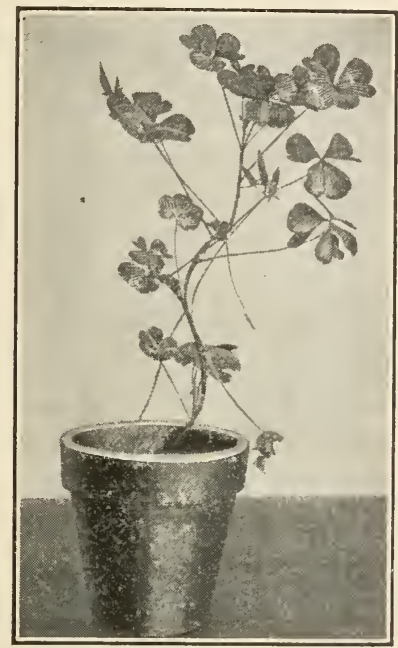

Oxalis plant in the light.

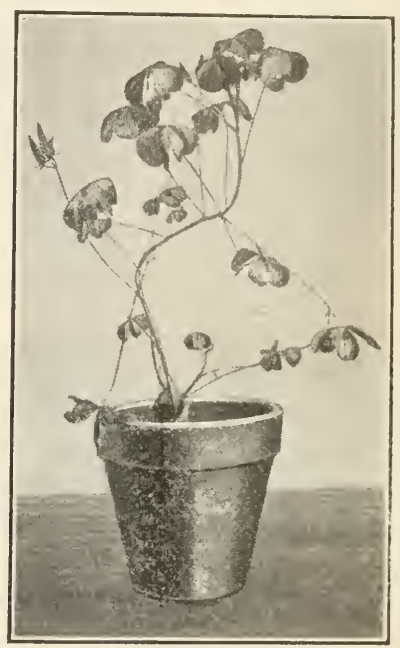

Oxalis plant after two bours in the dark.

tions of these forms may easily be found on any field trip. See how many different examples of leaf mosaics you can bring in to record in your notebook.

Effect of Absence of Light upon the Leaves of the Oxalis. ${ }^{1}$ - Place a potted oxalis in a dark closet or box for two or three hours, having previously exposed it to direct sunlight for a short time. What is the general position of the leaves after removal from the darkness? Compare with the position of the same leaves in the light.

Sleep Movements. - The examination of a number of young seedlings of buckwheat or sunflower shows that after a few hours in darkness the leaves droop. The leaves of the bean and oxalis

- See Hunter and Valentine, Manual, page 246. 
tend to droop or fold after a much shorter exposure to the dark. ness. These changes in position have been called sleep movements. Charles Darwin suggested that the leaves of a plant which take this position secure protection from injury by frost. In most cases the movement may be accounted for when we remember that leaf blades naturally turn their upper surfaces toward the light. In the absence of light the leaf blade might easily be influenced to droop or even fold by the counter stimulus of gravity.

Sensitiveness to Contact. - Leaves of some plants are also sensitive to the stimulus of contact. The sensitive plant (Mimosa pudica) is the best-known example. Here the leaflets of the compound leaf respond to the slightest touch by folding and drooping. Under normal conditions the leaf soon returns to its original position. Changes in temperature and moisture may totally prevent this movement, showing that the living matter in the plant is

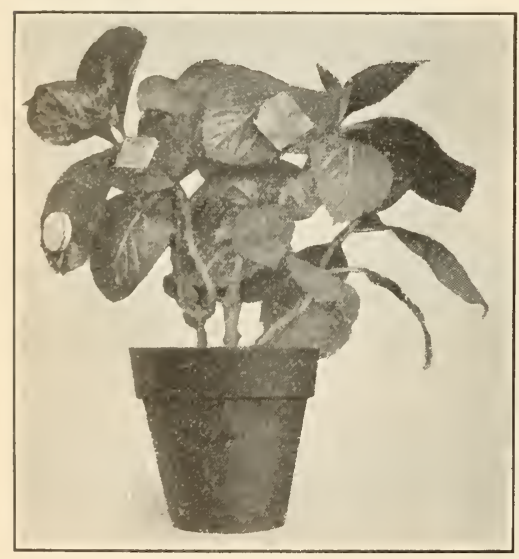

A hydrangea plant, upon the leaves of which disks of cork have been pinned in order to exclude sunlight from the leaf. most delicately attuned to the influences of its immediate surroundings.

The Sun a Source of Energy. - We all know the sun is a source of most of the energy that is released on this earth in the form of heat or light. Solar engines have not come into any great use as yet because fuel is cheaper. Actual experiments have shown that vast amounts of energy are given to the earth. When the sun is in the zenith, energy equivalent to one hundred horse power is received by a plot of land twenty-five by one hundred, the size of a city lot. Plants receive and use much of this energy by means of the leaves.

In which Part of a Variegated Leaf does Starch Exist? - Leave two plants, such as the Coleus (variety with red-colored leaves) or Tradescantia (the white-striped leaf variety) and another Coleus or Tradescantia with the 
leaves entirely green, for several days in a well-lighted window under the same conditions of light, heat, and moisture. After two days, pick several leaves from each plant and place them in separate jars in wood alcohol, which will extract the leaf green. When the leaves are entirely colorless, test the two sets of leaves witi tincture of iodine. Which leaves contain stareh? Which parts of the leaf contain starch? This experiment shows us that starch is present only in the green part of the leaf. ${ }^{1}$

Relation of Starch Formation to Sunlight. - Another simple experiment will give us the relation of the presence of starch to the sunlight.

Pin or sew several strips of black cloth, such as alpaca, over the leaves of a growing geranium. Place the plant in a sunny window for several days. (This can be reduced to hours if the plant has previously been kept in the dark for a day of two.) If we now

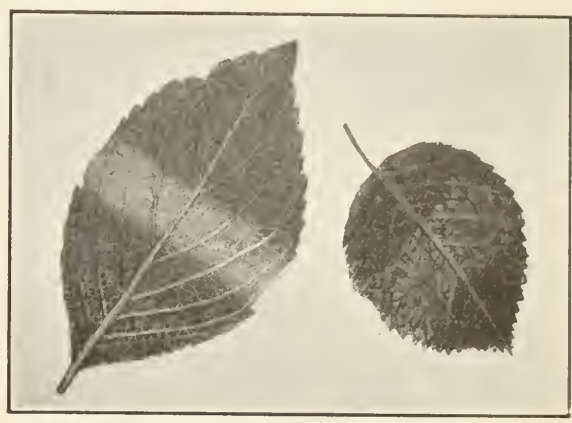

Starchless areas in leaves, caused by excluding sunlight with strips of black cloth.

extract the leaf green as before, and then test with iodine, we find that starch is present only in that part of the leaf which was exposed to the sun. A green leaf, when attachcd to the plant, and under natural conditions, forms starch in the sunlight. ${ }^{2}$

Examination of the Under Surface of a Leaf Under the Microscope. - Strip off the under surface of a leaf of Tradescantia, stretch it flat in water on a

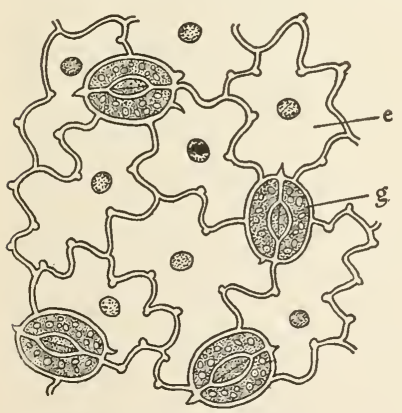

Surface view of epidermis of lower surface of a leaf; $e$, ordinary epidermal cell; $g$, guard cell.Tschirch. glass slide and examine it with a good hand lens (or, better, the low power of a compound microscope); numbers of little oral structures will be scen. These are called stomata (singular stoma). Notice the two eclls, usually kidney-shaped, one on each side of the stoma. These are the guard cells. By change in shape of these cells the opening of the stoma is made larger or smaller. Note also the larger irregular eells of the epidermis or outer covering of the leaf. About what is the ratio of the number of stomata to the number of epidermal cells in a small part of the leaf? Draw one or two stomata showing all parts, as seen under a low power of the microscope. If we now examine a very thin piece of a leaf cut in cross section, we can make out the relation of the stomata to the interior of the leaf.

Laboratory Exercise on Cross Section of the Leaf. - In a cross section of the leaf of Tradescantia, or any lily, find under the upper epidermis a layer of green cells closely packed together (called collectively the palisade layer). These cells are more or less columnar in shape. Under

1 See Hunter and Valentine, Manual, page 243.

${ }^{2}$ Ibid., page 242.

HUNTER'S BIOL. -9 
these are several rows of rather loosely placed cells, called collectively the spongy parenchyma. These cells do not contain so much leaf green as

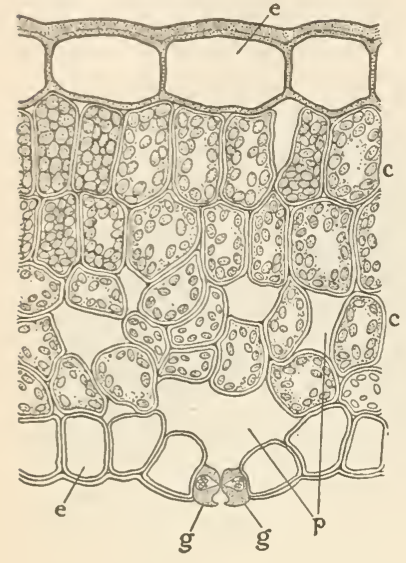

Section of a leaf; $e$, epidermis; $c$, cells containing chlorophyll granules; $p$, intercellular passages; $g, g$, guard cells of stoma. those of the palisade layer. Notice the spaces between these cells. In some cases they can be seen to communicate with the openings of the stomata in the lower epidermis. Look for the cut ends of one or more of the fibrovascular bundles or veins. The cells of which they are composed are seen to be greatly thickened. ${ }^{1}$

Cross Section of a Green Leaf. The leaf in cross section shows that the whole blade is a series of tissues, the epidermis being somewhat thicker walled for protection, the under surface pierced by numerous pores. Each of these pores connects with an air space which penetrates more or less the whole inside of the leaf, but especially the layer just outside the lower epidermis. The cells of the palisade layer we shall now consider more in detail.

Chloroplasts. - If we examine some of the plant cells forming part of the blade of the leaf, we find cells which are almost cylindrical in form. In the protoplasm of such cells are found a number of little bodies colored green, which are known as chloroplasts or chlorophyll bodies. If we place the leaf in wood alcohol, we find that the bodies still remain, but that the color is extracted, going into the alcohol and giving to it a beautiful green color. The chloroplasts are, indeed, simply part of the protoplasm of the cell stained green. If the plant is kept in the sun, the chloroplasts keep their green color, but in the dark this color is gradually lost. These bodies are of the greatest importance directly to plants and indirectly to animals. The chloroplasts, by means of the energy received from the sun, manufacture starch out of certain materials. These materials are soil water, which is passed up through the fibrovascular bundles into the veins of the leaf from the roots, and carbon dioxide, which is taken in through the stomata or pores, with which the under surface of the leaf is covered.

${ }^{1}$ For detailed laboratory exercises, see Hunter and Valentine, Manual, pages 47-49. 
Air necessary for Starch Formation. - The following experiment shows not only that sunlight is necessary for the formation of starch, but also that air must be present.

Experiment. - Select any small plant the leaves of which contain stomata on the lower surface (rose or lilac). Leave the plant in a dark room for several days, so that the starch in the leaves may be completely used up. Remove the plant from the dark room, and vaseline the lower surface of two or three leaves, marking them so that you will know them. After a few hours' exposure to direct sunlight, pick off the vaselined leaves and also some others from the same plant. Wash them in wood alcohol and then place them in iodine. What has happened in the case of the vaselined leaves? In the case of the other leaves?

Air is necessary for the process of starch making in a leaf, not only because carbon dioxide gas is absorbed (there are from three to four parts in ten thousand present in the atmosphere), but also because the protoplasm of the leaf is alive and must have oxygen. This it takes from the air around it. It has been found that plants can live in atmos-

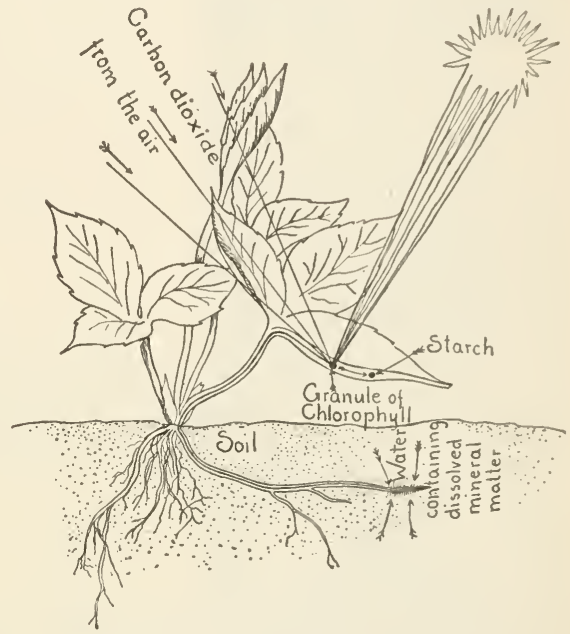

Diagram to illustrate the formation of starch. pheres containing as much as 10 per cent of carbon dioxide. If more than 10 per cent is present, they may die of suffocation, just as an animal would die if placed in air containing a large amount of carbon dioxide.

Comparison of Starch Making and Milling. - The manufacture of starch by the green leaf is not well understood. The process has been compared to the milling of grain. In this case the mill is the greer, part of the leaf. The sun furnishes the motive power, the chloroplasts are the millstones, and soil water and carbon dioxide are the raw products taken into the mills. The manufactured product is starch, and a certain amount of waste (represented by the chaff in a mill) is also given out. This waste material is the element oxygen. 
Oxygen given off by Green Plants. - It is possible to prove that oxygen is given off by green plants in sunlight. The common green frog scum seen in shallow ponds is often so full of bubbles that it is buoyed up by this means at the water's surface. If some of this plant or other green water weed is placed in a large battery jar or fruit jar in a sunny window, bubbles of gas will

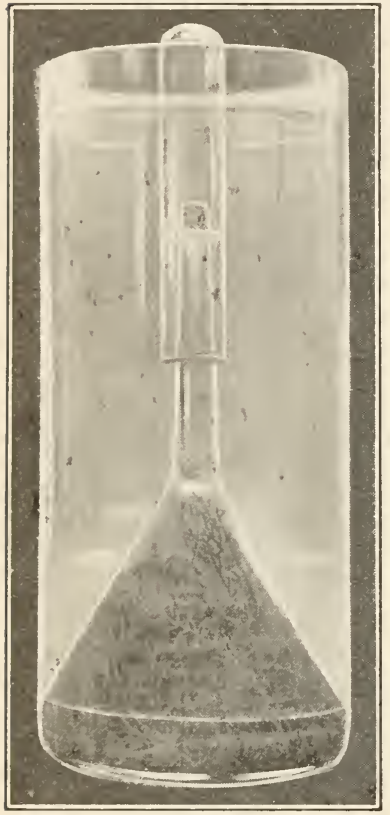

Experiment to show that oxygen is given off by green plants in the sunlight. be seen to arise from it, the amount increasing as the water is warmed by the sun's rays.

If a glass funnel is placed upside down so as to cover the plants, and then a test tube full of water inverted over the mouth of the funnel, the gas may be collected by displacement. After two or three days of hot sun, enough of the gas can be obtained to make the oxygen test. Carefully remove the tube, holding the thumb over the end of the tube to prevent the escape of the gas. A glowing match end thrust into the tube will burst into flame.

Leaf Structure and Functions. - To understand the process fully we must refer to a small portion of the leaf. Here we find that the cells of the green layer of the leaf, under the upper epidermis, perform most of the work. The carbon dioxide is taken in through the stomata and reaches the green cells by way of the intercellular spaces and by diffusion from cell to cell. Water reaches the green cells through the tracheal tubes of the veins. It then passes into the cells by osmosis and there becomes part of the cell sap. The light of the sun easily penetrates to the cells of the palisade layer, giving the energy needed to make the food. This whole process is a very delicate one, and will take place only when external conditions are favorable. For example, too much heat or too little heat stops starch making; the presence of stored food in the leaf, or of 10 per cent of carbon dioxide in the atmosphere, may stop its work. 
Photosynthesis. - The process by which starch is formed in green leaves in sunlight is called photosynthesis. This process is the formation of carbohydrate from the carbon dioxide absorbed from the air and from the water present in the cells of the leaf.

Chemical Action in Starch Making. - In the process of starch making in a leaf, water $\left(\mathrm{H}_{2} \mathrm{O}\right)$ and carbon dioxide $\left(\mathrm{CO}_{2}\right)$ are combined in such a way as to make starch, the molecule of which is expressed by the formula $\mathrm{C}_{6} \mathrm{H}_{10} \mathrm{O}_{5}$. This combination is expressed as follows: $5 \mathrm{H}_{2} \mathrm{O}+6 \mathrm{CO}_{2}=$ $\mathrm{C}_{6} \mathrm{H}_{10} \mathrm{O}_{5}+12 \mathrm{O}$. The starch thus formed is either stored in the leaf or changed by digestion to some form which ean pass by osmosis from cell to cell; that is, a soluble material like grape sugar. The oxygen is passed off through the stomata of the leaf. ${ }^{1}$

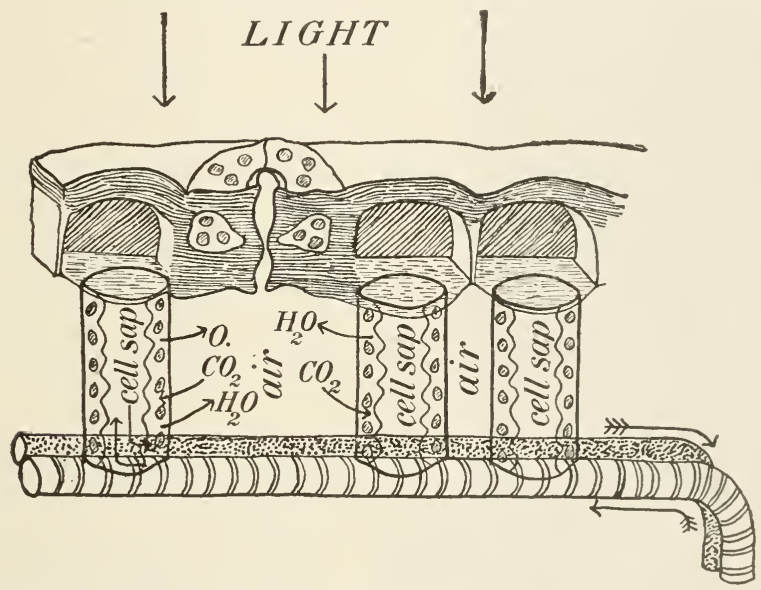

Diagram (after Stevens) to illustrate the chemical processes which take place in the cells of a green leaf in the sunlight.

Proteid Formation in the Plant. - Proteid material is a food which is necessary to form protoplasm. Proteid food is present in the leaf, and is found in the stem and root as well. Proteids can seemingly be manufactured in any plant cells, irrespective of their position in the plant body The presence of light does not seem to be a necessary factor. The minerals brought up in the soil water form part of its composition, and starch or grape sugar give three elements. The element nitrogen is taken up by the roots as a nitrate (nitrogen in combination with lime or potash), for plants are unable

1 It seems probable that food material is first marle in the form of a sugar, then changed to starch; when transported from one part of the plant to another it is changed back to sugar. 
to use free nitrogen of the air (with the exception of the nitrogen-fixing bacteria). See page 94. Proteids are probably not made directly into protoplasm in the leaf, but are stored by the cells of the plant and used when needed, either to form new cells in growth or to repair waste. While plants and animals get their food in different ways, they make it into living substance in exactly the same manner.

Rapidity of Starch Making. - Leaves which have been in darkness soon show starch to be present when exposed to light. Squash

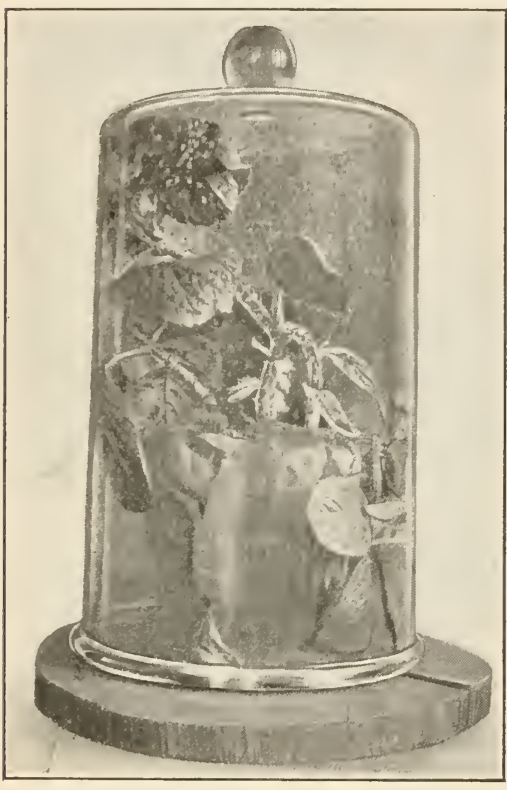

Experiment to show transpiration. Notice that roots covered with root hairs have grown out of the main stem of the plant in response to the moist condition existing outside of the rubber-covered flower-pot and within the bell jar. leaves make three fourths of an ounce for each square yard of surface. A corn plant sends 10 to 15 grams of reserve material into the ears in a single day. The formation of fruit, and especially the growth of the grain fields, show the economic importance of this fact. Not only do plants make their own food and store it away, but they make food for animals as well. And the food is stored in such a stable form that it may be sent to all parts of the world in the form of grain or other fruits.

\section{Evaporation of Excess Water.} - In the manufacture of starch and proteid an enormous amount of water is taken up by the roots and passed to the leaves to supply the needed amount of mineral matter. The excess of water, which often amounts in a single day to more than the entire weight of the plant, is evaporated (passed off as vapor) through the stomata. That water is passed through the blade of the leaf in the form of moisture is shown by the following experiment:- 
Pass the petiole of a green leaf through a cardboard cover into a glass of water. Seal the space between the petiole and cardboard with grafting wax (chewing gum will do). Invert another glass over the first. After an hour, examine the upper glass and notice where the moisture has collected. How did it get there?

The following experiment shows that the amount of water passed off through the leaves by the process called transpiration is great enough to be measured. Cover with a rubber cloth a flowerpot in which a vigorous plant is growing, so that only the stem and leaves are outside of the rubber cover. Before fastening the cloth, water the plant well. Now place the flower pot upon a pan of a balance and put weights in the other pan until the pans balance. Leave the plant in a sunny window for several hours, and after a given time note the position of the pans. Neasure the amount of water lost by removing weights till the pans balance again.

Amount of Water Lost by Transpiration. - A relatively large amount of water passes off by transpiration every twenty-four hours. A small grass plant on a summer's day evaporates more than its own weight in water. This would make nearly half a ton of water distributed to the air during twenty-four hours by a grass plot, twenty-five by one hundred feet, the size of the average city lot. According to Ward, an oak tree may pass off two hundred and twenty-six times its own weight in water during the season from June to Octcber.

From which Surface of the Leaf is Water Lost? - In order to find out whether water is passed out from any particular part of

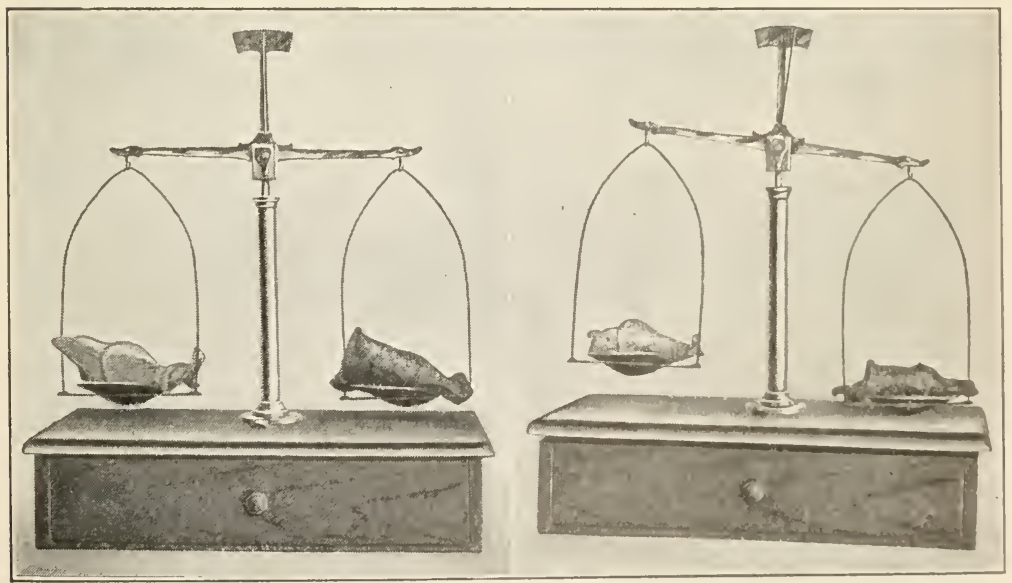

Experiment to show through which surface of a leaf water passes off. 
the leaf, we may remove two leaves of the same size and weight from some large-leaved plant - a mullein was used for the illustrations given - and cover the upper surface of one leaf and the lower surface of the other with vaseline. The petioles of each should be covered with wax or vaseline, and the two leaves exactly balanced on the pans of a balance which has previously been placed in a warm and sunny place. Within an hour the leaf which has the upper surface covered with vaseline will show a loss of weight. Examination of the surface of a mullein leaf shows us that the lower surface of the leaf is provided with stomata. It is through these organs, then, that water is passed out from the tissues of the leaf.

Regulation of Transpiration. - The stomata of leaves close at night. On days when there is little humidity they tend to close,
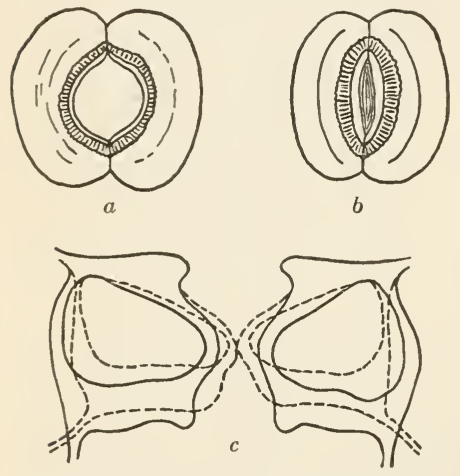

Diagrams of a stoma; $a$, surface view of an opened stoma; $b$, same stoma closed (after Hansen); $c$, diagram of a transverse section through a stomadotted lines indicate the closed position of the guard cells, the heavy lines the open condition. (After Schwendener.) but when the water supply is abunclant they open. This automatic regulation is of very great importance to the life of the plant, since evaporation of water is thus limited, and consequent wilting of the leaves prevented.

The change in the size of the opening of the stomata appears to be due to the fact that the protoplasm of the guard cell takes up and loses fluids rather easily. This process we have already noticed under the name of turgor. With an increase in the turgidity of the guard cells, which results after an osmotic inflow from surrounding cells of the leaf, the guard cells change shape so as to increase the size of the opening between them. Similarly, with a loss of water or other fluids from the guard cells, the opening becomes smaller.

The Effect of Transpiration on Water within the Stem. - It has already been noted that root pressure alone will not account for the rise of water to the tops of very tall trees. The following experiment shows that transpiration exerts a lifting power upon the fluids within the stem:- 
Into one end of a glass tube fit a rubber stopper with a hole through it Into this hole insert the stem (freshly cut off under water) of a leafy branch from an actively growing tree. Seal the stem'in with melted wax. Fill the tube with cool, boiled water, and immerse the open end in mercury as shown in the figure.

Respiration by Leaves. - All living things, with the possible exception of some bacteria, require oxygen in order to live. It is by means of the oxidation of food materials within the plant's body that the energy used in growth and movement is released. A plant takes in oxygen largely through the stomata of the leaves, to a less extent through the lenticels in the stem, and through the roots. In young plants, especially, much oxygen is taken up by the latter-named organs. Thus the rapidly growing tissues receive the oxygen necessary for them to perform their work. It can be shown by experiment that a plant uses up oxygen in the darkness; in the light the amount of

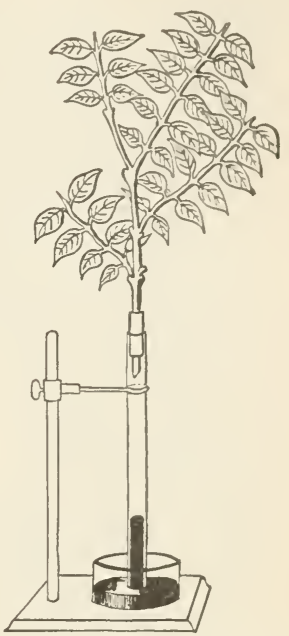

Apparatus to show the upward pull of leaves. (After Detmer.) oxygen given off as a by-product, in the process of starch making is, of course, much greater than the amount used by the plant.

Summary. - From the above paragraphs it is seen that a leaf performs the following functions:

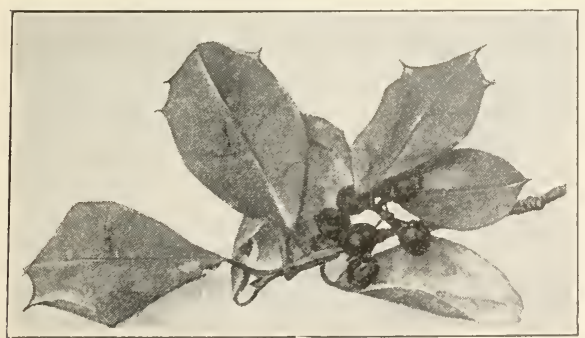

Modified leaves (holly). Note the spincs.
(1) breathing, (2) starch making, with the incidental passing out of oxygen, (3) formation of proteids, with their digestion and assimilation to form new tissues, and (4) the transpiration of water.

Modified Leaves. ${ }^{1}$ Leares as Spines. - Examine a holly leaf. Of what use might the
gers might such a leaf be exposed? Remember that holly keeps green in a much colder atmosphere

1 For exercises on modified leares, see Hunter and Valentine, Manual, pages $40,41,42,45,46$. 
than many other plants. Compare the spines of the honey locust, black locust, and barberry. Look for leaf traces and buds on the stem, and decide

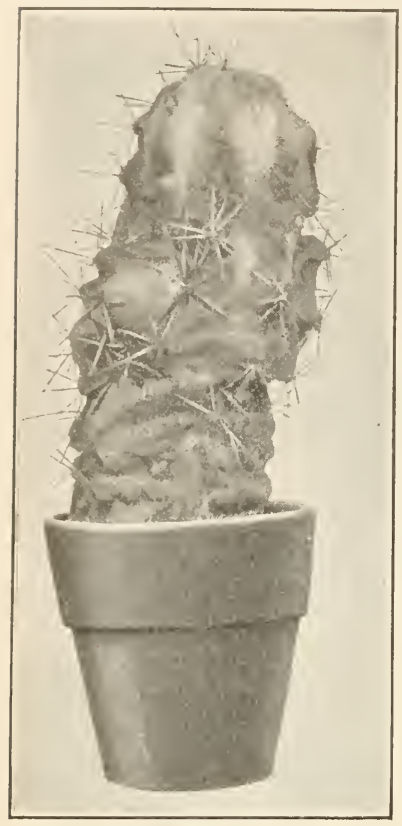

A cactus, showing the leaves modified into spines. from the relative position of the thorns and these structures which of the above-named structures are modified leaves. (Sometimes a spine may be part of a leaf, as the stipule.)

Cactus. - In the prickly pear cactus, notice that above the spines are little buds. The position of the bud shows the spine to be a modified leaf. What reason can you give for this modification of the leaf of the cactus? How is the plant body modified to meet the conditions of life in a desert? Note the thickened stem.

If a cactus is cut open, it will be found to contain a very considerable amount of water. The Indians of the New Mexican desert region, when far from a source of water, sometimes cut off the top of a large cactus, mash up the soft interior of the thickened stem, squeeze out the pulp, and thus obtain several quarts of drinkable water.

Protection by Hairs. - In the mullein, one of our hardiest weeds, the leaf is covered with a coating of finely branched hairs. Might such a covering be of use to the leaf? In what ways?

Leaves hodified for Use in Climbing. - Sometimes, as in the leaf of the pea, a part of the leaf is modified for the purpose of climbing. In this case a part of the leaf, called the tendril, becomes especially sensitive to the stimulus of touch, and upon touching an object coils around it. Almost any part of the leaf, or indeed the entire leaf, may be modified to become a tendril. What part of the leaf of the pea here forms the tendril? If material can be obtained, work out the morphology of modified parts of the clematis; wild grape; Virginia creeper.

Storage of Food or Water in Leaves. - Leaves may be modified for the storage of food or water. Test an onion, which is a collection of thickened leaves closely wrapped to form what is called a bulb, for starch, sugar, and proteid. Squeeze the leaves of the Sedum and notice the water contained in them. The Agave is a desert plant in which the leaves have become greatly thickened as a water and food storage. Make a list of any plants you know, as the cabbage, that store food in the leaves.

Reduced Leaves. - Leaves may be reduced to scales or lost altogether. In the asparagus what seem to be tiny leaves are branches which spring 
from the axils of the true, very tiny, scalelike leaves. The spines noted in the cactus are examples of reduced leaves.

Leaves as Insect Traps. - Most curious of all are the modifications of the leaf into insect traps. It frequently happens that the habitat of a plant will not furnish the raw food materials neessary to form proteid food and to build protoplasm. Nitrogen is the lacking element. The plant has become adapted to these conditions and obtains nitrogenous food from the bodies of insects which it catehes. Examples of insect traps are the eommon bladderwort (Utricularia), the Venus's flytrap (Dionoea muscipula), the sundew (Drosera rotundifolia), and certain of the pitcher plants.

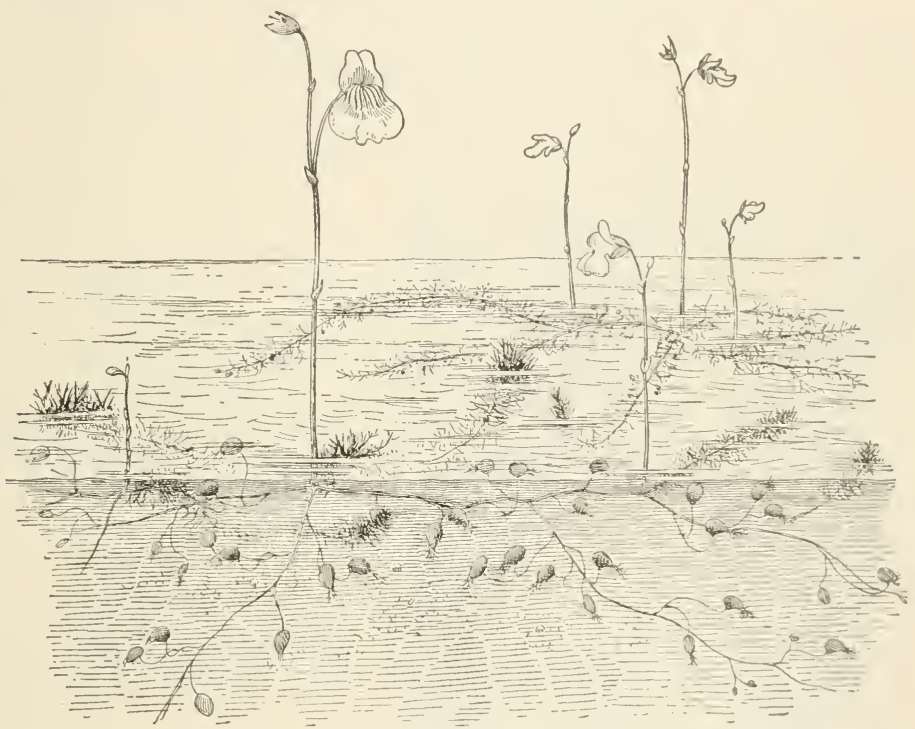

Bladderwort, showing finely dissected submerged leaves bearing blades which capture animalcula.

BLADDERWORT. - The simplest contrivance for the taking of animal food by the leaf is seen in the bladderwort. Here certain of the leaves are modified into little bladders provided with trapdoors which open inwards. Small water-swimming crustaceans (as water fleas, etc.) push their way into the trap and there die, perhaps of starvation. Bacteria, causing decay, soon break down their bodies into soluble substances, the nitrogenous portion of which is absorbed by the inner surface of the bladders and used by the plant as food.

Venus's Flytrap. - In the Venus's fiytrap, a curious plant found in our Southern states, the apex of the leaf is peculiarly modified to form an insect 
trap. Each margin $\mathrm{f}$ the leaf is provided with a row of hairs; there are also three central hairs on each side of the midrib. The hairs are sensitive to a stimulus from without. The blade is so constructed that the slightest stimulus causes a closing of the leaf along the midrib. The surface of the leaf is provided with many tiny glands, which pour out a fluid capable of digesting proteid food. Thus an insect, caught between the halves of ihe leaf blade, is held there and slowly digested.

SUNDEw. - In the sundew the leaves are covered with long glandular hairs, each of which is extremely sensitive to the stimulus of any nitrogenous substance. These hairs exude a clear, sticky fluid which first renders more difficult the escape of the insect caught in

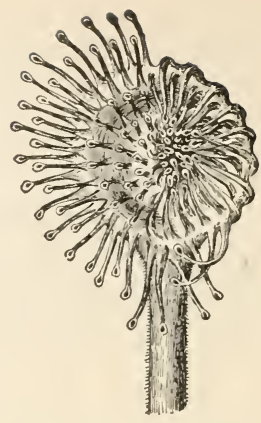

Leaf of sundew closing over captured insect.

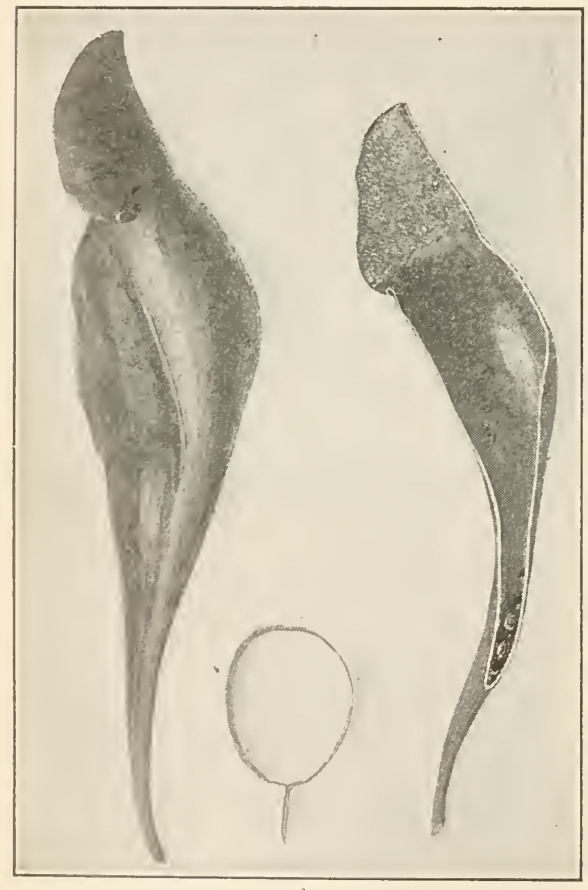

$a$

b

Pitcher plant; $a$, leaf; $b$, cross section; $c$, longitudinal section. Note the insects at the bottom, and the inward-pointing hairs at the top. the hairs, and then digests the nitrogenous parts of the insect thus caught. Charles Darwin, in a series of experiments, found that these hairs do not respond to the stimulus of falling raindrops, but that a bit of hair weighing

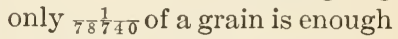
to cause the slight bending of the hairs.

Pitcher Plants. - The common pitcher plant has an urn-shaped leaf which is modified to hold water. Many small flies and other insects find their way into the pitcher and are eventually drowned in the cup. Whether the plant actually makes use of the food thus obtained is a matter unsettled. In a tropical form, called Nepenthes, the petiole of the leaf forms the pitcher, the blade of the leaf forming a kind of lid. In the fullgrown plants this lid stands open, perhaps as an attraction to insects. Honey glands 
on the pitcher lead the insect to its destruction. The insect slips into the fluid in the pitcher, is digested, and the proteid portion absorbed.

Leaves as Food. - Some leaves are used directly by man for food. Examples are cabbage, lettuce, Swiss chard, kale, broccoli, and many others. These leaves contain (with a large percentage of water) gluten (a proteid), starch, oil, and mineral matter. These foods, properly admixed with certain fleshy foods, are of great importance in giving a balance to diet.

Economic Use of Leaves. - The practical use of green plants to man is very great. Plants give off oxygen in the sunlight ancl use carbon dioxide, which is given off by animals in the breath. Thus parks containing green trees are truly the breathing places of the city.

Another very important use to man is seen in the fact that leaves, falling to the ground, help to form a rich covering of humus, which acts as a coat to hold in moisture. The forests are our greatest source of water supply. The cutting away of the forest always means a depletion of the reserve water stored in soil, with consequent floods and droughts in alternation.

\section{Reference Books \\ FOR THE PUPIL}

Andrews, Botany Ali the Year Round, pages 46-62. American Book Company.

Leavitt, Outlines of Botany. American Book Company.

Dana, Plants and their Children, pages 135-185. American Book Company.

\section{FOR THE TEACHER}

Gray, Structural Botany, pages 85-131. American Book Company.

Goodale, Physiological Botany, pages 337-353 and 409-424. American Book Company.

Darwin, Insectivorous Plants. D. Appleton and Company.

Green. Tcgetable Physiology. J. and A. Cliurchill.

Lubbock, Flowers, Fruits, and Leaves, Last Part. The Macmillan Company.

MacDougal, Practical Text-book of Plant Physiology. Longmans, Green, and Company.

Report of the Division of Forestry, U.S. Department of Agriculture, 1899.

Strasburger, Noll, Schenck, and Schimper. A Text-book of Botany. The Macmillan Company. 


\section{ECOLOGY}

Simplest Plant Body a Thallus. - It has been found by botanists that the plants which are the simplest in body structure are those which live in the water. Sometimes such simple plants are found upon rocks or on the bark of trees. In such plants we can dis-

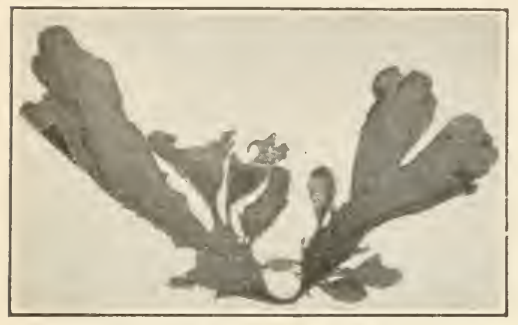

A red seaweed, an example of a thallus body. tinguish no root, stem, or leaf. The plant body may even be spherical in outline and consist of but a single cell. Such are the plants which give the green color often found on the bark of trees. Still other plants are threadlike in appearance. Others, as seaweeds, have a ribbon-shaped body. All of these diverse shapes of plant body are grouped under the general name of thallus. The simplest forms of plants have a thalluslike body.

Adaptation to Environment. - This kind of body is of use to a plant which lives in the water as a root to take in water. Plants, as well as animals, are greatly affected by what immediately surrounds them, their environment. It is believed (and we have shown in our experiments) that the environment (conditions of temperature, moisture, soil, etc.) is capable of changing or modifying the structure of plants very greatly. The change which a plant or animal has undergone, that fits it for conditions in which it lives, is called adaptation to environment.

The factors which act on plants and which make up their environment are soil, water, temperature, and light.

The first plants were probably water-loving forms. It seems likely that, as more land appeared on the earth's surface, plants became adapted to changed conditions of life on dry land. 
With this change in habit came a need of taking in water, of storing it, of conducting it to various parts of the organism. So it does not seem unlikely that plants came to have roots, stems, and leaves and thus adapted to their environment on dry land. We find in nature that those plants or animals which are best adapted or fitted to live under certain conditions are the ones which survive or drive other competitors out from their immediate neighborhood. Nature selected those which were best fitted to live on dry land, and those plants eventually covered the earth with their progeny.

As we have found in our experiments, young plants, and indeed any living plants, are delicate organisms, which are affected profoundly by the action of forces outside themselves. It is impossible not to see this after we have grown seedlings with and without light, with much water and with little water. Pea seedlings may grow for a time in sawdust, but we know that they will be much healthier and will live longer if allowed to germinate in soil under natural conditions.

Desert Conditions. - If we examine plants growing in a dry climate, as cactus, sage brush, aloe, etc., we find that the leaf surface is invariably reduced. Leaves are reduced to spines in the cactus. Some plants, such as the three-angled spurge, which bear leaves in a condition of moderate water supply, take on the appearance of a cactus under desert conditions. Thus they lose their evaporating leaf surface by having the leaves changed into spines.

This adaptation is evidently, if our experiments count for anything, the result of the action of forces outside the plants; that is, it is an adaptation to environment.

Water Supply. - Water supply is one of the important factors in causing changes in structure of plants. Plants which live entirely in the water, as do many of the plants known as algæ, have slender parts, stemlike, and yet serving the place of a leaf. The interior of such a plant is made up of spongy tissues which allow the air, dissolved in the water in which they live, to reach them. If leaves are present, as in the pond lily, the stomata are all in the upper side of the leaf. 


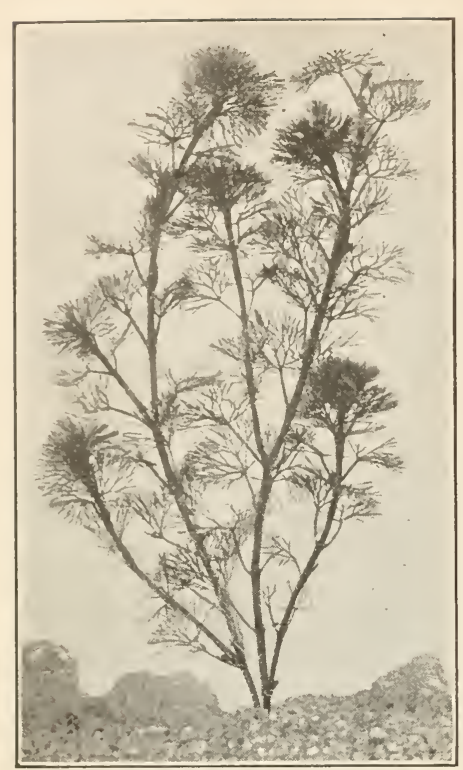

A water plant, showing the finely divided leaflike pa:ts.
Plants living in water have loose and spongy tissues; many large intercellular spaces are found in stems or leaves. In one pond lily (Nelumbo lutea) these spaces in the leaf communicate with large spaces in the veins of the leaf, and these in turn with spaces in the petiole, stem, and root, so that all parts of the plants are in communication with the air above. The roots of a plant living wholly in water are not needed for support, hence they are often short and stumpy. They do not need to be modified to absorb water; consequently the absorbing surface lacks root hairs. The whole plant, when under water, is usually modified to take water (and with it food) from its immediate environment.

Hydrophytes. - If water is present in such quantity as to saturate the soil in which the plant lives the conditions of its environment are said to be hydrophytic and such plant is said to be a hydrophyte.

Xerophytes. - The opposite of hydrophytic conditions is seen when the soil is very dry. Such a condition is known as xerophytic, and the plants living in these conditions are xerophytes. Such is the condition in a desert. We have seen that the most important adaptations of xerophytes are such as prevent evaporation of water from their bodies. The leaf surface is reduced, the leaves being changed into spines as in the eactus, or very greatly reduced in size, as in the switch plants of our alkali

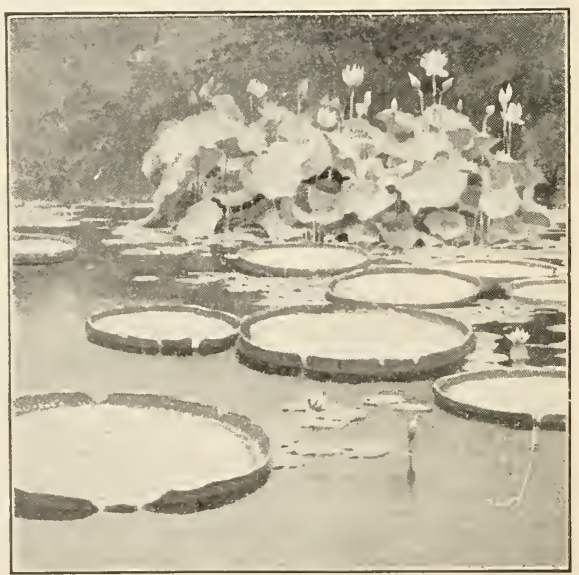

Plants with floating leaves. 
deserts. The stem may be thickened and full of water; a covering of hairs or some other covering may occur and lessen loss of moisture by evaporation. Examples of xerophytes are the cacti, yuccas, agaves, etc.

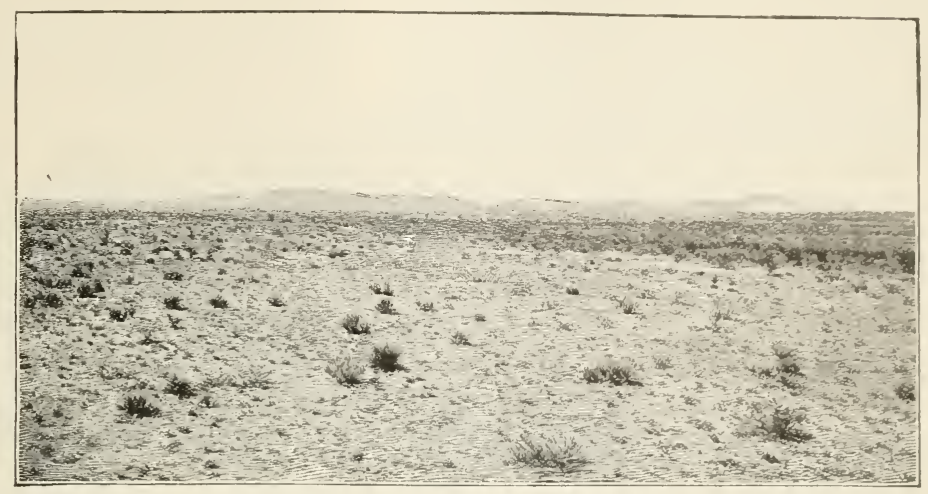

Xerophytic conditions. A typical desert.

Halophytes. - If the water or saturated soil in which the plant lives contains salts, such as sea salt or the alkali salts of some of our Western lakes, then the conditions are said to be halophytic, and a plant living under such conditions is known as a halophyte.

Halophytes show many characteristics which xerophytes show, spines or hairs, thick epidermis, fleshy leaves, all being characters which show that the water supply of the plant is limited. The density of the salt water in the soil makes it difficult for the plant to absorb water; hence these characters are developed.

Mesophytes. - Most plants in the Temperate Zone occupy a place midway between the xerophytes on one hand and hydrophytes on the other. They are plants which require a moderate amount of water in the soil and air surrounding them. Such are most of our forest and fruit trees, and many of our garden vegetables. Conditions of moderate moisture are called mesophytic; the plants living thus are known as mesophytes.

It may easily be seen that plants which are mesophytes at one time may under some conditions of weather be forced to undergo xerophytic or hydrophytic conditions. An oak tree may receive no water through the roots during the winter because the surface HUNTER'S BIOL. - 10 


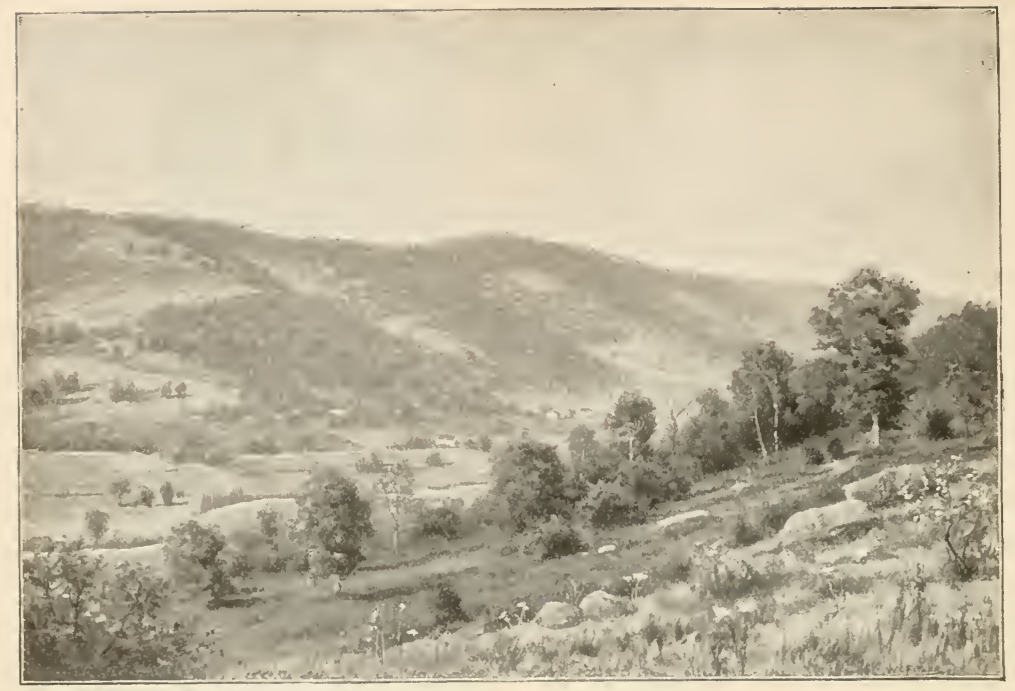

A mesophytic condition. A valley in central New York.

of the ground is frozen, thus preventing water from finding its way below the surface.

Plant Societies. Field Work. - Any boy or girl who has access to a vacant lot or city park can easily see that plants group themselves into societies. Certain plants live together because they are adapted to meet certain conditions. Societies of plants exist along the dusty edge of the roadside, under the trees of the forest, along the edge of the brook, in a swamp or a pond. It should be the aim of the field trips to learn the names of plants which thus associate themselves and the conditions under which they live, and especially their adaptations to the given conditions. ${ }^{1}$

Other Factors. - It is a matter of common knowledge that plants in different regions of the earth differ greatly from one another in shape, size, and general appearance. If we study the causes for these changes, it becomes evident that the very same factors which govern hydrophytic, xerophytic, and mesophytic conditions determine, at least in part, the habits of the plants growing in a given region - be it in the tropics or arctic regions. But in addition to water supply the factors of temperature, light, soil, wind, etc., all play important parts in determining the form and structure of a plant.

1 Suggestions for such excursions are found in Andrews, Botany all the Year Round, Lloyd and Bigelow, The Teaching of Biology, Ganong, The Teaching Botanist, and many other books. A convenient form of excursion is found in Hunter and Valentine, Manual, page 202. 
Desert Conditions. - In the deserts of Central Africa and those of the Western United States the conditions of temperature, and especially lack of moisture, are essentially the same. We find in both regions plants the leaves of which are either very small or entirely lacking, their place having been taken by spines or thorns. In some plants, Agave, for example, leaves are present, but are thick and fleshy to hold water.

Cold Regions. - Here plants, which in lowland regions of greater warmth and moisture have a tall form and luxuriant foliage, are stunted and dwarfed; the leaves are smaller and tend to gather in rosettes or are otherwise closely placed for warmth and protection. As we climb a mountain we find the average

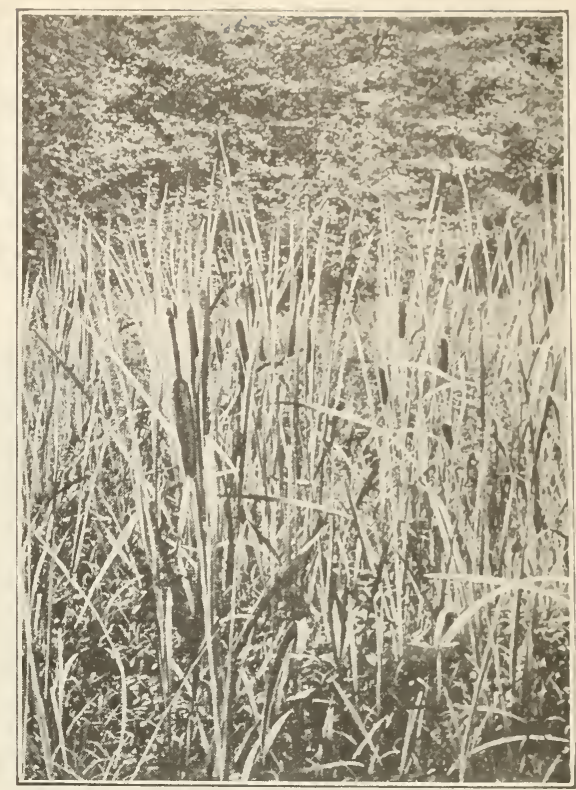

Two plant societies: in the foreground plants living in conditions of much moisture; in the background true mesophytes, a tree society.

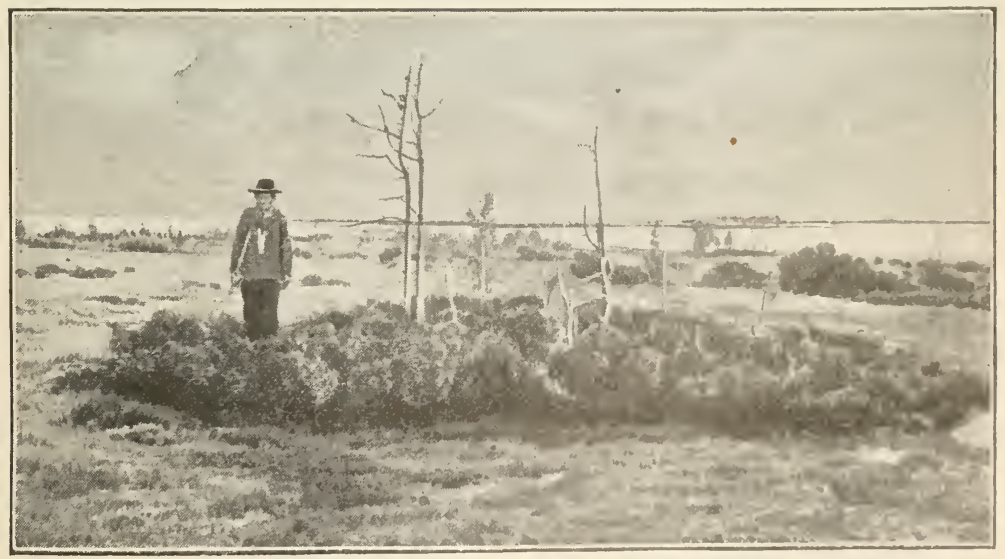

Polar limit of trees, northern Russia. 
size of plants decreases as we approach the line of perpetual snow. The largest trees occur at the base of the mountains; the same species of trees near the summit appear as mere shrubs. 'Continued cold and high winds are evidently the factors which most influence the slow growth and the size and shape of plants near the mountain tops. Cold, little light during the short days of the long winter, and a slight amount of moisture all act upon the vegetation of the arctic region, tending toward very slow growth and dwarfed and stunted form. Trees over five hundred years old have been noted in cold regions with trunks less than three feet in diameter at the base.

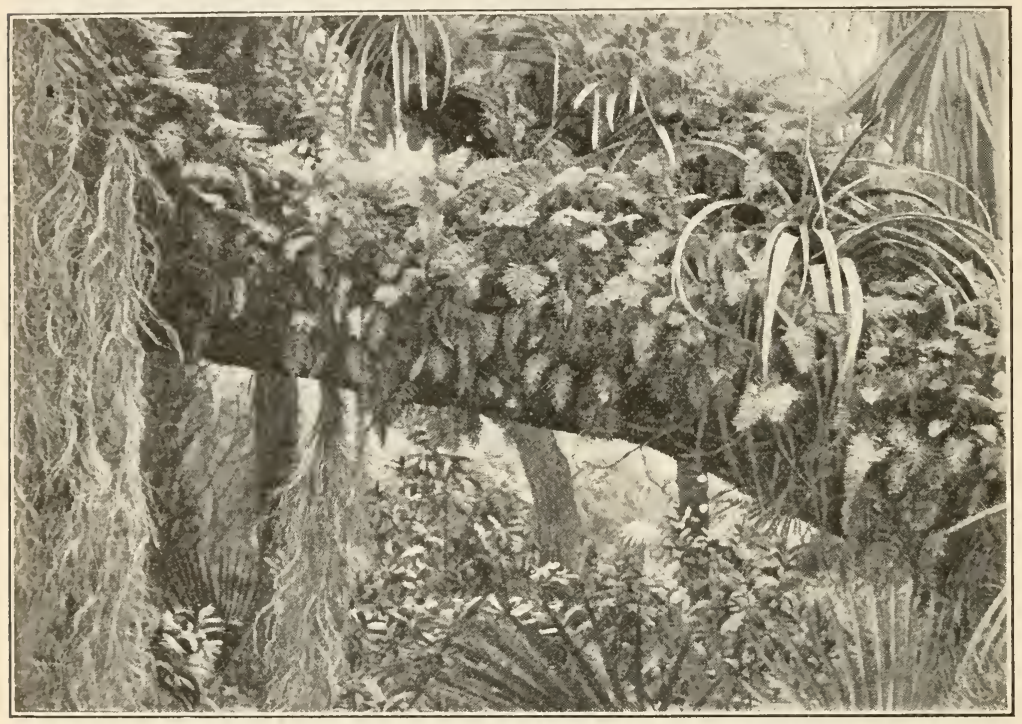

Conditions in a moist, semi-tropical forest. The so-called " Florida moss" is a flowering plant. Notice the resurrection ferns on the tree trunk.

Vegetation of the Tropics. - A rank and luxuriant growth is found in tropical countries with a uniformly high temperature and large rainfall. In general it may be estimated that the rainfall in such countries is at least twice as great as that of New York state, and in many cases three to four times as great. An abundant water supply, together with an average temperature of over $80^{\circ}$ Fahrenheit, causes extremely rapid growth. One of the bamboo family, the growth of which was measured daily, was found to increase in length on the average nearly three inches in the daytime and over five inches during each night. The moisture present in the atmosphere allows of the growth of many air plants (epiphytes), which take the moisture directly from the air by means of aërial roots. 
The absence of cold weather in tropical countries allows trees to mature without a thick coating of bark or eorky material. The trees all have a green and fresh appearance. Monocotyledonous plants prevail. Ferns of all varieties, especially the largest tree ferns, are abundant.

Plani Life in the Temperate Zones. - In the state of New York conditions are those of a typical temperate flora. Extremes of cold and heat are found, the temperature ranging from $30^{\circ}$ Fahrenheit below zero in the winter to $100^{\circ}$ or over in the summer. Conditions of moisture show an average rainfall of from 60 to $130 \mathrm{~cm}$. Cond tions of moisture in the country cause great differences in the plant covering.

In the eastern part of the United States the rainfall is sufficient to give foothold to great forests, which aid in keeping the water in the soil. In the middle West the rainfall is less, the prairies are covered with grasses and other plants which have become adapted to withstand dryness. In the desert region of the Southwest we find true xerophytes, cacti, switch plants, yuccas, and others, all plants which are adapted to withstand almost total absence of moisture. In the temperate zone the water supply is the primary factor which determines the form of plant growth.

\section{Reference Books \\ FOR THE PUPIL}

Andrews, Botany All the Year Round. American Book Company.

Leavitt, Outlines of Botany. American Book Company.

Coulter, Plant Relations. D. Appleton and Company.

Stevens, Introduction to Botany. D. C. Heath and Company.

\section{FOR THE TEACHER}

Bailey, The Survival of the Unlike. The Macmillan Company.

Darwin, Animals and Plants under Domestication, Chaps. IX, XII. D. Appleton and Company.

Kerner. Natural History of Plants. 4 Vols. Henry Holt and Company.

Schimper, Plant Geography. Clarendon Press.

Year Book, Department of Agriculture, 1894, 1895, 1898, 1900. 


\section{FLOWERLESS PLANTS}

Systematic Botany. - The plant world is divided into many tribes or groups. Any one who has visited a hothouse or a large garden is likely to notice this fact. And not only are plants placed in large groups which have some very conspicuous characters in common, but smaller groupings can be made in which perhaps only a few plants having common characters may be placed. If we plant a number of peas so that they will all germinate under the same conditions of soil, temperature, and sunlight, the seedlings that develop will each differ one from another in a slight degree. But in a general way they will have many characters in common, as the shape of the leaves, the possession of tendrils, form of the flower and fruit. The smallest group of plants or animals having certain characters in common that make them different from all other plants or animals is called a species. Individuals of such species may differ slightly; indeed no two individuals are exactly alike. It is known that in some cases seeds from plants which have thus varied to a considerable degree may reproduce these variations in the young. plants. This fact is made use of by plant breeders to produce new kinds of plants.

Species are grouped together in a larger group called a genus. For example many kinds of peas - the everlasting pea, the wild beach peas, the sweet peas, and many others - are all grouped in one genus (called Lathyrus or vetchling) because they have certain structural characteristics in common.

Nomenclature. - When we wish to identify a plant, we look it up by means of its generic and specific names in much the same way that we look up a name in a city directory. As in a directory the last name of the person is placed first, as Jones, John, so we find the Latin name Phaseolus given to the beans as a genus. Phaseolus vulgaris is the name of the common bean; Phaseolus lunatus, the pole or lima bean; and Phaseolus multiflorus, the scarlet runner.

System of Classification Artificial. - Plant and animal genera are brought together in still larger groups, the classification based on general likenesses in structure. Such groups are called, as they become successively larger, Family or Tribe, Order, and Class. Thus the whole plant and animal kingdom is artificially massed in separate divisions, the smallest of which contains a few individuals very much alike; and the largest of which contains very many groups of individuals, the groups having some characters in common. This is called a system of classification. 
Phanerogams and Cryptogams. - In the widest sense the plant world is divided into two great groups, the flowering plants, or Phanerogams, and the flowerless plants, or Cryptogams. This is an old system of classification, but it shows one very important distinction in the plant kingdom.

The flowerless plants are much simpler in structure than the flowering plants. We are apt to entirely overlook them in a easual glance at vegetation in a landscape. Thousands of species exist so small that we cannot see them with the unaided eye. Many kinds hide themselves in the water, while still others may lie flat on the ground or cling to the bark of trees and thus escape observation. Yet one of the cryptogams is over a thousand feet in length, one of the longest plants in the world.

Classification of the Plant Kingdom. - The entire plant kingdom has been grouped as follows by the later botanists:-

1. Spermatophytes. $\left\{\begin{array}{l}\text { Angiosperms, true flowering plants. } \\ \text { Gymnosperms, the pines and their allies. }\end{array}\right.$

2. Pteridophytes. The fern plants and their allies.

3. Bryophytes. Moss plants and their allies.

4. Thallophytos. Plants in which the plant body is a thallus, that is, the body is not divided into root, stem, and leaves. A seaweed and a mushroom are good examples. The Thallophytes form two groups: the Algæ and the Fungi.

The extent of the plant kingdom can only be hinted at, because each day new species are added to the lists. There are about 110,000 species of flowering plants and perhaps half as many flowerless plants. The latter consist of nearly 3500 species of fernlike plants, some 16,500 species of mosses, over 5600 lichens (plants consisting of a partnerslip betwcen algæ and fungi), approximately 55,000 species of fungi, and 16,000 species of algye.

Sexual Reproduction in Flowering Plants. - Flowering plants reproduce their kind by the formation of seeds. As we know, the flower produces in the ovary structures which are known as ovules. In the interior of the ovule is found a clear protoplasmic area which is called the embryo sac. In this area is a cell (the egg cell) which is destined to form the future plant. In the pollen grain is found another eell, the sperm. This cell, after the ger- 
mination of the pollen grain on the stigmatic surface of the flower, enters the ovule in the pollen tube and unites with the egg cell. This process, known as fertilization, is the most important event in the life of the plant, for it is only by means of this process that the ovule is stimulated to become a seed. The fertilized egg grows into the young plant within the seed, known as the embryo see page 34$)$.

This method of reproduction, called sexual reproduction, is found in the spermatophytes, that is, all seed-producing plants. In the flowerless plants a somewhat similar process takes place. Seeds are not formed, however, but structures called spores reproduce the plants.

Sexual and Asexual Spores. - A spore is usually considered to be a cell which has become dormant, but which will under favor-

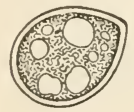

A spore of bread mold, highly magnified. able conditions again germinate to form a new plant. A spore, as we shall see, may be formed iri one of several ways. If formed by the union of two cells, as is the fertilized egg, it is then said to be a sexual spore. If, as is frequently the case, the spore is formed by the separation of a bit of protoplasm from the plant to form a resting cell, then it is called an asexual spore. In most of the so-called " spore plants" both sexual and asexual spores are formed at different times during the life history of the plant.

\section{Pteridophytes}

The Ferns and their Allies. - The fern plants include the true ferns, the horsetails or scouring rushes, and the club mosses. The true ferns are moisture-loving and shade-loving plants; they play an important part in the vegetation of the tropical forests. Many forms are found in the temperate regions; we even have some common ferns that remain green all winter. The ferns are among the most beautiful of our plants, and the study of a common form will amply repay the time so spent.

The Polypody (Polypodium vulgare). ${ }^{1}$ - The habitat of the polypody is damp woods and rocky glens. The ferns are usually hard to get up

${ }^{1}$ Hunter and Valentine's Manual, page 93. 
entire. The stem is underground. Large compound leaves (called fronds) are given off at intervals along the stem. We call the underground stem a rootstock. Try to find a reason for calling it a stem rather than a root.

Note the arrangement of the leaflets, or pinna, of the fern frond. Some of the pinnæ will show a series of little brown dots on the under surface. These structures, called coliectively the sori (singular sorus), are made up of a number of tiny spore cases. These spore cases, or sporangia, hold the asexual spores. Examine a sorus with your hand lens to make out its position on the pinna with reference to the veins.

Mount a small bit of the . fern leaf which contains a sorus under a very low power of the compound mieroscope. How are the sporangia arranged in the sorus?

If a single sporangium is gently separated from the mass and mounted carefully in alcohol and water on a slide, the following structures may be found: (a) the stalk; $(b)$ a thick wall row of cells, yellow in most specimens, which form

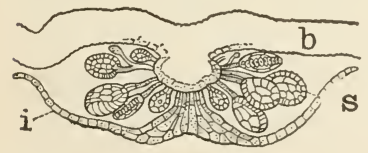

Section of sorus; $s$, sporangia; $i$, indusium, or covering; $b$, blade of the leaf. - Wossidlo.

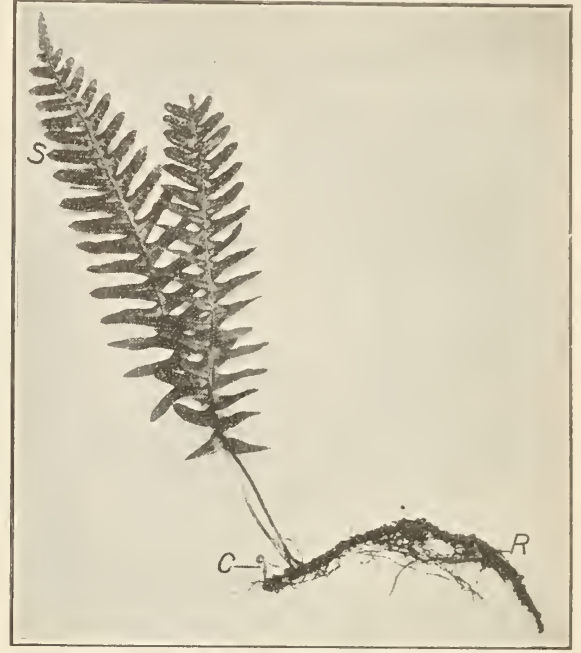

Rock fern, polypody. Notice the underground stem giving off roots $(R)$ from its under surface, and leaves $(C)$ from the upper surface. The compound leaf or frond may bear sori $(S)$ on the under side of the leaflets.

sporangium. A drop of glycerine run under the cover slip of a slide holding a fresh unopened sporangium soon causes the sporangium to snap open. If the sporangium is dry and on the under surface of the fern leaf, the spores will bescattered for a considerable distance. An explanation for this snapping open of the sporangium is found when we notice that the outer walls of the cells forming the annulus are thinner than the inner walls. This allows water to escape more rapidly on one side, and pressure from without causes the cells to bend outward

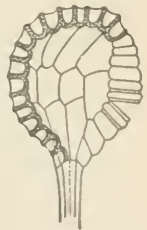

A sporangium 
Home Experiment. - Plant some spores on the surface of a moist brick or broken flowerpot. Cover them with a piece of glass so as to keep the air in which they remain warm and moist. Give them moderate heat (about $70^{\circ}$ Fahrenheit). After two or three weeks, if the surface is carefully scanned with a hand lens, very tiny green threadlike structures may be found. These structures grow rapidly to form flat heart-shaped bodies.

Prothallus. - Such a structure is called a prothallus. The prothallus clings to the surface of the brick by means of tiny rootlike

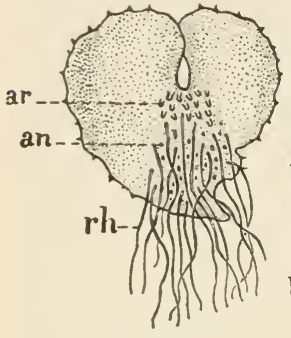

A

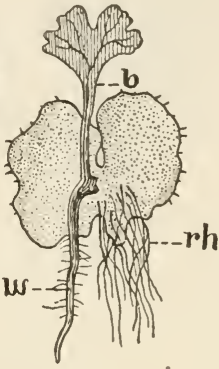

B

Prothalium of a common fern (Aspidium); $A$, under surface, showing rhizoids, $r h$, antheridia, $a n$, and archegonia, $a r ; B$, under surface of an older gametophyte, showing rhizoids, $r h$, and yourg sporophyte, with root, $w$, and leaf, $b$. (From Coulter, Plant Structures.)

Archegonia. - The last-named are called archegonia; they are found to be very tiny flask-shaped organs almost embedded in the surface of the prothallus. Each archegonium contains a single large cell. This we recognize as an egg cell.

Antheridia. - The other structures found among the rhizoids are called antheridia. Each antheridium contains a large number of very minute objects which are able to move about in water by means of lashlike threads of protoplasm. Each of these motile cells is called an antherozoid; they have, in fact, the same function as the sperm cells of the flowering plants. Because this part of the plant holds the egg cells and sperm cells, it is called the sexual generation of the fern.

Fertilization. - The sperm cells swim to the egg cells in water (rain or dew), being attracted to the mouth of the flask-shaped archegonium by an acid secretion which is poured out by the cells 
forming the neck of the flask. Fertilization is essentially the same process that has been described for the flowering plants, the sperm cell uniting with the egg cell to form a single cell, the fertilized egg.

Sporophyte and Gametophyte. - The direct result of fertilization is the growth of the egg cell by repeated division to form a little fern plant. Later the young plant strikes root, the prothallus dies away, and we have a fern plant which will later in the season produce asexual spores. The
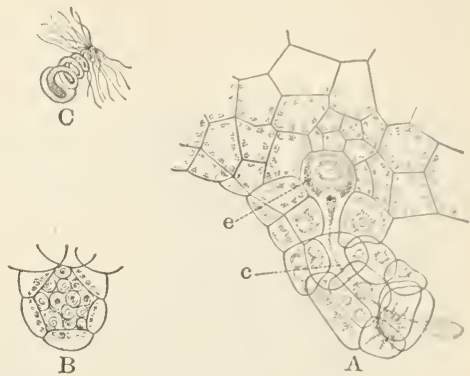

$A$, the archegonium with egg $(e)$ and canal $(c)$; $B$, antheridium; $C$, antherozoid, very highly magnified. - Strasburger.

leafy fern plant, because it produces asexual spores, is called the sporophyte. The prothallus, which forms the eggs and sperms, both of which are known as gametes, or sex cells, is called the gametophyte.

Alternation of Generations. - The fern plant during its entire life thus passes through two entirely different stages, or generations. The spore germinates to form a gametophyte, or sexual generation. This sexual generation in turn produces an asexual generation, or sporophyte. The alternation, in the life history of a plant or animal, of a sexual stage with an asexual stage is called an alternation of generations.

General Characters of the Fernlike Plants. - These plants pass through an alternation of generations; they have a distinct root, stem, and leaves; and the stem possesses conducting tubes or fibrovascular bundles; these are the distinguishing marks of the ferns and their allies. Fern plants show a great diversity in form and size. They vary from the great tree ferns of the tropics, some of which are thirty to forty feet in height, to tiny forms of almost microscopic size. The leaves of the ferns are among the most complex in form of any that we know. The position and shape of the spore cases differ greatly in different species of ferns; in some the edge of the leaflet is modified to hold the spores, in 
others the veins bear the spore cases, while in some ferns the entire leaf is modified into a spore-bearing organ.

The Horsetails. - This comprises a small group of plants, recognized by their erect habit of growth, the leaves coming out in whorls on the stem.

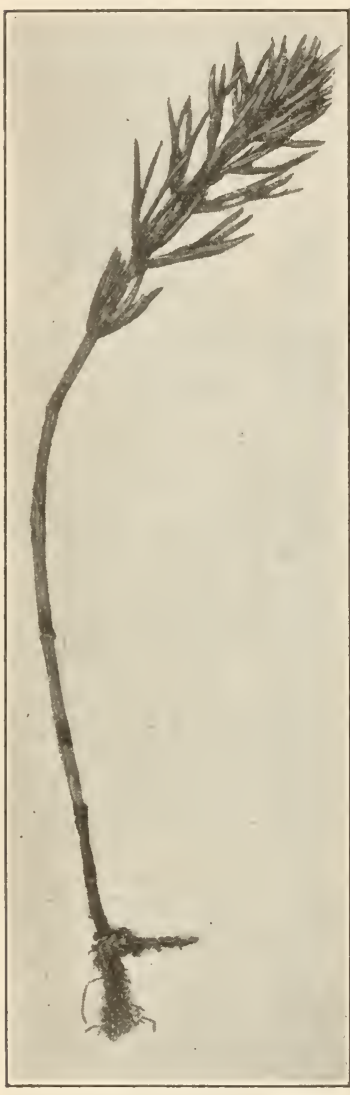

An equisetum, about one half natural size.

In most forms the stem contains considerable silica. This gave to the plant its former useful place in the household and its name of the scouring rush. If you burn one of these plants very carefully on a tin plate over a very hot fire, the delicate skeleton of silica may be seen. The horsetails, or Equisetums, were once a very important part of the earth's vegetation. Before the coal fields were formed the ancestors of these plants flourished as trees. A large amount of the coal of this country is undoubtedly formed from the trunks of the Equisetums of the Carboniferous age. At present they are represented by a very few species, none of which are over four or five feet in height.

Club Mosses. - Another relative of the fern is the club moss (Lycopodium). It is familiar to us as a Christmas decoration under the name of ground pine. It is chiefly of interest now as the representative of another group of plants that flourished during the Carboniferous age.

Economic Value of Ferns. - It may be said that the ferns as a group have formed a large part of the enormous deposits of almost pure carbon that we call coal, from which we now derive the energy to run our many engines.

\section{BRYOPHYTES}

Mosses, like ferns, are shade-loving and moisture-loving plants. They form velvety carpets in many of our forests, but they often show their preference for moist localities by covering the wooded shores of lakes and swamps.

Pigeon-wheat Moss. - One of the mosses frequently seen and easily recognized is the so-called pigeon-wheat moss (Polytrichum 
- commune). ${ }^{1}$ Unlike some mosses, it often inhabits dry localities. It may be found on some dry hillock close to the edge of the woods where it forms a reddish brown carpet. This red color is due largely to the presence of a great number of little upright stalks, bearing at the summit tiny capsules, which seem to grow up from the leafy moss plant. The resemblance of a large number of these stalks and capsules to a mimic field of grain has given the name pigeon-wheat moss to this form. Take home some of the moss plants for study in the laboratory. Take care to

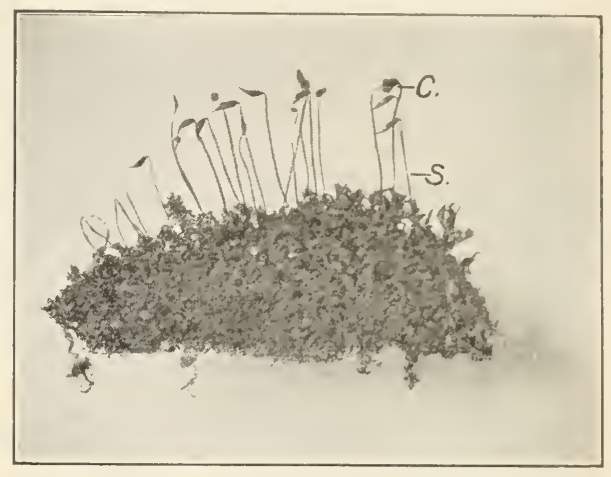

A group of moss plants, showing the stalk (S.) and capsule $(C$.$) of the spore-forming generation.$

find not only the plants bearing stalk and capsule, but also certain plants which terminate in a tiny rosette of leaves, this inclosing what seems to be a very small flower.

Leafy Moss Plant. - An examination of a leafy moss plant will show that it has rhizoids or hairlike roots, an upright stem, and green leaves. Make a drawing to show all the parts.

Notice the stalk and eapsule closely. The stalk grows directly from the end of the leafy plant. This capsule is provided with an outer cap. The cap, or calyptra, as it is called, seems to have somewhat the structure of a thatched roof. Under the cap is found a lid, or cover, to the capsule. Rcmove the cover very carefully; notice whether it is attached to the capsule. Now, turning the capsule upside down, tap it gently against the surface of your drawing paper. The dust that escapes is made up of a great number of spores.

Sporophyte. - The capsule is the sporangium of the moss plant. The stalk and capsule together form the sporophyte of the moss.

If we were to plant the spores of the moss in clamp sand, taking care to keep the sand moist and warm, we might obtain germinating spores. The spore germinates into a threadlike structure, very tiny, and not at all like the adult moss plant. This thread is called a protonema.

1 See Hunter and Valentine, Manual, page 90. 
Adult Moss Plants. - It soon develops rhizoids; tiny buds appear that . in time form the adult moss plant. These adult plants may grow only leaves, and become what are known as sterile plants; or they may develop into a plant that bears at the summit the little rosette of leaves previously referred to. Within the rosette lie a number of tiny organs which resemble the antheridia of the ferns in structure. They are in fact antheridia and hold large numbers of sperm cells. Other moss plants bear at the summit of the stem a tuft of leaves which hide a number of small flask-shaped archegonia. The archegonia contain each a single egg cell. These plants

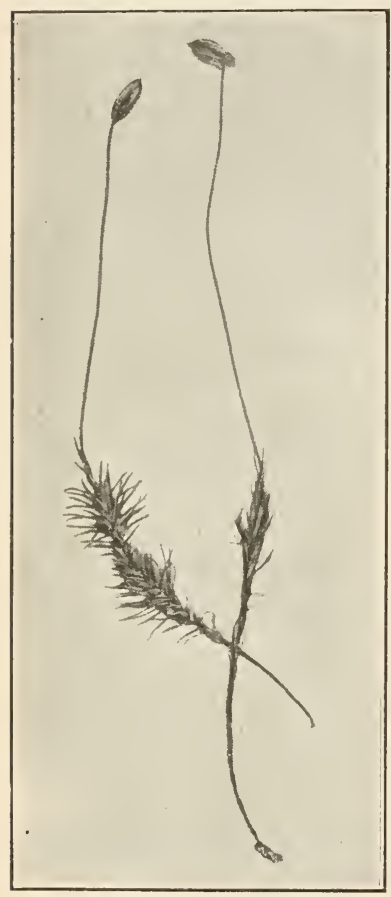

Pigeon wheat. A moss showing egg-bearing gametophyte and sporophyte (stalk and capsule), the latter entirely dependent upon the former.

form the sexual generation of the moss. After a sperm cell has been transferred to the egg cell a fusion of the two cells takes place. This, we remember, is the process of fertilization. In the mosses as well as the ferns the fertilization of the egg cell results in the growth of that part of the plant which forms and bears the asexual spores.

Alternation of Generations. - In the mosses also we have an alternation of generations. The leafy moss, bearing among its leaves the sex organs, antheridia and archegonia, gives place to a stalk and capsule bearing the asexual spores. This spore-bearing portion of the plant does not appear until after fertilization; then it grows directly out of that part of the plant that produces the egg cell. In fact, if we make a microscopic examination of this archegonium directly after fertilization, we find that the sporophyte is a direct outgrowth from the fertilized egg cell.

Sporophyte a Parasite.-One interesting fact comes out in connection with this growth of the sporophyte. It has no green leaves and must therefore obtain all its nourishment from the leafy moss plant, or gametophyte. The spore-bearing part of the plant is thus actually a parasite upon the gametophyte. 
The Liverworts. - Liverworts are mosslike plants which inhabit moist localities, some living in or on the surface of water, others on rocks or damp soil, and some even growing on the bark of trees. The liverworts have an irregular thallus-shaped or platelike body. Rhizoids are developed from the lower surface of the body. From the plant body arise upright structures which bear the antheridia and archegonia.

Their life history is nearly that of a moss. These plants may also reproduce themselves asexually by means of budlike structures called gemmie, The gemmæ, which are formed in cup-shaped organs on the upper surface of the plant, break off and under favorable conditions may form a new plant.

Economic Value of Mosses. - The mosses and their allies have little direct economic value. Indirectly they are of much benefit to mankind. In many localities they form a soft carpet, which is of great importance in holding water in the suil; thus they prevent erosion. They give off not a little oxygen to the atmosphere and must use considerable carbon dioxide in their manufacture of starch.

\section{Thallophytes}

We have already defined a thallus as a plant body which has no definite root, stem, or leaf. It may be platelike, ribbonshaped, threadlike, globular, or even irregular in form.

The thallus plants may be grouped in two great divisions: the Algce, water-loving thallophytes containing chlorophyll, and the Fungi, thallus plants which do not contain chlorophyll.

Fungi, Parasites, and Saprophytes. - As a direct result of the lack of chlorophyll in the cells, the fungi are unable to make their own food. They must obtain food from other plants or animals. Some take up their abode upon living plants or animals (in which case they are called parasites); others obtain their food from some dead organic matter. The latter are called saprophytes. The above facts make the group of the fungi of immense economic importance to man. Much of the space devoted to the fungi will be given up to a consideration of the relation of parasitic and saprophytic plants to their hosts, the living or dead organisms from which they obtain their food.

Mold. - One of the most common of all our fungi is the black mold (Rhizopus nigricans).

Experiments to determine the Growth of Mold. - Place a piece of bread in each of two wide-mouthed bottles or jars, add a little water, and ex- 
pose both jars to the air of the living room or kitchen for five minutes. Then cover both jars and plunge one into boiling water for a few minutes. Now place the jars side by side in a moderately warm room for two or three days. In which jar does growth appear first? Do both jars have like

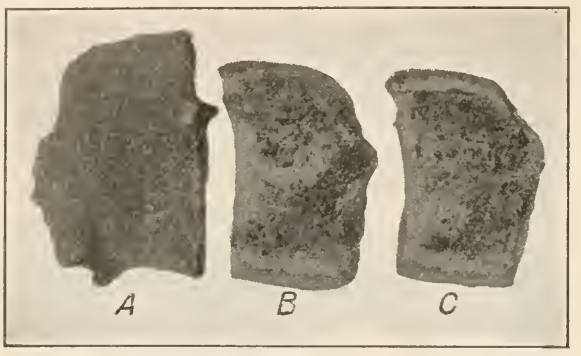

Experiment with mold on bread; $A$, in a living room; $B$, in an ice-box; $C$, above the stove in a kitchen. growth of mold in the given period of time?

Other experiments may be performed to show the relation of the growth of mold to light, to different degrees of moisture and to different temperatures. Why do things get moldy in a damp locality quicker than in a dry one? How would you account for the growth of mold inside of a jar of preserves or jelly? Can you determine by experiment whether black mold uses oxygen in its growth?

Directions for Growth of Mold. - Bread mold may be conveniently grown for laboratory use in small shallow dishes (Syracuse watch glasses, Petri dishes, or butter chips). If bread is exposed to the air for a few minutes and then left in the covered dishes for a day or two, with a bit of wet sponge or blotting paper in the dish to keep the air moist, a good supply of mold may be obtained in a convenient dish for observational purposes. ${ }^{1}$

Observations on Mold. - Examine the tangled mass of threads which cover the bread. This is called the mycelium, each thread being called a hypha. How do the hyphæ appear to be attached to the bread? Many of the hyphæ are prolonged into tiny upright threads, bearing at the top a little ball. With the low power of the microscope the structure of a sporangium may be made out. The dark-colored ones are full of ripe spores, which may be seen by lightly tapping the cover slip over the slide. How do the spores normally get out of the sporangium? Try to find some young sporangia and note the differences in size and color between them and the older ones. Draw a series of sporangia as seen under the low power.

This method of the production of spores is evidently asexual. These spores, if grown under favorable conditions, will

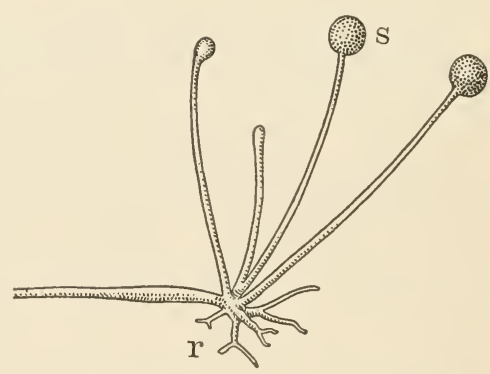

Bread mold; $r$, rhizoids; $s$, sporangium. produce more mycelia, which in turn bear sporangia. It has been found, however, that at some time during the life of the mold another method of reproduction is likely to occur.

' See Hunter and Valentine, Manual, page 83. 
Formation of Zygospores.-- Two hyphwe which are close-lying put out threads which communicate. The end of each of the threads cuts off a cell, and the two cells, each from a different hypha, flow together and mingle. In this condition they remain as a single resting cell. This cell, which puts a heavy wall around itself, is called a zygospore. In the process we called fertilization, we found that the two cells which united to form one cell were of different sizes. Here the cells are of the same size. When two cells of the same size unite to form a single cell, we call the process conjugation. The ultimate result of the conjugation of the two cells is that a new plant grows from the zygospore after a period of rest. During the resting stage the spore may undergo very unfavorable conditions, even to extreme dryness, heat, or cold. The use of the zygospore to the plant is evidently to continue the species during an unfavorable time in the life history of the plant. The process of conjugation is

A
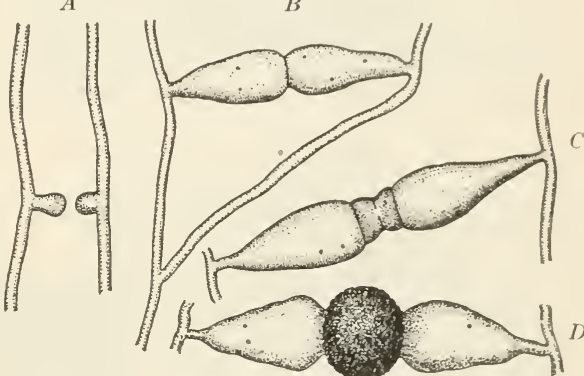

Conjugation of black mold; $A, B, C, D$, suecessive stages in the formation of the zygospore. probably a sexual process. Its significance is not well understood. ${ }^{1}$ Is there then an alternation of generations in the mold?

Physiology of the Growth of Mold. - Mold, in order to grow rapidly, evidently needs considerable moisture and heat. It obtains its food from the material on which it lives. This it is able to do by means of digestive ferments, which are given out by the rhizoids or rootlike parts of the hyphæ, by means of which the mold clings to the bread. These digestive ferments change the starch of the bread to sugar, and change the proteids into a form that can be osmosed into the hyphæ. Thus the plant is enabled to absorb the material. The foods are then changed into

1 It seems to have been proved recently that zygospores are formed by the union of two cells, from different filaments, one of which has male, the other female characters.

HUNTER'S BIOL. - 11 


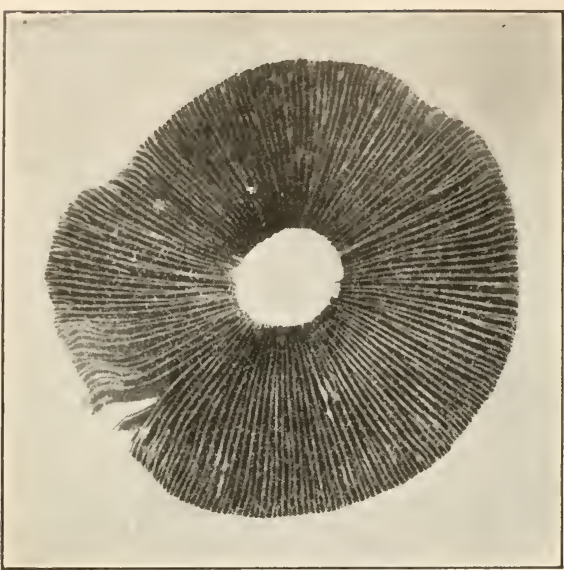

Spore print.

protoplasm or used to produce energy. This seems to be the usual method by which saprophytes assimilate the materials on which they live.

OTHER SAPROPHYTIC Fungi. - The mushroom resembles a tiny umbrella. The upper part is known to botanists as the cap; the cap is held up by a stalk or stipe. The under surface of the cap discloses a number of structures which radiate out from the central stipe to the edge

of the cap. These are the gills. If you place the cap of a mushroom gills downward on the surface of a piece of white paper, being careful not to disturb for at least twelve hours, it will be found that when the cap is removed a print of the shape and size of the gills remains on the paper. This is a spore print. It has been caused by the spores of the plant, which have fallen from the place where they were formed between the gills to the surface of the paper.

Mrcelium. - The mushroom is, then, the spore-bearing part of the plant. Where is the plant body? This question is answered if we dig up a little of the earth surrounding a mushroom. In the rich black soil is seen a mass of little whitish threads. These threads form the mycelium of the fungus. The hyphæ of this part of the plant body take food from the organic matter in the soil and digest

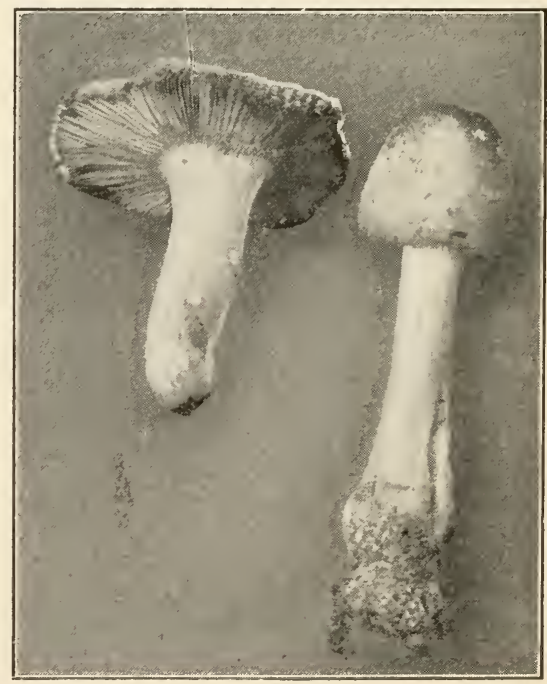

Mushrooms: the younger specimen, at the right, shows the mycelium. Photographed by Overton 
it in the same manner as did the hyphæ of black mold. The mushroom is a saprophyte. No sexual stage has yet been discovered.

Poisonous Mushrooms. - Fungi of the mushroom species are classed by botanists as edible and inedible. The latter are popularly known as toadstools. It is difficult to give the beginner any stated rules by which to distinguish the inedible from the edible species. A few general rules may be given, however, to the collector:-

Do not use mushrooms that are old or black.

Never collect those with swollen bases surrounded with saclike or scaly envelopes. (Such a structure forms the so-called death cup of the deadly Amanita.)

Do not collect mushrooms in the early stage known as buttons.

Do not use mushrooms with a milky juice.

Avoid fungi with a weblike ring around the upper part of the stipe. Be very cautious about trying new varieties. Better learn one or two edible species and stick to them. Beginners may safely eat any of the club or coral fungi found growing on dead trees in damp woods; also young puffballs and the morels, with their characteristically ridged surface.

Food Value of Mushrooms.The food value of the edible mushroom has been much overestimated. Recent experiments seem to show that, although they have a slight food value, they are far from taking the place of nitrogenous foods, as was formerly believed by scientists.

Shelf Fungus. - A near rela- tion to the mushroom is the bracket or tree fungus. This fungus is familiar to any one who has been in a forest in this part of the country.

An examination of specimens shows that the shelf or bracket is in reality a spore case, which is usually provided with a very considerable number of holes, slits, or pores in which the spores are formed. The spores, when ripe,

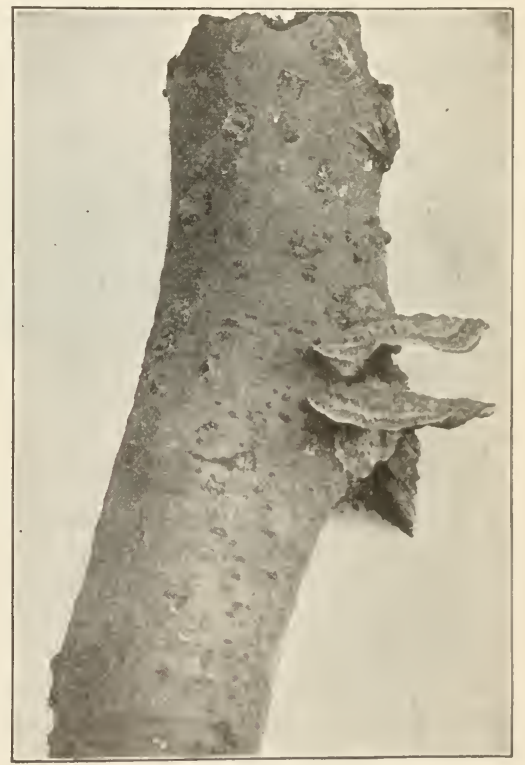

Shelf or bracket fungi on dead tree trunk. Photographed by Overton.

escape from the under surface of the spore-bearing body through the minute pores. The mycelium is within the tissue of the tree. Remove 
the bark from any tree infected with bracket fungus, and you will find the silvery threads of the mycelium sending their greedy hyphæ to all parts of the wood adjacent to the spot first attacked by the fungus. This fungus begins its life by the lodgment of a spore in some part of the tree which has become diseased or broken. Once established on its host, it spreads rapidly. There is no remedy except to kill the tree and burn it, so as to burn up the spores. Many fine trees, sound except for a slight bruise or other injury, are annually infected and eventually killed. In cities thousands of trees become infected through careless hitching of horses so that the horse may gnaw or crib on the tree, thus exposing a fresh surface for the growth of spores.

Field Work. - A field trip to a park or grove near home will show the great destruction of timber by this mcans. Count the number of perfect trees in a given area. Compare with the number of trees attacked by the fungus. Does the fungus appear to be transmitted from one tree to a tree near at hand? In how many instances can you discover the point where the fungus first attacked the tree?

Parasitic Fungi. - Of even more importance are the fung: that attack a living host. The most important of such plants from an economic standpoint are the rusts, smuts, and mildews which

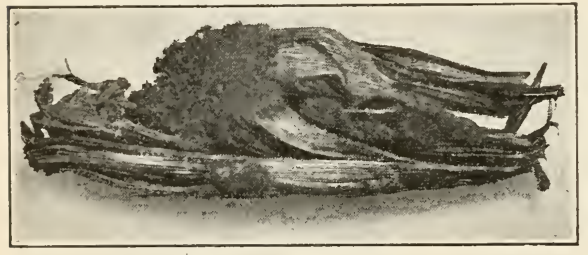

Corn smut, a fungus parasitic on corn; the black mass consists almost entirely of ripe spores. prey upon grain, corn, and other cultivated plants. Some of these are also parasitic upon fruit and shade trees. Damage extending to hundreds of millions of dollars is annually done by these plants.

Wheat Rust. - Wheat rust is probably the most destructive parasite in the world. For hundreds of years wheat rust has been one of the most dreaded of plant diseases, beeause it destroys the one harvest upon which the civilized world is most dependent. For a long time past the appearance of rust has been associated with the presence of barberry bushes in the neighborhood of the wheat fields. Although laws were enacted nearly two hundred years ago in New England to provide for the destruction of barberry bushes near infected wheat ficlds, nothing was actually known of the relation existing between the rust and the barberry until recently. It was then proved beyond doubt that the wheat rust passed part of its life as a parasite on the barberry and from it passed to the wheat plant. If a blade of wheat infected with rust is examined early in the summer, the leaf blade will show a collection of reddish brown spots or streaks. These 
spots are caused by collections of spores of the rust. The mycelium of the plant is within the blade of the leaf, where it takes its food supply from the living cells of the green leaf. The mycelium sends up stalks through the stomata of the leaf; it is these that hold the sporangia, filled witl myriads of yellow-brown spores. The spores produced in the summer time are thin-walled and easily blown by the wind; wherever they alight on a wheat plant, there they germinate to form another mass of hyphæ within the leaf. These parasites again produce more of the uredo-

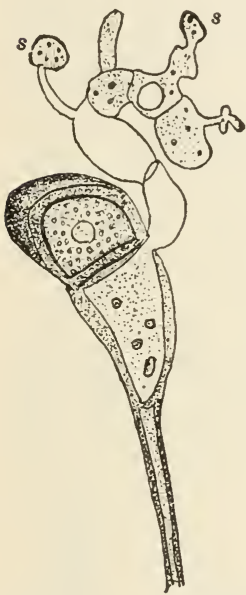

Teleutospore germinating and forming sporidia, $s, s$. (From Coulter, Plant Structures.) spores, as the summer spores are called. In the early fall the rust, instead of forming thin-walled spores, produces a curious, double, thickwalled spore in its place. This spore, known as a teleutospore, remains dormant during the winter. In the early spring it germinates wherever it happens to have fallen, as it is not at this stage a true parasite. Upon germination it forms a threadlike body. On this body are formed tiny sporelike structures which have been named sporidia. The sporidia germinate only upon the barberry, where they form a mycelium within the leaf.

This mycelium soon forms little masses of spore cases which, because of their appearance, are called cluster cups. The cluster cups may easily be seen with the naked eye on the surface of the infected barberry leaf. Spores from the cluster cups are carried by the wind to a neighboring wheat field, and there germinate upon the blade of wheat, to form the parasite we have already called wheat rust. In some cases the cluster-cup stage appears to be left out of the life cycle, the sporidia germinating directly upon the wheat plants.

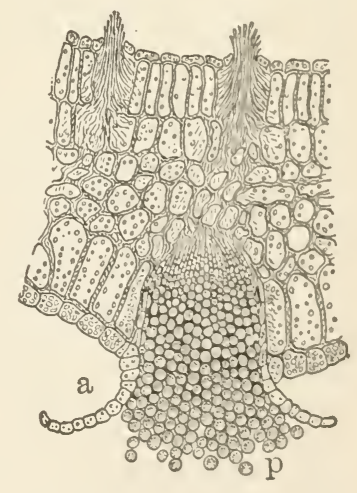

Section through a cluster cup of wheat rust in the leaf of barberry.

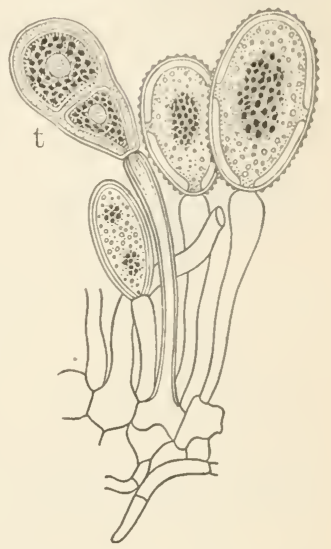

Uredospores and a teleutospore $(t)$ of wheat rust. De Bary. 
Mildews. - Another group of fungi that are of considerable economic importance is made up of the sac fungi. Such fungi are commonly called mildews. Some of the most easily obtained specimens come from the lilac, rose, or willow. These fungi do not penetrate the host plant to any depth,

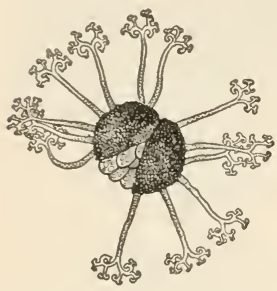

A perithecium broken open to show the asci. but cover the leaves of the host with the whitish threads of the mycelium. Hence they may be killed by means of applications of some fungus-killing fluid, as Bordeaux mixture. ${ }^{1}$ They obtain their food from the outer layer of cells in the leaf of the host. These mildews produce a spore-bearing portion known as a perithecium. When the perithecium becomes broken, a number of little sacs containing the spores are released. Each sac is called an ascus, and the spores contained within are ascospores. Each ascospore may germinate to form a new plant. Among other useful plants preyed upon by this group of fungi are the plum, cherry, and peach trees. (The diseases known as black knot and peach curl are thus caused.) Other sac fungi are the morels and truffles, the downy mildews, blue and green molds, and many other forms. One important member of this group is the tiny parasite found on rye and other grains, which gives us the drug ergot.

YEAST.-Although as a group the fungi are harmful to man in the economic sense, nevertheless there are some fungi that stand in a decidedly helpful relationship to the human race. Chief of these are the yeast plants. Yeasts are found to exist in a wild state in very many parts of the world. They are found on the skins of fruits, in the soil of vineyards and orchards, in cider, beer, and other fluids, while they may exist in a dry state almost anywhere in the air around us. In a cultivated state we find them doing our work as the agents which cause the rising of bread, and the fermentation in beer and other alcoholic fluids.

Size and Shape, Manner of Growth, etc. The common compressed yeast cake contains millions of these tiny plants, easily the smallest we have yet studied. In its simplest form a yeast plant is a single cell. If you shake up a bit of a compressed yeast cake in a mixture of sugar and water and then examine a drop of the milky fluid after twentyfour hours have elapsed, it will be found to contain

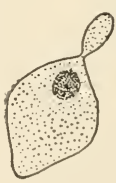

$A$

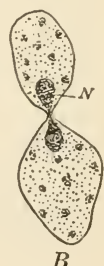

B

$A$, yeast plant bud just forming; $B$, bud almost ready to leave parent cell. Note the nucleus $(N)$ dividing into two parts. After Sedgwick and Wilson. vast numbers of yeast plants. The shape of such a plant is ovoid. Notice the granular appearance of the protoplasm of which it is formed. Look

\footnotetext{
${ }^{1}$ See Goff and Mayne, First P.inciples of Agriculture, page 59, for formula of Bordeaux mixture.
} 
for tiny clear areas in the cells; these are vacuoles, or spaces filled with fluid. The nucleus is hard to find in an unstained yeast cell; it can, however, be found in specimens which have been prepared by staining the previously killed cells with iron-hæmatoxylin. (Sce Lee, Vade Mecum, or Sedgwick and Wilson, General Biology.) Yeast cells grow rapidly and reproduce by a process of budding. Look for cells with smaller cells attached. Is there ever more than one cell budded off from a parent?

Draw several cells, showing buds as they appear to you under the high power of the compound microseope.

Spore Formation. - Most yeast plants seem to produce spores at some time during their existence. The spores are formed within a yeast cell, as many as four being produced within a single cell. These spores, under proper conditions, will germinate and form new plants. The yeast forms ascospores.

Conditions Favorable to Growth of Yeast.- Under certain conditions yeast, when added to dough, will cause it to rise. We also know that yeast has something to do with the process we eall fermentation. The following experiments will throw some light on these points:-

Label three pint fruit jars A, B, and C. Add one fourth of a compressed yeast cake to two cups of water containing two tablespoonfuls of molasses or sugar. Stir well and divide into three equal parts. Place one portion in each jar. Put one jar in the ice box on the ice, and one over the kitchen stove or near a radiator; boil the third jar by immersing it in a dish of boiling water, and place it next to B. Lay the covers on the jars. After twenty-four hours, look to see if any bubbles have made their appearance in any of the jars. Notice the color, taste, and odor of each jar. Lower a lighted match in a jar in which bubbles are rising. What gas is formed by the growth of yeast?

This experiment shows that yeast plants, like most other forms of plant life, will not grow in a cold atmosphere, and that they may be killed by too much heat. They grow freely in solutions containing sugar. Experiments may be performed to test whether they will grow in distilled water (which contains no organic matter), and as to their growth in pond water. They thrive in a solution containing compounds of nitrogen, named after its discoverer, Pasteur's solution. ${ }^{1}$ Yeasts are saprophytes. In order to grow, they must be supplied with food materials that will build up protoplasm as well as release energy.

Fermentation a Chemical Process. - In this process of grow th the sugar of the solution in which they live is broken up by a digestive ferment or

1. The formula is :--

838 c.c.
10 c.c.
150 c.c.
2 grams
2 grams
2 grams

distilled water. ammonium tartrate. saturated solution of grape sugar. magnesium sulphate. calcium phosphate. potassium phosphate. 
enzyme into carbon dioxide and alcohol. This may be expressed by the following chemical formula: $\mathrm{C}_{6} \mathrm{H}_{12} \mathrm{O}_{6}=2\left(\mathrm{C}_{2} \mathrm{H}_{6} \mathrm{O}\right)+2\left(\mathrm{CO}_{2}\right)$. This means that the sugar forms alcohol and earbon dioxide. This process, which we call fermentation, is of the greatest importance in the brewing industry.

Beer MaKing. - Brewers' yeasts are cultivated with the greatest eare; for the different flavors of beer seem to depend largely upon the condition of the yeast plants. Beer is made in the following manner: Sprouted barley, called malt, in which the stareh of the grain has been changed to grape sugar by a process of digestion, is killed by drying in a hot kiln. Then hops are added to give the mixture a bitter taste. Now eomes the addition of the yeast plants, which multiply rapidly under the favorable conditions of food and heat. Fermentation results on a large scale from the breaking down of the grape sugar, the alcohol remaining in the fluid, the carbon dioxide passing off into the air. The process is stopped at the right instant, and the beer is stored either in bottles or casks.

In bread making the rapid growth of the yeast plants is facilitated by placing the pan containing the mixture in a warm place over night. Fermentation results fiom the rapid growth of the yeast in the dough; the earbon dioxide remains as the bubbles so familiar to the bread maker, making the bread light and more digestible; the alcohol produced is evaporated during the process of baking.

Bacteria. - The bacteria are found in the earth, the water, and the air. "Anywhere but not everywhere," as one writer has put it. They swarm in stale milk, in impure water, and in any decaying material.

These tiny plants, "man's invisible friencls and foes," are of such importance to mankind that thousands of scientists devote their whole lives to their study, and a science called bacteriology has been named after them.

Size and Form. - In size, bacteria are the most minute plants known. A bacterium of average size is about $\frac{1}{5000}$ of an inch in length, and perhaps $\frac{1}{250} \overline{0}$ of an inch in diameter. Some species are much larger, others smaller. A common spherical form is $\frac{1}{5000}$ of an inch in diameter. It will mean more to us, perhaps, if we remember that several millinns of bacteria of average size may be placed within the area formed in this letter $o$. Three well-defined forms of bacteria are recognized: a spherical form (alled a coccus, a rod-shaped bacterium, the bacillus, and a spiral form, the spirillum. Most bacteria are capable of movement 
when living in a fluid. Such movement, seems to be caused by tiny lashlike threads of protoplasm called cilia. The cilia project from the body, and by a rapid movement cause locomotion to take place. Bacteria reproduce with almost incredible rapidity. It is estimated that a single bacterium, by a process of division called fission, will give rise to over $16,700,000$ others in twentyfour hours. Dr. Prudden has estimated that such a bacterium, if allowed to develop unchecked for five days, would fill all the oceans of this earth to a depth of one mile. Under unfavorable conditions they stop dividing and form spores, in which state they remain until conditions of temperature and moisture are such that growth may begin again.

Method of Study. - Bacteria can be studied only with the aid of the microscope. In order to get, a number of bacteria of a given kind to study, it becomes necessary to grow them in what is known as a pure culture. This is done by first growing the bacteria in some medium such as beef broth, gelatin, or on potato. ${ }^{1}$ The material used as a growth medium is at first sterilized by heating to such a temperature as to kill all life that

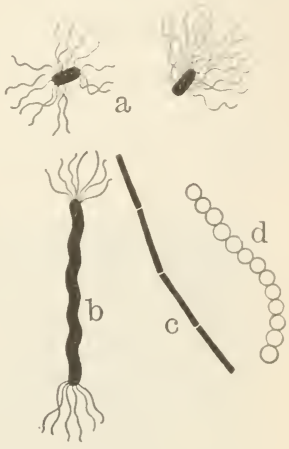

Bacteria, highly magnified; $a$, the germ of typhoid fever, stained to show the cilia; $b$, a spiral ciliated form; $c$, a rodshaped form, in chains; $d$, a spherical form. $a, b$, from Engler and Prantl.

might be there. Now expose the material to the air of the schoolroom in a shallow dish (known as a Petri dish) or a test tube in the case of beef broth, for say five minutes. Then cover the dish or tube and put it away in a warm place for a day or two. Little spots appear on the surface of the gelatin or potato, or the beef broth becomes cloudy.

Pure Culture. - The spots are colonies composed of millions of bacteria. If now we wish to study one given form, it becomes nccessary to isolate them from the others on the plate. This is done by the following process: A platinum needle is first passed through a flame to sterilize it, that is, to kill all living things that may be on the necdle point. Then the needle is dipped in a colony containing the bacteria we wish to study. This mass of bacteria is quickly transferred to another sterilized plate, and this plate is immediately covered to prevent any other forms of bacteria from cntering. When we have succeeded in isolating the kind of bacteria in a given dish, we are said to have a pure culture.

Fermentation. -- Bacteria play an important part in the process of fermentation. For example, bacteria act upon the

1 For directions for making a. culture medium, see Prahody, Manual of Physiology. 
alcohol in cider, and by a chemical process change the alcohol to vinegar. Others, called the lactic acid bacteria, bring about the souring of milk by acting on the sugar found in the milk. Thus they aid in butter and cheese making. Others give the flavor to cheese or butter. Some are of great economic importance, as we have already seen, in their relation to the roots of some plants, where they fix nitrogen in such a form that it can be used by the plants as food. Bacteria seem to prefer to feed upon substances that contain nitrogen, this element being necessary to

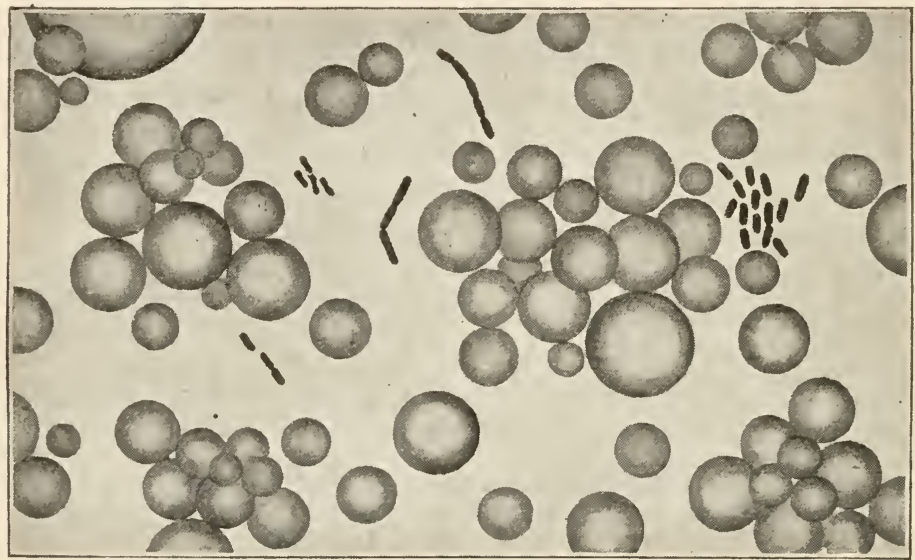

Microscopic appearance of ordinary milk showing fat globules and bacteria. The cluster of bacteria on left side are lactic-acid-forming germs. (H. L. Russell, Wis. Bul. No. 62.)

form protoplasm. They are found in great numbers upon all nitrogenous foods, as milk, meats, fish, etc. Feeding upon such substances, they decompose them and cause decay to take place.

Typhoid. - Such bacteria as are parasitic in the human body may cause disease. Sometimes the harm is done by certain poisons called ptomaines, which are formed by the bacteria during the process of growth. The disease we call typhoid fever is thus caused. The bacterium causing the fever is taken into the body through the mouth in water, milk, or other food. Once in the intestine the bacteria multiply very rapidly, producing a ptomaine. This poison gets into the blood and is passed to all parts of the 
body, causing the symptoms of the disease we call typhoid. To prevent the spread of this disease, we must guard our water and milk supply most carefully, in order to prevent any of the bacteria which cause the disease from gaining entrance into the body.

Tetanus or Blood Poisoning. - The bacterium causing blood poisoning is another ptomaine-forming germ. It lives in the earth and enters the body by means of cuts or bruises. It seems to thrive best in less oxygen than is found in the air. It is therefore important not to close up with court plaster wounds in which such germs may have found lodgment. It, with typhoid, is responsible for four times as many deaths as bullets and shells in time of battle. The wonderfully small death rate of the Japanese army in their war with Russia was due to the fact that the Japanese soldiers always boiled their drinking water before using it, and their surgeons always dressed all wounds on the battle field, using poweriul antiseptics in order to kill any bacteria that might find lodgment in the exposed wounds.

Tuberculosis. - Another bacterium that is responsible for nearly one seventh of all the yearly deaths in the world is the so-called $t u$ bercle bacillus. It causes the disease called tuberculosis. This disease is not caused by a ptomaine, but by the growth of the bacteria in the lungs, and other parts of the body, where they eat away the tissues of the lungs and form little masses of new tissue, called tubercles. Tuberculosis may be contracted by taking the bacteria into the throat or lungs in the air we breathe. Although there are always some of the germs in the air of an ordinary city street, and though we doubtless take some of these germs into our bodies every day, yet the bacteria seem able to gain a foothold only under certain conditions. It is only when the tissues are in a worn-out condition, when we are "run down," as we say, that the parasite may obtain a foothold in the lungs. Even if the disease gets a foothold, it is quite possible to cure it if it is taken in time. The germ of tuberculosis is killed by exposure to bright sunlight and fresh air. Thus the course of the disease may be arrested, and a permanent cure brought about, by a life in the open air, the patient sleeping out of doors, taking plenty of nourishing food and moderate exercise. 
Many other diseases have been traced to bacteria. Diphtheria and asiatic cholera are the best known. Grippe, pneumonia, whooping cough, and colds are believed to be caused by bacteria Other diseases, as malaria, yellow fever, and probably smallpox, scarlet fever, and measles, are due to the presence in the blood of a one-celled animal parasite.

Methods of Fighting Germ Diseases. - As we have seen, diseases produced by bacteria may be caused by the bacteria being transferred from one person directly to another, or the disease may obtain a foothold in the body in food, or water, by breathing in the germs in the air, or by taking them into the blood through a cut or wound.

In the prevention of germ diseases we must fight the germ by attacking the parasites directly with poisons that will kill them (such poisons are called germicides or disinfectants), and we must strive to make the persons coming in contact with the disease unlikely to take the disease. This insusceptibility or immunity may be either natural or acquired. Immunity may be acquired by means of such treatment as the anti-toxin treatment for diphtheria. This treatment, as the name denotes, is a method of neutralizing the poison (toxin) caused by the bacteria in the system. It was discovered a few years ago that the serum of the blood of

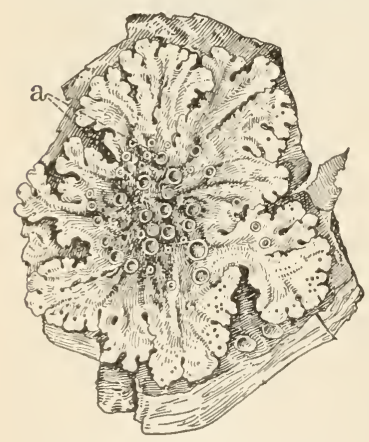

A lichen (Physcia stellaris); $a$, spore-bearing organs. an animal immune to diphtheria is capable of neutralizing the poison produced by the diphtheria-causing bacteria. Horses are rendered immune by giving them large doses of the diphtheria toxin or poison. The serum of the blood of these horses is then used to inoculate the patient suffering from or exposed to diphtheria, and thus the disease is checked or prevented altogether.

Lichens. - Lichens may be found incrusting rocks, tree trunks, or other exposed localities. They have in general a grayish color, although they may be red, yellow, or black. The form of the body is usually that of a thallus, being 
flat and irregular. One of the commonest of the lichens (Physcia), found on stone walls or tree trunks, produces cup-shaped bodies from the thallus, in which spores are formed. Most lichens have definite spore-producing structures which protrude from the upper surface of the thallus. A lichen is of interest to us chiefly because it shows a partnership to exist between certain green plants, called the algæ, and the fungi. A lichen is thus composed of two plants, one at least of which may live alone, but which have
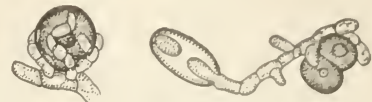

Stages in the formation of the lichen thallus, showing the relation of the threadlike fungus to the green cells of the alga. After Bornet. formed a partnership for life, and have divided the duties of such life bctween them. In most lichens the alga, a green plant, forms starch and nourishes the fungus. The fungus, in turn, produces spores, by means of which new lichens are started in life. The body of the lichen is usually protected by the fungus, which is stronger in structure than the green part of the combination. This process of living together for mutual advantage is called symbiosis. Some animals thus combine with plants; for example, the tiny animal known as the hydra with certain of the one-celled algie Animals also frequently live in this relation to each other.

Algæ. - The algæ are a very diverse collection of plants, containing some of the smallest and simplest as well as some of the

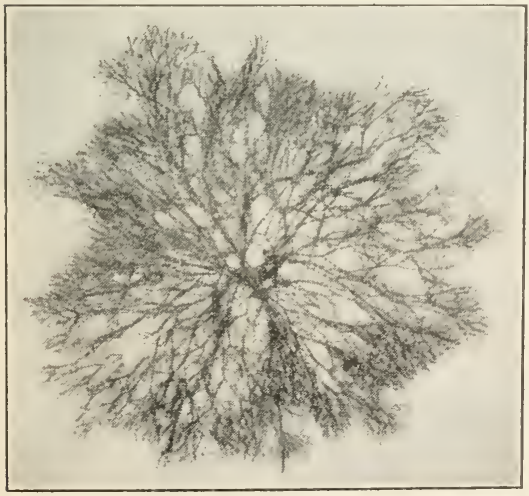

A red seaweed, showing a finely dividel thallus body. largest plants in the world. The tiny one-celled Pleurococcus is an example of the former; the giant kelps of the Pacific Ocean, which attain a length of over one thousand feet, of the latter. The body of the algæ is a thallus, which may be platelike, circular, ribbon-formed, threadlike, or filamentous. It may even be composed of a single cell. A large number of the algx inhabit the water, either fresh or salt. In color they vary from green through the shades of blue-green to yellow, brown, and red. These colors are best seen in the seaweeds, all of which, however, contain chlorophyll. In the red 
and brown seaweeds the chlorophyll is concealed by other coloring material in the plant body. In the olive-brown fucus (the common rockweed) it is easy to prove the presence of chlorophyll by cutting open the bladders which are found in the plant body. Chlorophyll may also be extracted by placing the plant in alcohol. The red seaweeds are among the most beautiful and delicate of

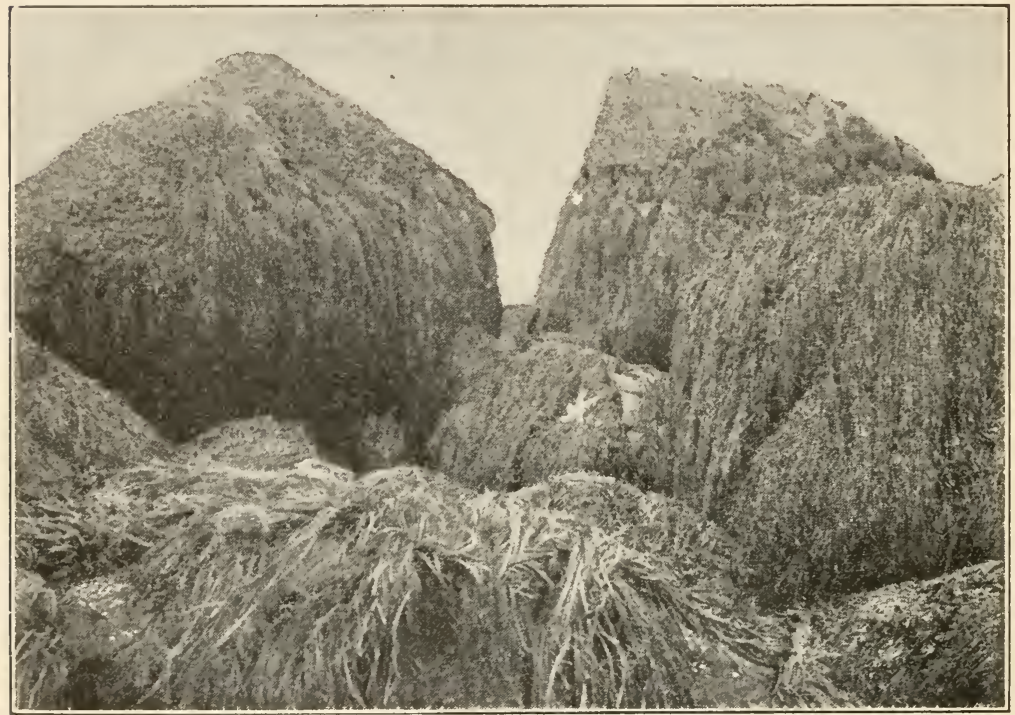

Rockweed, a brown alga, showing the distribution on rocks below highwater mark.

all plants. They may be mounted under water upon cardboard and then studied after drying. ${ }^{1}$

Green Algæ. - The collection of plants known as the green algæ are of more interest to us because of their distribution in the fresh waters of New York state, and also because of their economic importance as a supply of oxygen for fish and other animals in the waters of our inland lakes and rivers. Our attention is called to them in an unpleasant way at times, when, after multiplying very rapidly during the hot summer, they die rapidly

1 For the study of a seaweed, see Hunter and Valentine, Manual, page 81. For reference reading, see Bergen and Davis, Principles of Botany, page 172 
and leave their remains in our water supply. Much of the unpleasant taste and odor of drinking water comes from this cause.

Pond Scum (Spirogyra). - This alga is well known to every boy or girl who has ever seen a small pond or sluggish stream. It grows as a slimy mass of green threads or filaments. Frequently it is so plentiful as almost to cover the surface of the water, buoyed up by little bubbles of a gas which seems to arise from the body of the plant. If we place some of the Spirogyra in a deep dish of water, taking care to put the dish in the sun,

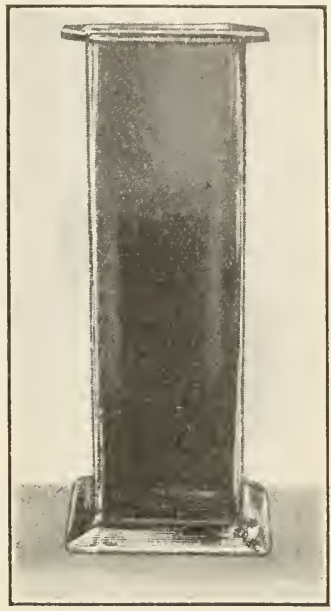

A

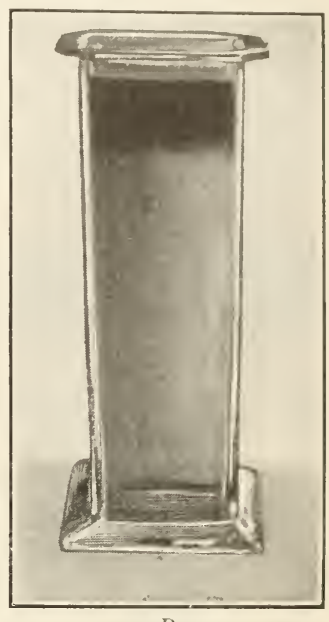

B

$A$, jar of water containing pond scum; $B$, same jar after an hour in the sunlight.

the green plant will be found to give off enough gas to cause the plants to float near the surface. If we collect some of this gas, we can easily prove that it is oxygen. The person who sees a pond with a covering of slimy pond scum, knowing this fact, should no longer feel that the pond is a menace to health, unless, indeed, it is a place where mosquitoes live and breed.

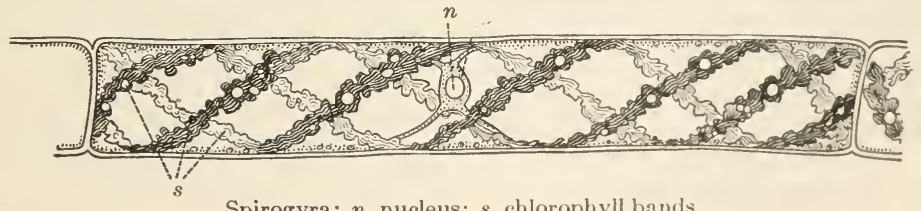

Spirogyra: $n$, nucleus; $s$, chlorophyll bands.

Suggestions for Observational Work. ${ }^{1}$ - Under the low power of the microscope, try to make out the length of one of the filaments of Spirogyra. Do

${ }^{1}$ For fuller directions, see Hunter and Valentine, Manual, page 79. 
the filaments branch? Are they fastened at one end? A filament is composed of a number of cells placed end to end. Notice a single cell rather carefully with the low power first, and then under the high power. The following structures can be made out by the careful observer:-

(a) The cell wall.

(b) The chlorophyll bands. Determine if there is one or more in a single cell. The number varies in different species. wall.

(c) The colorless protoplasm; this is usually best seen close to the cell

(d) The nucleus, suspended in the middle of the cell by strands of protoplasm.

Draw a single cell as you see it under the high power of the microscope, and label each part mentioned above.

Pond scum may grow by a simple division of the cells in a filament. Another method of reproduction is seen in this plant. The cells of two adjoining filaments may push out tubes which

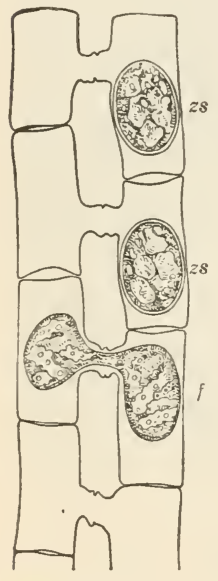

Conjugation of Spirogyra; $z s$, zygospore; $t$, fusion in progress. meet, thus connecting the cells of two different filaments with each other. Meantime the protoplasm of the cells thus joined condenses into two tiny spheres; the bands of chlorophyll are broken down, and ultimately the contents of one of the cells passes over tha tube and mingles with the cell of the neighboring filament, with which it was previously connected by the tube formed from the cell walls. As in black mold, the result of this process of fusion is a thick-walled resting cell which we call a zygospore. This cell can withstand considerable extremes of heat and cold, and may be dried to such an extent that it is found in dust or in the air. Under favorable conditions, this spore will germinate and produce a filament.

Conjugation. - The process in which two cells of equal size unite to form a single cell is called conjugation. It is believed to be a sexual process which corresponds in a way to the fertilization in the higher plants. If material is obtainable, draw several stages in the process of conjugation. ${ }^{1}$

1 Material which shows conjugation is not always easy to obtain. Conjugation usually takes place most freely in the fall of the year. When material is obtained it may be preserved in a 4 per cent solution of formol. Material killed in a 5 per cent solution of chromic acid and then preserved in 70 per cent alcohol or 4 per cent formol shows the details of cellular structure. 
Pleurococcus. - The simplest of all green plants are the one-celled algæ. One of the commonest forms is the plant called Pleurococcus, which is found in vast numbers on the bark of trees, on moist fence posts, on the shaded parts of buildings and other moist localities. ${ }^{1}$

If we gently scrape some of the green material from a bit of bark containing these plants into a shallow dish containing water, and after a few minutes transfer some of the material to a glass slide and examine it under the high power of the microscope, something of the structure of the tiny plants can be made out.

Plant Body. - The plant body of the Pleurococcus is found to ernsist of a single very small green cell. This is surrounded by a rather prominent wall of cellulose or woody material. Notice the protoplasmic contents of the cell. Is the chlorophyll arranged in a definite manner as in the cell of Spirogyra? Notice that many of the cells are joined together to form colonies. How many cells do you find in such a colony? Do the number of cells thus grouped together differ? Draw several colonies in different stages. In such a simple plant as the Pleurococcus we find no other method of .eproduction plainly seen except that by simple division. This is an asexual method known as vegetative reproduction.
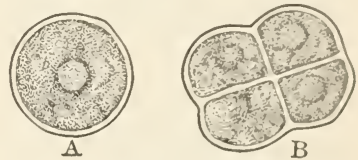

Pleurococcus: $A$, single cell; $B$ colony of four cells formed by division of the original cell, $A$.

Formation of Zoöspores. - Under some circumstances, however, certain species of Pleurococcus are known to give rise to a cell which is capable of movement in water by means of two whiplash threads of protoplasm which protrude from one end of the cell. This motile cell is called a zoöspore (animal spore). It does resemble a very simple animal at this stage of its existence. The spore thus formed is an asexual spore which may swim away from the parent plant and found colonies in a new locality.

Diatoms. - These plants are found in vast numbers living on the mud or stones at the bottom of small streams. The plant body is inclosed in a cell wall composed largely of silica or glass. Many of the diatoms are free-swimming. They compose a large percentage of the living organisms found near the ocean's surface. The plant body is inclosed by cell walls composed of two valves which fit into each other like a box and its cover. The cell color is brown.

Diatoms are found as fossils, and

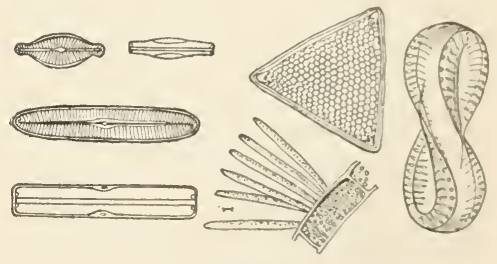

Diatoms. make up a large proportion of many rocks. The silicious skeletons in such rocks are made of commercial importance, the rock forming a basis for polishing powders.

1 See Hunter and Valentine, Manual, page 77. HUNTER'S BIOL. - 12 


\section{Reference Books \\ FOR THE PUPIL}

Andrews, Botany All the Year Round, Chap. X. American Book Company.

Atkinson, Lessons in Botany, Chaps. III, XIX-XXIX.

Coulter, Plant Studies, XVII, XXIV. D. Appleton and Company.

Conn, Bacteria, Yeasts, and Molds in the Home. Ginn and Company.

How to grow Mushrooms. Bul. No. 53, U.S. Department of Agriculture.

Mushroom Poisoning. Cir. No. 13, U.S. Department of Agriculture.

Parsons, How to know the Ferns. Charles Scribner's Sons.

Prudden, Dust and its Dangers. G. P. Putnam's Sons.

Prudden, Story of the Bacteria. G. P. Putnam's Sons.

\section{FOR THE TEACHER}

Goodale, Physiological Botany. American Book Company.

Leavitt, Outlines of Botany. American Book Company.

Atkinson, Mushrooms, Edible and Poisonous. Andirews and Church.

Bergen and Davis, Foundations of Botany (Cryptogamic portion). Ginn and Company.

De Bary, Comparative Anatomy of Phanerogams and Ferns. Clarendon Press.

De Bary, Comparative Morphology and Biology of the Fungi, Mycetozoa and Bacteria. Clarendon Press.

Marshall, The Mushroom Book. Doubleday, Page and Company.

Sedgwick and Wilson, General Biology. Henry Holt and Company.

Strasburger, Noll, Schenck, and Schimper, A T'ext-book of Botany. The Macmillan Company.

Ward, Timber and Some of its Diseases, Chaps. V, VI, VII, X-XIII. The Macmillan Company.

Year Book, U.S. Department of Agriculture, 1894, 1897, 1900. Bul. No. 16. 


\section{PART II. ZOÖLOGY}

\section{PROTOZOA}

A Hay Infusion. - The smallest and simplest plants studied were composed of a single cell; the simplest animals are likewise composed of but one cell. Place a wisp of hay or straw in a small glass jar nearly full of water, and leave it for a few days in a warm room. Certain changes are seen to take place in the contenis of the jar; the water after a little gets cloudy and darker in color; a scum appears on the surface, which is made up of bacteria. These bacteria evidently aid in the decay which (as the unpleasant odor from the jar testifies) is taking place. Later, small one-celled animals appear; these multiply with wonderful rapidity, so that in some cases the surface of the water seems to be almost white with active one-celled forms of life. If we ask ourselves where these animals come from, we are forced to the conclusion that they must have been in the water, the air, or the hay. Hay is dried grass, which may have been cut in a field near a pool containing these creatures. When these pools dried up, the wind may have scattered some of these little organisms in the dried mud or dust. Some may exist in a dormant state on the hay, the water serving to awaken them to active life. In the water too there may have been some living cells, plant and animal. In the decaying hay and in water are cell food in abundance, both inorganic and organic. Living cells increase rapidly here because of the favorable conditions under which they exist. This combination of living and dead matter just described is called a hay infusion.

Study of the Paramœcium. ${ }^{1}$ - Let us now take up the study of one of these simple one-celled animals found in a hay infusion. For this purpose the compound microscope, slides, coverslips, a little powdered carmine, and an infusion containing paramøcia are necessary. Paramœecia usually appear in a hay infusion in three or four days.

The form of the paramœeium, or slipper animalcule, as it is sometines called, is elongated, oval in outline, and somewhat flattened. Notice that

${ }^{1}$ Hunter and Valentine, Manual, page 163. 
one end is slightly pointed. This is called the anterior end. Do the animals always move at the same rate of speed? Do they ever turn over, or is one side always uppermost? What happens when they meet an obstruction?

The locomotion of the paramœcium is caused by the movement of a number of tiny threads of protoplasm, the cilia. These cilia lash the water

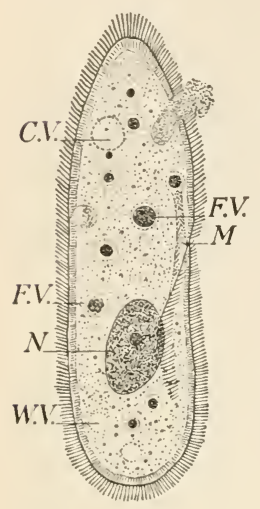

Paramoecium. Greatly magnified. From side. F.V., food vacuole; $C . V$., contractile vacuole; $M$, mouth; $N$, nucleus; IV $V$., water vacuole. (After Sedgwick and Wilson.) like a multitude of tiny oars. If a little powdered carmine is allowed to run under the cover glass, the currents of water caused by the cilia may easily be seen.

Some of the carmine grains may be found later inside the body of the paramœecium. Notice carefully the direction taken by the currents of water bearing the carmine grains (or food particles), and try to locate a funnel-like opening. At the bottom of this funnel is the mouth.

You will notice that the particles of carmine (or food materials) are gathered in to little balls within the almost transparent protoplasm of the cell. These masses of food seem to be inclosed within a little area, containing fluid, called a vacuole. Other vacuoles appear to be clear; these are spaces in which food has been digested. One or two other larger vacuoles may sometimes be found, these are the contractile vacuoles; their purpose seems to be to pass off waste material from the cell body. This is done by pulsation of the vacuole, which ultimately bursts, passing out fluid waste to the outside. Solid wastes are passed out of the cell in somewhat the same manner. The nucleus of the cell is not visiole in living specimens. In a cell that has been stained it has been found to be a double structure, consisting of one large and one small portion.

Make a drawing of a paramœcium, showing as many of the above-mentioned parts as you can find.

Response to Stimuli. - In the paramœeium, as in the one-celled plants, the protoplasm composing the cell can do certain things. Protoplasm responds, in both plants and animals, to certain agencies acting upon it, coming from without; these agencies we call stimuli. Such stimuli may be light, differences of temperature, presence of food, electricity, or other factors of its surroundings. Plant and animal cells may react differently to the same stimuli. In general, however, we know that protoplasm is irritable by some of these factors. To severe stimuli, protoplasm usually responds by contracting, another power which it possesses. We know, too, that plant and animal cells take in food and change the food to protoplasm, that they breathe, that they may waste away and repair themselves, and that new plant and animal cells are reproduced frem the original bit of protoplasm, a single cell. 
Reproduction of Paramerium. - Sometimes a paramocium may be found in the act of dividing by the process known ats fission, to form two

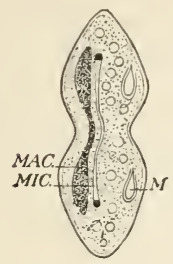

Paramœeium dividing by fission. Greatly magnified. $M$, mouth; $M A C$., macronucleus; $M I C$., micronucleus. (After Sedgwick and Wilson.) new cells, ach of which contains half of the criginal cell. This is a method of asexual reproduction.

Frequently another method of reproduction may be observed. This is called conjugation and somewhat resembles the same process in the thallophytes. Two cells of equal size attach themselves as shown below, complicated changes take place in the nuclei of the two cells thus united, and after a short period of rest the two cells separate as two new individuals. These new animals appear to be rejuvenated as a result of conjugation, and may continue to reproduce asexually by fission for a long period of time. Evenually, however, it seems necessary for the cells to conjugate in order to continue their existence. This stage of conjugation we believe in the plants to be a sexual stage. There seems every reason to believe that it is a like stage in the life history of the paramœeium.

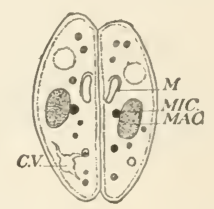

Paramoecium conjugating. Greatly magnified. M, mouth; Mic, micronucleus; Mac., macronucleus; C.V., contractile vacuole. (After Sedgwick and Wilson.)

Amœba. - In order to understand more fully the life of a simple bit of protoplasm, let us take up the study of the amœba, a type of the simplest form of life known, either plant or animal. Amoba may be obtained from the dead leaves in the bottom of small pools, from the same source in fresh-water aquaria, from the roots of duckweed or other small water plants, or from green algæ growing in quiet localities. No sure method of obtaining them can be given. Unlike the plant and animal cells we have examined, the amoba has no fixed form. Viewed under the compound microscope, it has the appearance of an irregular mass of granular protoplasm. Its form is constantly changing as it moves about. This is due to the pushing out of tiny projections of the protoplasm of the cell, called pseudopodia (false feet). The outer layer of protoplasm is not so granular as the inner part; this outer layer is called ectoplasm, the inside being called endoplasm. In the central part of the cell is the nucleus. This 


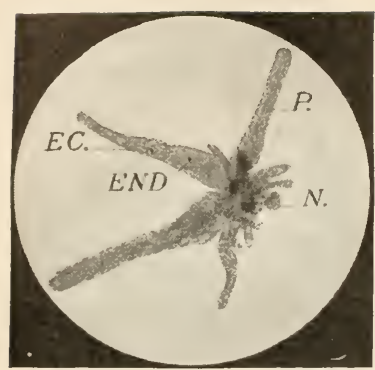

Amoba, with pseudopodia $(P)$ extended; $E C$., ectoplasm; $E N D$., endoplasm; the dark area $(N)$ is the nucleus. From photograph loaned by Prof. G. N. Calkins.

important organ is difficult to see except in cells that have been stained.

The locomotion is accomplished, according to Professor Jennings of the University of Pennsylvania, by a kind of rolling motion, "the upper and lower surfaces constantly interchanging positions." The pseudopodia are pushed forward in the direction which the animal is to go, the rest of the body following.

Although but a single cell, still the amœba appears to be aware of the existence of food when food is near at hand. Food may be taken into the body at any point, the semifluid protoplasm simply rolling over and ingulfing the food material. Within the body, as in the paramocium, the food is inclosed within a fluid space or vacuole. The protoplasm has the power to take out such material as it can use to form new protoplasm or give energy. It will then rid itself of any material that it cannot use. Thus it has the power of selective absorption, a character found in the protoplasm of plants previously studied.

The cell absorbs oxygen from the water by osmosis through its membrane, giving up carbon dioxide in return. Thus the cell breathes.

Waste products formed from the oxidations, which take place in the cell are passed out by means of the contractile vacuole.

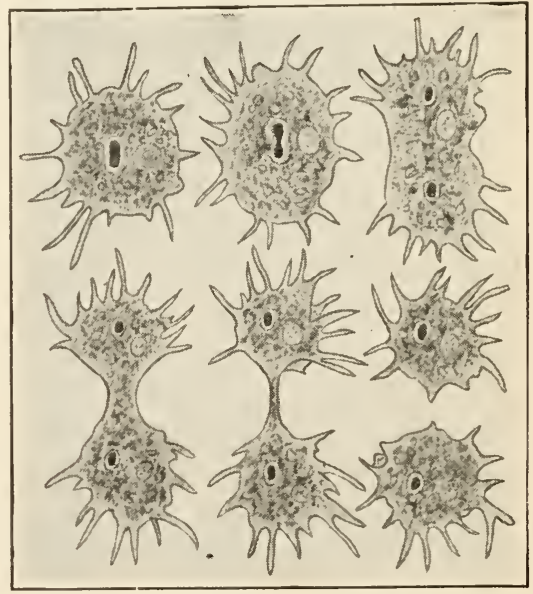

Amoba, showing the changes which take place during division. The dark body in each figure is the nucleus; the transparent circle, the contractile vacuole; the outer, clear portion of the body the ectoplasm; the granular portion, the endoplasm; the granular masses, food vacuoles. Much magnified. 
The amœba, like other one-celled organisms, reproduces by the process of fission. A single cell divides by splitting into two others, each of which resembles the parent cell except that they are of less bulk. When these become the size of the parent amœba, they in turn each divide. This is a kind of asexual reproduction.

When conditions unfavorable for life come, the amoba, like some one-celled plants, encysts itself within a membranous wall. In this condition it may become dried and be blown through the air. Upon return to a favorable environment it begins life again as before.

From the study of the amœbalike organisms which are known to cause malaria and by comparison with the amœbæ which live in our ponds and swamps, it seems likely that every amoba has a complicated life history during which it passes through a sexual stage of existence. Such a stage is seen in the conjugation of the paramœcium.

The Cell as a Unit. - In the daily life of a one-celled animal we find the single cell performing all the activities which we shall later find the many-celled animal is able to perform. In the amœba no definite parts of the cell appear to be set off to perform certain functions; but any part of the cell can take in food, can absorb oxygen, can change the food into protoplasm and excrete the waste material. The single cell is, in fact, an organism.

One-celled Plants and Animals Compared. - In our consideration of the algæ we found that the simplest of all plants consists of a single cell. This cell might be fixed in one

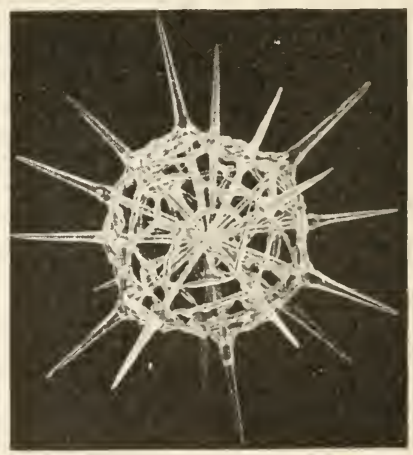

Skeleton of Radiolarian. Highly magnified. From model at American Museum of Natural History. place, as the common form of pleurococcus, or it might move about by means of cilia (as seen in the motile stage of pleurococcus and in many other single cells considered to be plants). While single-celled animals are usually free-swimming, nevertheless some (especially parasitic protozoa) do not move about. So the power 
of movement is not alone sufficient to distinguish plants from animals. Both one-celled plants and animals require oxygen to maintain life, as has been shown by repeated experiments. The protoplasm of which the cell is composed reacts to the same stimuli in both plants and animals. The one distinction that seems to exist between a plant and animal cell is that in the plant cell food is manufactured by means of the chlorophyll contained in it. Animal cells contain no chlorophyll and require organic food.

Habitat of Protozua. - Protozoa are found almost everywhere in shallow water, seemingly never at any great depth. They appear to be attracted near to the surface by light and the supply of oxygen. Every fresh-water lake swarms with them, the ocean contains countless myriads of many different forms.

UsE AS FOOD. - They are so numerous in lakes, rivers, and the ocean as to form the food for many animals higher in the scale of life. Almost all fish that do not take the hook and that travel in "schools," or com. panies, migrating from one place to another, live partly on such food. Mary feed on slightly larger animals, which in turn eat the Protozoa. Such fish have on each side of the mouth attached to the gills a series of small structures looking like tiny rakes. These are called the gill rakers, and are used by the fish to collect tiny organisms out of the water as it passes over the gills. The whale, the largest of all mammals, strains protozoans and other small animals and plants out of the water by means of hanging plates of whalcbone, the slender filaments of which form a sieve from the top to the bottom of the mouth.

Skeleton Building. - Some of the Protozoa build elaborate skeletons. These may be formed outside of the body, being composed of tiny microscopic grains of sand, or other materials. In some forms the skeleton is internal, and may be made of lime which the animals take out of the water. Still other Protozoa construct shells which house them for a time; then, growing larger, they add more chambers to their shell, forming ultimately a covering of great beauty. These shells or skeletons of Protozoa, falling to the sea bottom, cover the ocean floor to a depth of several feet in places.

The Protozoa have also played an important part in rock building. The chalk cliffs of England and other chalk formations are made up to a large extent of the tiny skeletons of Protozoa, called Foraminifera. Some limestone rocks are also composed in large part of such skeletons.

Flagellates.- Some cells show characters which are like both plants and animals. Such are the group of organisms known as flagellates. All flagellates move through the water by means of one or two (rarely more) long threads of protoplasm, or cilia. Some flagellates are provided with 
chlorophyll, while others appear to take in food in the same manner as animal cells. They have a red pigment spot at one end of the cell body. This spot is sensitive to light, hence it has been called an eyespot. A common flagellate is called Euglena. The green color of stagnant pools is due to the presence of enormous numbers of this organism in the water.

Relation of Protozoa to Disease. - The study of the life history and habits of the Protozoa has resulted in the finding of many parasitic forms, and the consequent explanation of some kinds of disease. One parasitic protozoan, like an amœba, is called Plasmodium malarice. It causes the disease known as malaria. Part of its life is passed within the body of a mosquito (the anopheles), into the stomach of which it passes when the mosquito sucks the blood from a person having malaria. Within the body of the mosquito a complicated part of the life history takes place, which results in a stage of the parasite establishing itself within the glands which secrete

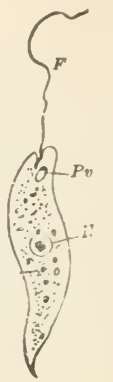

Euglena ; $F$, flagel$\operatorname{lum} ; N$, nucleus; $P v, \quad$ contractile vacuole. the saliva of the mosquito. When the mosquito pierees its human prey a second time, some of the parasites are introduced into the blood along with the saliva. These parasites enter the corpuscles of the blood, inercase rapidly in size, and then form spores. The process of spore formation results

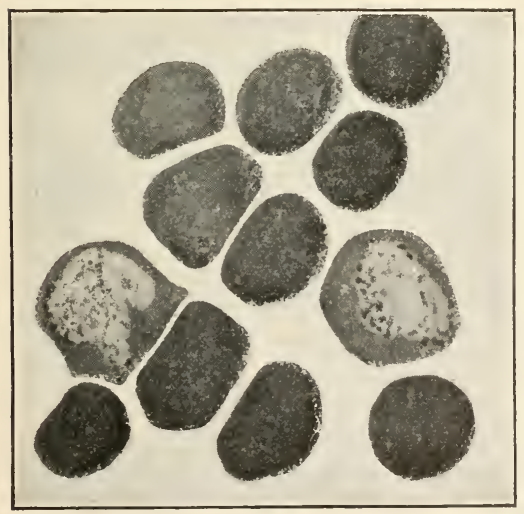

Blood corpuscles of a patient with malarial fever. Two corpuscles contain the parasites. Photograph, greatly enlarged, by Davison. in the chill of malaria. Later, when the spores almost fill the blood corpuscle, it bursts, and the parasites enter the blood. There they release a poison which causes the fever. The spores may again enter the blood corpuseles and in forty-eight or seventy-two hours repeat the process thus described.

Another group of piotozoan parasites are called trypanosomes. One of this family lives in the blood of native African zebras and antelopes; seemingly it does them no harm. But if one of these parasites is twansferred hy the dreaded tsetse fly to one of the domesticated horses or caltle of the eolonist of that region, death of the animal results.

Another fly is believed to carry a specimen of trypanosome to the natives of Central Africa, and to cause "the dreaded and incurable sleepilg sick- 
ness." This disease carries off more tilan fifty thousand natives yearly, and many Europeans have succumbed to it.

\section{Classification of Protozoa}

The following are the principal classes of Protozoa, examples of which we have seen or read about :

Class I. Rhizopoda (Gk. = root footed). Having no fixed form, with pseudopodia.

Either naked as Amoba or building limy (Foraminifera) or glasslike skeletons (Radiolaria).

Class II. Infusoria (in infusions). Usually active ciliated Protozoa. Examples, Paramocium, Vorticella.

Class III. Sporozoa (spore animals). Usually parasitic and non-active. Example, Plasmodium malarie.

\section{Reference Books \\ FOR THE PUPIL}

Davison, Practical Zoülogy, pp. 178-184. American Book Company. Herrick, Text-book in General Zoölogy, Chaps. II, V. American Book Company. Jordan, Kellogg, and Heath. Animal Studies, Chap. III. D. Appleton and Company.

\section{FOR THE TEACHER}

Dodge, General Zoölogy, pages 54-65. American Book Company. Calkins, G. N., The Protozoa. The Macmillan Company.

Linville and Kelly, General Zoölogy, Chap. XXI. Ginn and Company. Parker, T. J., Lessons in Elementary Biology. The Macmillan Company. Sedgwick and Wiison, General Biology. H. Holt and Company.

Wilson, E. B., The Cell in Development and Inheritance. The Macmillan Company. 


\section{METAZOA}

Division of Labor. - If we compare the amœba and the paramœcium, we find the latter a more complex organism than the former. An amœba may take in food through any part of the body; the paramœcium has a definite gullet; the anneba may use any part of the body for locomotion; the paranocium has definite parts of the cell, the cilia, fitted for this work. Since the structure of the paramœcium is more complex, we say that it is a "higher" animal.

As we look higher in the scale of life, we invariably find that certain parts of a plant or animal are set apart to do certain work and only that work. This has resulted in what is called division of labor. Just as in a community of people, there are some men who do rough manual work, others who are skilled workmen, some who are shopkeepers, and still others who are professional men, so among plants and animals, wherever collections of cells live together to form an organism, there is division of labor.

One of the simplest of all colonies is a collection of cells called Pandorina. This is a colony of sixteen cells, whether plant or animal is uncertain, which have become joined by living together in a mass of jellylike material secreted by the cells. They move by means of cilia, and, as a resuit of living together, move faster through the water and thus obtain more food than one alone.

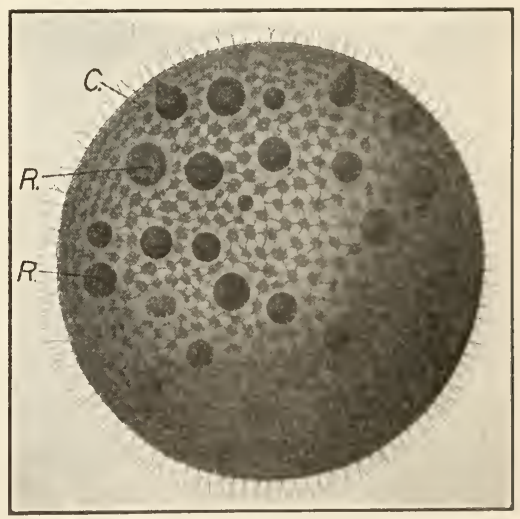

Colony of volvox: $R$, reproductive cells; $C$, ciliated cells. (After Kny.)

Another form where division of labor is begun is scen in the plant (or animal) called Volvox. This is a hollow sphere of cells, the greater number 
of which are ciliated and obtain food for the colony; a few, however, have no cilia. These are the reproductive cells, which later break away, and give rise to new colonies when the old one dies.

Protozoa and Metazoa. - Thus there have come to exist in the animal world two types of life: the Protozoa, or one-celled individuals, and the Metazoa, or many-celled animals.

In the Protozoa the life processes of growth, waste and repair, and reproduction, are carried on by a single cell. In the Metazoa each of these functions is performed by collections of cells. In the Netazoa, too, division of labor becomes increasingly more perfect as we ascend the scale of complexity in form and structure toward the highest type of all, man.

Tissues and Organs. - As we have seen in plants, this results in a large number of collections of cells in the body, each collection alike in structure and performing the same function. Such a collection of cells we call a tissue.

Frequently several tissues have certain functions to perform in conjunction with one another. The arm or leg of the human body performs movement. To do this, several tissues, as muscles, nerves, and bones, must act together. A collection of tissues performing certain work is called an organ.

Tissues in the Human Body. - Every animal body above the protozoan is composed of a certain number of tissues. The cells making up these tissues have certain well-defined characteristics. Let us see what these cells may be, what their structure is, and, in a general way, what function each has in the human body.

(1) Muscle Cells. - A large part of our body is made up of muscle. Muscle cells are elongated in shape, and have great contractile power. In man they may be of two kinds, voluntary (under control of the will) and involuntary.

(2) Epithelial Cells. - Such cells cover the outside of a body or line the inside of the cavities in the body. The shape of such cells varies from flat plates to little cubes or columns. Some epithelial cells bear cilia.

(3) Connective Tissue Cells. - Such cells form the connection between tissues in the body. They are characterized by possessing numerous long processes. They also secrete, as do many 

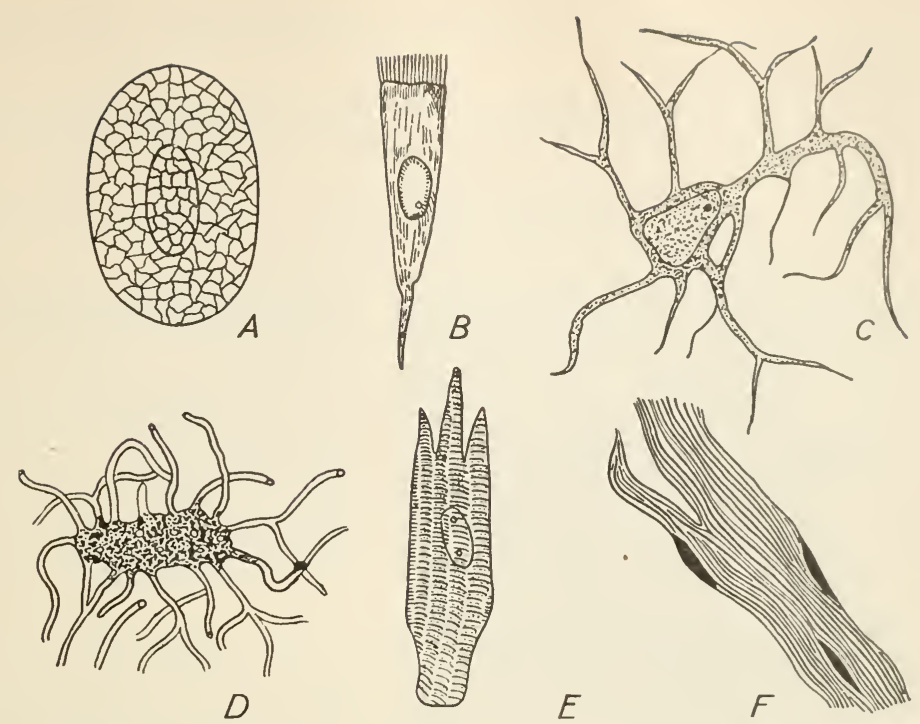

$A$, blood cell; $B$, a cilizted cell; $C$, a nerve cell showing axis eylindei at $C ; D$, bone-forming cell; $E$, a heart muscle cell; $F$, fibrous connective cells.

other cells, a substance like jelly, called intercellular substance. This stands in the same relation to the cells as does mortur to the bricks in a wall.

Several other types of cells might be mentioned, as blood cells, cartilage cells, bone cells, and nerve cells. A glance at the figure shows their great variety of shapes and sizes.

Functions Common to all Animals. - The same functions performed by a single cell are performed by a many-celled animal. But in the Metazoa the various functions of the single cell are taken up by the organs. In a complex organism, like man, the organs and the functions they perform may be briefly given as follows:

(1) The organs of food taking: mouth and parts which place food in the mouth.

(2) The organs of digestion: the food tube and the glands connected with it. The fluids secreted by the latter change the foods from a solid form (usually insoluble) to that of a fluid. such 
fluid may then pass by osmosis through the walls of the food tube into the blood.

(3) The organs of circulation: the tubes through which the blood, bearing its organic foods and oxygen, reaches the tissues of the body.

(4) The organs of respiration: the organs in which the blood receives oxygen and gives up carbon dioxide.

(5) The organs of excretion: such as the kidneys and skin, which pass off nitrogenous waste matter from the body.

(6) The organs of locomotion: muscles and their attachments and connectives, namely, tendons, ligaments, and bones.

(7) The organs of nervous control: the central nervous system, which has control of coördinated movement.

(8) The sense organs: such as sight, hearing, smell, taste, and touch.

Almost all animals have the functions mentioned above. In most, the various organs mentioned are more or less developed, although in the simpler forms of animal life some of the organs mentioned above are either very poorly developed or entirely lacking.

\section{Reference Bonks}

FOR THE PUPIL

Herrick, Text-book in General Zoölogy, Chap. III. American Book Company. Holder, Half Hours with the Lower Animals, Chap. I. American Book Company. French, Animal Activities, Chaps. III, XI. Longmans, Green, and Company.

FOR THE TEACHER

Dodge, General Zoölogy, Chaps. VII-X. American Book Company. Parker, Lessons in Elementary Biology. The Macmillan Company. Sedgwick and Wilson, General Biology. Henry Holt and Company. Verworn, General Physiology. The Macmillan Company. 


\section{SPONGES}

\section{Limy Sponge (Grantia).}

The sponge is the simplest of all Metazoa. One of the commonest forms is Grantia, a tiny urn-shaped object found in salt water attached to piles orstones. It is abundant in Long Island Sound.

For this exercise have small vials containing specimens of Grantia preserved in formol or alcohol. The body is attached at one end. What do you find at the opposite end? Label the hole the osculum. This leads into a cavity called the cloaca. The wall of the

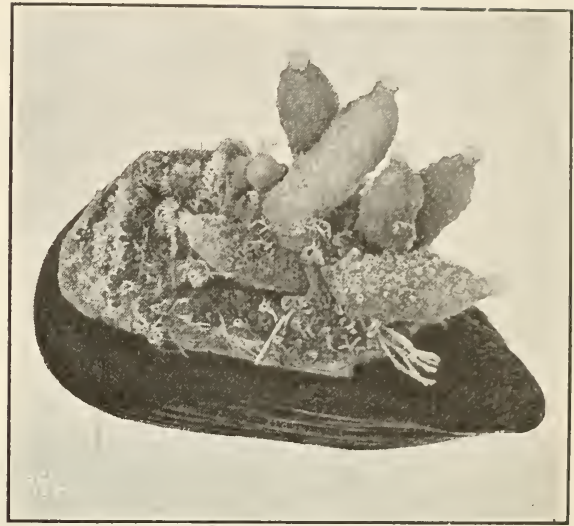

Grantia, a limy sponge, on the shell of a mussel. From photograph loaned by American Museum of Natural History.

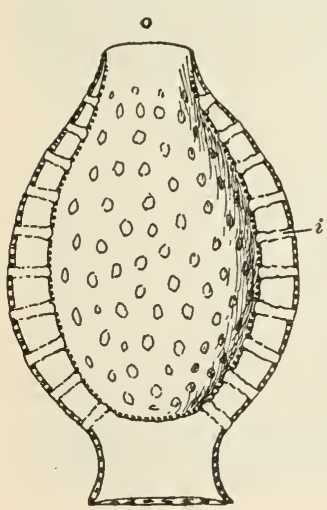

Diagram of a simple sponge; $i$, inhalant opening; $o$, exhalant opening or osculum.

body is pierced by a number of tiny holes or pores which communicate with the cloaca. The shape of the sponge is maintained by a skeleton composed of many tiny pieces or spicules of carbonate of lime. Notice the edge of the osculum. Make a drawing of the Grantia twice natural size, showing all the above structures.'

An examination with the microscope shows the pores of the sponge to be lined with ciliated cells. These, by means of movements of the cilia, set up a current of water toward the cloaca. This current bears food particles, tiny plants and animals, which are seized and digested by the ciliated cells. These cells seemingly pass on the food to the other cells of the body. The middle layer

${ }^{1}$ See Hunter and Valentine, Manual, page 159. 
of the body is composed of structureless material containing cells which secrete lime to form the spicules. Eggs and sperms are also developed in this layer and are set free when ripe to develop in the water.

Spicules may be freed from the living part of the sponge by placing a Grantia in a strong solution of caustic soda for a few minutes. Mount a little of the sediment from the bottom of the dish in water or glycerine. Note the different forms of the spicules. Draw several for your notebook.

Development of the Sponge. - In the case of the sponge, as in most plants and animals, the life history begins with a single cell, the fertilized egg. This cell, as we remember, has been formed by the union of two other cells, a tiny (usually motile) cell, the sperm, and a large cell, the egg. After the egg is fertilized by a sperm cell, it splits into two, four, eight, and sixteen cells; as the number of cells increases, a hollow ball of cells called the blastula is formed (somewhat like the Volvox); later this ball sinks in on one side and a double-walled cup of cells, now called a gastrula, results.

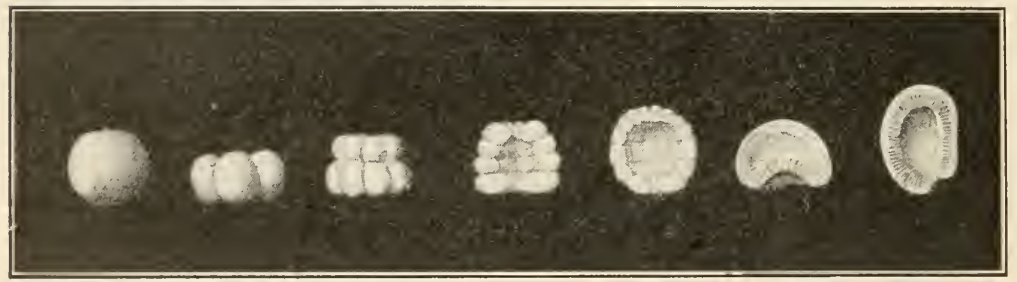

Stages in the segmentation of an egg, showing the formation of the gastrula.

Practically all animals pass through the above stages in their development from the egg, although these stages are often not plain to see because of the presence of food material (yolk) in the egg. The gastrula, which swims by means of cilia, soon settles down, a skeleton is formed, other changes resulting in the formation of pores and osculum take place, and the sponge begins life as an adult. The early stages of life when an animal is unlike the adult are known as larval stages; the animal at this time is called a larva.

The young sponge consists of three layers of cells: those of the outside, developed from the outer layer of the gastrula, are called 
ectoderm; the inner layer, developed from the inner layer of the gastrula, the endoderm. A middle structureless layer, called the mesoglea, is also found. In higher animals this layer (called mesoderm) gives rise to muscles and parts of other internal structures.

Other Sponges. - Sponges may be placed, according to the kind of skeleton they possess, in the following groups:

(1) The limy sponges, in which the skeleton is eomposed of spicules of carbonate of lime. Grantia is an example.

(2) The glassy sponges. Here the skeleton is made of silica or glass. Some of the rarest and most beautiful of all sponges belong in this elass. The Venus's flower basket is the best known.

(3) The horny fiber sponges. These, the sponges of commerce, have the skeleton composed of tough fibers of material somewhat like

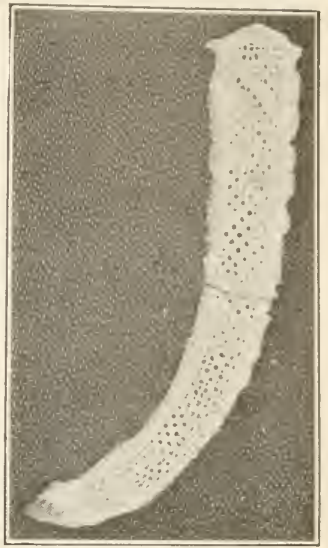

Venus's flower basket: a sponge with a glassy skeleton. that of cow's horn. This fiber is elastic and has the power to absorb water. In a living state, the horny fiber sponge is a dark-colored fleshy mass,

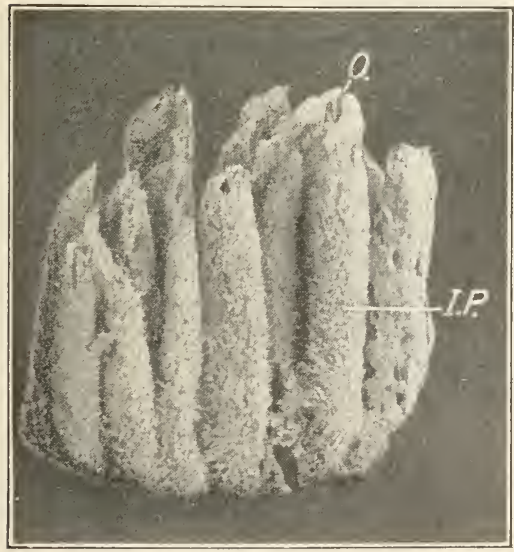

A horny fiber sponge; I.P., the incurrent pores; $O$, osculum. Notice that this sponge is made up of apparently several individuals. One fourth natural size. usually found attached to rocks. The warm waters of the Mediterranean Sea and the West Indie's furnish most of our sponges. The sponges are pulled up from their resting place on the bottom, either by means of long-handled rakes operated by men in boats, or are seeured by divers. They are then spread out on the shore in the sun, and the living tissues allowed to decay; then after treatment consisting of beating, trimming, and bleaching, the bath sponge is ready for the market.

Relation to Environment. Sponges are found in both fresh and salt water. ${ }^{1}$ They are found

1 Only one species of fresh water sponge, Spongilla, is known in this country. 
at all depths and in water of temperatures of varying degrees. The same species of sponge in different localities may assume very different shapes, the immediate surroundings acting upon the animal so as to change its form. They appear to be protected from fish and other animals because of their color and form, their skeleton, and an unpleasant odor.

\section{REFERENCE Books \\ FOR THE PUPIL}

Herrick, Text-book in General Zoölogy, Chap. VI. American Book Company. Holder, Half Hours with the Lower Animals, Chap. II. American Book Company. Jordan, Kellogg, and Heath, Animal Studies, Chap. IV. D. Appleton and Company.

FOR THE TEACHER

Miner, A Guide to the Sponge Alcove. Guide Leaflet, No. 23. American Museur. of Natural History, New York.

Parker and Haswell, Text-book of Zoölogy. The Macmillan Company. 


\section{CCELENTERATES}

The Cœlenterata. - The sponge, as we have seen, is an animal of simple form and of a low order in the scale of life. Another simple animal is the hydra - a type of the group Coelenterata. The group Colenterata includes animals which have a common food tube and body cavity.

Hydra. - The common hydra lives in fresh water. It may be found living on dead leaves, submerged sticks, stones, or weeds in almost any fresh-water pond. In a small fresh-water aquarium, they almost always attach themselves to the side of the jar, where they can be watched and their movements observed. ${ }^{1}$

Notice that when contracted they resemble a little whitish ball of jellylike substance. When undisturbed they elongate into a hollow cylinder attached at one end. A small oval opening is found at the free end, surrounded with a number of little waving arms called tenta-

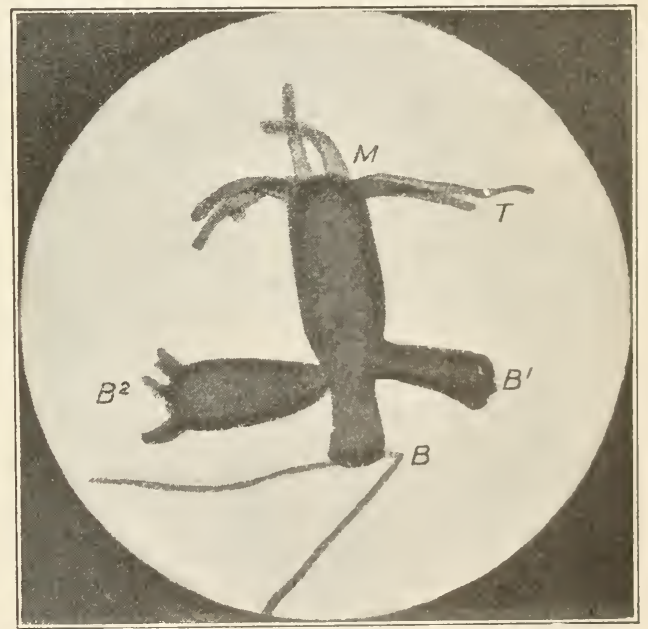

Budding hydra, as seen under the low power of a compound microscope; $B$, attached end; $B^{1}, B^{2}$, buds; $M$, mouth; $T$, tentacles.

cles. Count them to see how many there are. If by chance a small water flea or other crustacean on which the hydra feeds

1 See Hunter and Valentine, Manual, page 151. 
happens near enough to touch one of the tentacles, it is seen to stop suddenly as if paralyzed and is then grasped by the tentacle and carried toward the opening. The hydra is simply a hollow bag, the digestion of the prey taking place within it. The waste products are passed out through the opening between the tentacles where food is taken in.

The hydra may change its position from time to time. The animal bends over, the base is unfastened, and the animal "walks" on its tentacles to a new point of attachment.

Structure of Body Wall. - The body wall of the hydra seen in a cross section is found to be made up of two layers of cells. As in the sponge, the inner layer serves for the purpose of taking in and digesting the food. This layer is the endoderm. The outer layer of cells (called ectoderm) furnishes the animal with weapons of offense and defense. This outer layer is also provided with cells which are sensitive (sense cells). Between the inner and outer layers of cells is a structureless substance called the mesoglea, in which are found musclelike fibers, extensions of the protoplasm of the inner outer layer. Scattered among these musclelike fibers are some of the cells of the outer wall, irregular in shape, which have migrated in from the outer layer. These cells are the nerve cells. They furnish the animal with pathways of sensation and provide a means of coördinated movement.

Organs of Offense and Detense. - If the cells of the outer part of the tentacle are examined under the microscope, we find how
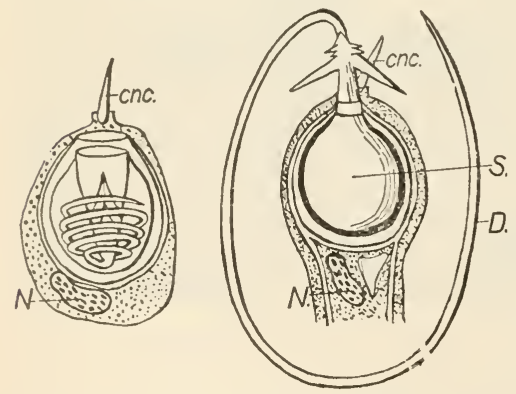

Stinging cells (cnidoblasts); cnc., cnidocil; d., dart; n., nucleus; s., sac. (Drawing, greatly enlarged, after Parker and Hasweli.) the animal is able to paralyze its prey. Here are found many cells, the bodies of which resemble little bags. One end of the cell projects from the outer surface of the tentacle. These cells are the cnidoblasts, or stinging cells. Each cell has in its body a small sac filled with an acid. Attached to this bag and rolled up in it is a long hollow dart, which can be expelled when the cell is "set off." This is done by an animal or substance brushing against a triggerlike projec- 
tion from the cnidoblast. The "explosion" of the cell results in the ejection of the dart and injection of the poisonous acid into the victim. The animal hit by a number of these darts is usually so paralyzed that further resistance is impossible.

Food Taking. - The tentacles then reach out like arms, grasp the food, and bend over with it toward the mouth. Digestion takes place by means of a fluid given out from some of the cells near the mouth. After the food has been partially digested, many of the cells lining the cavity put out pseudopodia, which grasp and ingest the food particles. The tentacles are hollow, and the body cavity extends into them. From this cavity food may be taken up by cells in all parts of the body near where it is to be used. The outer layer of this little animal does not digest the food, but receives some of it already digested from the inner layer. This food passes from cell to cell, as in plants,

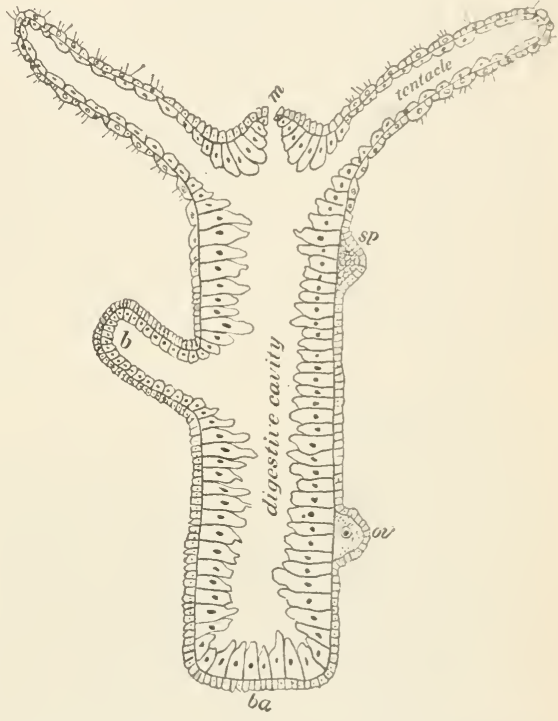

Longitudinal section of a hydra; $b$, bud; $b a$, attached end; $m$, mouth; ov, ovary; $s p$, spermary holding sperm cells.

by osmosis. The oxygen necessary to oxidize the food is passed through the body wall, seemingly at any point, for there are no organs for respiration (breathing).

Division of Labor. - We have here then a step toward a more complex animal, for certain parts of the body here have certain work to perform. The outside for sensation, offense and defense, and for movement and coördination of parts, and the layer forming the interior of the bag for taking in food, digesting it, and distributing it to other parts of the body.

Reproduction. - The hydra reproduces itself either by budding 
or by the production of new animals by means of eggs and sperms, sexually. The bud appears on the body as a little knob, sometimes more than one coming out on the same hydra. At first the bud is part of the parent animal, the body cavity extending into it. After a short time (usually a few days) the young hydra separates from the old one and begins life anew in another place. This is asexual reproduction.

The hydra also reproduces by eggs and sperms. These sperms are collected in little groups which usually appear near the free end of the animal, the egg cells developing near the base of the same hydra. Both eggs and sperms grow from the middle layer of the animal. The sperms when ripe are set free in the water, one of them unites with an egg, which is usually still attached to the body of the hydra, and development begins which results in the growth of a new hydra in a new locality.

Medusa. - The colenterate animals are a very large group and contain many other animals than the hydra. All of this group of

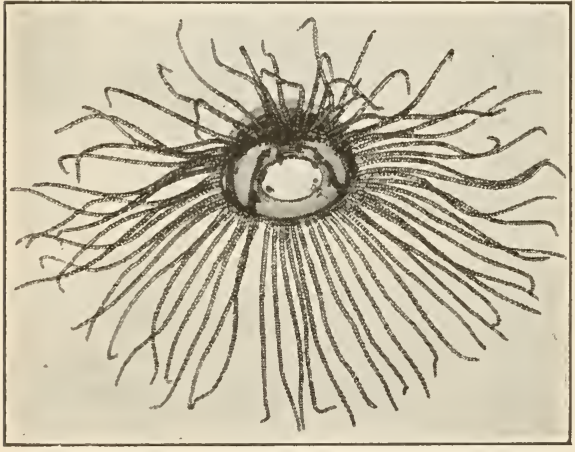

Medusa (Gonionemus murbachii), showing tentacles, mouth, digestive canals, and reproductive bodies. Photographed from the model at the American Museum of Natural History. animals are found in the water, by far the greatest number of forms living in the ocean. Among the most interesting of all the colenterates inhabiting the salt water are the jellyfishes or medusæ.

For the study of the Medusae $^{1}$ use Gonionemus preserved in formol. Why should you call it a "jellyfish"? Notice the shape of the animal, somewhat like an umbrella with a short handle. What do you find hanging from the edge of the umbrella? The tentacles of the medusa are provided with stinging cells. Find and describe the mouth at the end of the handle of the umbrella (manubrium). (N.B. A little carmine or methylene blue dissolved in water may be forced into the mouth of the specimen with a small medicine dropper. This will show clearly the digestive cavity and its canals). Notice the course taken by the canals forming the digestive tract. Hanging just under the radial canals of the digestive tract are found the reproductive bodies, eggs or sperms.

\section{See Hunter and Valentine, Manual, page 156.}


Draw the medusa twice natural size, showing all the above parts neatly labeled.

Development. - The egg of the medusa after fertilization undergoes a number of changes. First the egg splits in two, then four, eight, and ultimately a mass of cells. This process is known as segmentation. These cells form a hollow ball of cells and swim through the water by means of cilia. Ultimately this little animal settles down on one end and becomes fixed to a rock, seaweed, or pile. The free end becomes indented in the same manner as a hollow rubber ball may be pushed in on one side. This indented side becomes a mouth, tentacles develop around the orifice, and we have an animal that looks very much like the hydra. This animal, now known as a hydroid polyp, buds rapidly and soon forms a colony of little polyps, each of which is connected with its neighbor by a hollow food tube. The hydroid polyp differs from its fresh-water cousin, the hydra, by usually possessing a tough covering which is not alive.

Hydroid Colony (Pennaria). ${ }^{1}$ - (Material put up in formol may be handed out to the class in small vials). In the portion of the colony you have, where are the polyps located? Examine a single polyp and make out all you can regarding $(a)$ its general form, $(b)$ the position of tentacles, $(c)$ the position of the mouth. The buds which form the free-swimming medusæ are frequently found budding out of the wall of the polyp. Can you describe them?

Demonstration. - Stained polyps and part of the branch, using the compound microscope. Draw part of a colony four times natural size. Label all the points mentioned above.

Alternation of Generations in Cœlenterates. - The lives of a hydroid and a medusa are seen thus to be intimately connected with each other. A hydroid colony produces new polyps by budding. This we know is an asexual method of reproduction. There come from this hydroid

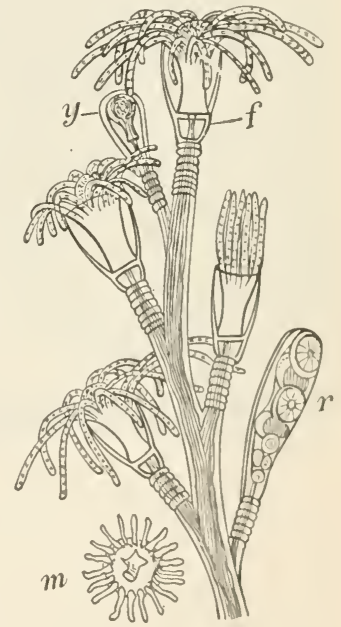

A hydroid colony of six polyps; $f$, feeding polyp; $r$, reproductive polyp; $m$, a medusa; $y$, young polyp. colony, however, little buds which give rise to medusæ. These 
medusæ produce eggs and sperms. Their reproduction is sexual, as was the reproduction by means of eggs and sperms from the prothallus of the fern. So we have in animals, as well as in plants, an alternation of generations.

Sea Anemone. - Those who have visited our New England coast are familiar with another cœlenterate called the sea anemone. This animal gets its name from the fact that, seen in a little rocky pool along the shore, it looks like a beautiful flower of a golden yellow or red color. The body of the sea anemone is like the hydra, a column attached at one end. The

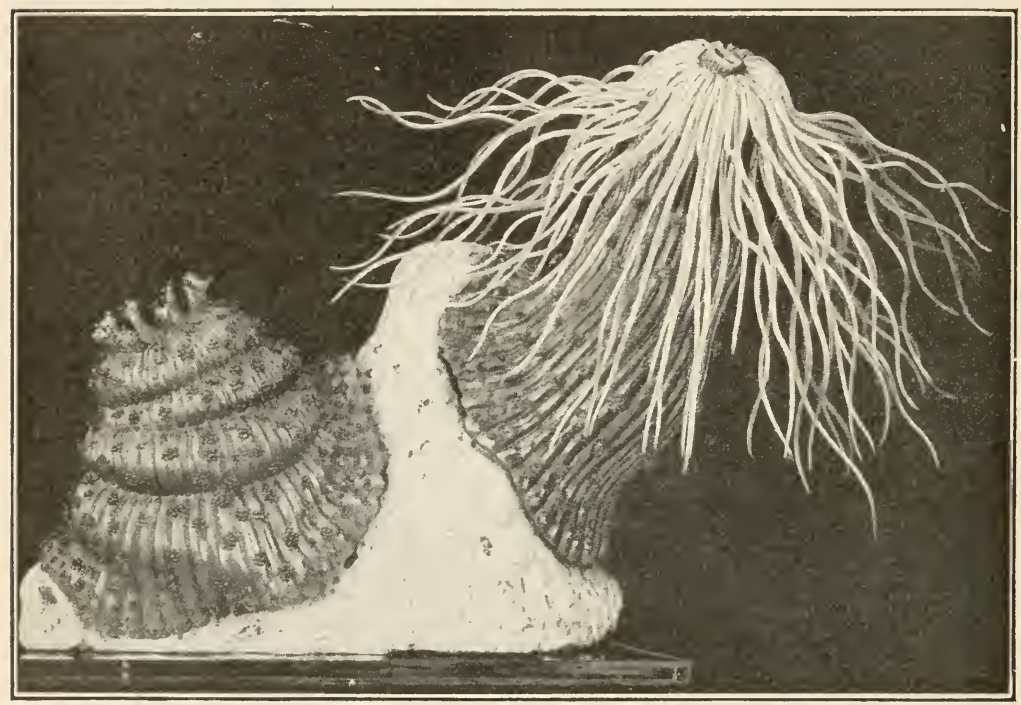

Sea anemone. About natural size. The right-hand specimen is expanded. Note the mouth surrounded by the tentacles. The left-hand specimen is contracted. From model at the American Museum of Netural History.

free end is provided with a mouth surrounded with a great number of tentacles. These, when expanded, look like the petals of a flower. The sea anemone is a very voracious flower, for by means of the batteries of stinging cells in its tentacles it is able to catch and devour fishes and other animals almost as large as itself. When clisturbed or irritated, the animal, like the hydra, contracts into a slimy ball.

Although the sea anemone is like a large hydra in appearance, its interiol is different. The hollow digestive cavity contains a number of partitions more or less complete, which run from the outer wall toward the middle 
of the cavity. Part of the cavity, as in the hydra, is given up to digesting the food. Food, which is often taken alive into the body, is killed by means of stinging cells found in the long threadlike tentacles developed near the base of the cavity.

The partitions or mesenteries, as they are called, are usually double. These perform in the coral polyp, which is like a miniature sea anemone in structure, a very important function.

Coral. ${ }^{1}$ - (Madreporic coral or our common Astrangia may be used for obscrvations.) Test with a drop of hydrochloric acid. What substance is present? Examine a picee of the ordinary white branching coral (madrepore) with the hand lens. Notice the little holes at intervals over

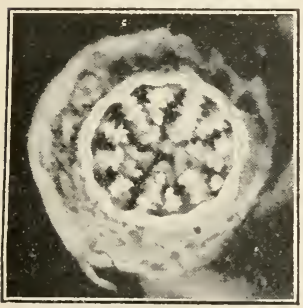

A single coral cup, showing the walls of lime built by the mesenteries. From a photograph loaned by the American Museum of Natural History.

the surface. Do you find little partitions in these koles?

These cuplike depressions were once occupied by the coral animals or polyps, each in its own cup. The mesenteries of the coral polyp are double and hollow on the under surface. The partitions seen in the coral cups lie between these mesenteries, and are formed by them when the animal is alive. Sea water has a considerable amount of lime in its composition. This lime (calcium earbonate) is taken from the water by certain of the cells of the coral polyp and deposited around the base of the animal and between the mesenteries, thus giving the appearance just seen in the cups of the coral branch.

Asexual Reproduction. - These polyps reproduce by budding, and when alive eover the whole coral branch with a continuous living mass of polyps, each connected with its neighbor. In this way great masses of coral are formed. Coral, in a living state, is alive only on the surface, the polyps building outward on the skeleton formed by their predecessors.

Economic Importance of Corals. - Only one (Astrangia) of a great many different species of coral lives as far north as New York. In tropical waters they are very abundant. Coral building has had and still has an immense influence on the formation of islands, and even parts of continents in

1 See Hunter and Valentine, Manual, page 157. 
tropical seas. Not only are many of the West Indian islands composed largely of coral, but also Florida, Australia, and the islands of the southern Pacific are almost entirely of coral formation.

Coral Reefs. - The coral polyp can live only in clear sea water of moderate depth. Fresh water, bearing mud or other impurities, kills them immediately. Hence coral reefs are never found near the mouths of large fresh-water rivers. They are frequently found building reefs close to the shore. In such cases these reefs are called fringing reefs. The socalled barrier reefs are found at greater distance (sometimes forty to fifty miles) from the shore. An example is the Great Barrier Reef of Australia. The typical coral island is called an atoll. It has a circular form inclosing a part of the sea which may or may not be in communication with the ocean outside the atoll. The atoll was perhaps at one time a reef outside a small island. This island disappeared, probably by the sinking of the land. The polyps, which could live in water up to about one hundred and fifty feet, continued to build the reef until it arose to the surface of the ocean. As the polyps could not exist for long above low water line, the animals died and their skeletons became disintegrated by the action of waves and air. Later birds brought a few seeds there, perhaps a cocoanut was washed ashore; thus plant life became established in the atoll and a new outpost to support human life was thus established.

\section{Class,ification of Ceglenterates}

Class I. Hydrozoa. Body cavity containing no mesenteries, usually alternation of generation. Examples: Hydra, hydroid pennaria.

Class II. Scyphozoa. Examples: large jellyfishes.

Class III. Actinozoa. Mesenteries present in body cavity. Examples: sea anemones and corals.

Class IV. Ctenophora.

\section{Reference Books \\ FOR THE PUPIL}

Herrick, Text-book in General Zoülogy, Chap. VII. American Book Company. Davison, Practical Zoölogy, pages 167-175. American Book Company. Holder, Half Hours with the Lower Animals. American Book Company.

FOR THE TEACHER

Agassiz, A First Lesson in Natural History. D. C. Heath and Company. Dana, Coral and Coral Islands. Dodd, Mead, and Company. Parker, Elementary Biology. The Macmillan Company. 


\section{THE STARFISH AND ITS ALLIES}

Structure of $a$ Starfish..$^{1}$ - A glance at the body of a starfish shows us that the name is rightly given. The body is called the disk; the five radiating structures the arms or rays. The term echinoderm (meaning spinyskinned) is also an apt one, as an examination of the dried specimen before us will show. The skeleton of the animal is literally embedded in the skin and protrudes as many thousands of little spines. Closer examination reveals the fact that the skeleton is composed of very many tiny plates, all articulated together in such a way as to give great flexibility as well as strength to the framework of the starfish.

Notice that the thin skin covers the skeleton, but that in a ray broken in cross section the interior of the ray is hollow. In the starfish the arms have the position of radii of a circle; hence the animal is said to be radially symmetrical.

Notice the differences between the dorsal and ventral surfaces. The latter is called the oral surface because of the position of the mouth, which can be seen as a hole in the center of the disk. In living specimens the baglike stomach is frequently found projecting from this hole.

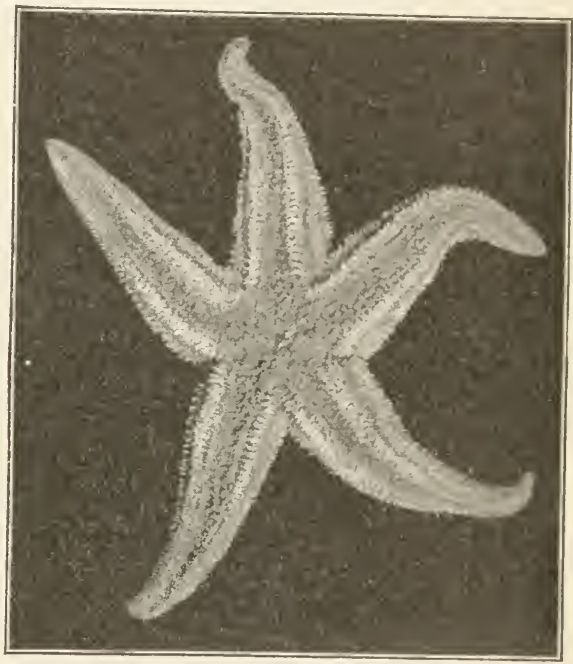

Ventral or under surface of the starfish. The dark circle in the middle is the mouth, from which radiate the five ambulacral grooves, each filled with four rows of tube feet. Photograph half natural size, by Davison.

The five grooves, which lead outward along the rays from the area around the mouth, are known as the ambulacral grooves because they contain the ambulacre or tube feet. In the dried specimen the tube feet may be found as very small dried projections in the grooves. There are four rows of tube feet in each groove. Estimate the number of tube feet in a single row and thus figure out the number of tube feet in a starfish. Do you belicve the number to be exactly the same for every starfish? Give reasons for your answer. Locomotion in the starfish is performed by the movement of hundreds of the little suckerlike feet. The process of movement of a single tube foot is a complicated one. It is performed partly by means of muscles, but chiefly by means of the passage of water through a system of water tubes within the body of the animal.

1 See Hunter and Valentine, Manual, page 147. 


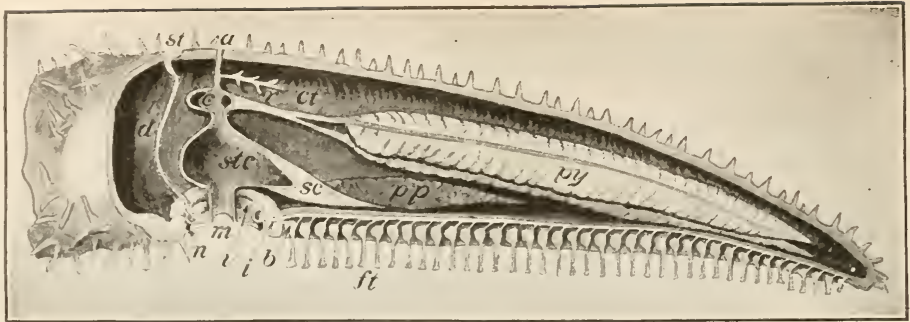

Vertical section through one arm of a starfish; $b$, ampulla; $d$, water canal opening at madreporic plate $(s t) ; i$, radial water tube; $m$, mouth; $f t$, tube feet; $p y$, digestive gland; $s t c$, stomach. Davison, Zoölogy.

On the dorsal (aboral) side of the animal you will find a raised body about the diameter of a pencil. This body, which under the microscope has the structure of a very fine sieve, is called the madreporic plate. Through this plate water passes into a system of water tubes and reservoirs. These tubes extend ultimately into the rays, there ending in the individual tube feet.

Method of Locomotion. - If we could examine the connection of a tube foot with the system of water canals, we should find that water passing from the canals in the rays flows into a tiny receptacle connected with the tube foot. If the tube foot is to be extended, the muscles in the wall of the ampulla (the receptacle next the tube foot) contract. This forces the water out, closing a tiny valve on the side of the radial canal and sending the water into the tube foot, thus causing it to lengthen. The end of the tube foot is composed of a little disk of muscle, thicker at the outer side than on the inner. When this disk is placed against an object, and when water is withdrawn from the tube foot into the ampulla, the disk becomes fastened again by suction. If now the muscles in the wall of the tube foot contract, and this process takes place simultaneously and in hundreds

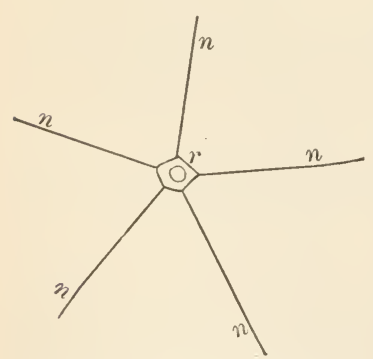

Diagram of nervcus system of $\mathrm{starfish;} r$, nervous ring around mouth; $n$, radial nerves to each arm, ending at the eye. of the feet, it can be seen that the body of the starfish is drawn forward a short distance. To release the tube foot water is pumped in from the ampulla by the process mentioned above. The same act repeated again and again results in locomotion at the rate of about six inches per minute in an adult starfish.

The Nervous System and its Work. - The movements of the tube feet, although not in unison, are coördinated to act for a common purpose. If the animal starts to move in a given direction, the tube feet in the different rays all pull in the same direction. It has been found that this is due to the presence of a ring of nervous tissue, strands of which extend out into 
each ray, ending on the muscles of the tube feet. If this nerve ring is cut, then the different rays do not act together, but one set of tube feet pull in one direction and those of another ray pull in another, thus preventing locomotion. At the extreme end of each ray the nerve is found to end in a tiny eye spot. In your specimen it may show as a salmon-pink spot at the outer end of the ambulacral groove. This eye spot probably cannot distinguish form, but by means of it the starfish can distinguish between light and darkness.

Organs of Breathing. - The starfish spends most of its life in the water, although it may be found attached to rocks or under moist seaweed after the tide has receded. In common with all animals and plants it must have oxygen. Some oxygen is taken in with the water in the system of water tubes within the body, and some is taken out of the water by means of delicate fingerlike processes of the skin called branchice. The branchiæ protrude from between the spines of the dorsal surface. They may be withdrawn by the animal. They are much too delicate to withstand drying and cannot be seen on the specimen you are studying.

Food of the Starfish. - The food and method of fecding are of considerable interest to us because of the economic value of the clams. oysters, and other mollusks on which the starfish feed. Starfish are enormously destructive of young clams and oysters, as the following eviclence, collected by Professor A. D. Mead of Brown University, shows. A single starfish was confined in an aquarium with fifty-six young clams. The largest clam was about the length of one arm of the starfish, the smallest about ten millimeters in length. In six days every clam in the aquarium was devoured. The method of capturing and killing their prey shows that they, in some instances, appear to smother the mollusk by wrapping around it with their soft baggy stomach. The latest evidence on the subject, however, seems to show that they wrap around the valves of the mollusk and actually pull apart the valves by means of their tube feet, some of which are attached to one valve and some to the other of their victim. Once the soft part of the mollusk is exposed, the stomach envelops it and it is rapidly digested and changed to a fluid. ${ }^{1}$ This it can do because of the five large digestive glands which occupy a large part of each ray, and which pour their digestive fluids into five pouchlike extensions of the stomach extending into each ray.

Damage to the amount of thousands of dollars is done annually to the oysters in Connecticut alone, by the ravages of starfish. During the summer months the oyster boats are to be found at work raking the beds for starfish, which are collected and thrown ashore by the thousands.

${ }^{1}$ Observation by one of my pupils, F. T. Lacy, seems to show that in the case of the mussel the starfish inserts part of the stomach into the hole through which the byssus protrudes, and kills the mussel by means of the digestive fluid. When the shells gape, the starfish finishes the meal at its leisure. 


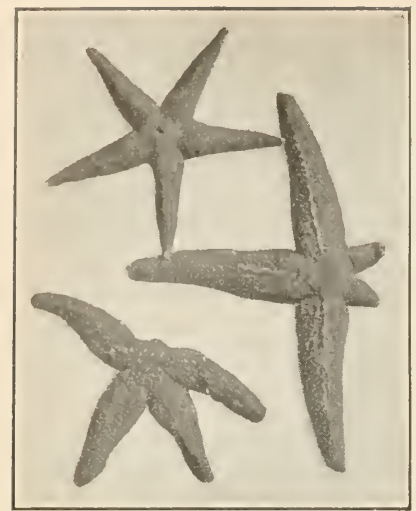

Starfish, showing regeneration of lost arms. Notice that in the lowest specimen the arm is just beginning to regenerate.

REgeneration. - It is no uncommon thing to find starfish with fewer arms than the normal number. In such specimens small arms are frequently seen, making it appear likely that, once having lost an arm, it might grow again. Such is indeed the case, the starfish having the ability to regenerate (grow anew) lost parts. If a starfish should lose all five rays, it is possible that under favorable conditions it might regenerate all its lost parts and become as active as ever in the destruction of shellfish.

Development. - Besides this asexual method of regeneration, the starfish reproduces sexually by means of eggs and sperms. The sexes are separate. The eggs are passed into the water; fertilization takes place near the surface of the water, where the eggs and sperms are found in great numbers during the breeding season (June-July in Long Island Sound). Development proceeds at first as in the jellyfish, the egg segmenting to form a blastula and gastrula. Development does not proceed directly into a starfish, however, the animal being at first very unlike the adult. It swims freely until a limy skeleton is developed. The starfish larva eventually buds off a tiny star-shaped body which actually lives on the tissues of the larva, eventually becoming a tiny starfish no larger than a small pin head. At this stage of their existence they are found on eelgrass and other salt-

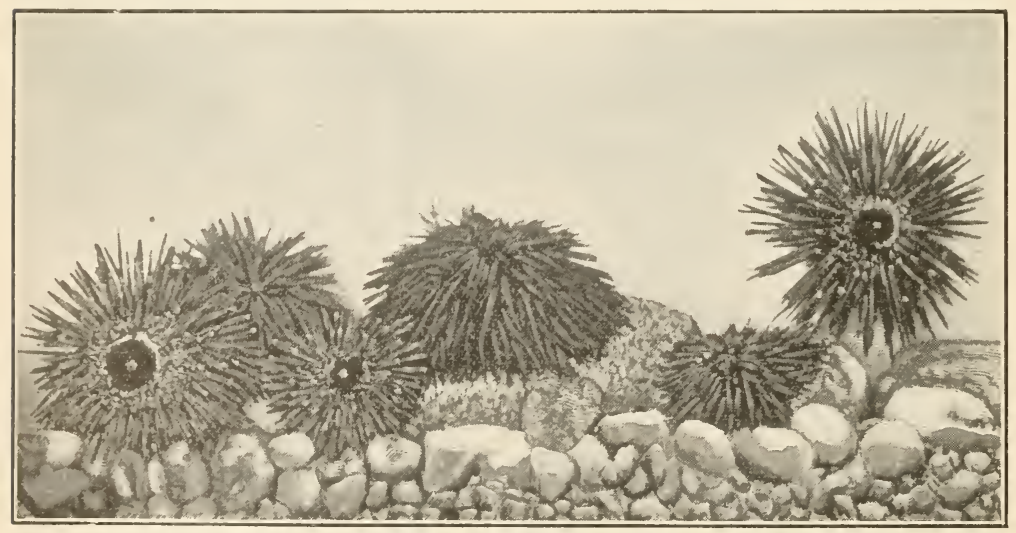

Sea urchins (Arbacia) showing mouth, tube feet, and movable spines. 
water plants. A rapid increase in size takes place at this time; the young after two weeks at the most go to the bottom and begin their life there. It is estimated that if seaweed should be taken out of the water during the months of June and July in the region of Long Island Sound, enough young starfish would be killed to save over six million clams per week for each wagon-load of seaweed removed.

Other Echinoderms. - Other echinoderms, which are frequently seen, but which have less economic importance, are the sea urchins, sand dollars, sea cucumbers, and sea lilies or crinoids.

The sea urchin is found all along our northern coast, living in the tide pools along the shore and also in deep water off the coast.

The body of the sea urchin is almost hemispherical in general form, and is provided with a large number of long spines, which are movable. Locomotion is performed by means of the tube feet, as in the starfish, but the spines are used to some extent as levers. Food is ground up by means of a set of five strong teeth, placed just within the mouth.

The sand dollar is a very much flattened form of starfish, modified to withstand the pressure of the cleep water in which it is found. Another deep-sea form is the basket star, a much-branched, five-armed form. Others are the brittle stars, so called from their habit of casting off their arms when disturbed.

The sea cucumber has a leathery skin, only fragments of lime being found scattered through it. The internal structure is much like that of the starfish. It has the curious habit of ejecting all its digestive organs when disturbed.

The crinoids were once far more common than they are to-day. Their fossil remains form a large part of some of our limestone rocks.

\section{Classification of Echinoderms}

Class I. Crinoidea. Mostly extinct forms. Deep-sea attached forms. Example, crinoid (sea lily).

Class II. Asteroidea. Free moving, usually five-armed echinoderms. Example, starfish.

Class III. Ophiuroidea. Free moving echinoderms with movable arms distinct from disk. Example, brittle star.

Class IV. Echinoidea. Echinoderms with no free arms, spines usually movable and well developed. Examples, sea urchin and sand dollar.

Crass V. Holothurioidea. Soft bodied forms, the skeleton consisting of scattered limy spicules. Example, sea cucumber.

\section{Reference Books}

FOR THE TEACHER

Dodge, General Zoölogy, pages 87-95. American Book Company.

Parker and Haswell. A T ext-book of Zoölogy. The Macmillan Company. 


\section{WORMS}

The Earthworm. - The earthworm belongs to a group of animals called the annelids. They are so called because the body is made up of a large number of rings or segments. (Lat. annulus, a ring.)

Study a living worm in order to answer the following questions.

Careful study of several worms will show that the number of segments varies, the larger worms having more segments. Do the segments vary greatly in width? In shape?

Notice the color of the worm; is it like that of the ground in which it lives? Do the dorsal and ventral surfaces differ in color? ('an you ae-

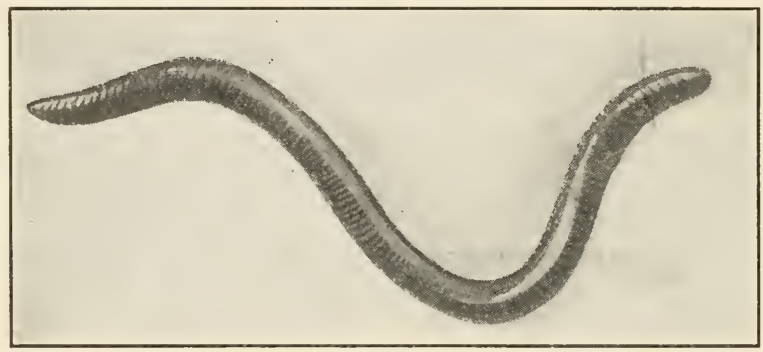

The earthworm. Note the swolien area, the clitellum. Photographeri hy Ovcrton.

count for this? The earthiworm is an example of a bilaterally symmetrical animal, that is, one in which the right side is a counterpart of the left side. Compare with the starfish or sea anemone. Are the latter animals also bilaterally as well as radially symmetrical?

The two ends of the worm differ somewhat in appearance, the anterior end being pointed and the posterior rather flattened. Tests made with a pencil or other pointed object will show which end is more sensitive to touch. Which end usually goes first in crawling?

Measure an earthworm when it is extended and compare with the same worm contracted. Note the difference in length. This is accounted for when we understand the method of locomotion. Under the skin are two sets of muscles, an outer set which passes in a circular direction around the body, and an inner set which runs the length of the body. The body is lengthened by the eontraction of the eircular muscles. How might the body of an earthworm be shortened?

Put your finger over the under surface of the worm. Notice the roughness. Examine the surface with a hand lens. Four rows of very minute

1 See Hunter and Valentine, Manual, page 131. 
bristles called scte may be found. Determine if these rows are single or double. How many setæ to a segment?

Every segment exeept the first three and the last is provided with setæ. Each seta has attached to it small inuscles, which turn the seta so it may point in the opposite direction from which the worm is moving. If you watch your specimen carefully, you will see that locomotion is accomplished by the thrusting forward of the anterior end; then a wave of inuscular contraction passes down the body, thus shortening the body by drawing up the posterior end. The seta at the anterior end serve as anchors which prevent the budy from slipping backward as the posterior end is drawn lip.

Make a drawing of several segments to show the arrangement of setæ.

Notice that living earthworms tend to collect along the sides of a dish or in the corners. This seems to be due to an instinct which leads them to inhabit holes in the ground.

Test a worm by placing half in and half out of a darkened box. Which does it seem to prefer, light or darkness? There are no eyes visible. A careful study of the worm with the microscope, however, has revealed the fact that seattered through the skin of the anterior segments are many little structures which not only distinguish between light and darkness, but also light of low and high intensity, as well as the direction from which it comes. A worm has no ears or special organs of feeling. We know that although a worm responds only to vibrations of low pitch, the sense of touch is well developed in all parts of the body. Notice especially how the worm uses the whole anterior end to feel with. Jar the dish in which the worm rests lightly, and note the reaction that takes place.

Feeding Habits. - Worms may be kept in the laboratory for some time in a glass dish or box filled with soil. They feed on pieces of lettuce or cabbage leaf. A feeding worm will show the

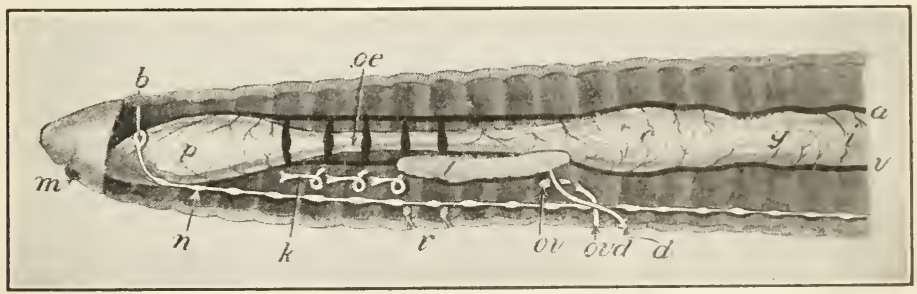

Forepart of an earthworm with the left hody wall removed; $a$, dorsul blool vcss $1 ; b$, hrain; $c$, crop; $g$, gizzard; $i$, intestine; $k$, nephridia; $m$, mouth; $n$, one of the ganglia of the nerve cord; oe, esophagus; $p$, pharynx; $v$, ventral blood vessel. Davison, Zoölogy.

proboscis, an extension of the upper lip which is used to push food into the mouth. The earthworm is not provided with nard jaws or teeth. Yet it literally eats its way through the hardest HUNTER'S BIOL. -14 
soil. Inside the mouth opening is a part of the food tube called the pharynx. This is very muscular so that it can be extended and withdrawn by the worm. When applied to the surface of any small pebble or leaf, it acts as a suction pump and draws it into the food tube. As the worms take organic matter out of the ground as food, they pass the earth through the body in order to get this

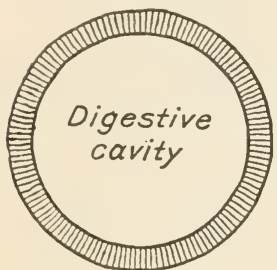

A

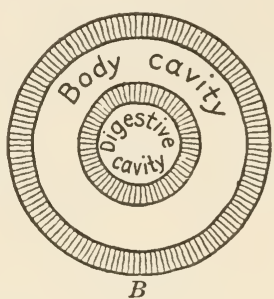

Diagrammatic cross section of the body of a cœlenterate $A$, and that of a worm $B$. food. The earth is mixed with fluids poured out from glands in the food tube, and is passed out of the body and deposited on the surface of the ground, in the form of little piles of moist earth. These are familiar sights on all lawns; they are called worm casts. Charles Darwin calculated that fifty-three thousand worms may be found in an acre of ground, and that ten tons of soil might pass through their bodies in a single year to be brought to the surface. Earthworms, in spite of their fondness for some garden vegetables and young roots, do an immense amount of good by breaking up the soil, thus allowing water and oxygen to penetrate to the roots of plants.

Comparison between Hydra and Worm. - The digestive tract of the worm is an almost straight tube inside of another tube. The latter is divided by partitions which mark the boundary of each segment. The outer cavity is known as the body cavity. In the hydra no distinction existed between the body cavity and digestive tract. In the animals higher than the cœlenterates the digestive tract and body cavity are distinct. The digested food material passes by osmosis into the body cavity. Some food reaches the blood vessels and is pumped over the body, most of it is used by the organs which it bathes. Nitrogenous waste is excreted from each segment through a pair of coiled tubules called nephridia.

Course of Blood. - In a large earthworm the course of the blood is easy to follow. Notice the position of the dorsal blood vessel. Watch it at one point. The blood vessel expands as the 
blood passes slowly forward. The whole dorsal blood vessel, and especially several tubes which connect it with a ventral vessel on the opposite side, are contractile. These connecting tubes are known as hearts, because they serve to pump the blood in a definite direction. Compare the rate of pulsation with your own pulse.

Respiration. - No gills or lungs are present, the thin skin acting as an organ of respiration. But the worm is unable to take in oxygen unless the membranelike skin is kept moist. Respiration in the earthworm is simply the exchange or osmosis of gases through the skin, the oxygen passing into the blood, the carbon dioxide formed from the oxidation taking place within the body of the worm passing out.

Development. - Notice in some worms the swollen area (about one third the distance from the anterior end) called the girdle or clitellum. This area forms a little sac in which the eggs of the worm are laid. As it passes toward the anterior end of the worm, it receives the sperms and a nutritive fluid in which the eggs live. The fertilized eggs are then left to hatch. The capsules may be found in manure heaps, or under stones in May or June; they are small yellowish or brown bags about the diameter of a worm. If possible, procure some young worms and compare them with older ones.

Regeneration. - Earthworms possess to a large degree the power of replacing parts lost through accident or other means. The anterior end may form a new posterior end, while the posterior end must be cut anterior to the clitellum to form a new anterior end. This seems to be in part due to the greater complexity of the organs in the anterior end.

The Sandworm. - Other segmented worms are familiar to some of us. The sandworm, used for bait along our eastern coast, is a segmented worm which lives between tide marks in sandy localities. It is plainly segmented, each segment bearing a pair of locomotor organs called parapodia (meaning side feet). A part of each parapodium is prolonged

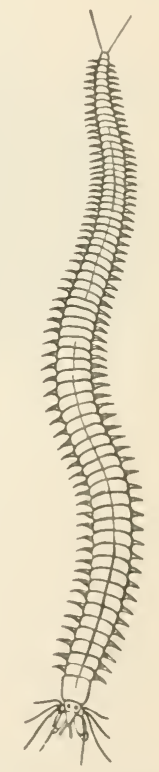

A marine worm (Nereis). into a triangular gill. The animal has a distinct head, which is provided with tentacles, palps, and eye spots. The mouth has a pair r! hard jaws which may be protruded. In this way the animal seizes ancl draws prey into its mouth. The sandworm swims near the surface of the water, the body bending in graceful undulations as the parapodia, like little oars, force the worm forward. They spend most of the time in tubes in 
the sand; these tubes are constructed of slime excreted from the body of the worm. ${ }^{1}$

The LeEch. - The common leech or bloodsucker is a flattened stgmented worm, inhabiting fresh-water ponds and rivers. The adult is provided with two sucking disks, by means of which it fastens itself to objects. The mouth is on the lower surface close to the anterior disk. Locomotion is accomplished by swimming or by means of the suckers, somewhat after the manner of a measuring worm. They feed greedily and are often found gorged with blood, which they suck from the body of the victim. Discomfort, but no danger, attends the bite of the bloodsucker, so dreaded by the small boy.

Unsegmented Worms. - Some worms are unsegmented; such are the flatworms and roundworms. A common leaflike form of

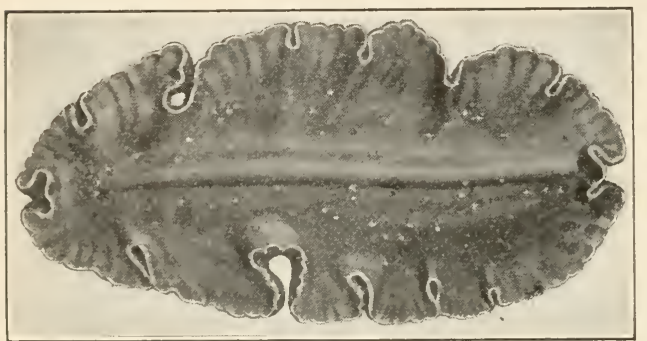

A flatworm ( $Y$ ungia A urantiaca), much magnified. From model in the American Museum of Natural History. flatworm may befound clinging to stones in our fresh water ponds or brooks. Most flatworms are, however, parasites on other animals. Of much interest to us is the life history of the flatworm infesting the liver of sheep, causing the disease called liver rot, which causes annually a loss of several millions of dollars' worth of sheep. This worm is called the liver fluke because of its abode in the liver of the sheep. The developing eggs pass out from the liver into the intestine and thence outside of the body. If the egg happens to be deposited in water, it develops, otherwise it dies. The embryo is a little oval, ciliated creature, microscopic in size. This embryo swims about until it reaches a water snail. Here it lives as a parasite, loses its cilia, becomes larger, and gives rise to a number of little larvæ called redic. The rediæ give rise to more larvæ, some like themselves and others tadpole-shaped. The latter larvæ leave the snail, swim

1 If the living sandworm is obtainable, a laboratory period may be devoted to its activities. See Hunter and Valentine, Manual, page 133. 
to the shore of the pond, and encyst themselves in the grass near its border. If this grass is eaten by sheep, the encysted larvæ (called cercarice) are taken into the digestive tract and then develop into adult Hukes.

Cestodes or Tapeworms.These parasites infest man and many other vertebrate animals. The tapeworm (Tonia solium) passes through two stages in its life history, the first within a pig, the second within the intestine of man. The eggs of the worm are taken in with the pig's food. The worm develops within the intestine of the pig, but soon makes its way into the muscles. If man eats pork

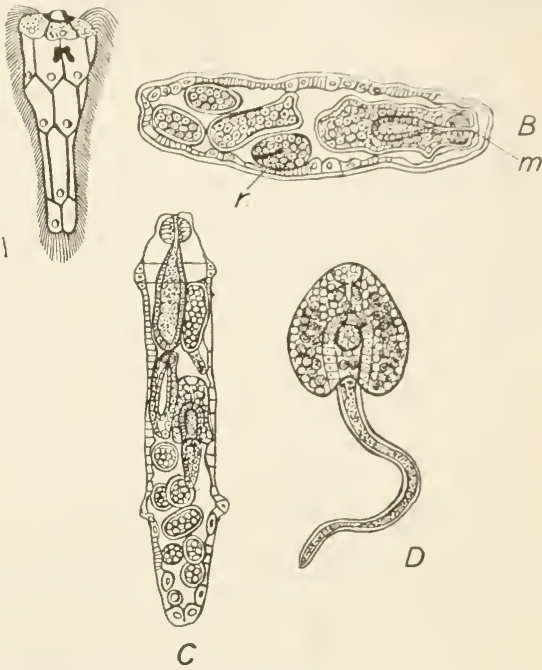

Development of the liver fluke; $A$, ciliated larva; $B$, sporocyst, containing new sporocyst $(r)$, and redia $(m) ;$.$C , redia, containing daughter redia and$ tadpolelike cercaria; $D$, fully developed cercaria. containing these worms, he may become a host for the tapeworm. The animal, which at this stage consists of a round headlike part provided with hooks, fastens itself to the wall of the intestine. This head now buds off a series of segmentlike structures, which are practically bags full of eggs. These structures, called proglottids, break off from time to time, thus allowing the eggs to escape. The proglottids have no separate digestive systems, but the whole body surface, bathed in digested food, absorbs it and is thus enabled to grow rapidly.

Roundworms. - Still other wormlike creatures called roundworms are of importance to man. Some, as the vinegar eel found in vinegar, or the pinworms parasitic in the lower intestine of man, do little or no harm. The pork worm or Trichina, however, is a parasite which may cause serious injury. It passes through the first part of its existence as a parasite in a pig or other vertebrate (dog, cat, ox, or horse), where it encysts itself in the muscles 
of its host. In the case of pork, if the meat is eaten in an uncooked condition, the cyst is dissolved off by the action of the digestive fluids, and the living trichina becomes free in the intestine of man. Here it bores its way through the intestine walls and enters the muscles, causing inflammation there. This causes a painful disease known as trichinosis.

Some roundworm parasites live in the skin, and others live in the intestines of the horse. Still others are parasitic in fish and insects, one of the commonest being the hair snake, often seen in country brooks.

\section{Classification of Segmented Worms (Annulata)}

Class I. Chatopoda (bristle-footed). Segmented worms having setæ.

Subclass I. Polychœta (many bristles). Having parapodia and usually head and gills. Example, sandworm.

Subclass II. Oligochata (few bristles). No parapodia, head, or gills. Example, earthworm.

Class II. Discophora (bearing suckers). No bristles, two sucking disks present. Example, leech.

\section{Platyhelminthes (Flatworms)}

Body flattened in dorso-ventral direction.

Class I. Turbellaria. Small aquatic, mostly not parasitic. Example, planarian worm.

CLASs II. Trematoda. Usually parasitic worms which have complicated life history. Example, liver fluke of sheep.

Class III. Cestoda. Internal parasites having two hosts. Example, tapeworm.

\section{Nemathelminthes (Roundworms)}

Threadlike worms, mostly parasitic. Examples, vinegar eel and Trichina.

\section{Reference Books}

FOR THE PUPIL

Davison, Practical Zoölogy, pages 150-161. American Book Company. Herrick, Text-book in General Zoölogy, Chap. IX. American Book Company. Jordan, Kellogg, and Heath, Animal Studies, VI. D. Appleton and Company.

FOR THE TEACHER

Darwin, Earthworms and Vegetable Mould. D. Appleton and Company. Sedgwick and Wilson, General Biology. Henry Holt and Company. 


\section{CRUSTACEANS}

The Crayfish (Cambarus affinis). - Crayfish live in fresh-water lakes and streams. There they may be caught under projecting stones in clear streams by hand. From muddy streams they may be taken by means of a weighted net, which is pulled along the bottom. Although they prefer the water, they are sometimes found at some distance from any large body of water; such animals are supposed to be migrating.

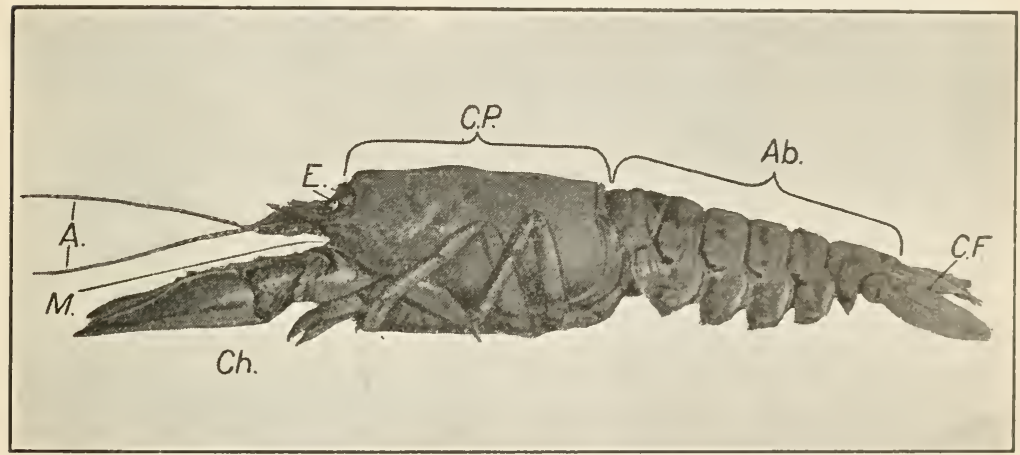

Crayfish; A., antennæ; $E$., stalked eye; C.P., cephalothorax; Ab., abdomen; C.F., caudal

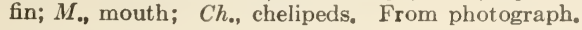

The Structure and Activities of the Crayfish. - Living crayfish in dishes of water should be provided for this exercise ${ }^{1}$ Notice the color of the living erayfish. In the natural habitat the colors blend with its surroundings, so that it is difficult to distinguish a crayfish from the bottom on which it rests. The animal is thus said to be protectively colored.

The body is composed of a series of rings or segments. This fact is not apparent at the anterior end of the body, where the head and middle region (thoracic region) are covered by one piece of the skeleton. This is called the cephalothorax. Count the number of segments in the abdomen (the posterior region). This number is constant for every crayfish.

The shell is a true exoskeleton, that is, it is formed by the skin. As in the exoskeleton of the insects, an animal material called chitin forms the basis, but in this case the skeleton is strengthened by the addition of lime. Test a piece of the shell with acid. What results? Is anything left

1 For full laboratory directions see Hunter and Valentine, Manual, page 121. 
behind? What is this, animal or mineral matter? Examine the shell of a dead crayfish and try to find out how the segments of the abdomen are joined together. Notice the different positions taken by the abdomen in the living animal. How might this be accounted for mechanically?

The small appendages attached to the under surface of the segments are called the swimmerets or pleopods. How many are attached to each seg-

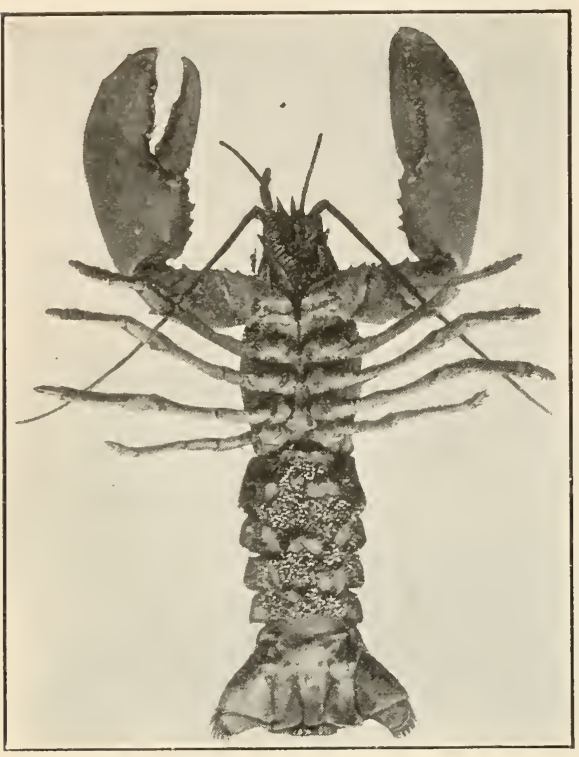

Female lobster, showing eggs attached to the swimmerets. From photograph loaned by the American Museum of Natural History. ment? Observe the movement when in the water. Why are they called swimmerets? Notice that each plcopod is made up of three pieces, a base and two branches. Now look at the broad appendage that, together with the last scgment of the abdomen, forms a broad finlike apparatus, the caudal fin. You will find this appendage likewise composed of three pieces; it is homologous to the pleopods. This appendage is known as the uropod. Crayfish normally swim very rapidly in a backward direction by means of a sudden jerking of the caudal fin. Other methods of locomotion may be observed by allowing the animal to walk in a shallow pan with a little water in it. Note the position and number of jointed legs that are used in locomotion. Is the large pair of pincher legs used for this purpose? If so, to what extent? Crayfish have a definite method in the movement of the walking legs, the first and third moving in alternation with the second and fourth legs on the same side of the animal. Test a crayfish to see if this rule holds true. Do you find any other methods of locomotion than the ones mentioned?

Watch the animal in its movements to see if, in avoiding objects, it first allows certain parts of the body to touch the object. The longer of the two pairs of feelers (the antennce) function as organs of touch. Hairs which are sensitive to touch are also found in various other parts of the body. The bases of the antennæ are broad, and a small flat piece projects outward from this basal portion. The antennæe are believed to have also the function of smell. Crayfish are thus able to learn of the presence of food at a considerable distance away. The short appendages immediately in front of the antennæ are called the antennula (little antennæ). Notice that the four stalks are in reality two branches from one base on each side. Part of this appendage is believed to contain the organ of hearing. Test in any manner that you can the sight of the crayfish. Test with 
moving objects at a little distance and then close to the animal. You may also test to see if the animal can distirguish light from darkness. This may be done by covering half of the tray in which the crayfish is confined. Then place the animal in the light end of the tray to see if it will travel toward the dark end of the tray. 'This may be repeated by placing the animal in the dark end. Thus it will be possible to discover the reaction of the animal to the light. Notice the position of the stalked eyes. Toureh the eye with a pencil; is it freely movable? In what direction? Notice how well the eye is protected from injury. The anterior end of the carapace projects to form a spiny process; this, with the sorket in which the eye rests and its position on the side of the head, forms ample protection

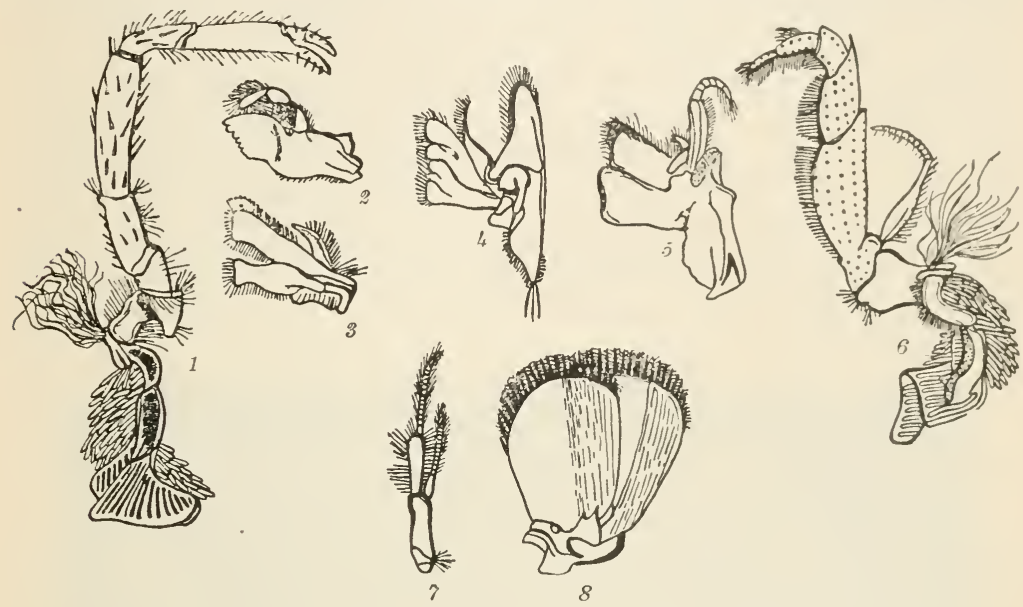

Mouth parts of the crayfish; 1 , walking appendage, showing at tachment of gill: 2 , the jaw, with palp; 3 , first maxilla (second maxilla not shown); 4 , third maxilliped; 5 , second maxilliped, showing baler; 6 , first maxilliped, showing gill at tached; 7 , swimmeret; 8 , uropoc..

to this important organ. The eyes of the crayfish, like those of an insect, are compound. They differ from those of the insect in being borne on stalks. If a small bit of the exoskeleton covering the eye is placed under the compound microscope, it will be found to be made up of a number of little rectangles; this shows the size and shape of a surface view of the units composing the compound eye.

If it is possible to have the aquarium holding the crayfish in the schoolroom, the method of feeding may be watched. Notice that the pincher claws (chelipeds) are used to hold and tear food, as well as for defense and offense. Living food is obtained with the aid of the chelipeds. Food is shoved by the chelipeds toward the mouth; it is assisted there by several small appendages called foot jaws (maxillipeds) and to a slight degree by two still smaller paired maxillo just under the maxillipeds. Ultimately the food reaches the hard jaws and, after being ground between them, is passed down to the stomach. If you hold the crayfish in such a position that you can pour a little beef juice or other edible fluid over the mouth parts, it will he possible to observe the mouth parts work as they do in a state of nature. 
The mouth parts of a crayfish resting in the aquarium are observed to be constantly in motion, despite the fact that no food is present. If the crayfish is taken out of the water and held with the ventral surface upmost, a little carmine (dissolved in water) may be dropped on the lower surface of the animal. This carmine runs down under the carapace. If now the animal is held in water in the same position, the carmine will appear from both sides of the mouth, seemingly propelled by something which causes it to emerge in little puffs. If we remove the maxillipeds and maxillæ from a dead specimen, we find a groove leading back from each side of the mouth to a cavity of considerable size on each side of the body under the carapace. This is the gill chamber. It contains the gills, the organs which take oxygen out of the water. The second maxillæ are prolonged down into the groove to serve as bailers or scoops. By rapid action of this organ a current of water is maintained which passes over the gills.

The gills are outside of the body, although protected by the carapace. If the carapace is partly removed on one side, they will be found, looking somewhat like white feathers. The blood of the crayfish passes by a series of vessels into the long axis of the gill; in this organ the blood tubes divide into very minute tubes, the walls of which are extremely delicate. Oxygen, dissolved in the water, passes into the blood by osmosis, during which process the blood loses some carbon dioxide. Notice that the gills are kept from drying by being placed in a nearly closed chamber, which is further adapted to its function by means of the row of tiny hairs which border the lower edge of the carapace.

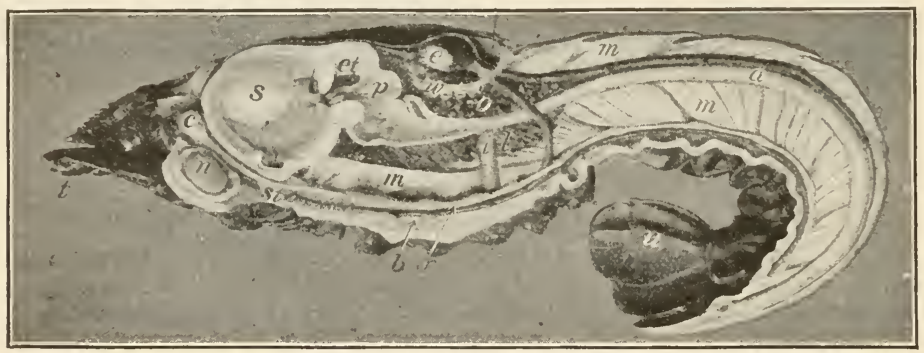

Crayfish with the left half of the body structures removed; $a$, intestine; $b$, ventral artery; $c$, brain; $e$, heart; $e t$, gastric teeth; $i$, oviduct; $l$, digestive gland; $m$, muscles; $n$, green gland (kidney); $o$, ovary; $p$, pyloric stomach; $r$, nerve cords; $s$, cardiac stomach; $s t$, mouth; $u$, telson; $w$, openings of veins into the pericardial sinus. Twice natural size. Davison, Zoölogy.

The laboratory exercise should conclude with a drawing of the animal from the side, about natural size, with part of the carapace cut away to show the gills. Show as many of the above-mentioned parts as possible. For other useful drawings see Hunter and Valentine, Manual, page 124.

Circulation. - The circulation of blood in the crayfish takes place in a system of thin-walled, flabby vessels which are open in places, allowing the blood to come in direct contact with the tissues to which it flows. The heart lies on the dorsal side of the body, inclosed in a delicate bag, into which all the blood in the body eventually finds its way during its circulation. 
Digestion. - Food which is not ground up into pieces small enough for the purpose of digestion is still further masticated by means of three teeth, strong projections, one placed on the midline and two on the side. walls of the stomach. The exoskeleton of the erayfish extends down into the stomach, thus forming the gastric mill just deseriberl.

The stomach is divided into anterior and posterior parts separated from each other by a constriction. The posterior part is lined with tiny pro jections from the wall which make it aet as a strainer for the food pasing through. Thus the unbroken particles of food are kept in the anterior end of the stomach. Opening into the posterior end of the stomach are two large digestive glands which further prepare the food for absorption through the walls of the intestine. Onee in the blood, the fluid food is circulaterl through the body to the tissues which need it.

Nervous System. - The internal nervous system of a crayfish consists of a series of collections of nerve cells (ganglia) connected by means of a double line of nerves. Posterior to the gullet this chain of ganglia is found on the ventral side of the body, near the body wall. It then encircles the gullet and forms a brain in the head region, the latter formed from several ganglia which have grown together. From each of the ganglia, nerves pass off to the sense organs and into the muscles of the body. These nerve fibers are of two sorts, those bearing messages from the outside of the body to the eentral nervous system (these messages result in sensations), and those which take outgoing messages from the central nervous system (motor impulses), which result in muscular movements.

Development. - The sexes in the erayfish are distinet. The developing eggs, which are provided with a considerable supply of food material, are glued fast to the swimmerets of the inother, and there develop in safety. The young, when they first hateh, remain clinging to the swimmerets for several weeks.

Excretion of. Wastes. - On the basal joint of the antennæ are found two projections, in the eenter of which are found tiny holes. These are the openings of the green glands, organs which have the function of the elimination of nitrogenous waste from the blood, the function of the human kidneys.

Characters of Crayfish and its Allies. - Our study of crayfish shows us that animals belonging to the same group as itself have several well-marked characteristics. The most important are the presence of a segmented limy exoskeleton, gills, jointed appendages, a pair to each segment of the body (except the last); and, as we shall see later, they pass through a metamorphosis or change of form before they reach the adult state. We find that the Crustacea fall naturally into two classes, those in which the number of pairs of appendages is indefinite, and those in which the number is fixed 
at nineteen. In this latter class are placed the crayfish, lobster, blue crab, shrimp, and most of our common crustaceans.

The North American Lobster. - In structure it is almost the counterpart of its smaller cousin, the crayfish. Its geographical range is a strip of ocean bottom along our coast, estimated to

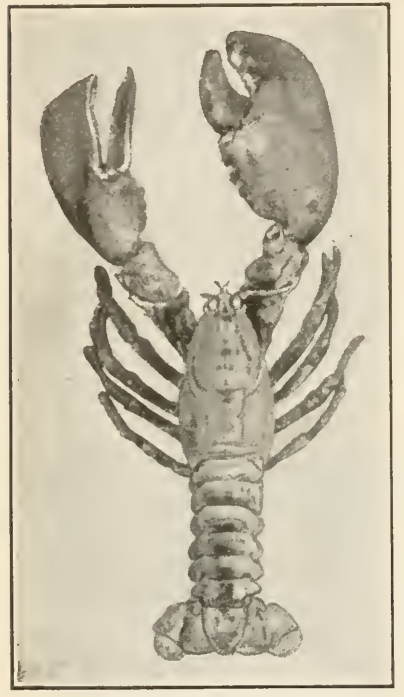

North American Lobster. This specimen, preserved at the U.S. Fish Commission, was of unusual size and weighed over twenty pounds. Notice the chelipeds. vary from thirty to fifty miles in width. This strip extends from Labrador on the north to Delaware on the south. The lobster is highly sensitive to changes in temperature. It migrates from deep to shallow water or vice versa according to the temperature of the water, which in winter is relativeiy warmer in deep water and cooler in shallows. Sudden changes in the water of a given locality may cause them to disappear from that place. The more abundant food supply near the shore also aids in determining the habitat of the lobster. Lobsters do not appear to migrate north and south along the coast. While little is known about their habits on the ocean bottom, it is thought that they construct burrows somewhat like the crayfish, in which they pass part of the time. As they have the color of the bottom and as they pass much of their time among the weedcovered rocks, they are able to catch much living food, even active fishes falling prey to their formidable pinchers. They move around freely at night, usually remaining quiet during the day, especially when in shallow water. They eat some dead food; and thus, like the crayfish, they are scavengers.

Development. - The female lobsters begin to lay eggs when about seven inches in length. Lobsters of this size lay in the neighborhood of five thousand eggs; this number is increased to about ten thousand in lobsters of moderate size (ten inches in 
length); in exceptionally large specimens as many as one hundred thousand eggs are sometimes laid. The eggs are laid every alternate year, usually during.the months of July and August. Eggs laid in July or August, as shown by observations made along the coast of Massachusetts, hatch the following May or June. The eggs are provided with a large supply of yolk (food), the development of the young animal taking place at the expense of this food material. After the young escape from the egg they are almost transparent and little like the adult in form. During this period of their lives the mortality is very great, as they are the prey of many fish and other free-swimming animals. It is estimated that barely one in five thousand survives this period of peril. At this time they grow rapidly, and in consequence are obliged to shed their exoskeleton (molt) frequently. During the first six reeks of life, when they swim freely at the surface of the water, they molt from five to six times. ${ }^{1}$

Molting. - During the first year of its life the lobster molts from fourteen to seventeen times. Dur-

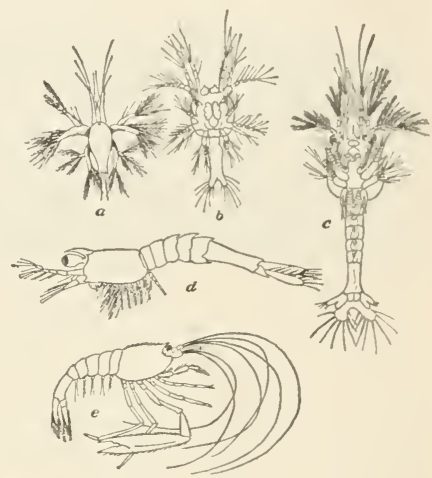

Metamorphosis of a shrimp; $a$, nauplius or earliest stage; $b, c, d$, later larval stages; $e$, adult. Note that as the animal grows more appendages appear, and that these develop back ward from the anterior end. ing this period it attains a length of from two to three inches. Molting is accomplished in the following manner: The carapace is raised up from the posterior side and the body then withdrawn through the opening between it and the abdomen. The most wonderful part of the process is the withdrawal of the flesh of the large elaws through the very small openings which connect the limbs with the body. The blood is first withdrawn from the appendage; this leaves the flesh in a flabby condition (a

${ }_{1}$ Recent economic investigations upon the eare of the young developing lobster show that animals protected during the first few months of free existence have a far better chance of becoming adults than those left to grow up without protection. Later in life they sink to the bottom, and because of their protectively colored shell and the habit of hiding under rocks and in burrows, they are comparatively safe from the attack of enemies. 
state similar to the taproot which has lost water by osmosis) so that the muscles can be drawn through without injury. The lobster also molts a part of the lining of the digestive tract as far as the posterior portion of the stomach. Immediately after molting the lobster is in a helpless condition, and is more or less at the mercy of its enemies until the new shell, which is secreted by the skin, has grown. This process takes several weeks to complete.

Economic Importance. - The lobster is highly esteemed as food, and is rapidly disappearing from our coasts as the result of overfishing. Between twenty million and thirty million are yearly taken on the North Atlantic coast. This means a value at present prices of about $\$ 15,000,000$. Laws are now enacted in New York and other states against overfishing. Egg-carrying lobsters must be returned to the water, all smaller than six to nine inches in length (the law varies in different states) must be put back; other restrictions are placed upon the taking of the animals, in hope of saving the race.from extinction. Some states now hatch and care for the young for a period of time; the United States Fish Commission is also doing much good work, in hope of restocking to some extent the now almost depleted waters.

Shrimps. - Several other common crustaceans are near relatives of the crayfish. Among them are the shrimps and prawns, thinshelled, active crustaceans common along our eastern coast. In spite of the fact that they form a large part of the food supply of many marine animals, especially fishes, they do not appear to be

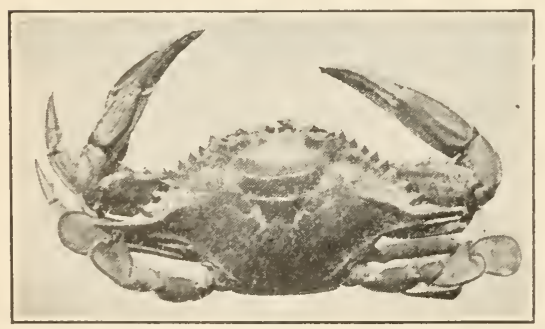

The edible blue crab. From photograph loaned by the American Museum of Natural History. decreasing in numbers. Besides this value as a food, they are also used by man, the shrimp fisheries in this country aggregating almost $\$ 1,000,000$ yearly.

The Blue Crab.-Another edible crustacean of considerable economic importance is the blue crab. Crabs are found inhabiting muddy bet- 
toms; in such localities they are caught in great numbers in nets or traps baited with decaying meat. They are, indeed, among our most valuable sea scavengers, although they are "arnivorous hunters as well. The body of the erab is short and liroad, being flattened dorso-ventrally. The abdomen is much reduced in size. Usually it is carried close to the under surface of the cephalothorax; in the female the eggs are carried under its ventral surface, fastened to the rudimentary swimmerets. The young crabs differ considerably in form from the adult. They undergo a complete metamorphosis (change of form), and their method of life differs from the adult. Immediately after molting, crabs are greatly desired by man as an article of food. They are then known as "shedders," or soft-shelled crabs.

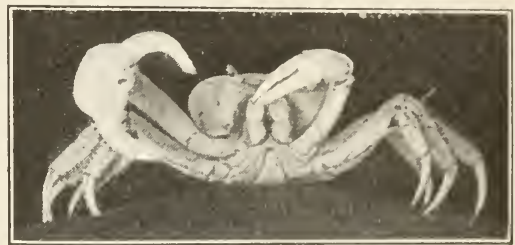

The fiddler crab. From photograph loaned by the American Museum of Natural History.

Other Crabs. - Other crabs seen along the New York coast are the prettily colored lady crabs, of ten seen running along our sandy beaches at low tide; the fiddler crabs, interesting because of their burrows and gregarious habits; and perhaps most interesting of all, the hermit crabs. The hermit crabs use the shells of snails as homes. The abdomen is soft,

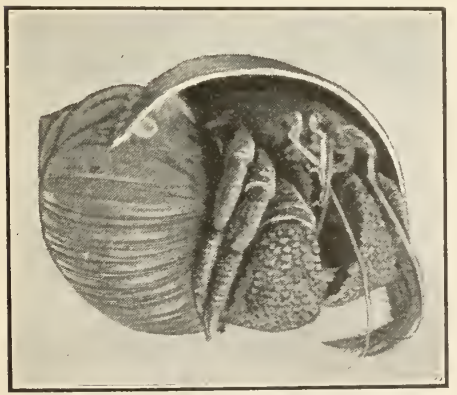

Hermit crab, about twice natural size. From photograph loaned by the American Museum of Natural History. and unprotected by a limy exoskeleton, and has adapted itself to its conditions by curling around in the spiral snail shell, so that it has become asymmetrical. These tiny crabs are great fighters and wage frequent ducls with each other for possession of the more desirable shells. They exchange their borrowed shells for larger ones as growth forces them from their first homes.

The habits of these animals, and those of the fiddler erabs, might be studied with profit by some eareful boy or girl who spends a summer at the seashore and has the time and inclination to devote to the work. Of especial interest would be a study of the food and feeding habits of the fiddler crabs. 
A deep-water erab of ten seen along Long Island Sound is the spider erab, or sea spider as it is incorrectly ealled by fishermen. This animal, with its long spiderlike legs, is neither an active runner or swimmer; it is, however, protectively colored like the dark mud and stones over which it erawls. The resemblance to the bottom is further heightened by the rough body covering, which gives a hold for seaweeds and sometimes sessile animals, as barnacles, hychroids, or sea anemones, to fasten themselves.

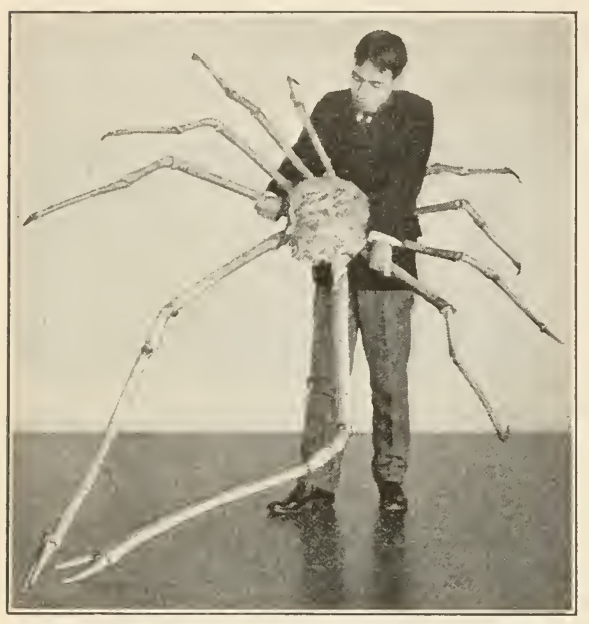

Giant spider crab from Japan. From photograph loaned by the American Museum of Natural History.

A spider crab from the Sea of Japan is said to be the largest crustacean in the world, specimens measuring eighteen feet from tip to tip of the first pair of legs having been found.

Symbiosis. - Certain of the spider crabs, as well as some of the larger deepwater hermit crabs, have come to live in a relation of mutual helpfulness with hydroids, sponges, and sea anemones. These animals attach themselves to the shell of the crab and are carried around by it, thus receiving a constant change of position and a supply of food. What they do for the crab in return is not so evident, although one large Chinese hermit regularly plants a sea anemone on its big claw; when forced to retreat into its shell, the entrance is thus effectually blocked by the anemone. The living of animals in a mutually helpful relation is called symbiosis. Of this we have already had some examples in plants as well as among animals. (See Lichens, page 172.)

Habitat. - Most crustaceans are adapted to live in the water; a few forms, however, are found living on land. Such are the wood lice, the pill bugs, which have the habit of rolling up into a ball to escape attack of enemies, the beach fleas, and others. The cocoanut crab of the tropics climbs trees in search of food, returning to the water, at intervals, to moisten the gills. 
Classification. - All the forms of crustaceans mentioned belong to that subclass of crustaceans called the Malacostraca, the characters of the group being a definite number of segments and appendages. All having five pairs of walking appendages are called decapods. How many of the above-mentioned forms are decapods?

Entomostraca. - Another subclass of crustaceans, in which the number of appendages is not fixed, is the group Entomostraca. They are mostly small animals, some species existing in countless numbere. Such are the fairy shrimps found appearing in early spring in fresh-water ponds, little translucent swimming forms from one half to three fourths of an inch in length. Another fresh-water form often seen in aquaria is the water flea (Daphnia). From the economic standpoint, probably the most important crustaceans that we shall study are the copepods. These tiny animals are barely visible to the naked eye. They are found in almost every part of the world, from the arctic seas to those of the tropics, and in fresh as well as salt water. They are so numerous that the sea in places is colored by their bodies. So prolific are they that it is estimated that one copepod may produce in a single year four billion five hundred million offspring. These animals form a large part of the food supply of many of our most important food fishes as well as the food of many other aquatic animals. They are, then, in an indirect way, of immense economic value.

Degenerate Crustaceans. - One of the most

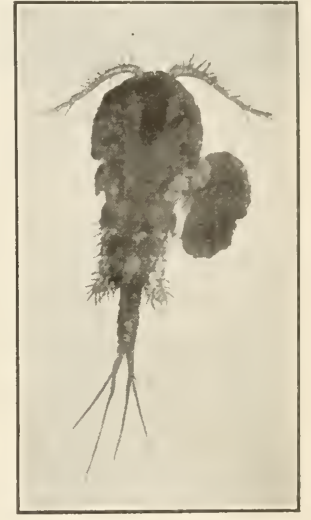

Cyclops, a common copepod, enlarged about twenty times. A mass of eggs at the right. interesting forms to a zoölogist is the goose barnacle. This crustacean is free-swimming during its early life. Later, however, after passing through several changes in form during its development, the barnacle settles down on a rock or some floating object, fastens itself along the dorsal surface, and remains so fastened during the rest of its life. Food comes to it in a current of water, which is set in motion by the rhythmical beating of the appendages. Thus food particles are carried along the ventral side of the body to the mouth. Such animals are said to be degenerate.

Parasitic Crustaceans.-Other crustaceans have become even more helpless and have come to take their living from other animals. In some cases they are simply a bag for absorbing nourishment from the host on which they are fastened. Such is the Sacculina, a degenerate crustacean that lives 


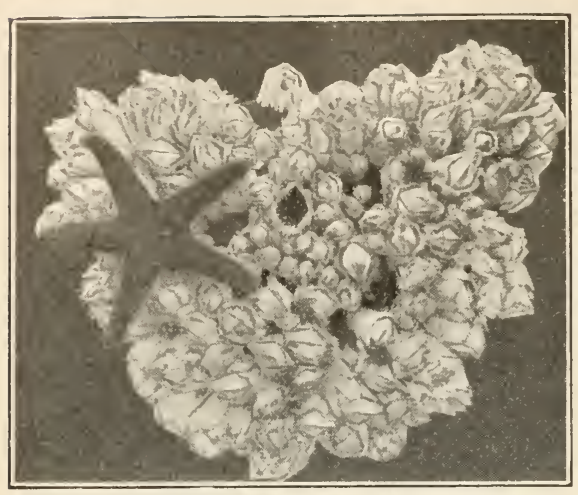

Group of acorn barnacles (closed), with starfish moving over the mass. Each shell contains a fixed, degenerate crustacean.

attached to the body of the crab. Others attach themselves to fishes and are known to fishermen as fish lice.

\section{Characters Common to} all Crustaceans. - In spite of all the differences in structure found in the various crustaceans studied, there are a number of characters possessed by all crustaceans in common. They have a segmented body covered with an exoskeleton; the latter contains chitin and carbonate of lime. The body is bilaterally symmetrical (except in the hermit crab). The appendages are jointed and branched. Two pairs of antennæ are present. The eyes are stalked and compound. Crustaceans breathe by means of gills and are mostly aquatic.

\section{Referexce Books \\ FOR THE PUPIL}

Burnet, School Zoölogy, pages 67-73. American Book Company.

Davison, Practical Zoölogy, pages 133-141. American Book Company.

Herrick, Text-book in General Zoülogy, Chap. XIII. American Book Company. Jordan, Kellogg, and Heath, Animal Studies, Chap. IX. D. Appleton and Company.

Hunter and Valentine, Laboratory Manual of Biology, pages 138-146. Henry Holt and Company.

\section{FOR THE TEACHER}

Herrick, The American Lobster. Report of U.S. Fish Commission, 1895.

Parker, Elementary Biology. The Macmillan Company.

Parker and Haswell, Text-book of Zoölogy. The Macmillan Company. 


\section{INSECTS}

Insects and Crustaceans Compared. - Both crustaceans and insects belong to a great group of animals which agree in that they have jointed appendages and bodies, and that they possess an exoskeleton. This group is known as the Arthropoda.

Insects differ structurally from crustaceans in having three regions in the body instead of two. The number of legs (three pairs) is definite in the insects; in the crustaceans the number sometimes varies (as in the Entomostraca), but is always more than three pairs. The exoskeleton, composed wholly of chitin in the insects, is usually strengthened with lime in the crustaceans. Both groups have compound eyes, but those of the crustacea are stalked and movable. The crustaceans receive sensations of touch by means of sensory hairs which protrude from the exoskeleton. The other sense organs do not differ greatly. The most marked differences are physiological. The crustaceans take in oxygen from the water by means of gills, while the insects are air breathers, using for this purpose air tubes called trachece.

The young of both insects and crustaceans usually undergo several changes in form before the adult stage is reached. They are thus said to pass through a metamorphosis. Both insects and crustaceans, because of their exoskeleton, must molt in order to increase in bulk.

The insects are divided into a number of large groups called orders. The insects found in each order possess certain characters in common. We shall now examine several representatives from some of the different orders of insects commonly met with.

\section{The Order Orthoptera}

The Locust. - The locust or short-horned grasshopper is a type of the class Insecta, which is characterized by possessing at 
body made up of segments, having jointed appendages, three pairs of legs, and breathing through a system of air tubes called trachea. It also belong's

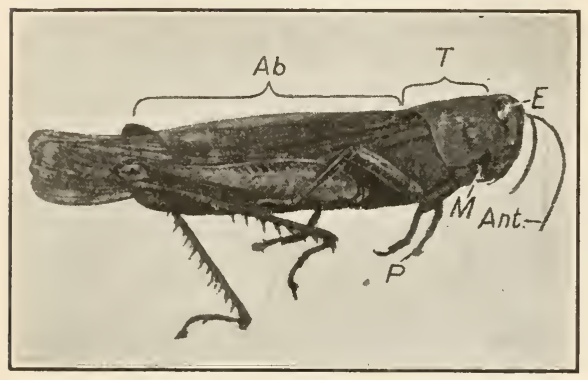

Locust (red-legged grasshopper); $A b$, abdomen; Ant., antennæ; $E$, eye; $\boldsymbol{M}$, mouth; $P$, pads on feet; $T$, thorax. to the order Orthoptera (straight wings) because the hind wings, when at rest, lie folded up lengthwise close to the body.

External Structure. ${ }^{1}$ - Any common form, as Melanoplus femur-rubrum, may be used. Examine the body of the grasshopper. The anterior region is the head, the middle part the thorax, the posterior the abdomen. To which region are wings and legs attached? Which region is the stoutest? Notice that the body is covered with an exoskeleton. This is composed of chitin, a substance chemically akin to that of a cow's horn.

The grasshopper makes its home in fields of grass. Some species live in vacant lots where there is considerable earth exposed. Do such grasshoppers ever have the color of their surroundings? How might this be of service to them?

Examine the legs of a living grasshopper, with a view to finding out their position when at rest. Examine the hind legs. Do you find any adaptations present which fit the legs for jumping? Examine the hooks and pads on the last segment or tarsus. Look for other adaptations. Besides flying and hopping, the grasshopper also crawls. In a resting position, it clings by means of the hooks and pads on the foot or tarsus.

Spread out the wings. Note their position. Note any differences between the two pairs. Which pair would be most useful in flight? Notice the delicate lacelike underwings, the supporting veins of which are composed of tubes that carry blood and air.

Notice the abdomen carefully. The most anterior segment is incomplete, and bears an oval structure, the tympanum, or ear drum. Count the number of complete segments in the abdomen. The female grasshopper has the free end of the abdomen modified for the purpose of egg laying. Note the two-parted structures making up the ovipositor or egg layer. The male has a more rounded abdomen.

Observation of the abdomen of a living grasshopper shows a frequent movement of the abdomen. Count the number of movements in a minute. This is the breathing of the grasshopper. Along the side of the abdomen in eight of the segments (in the red-legged grasshopper) are found tiny openings called spiracles. A large spiracle may easily be found in the middle segment of the thorax. These spiracles open into little tubes called tracher. The trachex carry air to all parts of the body. By the movements of the abdomen just noted, air is drawn into and forced out of the tracheæ.

1 For laboratory directions see Hunter and Valentine, Manual, page 101. 
Tracheæ. - The tracheæ divide and subdivide like branches of a tree so that all the body cavity is reached by their fine endings. Some even pass outward into the veins of the wings. Each of these tubes contains air. The blood of an insect does not circulate through a system of closed blood tubes as in man, but instead it more or less completely fills that part of the body eavity which is not filled with other organs. A heart (a hollow muscular organ containing several openings, situated on the dorsal side of the insect) causes movement of the blood inside the body cavity in much the same way that a rubber bulb would circulate water if squeezed inside a

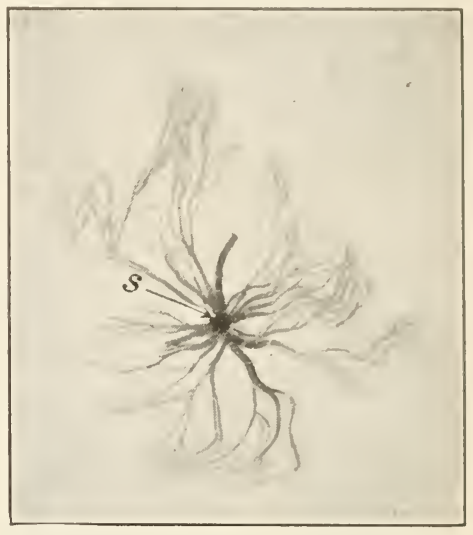

Spiracle with its trachex removed from an insect; $s$, spiracle. Three times natural size. Photographed by Davison. pail of water, so that sooner or later the blood comes in contact with the oxygen passed in through the trachex.

Muscular activity. - Insects have the most powerful muscles of any animals of their size. Relatively, an enormous amount of energy is released during the jumping or flying of a grasshopper. The tracheæ pass directly into the muscles, where oxidation takes place when the muscles are exercised. Thus oxygen is taken directly to the parts of the body where it is to be used. The body temperature of the grasshopper is slightly higher than the surrounding air. Why?

Mouth Parts. - Feed a grasshopper with a blade of grass. Note how the animal holds the grass. What appendages are uscd? Note the upper lip and lower lips, the latter biparted. The dark brown jaws (mandibles) may be seen underneath. Below them are a pair of smaller pointed parts, the maxillæ, to which are attached a pair of jointed palps. Note also that palps are attached to the lower lip.

Food Taking and Blood Making. - The plant food taken by the grasshopper is held in place in the mouth by means of the little jaws or maxillæ while it is cut into small pieces by the mandibles. 
Just behind the mouth is a large crop into which empty the contents of the salivary glands. It is this fluici mixed with digested food that we call the "grasshopper's molasses." After the food is digested by the action of the saliva and other juices, it passes in a fluid state through the walls of the intestine where most of it becomes part of the blood. As blood it is passed on to tissues, such as muscle, to be used in repairing that which is used up during the flight of the insect. Some of the foods are doubtless at once oxidized to release energy for the active insect.

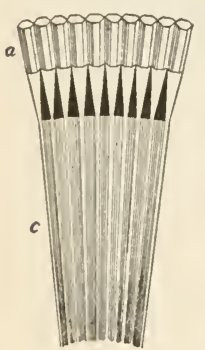

Longitudinal section of part of the compound eye of an insect; $a$, facets; $c$, nerves.

Eyes. - A considerable part of the surface of the head of the grasshopper is taken up by the compound eyes. Compare them with your own in position. Examination with a lens shows the whole surface to be composed of tiny hexagonal spaces called facets. Each facet is believed to be a single eye, with perhaps distinct vision from its neighbor. The grasshopper also has three simple eyes on the front of the head. Find them.

Other Sense Organs.-The segmented feelers or antenne have to do with the sense of touch and smell. The ear of the grasshopper is found under the wing on the first segment of the abdomen as before noted. Covering the body and on the appendages, are found hairs (sensory hairs) which appear to be sensitive to touch.

Nervous System. - The nerve chain, as in the crayfish, is on the ventral side of the body. As in the crayfish, it passes around the gullet near the head to the dorsal side, where a collection of ganglia forms the brain. Nerves leave the central system as outgoing fibers which bear motor impulses. Other nerve fibers pass inward, and produce sensations.

Make a careful drawing of the locust, showing as many of the above parts as you can, and label them neatly.

Life History. - The female red-legged locust lays its eggs by digging a hole in the ground with its ovipositor or egg layer, the modified end of the abdomen. From twenty to thirty eggs are laid in the fall; these hatch out in the spring as tiny wingless grasshoppers, otherwise like the adult. As in the crayfish, the young molt in order to grow larger, each grasshopper undergoing several molts before reaching the adult state. In the fall most of the adults die, only a few surviving the winter.

Economic Importance of the Grasshopper. - As far back as Biblical times, the grasshopper was noted for its destructive- 
ness. Frequent mention has been made of damage wrought by them in the early history of this country. In recent times, the damage has been appalling, especially in the central WVest. In 1874-1876 the damage to crops by the Rocky Mountain locust has been estimated at $\$ 200,000,000$. At certain times, these locusts migrate from Colorado, Wyoming, and Dakota, where they breed during the summer, and descend in countless millions upon the grain fields to the eastward. Fortunately these invasions have been rare.

Relatives of the Locust. - One member of this group that we associate with the grasshopper is the cricket. In structure and life habits it resembles the locust. Crickets live most of the time under logs or stones, and seem to prefer darkness to light. The cheerful chirp of the male house cricket is made by rubbing the thickened edge of one wing against a rasplike projection on the opposite wing. The rate of the chirp seems to depend upon the temperature of the surrounding air. Another musician known to all is the katydid. This insect, with its green body and wings, can scarcely be distinguished from the leaves on which it rests. This affords the katydid immunity from attack by many enemies. The protection thus received illustrates what is called protective resemblance. The walking stick, which resembles the twigs on which it is found, and the walking leaf insect of the tropics, are other examples of protective resemblance.

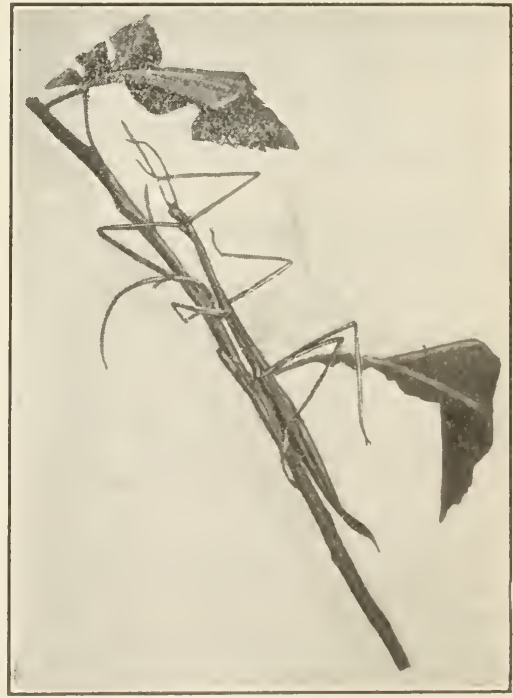

The walking stick on twig, showing protective resemblance.

The mantis, shown in the illustration on the following page, is provided with strongly built forelegs, with which it seizes and 


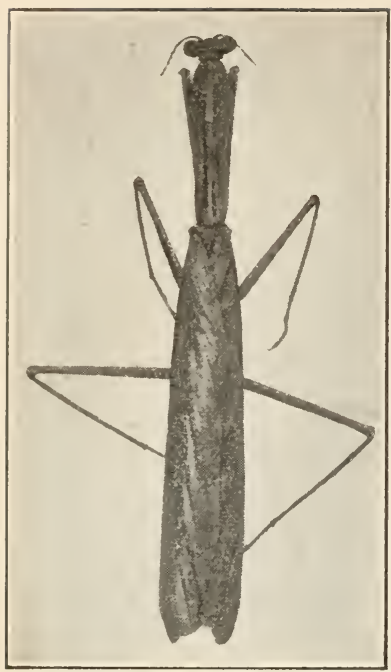

Mantis, showing aggressive resemblance.

holds insects on which it preys. The mantis has the color of its immediate surroundings, and is thus enabled to seize its prey before the latter is aware of its presence. This is known as a case of aggressive resemblance, because by means of its likeness to its surroundings the animal is enabled to attack its prey more easily.

\section{The Order Lepidoptera}

\section{The Monarch Butterfly. ${ }^{1}$ - The body} of the butterfly, as that of the grasshopper, is composed of three regions. This division of the body is characteristic of all insects.

Compare with the grasshopper as to the number and comparative size of the legs. Notice that the first pair is so short that they are not used for walking. Compare the wings with those of the grass-
hopper as to size and shape. Which insect probably has the best powers of flight?

If the wing is touched with the fingers dust comes off. A bit of the wing examined under the compound microscope shows this dust to be composed of tiny scales, which cover the membranous wing somewhat as shingles cover a roof. The scales give color to the wing. Each scale is fastened in place by means of a tiny projection which fits into a socket of the wing. Make a drawing to show several scales and their method of attachment.

In the fall the following questions may be answered from living butterflies: How are the wings used in flight? How are they held when at rest? What is the position of the legs when at rest? How are they used in walking? Are any structures present which aid in clinging to objects?

Let the butterfly feed on sugar and water. The long structure which looks somewhat like a tiny watch spring is the proboscis. Compare its position when in use and not in use. This organ is formed of the two maxillæ, each of which forms half of the tube through which the fluid food is taken into the mouth.

The fluffy structures on each side of the mouth are the labial palps. They have to do with sensation, probably that of detection of odors. As pollen

${ }^{1}$ It is not expected that a pupil can make all the observations noted below on the butterfly and moth as well as on their development. Much of this work can be done as extra observational work when the forms are obtainable: Work in the early spring (when this study is usually taken up) would preclude the possibility of some of the laboratory suggestions outlined. For laboratory directions see Hunter and Vaientine, Manual, page 105. 
carriers they are of importance. Notice the large compound eyes at the side of the head, as in the grasshopper. The antennæ, sensory organs which have to do with hearing and smelling, are knobbed at the ends. The hairs which cover the body are modified on the wings to form scales. Some of these hairs have to do with the sense of touch.

The Senses. - Experiments may easily be made outdoors in the fall of the year to determine if the butterfly can distinguish color. Make careful note of the different flowers visited by a butterfly during a given period of time. Are flowers of certain colors visited during that time? Experiments may also be made to see if the odors of flowers are factors which determine the insects' visits. In most insects the sense of smell is better developed than that of sight. In most

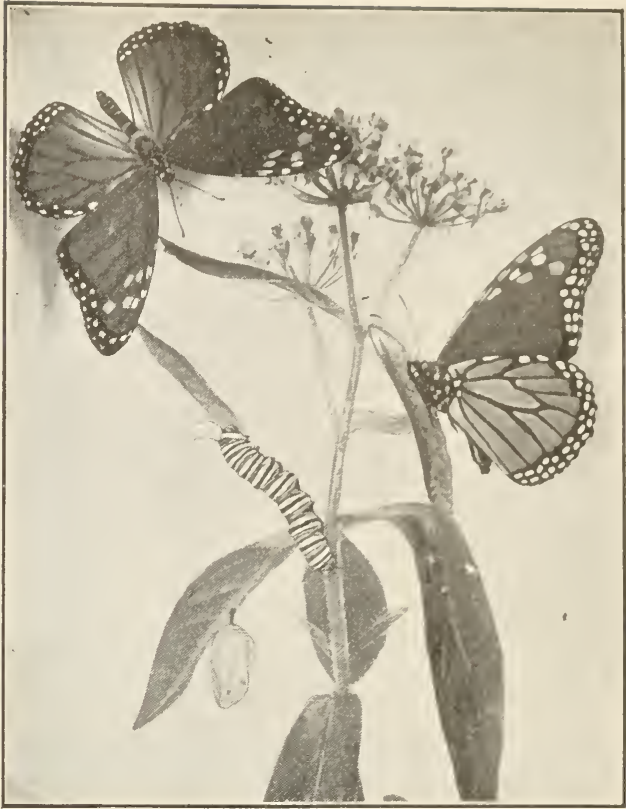

Monarch butterfly; adults, larva, and pupa on milkweed. From photograph loaned by the American Museum of Natural History.

butterflies the antennæ contain the sense cells which have to do with odor; in some male butterflies, however, a pouch on the wing serves as a help in distinguishing the presence of nectar in a flower.

Make a drawing of the butterfly, showing as many as possible of the structures mentioned. Carefully label each part. A drawing of the head

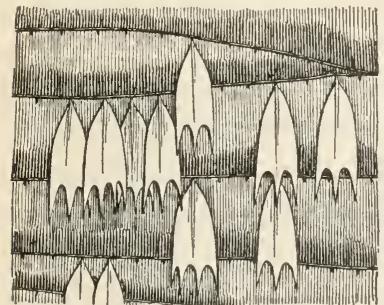

Part of the wing of a moth (Samia), magnified to show the arrangement of scales. as seen from the side, enlarged about four times, will be useful.

The monarch or milkweed butterfly (Anosia plexippus) is one of our commonest insects. Its orange-brown, blackveined wings are familiar to every boy or girl who has been outdoors in the country during the fall months. The adult female lays her eggs in the late spring on the milkweerl. The eggs are fastened singly to the under side of milkweed 
leaves; they are tiny sugarloaf-shaped dots a twentieth of an inch in length. Some wonderful instinct leads the animal to deposit the eggs on the milkweed, for the young feed upon no other plant. Eggs laid in May hatch out in four or five days into rapid-growing caterpillars, each of which will molt several times before it becomes full size. The animal at this stage is known as a larva. ${ }^{1}$

The Caterpillar. - Field Work. The monarch caterpillar has its body covered in a banded combination of yellow and green. Note the horns that are sometimes protruded from the head. Notice where you find the animals; is their color a protection? The caterpillar is very unpleasant to the taste; by means of its conspicuous color the animal warns birds that it is not good to eat. This is known as warning coloration.

The body of the caterpillar is segmented and provided with several pairs of legs. Notice that the number of segments is the same as in the adult butterfly. The true or butterfly legs are found on the anterior segments of the body. Compare them with the false legs or prolegs found more posteriorly. Notice the tips of the legs. How are the legs adapted to clinging? How are the true legs used when the caterpillar is feeding? Watch the caterpillar when it is feeding; the mouth parts are very different from the adult. It is at this stage that caterpillars are of considerable economic importance because of the damage they do to trees and other green plants.

Formation of Pupa. - After a life of a few weeks at most, the caterpillar stops eating and begins to spin a tiny mat of silk upon a leaf or stem. It attaches itself to this web by the posterior pair of prolegs, and there hangs until a last moit (which occurs within twenty-four hours after attachment) gives the animal the form it assumes in the stage known as the chrysalis or pupa.

The Pupa. - Field work. The chrysalis of the monarch is green in color with gold spots. It may be found upon almost any green plant, fence, or even stone, as the animal leaves its food plant before going into this stage. If you find one, examine it carefully. Make out the three parts of the body; the wings, antennæ, and legs may be seen closely folded against the body. The spiracles also show plainly.

The Adult. - After a week or more of inactivity the exoskeleton is split along the dorsal side, and the adult butterfly emerges. At first the wings are soft and much smaller than in the adult. Within fifteen minutes to half an hour after the butterfly emerges, however, the wings are full sized, having been pumped full of blood.

In the adult form the animal may survive the winter. The milkweed butterfly is a strong flyer, and has been found over five

${ }^{1}$ For laboratory work see Hunter and Valentine, Manual, page 107. 
hundred miles at sea. They may migrate southward upon the approach of the cold weather. Some common forms, as the mourning cloak ( $\mathrm{Va}$ nessa antiopa), hibernate in the North, passing the cold

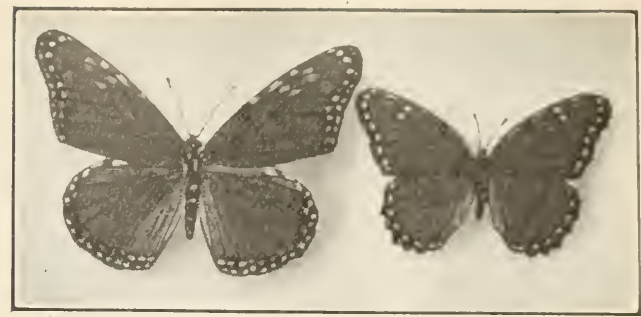

The monarch and viceroy butterflies; the latter (at the right) is a mimic.

weather under stones or overhanging clods of earth.

Mimicry. - The monarch butterfly is an example of a race which has received protection from enemies in the struggle for life, because of its nauseous taste and, perhaps, because its caterpillar feeds on plants of no commercial value.

Another butterfly, less favored by nature, resembles the monarch in outward appearance. This is the viceroy (Basilarchia archippus). It seems probable that in the early history of the species called viceroy some of this edible form escaped from the birds because they resembled in color and form the species of inedible monarchs. These favored individuals produced new butterflies which resembled the monarch more closely. So for generation after generation the ones which were most like the inedible species were left, the others becoming the food of birds. Ultimately a species of butterflies was formed that owed its existence to the fact that it resembled another more favored species. This is known as mimicry, and the viceroy is called a mimic.

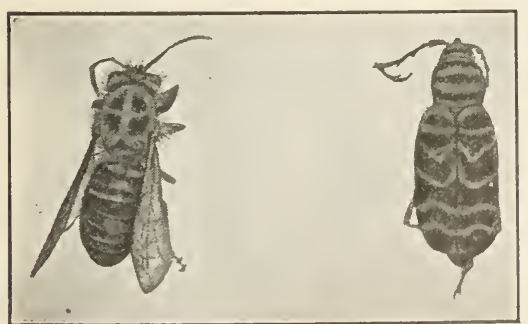

Hornet mimicked by locust-borer, a beetle.
Dimorphism and Polymorphism.It has been found that, when a butterfly produces two broods during one season, the individuals in these broods may differ considerably from cne another. The tiger swaliow-tail is an example. It has also been found that, if the early pupx are kept in an ice box during part of the summer and then allowed to hatch out with the pupx of the second broorl, the forms are then alike in appearance. It would thus seem that the wame factors 


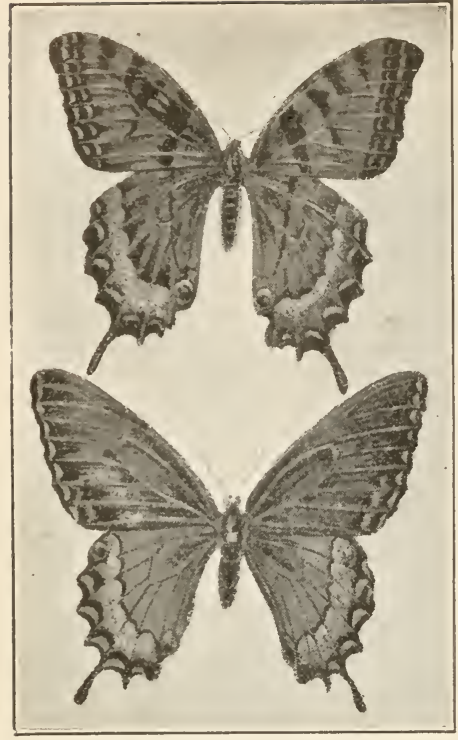

The tiger swallow-tail, showing two forms of females. which play such important parts in the life of plants also play, in some cases at least, equally important parts in molding the form and structure of animals.

The Moth. - The Cecropia (Samia cecropia) may be used for laboratory work. Note the general resemblance to the butterfly. Several differences may be noticed, however. The body is much stouter than that of the butterfly. The wings and body appear to have a thicker coating of hairs and scales. Notice also the feathery antennæ. What is the resting position of the wings? When you draw the moth, be sure to show the color markings of the wings.

The Egg. - The eggs, creamcolored and as large as a pin head, are deposited in small clusters on the under side of leaves of the food plant. The young are at first tiny black caterpillars, which later change color to a bluish green, with and red along the dorsal side.

Study of Caterpillar. - Captive Cecropias will frequently lay eggs which may be watched in development by placing the young caterpillars in a box with leaves of willow or wild cherry. Watch such an animal, and describe the process of molting. Which end molts first? How do they get out of the old skin? Is the color of the feeding caterpillars like that of the leaves? On which side of the leaves do they rest? How are the leaves held in feeding? Are any other parts of the animal besides the jaws used in feeding?

The Pupal Stage. - Unlike the butterfly, the moth passes the quiescent stage in a case of silk or other material called a cocoon. The cocoons of Cecropia may be found in the fall on willows or alders. Such cocoons found in meadows or fields are usually larger than those found on the hillsides, probably because of a difference in the food supply of the larva which spun the cocoon.

Study of a Cocoon and Pupa. ${ }^{1}$ - Where do you find them, and how are they attached? Of what materials is the cocoon made? An interesting report would be the formation of the cocoon. This may be watched by

2 See Hunter and Valentine, Manual, page 108. 
cutting off the food supply of caterpillars in captivity as they will usually, in such event, at once begin the spinning of a cocoon.

If the cocoon is cut open lengthwise, the dormant insect or chrysalis will be found together with the cast-off skin of the caterpillar which spun the case. You can easily make out the parts of the adult moth, the antennæ and wings folded close to the body. Notice how the head and thorax are crowded together. Find the weak spot in the cocoon through which the adult makes its escape. Draw the pupa in the cocoon, and label all its parts.

Silkworms. - The American silkworm (Telea polyphemus) is another well-known moth. The cocoons, made in part out of the leaves of the elm, oak, or maple, fall to the ground when the leaves drop, and hence are not so easily found as those of the Cecropia. This moth is a near relative of the Chinese silkworm, and its silk might be used with success were it not for the high

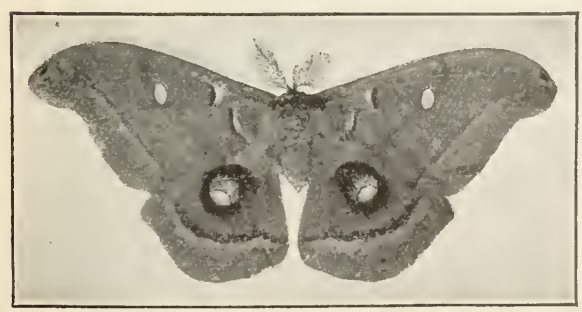

Polyphemus, one half natural size. Photographed by Davison.

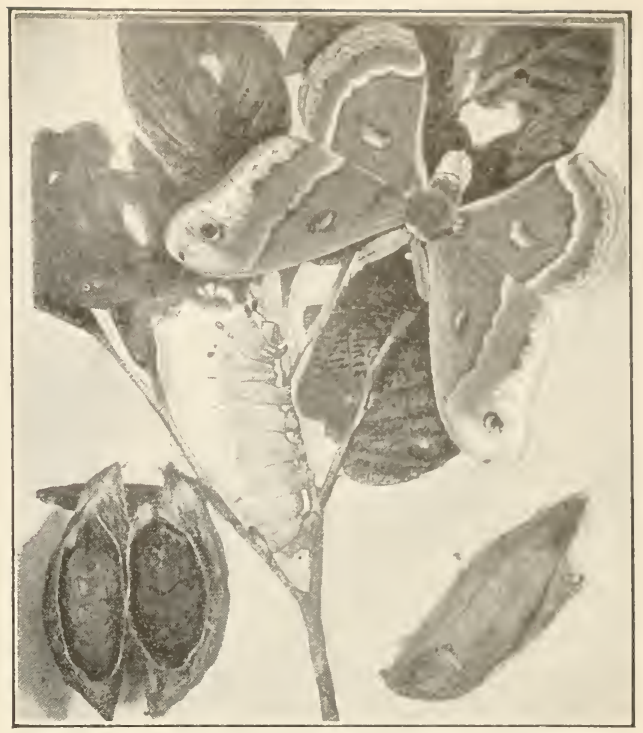

Life history of the Cecropia moth. Above, the adult; the larva (caterpillar) in center; the pupal case to right, below; the same cut open at left, below. From photograph loaned by the American Museum of Natural History. rate of labor in this country. The Chinese silkworm is now raised with ease in southern California. China, Japan, Italy, and France, because of cheap labor, are still the most successful silk-raising countries. It is estimated that it takes the silk from 
at least twenty-five thousand cocoons to form the material for a single dress.

Harm done by Moth Larvæ. - From the economic standpoint the harm done by the moths far outweighs the good they may

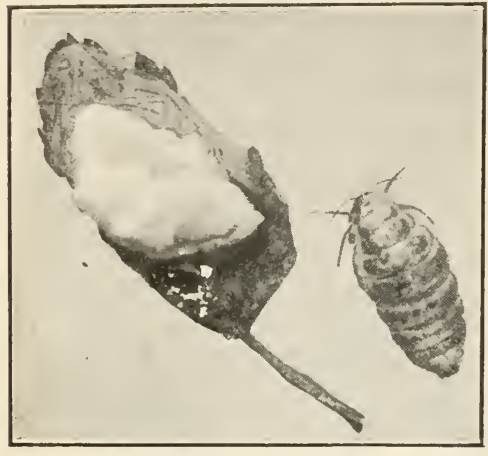

Female tussock moth which has just emerged from the cocoon at the left upon which it has deposited over two hundred eggs. From photograph, slightly enlarged, by Davison. have done. Although they pollinate flowers to some extent, still the butterflies are greater bearers of pollen. Great damage is done annually by the larvæ of moths. Massachusetts has spent some $\$ 3,000,000$ in trying to exterminate the imported gypsy moth. The codling moth, which bores into apples and pears, is estimated to ruin yearly $\$ 3,000,000$ worth of fruit in New York. Among these pests, the most important to the dweller in a large city is the tussock moth which destroys our shade trees. The caterpillar may easily be recognized

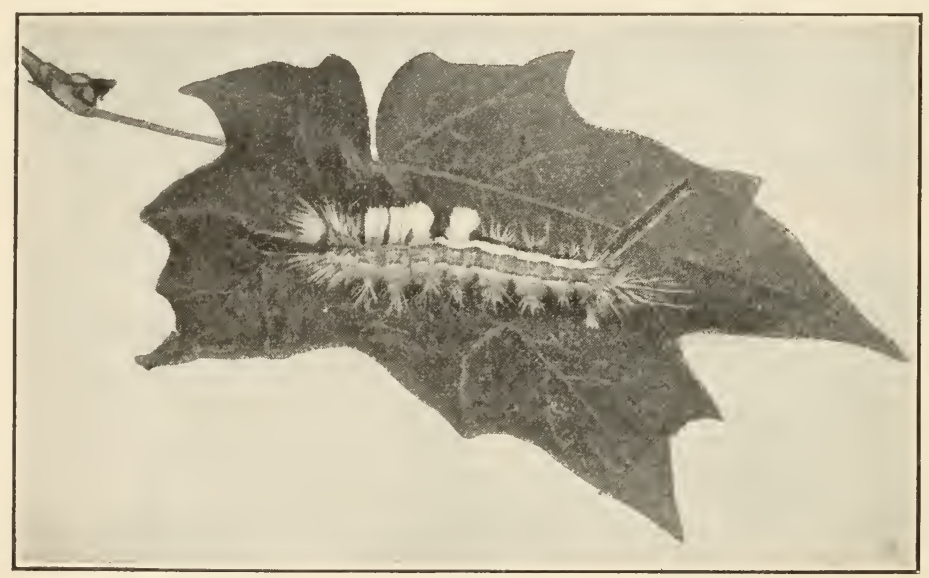

Larva of tussock moth. From photograph, twice natural size, by Davison 
by its hairy, tufted red head. The eggs are linid on the bark of shade trees in what look like masses of foan. By collecting and burning the egg masses in the fall, we may save many sharle trees the following year.

Other enemies of the shade trees are the fall webworm, the forest caterpillar, and the tent caterpillar; the last spins a tent which serves as a shelter in wet weather. Among the greatest enemies to crops are the cankerworm, the measuring worm, the corn worm, and the cotton-boll worm. The last annually damages the cotton crop to the amount of several millions of dollars.

The larvæ of the peach, apple, and other fruit borers damage the trees by boring into the wood of the tree on which they live. The clothes moth, a well-known house pest, lays its eggs in woolen materials, upon which the larvæ feed.

\section{Differences Between Moths And Butterflies}

ButTERFLY

Мотн

Antennæ threadlike, usually Antennæ feathery or rarely knobbed at tip.

Fly in daytime.

threadlike, never knobbed.

Wings held vertically when at Usually fly at night. rest.

Pupa naked.

Wings held horizontally or folded over the body when at rest.

Pupa covered by a cocoon.

Adaptations. - Butterflies and moths are wonderfully adapted to the lives they lead. Instinct leads them to place the eggs on the food plant where food is provided for the young. The edible larvæ are often colored like the plants on which they rest, those not good to eat receive immunity by having bright colors or conspicuous markings which warn away their enemies.

The protective coloration which has been developed in some species of butterflies undoubtedly plays an important part in preserving those species. One of the most interesting examples of this is seen in the ease of the dead-leaf butterfly of India. This butterfly at rest exactly resembles a dead leaf; in flight it is con- 


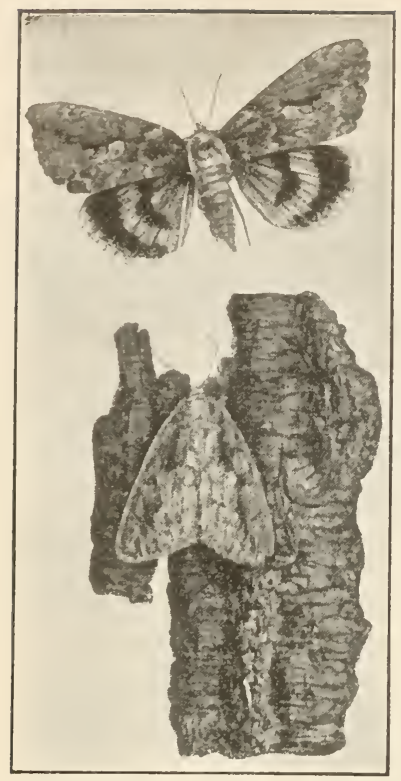

The underwing moth; above, flying; below, at rest on bark. spicuous. The underwing moth is another example of a wonderful simulation of the background of bark on which the animal rests in the daytime. At night the brightly colored under wings probably give a signal to others of the same species. The beautiful luna moth, in color a delicate green, rests by day among the leaves of the hickory. The small measuring worms stand out stiff upon the branches on which they crawl, thus simulating lateral twigs. Hundreds of other examples might be given.

This likeness of an animal to its immediate surroundings has already been noted as protective resemblance.

\section{Reference Books}

FOR THE PUPIL

Burnet, School Zoölogy, pages 101-111. American Book Company.

Davison, Practical Zoology, pages 68-91. American Book Company. Herrick, Text-book in General Zoölogy, Chap. XV. American Book Company.

FOR THE TEACHER

Dodge, General Zoölogy, pages 113-118. American Book Company. Dickerson, Moths and Butterfies. Ginn and Company. Sanderson, Insects Injurious to Staple Crops. John Wiley and Sons.

\section{The F'LIES}

The House Fly. ${ }^{1}$ - Examine a house fly, find the divisions of the body. Notice the small hairs covering parts of it. The wings appear to be only two in number - hence the name Diptera. Behind the gauzy wings you will find the second pair of wings have developed as knobbed hairs, called the balancers. They seem to have the double function of giving aid in balancing and in hearing.

Notice the shape of the head. Is it freely movable? The antennæ are very short, while the eyes are enormously developed. Test with moving

${ }^{2}$ See Hunter and Valentine, Manual, page 114. 
objects the keenness of vision and especially the distance at which a fly notices movement of an object.

Feed the fly with a drop of sugar solution. Study the movement of the organ called the proboscis. This proboscis is made up chiefly of the maxilla, together with the labial palps, the mandible being undereloped. Food is obtained by lapping and sucking. Notice the flaplike extensions on each side of the proboseis; these are roughened on the under surface. It is the rubbing of this filelike organ over the surface of the skin that causes the painful bite of the horse fly. If possible, examine the foot of a fly under a low magnification of the compound microseope. The foot shows a wonderful adaptation for clinging to smooth surfaces. Two or three pads, each of which bears tubelike hairs that secrete a sticky fluid, are found on its under surface. It is by this means that the fly is able to walk upside down.

Home Experiments. - Test the keenness of scent in the fly by placing in an exposed place a bit of meat, some bread, salt, sugar, and other foods, some of which have distinct odor. Cover each food with tissue paper. Which food attracts the most flies?

Test the sense of taste of the fly by the following experiment.

Place in a netting cage four butter chips containing a solution of sugar, salt, alum, and strychnine or other bitter fluid. Place in the cage a number of flies, and at the end of a given period count the number at each dish. Do flies appear to have the sense of taste?

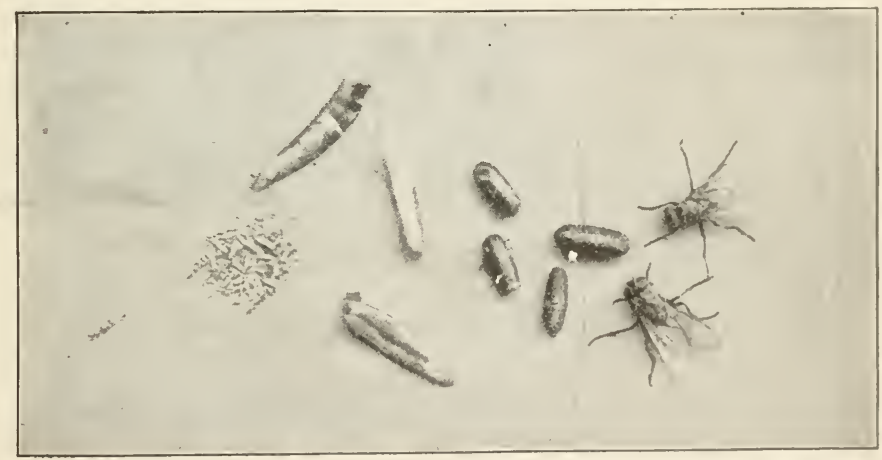

Life history of house flies, showing from left to right the eggs, larva, pupæ, and adult flies. Photograph, about natural size, by Overton.

The House Fly a Pest. - The house fly is recognized the world over as a pest. Not only do flies spoil much food by means of their filthy habits, but the far more important charge of spreading disease is now laid to them. The bacteria causing typhoid fever might be carried on their feet; so flies could easily carry the typhoid bacteria to a dish of milk, thus infecting the milk and causing danger to all drinking it.

Development. - The development of the house fly is very rapid HUNTER'S BIOL. -16 . 
A female may lay from one hundred to two hundred eggs. These are usually deposited in filth or manure. In warm weather within a day after the eggs are laid the young maggots, as the larvæ are called, hatch. After about one week of active feeding these wormlike maggots become quiet and go into the pupal stage, whence under favorable conditions they emerge within another week as adult flies. The adults breed at once, and in a short summer there may be over ten generations of flies. This accounts for the great number. Fortunately few flies survive the winter.

The Mosquito. - Among the flies are some of the greatest human pests. The mosquito is one relative which is known to

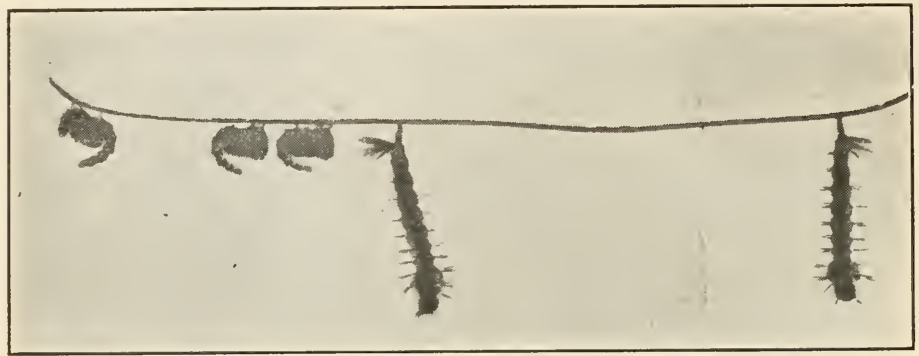

Three pupæ and two larvæ of mosquitoes at the surface of the water, breathing. The black line is the water surface. From photograph from life, twice natural size, by Davison.

harbor the small one-celled parasite (a protozoan) which causes malaria. Another species of mosquito is a carrier of yellow fever. Mosquitoes lay eggs in tiny rafts of one hundred or more eggs in any standing water. Rain barrels, gutters, or old cans may breed in a short time enough mosquitoes to stock a neighborhood. The larvæ are known as wigglers. They breathe through a tube in the posterior end of the body and may be recognized by their peculiar movement when on their way to the surface to breathe. The fact that both larvæ and pupæ take air from the surface of the water makes it possible to kill the mosquito during these stages by pouring crude oil on the surface of the water where they breed. The introduction of goldfish or other small fish into water where they breed is another effective means of killing this pest.

Economic Importance of Other Flies. - Other flies which are of 
great economic importance are the Hessian fly, the larvæ of which feeds on young wheat; the bot fly, which in a larval state is a parasite on horses; the dreaded tsetse fly of South Africa, which is now believed to cause disease in horses and cattle by means of the transference of a parasitic protozoan, much like that which causes malaria in man; and many others.

Among the few flies useful to man may be mentioned the tachina flies, the larvæ of which feed on the cut worm, the army worm, and various other kinds of injurious caterpillars.

\section{Reference Books}

$$
\text { FOR THE PUPIL }
$$

Davison, Practical Zoölogy, pages 39-52. American Book Company.

Herrick, Text-book in General Zoölogy, pages 183-186. American Book Company. Farmers' Bulletin. How Insects affect Health in Rural Districts. U.S. Department of Agriculture.

\section{The Order Neuroptera}

The Dragon Fly. - The dragon fly receives its name because it preys on insects. It eats, when an adult, mosquitoes and other insects which it captures while on the wing. Its large lacelike wings give it power of very rapid flight, while its long narrow body is admirably adapted for the same purpose. The large compound eyes placed at the sides of the head give keen sight. Notice the powerful jaws (almost covered by the upper and lower lips). Compare the position of the wings when at rest with those of the grasshopper. The wings in this case are adapted for swift flight.

The long thin abdomen does not contain a sting, contrary to the belief of most children. These in-

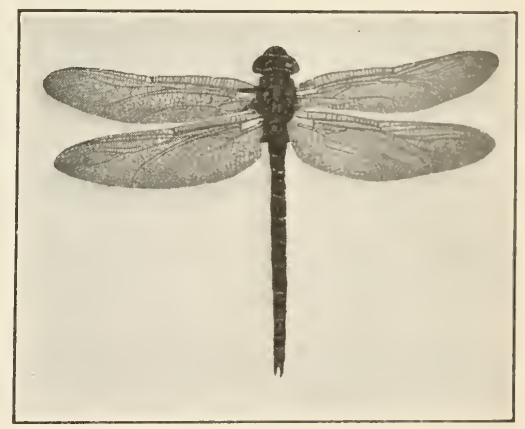

Dragon fly. Notice the long abclomen and large compound eyes. sects deposit their eggs in the water, and the fact that they may be often seen with the end of the abdomen curved down under the surface of the water in the act of depositing the eggs, has given rise to the belicf that they were then engaged in stinging something. The egg hatches into a form of larva called a nymph, which in the dragon fly is characterized by a greatly developed lower lip. When the animal is at rest, the 
lower lip covers the large biting jaws which can be extended so as to grasp and hold its prey. The nymphs of the dragon fly take oxygen out of the water by means of gill-like structures placed in the posterior part of the food tube. They may live as larvæ from one summer to as long as two years in the water. They then crawl out on a stick, molt by splitting the skin down the back, and come out as adults.

A nearly related form is the damsel fly. This may be distinguished from the dragon fly by the fact that when at rest the wings are carried close to the abdomen, while in the dragon fly they are held in a horizontal position. ${ }^{1}$

May Flies. - Another near relative of the dragon fly is the May fly. These insects in the adult stage have lost the power to take food. Most of their life is passed in the larval stage in the water. The adults sometimes live only a few hours, just long enough to deposit their eggs.

\section{The Order Coleoptera}

Beetles. - Beetles are the most widely distributed of all insects and by far the most numerous. There are over one hundred thousand living species; more than all other animals in the world exclusive of the insects.

Any beetle will show the following characteristics: ${ }^{2}$ (1) The body is usually heavy and broad. Its exoskeleton is hard and tough. The lower side of the abdomen is also hard. The chitinous covering is better developed in the beetles than in any other of the insects. (2) The three pairs of legs are stout and rather short. (3) The outer wings are hard and fit over the under wings like a shield. These sheathlike wings are called elytra. (4) The mouth parts are fitted for biting. They consist of very heavy curved pincher-shaped mandibles, which are provided with palps. There is an upper and lower lip.

The Living Beetle. - Use any large beetle to answer the following questions. Identify the above-named parts in your specimen. Test the ability of any large beetle to bite. Are the jaws strong? Give proofs. Do the jaws move in the same plane with your own? Does the beetle have antennæ (feelers)? How does the beetle use its legs in walking? Is there any regular order? If the animal is allowed to walk over an ink pad or through a drop of ink, its track may easily be traced on paper and then transferred to your notebook. In what respects is the beetle protected from its enemies? How is it adapted to the life it leads?

${ }^{1}$ The old seven-order system of classification is useful for pupils of first year in the high school. This allows a place for many forms otherwise not easily classified under the order Neuroptera. 112.

${ }_{2}^{2}$ For laboratory directions on beetles, see Hunter and Valentine, Manual, page 
Make a drawing of the beetle, natural size, to show as many of the above parts as possible.

The Life History of a Beetle. - The June bug (May beetr) and potato beetle are excellent examples. May beetles lay their eggs in the ground, where they hatch into cream-colored grubs. A grub differs from the larval fly or maggot in possessing three pairs of legs. These grubs live in burrows in the ground. Here they feed on the roots of grass and garden plants. The larval form remains underground for from two to three years, the latter part of this time as an inactive pupa. During the latter stage it lies dormant in an ovoid area excavated by it. Eventually the wings (which are budlike in the pupa) grow larger, and the adult beetle emerges fitted for its life in the open air.

Economic Importance. - Among the beetles which are of economic importance is the potato beetle which destroys the potato plant. This beetle formerly lived in Colorado upon a wild plant of the same family as the potato and came east upon the introduction of the potato into Colorado, evidently preferring cultivated forms to wild forms of this family. The snout beetles or weevils do much damage to stored grains and fruits. Other beetles known as the borers produce larvæ which bore into trees

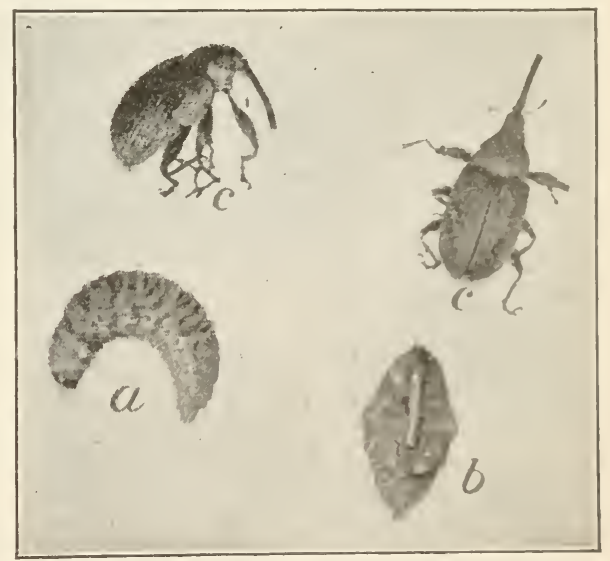

Cotton-boll weevil; $a$, larva; $b$, pupa; $c$, adult. From photograph, enlaiged four times, by Davison. and then feed upon the sap of the tree. Many trees in our Adirondack Forest Reserve annually succumb to these pests. Most fallen logs will repay a search for the larvæ which bore between the bark and wood. Among the most destructive of all in city homes are the carpet beetles. 
Firefly. - One form not usually considered by boys and girls as a beetle is the firefly. The light produced by this beetle is believed by scientists to be caused by a true oxidation of fatty substances stored in the cells of the lower surface of the abdomen.

Beetles Useful to Man. - Several beetles are of value to man. Most important of these is the natural enemy of the orange-tree

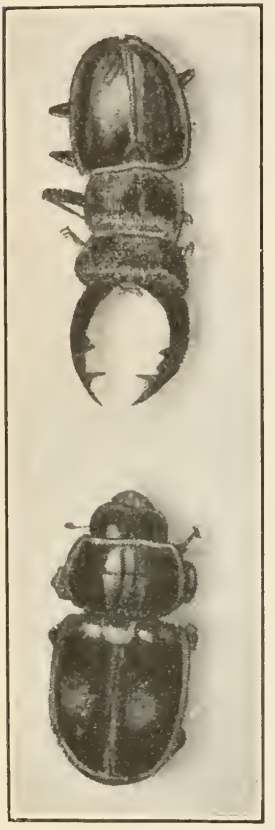

The stag beetle, showing sexual dimorphism. Male above, female below. Natural size. scale, the ladybug, or ladybird beetle. This insect preys upon the scale insect. In New York state it may often be found feeding upon plant lice or aphids which live on rose bushes. The carrion beetles and many water beetles act as scavengers. The sexton beetles bury dead carcasses of animals. These beetles are provided with antennæ that have the end segments peculiarly modified for the purpose of smelling.

Sexual Dimorphism. - Among beetles, as among other insects, the two sexes sometimes show marked differences. This is particularly well shown in the case of the stag beetle, shown in the illustration. This difference in form between male and female of a given species is known as sexual dimorphism.

\section{HEMIPTERA}

Bugs. - The cicada, or as it is incorrectly called, the locust, is a familiar insect to all. Its droning song is one of the accompaniments of a hot day. The song of the cicada is produced by a drumlike organ which can be found just behind the last pair of legs. The sound is caused by a rapid vibration of the tightly stretched drumhead.

Characteristics of the Cicada. - In a living animal notice that the body is heavy and bulky. The wings, four in number, are relatively small, but the powerful muscles give them very rapid movement. The anterior wings are larger than the posterior. The legs are not large or strong; the movement when crawling being sluggish. Note the color of the body; evidently the insect depends upon protection by means of assuming the colors of the 
objects on which it rests. The principal characteristics of the cicada, and of all bugs, is that the mouth parts are prolonged into a beak with which the animal first makes a hole and then sucks up the juices of the plants on which it lives.

Life History. - The 17-year cicada lays her eggs in twigs of trees and in doing this causes the death of the twig. The young leave the tree immediately after hatching, burrow under ground, and pass from thirteen to seventeen years there. In the South this period is shortened. 'They live by sucking the juices from roots. During this stage they somewhat resemble the grub of the beetle (June bug) in habits and appearance. When they are about to

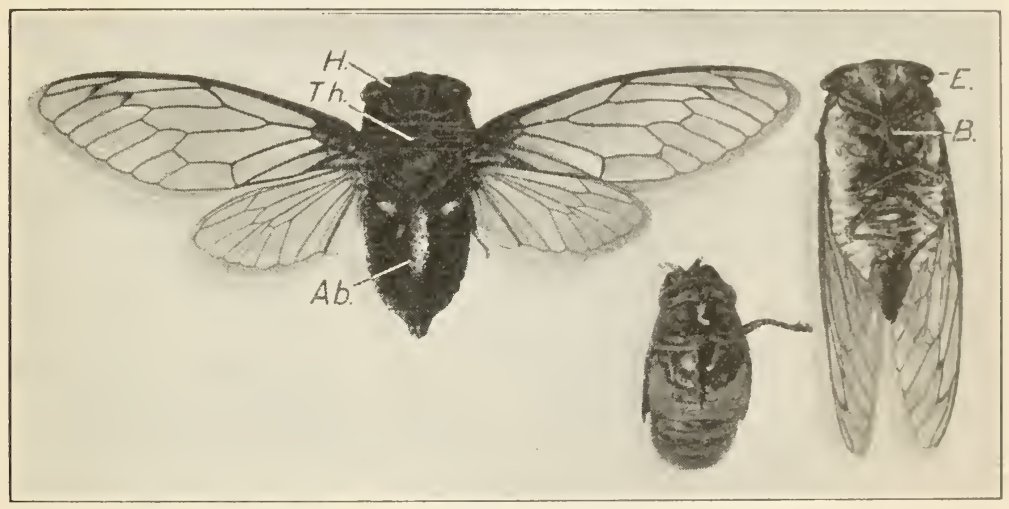

1

2

S

Cicada: 1 , adult with wings spread, showing abdomen $(A b$.$) , head (H$.$) , thorax (T h$.$) ;$ \&, pupal case, showing the split down the back; 3 , ventral view, showing beak ( $\left.B_{\text {. }}\right)$, eye, $\left(E_{\text {. }}\right)$.

molt into an adult, they climb above ground, cling to the bark of trees, and then crawl out of the skin as adults.

Economic Importance. - The bugs are among our most destructive insects. The most familiar examples of our garden pests are the squash bug; the chinch bug, which yearly does damage estimated at $\$ 20,000,000$ by sucking the juice from the leaves of grain; the scale insects, our greatest fruit tree pests, especially in the orange groves of California; and the plant lice or aphick.

Aphids. - The aphids are among the most interesting of the hemiptera. They are familiar to all as the tiny green lice seen swarming on the stems and leaves of the rose and other cultivated plants. 


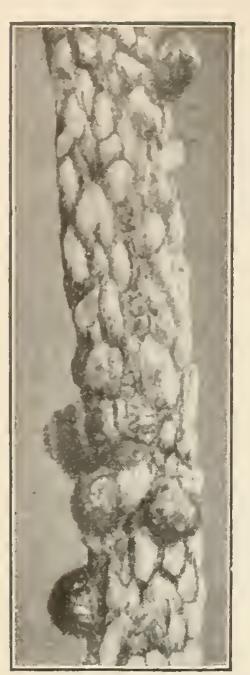

Maple scale, five adults and many young. From photograph, enlarged twice, by Davison.

They suck the juices from stem and leaf. Plant lice have a remarkable life history. Early in the year eggs develop. into wingless females, which produce living young, all females. These in turn reproduce in a similar manner, until the plant on which they live becomes overcrowded and the food supply runs short. Then a generation of winged aphids is produced. These fly away to other plants, and reproduction goes on as before until the approach of cold weather, when males and females appear. Fertilized eggs are then produced which give rise to young the following season.

The aphids exude from the surface of the body a sweet fluid called honeydew. This is given off in such abundance that it is estimated if an aphid were the size of a cow it would give two thousand quarts a day. This honeydew is greatly esteemed by other insects, especially the ants. For the purpose of obtaining it, some ants care for the aphids, even providing food and shelter for them. In return the aphid, stimulated by a stroking movement of the antenna of the ant, gives up the honeydew to its protector.

Some aphids are extremely destructive to vegetation. One, the grape Phylloxera, yearly destroys immense numbers of vines in the vineyards of France, Germany, and California.

\section{The Order Hymenoptera}

This order contains some of the most highly developed insects. We have already learned something of the structure and habits of the bees, in connection with the study of the pollination of Howers. Let us now find out about their wonderful communal life. In the order Hymenoptera are placed bees, ants, and wasps, insects which have developed a complicated social life. In connection with this communal life. nature has worked out a division of 
labor which is very remarkable. This can be seen in tracing out the lives of several of the communal insects.

Solitary Wasps. Some bees and wasps lead a solitary existence. The solitary and digger wasps do not live in communities. Each female constructs a burrow in which she lays eggs and rears her young. The young are fed upon spiders and insects previously caught and then stung into insensibility. The nest is closed up after food is supplied and the young later gnaw

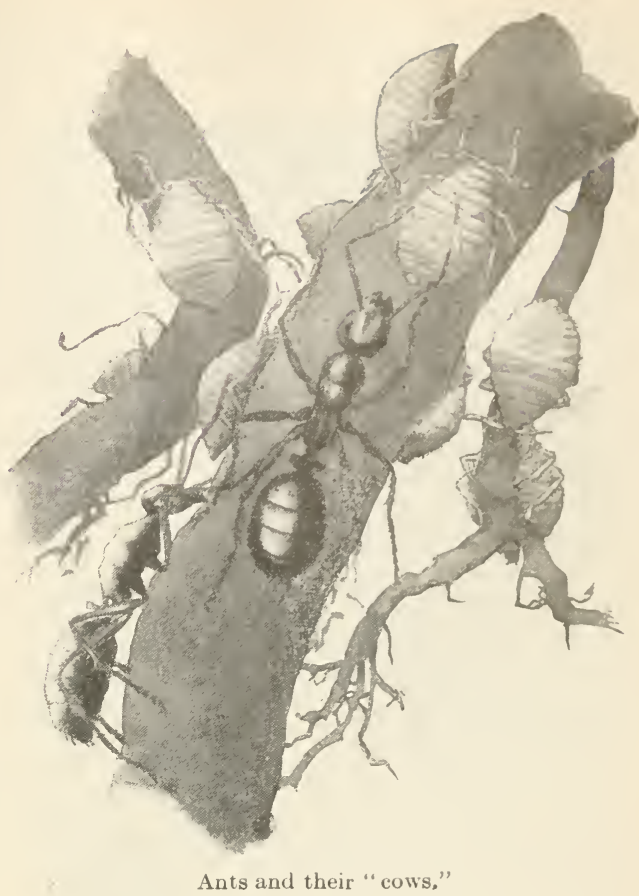
their way out. In the life history of such an insect there is no communal life.

Bumblebee. - In the life history of the big bumblebee we see the beginning of the community instinct. Some of the female bees (known as queens) survive the winter and lay their eggs the following spring in a mass of pollen, which has been previously gathered and placed in a hole in the ground. The young hatch as larvæ, then pupate, and finally become workers, or females. In the working bee the egg-laying apparatus, or ovipositor, is molified to be used as a sting. The workers bring in pollen to the queen, in which she lays more eggs. Several broods of workers are thus hatched during a summer. In the early fall a brood of males or drones, and egg-laying females or queens, are produced instead of workers. 
It is by means of these egg-producing females that the brood is started the following year, as stated on the preceding page.

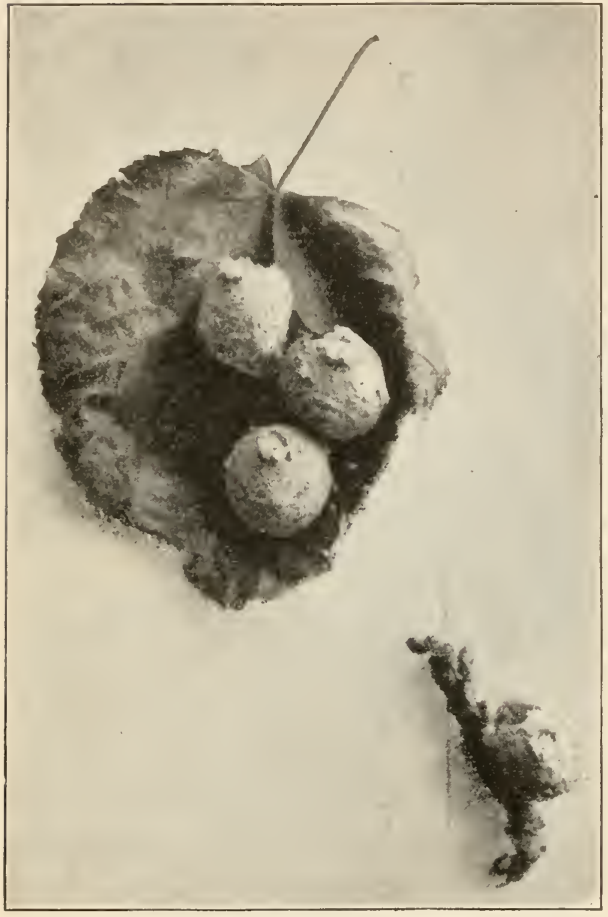

Nests of solitary wasps on an apple leaf. From photograph by Overton.

The Honeybee. - The most wonderful communal life is seen, however, among the honeybees. Their daily life may be easily watched in the schoolroom, by means of one of the many good and cheap observation hives now made to be placed in a window frame. ${ }^{1}$

The honeybee in a wild state makes its home in a hollow tree; hence the term bee tree. In the hive the colony usually consists of a queen, or egg-laying female, a few hundred drones, or males, and several thousand working females, or workers. The colonies vary greatly in numbers. In a wild state there are fewer making up the colony. The division of labor is well seen in a hive in which the bees have been living for some weeks. The queen does nothing except lay eggs, sometimes laying three thousand eggs a day and keeping this up, during the warm weather, for several years. She may lay one million eggs during her life. She does not, as is popularly believed, rule the hive, but

1 Directions for making a small observation hive for school work can be found in Hodge, Nature Study and Life, Chap. XIV. Bulletin No. 1, U.S. Department of Agriculture, entitled The Honey Bee, by Frank Benton, is valuable for the amateur bee keeper. It may be obtained for twenty-five cents from the Superintendent of Documents, Union Building, Washington, D.C. 
is, on the contrary, a captive most of her life. Most of the eggs are fertilized by the sperm cells of the males; the unfertilized eggs develop into males or drones. After a short existence in the hive the diones are usually driven out by the workers. The fertilized eggs may develop into workers, or, if the young larva is fed with a certain kind of food, it will develop into a young queen.

The cells of the comb are built by the workers out of wax secreted from the ventral surface of the bodies. The wax is cut off in thin plates by means of the wax shears between the two last joints of the hind legs. These cells are used by the queen to

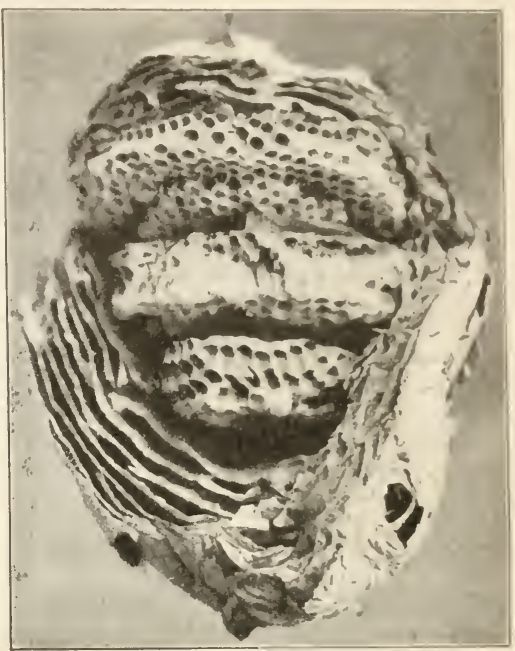

Hornets' nest, opened to show the cells of the comb. From photograph by Overton. place her eggs in, one to each cell, and the young are hatched after three days to begin life as footless white grubs.

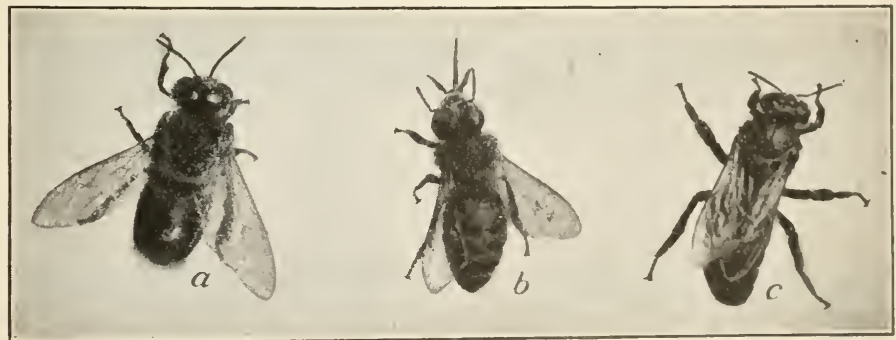

Honeybees; $a$, drone; $b$, worker; $c$, queen. From photograph by Davison.

For a few days they are fed on partly digested food called bee jelly, regurgitated from the stomach of the workers. Later they receive pollen and honey to eat. A little of this mixture, known 
as beebread, is then put into the cell, the lid covered with wax by the working bees, and the young larvæ allowed to pupate. After about two weeks of quiescence in the pupal state, the adult worker breaks out of the cell and takes her place in the hive, first caring for the young as a nurse, later making excursions to the open air after food as an adult worker.

If new queens are to be produced, several of the cell walls are broken down by the workers, making a large ovoid cell in which one egg develops. The young bee in this cell is fed during its whole larval life upon bee jelly and grows to a much larger size than an ordinary worker. When a young queen appears, great excitement pervades the community; the bees appear to take sides; some remain with the young queen in the hive, while others follow the old queen out into the world. Here they usually settle around the queen, often hanging to the limb of a tree. This is called swarming. This instinct is of vital importance to the bees, as it provides them with a means of forming a new colony. For while the bees are swarming, certain of the workers, acting as scouts, determine on a site for their new home; and, if undisturbed, the bees soon go there and construct their new hive. A swarm of domesticated bees, however, may be quickly hived in new quarters.

We have already seen (see pages 37 and 38 ) that the honeybee gathers nectar which she swallows, keeping the fluid in her crop until her return to the hive. Here it is regurgitated into cells of the comb. It is now thinner than what we call honey. To thicken it the bees swarm over the open cells, moving their wings very rapidly, thus evaporating some of the water in the honey. A hive of bees have been known to make over thirty-one

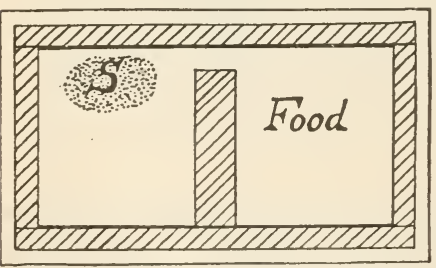

Diagram of an artificial ants' nest; $S$, moistened sponge. After Miss Fielde. pounds of honey in a single day, although the average record is very much less than this.

Ants. - Other social Hymenoptera are the ants. The social habits of these insects have long been a subject of study. An artificial ants' nest can easily 
be made and the whole colony studied in the schoolroom or at home. ${ }^{1}$

Ants are the most truly communal of all the insects. Their life history and habits are not so well known as those of the bee, but what is known shows even more wonderful specialization. The inhabitants of a nest may consist of wingless workers, which in some cases may be of two kinds, and winged males and females.

Ant larvæ are called grubs. They are absolutely helpless and are taken care of by nurses. The pupæ may often be seen taken out in the mouths of the nurse ants for sun and air. They are mistakenly called ants' eggs in this stage.

The colonies consist of underground galleries with enlarged storerooms, nurseries, etc. The ants are especially fond of honeydew secreted by the aphids or plant lice. Some species of ants provide elaborate stables for the aphids, commonly called ants' cows, supplying with food and shelter and taking the honeydew as their reward. This they obtain by licking it from the body of the aphids. A western form of ant, found in New Mexico and Arizona, rears a scale insect on the roots of the cactus for this same purpose.

It is probable that some species of ants are among the most warlike of any insects. In the ease of the robber ants, which live entirely by war and pillage, the wcrkers have become modified in

1 A successful nest for the schoolroom is made and described by Miss Adelc M. Fielde. See the Biological Bulletin, Vol. VII, No. 4, September, 1904.

The floor of the nest is a pane of window glass six by ten inches. Build a wall by cementing with crockery cement four half-inch strips of thicker glass, and upon these cement four more strips, making the wall at least one quarter of an inch high. The space inside is divided by one or two partitions built the same as the outer wall. Spaces should be allowed for communication between chambers. The whole outer surface of the nest thus made may be covered with black paper to make it opaque. A lining of Turkish toweling is glued to the top of the wall. The cover, which rests on the toweling, should be either of glass made opaque, or better, of glass (such as ruby glass of dark rooms) that will exclude most of the ultra-violet light rays. It is best to provide a separate roof for cach chamber. Ants need moisture, so that a small bit of moist sponge should be kept in the room where the ants live. The food chamber, where bits of cake, banana, apple, or other food mixed with honey or molasses, are placed, should also be kept moist.

To stock such a nest, dig up a small colony and transfer them, along with some earth, to the schoolroom. To separate the ants from the earth place them with the earth on a little island of wood in a basin of water. On one side of the island place a glass plate and shade this plate by a piece of opaque paper raised slightly above the glass. The ants soon remove themselves and their young to the dark area and may then be transferred to the nest. Ant colonies have been kept for three or four years in such a nest. 
structure, and can no longer work, but only fight. Some species go further and make slaves of the ants preyed upon. These slaves do all the work for their captors, even to making additions to their nest and acting as nurses to their young.

The entire communal life of the ants seems to be based upon the perception of odor. If an ant of the same species but from a different nest be put

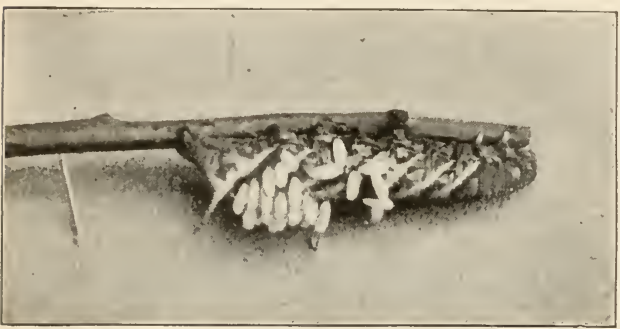

Tomato worm and cocoons of ichneumons. From photograph by Overton. into another colony, it will be set upon and either driven out or killed. Ants never really lose their community odor; those absent for a long time, on returning, will be easily distinguished by their odor, and eagerly welcomed by the mem-

bers of the nest. The talking of ants (when they stop each other, when away from the nest, to communicate) is evidently a process of smelling, for they caress each other with the antennæ, the organs with which odors are perceived.

Ichneumons. - One of the Hymenoptera (incorrectly called a fly), the ichneumon fly, is of considerable importance, because of its habit of laying its eggs and rearing the young in the bodies of caterpillars which are harmful to vegetation. Some of the ichneumons even bore into trees in order to deposit their eggs in the larvæ of wood-boring insects. It is safe to say that by the

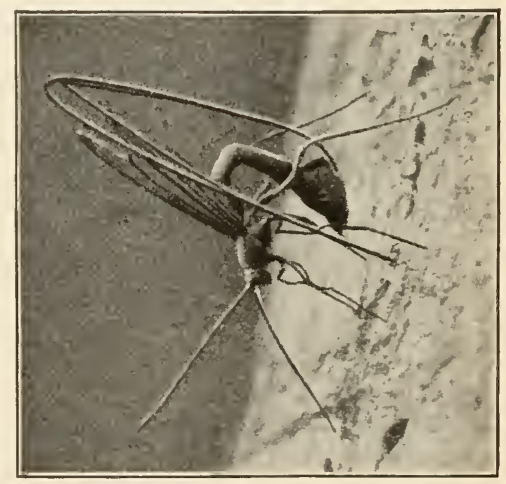

Thalessa boring in an ash tree to deposit its eggs in the burrow of a horn-tail larva, a wood borer. From photograph, natural size, by Davison. 
above means the ichneumons save millions of dollars yearly to our country.

\author{
Rewerence BoOKS \\ FOR THE PUPI,
}

Davison, Practical Zoölogy, pages 52-68. American Book Company.

Herrick, Text-book in General Zoölogy, Chap. XV. American Book Company.

Jordan, Kellogg, and Heath, Animal Studies, Chap. XXII. U. Appleton and Company.

Needham, Outdoor Studies. American Book Company.

FOR THE TEACHER

Comstock, Insect Life. D. Appleton and Company.

Lubbock, Ants, Bees, and Wasps. D. Appleton and Company. 


\section{SPIDERS AND MYRIAPODS}

Structure of the Spider. - Use any large spider for the following work, preferabiy Argiope, the brightly colored garden spider. ${ }^{1}$

Examine the large spider carefully. Notice that it differs from an insect in having the head and thorax joined together to form a cephalothorax.

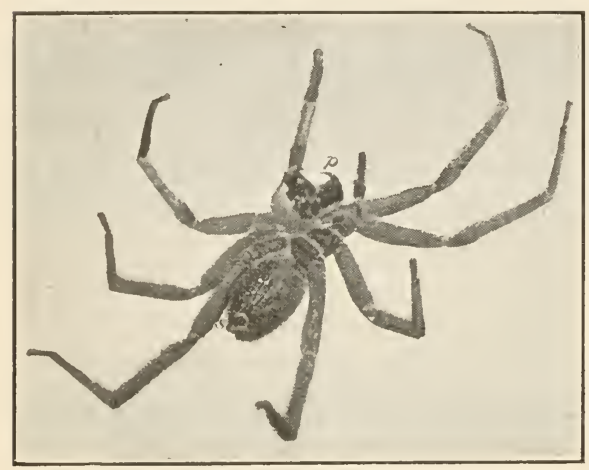

Гarantula on its back; $p$, poison fang; $s$, spinneret. Reduced from photograph by Davison.

Notice the number of legs; here is another difference from insects. Look on the dorsal side of the cephalothorax. The glistening black objects are simple eyes, of which there are usually four pairs. IT hat is the number and position of eyes in this specimen? Make a cliagram. Argiope breathes by means of lunglike sacs in the abdomen, the openings of which can sometimes be seen just behind the most posterior pair of legs. Another organ possessed by the spider, which insects do not have (except in a larval form), is known as the spinneret. This is a set of glands which secrete in a liquid state the silk which the spider spins. On exposure to air this fluid hardens and forms a rery tough building material rhich combines lightness with strength. Look carefully at a spider spinning and decide where the spinnerets are located. ${ }^{2}$

USES AND FORM OF THE WEB. - The web-making instinct of spiders forms an interesting study. Our common spiders may be grouped according to the kind of home they build. The web in some cases is used as a home, in others it forms a snare or trap. In some cases the web is used for ballooning, spiders having been noticed clinging to their webs miles out at sea. The webs seen most frequently are the so-called cobwebs. These usually serve as a snare rather than a home, some species remaining away from the web. In other cases the spider hangs, back downward, under a thin sheet of filmy cross lines.

The funnel-web makers form a closely woven web which is usually attached to grass or may be found in corners of a building. From one end of the

1 For laboratory work see Hunter and Valentine, Manual, page 117.

2 Useful laboratory or home work may be given in the form of tabular comparisons between the various species of the arthropods. For examples of such tables see Hunter and Valentine, Manual, pages 116, 120, 127, 130. 
web a funnel-like tube runs downward and inward. In this tube the spider spends most of the time, running out to eatch insects which may become entrapped. At the lower end of the tube is an opening through which the spider may escape in time of necessity. The funnel-web builders are strong-legged, active spiders.

The orb-weaving spiders spin webs of geometrical exactness in bushes or long grass. They are usually of almost circular form with a spirally wound center thread supported on guy lines which are attached firmly to surrounding objects. These webs, which act both as homes and snares, are made of two kinds of silk, a supporting thread, tough but rather inelastic, and a thinner elastic sticky thread, out of which the snare is woven. The outer part of the web forms the snare. The central part of the web usually contains a shield of closely woven silk on which the spider may rest. Some orb weavers live near one edge of the web, hanging suspended within easy reach of a possible capture. In traveling over the outer part of the web the spider uses the guy lines only, as otherwise it might destroy its own web. Why?

One of the commonest of the orb weavers is a large yellow and black spider known as Argiope. Their webs may be found in almost any garden or yard.

Find such a web. Describe its location. How is it attached? How many guy lines does it contain? Look for the central shield on which the

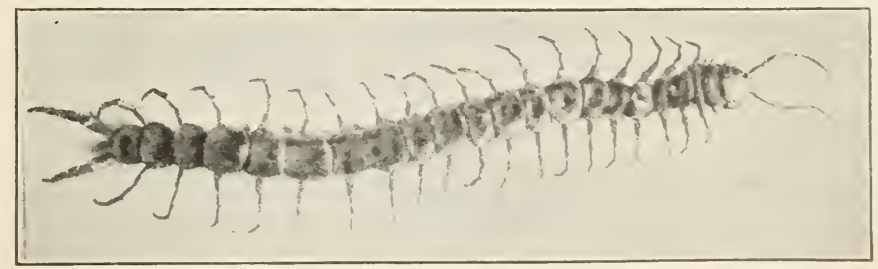

A poisonous centiped from Texas. Half natural size. From photograph by Davison.

spider rests. Do you find a "winding stair"? Notice the open area between the central home of the spider and the outer or spiral zone of the web. This area, known as the free zone, gives opportunity for free inovement around the web, as the spider does not travel on the sticky outer portion.

Other Forms of Web. - Other forms of webs are seen in the wonderful nest of the trapdoor spider which, after excavating a hole in the ground, lines it with silk and then makes a lid of earth also lined with silk. This lid is closed by the spider after its retreat to the hole. Other spiders use the web for bridge building. In this case a long single strand is spun which is allowed to float off behind the spider into the air. This is flown like a HUNTER'S BIOL. -17 
kite until it catches some projection, when the spider hauls in the slack, makes it fast, and travels across on the slender bridge thus built.

Myriapods. - IVe are all familiar with the harmless and common thousand legs found under stones and logs. It is a representative of the group of animals known as the millepeds. These animals have the body divided into two regions, head and trunk. They have two pairs of legs for each body segment. The centipeds, on the other hand, have only one pair of legs to each segment. None of the forms in the eastern part of the United States àre poisonous.

\section{Classification of Arthropoda.}

Cuass, Crustacea. Arthropods with limy and chitinous exoskeleton, breathing by gills, and having two pairs of antennæ.

Subclass I. Entomostraca. Crustacea with a variable number of segments, chiefly small forms with simple appendages. Some degenerate or parasitic. Examples, barnacles, water flea (Daphnia), and copepods (Cyclops).

SubClass II. Malacostraca. Usually large crustacea having nineteen pairs of appendages. Examples, American lobster (Homarus americanus), crab (Cancer), or shrimp (Palamonetes).

Class, Hexapoda (insects). Arthropoda having chitinous exoskeleton, breathing by air tubes (trachea), and having three distinct body regions.

Order, A ptera (without wings). Several wingless forms. Examples, springtails.

Order, Orthoptera (straight wings). Example, Rocky Mountain locust.

Order, Lepidoptera (scale wings). Examples, cabbage butterfly, cecropia moth.

Order, Diptera (two wings). Examples, house fly, mosquito.

Order, Hemiptera (half wing). Examples, all true bugs, plant lice, and cicada.

Order, Neuroptera (nerve wings). Examples, May fly, dragon fly.

Order, Coleoptera (shield wings). Examples, beetles.

Order, Hymenoptera (membrane wings). Examples, bees, wasps, ants.

Class, Arachnida. Arthropoda with head and thorax fused. Six pairs of appendages. No antennæ. Breathing by both lungs (spiders) or tracheæ. Examples, spiders and scorpions.

Class, Myriapoda. Arthropoda, having long bodies with many segments; one or two pairs of appendages to each segment. Breathing by means of tracheæ. Example, centiped.

\section{ReFerexce Books}

FOR THE PUPIL

Needham, Outdoor Studies. American Book Company.

FOR THE TEACHER

Emerton, The Structure and Habits of Spiders. Knight and Millet. 


\section{MOLLUSKS}

Mollusca. - The name Mollusca (Latin mollis=soft) gives the character which chiefly aids us in identifying a mollusk. The body is soft and unsegmented. It is usually covered with a limy shell, formed by the agency of a delicate envelope called the mantle. The animal usually possesses a single muscular foot, by means of which locomotion takes place. There are several groups of mollusks which are, as we shall see, quite unlike in appearance and in habits.

The Shell of the Fresh-water Mussel (Unio species). ${ }^{1}$ - Notice that the shell is made up of two parts or valves. Such a shell is called a bivalve. Notice that the valves are joined together by a structure, somewhat elastic, called the hinge ligament. Close the two shells; why do the shells spring open again? The lines which run more or less parallel to the edge of the shell are called lines of growth. If a line of growth once represented the outer edge of the shell, then find the oldest part of the shell. This raised area is called the umbo. It is always possible to locate the anterior end of the shell because the umbo points toward that end. The hinge ligament marks the dorsal side of the animal.

The shell is covered on the outside by a thin layer of horny material. This is called the periostracum. Can you explain why it does not

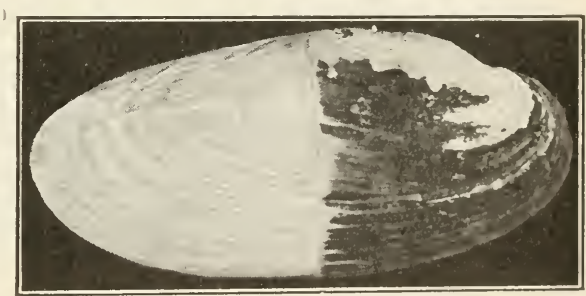

Shell of fresh-water clam, the left half polished to show the prismatic layer. cover the entire shell? The shell proper, if tested with acid, will be found to contain considerable lime.

Draw, natural size, a single valve, and locate the hinge ligament, umbo, and lines of growth. Place the dorsal surface upmost in the drawing.

Mussels may be opened by first placing the living animal in hot water until the shell gapes. Then insert a knife, keeping the blade close to the inner surface of one valve, cut through the tough muscles which hold the shells together, and the shells will open. Notice the mother of pearl covering the inner surface. Notice in a freshly opened clam that a delicate membrane, the mantle, adheres to the shell.

Structure of Shell. - The shell, if examined in cross section with a good lens, is seen to be made up of three layers: the outer periostracum, made

${ }^{1}$ See Hunter and Valentine, Manual, page 138, for exercise on Venus Mercenaria. 


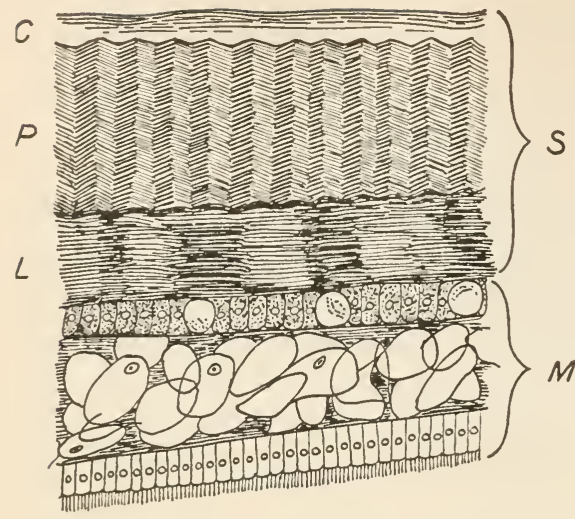

Vertical section of shell and mantle of a mollusk; $C$, periostracum; $P$, prismatic layer; $L$, laminated layer; $S$, shell; $M$, mantle. (After Claus.) up of material much like that which forms a cow's horn, or chitin; a middle layer composed of tiny prisms of lime held in by the horny material (this layer is called prismatic layer); and an inner layer (the laminated layer), made up of layers of lime and horn alternating parallel to the surface of the shell. The inner layer is formed by the action of the whole surface of the mantle. The two outer layers are made by the edge of the mantle only. So a shell grows in thickness largely from the inner surface of the mantle, while it grows in diameter from the edge of the mantle only.

The Open Shell. - Pull the shells completely open. Find on the dorsal side projections and grooves which fit into each other when the shell is closed. These are the hinge teeth. Compare the number in each shell. How might they be of use to the animal? Find the marks on the shell where the adductor muscles were fastened. What was the use of the adductor muscles? Why do dead mussels always have the shell partly open?

Draw one opened valve showing all above parts. Label the anterior and posterior adductor muscle scars, according to position.

Body and Mantle Cavity. - In one valve lies the body of the clam. If we remove the mantle, we shall find under a roundish soft mass, the body, or visceral mass. Surrounding the visceral mass but ventral to it is a cavity bounded on the outside by the inner surface of the mantle. This is the mantle cavity. In life this cavity is full of water. See if you can discover how and where water gets in. In a living mussel the posterior edge of the mantle on the right side is folded so as to fit with the adjoining edge of the mantle on the left side. The funnel-like openings thus formed are called siphons.

Siphons. - The siphons can best be seen in living mussels which have been left quiet for some time in an open trough or tank. If a little powdered carmine is allowed to drop from a medicine dropper close to the siphons (the fringed edges of which may be seen extending from the shell), a current of water will be seen to draw in and expel the carmine grains. Where is the incurrent siphon with reference to the excurrent? (In the "long-necked" or "soft" clam the siphons are greatly developed and are made of

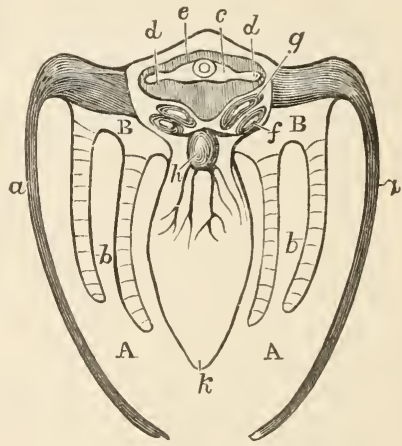

Cross section of a mollusk; $A$, mantle cavity; $a$, shell; $b$, gills; $B$, eloacal cavity; $k$, body. 
tough muscles. If they are cut lengthwise, the two tubes, incurrent and excurrent, can be easily seen.) The siphon permits water, bearing food and oxygen, to get into the mantle cavity. Here are found the gills,

The Gills. - The gills are striated platelike structures lying on each side of the visceral mass. How many gills on each side? Any difference in size of those on one side? When the clam is in a natural position, the gills hang freely in the mantle cavity. In structure each gill is a long, narrow bag open on the dorsal side. This baglike opening leads into a second cavity, dorsal to the mantle cavity. This space, called the cloacal cavity, is in communication with the outside through the excurrent siphon. A mussel when viewed from one end or in cross section somewhat resembles. a book. The shell has the position of the board cover, the mantle the paper pasted to its inner surface, the gills the fly leaves, and the body the printed pages in the book.

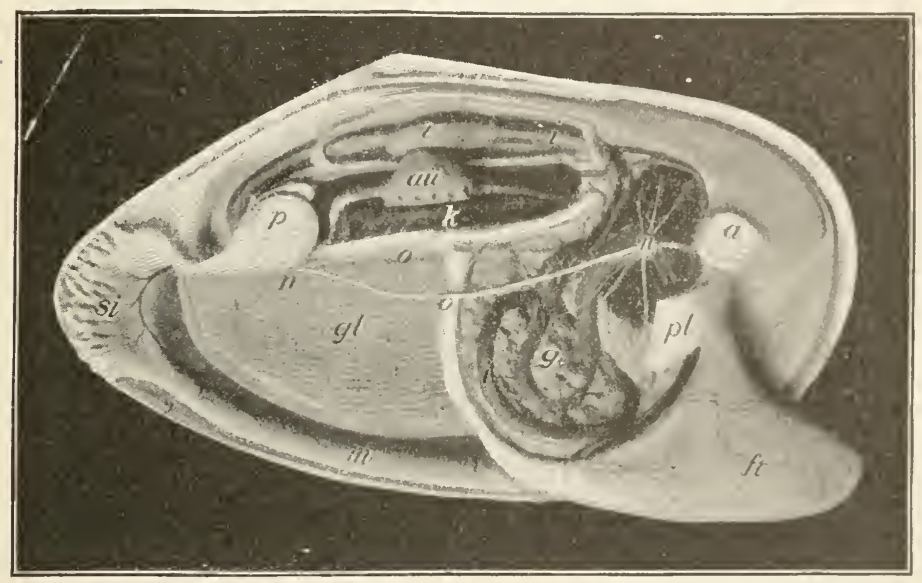

A fresh-water mussel with the right valve, mantle, and gills and some tissue at the base of the foot removed ; $a$, anterior adductor muscle; $a u$, auricle of the heart ; $f t$, foot ; $g$, reproductive gland; $g l$, gill ; $i$, intestine ; $k$, kidney; $m$, mantle $; n$, nerve ganglia connected by nerve cords $o ; p$, posterior adductor ; $p l$, labial palps ; si, siphon; $v$, ventricle. The dark lines on the mantle and foot are blood vessels. Davison, Zoölogy.

Circulation of Water over Gills. - We have already observed that a more or less constant circulation of water takes place; carmine entering through the incurrent siphon passes out through the excurrent siphon. How is this circulation explained? If a small piece of the gill of a clam or oyster is placed in a drop of the fluid found in the mantle cavity and examined under the compound microscope, the explanation is found. The surface of the gill is seen to be pierced by numerous holes. These holes, 
and most of the surface of the gill, are lined with ciliated cells, the cilia of which, beating more strongly toward the cloacal cavity, cause a current of water to flow over the gills and through the holes into the cloacal cavity. Cilia are also found lining the inner surface of the mantle and on the labial palps, which we shall take up later.

Structure of Gills. - The internal structure of the gills is such that blood slowly circulates through a network of thin-walled spaces, which, in the margin of the gill, are separated from the water by only a single layer of thin cells. Through this layer oxygen is taken by osmosis from the water, and carbon dioxide given up. The latter gas is passed off in the water through the excurrent siphon.

Food Getting. - The cilia of the gills (and of the mantle cavity in general) play an important part in food getting. The clam, because of its sedentary life, must receive its food in the water which enters the mantle cavity. Food consists principally of onecelled animals and plants. This food is collected by the cilia surrounding the ostia, or holes in the gills, and is passed to the labial palps, four little flaps which surround the mouth. The mouth may be found at the anterior end of the visceral mass. The ciliated palps act as lips and pass the food on into the mouth.

Food TuBE. - The food tube and its digestive gland (the latter a greenish mass easily seen through the body wall) occupies part of the visceral mass. It is a thin-walled tube which makes several turns before leaving the body. The stomach is a slight enlargement surrounded by the dark-colored digestive gland. This gland has the same function as the pancreas of higher animals.

Circulation of Blood. - The circulation of the blood in the clam is of chief interest to us because of the curious heart, which is well developed, and has somewhat the same action as in the higher animals. The heart may easily be found in a living clam and the rate of beating counted. It is located near the surface of the dorsal side of the body close to the hinge ligament. It consists of two chambers, an auricle, which receives the blood, and a ventricle, which by muscular contraction pumps the blood on its course. The heart is surrounded by a thin-walled 
pericardium or sack. The intestine passes directly through the heart, a condition found in no other group of animals.

Locomotion. ${ }^{1}$ - Locomotion may be observed if mussels are kept in an aquarium. The fleshy foot is thrust down into the mud or sand and then contracted. This action pulls the clam forward for a short distance. Locomotion is thus very slow.

The Nervous Srstem. - Although the mussel appears to have no organs of sight or hearing, yet it is provided with a complicated nervous system which appears to have much to do with museular activity. Three large collections of nerve cells (called ganglia) are found, one near each adductor muscle and one near the foot (see diagram).

Early Development. - The early life history of most mollusks includes a free-swimming stage before the young possess a shell. At this time the tiny larva swims by means of eilia, near the surface of the water. The fresh-water mussel at an early stage attaehes itself to the gills of a fish, thus living for a time as a parasite. Eventually all bivalve mollusks come to live near the bottom, where they are near a souree of food supply.

The Oyster. - The chief difference between the oyster and the clam lies in the fact that the oyster is fastened by one valve to some solid object, while the clam and the fresh water mussel move about. This results in an asymmetry in the shell of the oyster.

Oysters are never found in muddy localities, for in such places they would be quickly smothered by the sediment in the water. They are found in nature clinging to stones or on shells or other objects which project a little from the bottom. Here food is abundant and oxygen is obtained from the water surrounding

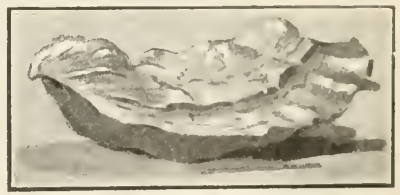

Shell of oyster, showing asymmetry. them. Hence oyster raisers throw oyster shells into the water to hold the young off the muddy bottom.

In some parts of Europe and this country where oysters are raised artificially, stakes or brush are sunk in shallow water so that the young oyster, which is at first free-swimming, may escape the danger of smothering on the muddy bottom.

After the oysters are a year or two old they are taken up and put down in deeper water as seed oysters. At the age of three

1 See Hunter and Valentine, Manual, page 142. 
and four years they are ready for the market. Sometimes oysters are artificially fattened by placing them on beds near the mouths of fresh water streams. Too often these streams are the bearers of much sewage, and the oyster, which lives on microscopic organisms, takes in a number of bacteria with other food. Thus a person might become infected with the typhoid bacillus by eating raw oysters.

The oyster industry is one of the most profitable of our fisheries. Nearly $\$ 30,000,000$ a year has been derived during the last decade from such sources. Hundreds of boats and thousands of men are engaged in dredging for oysters. Some of the most important of our oyster grounds are Long Island Sound and Chesapeake Bay.

Clams. - Other bivalve mollusks used for food are clams and scallops. Two species of the former are known to New Yorkers,

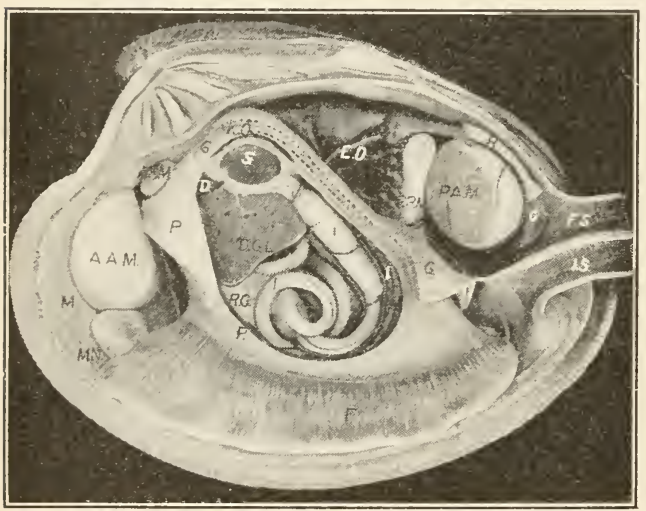

Round clam (Venus Merceneria); A.A.M., anterior adductor muscle; A.R.M., anterior retractor muscle; $P . A . M$., posterior adductor muscle; P.R.M., posterior retractor muscle; $F$., foot; $C$., cloacal chamber; I.S., incurrent siphon; F.S., excurrent siphon; EO., heart; $G$., gills; $M_{\text {., }}$ mantle; $D . G L$., digestive glands; $S$. , stomach; $I$. , intestine; $P$., palp; $R$., posterior end of digestive tract. one as the "round," another as the "long" or "s oft-shelled" clams. The former (Venus Merceneria) was called by the Indians quahog, and is still so called in the Eastern States. The blue area of its shell was used by the Indians as wampum, or money. The quahog is now extensively used as food. The "long" clam (Mya arenaria) is considered better eating by the inhabitants of Massachusetts and Rhode Island. This clam was highly prized as food by the Indians. The long siphon, incorrectly called neck, enables these clams to burrow deep into the mud and yet take food and 
oxygen from the water above. The clam industries of the eastern coast aggregate over $\$ 1,000,000$ a year.

Scallop. - The scallop, another highly esteemed mollusk, forms an important fishery. The scallop rests on one valye on the bottom in shallow water and if disturbed swims away by clapping the valves rapidly together. The single adductor muscle is eaten, whereas in the clam the soft parts of the body are used as food.

A Univalve Shell. - Any large univalve shell, as Fulgur, may be used in the laboratory. ${ }^{1}$ The shell, which is one piece, is called a univalve. Notice the spiral arrangement of the shell. How-many turns does it make? The

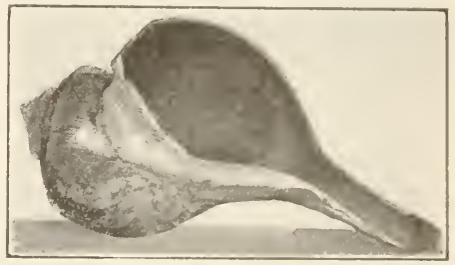

Fulgur, a univalve mollusk common in Long Island Sound, which does much harm by boring into the shells of edible mollusks.

lines of growth run parallel, as in the clam, to the edge of the shell. Hold the opening toward you. The opening is known as the aperture. When the animal is alive, part of the body is protruded through this.

Draw the shell twice natural size, showing all above parts.

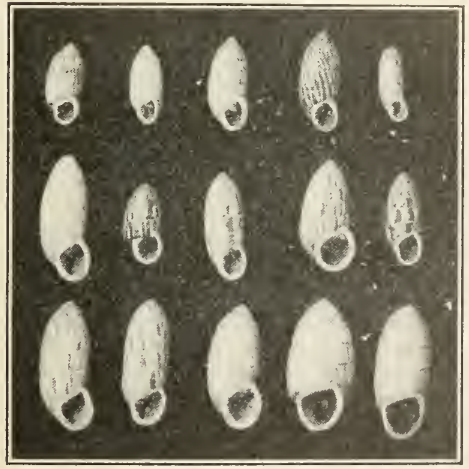

Strophias from different localities at $\mathrm{An}$ dros and New Providence, Bahamas. From photograph loaned by the American Museum of Natural History.

Living Snail. - (Use the pond snail Limnea or Physa.) Watch the move'ment of living snails in the aquarium. The large fleshy mass which protrudes from the shell is called the foot. Try to decide how locomotion takes place as the animal mores along the side of the aquarium.

Watch the animal as it fecds. What kind of food does this snail rat? Notice the position of the mouth. Is there any distinct head? These animals are called gastropods (stomachfooted). Do you see any reason for this name? Find the two tentacles or horns. Touch them with a pencil. What happens? Look for the dark eye-spots at the base of the tentacles. Make any experiments you can to see if the snail can distinguish between light and darkness. (Cover part of the dish and leave it for some minutes undisturbed.) Do you find any other structures protruding from the edge of the foot? Two siphons, one for talking in water, the other for sending it out, maty be found.

Gastropods. - Snails, whelks, slugs, and the like are called gastropods because the foot oceupies so much space that most of the organs of the

${ }^{1}$ See Hunter and Valentine, Manual, pages 143 and 145. 


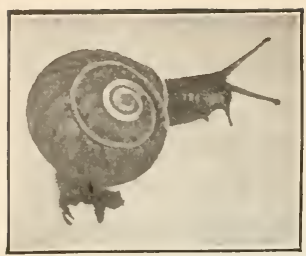

Forest snail, showing the two tentacles with an eye on the end of each. From photograph by Davison.

body, including the stomach, are covered by it. In most gastropods the body is spirally twisted in the shell. In the garden slug, the mantle does not secrete a shell and the naked body is symmetrical. The twisting of the body is not seen in very young snails, so that this peculiar state is believed to be something secondary which has appeared as a consequence of the animal's bearing a shell.

Variability of Sxail Shells. - Snail shells are very variable in shape and color markings, as may be seen if several of the same species be examined carefully. Varieties of snails in mountain valleys in certain of the Hawaiian Islands are found to be quite distinct, each in its own valley. Yet it is quite certain that all the snails of these several varieties were at one time alike. Helix nemoralis, a European snail, has been introduced into this country and has multiplied so rapidly and varicd so greatly that in an area one thousand feet in diameter three hundred and eighty-five varieties have been collected, each slightly differing from the other either in color or form of shell. ${ }^{1}$

Feeding Habits. - The mouth of the snail is easily found on the under side of the foot. Just within the mouth is the lingual ribbon. The ribbon consists of a flap of membrane bearing many sharp, filelike teeth, microscopic in size. This structure, which is moved by muscles, passes over a pad of cartilage and rubs, filelike, against the surface to which it is applied. In this manner some snails can bore circular holes in shells of other mollusks, in order to get the soft part, which they use as food. An example of a univalve mollusk which thus obtains food is the oyster drill, which annually does thousands of dollars' worth of damage to the oysters. In Europe and this

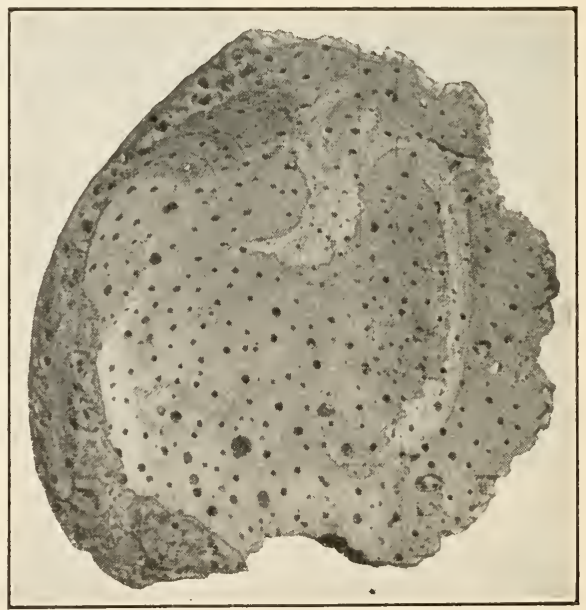

Shell full of holes bored by the oyster drill and a boring sponge. country slugs and some snails do considerable damage to gardens by eating young plants. The snail Physa may be observed feeding on tiny

${ }^{1}$ See Howe, Amer. Nat., December, 1898. 
plants on the surface of the aquarium and the action of the lingual ribbon noted.

Breathing. - Most gastropods breathe by means of gills which are located, as in the clam, in the mantle cavity. But in some snails, the pulmonates, the mantle cavity forms a sac which opens to the outside of the body by a tiny slit. In this cavity air is taken. Its walls are filled with blood ressels, and oxygen is then taken up by the blood as carbon dioxide is released. The pulmonates are true air breathers, and may frequently be seen in an aquarium taking down a bubble of air for use under water.

Senses. - Snails and slugs can distinguish light from darkness, as may be easily proved by experiment. The tentacles are the most sensitive parts of the body. Certain parts of the animal seem to be used for testing the water, and in the land snails these organs seem to be used to smell with. The nervous system as in the clam consists of three collections of nerve cells, or ganglia, nerves connecting these centers, and numcrous cells in the outer part of the body ealled sensory cells. These cells are sensitive to any stimulus received from outside the body.

Development. - Eggs of the pond snails are laid in little masses, sometimes in strings, and are often found fastened in a jelly to the side of the aquarium. The snails hatch and at first swim about, later settling down as the shell is formed. Thus they undergo a complete metamorphosis, as do their relatives the clams and oysters.

Cephalopods. - Squid, Cuttlefish, and Octopus. The name cephalopod means head-footed. As the figure shows, the mouth is surrounded with a circle of tentacles. The shell is internal or lacking, the so-called pen of the cuttlefish being all that remains of the shell. The squid, or cuttlefish, is strangely modified for the life it leads. It mores through the water more swiftly than a fish by squirting water from the siphon. It can seize its prey with the suckers on the long tentacles and tear it in pieces by means of its horny parrotlike beak. It is protected from its enemies and is enabled to catch its prey because of its ability to change color quickly. This change of color is caused by the move-

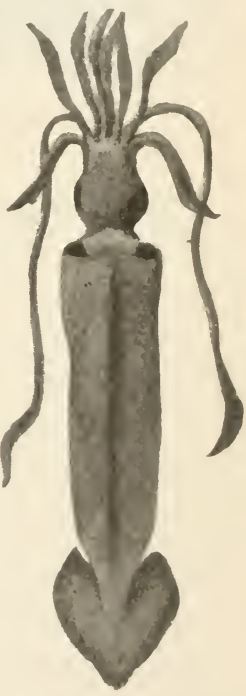

The squid. One fourth natural size. Davison, Zoölogy. ment of certain color-bearing cells under the skin. In this way the animal simulates its surroundings. The euttlefish has an ink bag near the siphon which contains the black sepia. A few drops of this ink squirted into the water effectually hide the animal from its encmy.

To this group of animals belongs also the octopus, or deril fish, a ceph. alopod known to have tentacles over thirty feet in length. The paper 
nautilus and pearly nautilus, the latter made famous by our poet Holmes, also belong to this group.

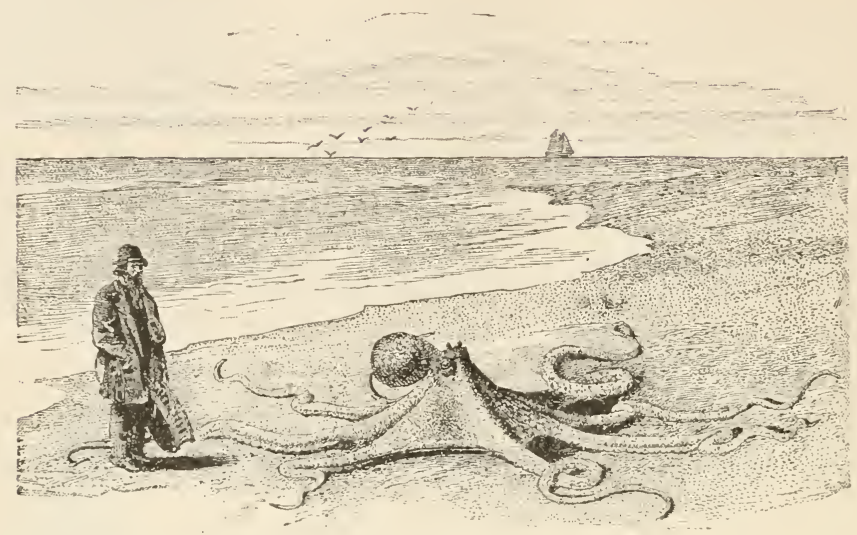

Octopus.

Habitat of the Mollusks. - Mollusks are found in almost all parts of the earth and sea. They are more abundant in temperate localities than elsewhere, but are found in tropical and arctic countries. They are found in all depths of water, but by far the greatest number of species live in shallow water near the shore. The cephalopods live near the surface of the ocean, where they prey upon small fish. The food supply evidently determines to a large extent where the animal shall live. Some mollusks are scavengers, others feed on living plants.

We have found in the forms of Mollusca studied that almost all mollusks live in the water. There is one great group which forms. a general exception to this, certain of the snails and slugs called pulmonates. But even these animals are found in damp localities, and at the approach of drought they become inactive, remaining within the shell. The European snail (Helix pomatia), imported to this country as a table delicacy, exists for months by plugging up the aperture to the shell with a mass of slimy material which later hardens, thus protecting the soft body within.

Economic Importance. - In general the mollusks are of much economic importance. The bivalves especially form an important 
source of our food supply. Many of the mollusks also make up an important part of the food supply of botton-feeding fishes. On the other hand, some mollusks, as $\mathrm{Na}$ tica, bore into other mollusk shells and eat the animal thus attached. Some boring mollusks, for example the ship worm ( Teredo navalis), do much damage, especially to wharves, as they make their home in piles. Still others bore holes in soft rock and live

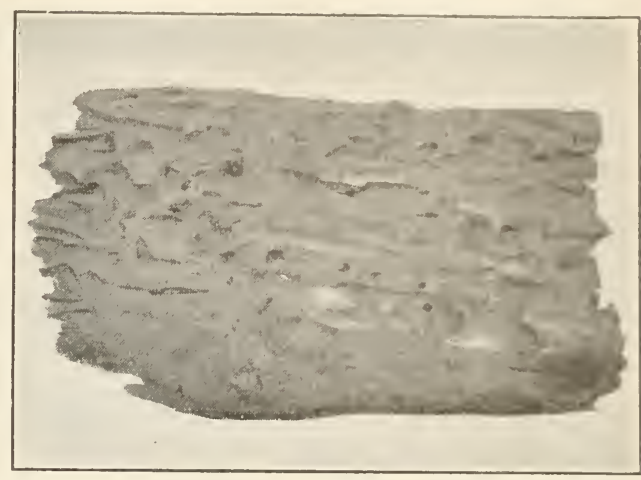

Piece of timber, showing holes bored by the ship worm. there.

The shells of mollusks are used to a large extent in manufacture and in the arts, while they form a money basis still in parts of the world. Sepia comes from a cuttlefish.

Pearls and Pearl Formation. - Pearls are prized the world over. It is a well-known fact that even in this country pearls of some value are sometimes found within the shells of such common bivalves as the fresh-water mussel or oyster. Most of the finest, however, come from the waters around Ceylon. If a pearl is cut open and examined carefully, it is found to be a deposit of the mother-of-pearl layer of the shell around some central structure. It has been believed that any foreign substance, as a grain of sand, might irritate the mantle at a given point, thus stimulating it to secrete around the substance. It now seems likely that perfect pearls are due to the growth within the mantle of the clam or oyster of certain parasites, stages in the development of a flukeworm. The irritation thus set up in the tissue causes mother-of-pearl to be deposited around the source of irritation, with the subsequent formation of a pearl.

\section{Classification of Molitusks}

Class I. Pelecypoda (Lamellibranchiata). Soft-bodied unsegmented animals showing bilateral symmetry. Bivalve shell, platelike gills. Examples, clam (Mya arcnaria), scallop (pecten), oyster (Ostrea), and fresh-water mussel (Unio). 
Class II. Gastropoda. Soft bodies asymmetrical; univalve shell or shell absent. Some forms breathe by gills, others by lunglike sacs. Examples, pond snail, land snail (Helix), and slug.

Class III. Cephalopoda. Bilaterally symmetrical mollusks with mouth surrounded by tentacles. Shell may be external (nautilus), internal (squid), or altogether lacking (octopus). Examples, squid, octopus.

\section{Reference Books \\ FOR THE PUPIL}

Davison, Practical Zoölogy, pages 142-150. American Book Company.

Herrick, Text-book in General Zoölogy, Chap. XI. American Book Company.

Heilprin, The Animal Life of our Seashore. J. B. Lippincott Company.

Jordan, Kellogg, and Heath, Animal Studies. D. Appleton and Company. Morgan, Animal Sketches, Chap. XXI. Longmans, Green, and Company.

\section{FOR THE TEACHER}

Bulletin, U.S. Fish Commission, 1889.

Brooks, The Oyster. Johns Hopkins Press.

Cooke, The Mollusca, Cambridge Natural History. The Macmillan Company.

Kellogg, The Life History of the Common Clam. Bulletin, U.S. Fish Commission Vol. XIX, page 193.

Parker, Elementary Biology. The Macmillan Company.

Parker and Haswell, Text-book of Zoölogy. The Macmillan Company. 


\section{FISHES}

THE ordinary stickleback is a hardy fish easily kept in aquaria in the schoolroom. It (or any other small fish, as the brook minnow or goldfish) may be used in the following exercise. ${ }^{1}$

The Body. - The body of the fish runs insensibly into the head, the neck being absent. Notice the long, narrow body. How is it adapted for the method of life? Certain cells in the skin secrete mucus or slime. How might the slimy surface of the body be useful to the fish? If the fish is in an aquarium with surroundings like that of its natural habitat, decide whether the color of the fish is protective.

The Appendages and their Uses. - The appendages of the fish consist of paired and unpaired fins. The paired fins are four in number, and are believed to be homologous with the paired limbs of a man. Compare the fish with the diagram in the book and locate the paired pectoral and pelvic fins. (These are so called because they are attached to the bones forming the pectoral and pelvic girdles. See page 275.) Find, by comparison with the diagram, the dorsal, anal, and caudal fins. How many unpaired fins?

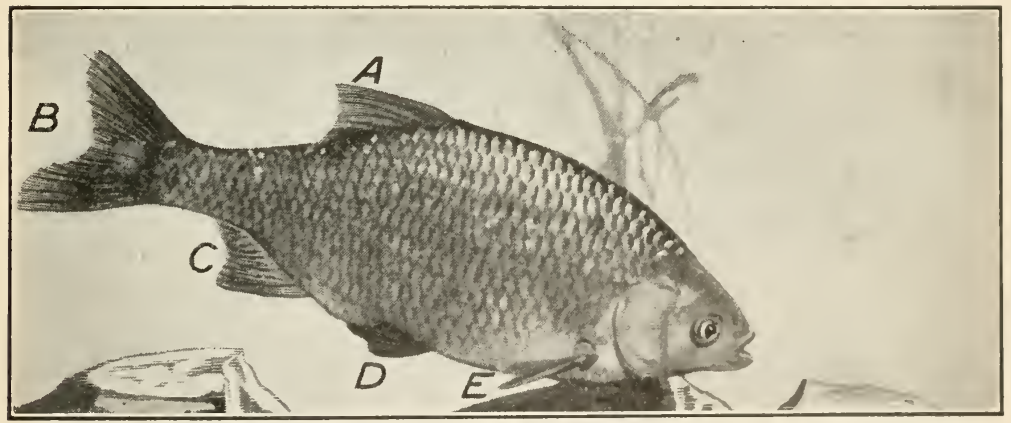

The fins of a fish: $A$, dorsal; $B$, caudal; $C$, anal; $D$, pelvic; $E$, pectoral.

The stickleback, as the name indicates, has the front dorsal fin so modified as to form a number of sharp spines. (There are five in the common brook stickleback of New York state.) A careful study of a fish in the school aquarium will help to an understanding of the uses of the different fins. Decide what part in the locomotion of the fish is taken by the caudal fin. Do the other fins function in forward movement? Which fins are used in turning? In backing? Are any used in balancing? Do any parts of the body play a part in locomotion?

${ }^{1}$ See Hunter and Valentine, Manual, page 167. 
The Senses. - Notice the position of the eyes from the front and in a side view of the fish. Is the position of advantage and how? The eye is globular in shape. Such an eye has been found to be very near sighted. Thus it is unlikely that a fish is able to perceive objects at any great distance from it. The eye is unprotected by eyelids, but the position on the sides of the body affords some protection. There is much opportunity for a careful boy or girl to make simple experiments to determine how much and how far the fish can see.

Feed the fish; does it appear to see the food or to go to the food by a sense of smell? The nostrils of a fish can be proved to end in little pits, one under each nostril hole. Thus they differ from our own, which are connected with the mouth cavity. In the catfish, for example, the barbels or horns receive sensations of smell and taste. The sense of perceiving odor is not as we understand the sense of smell, for a fish perceives only substances that are dissolved in the water in which it lives. The senses of taste and touch appear to be less developed than the other senses. A fish rejects bits of food which it does not like.

Breathing. - Notice that a fish, when swimming quietly or when at rest, seems to be biting when no food is present. A reason for this act is to be seen when we introduce a little finely powdered carmine into the water near the head of the fish. It will be found that a current of water enters the mouth at each of these movements and passes out through two slits found on each side of the head of the fish. Investigation shows us that

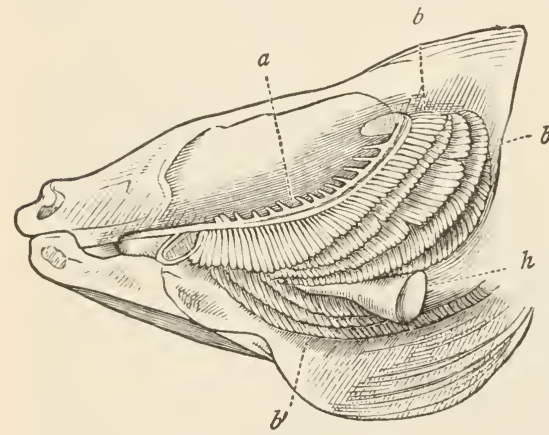

Gills and heart of the fish, exposed by removal of gill cover on left side; $a$, first of the four bony arches which carry the gills; $b$, gills; $b^{\prime}$, lower edges of gills on the right side; $h$, heart. arch previously mentioned. Blood passes into the gill filament, and there comes in contact with the free oxygen of the water bathing the gills. An exchange of gases through the walls of the gill filaments results in the loss of carbon dioxide and a gain of oxygen by the blood. Possibly other waste products find their way into the water bathing the gill filaments, the wastes being carried off by the current of water passing over the gills.

Teeth. - Notice the arrangement and number of the teeth in the stickleback. Sticklebacks are carnivorous, preying upon the eggs and young of other small fish inhabiting the brooks where they live. They also feed upon decaying and live vegetable matter, especially algæ. The teeth of 
the stickleback are small and evidently useful for seizing and holding prey. This fish, like many other species, is a hunter and uses the tecth as weaj)ons of offense as well as for defense. How are the tecth of the stickleback adapted to their functions? The tongue in most fishes is wanting or very slightly developed.

Gill Rakers. - If we open wide the mouth of any large fish and lowk inward, we find that the mouth cavity leads to a funncl-like oponing, the gullet. On each side of the gullet we can see the gill arehes, guarded on the inner side by a series of sharp pointed structures, the gill rakers. In some fishes in which the teeth are not well developed, there seem: to bu it greater development of the gill rakers, which in this ease are used to strain out small organisms from the water which passes over the gills. Many fishes, as the shad and menhaden, make such use of the gill rakers.

Digestive Srstem. - The gullet leads directly into a baglike stomach. There are no salivary glands in the fishes. There is, however, a large liver, which appears to be used as a digestive gland. 'This organ, because of the oil it contains, is of considerable economic importance. Many fishes have a number of pocketlike outgrowths from the intestines. These structures, called the pyloric caca, are believed to secrete a digestive fluid. The intestine ends at the vent, which is usually located on the ventral side of the fish, immediately in front of the anal fin.

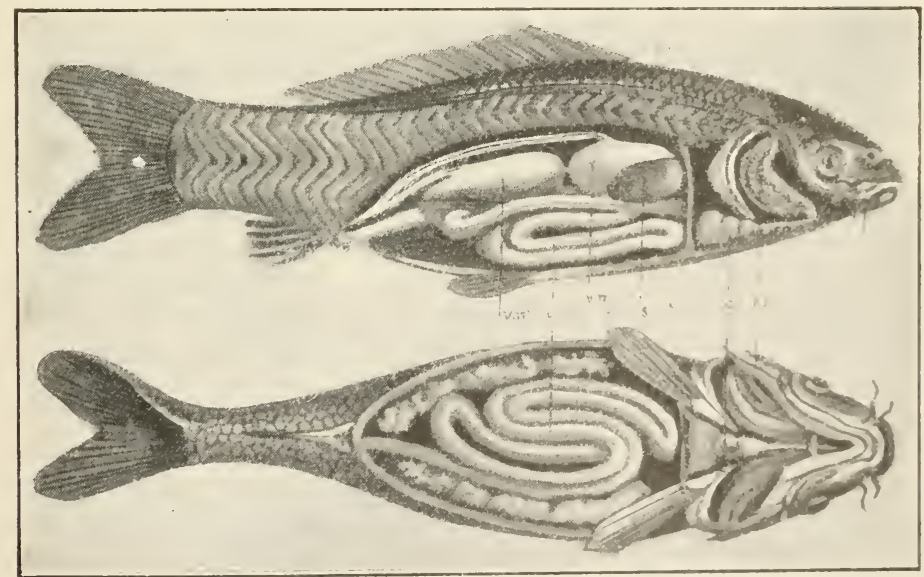

Anatomy of the carp ; $b r$, branchiæ, or gill openings ; $c$, heart ; $f$, liver ; $2 n$, swimming bladder; $c i$, intestine.

Swim BLADDER. - An organ of unusual significanec, ealled the swim bladder, is connected with the digestive tract in front of the stomach. In young fishes of many species this connection is a tube, which in some forms HUNTER'S BIOL. - 18 
persists throughout life, but which in other fish becomes closed, a thin, fibrous cord taking its place. The swim bladder aids in giving the fish such a volume that it displaces a weight of water about equal to its own weight. The walls of the organ are richly supplied with blood vessels, and it thus undoubtedly serves as an organ for taking in oxygen. It has been compared to a lung of the higher vertebrates.

Circulation of THE BLOOD. - In the vertebrate animals the blood is said to circulate in the body, because it passes through a more or less closed system of tubes in its course around the body. In the fishes the heart is a two-

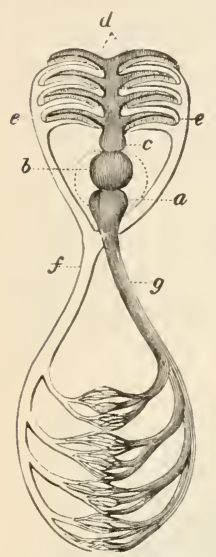

Plan of circulation in fishes; $a$, auricle; $b$, ventricle; $c$, branchial artery; $e$, branchial veins, bringing blood from the gills, $d$, and uniting in the aorta, $f ; g$, vena cava, returning blood to heart. chambered muscular organ, a thin-walled auricle leading into a thick-walled muscular ventricle. The blood is pumped from the heart to the gills; there it loses some of its carbon dioxide; it then passes on to other parts of the body, eventually breaking up into very tiny tubes called capillaries. From the capillaries the blood returns, in tubes of gradually increasing diameter, toward the heart again. During its course some of the blood passes through the kidneys and is there relieved of part of its nitrogenous waste. (See Chap. XXX.)

Circulation of blood in the body of the fish is rather slow. The temperature of the blood being nearly that of the surrounding media in which the fish lives, the animal has incorrectly been given the term cold-blooded.

Nervous System. - As in all vertebrate animals, the brain and spinal cord of the fish are inclosed in a series of bony structures called vertebræ. The central nervous system consists of a brain, with nerves leading to the organs of sight, taste, smell, the ear, and to such parts of the body as possess the sense of touch; a spinal cord; and spinal nerves. Nerve cells located near the outside of the body send in messages to the central system, which are there received as sensations. Cells of the central nervous system in turn send out messages which result in the movement of muscles.

We have already learned something of the senses of a fish. That of hearing is poorly developed, the ear being largely an organ of balancing. Along each side of almost every species of fish is found a line, which consists of a series of tiny pits each connected with its neighbor. ${ }^{1}$ This lateral line, as it is called, is believed to have to do with the sense of touch.

Skeleton. - In the vertebrates, of which the bony fish is an example, the skeleton is under the skin and is hence called an endoskeleton. It consists of a bony framework, the vertebral column, and certain attached

1 This line is plainly visible in some fishes because of its dark color. 
bones, the ribs, with other spiny bones to which the unpaired fins are attached. The paired fins are attached to the spinal column by two collections of bones, known respectively as the pectoral and pelvic girdles. The bones serve in the fish for the attachment of powerful muscles, by means of which locomotion is accomplished.

The Egg-laying Habits of the Bony Fishes. - The stickleback has the rather curious habit (for a fish) of nest building. The nest is attached to waterweeds or a submerged stick. It is almost circular in outline, and in the case of the common stickleback is about two inches in diameter. A hole in the top gives access to the interior. In this nest the female deposits her eggs, which are then guarded by the male until the young hatch out. The freshwater sunfish also has the habit of nest building, its nest being scooped out in the sand of the lake or river bed.

The eggs of most bony fishes are laid in great numbers at the time of spawning. This number varies from a few thousand in the trout to many hundreds of thousands in the shad and several millions in the cod. The time of egg laying is usually spring or early summer. Usually the eggs are left to develop by themselves, sometimes attached to some submerged object, but more frequently free in the water. They are exposed to many dangers, and both eggs and developing fish are eaten, not only by birds, fish of other species, and other water inhabitants, but also by their own relatives and even parents. Consequently a very small percentage of eggs ever reach maturity.

The Relation of the Spawning Habits to Economic Importance of Fish. - The spawning habits of fish are of great importance to us because of the economic value of fish to mankind, not only directly as a food, but indirectly as food for other animals in turn valuable to man. Many of our most desirable food fishes, notably the salmon, shad, sturgeon, and smelt, pass up rivers from the ocean to deposit their eggs. The salmon is said to travel thousands of miles, swimming against strong currents much of the way, leaping rapids and falls, in order to deposit her eggs in suitable localities, where the conditions of water and food are requisite, and the water shallow enough to allow the sun's rays to warm the water sufficiently to cause the eggs to develop. At the 
time of the spawning migration the saimon are taken in vast numbers. The salmon fisheries net over $\$ 13,000,000$ annually, the shad at least $\$ 1,500,000$, the smelt fishery nearly $\$ 150,000$ more. The total annual value of the fisheries of the United States is over $\$ 50,000,000$. But the profits from these fisheries are steadily decreasing because of the yearly destruction of untold millions of eggs which might develop into adult fish. State and government interposition is in many cases coming too late, for at the present rate of destruction many of our most desirable food fishes will

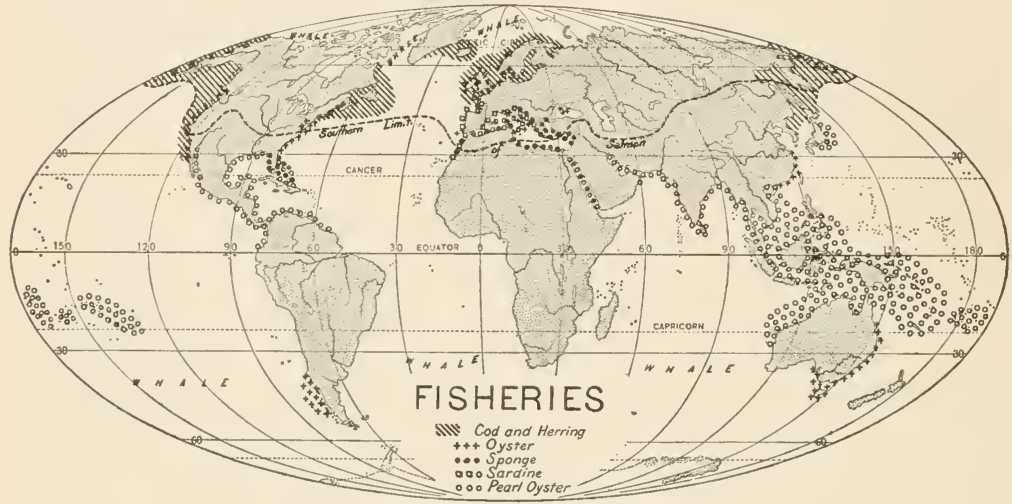

Fisheries-Percentage Product

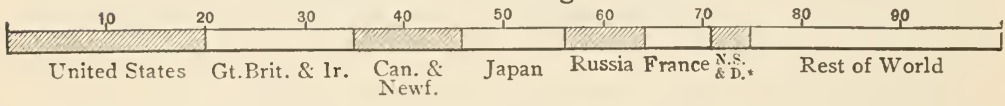

soon be extinct. The sturgeon, the eggs of which are used in the manufacture of the delicacy known as caviare, is an example of a fish that is almost extinct in this part of the world.

Other deep-water fish do not go up rivers to spawn, but lay their eggs in the sea. In such eggs there is found a tiny oil drop, which, being lighter than water, causes the egg to come to the surface of the water, where the heat of the sun may favorably influence development. Other fish change their habitat at different times during the year, moving in vast schools northward in summer and southward in the winter. In a general way such migrations follow the coast lines. Examples of such migratory fish are the cod, 
menhaden, herring, and bluefish. The migrations are due to temperature changes, to the seeking after fond, and to the spawning instinct. Some fish migrate to shallower water in the summer and to deeper water in the winter; here the reason for the migration is doubtless the change in temperature.

The herring fisheries have always been a source of wealth to the inhabitants of northern Europe. The banks and shallows of the coast of Newfoundland were undoubtedly known to the Norsemen long before the discovery of this country by Columbus.

Classification of Fishes. - The animals we recognize as fishes are grouped by naturalists into four groups:

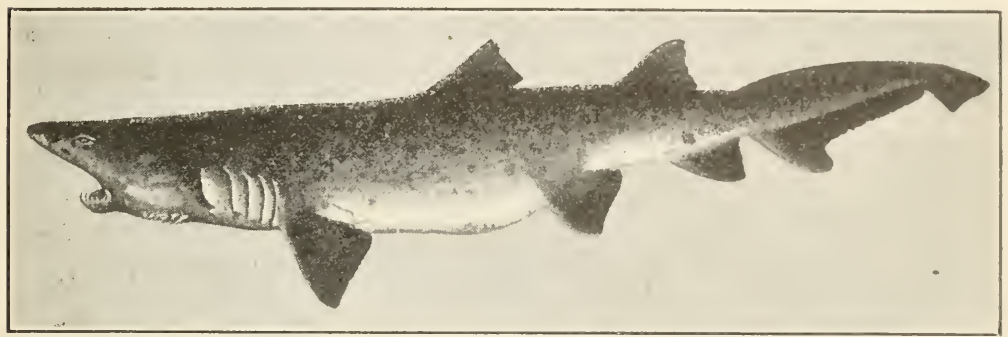

Sand shark, an elasmobranch. Note the slits leading from the gills. From photograph loaned by the American Museum of Natural History.

1. The Elasmobranchs. - These fishes have a skeleton formed of cartilage which has not become hardened with lime. The gills communicate with the surface of the body by separate openings instead of having an operculum. The skin is rough and the eggs few in number. In some members of this group the young are born alive. Sharks, rays, and skates are Elasmobranchs.

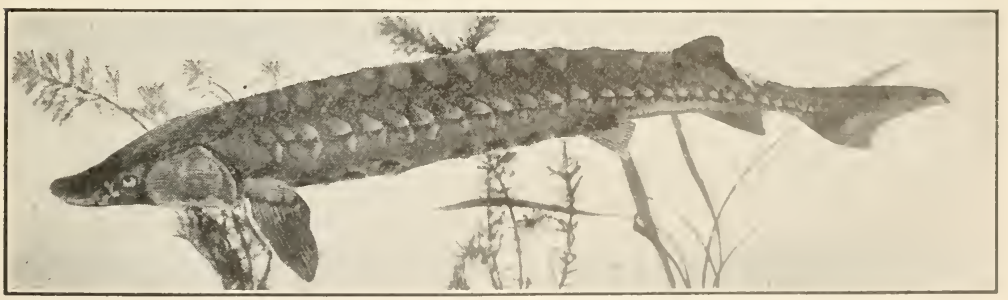

Sturgeon (Acipenser sturio), a ganoid fish.

2. Ganoids. - Fish in which the body is protected by a serics of platelike scales of considerable strength. These fishes are the only remnant of 
what once was the most powerful group of animals on the earth, the great armored fishes of the Devonian age. The gar pike is an example.

3. The Teleosts or Bony Fishes.

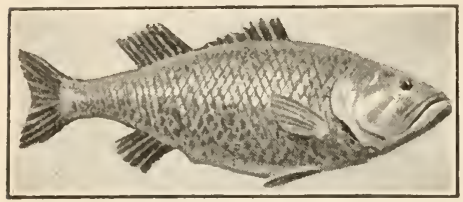

A bony fish. - They compose ninety-five per cent of all living fishes. In this group the skeleton is bony, the gills are protected by an operculum, and the eggs are numerous. Most of our common food fishes belong to this class.

4. The Dipnoi or Lung Fishes. - This is a very small group, in many respects more like amphibians than fishes, the swim bladder being used as a lung. They live in tropical Africa, South America, and Australia, inhabiting the rivers and lakes there. They withstand drying up in the mud during the dry season, lying dormant for long periods of time in a ball of mud and waking to active life again when the mud coat is removed by immersion in water.

\section{REFERENCE Books \\ FOR THE PUPIL}

Davison, Practical Zoölogy, pages 185-199. American Book Company. Herrick, Text-Book in General Zoülogy, Chap. XIX. American Book Company. Nature Study Leaflets, XIII. N.Y. Department of Agriculture.

Hunter and Valentine, Laboratory Manual of Zoölogy, page 167. Henry Holt and Company.

Jordan, Kellogg, and Heath, Animal Studies, XIV. D. Appleton and Company.

FOR THE TEACHER

Jordan and Evermann, American Food and Game Fishes. Doubleday, Page, and Company.

Kingsley, Text-book of Vertebrate Zoölogy. Henry Holt and Company.

Riverside Natural History. Houghton, Mifflin, and Company. 


\section{AMPHIBIANS}

The Frog; ${ }^{1}$ Body. - In the body of man we find two distinct regions, the head and trunk. Are such regions to be found in the frog? How is the shape of the body fitted for life in the water?

Habitat. - There is considerable difference in the habitat of the green frog and the leopard frog. The former may usually be found in ponds or brooks in which considerable vegetation is found. The latter live in pools or woody swamps in which the bottoms are dark from a background of dead leaves or mud. Remembering this, how might the color of the frog harmonize with its surroundings? Is this of advantage to the frog? In what respects?

Protective Resemblance. - Notice the position of the frog at rest in the water. In its natural habitat a frog in this position would scarcely be noticed, so perfeet is the resemblance to the surroundings. Notice that the only parts of the frog that show above the surface of the water are the eyes and that part of the head bearing the nostril holes.

A ppendages. - Compare the anterior limb with your own arm. Identify in each, upper arm, forearm, and hand. Note the number of fingers. In the same manner find the thigh, shank, and foot in the posterior limb. In what respects do ankle and foot differ in the frog and in man? What adaptations for locomotion (swimming) do you find in the frog?

Skin. - Notice the slimy skin of the frog. This is due to the presenee in the skin of cells which secrete and pour out mucus. Might this slime be of any use to the animal? The skin of the frog is supplied with numerous tiny blood vessels. The blood in these thin-walled tubes gains oxygen from the surrounding atmosphere and from the water, while carbon dioxide is given off. Thus the skin is used in the process of respiration.

The Eye. - The eye of the frog differs somewhat in shape from our own. Note the positions on the side of the head. Touch the eye. How is it protected? Look for a delicate fold, the nictitating membrane (sometimes ealled the third eyelid), which may be drawn over the eye.

Have you any experience as to the keenness of vision in the frog? Do they jump into the water because they see or hear you? Any experiment which will throw light on this point will make an interesting piece of original work for extra eredit. Can you perform any experiment which will show whether the frog prefers light to darkness?

Ear. - The tympanic membrane or eardrum of the frog may be found on the side of the head. It is a circular area of tightly stretched skin. In man the ear drum is beneath the surface of the body near the inner end of the canal or tube which we see in the external ear. In the frog and in man a connection exists between the mouth and the inner surface of the ear drum. This tube is known as the Eustachian tube.

Home Experiment. - Give an aceount of any experiment that you may perform that will prove that frogs ean hear, or the nature of sounds that attract their attention.

${ }^{1}$ For laboratory exercise see Hunter and Valentine, Manual, page 170. (Either the green frog or the leopard frog may be used for the laboratory suggestions given in this book.) 
Mouth. - Note the shape, position, and relatively large size of the mouth in the frog as compared with man.

Make a drawing of the frog in a natural position, having all parts visible in the drawing carefully labeled.

Characteristics of Amphibia.-The frog belongs to the class of vertebrates known as the Amphibia. As the name indicates, members of this group pass more or less of their life in the water, although in the adult state they are provided with lungs. In the earlier stages

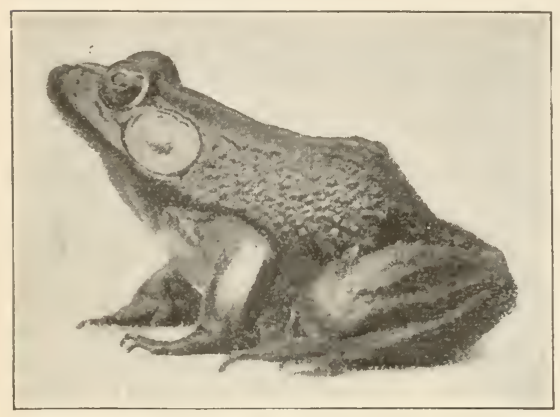

Full-grown green frog, about half natural size. Photographed by Overton. of their development they take oxygen into the blood by means of gills. At all times, but especially during the winter, the skin serves as a breathing organ. The skin is soft and unprotected by bony plates or scales. The heart has three chambers, namely, two auricles and one ventricle. Most amphibians undergo a complete metamorphosis.

Life Habits of Green Frog. - The green frog inhabits shallow fresh-water ponds, streams, and marshes. Much of the daytime they may be seen sunning themselves. They live to a large extent upon insects, which they catch by protruding their long bi-cleft tongue. They also eat small algæ and aquatic animals, and are in fact omnivorous, even eating their own young.

Life History. - During the first warm days in March or April, look for gelatinous masses of frog's eggs attached to sticks or waterweed in shallow ponds. Collect some and try to hateh them out in a shallow dish in the window at home. Nake experiments to learn whether temperature affects the development of the egg in any way. Place eggs in dishes of water in a warm room and in a cold room, also some in the ice box. Make observations for several weeks as to rate of development of each lot of eggs. Also try placing a large number of eggs in one dish, thus cutting down the supply of available oxygen, and in another dish near by under the same conditions of light and heat place a few eggs. Do both batches of eggs develop with the same rapidity? In all these experiments be sure to use eggs from the same egg mass, so as to insure all being of the same age.

Development. - The eggs of the frog are laid in shallow water in the early spring. Masses of several hundred are deposited at a 
single laying. Immediately before leaving the body of the female they receive a coating of jellylike material, which swells up after the eggs are laid. Thus they are protected from the attack of fish or other animals which might use them as food. The fertilized egg soon segments (divides into many cells), and in a few days, if the weather is warm, these cells have grown into an oblong body which shows the form of a tadpole. Shortly after the tadpole wriggles out of the jellylike case and begins life outside the egg. At first it remains attached to some waterweed by means of a suckerlike projection; later a mouth is formed at this point and the tadpole begins to feed upon algæ or other tiny water plants. At this time gills are present on the outside of the body. Soon after this, the external gills are replaced by gills which grow out under a fold of the skin which forms an operculum somewhat as in the fish. Water reaches the gills through the mouth and passes out through a hole on the left side of the body. As the tadpole grows larger, legs appear, the hind legs making their appearance first, although for a long time locomotion is performed by means of the tail. In some species of frogs the changes from the egg to adult are completed in one summer.

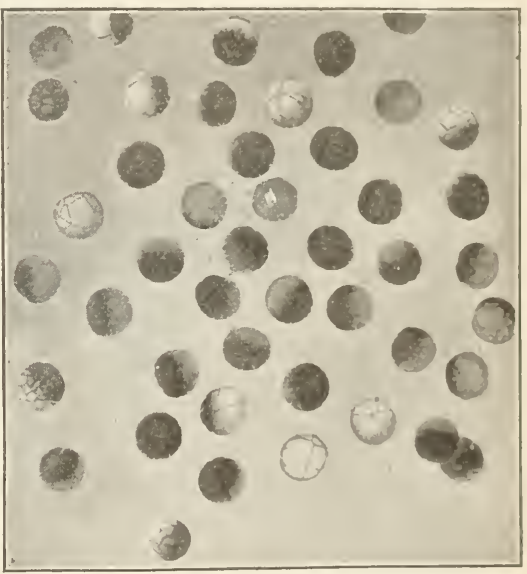

Frog's eggs from three to ten hours oll. All stages from four cells to thirt $y-t$ wo cells may be noted. From photograph, enlarged four times, by Davison.

A month or two after hatching, the tadpole begins to eat less, the tail is used up rather rapidly (being absorbed into other parts of the body), and before long the transformation from the tadpole to the young frog is complete. In the green frog and bullfrog the metamorphosis is not completed until the beginning of the second summer. The large tadpoles of such forms bury then selves in the soft mud of the pond bottom during the winter. 
Early during its transformation the tadpole loses its gills, these being replaced by lungs. At this time the young animal may be seen coming to the surface of the water after a bubble of air. Changes in the diet of the animal also take place at this stage of metamorphosis; the long coiled intestine is transformed into a

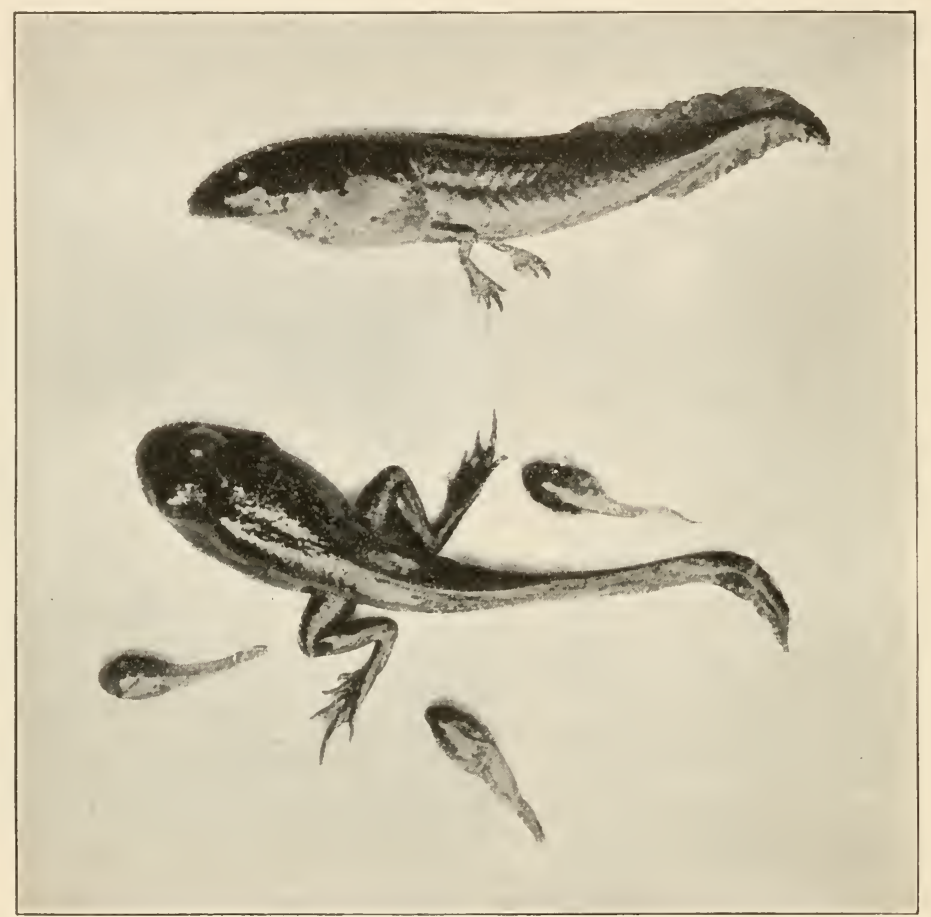

Stages in the life of tadpoles of the green frog. The two large tadpoles are in their second summer. Photographed by Overton.

much shorter one in the adult. The animal, now insectivorous in its diet, becomes provided with tiny teeth and a mobile tongue, instead of keeping the horny jaws used in scraping off algæ. After the tail has been completely absorbed and the legs have become full grown, there is no further structural change and the metamorphosis is said to be complete. 
The Common Toad. - One of the nearest of the allies of the frog is the common toad. The eggs, like those of the frog, are deposited in fresh-water ponds, especially small pools. The egrrlaying season is later than that of the frog. The eggs are laid in strings, as mary as eleven thousand eggs having been laid by a single toad.

Field Work. - The egg-laying season in New York state is carly May. At this time procure a female that has not laid her eggs and place her in an aquarium. If undisturbcd, she may lay her eggs in ('aptivity. Compare the bulk of the eggs after they are laid with the size of the toad that laid them. This apparent discrepancy is eaused by the swolling of the gelatinous substance around them. If possible, count the number of eggs laid by one female. ${ }^{1}$

Toad tadpoles may be distinguished from those of the frog, as they are darker in color, and have a more slender tail and a relatively larger body than those of the frog. The metamorphosis occupies only about two months at the temperature of New York. During the warm weather the tail is absorbed with wonderful rapidity, and the change from a tadpole with no legs to that of the small toad living on land is often accomplished in a few hours. This has given rise to the story that it has rained toads in a given locality, because during the night thousands of young toads have changed habitat from the water to the land.

The toad is of great economic importance to man because of its diet. No less than eighty-three species of insects, mostly in jurious, have been proved to enter into the dietary. ${ }^{2} \quad A$ toad has been observed to snap up one hundred and twenty-eight flies in half an hour. Thus at a low estimate it could easily destroy one hundred insects during a day and do an immense service to the garden during the summer. It has been estimated by Kirkland that a single toad may, on account of the cutworms which it kills, be worth $\$ 19.88$ each season it lives. Toads also feed upon slugs and other garden pests.

Other Amphibians. - The tree frogs (called tree toads) are familiar to us in the early spring as the peepers of the swamps. They are among the earliest of the frogs to lay their eggs. During

1 See Hodge, Nature Study and Life.

2 (See Kirkland, Habits, Food and Economic Importance of the American T'oad.) Bul. 46, Hatch Experiment Station, Amherst, Mass. 
adult life they spend most of their time on the trunks of trees, where they receive immunity from attack because of their color markings. The feet of the tree toad are modified for climbing by having little disks on the ends of the toes, by means of which it is

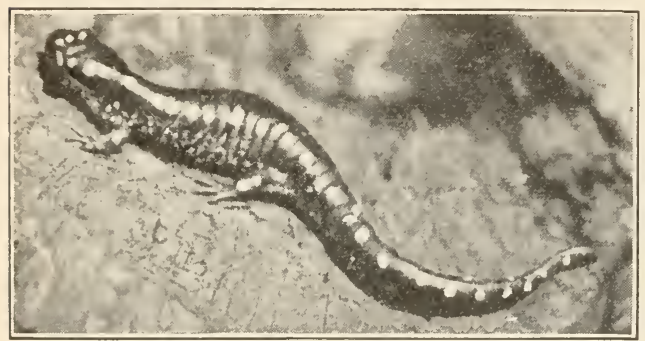

Spotted salamander. From photograph loaned by the American Museum of Natural History. able to cling to vertical surfaces.

Another amphibian is the salamander, a smooth-skinned, fourlimbed animal, often incorrectly called a lizard. These animals pass their early life in the water, later coming out on land. After passing through the stages of the segmenting egg, with few exceptions they breathe by means of external gills; later they may develop lungs. A few never have lungs, but breathe through the moist skin.

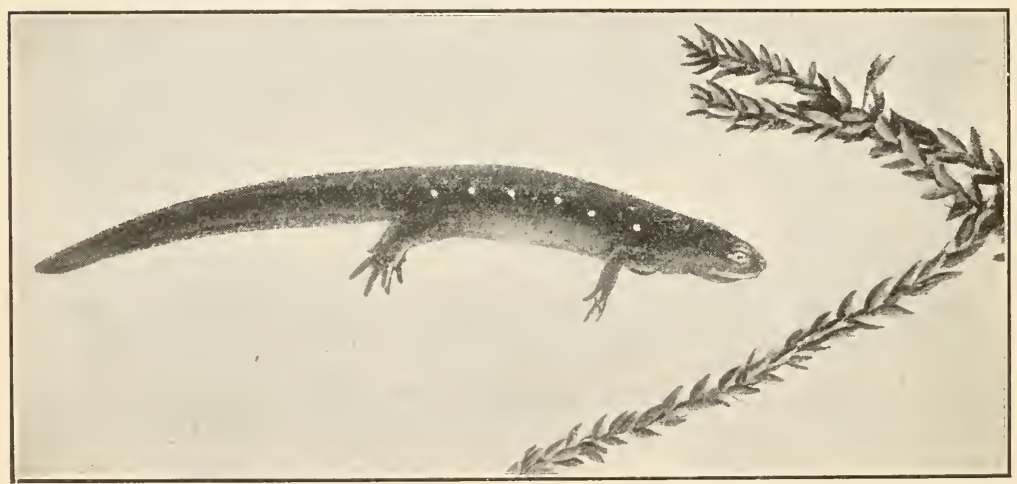

Newt. From photograph loaned by the American Museum of Natural History.

Still other amphibians are the mud puppies, sirens or mud eels, and the axolotl. All of the above animals differ from the reptiles in having a smooth skin with no scales, and in passing the early stage of their existence in the water. 


\section{Classification of Amphibia mentioned}

OrDer I. Urodela. Amphibia having usually poorly developed appendages. Tail persistent through life. Examples, mud puppy, newt, salamander.

Order II. Anura. Tailless amphibia, which undergo a metamorphosis breathe by gills in larval, by lungs in adult, state. Examples, toad and frog.

\section{Reference Books \\ FOR THE PUPIL}

Davison, Practical Zoölogy, pages 199-211. American Book Company.

Herrick, Text-book in General Zoölogy, Chap. XX. American Book Company. Nature Study Leaflets, XVI, XVII. N.Y. Department of Agriculture.

Hunter and Valentine, Laboratory Manual of Biology, pages 170-177. Heury Hol* and Company.

Jordan, Kellogg, and Heath. Animal Studies. D. Appleton and Company.

FOR THE TEACHER

Holmes, The Biology of the Frog. The Macmillan Company.

Parker and Haswell, Text-book of Zoölogy. The Macmillan Company. 


\section{REPTILES}

The Spotted or Mud Turtle (Chelopus guttatus). - For a classroom exercise use living turtles. The body is flattened, and is covered on the dorsal and ventral sides by a bony framework. This covering is composed of plates cemented to the true bone underneath, the whole forming one horny cover. What is the general arrangement of these plates? The dorsal covering is known as the carapace, the ventral one the plastron, the connection between them the bridge. Allow the animal to remain quiet for a moment, then touch the head suddenly. What is one function of the shell? In the box turtle this adaptation is made more evident by a hinge in the plastron which fits over the head and legs after they are withdrawn into the shell.

Adaptations. - Place a lively turtle on its back. How does it attempt to regain equilibrium? Notice the long neck. The long neck and powerful horny jaws are of great use to the animal in food getting. Allow the turtle to crawl on the table. Then place it in a dish of water. How are the legs adapted to movement in the water? How is the foot adapted for other purposes?

Turtles are very strong for their size. The stout legs carry the animal slowly on land, and in the water, being slightly webbed, they are of service in swimming. The strong claws are used for digging especially at egg-laying season, for some forms of turtles dig large holes in sandy beaches in which the eggs are deposited.

Watch a turtle feeding. Notice that the claws are used. How? The absence of teeth makes it necessary for the turtle to tear the food with the aid of the strong claws.

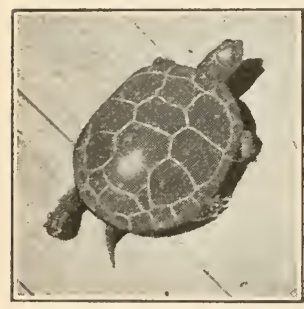

Western painted turtle.

The sense of hearing in the turtles is not keen. The tympanic membrane can be seen just behind the eyes on the sides of the head. Can you determine by experiment anything regarding keenness of vision in the turtle? Is the turtle protectively colored? Describe any evidences you may see. Notice that the yellow, ventral side would harmonize the general coloring, looking through the water toward the surface of the pond. The yellow dots on the black background look in the water much like small stones or sand grains.

Draw the turtle, natural size, from the dorsal side and label all the parts you know.

The Turtles. - The turtles form a large and interesting group of animals. They are mostly aquatic in habit. Some exceptions are found, however, as in the case of the box tortoise (Cistudo Carolina) and the giant tortoise of the Galapagos Islands. This latter animal attains a weight of three hundred pounds or more and may be over four feet in length and almost three feet in 
thickness. Many of the sea-water turtles are of large size, the leatherback and the green turtle often weighing six hundred to seven hundred pounds each. The flesh of the green turtle and especially the diamondback terrapin, an animal found in the salt marshes along our southeastern coast, are highly esteemed as food. Unfortunately for the preservation of the species, these animals are usually taken during the breeding season, when they go to sandy beaches to lay their eggs.

Characteristics of the Reptilia. - The turtle belongs to the class of vertebrates known as the Reptilia. These animals are characterized by having scales developed from the skin. These in the turtle have become bony and are connected with the internal skeleton. Turtles always breathe by means of lungs, differing in this respect from the amphibians. They seem to show their distant relationship to birds in that their eggs are large and are encased in a leathery, limy shell.

Lizards. - Lizards may be recognized by the long body with four legs of nearly equal size. The body is covered with scales. The animal never lives in water, it is active in habit, and it does not undergo a metamorphosis. Salamanders (commonly called lizards) have a moist skin, and belong to the Amphibia. Lizards are harmless creatures, the Gila monster of New Mexico and Arizona, a poisonous variety, being the one exception. Lizards are, on the whole, of economic importance to man because they eat insects and include the injurious ones in their dietary. Certain lizards, including injurious ones, notably the chameleon and our common fence lizard, have the power to change the color of the skin. This forms a protective adaptation, for they thus assume the color of their immediate surroundings. The horned toad of our Western states shows another wonderful case of protective adap- 


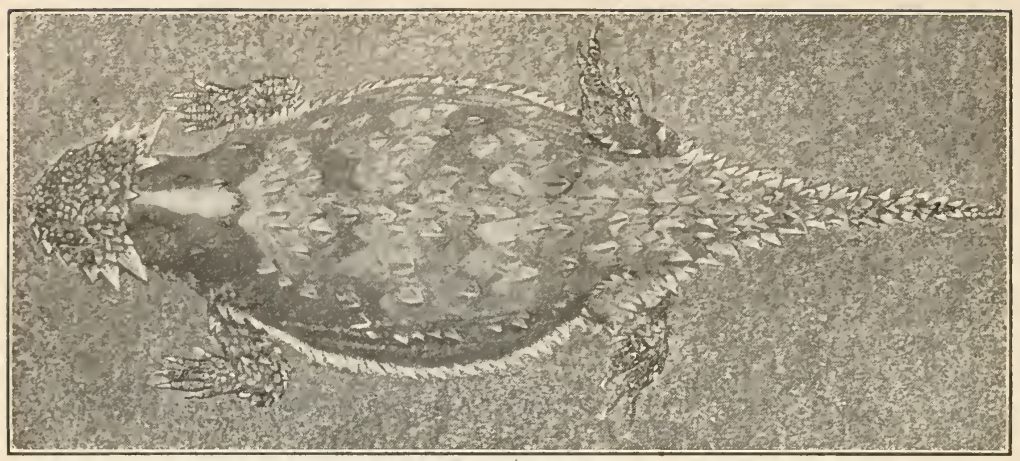

Horned toad. Note the protective resemblance.

tation. The iguana of Central America and South America is among the largest of lizards, growing to a length of three feet or more. It has the distinction of being one of the few edible lizards.

Snakes. - Probably the most disliked and feared of all animals are the snakes. This feeling, however, is rarely deserved. Our

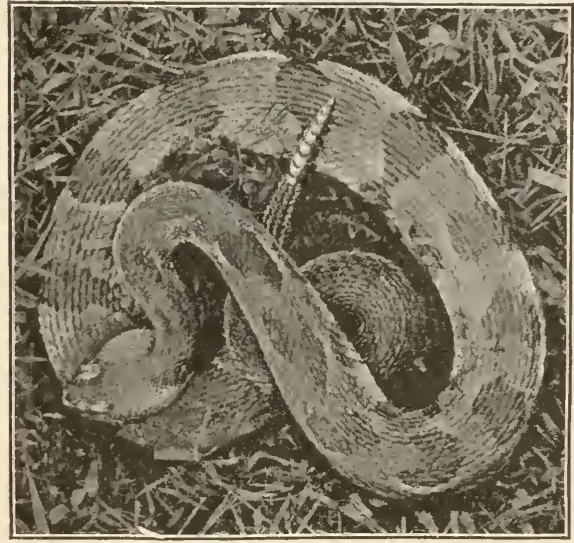

Rattlesnake three feet long coiled ready to strike. In this position it can dart its head forward two feet only. From photograph by Davison. common snakes are harmless and were it not for the fact that they live upon insect-destroying animals, as toads, frogs, and birds, we might even say that they are useful to man.

Snakes are almost the only legless vertebrates. Although the limbs are absent, still the pelvic and pectoral girdles are developed. The very long backbone is made up of a large number of vertebræ, as many as four hundred being found in the boa constrictor. Ribs are attached to all vertebræ in the region of the body cavity. 
Locomotion. - Locomotion is performed by pulling and pushing the body along the ground, a leverage being obtained by means of the broad flat scales, or scutes, with which the ventral side of the body is covered. Snakes can also move without twisting the body. This is accomplished by a regular drawing forward of the scutes (with the ribs under them) and then pushing them backward rather more violently.

Feeding Habits. - The bones of the jaw are very loosely joined together. Thus the mouth of the snake is capable of wide distention. It holds its prey by means of incurved teeth, two of which (in the poisonous snakes) are hollow, and serve as a duct for the passage of poison. The poison glands are found at the base of the curved fangs in the upper jaw. The tongue is very long and cleft at the end. It is an organ of touch and taste, and is not, as many people believe, used to sting with. The food is swallowed whole, after having been caught by the teeth, and pushed

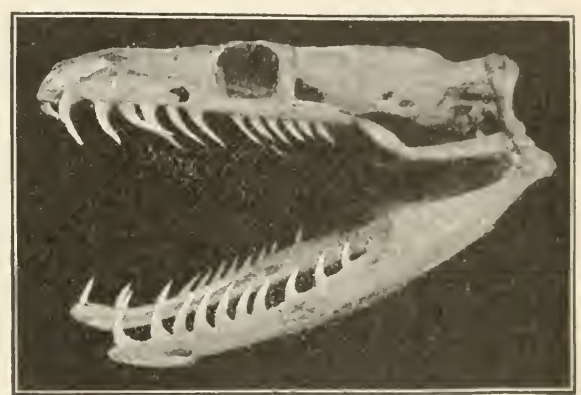

Skull of boa constrictor, two thirds natural size. From photograph by Davison. down by rhythmic contractions of the muscles surrounding the gullet. They refuse other than living prey. After a full meal, one of which is sufficient for weeks, the snake remains in a torpid condition.

Adaptations. - The extreme length of the body in the snake has resulted in the modification of the form of its internal organs. One long, narrow lung is developed instead of two. The glands of the body cavity are long and slender, while the kidneys are placed so that one is anterior to the other.

Snakes are usually colored to harmonize with their surroundings. Thus they may approach and seize their prey before it escapes. They are not extremely prolific animals, but hold their own with other forms of life, because of their numerous adaptations HUNTER'S BIOL. -19 
for protection, their noiseless movement, protective color, and, in some cases, by their odor and poison.

Poisonous Snakes. - Not all snakes can be said to be harmless. The bite of the rattlesnake of our own country, although dangerous, seldom kills. The dreaded cobra of India has a record of over two hundred and fifty thousand persons killed in the last thirty-five years. The Indian government yearly pays out large sums for the extermination of venomous snakes, over two hundred thousand of which have been killed during a single year.

Alligators and Crocodiles. - The latter are mostly confined to Asia and Africa, while the former are natives of this continent and

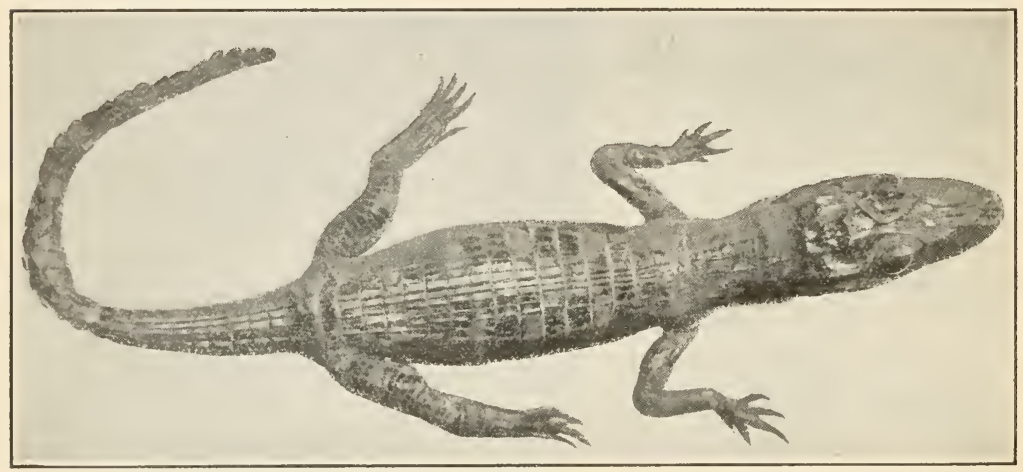

Young alligator. One fourth natural size.

South America. The chief structural difference between them is that the teeth in alligators are set in long sockets, while those of the crocodile are not. Both of these great lizardlike animals have broad, flattened tails adapted to swimm!ng. The eyes and nostril holes protrude from the head, so that the animal may float motionless near the surface of the water with only eyes and nostrils visible. The nostrils are closed by a valve when the animal is under water. They feed on fishes, but are known to attack large animals, as horses, cows, and even man. They seek their prey chiefly at night; and spend the day basking in the sun. The crocodiles of the Ganges River in India levy a yearly tribute of many hundred lives from the natives. 


\section{Clansification of Reptiles}

Order I. Chelonia (turtles and tortoises). Flattened reptiles with body enclosed in bony case. No teeth or sternum (brcast bone). Examples, snapping turtle, box tortoise.

ORDER II. Lacertilia (lizards). Body covered with scales, usually having twopaired appendages. Breathe by lungs. Example, fence lizard, horned toad.

Order III. Ophidia (snakes). Body elongated, eovered with seales. No limbs present. Examples, garter snake, rattlesnake.

Order IV. Crocodilia. Freshwater reptiles with elongated body and bony scales on skin. Two paired limbs. Examples, alligator, crocodile.

\section{Reference Books \\ FOR THE PUPIL}

Davison, Practical Zoölogy, pages 211-226. American Book Company.

Herrick, Text-book in General Zoölogy, Chap. XXI. American Book Company. Jordan, Kellogg, and Heath, Animal Studies, Chap. XVI. D. Appleton and Company.

FOR THE TEACHER

Riverside Natural History. Houghton, Mifflin, and Company. Parker and Haswell, Text-book of Zoölogy. The Macmillan Company. 


\section{BIRDS}

THE following questions may be worked out during a visit to a zoölogical park or during a field trip. ${ }^{1}$

Pick out some particular bird for your study and take notes upon the following series of questions. Do not expect to be able to answer all the questions which follow.

Protection. - Does the bird rest or nest in trees, bushes, or grass? In general, what are the colors of the bird? Do they harmonize with the surroundings when the bird is at rest? Look especially for birds on the nest. Often such birds will remain quiet, allowing the observer almost to touch

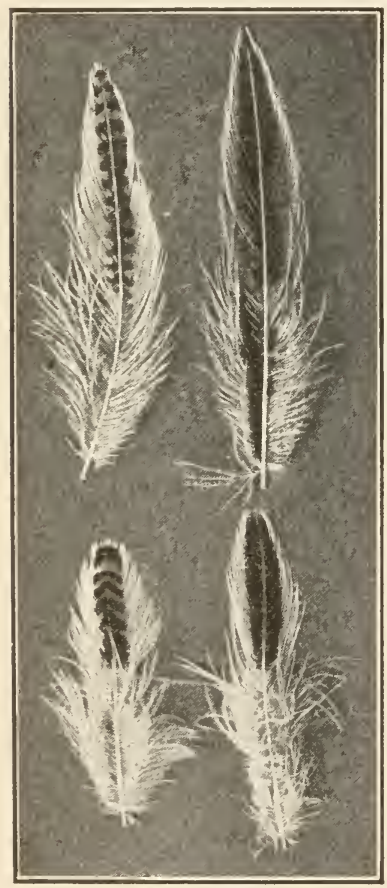

Feathers of a meadow lark. Which of the above are used for flight? Why? From photograph loaned by the American Museum of Natural History. them before they attempt to fly away. In some cases the light, glinting through the trees, gives a mottled or banded appearance to the leaves, somewhat resembling the same kind of markings on a bird.

Flight. - Watch a bird in flight. Try to determine the exact changes in the position of the wings that take place. The tip of the wing usually describes a curve which results in the forming of the figure $\infty$. Notice that the rate of movement of the wing differs greatly in different birds. Birds with long, thin wings, as the hawks and gulls, move the wing in flight with much less rapidity than those with short, wide wings, as the grouse or quail. The latter birds start with much less apparent effort than the birds with longer wings; they are, however, less capable of sustained flight.

The wing of a bird is slightly concave on the lower surface when outstretched. Thus on the downward stroke of the wing more resistance is offered to the air.

Under the covering of feathers the parts of the wing may be made out. This may easily be done from a fowl at home, or dead sparrows may be used in the laboratory. Find and identify the parts corresponding to the human arm, forearm, and hand. The last division of the wing is homologous to our

1 Bird activities may best be studied out of doors. Any city park offers more or less opportunity for such study, for several of our native birds make the parks their home. If not these, then the English sparrow can be found anywhere in the East. The best time for making observations is early in the morning, especially in the Spring season. 
hand and wrist, the third and fourth fingers are absent while the wrist bnnes and fingers of the fowl have grown together, thus giving greilter strength and support. This is evidently an adaptation for flight.

Feathers. - Few people realize that the body of a bird is not completely covered with feathers. Look for featherless areas on the body of the bird you are working with. Notice that feathers are of several shapes. Soft down feathers cover the body, serving for bodily warmth. In the wings we find quill feathers; these are adapted for servier in flight. Lut 11 . examine a single quill feather more closcly. The main axis of the frather, called the shaft, is hollow, light, and strong. From the shaft, lateral branches, called barbs, are given off. The barbs give rise to still smaller lateral structures, the barbules, the latter just visible te the naked cye. Fache barbule is interlocked with its neighbor by means of many microscopie horoks. the barbicels. If you attempt to pull apart the barbs of a feather, you will find that they stick together. What is the reason for this? Ulight this arrangement be of use in flight, and if so, how?

Draw a quill feather and show all the parts visible to the naked eye.

Feathers. - Feathers are developed from the under layer of the skin. At first they appear to be tiny, pimplelike projections. They are formed in almost exactly the same manner as are the scales of a fish or a lizard. The first feathers developed on the body are evidently for protection against cold and wet. In aquatic birds the feathers are oiled constantly, and thus shed water. The feathers of most male birds are brightly colored. This seems to make them attractive to the females of the species; thus the male may win its mate.

Perching. - The habit of perching is an interesting one. In many perching birds the tendons of the leg and foot, which regulate the toes, are self locking; thus while asleep such birds balance themselves perfectly. A certain part of the ear, known as the semicircular canals, has to do with the function of halancing. In the flamingoes, which do not perch, balancing appears to be automatic and self-regulating; thus the bird is able to go to sleep when in an upright position.

Tail. - The tail is sometimes used in balancing; its chief function, however, appears to be that of a rudder during flight. Note that the tail is merely a small protuberance of the body, the feathers which grow there give it the shape. In many hirds, under the skin of the tail is located a large oil gland, whence comes the supply of oil that is used in waterproofing the feathers.

Adaptation in the Lower Limbs. - In the leg identify the thigh, the shin, and foot. The ankle of the bird is extremely long, the seven bones found 
in man are here in part lost and partly grown together. Scales are found on the ankle and foot; in very early life they resemble feathers, both in appearance and manner of growth. If mounted specimens are obtainable, notice the different feet in different birds. Some have the foot adapted to perching, others for swimming, others wading, etc. Take some one example and attempt to explain all the devices which serve to adapt the foot to its use. Is there anything in the life of the bird that would make the correlation of the adaptation of the foot for scratching and perching? Note the method of walking in a sparrow, robin, and pigeon. What is there about the position or structure of the leg that adapts it for walking or hopping? In the ostrich and cassowary the wings are not used for flight;

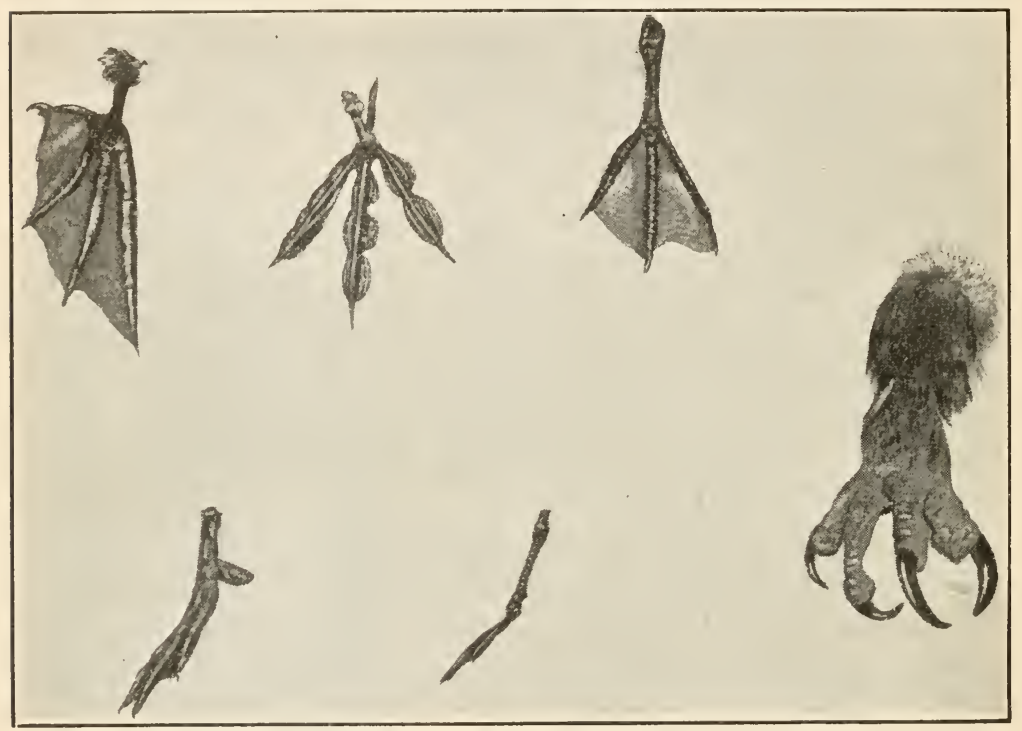

Explain, after reading the paragraph on adaptation in the lower limbs, how each of the above feet are fitted to do their work. From photograph loaned by the American Museum of Natural History.

here the lower limbs have taken up the function of rapid motion. Notice any adaptations for aquatic life that you may find, and explain in each case how the part described is fitted for the work to be done. The foot of the common barnyard duck, for example, is much like that of the alligator.

The Skeleton. - The whole skeleton combines lightness, flexibility, and strength. Many of the bones are hollow or have large spongy cavities. The bones of the head and neck show many and varied adaptations to the life that the bird leads. The vertebræ which form the framework of the neck are strong and 
yet flexible. They vary greatly in shape and also in number. The swan, seeking its food under water, has a neck containing twentythree long vertebræ; the English sparrow, in a different environment, has only fourteen short ones. Some bones, notably the breastbone, are greatly developed in flying birds for the attachment of the muscles used in flight.

Bill. - The form of the bill shows adaptation to a wonderful degree.

Exercise for a Trip to a Museum or Zoölogical Park. - Note a number of different-shaped bills. How is the bill adapted to taking the food for the bird ? Seek for uses in each case. Remember that a bird uses its bill as some animals use claws and teeth. Birds, except the parrot and some of the birds of prey, rarely use the claws in feeding. The bills vary greatly according to the habits of the birds. A duck has a flat bill for pushing through the mud and straining out the food; a bird of prey has a curved or hooked beak for tearing; the woodpecker has a sharp straight bill for piercing the bark of trees in search of the insect larvæ which are hidden underneath.

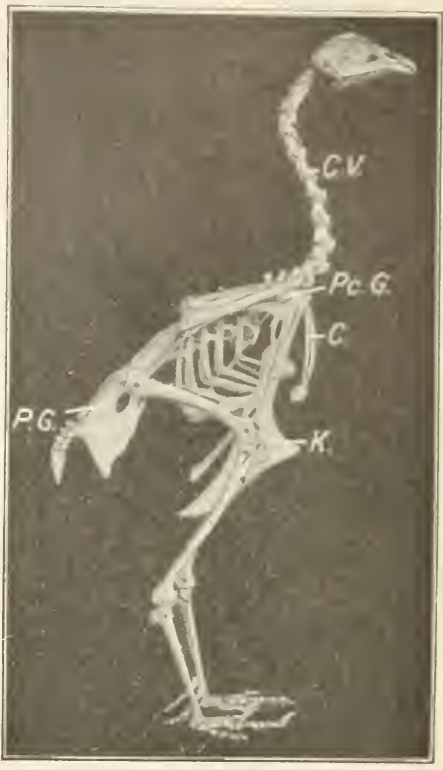

Skeleton of a fowl; $C$., clavicle;.C. $V_{\text {., cer- }}$ vical vertebræ; $K$., keeled sternum; P.G., pelvic girdle; Pc.G., pectural girdle.

Birds never have teeth, except possibly in the embryo stage. The edge of the bill may be toothlike, as in some fish-eating ducks; these, however, are not true teeth. Frequently, too, the tongue has sharp toothlike edgres which serve the same purpose as the reeurved teeth of the frog or snake. With care you may be able to make out the use of the tongue in eating and drinking in some bird. Report in elass the result of your observations.

Reason for High Temperature and Rapid Heart Beat in Birds. - Make observations on a bird as to the rapidity of the movements made in breathing (respiratory movements). Compare them with your own as to rapidity. Compare the rate of heart beat in your own body and that of a bird (a live sparrow or canary). To take your own pulse, find the artery in your wrist or on the side of your head about an inch abore the midpoint, on a line between the ear and eye. The heart of the bird may casily be felt by holding the hand against its breast. If now the temperature of the body of the bird be taken (by holding a clinical thermometer under the wing), and this compared with that of your own body taken under the arm, a considerable difference will be noticed. 


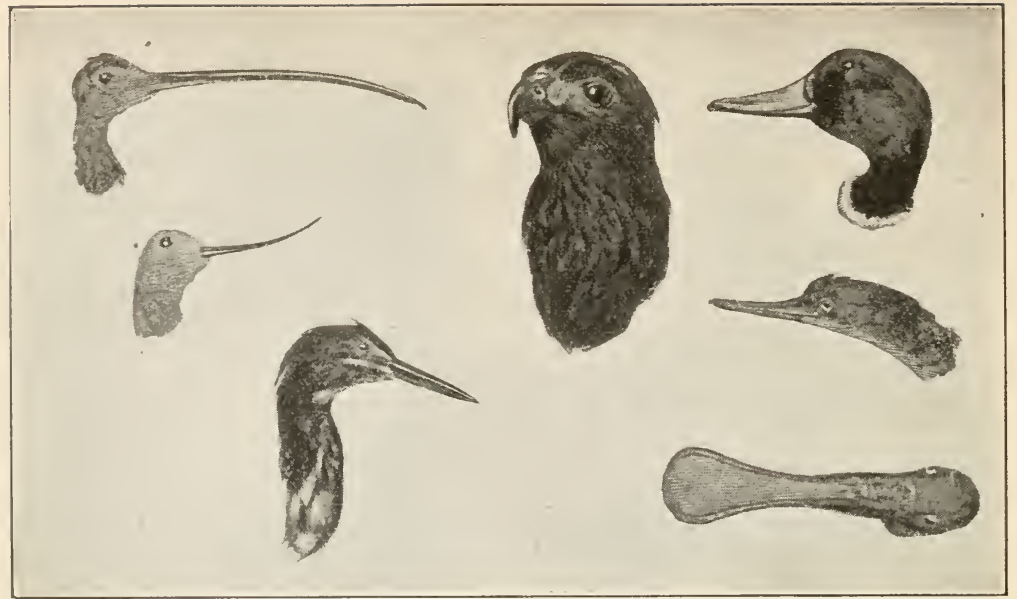

Adaptations in the bills of birds.

The rate of respiration, of heart beat, and the body temperature are all higher in the bird than in man. All these correlated facts show that, because of the increased activity of the bird, there comes a necessity for a greater and more rapid supply of oxygen, an increased blood supply to carry the material to be used up in the release of energy, and a means of rapid excretion of the wastes resulting from the process of oxidation. The bird may be compared to a high-pressure steam engine. In order to release the energy which the bird uses in flight, a large quantity of fuel which will oxidize quickly must be used. Birds are large eaters, and the digestive tract is fitted to digest the food quickly and to release the energy when needed, by having a large crop in which food may be stored in a much softened condition. As soon as the food is part of the blood it may be sent rapidly to the places where it is needed, by means of the large four-chambered heart and large blood vessels.

This is one of the greatest adaptations to the active life led by a bird. Man breathes from twelve to fourteen times per minute. Birds breathe from twenty to sixty times a minute. The lungs are not large, but the bronchial tubes are continued 
through the lungs into hollow spaces filled with air, which are found between the organs of the body.

The high temperature of the bird is a direct result of this rapid oxidation and also because the feathers and the oily skin form an insulation which does not readily permit of the escape of heat. This fact is of much use to the bird in its flights at great altitucles, where the temperature is often very low.

The Nervous System and the Senses. - The central nervous systrm is well developed. A large forebrain is found, which, according to a series of elaborate experiments with pigeons, is found to have to do with the conscious life of the bird. The cerebellum takes care of the acts which are purely mechanical and are concerned with the living (digestion, absorption, beating of the heart, etc.) of the bird.

Sight is probably the best developed of the senses of a bird. The keenness of vision of a hawk is proverbial. It has been noticed that in a bird which hunts its prey at night, the eyes look toward the front of the face. In a bird which is hunted, as in the dove, the eyes are placed at the side of the head. In the case of the woodcock, which feeds at night in tie marshes, and which is in constant danger from attack by owls, the eyes have come to lie far back on the top of the head. Hearing is also well developed in mo:t birds; this fact may be demonstrated with any canary.

The sense of smell does not appear to be well developed in any bird, and is especially deficient in seed-eating birds, most sceds having little odor.

Nesting Habits. - Among the most interesting of all instincts shown by birds are the habits of nest building. We have found that some invertebrates, as spiders and ants, protect the eggos when laid. In the vertebrate group some fishes (as the sunfish and stickleback) make nests for the deposition of the eggs. But most fishes, and indeed other vertebrates lower than the birds, leave the eggs to be hatched by the heat of the sun. Birds incubate their eggs, that is, hatch them by the heat of their own bodies.

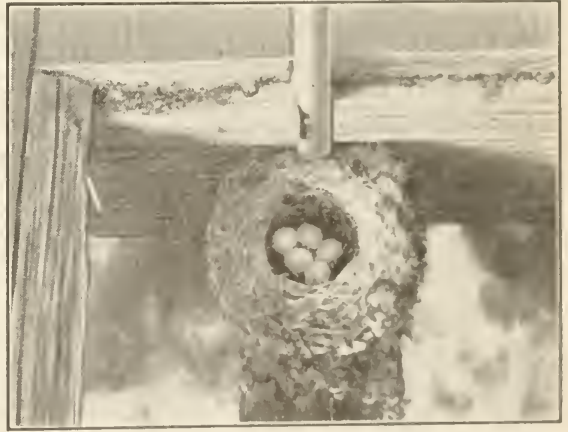

Nest of a phobe umler (he harn tlour. 
Hence a nest, in which to rest, is needed. The ostrich is an exception; it makes no nest but the male and the female take turns in sitting on the eggs. Such birds as are immune from the attack of enemies, either because of their isolation, or their protective

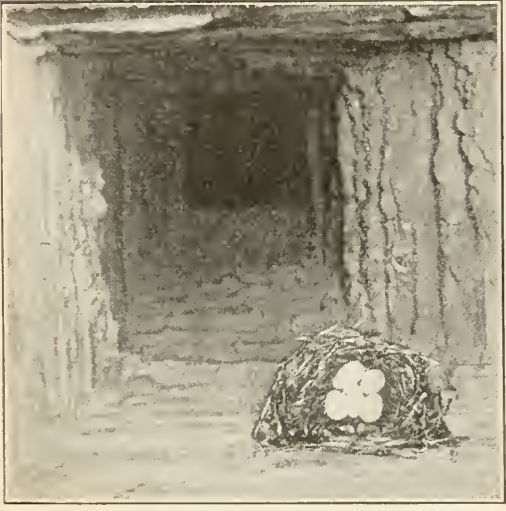

Nest of the chimney swift. coloration (as the puffins, gulls, and terns), build a rough nest among the rocks or on the beach. The eggs, especially those of the tern, are marked and colored so as to be almost indistinguishable from the rocks or sand on which they rest. Other birds have made the nest a home and a place of refuge as well as a place to hatch the eggs. Such is the nest of the woodpecker in the hollow tree and the hanging nest of the oriole. Some nests which might be easily seen because of their location are often rendered inconspicuous by the builders; for example, the lichen-covered nest of the humming birds.

Care of the Young. - After the eggs have been hatched the young in most cases are quite dependent upon the parents for food. Most young birds are prodigious eaters; as a result they grow very rapidly. It has been estimated that a young robin eats two or three times its own weight in worms every day. Many other young birds, especially kingbirds, are rapacious insect eaters. In the case of the pigeons and some other birds, food is swallowed by the mother, partially digested in the crop, and then regurgitated into the mouths of the young nestlings.

Food of Birds. - The food of birds makes them of the greatest economic importance to our country. This is because of the relation of insects to agriculture. A large part of the diet of most of our native birds includes insects harmful to vegetation. Investigations undertaken by the U.S. Department of Agriculture (Division of Biological Survey) show that a surprisingly large number 
of birds once believed to harm crops really perform a service to the farmer by killing injurious insects. Even the much maligned crow lives to a large extent upon insects. During the entire year, the crow eats about 25 per cent insect food and 29 per cent grain. In May, when the grain is sprouting, the crow is a pest, but he makes up for it during the remainder of the summer by eating harmful insects. The robin, whose presence in the cherry tree we resent, during the rest of the summer does untold good by feeding upon noxious insects. Birds, as a rule, feed upon the substances which are most abundant around them at the time. The following quotation from I. P. Trimble, A Treatise on the Insect Enemies of Fruit and Shade Trees, bears out this statement: "On the fifth of May, 1864, . . . seven different birds . . . had been feeding freely upon small beetles. . . There was a great flight of

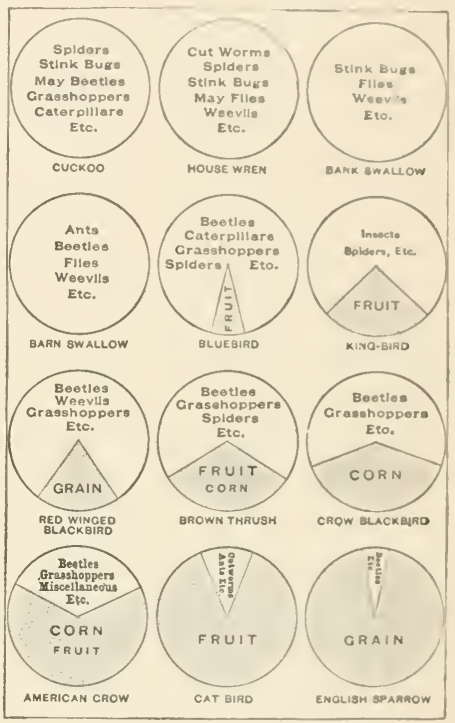

Food of some common birds.

beetles that day; the atmosphere was teeming with them. A few days after, the air was filled with Ephemera flies and the same species of birds were then feeding upon them." 1

${ }^{1}$ During the outbreak of Rocky Mountain locusts in Nebraska in 1874-1577, Professor Samuel Aughey saw a long-billed marsh wren earry thirty loeusts to her young in an hour. At this rate, for seven hours a day, a brood would consume 210 locusts per day, and the passerine birds of the eastern half of Nebraska, allowing only twenty broods to the square mile, would destroy daily $162.771,000$ of the pests. The average locust weighs about fifteen grains, and is capable cach dav of consuming its own weight of standing forage crops, which at $\$ 10$ per ton would be worth $\$ 1,743.97$. This case may serve as an illustration of the vast good that is done every year by the destruction of insect pests fecl to nestling bircls. And it should be remembered that the nesting season is also that when the destruction of injurious insects is most needed; that is, at the period of greatest agricultural activity and before the parasitic insects can be depended on to reduce the pests. The encouragement of birds to nest on the farm and the discouragement of nest robbing are therefore more than mere matters of sentiment: they return an actual cash equivalent, and have a definite bearing on the suceess or failure of the crops. Year Book of the Department of Agriculture. 
There are exceptions to the above general rule, as is seen by the fact that locust-catching starlings breed in large numbers in localities where locusts have deposited their eggs. At seasons when the number of locusts hatched are few, many starlings die from lack of food.

Not only do birds aid man in his battles with destructive insects, but seed-eating birds eat the seeds of weeds. This fact alone is sufficient to make birds of vast economic importance.

Not all birds are insect feeders. Some, as the cormorants, ospreys, gulls, and terns, are active fishers. Sea birds also live upon shellfish, and crustaceans (as small crabs, shrimps, etc.); some even eat organisms of a lower grade of life. The kea parrot takes its meal from the muscles forming the backs of living sheep, while other birds of prey eat living mammals, sometimes of considerable size.

Extermination of our Native Birds. - Within our own times we have witnessed the almost total extermination of some species of our native birds. The American passenger pigeon, once very abundant in the middle west, is now practically extinct. Audubon, the greatest of all American bird lovers, gives a graphic account of the migration of a flock of these birds. So numerous were they that when the flock rose in the air the sun was darkened, and at night the weight of the roosting birds broke down large branches of the trees in which they rested. To-day hardly a single specimen of this pigeon can be found. Wholesale killing for plumage, eggs, and food, and alas, often for mere sport, has caused the decrease of our common song birds to a small percentage of their former number within the past fifteen years. Every crusade against indiscriminate killing of our native birds should be welcomed by all thinking Americans. Without the birds the farmer would have a hopeless fight against insect pests. The effect of killing native birds is now well seen in Italy and Japan, where insects are increasing yearly and do greater damage each year to crops and trees.

Of the eight hundred or more species of birds in the United States only two species of hawks, the great horned owl, the cowbird, and the English sparrow may be considered as enemies of man. 
The English Sparrow. - The English sparrow is an example of a bird introduced for the purpose of insect destruction, that has done great harm because of its relation to our native birds. Introduced at Brooklyn in $\mathbf{1 8 5 0}$ for the purpose of exterminating the canker worm, it soon abandoned an insect diet and has driven out most of our native insect feeders. Dirty and very prolific, it has worked its way from the East as far as the Pacific coast. In this area the bluebird, song sparrow, and yellowbird have all been forced to give way, as well as many larger birds of great economic value and beauty. The English sparrow should be exterminated.

Geographical Distribution and Migrations. - Most of us are aware that some birds remain with us in a given region during the whole year, while other birds appear with the approach of spring, departing southward with the warm weather in the fall of the year. Such birds we call migrants, while those that remain the year round are called residents.

In Europe, where the problem of bird migration has been studied carefully, migrations appear to take place along welldefined paths. These paths usually follow the coast very exactly, although in places they may take the line of coast that existed in former geological times. This seems to show that when a path has been established, it is handed down from one generation of birds to the next and so to successive generations.

In this country the migration routes are comparatively unknown. It has been found that the Mississippi Valley, a former arm of the sea, forms one line of migration, while the north Atlantic seacoast is another route. There is opportunity for a careful observer to learn much of the spring or fall migrations in the particular part of the country in which he resides. All information thus obtained should be sent to the secretary of the American Ornithologists' Union or to W. W. Cooke of the Binlogical Survey, who has done much to establish what we already know about bird migration in this country.

It has been recently shown by the Department of Agriculture that the southern movement of migratory birds in the fall of the year is not due entirely to the advent of cold weather. It is 
largely a matter of adjustment to food supply. A migrant almost always depends to a large extent upon fruits, seeds, and grains as part of its food. Most winter residents, as the crow, are omnivorous in diet. Others, as the sparrows, may be seed eaters, but under stress may change their diet to almost anything in the line of food; still others, as the woodpeckers, although insect-eating birds, manage to find the desired food tucked away under the bark of trees. Most insect-eating birds, however, because their food is found on green plants, are forced southward by the cold weather. Migrations are almost entirely due to need of food which cannot be obtained during a time when vegetation is dormant and the ground is frozen.

Classification of Birds. - Birds are divided into two great groups, depending on the development of the keel, that is, the part of the sternum to which the muscles used in flight are attached. This bone is well known to every one who has ever picked the breastbone of a chicken. Hence all flying

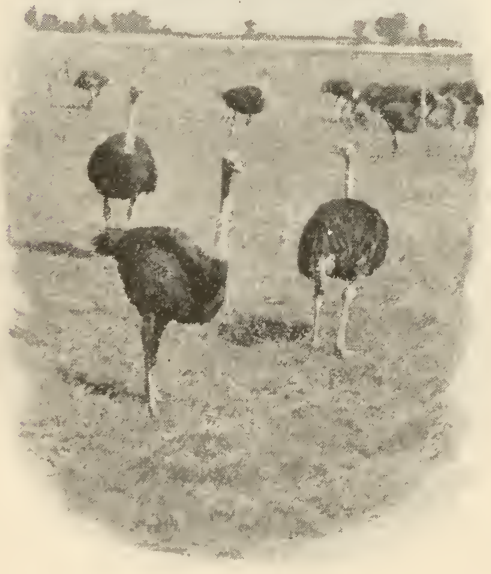

African ostrich (Struthio camelus). birds are placed in a group called the Carinatoe.

Birds in which the keel of the breastbone is not well dereloped, such as the ostrich and cassowary, are said to belong to the Ratitce. These birds make up for their lack of wing development by having the legs strong and long.

The flying birds are further subdivided into a number of orders, the classification based upon the adaptations of different parts of the bird, especially the legs and feet, the wings and the bill, to different functions. We shall not troub!e ourselves to learn all the different groups, but shall content ourselves with picking out some of the more evident and important ones.

I. Perching Birds. - To this order belong most of our common birds, 
- sparrows, swallows, larks, blackbirds, orioles, kingbirds, and many others well known to every bird lover. In this group the toes are so placed, three toes being turned forward and one backward, as to be perfectly adapted to perching. A large number of our sweetest songsters belong among the perchers, the warblers, wrens, thrushes, bluebirds, and last but not least, our robin.

II. The Fowls or GallinaCEOus BirDs. - This order is of great economic importance. From the jungle fowl, found wild in the jungles of India, all our domesticated fowls have descended. Other familiar exam-

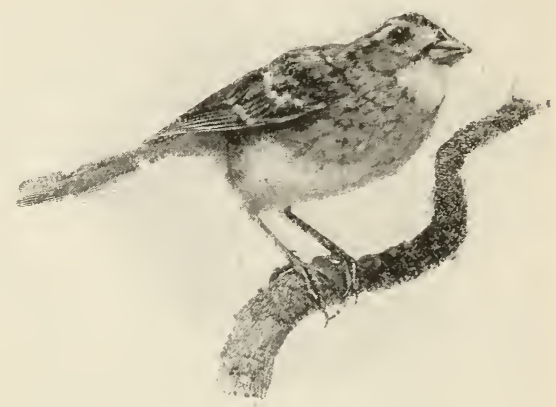

White-throated sparrow (Zonotrichia albiculiis). ples are the turkeys, quails, partridge or ruffed grouse, and the pheasants and prairie chickens. In this group the legs are strong and stout, the body thickset, the bill and claws rather blunt. Birds of this order do not fly far in a state of nature, preferring to live on or near the ground. Such birds as the ruffed grouse, which nest on the ground, are almost invariably protectively

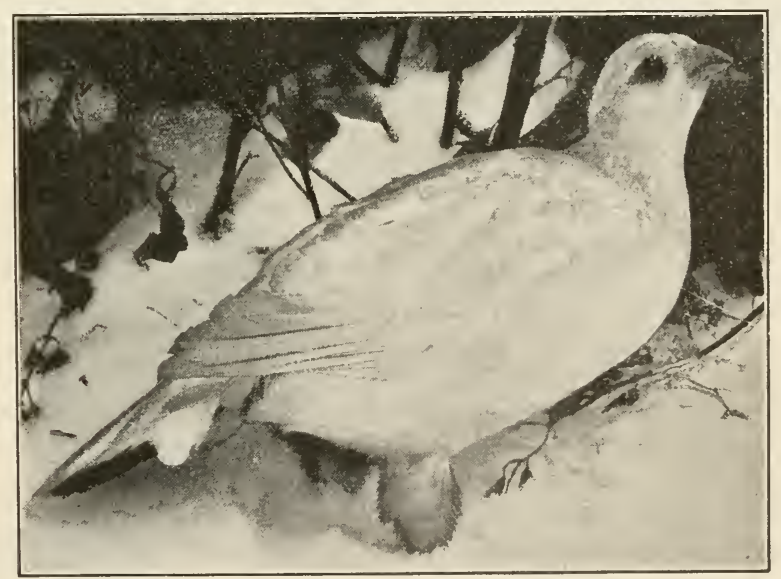

Ptarmigan in winter. Davison, Zoölogy.

colored Another interesting example of protective resemblance in this group is seen in the ptarmigan. This bird in the winter is white as the 


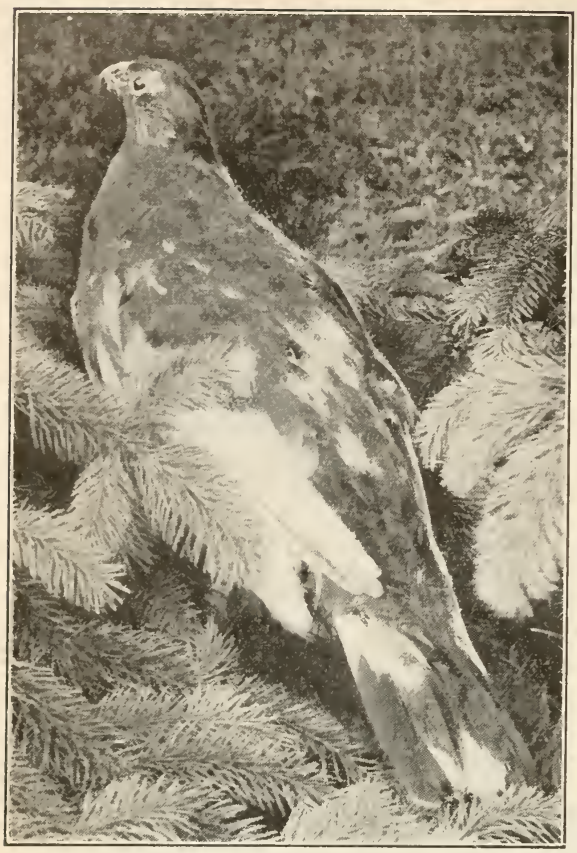

snow which surrounds it; in the spring it molts, turning to a gray and white, thus resembling the lichens among which it feeds.

III. Birds of Prey. These birds are characterized by the strong hooked beak, adapted to tearing, and by the sharp claws, which are curved and strong. The need of a gizzard, which is a prominent part of the digestive tract in a grain-eating bird, has here almost completely disappeared, the crop serving to macerate the food. Owls show this use of the muscular gullet and crop, for the hair and skeletons of the mice which form their prey are ejected in a small ball, by means of this muscular organ. Members of this group that

Ptarmigan in summer. Davison, Zoölogy.

are best known to us are the hawks, the condor, with its great sweep of ten feet from wing to wing, and the cagle. To the hawks belong two birds which are, because of their habits, harmful to man. They are the sharp-shinned hawk and Cooper's hawk.

IV. WAders. - These are birds with unusually long legs and long necks, the latter character being a natural correlation of greatest service in food getting. Examples are the mud hen or coot, the snipe, crane, heron, and stork. The last two are the giants of the group.

The Swimers and Divers. Birds placed in these orders have

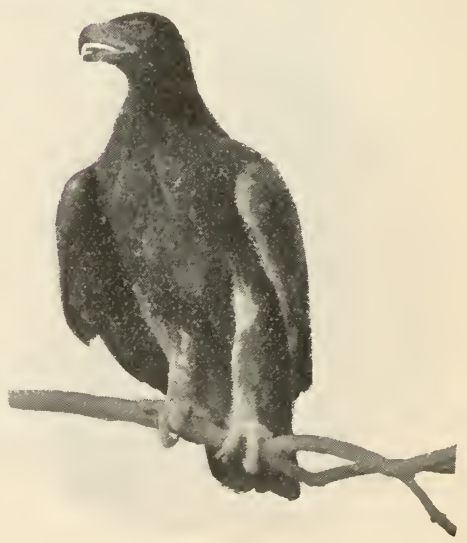

Golden eagle (Aquila chrysaëtos). North America and Europe. Copyright, 1901, by N.Y. Zoölogical Society. 


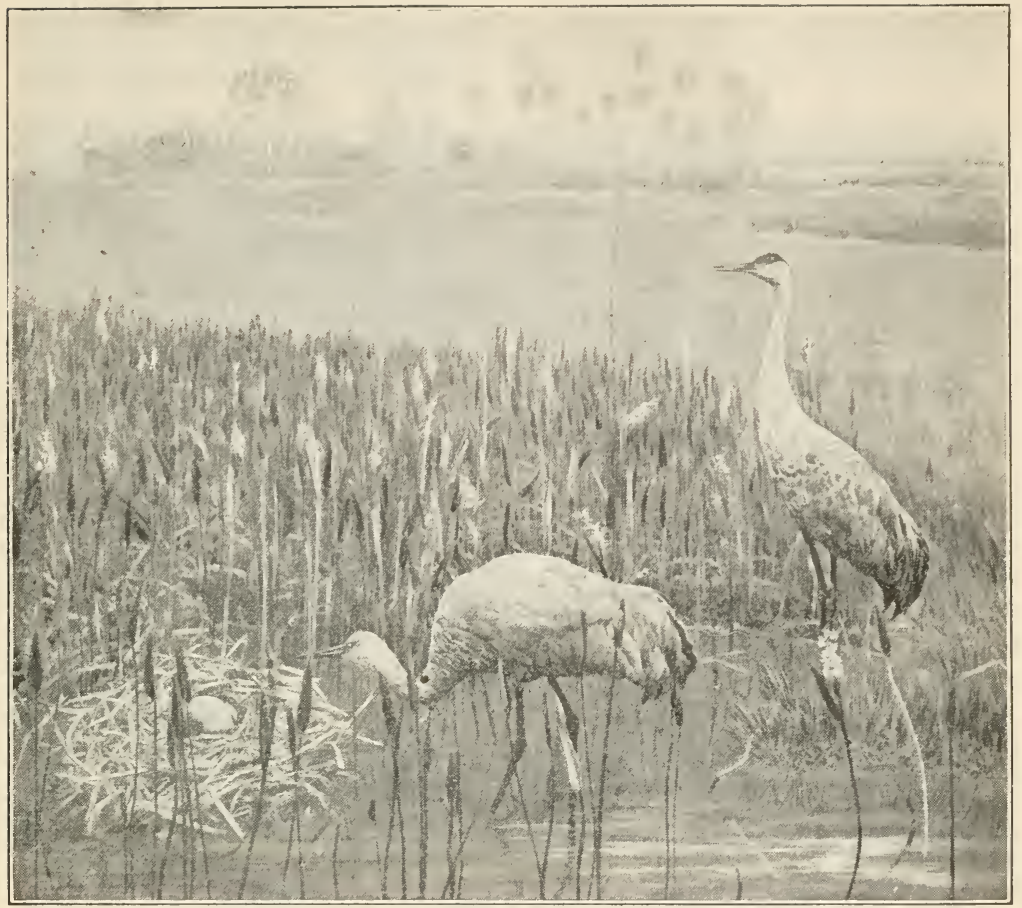

Sandhill crane, showing habitat. From mounted group at the American Museum of Natural History.

the feet webbed, the wings are often adapted for long and swift flight. In this division are placed the gulls, terns, ducks, geese, loons, auks, and puffins.

Other Orders. - Other orders of birds which we are likely to see and recognize may be mentioned. They include the doves, the only remaining native representative being the mourning dove; the woodpeckers, strong and long of bill, the friend of the lumberman as a savior of the trees from boring pests which live under the bark; the swifts and humming birds, the latter among the tiniest of all vertebrate animals; and the parrots, of which we have only one native form, the Carolina paroquet (Conurus carolinensis). This bird once had a range north as far as the Great Lakes; now it is found only in South America.

Relationship of Birds and Reptiles. - The birds afford an interesting example of how the history of past ages of the earth has given us a clew to the structural relation which birds bear to other animals. Several years HUNTER'S BIOL. -20 
ago, two fossil skeletons were found in Europe of a birdlike creature which had wings and feathers, and also teeth and a lizardlike tail. From these fossil remains and certain structures (as scales) and habits (as the egg-

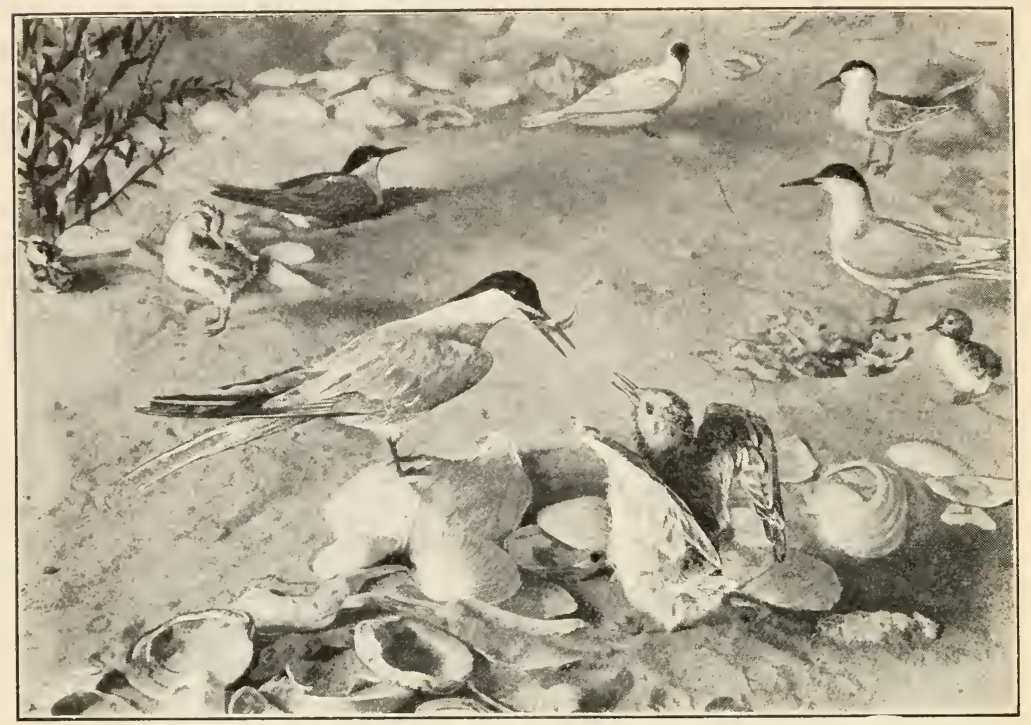

Common tern (Sterna hirundo) and young, showing nesting and feeding habits. From group at American Museum of Natural History.

laying habits), naturalists have concluded that birds and reptiles in distant times were nearly related and that our existing birds probably developed from a reptilelike ancestor millions of years ago.

\section{Classification of Birds}

Division I. Ratitce. Running birds with no keeled breastbone. Examples, ostrich, cassowary.

Division II. Carinata. Birds with keeled breastbone.

Order I. Passeres. Perching birds; three toes in front, one behind. One half of the birds are included in this order. Examples, sparrow, thrush, swallow.

Order iI. Gallince. Strong legs; feet adapted to perching. Beak stout. Examples, jungle fowl, grouse, quail, domestic fowl.

Order iIt. Raptores. Birds of prey. Hooked beak. Strong claws. Examples, eagle, hawk, owl.

ORDER iv. Grallatores. Waders. Long neck, beak, and legs. Examples, snipe, crane, heron. 
Order v. Natatores. Divers and swimmers. Legs short, toes webbed. Examples, gull, duck, albatross.

Order vi. Columba. Like Gallinæ but with weaker legs. Examples, dove, pigeon.

Order vil. Picarice. Woodpeckers. Two toes point forward, two backward, and adaptation for climbing. Long, strong bill.

\section{Reference Books \\ FOR THE PUPIL}

Herrick, Text-book in General Zoölogy, Chaps. XXII, XXIII. American Bock Company.

Beebe, The Bird. Henry Holt and Company.

Nature Study Leaflets, XXII, XXIII, XXIV, XXV. Cornell University.

FOR THE TEACHER

Apgar, Birds of the United States. American Book Company.

Beebe, The Bird. Henry Holt and Company.

Bulletins of U.S. Department of Agriculture, Division of Biological Survey, Nos. 1, 6, 15, 17. See also Year Book, 1899.

Chapman, Bird Life. D. Appleton and Company.

Riverside Natural History, Vol. IV. Houghton, Mifflin, and Company. 


\section{MAMMALS}

The Rabbit. - Living rabbits may be kept in the schoolroom in a box open at one end, the open end protected by a door covered with wire screening. A rabbit thus kept, if given a little care, soon becomes accustomed to his surroundings and will prove a very acceptable addition to the laboratory.

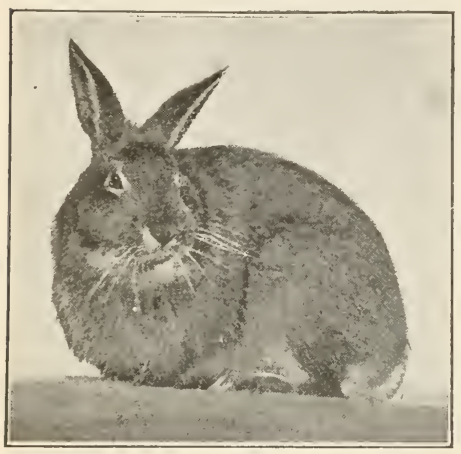

Wood hare. From photograph loaned by the American Museum of Natural History.

Adaptations to Its Life. - The rabbit in a wild state makes its home under clumps of dried grass, brush, and the like. Its English cousins make burrows in the ground. The rabbit escapes obscrvation from its enemies by means of its color, which often closely resembles that of the thickets in which it hides. Notice the body covering; is it uniform in color and thickness? The hair forms a protection from the cold. In summer the color of the coat is more earthlike than in the winter. Some arctic forms undergo a complete change of coat from gray in summer to white in the winter.

Compare the fore limbs of the rabbit with your own arms; do you find upper arm, forearm, wrist, and hand ? In the same manner find the parts corresponding to thigh, shank, and foot in your own leg. Notice the different methods of locomotion in the rabbit; seek the ways in which the limbs of the rabbit are adapted to the function of locomotion. Notice the feet to see if they are adapted for digging or for any other purpose.

The rabbit relies principally on swiftness and agility in flight rather than in ability to cope with an enemy with teeth and claws. Frequently they will remain in absolute quiet, allowing their arch-enemy, the dog, to pass close to them, relying on their protective coloration to escape notice. When chased by the dog, they have the instinct of running in a circle and will during the chase suddenly jump to one side at a sharp angle in order to throw the dog off the scent.

The teeth are of considerable importance in connection with the food and the method of obtaining food. Notice the prominent cutting teeth (the incisors). Note the cleft upper lip. Fced a carrot to the rabbit and determine the use of the cleft. Which jaws move during focding? Notice that they move sidewise as well as vertically; this horizontal movement is of considerable use in grinding the food.

If you cxamine the prepared skull of a rabbit the different kinds of teeth may be easily identified and their functions learned. In front are found the incisors. How many in each jaw? Separated from the incisors by a gap are the molars or grinding teeth. How are such teeth adapted to their function? With a hand glass note the position of the 
molars in your own mouth. Do you find teeth of any other shape than those just described?

Compare the position and shape of the eye with that of your own. Is the eye protected in any other way than by position? Note the bony eye socket in the skull, the lids (number), and any other adaptations. Touch the eye very lightly and see the third or "winking " eyclid (the nictitating membrane).

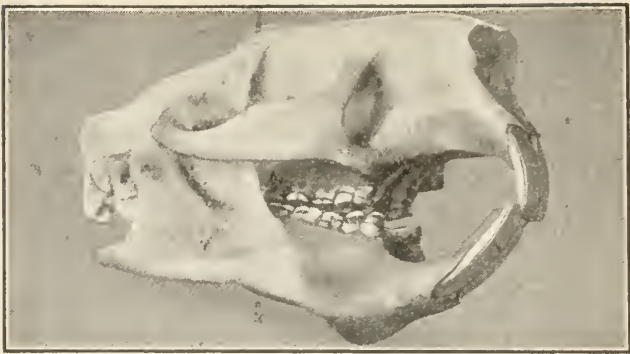

Skull of a porcupine, a rodent. Notice the large overlapping incisor teeth. Compare with teeth of dog (see page 313 ).

Notice the shape and position of the external ear. Compare with the head in length. The external ear collects the sound waves and sends them into the internal ear, the true organ of hearing (see page 421). Test the animal's response to sounds, especially when the maker of the sound is hidden. Is the hearing of the rabbit acute? (The above problem makes a good series of home experiments.)

Notice the mobility of the nose, especially when the animal is sniffing, By means of some strongly smelling substances, determine whether the rabbit easily perceives odors. Try to determine whether the saying that the whiskers of a cat or rabbit are used to smell with has any foundation in fact. Notice whether the hairs move at the same time the odor is presented.

Skeleton. - The rabbit is provided with a bony skeleton which gives support to the muscles and also protects the delicate organs of digestion, res-

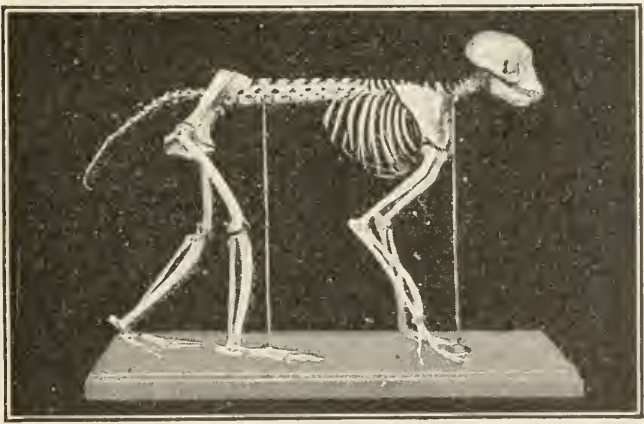

The skeleton of a monkey, a typical mammal. piration, etc., under the ribs. Compare with the skeleton of man in this respect (see page 372 ). The bones of the skeleton may be divided into two groups as in man, - those of the axial skeleton, the vertebræ, and bones of the head; and those of the appendages, including the pectoral anà pelvic arches, where the appendages are attached to the axial skeleton. Part for part and almost bone for bone the skeleton of the rabbit may be compared with that of man (see page 372 ). The chief differences exist in the appendages, where the erect animal, man, has the bones of the 
hand and foot considerably modified from those of an animal which uses all the appendages for locomotion. The digestive tract is also much like that of man. (See page 330.)

Organs of Digestion. - The digestive glands, and the salivary, gastric, intestinal, and pancreatic glands have nearly all the same position and functions. The glands which act upon starch are better developed in the rabbit than in man because of the predominance of starchy foods used by the rabbit. The intestine is longer than in flesh-eating animals.

Circulation. - In all mammals (of which the rabbit is an example) the blood in its circulation passes through a four-chambered heart. There is a system of closed blood tubes which, according to the position and function, are named arteries, veins, and capillaries. The whole process of circulation is identical with that process in man (see Circulation, page 350 ). The lungs and heart are separated from the lower part of the body cavity by means of a thin-walled plate of muscle, called the diaphragm. This diaphragm occurs in all mammals.

Oxygen is taken up by the blood and respiration takes place in a similar manner to that process in man.

In like manner the organs of excretion of nitrogenous waste, the skin and kidneys, eliminate the waste from the body in the same manner as it is done in man.

Nervous System. - The brain and central nervous system of the rabbit are well developed. A brain, which has a large cerebrum and other characteristics of the brain of man, supplies sense organs through twelve cranial (brain) nerves (see The Nervous System, page 400). The senses, especially those of sight and hearing, are also highly developed and are very acute. We have seen that the eyes are so placed that the animal is able to look to the sides and behind without turning the head. Organs of taste, the taste buds, such as are found in man, are also developed in the rabbit. The sense

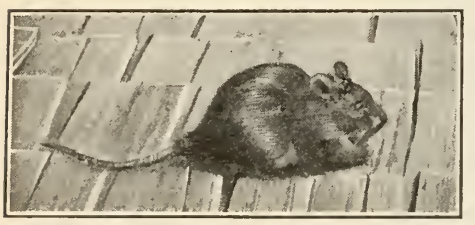

The common house rat. From photograph, about one fourth natural size. of touch appears to be well developed over the entire body, but is especially keen in the region of the nose (see The Senses, page 419).

\section{Characters of Mammals. -} Vertebrate animals which have a hairy coat and which nurse the young by means of milk-producing glands (the mammary glands) are called mammals. Such evidently is the rabbit. Rats, woodchucks, cattle, dogs, cats, and man are all examples of this group. Man is by far the best mentally developed of all this group and is therefore spoken of as the highest of the mammals. 
Rodents. - The mammals are divided into a number of smaller groups, called orders. The rabbit, because it has prominent incisor teeth and no canine $(\operatorname{dog})$ teeth, is placed in the order of the rodents. Among the fourteen orders of mammals the rodents are estimated to comprise fully one half of the total number of species.

Although most rodents may be considered as pests (as the rat and mouse), others are of use to man. Some of this order furnish food to man, as the rabbit, hares, and squirrels. The fur of the beaver, one of the largest of this order, is of considerable value, as are the coats of several other rodents. The fur of the rabbit is used in the manufacture of felt hats. The quills of the porcupines (greatly developed and stiffened hairs) have a slight commercial value.

Other Orders of Mammals. - The lowest are the monotremes, animals which lay eggs like the birds, although they are provided with hairy covering like other mammals. Such are the spiny ant-eater and the duck mole.

All other mammals bring forth their young alive. The kangaroos and opossum, however, are provided with a pouch on the ventral side of the body in which the very immature, blind, and helpless young are nourished until they are able to eare for themselves. These pouched animals are called marsupials.

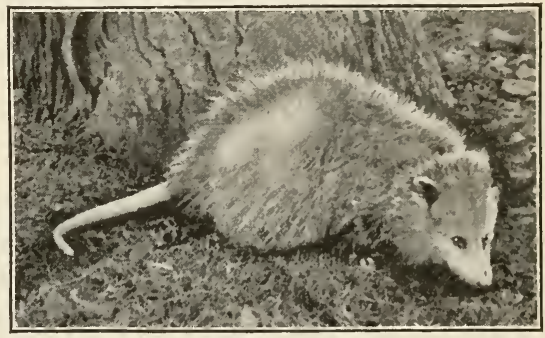

Virginia opossum. From photograph, one eighth natural size, by N. F. Davis.

The other mammals, in which the young are born able to eare for themselves, and have the form of the adult, may be briefly classified as follows:

Character

Eclentates Toothless or with very simple teeth

Rodents

Cetaceans
Incisor teeth, chisel-shaped, usually two above and two below

Adapted to marine life, teeth sometimes platelike
EXAM PLES

Ant-eater

Sloth

Armadillo

Beaver, Rat

Poreupine, Rabbit

Squirrels

Whales

Porpoise 
Ungulates Hoofs, teeth, adapted for grinding; herb eaters

Carnivora Long canine teeth, sharp and long claws; flesh eaters

Chiroptera Fore limbs adapted to flight, teeth pointed

Primates
Erect or nearly so, fore appendage provided with hand (a) Odd-toed

Horse

Rhinoceros

Tapir

(b) Even-toed

$\mathrm{Ox}$

Pig

Sheep

Deer

Dogs

Cats

Lions

Bears, etc.

Seals and Sea lions

Bat

Monkeys

Apes

Man

Adaptations in Mammalia. - Mammals are considered the highest type of all animals for reasons that have already been given. Of the thirty-five hundred species, most inhabit continents; few species are found on different islands, and some, as the whale, inhabit the ocean. They vary in size from the whale and the elephant to tiny shrew mice and moles. Adaptations to different habitat and methods of life abound; the seal and whale have the limbs modified into fins, the sloth and squirrel have limbs peculiarly adapted to climbing, while the bats have the fore limbs modeled for flight. In those mammals known as rodents, the teeth are so modified that on the upper and lower jaw two prominent incisor teeth can be used for gnawing. These teeth keep their chisel-like edge because the back part of the teeth is softer and wears away more rapidly. The beaver fells trees with them. We are all familiar with the destructive gnawing qualities of one of the commonest of all rodents, the rat.

Carnivorous Mammals. - As the word carnivorous denotes, these animals are to a large extent flesh eaters. In a wild state they hunt their prey, which is caught and torn with the aid of well-developed claws and long, sharp canine teeth. These teeth, 


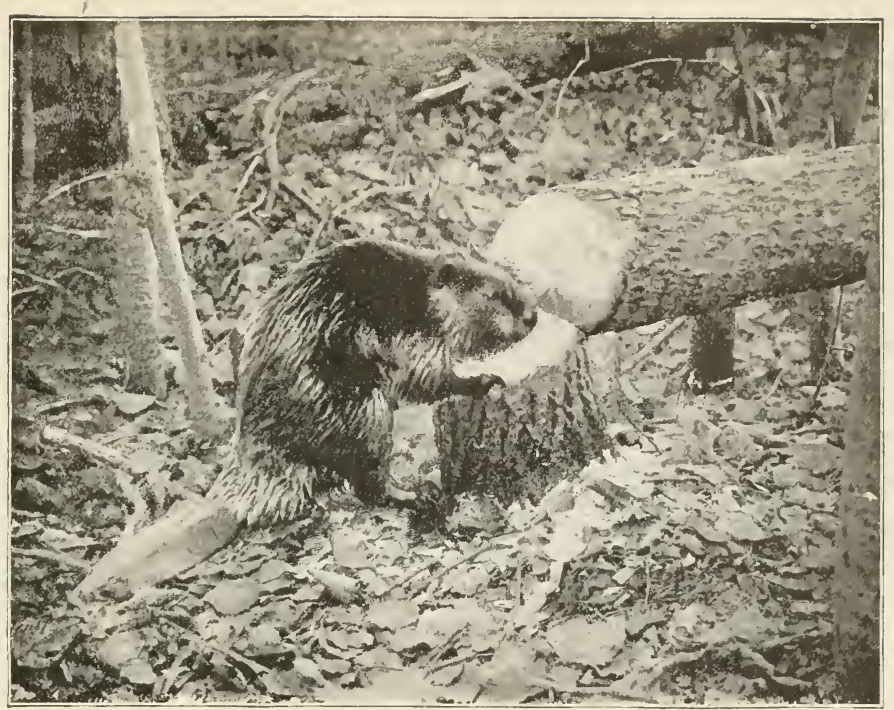

Beaver (Castor canadensis). North America. Copyright, 1900, by A. Radcliffe Dugmore.

so well developed in the dog, are known as the dog teeth. All flesh-eating mammals are wandering hunters in a state of nature; many, as the bear and lion, have homes or dens to which they retreat. Some, for example bears and raccoons, live at least part of the time upon berries and fruit. Seals, sea lions, and walruses are adapted to a life in the water. Especially in the seals, the hind limbs are

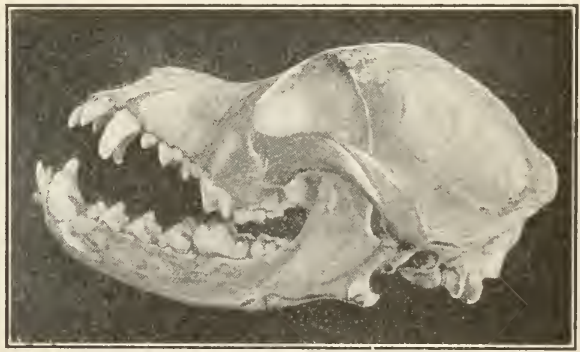

Skull of a dog. Notice the size and shape of the canine teeth. almost useless on land. Some of the fur bearers, as the otter and mink, lead a partially aquatic life. Others in this great group prefer regions of comparative dryness, as the inhabitants of the South African belt. Some have come to live most of their time in the trees, the raccoon being an example. Many have adapta- 
tions for food getting and escape from enemies, the seasonal change in color of the weasel is an example of an adaptation which serves both of the above purposes. This is only one of hundreds of others that might be mentioned.

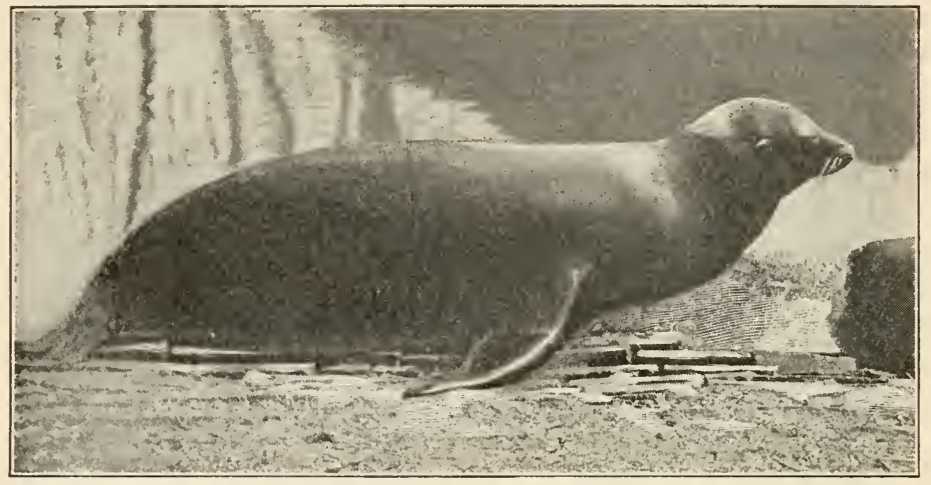

The California sea lion (Zalophus californianus). Photographed in the Philadelphia Zoölogical Gardens by Davison.

Economic Importance. - The Carnivora as a group are of much economic importance as the source of most of our fur. The fur seal fisheries alone amount to millions of dollars annually. Otters, skunks, sables, weasels, and minks are of considerable importance as fur products. In India tigers do considerable harm in some localities, and in our own country wolves, pumas, and wild cats do some damage.

Ungulates: Hoofed Mammals. - This group includes the domesticated animals as the horse, cow, sheep, and pig. A group of animals which originally roamed wild, they eventually came under the subjugating influence of man. Now they form a source of the world's wealth, and are an important part of the wealth of the United States.

The order of ungulates is a very large one. It is characterized by the fact that the nails have grown down to become thickened as hoofs. In some cases only two (the third and fourth) toes are largely developed. Such animals have a cleft hoof, as in the ox, deer, sheep, and pigs. These form the even-toed ungulates. 


\section{Even-toed Ungulates.}

- The deer family are the largest in number of species and individuals among our native forms, and in fact the world over. Among them are the common Virginia deer of the Eastern states, the whitetailed deer of our Adirondack forests. All males of the deer family possess horns which are solid and are shed annually. The antelopes and giraffes have also solid horns, but

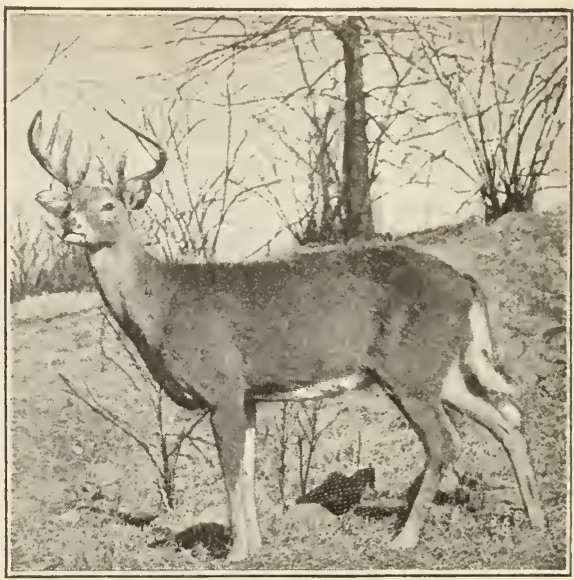

Virginia deer. From photograph loaned by the American Museum of Natural History. do not shed them. The bison, or buffalo, is nearly related to the deer and wild cattle. Formerly bisons existed in enormous numbers on our Western plains. They were hunted by whites and Indians for the hides and tongues only, and thousands of

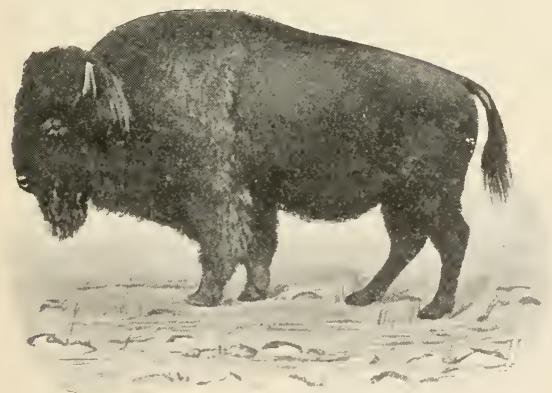

The buffaio (bison). Thotographed by the New York Zoölogical Society. carcasses were left to rot after a hunt. They are now almost extinct.

Odd-toed Ungulates. - In some ungulates the middle toe of the foot has become largely developed, with the result that the animal stands on it. Such are the zebra and the horse, and the rhinoceros, which has also the second and fourth toes in each foot.

Geologic History of the Horse. - We have, from time to time, made reference to the fact that certain forms of life, now almost extinct, flourished on the earth in former geologic periods. One type of animal which under domestication has become greatly improved is the horse. It is interesting 
to note that America was the original home of the horse. Ages ago, the ancestor of the present horse was not larger than a fox terrier, and instead of having one toe prolonged into a hoof, it walked on five toes. Later changes probably caused the little horse to abandon the life it led in the swamp for that on drier land. At that time it was about the size of a sheep and had three toes in each foot. Later the longer-legged and single-toed horses probably became speedier, thus escaping from the numerous carnivores which must have preyed upon them. So ultimately by very gradual variation the present horse was evolved. This purely hypothetical history was probably repeated with variations in the case of many other species of animals.

Man's Place in Nature. - Although we know that man is separated mentally by a wide gap from all other animals, in our study of physiology we must ask where we are to place man. If we attempt to classify man, we see at once he must be placed with the vertebrate animals because of his possession of a vertebral column. Evidently too, he is a mammal, because the young are nourished by milk secreted by the mother and because his body has at least a partial covering of hair. Anatomically we find that we must place man with the apelike mammals, because of these numerous points of structural likeness. The group of mammals which includes the monkeys, apes, and man we call the primates.

\section{Reference Books \\ FOR THE PUPIL}

Davison, Practical Zoölogy, pages 261-292. American Book Company.

Herrick, Text-book in General Zoölogy, Chap. XXIV. American Book Company Ingersoll, Wild Neighbors. The Macmillan Company.

Ingersoll, Life of the Mammals. The Macmillan Company.

\section{FOR THE TEACHER}

Dodge, General Zoölogy, pages 177-202. American Book Company. Riverside Natural History. Houghton, Mifflin, and Company. 


\section{PART III. HIUMAN PHYSIOLOGY}

\section{FOODS}

Why we need Food. - We have already defined food as anything that forms material for the growth or repair of the body of a plant or animal, or that furnishes energy for it. Food, then, not only furnishes our body with material to grow, but also gives us the energy we expend in the acts of walking, running, breathing, and even in thinking.

Nutrients. - Certain nutrient materials form the basis of food of both plants and animals. These have been stated to be carbohydrates (starches, sugars, gums, etc.), hydrocarbons (fats and oils, both animal and vegetable), proteids (such as lean meat, eggs, the gluten of bread), and mineral matter and water. Oxygen, although not a nutrient, ought to be considered as food because it enters into the composition of the body, and without it no energy could be released. Let us apply this general knowledge with reference to the human body in order to determine the uses made of food taken into the body; for parts of the human body, be they muscle, blood, nerve, bone, or gristle, are built up from the nutrients in our food.

The Body a Machine. - The body has been likened to a machine in that it turns over the latent or potential energy stored up in food into kinetic energy (mechanical work and heat) which is manifested when we perform work. One great difference exists between an engine and the human body. The engine uses fuel unlike the substance out of which it is made. The human body, on the other hand, uses for fuel the same substances out of which it is formed; it may, indeed, use part of its own sulstance for food.

Let us now consider more in detail the nutrients used by man as food, and determine the use of each to him.

Proteids. - As we know, proteids, in some manner unknown to us, are manufactured in the leaves of plants. Proteid sub- 
stances contain the element nitrogen. Hence such foods are called nitrogenous foods. Although about four fifths of the atmosphere is composed of nitrogen, yet plants are unable to take it from the air, but are forced to absorb it through the roots in the form of nitrates dissolved in the water in the soil. Herbivorous animals eat the plants, take into their bodies the stored nitrogenous foods, and change this food into protoplasm. Man himself must form the protoplasm of his body (that is, the muscles, tendons, nervous system, blood corpuscles, the living parts of the bone and the skin, etc.) from nitrogenous food. Some of this he obtains by eating the flesh of animals, and some he obtains directly from plants (for example, peas and beans). Because of their chemical composition, proteids are considered to be flesh-forming foods. They are, however, oxidized to release energy if occasion requires it.

Organic Fats and Oils. - Fats and oils, both animal and vegetable, are the materials from which the body derives much of its energy. The chemical formula of a fat shows that, compared with other food substances, there is very little oxygen present; hence the greater capacity of this substance for uniting with oxygen. The rapid burning of fat compared with the slower combustion of a piece of meat or a piece of bread illustrates this. A pound of butter releases over twice as much energy to the body as does a pound of sugar or a pound of steak. Human fatty tissue is formed in part from fat eaten, but carbohydrates and even proteids may be changed and stored in the body as fat. The Arcticliving tribes exist almost entirely on the blubber of the walrus or the whale. The blubber not oxidized in the body is stored as fat, thus forming an insulation under the skin, which aids in keeping the body warm.

Carbohydrates. - We see that the carbohydrates, like the fats, contain carbon, hydrogen, and oxygen. Here, however, the oxygen and hydrogen are united in the molecule in the same proportion as are hydrogen and oxygen in water. Carbohydrates are essentially energy-producing foods. They are, however, believed to be of some use in building up or repairing tissue. Some experiments seem to indicate that carbohydrates may be formed directly into tissue. It is certainly true that in both plants and 
animals, such foods pass directly; together with foods containing nitrogen, to repair waste in tissues, thus giving the needed proportion of carbon, oxygen, and hydrogen which is to unite with the nitrogen in forming the protoplasm of the body.

Inorganic Foods. - IVater forms a large part of almost every food substance. The human body, by weight, is composed of about sixty per cent water. When we drink water, we take with it most of the inorganic salts used by the body in the making of bone and in the formation of protoplasm. Sodium chloride (table salt), an important part of the blood, is taken in as a flavoring upon our meats and vegetables. So important is this food that life is often given in exchange for it by herbivorous animals, as the deer. Man will also endure great hardships to get salt. ${ }^{1}$ Phosphates of lime and potash taken in water are important factors in the formation of bone.

Uses of Nutrients. - The following table sums up the uses of nutrients to man: ${ }^{2}$

Proteid.

White (albumen) of eggs, curd (casein) of milk, lean meat, gluten of wheat, etc.

Fats....

Fat of meat, butter, olive oil, oils of corn and wheat, etc.

Carbohydrates................ Transformed into fat.

Forms tissue (muscles, tendon, and probably fat).

Form fatty tissue.

Sugar, starch, etc.

Mineral matters (ash).

Phosphates of lime, potash, soda, etc.

${ }^{1}$ Animals will travel long distances to obtain salt. Men will barter gold for it; indeed, among the Gallas and on the coast of Sierra Leone, brothers will sell their sisters, husbands their wives, and parents their children for salt. In the district of Accra, on the gold coast of Africa, a handful of salt is the most valuable thing upon earth after gold, and will purchase a slave or two. Mungo Park tells us that with the Mandingoes and Bambaras the use of salt is such a luxury that to say of a man, 'he flavors his food with salt,' is to imply that he is rich; and children will suck a piece of rock salt as if it were sugar. No stronger mark of respect or affection can be shown in Muscovy than the sending of salt from the tables of the rich to their poorer friends. In the book of Leviticus it is expressly commanded as one of the ordinances of Moses, that every oblation of meat upon the altar shall be seasoned with salt, without lacking; and hence it is called the Salt of the Covenant of God. The Greeks and Romans also used salt in their sacrificial cakes; and it is still used in the services of the Latin church - the 'parva mica,' or pinch of salt, being, in the ceremony of baptism, put into the child's mouth, while the priest says, 'Receive the salt of wisdom, and may it be a propitiation to thee for eternal life.' - Letheby, On Food.

2 W. O. Atwater, Principles of Nutrition and Nutritive Value of Food. U.S. Dept. of Agriculture, 1902. 
How the Nutritive Value of Food has been Discovered. - For a number of years, experiments have been in progress in different parts of the civilized world which have led to the beliefs regarding food that have just been quoted. One of the most accurate and important series of experiments was made a few years ago by the late Professor W. O. Atwater of IVesleyan University, in coöperation with the United States Department of Agriculture. By means of a machine called the respiration calorimeter (Lat. calor $=$ heat + metrum $=$ measure) which measures both the products of respiration and the heat given off by the body, it has been possible to determine accurately the value of different kinds of food, both as fuel and as tissue builders. This respiration calorimeter is described by Professor Atwater as follows:-

"Its main feature is a copper-walled chamber 7 feet long, 4 feet wide, and 6 feet 4 inches high. This is fitted with devices for maintaining and measuring a ventilating current of air, for sampling and analyzing this air, for removing and measuring the heat given off within the chamber, and for passing food and other articles in and out. It is furnished with a folding bed, chair, and table, with scales and appliances for muscular work, and has telephone connection with the outside. Here the subject stays for a period of from three to twelve days, during which time, careful analyses and measurements are made of all material which enters the body in the food, and of that which leaves it in the breath and excreta. Record is also kept of the energy given off from the body as heat and muscular work. The difference between the material taken into and that given off from the body is called the balance of matter, and shows whether the body is gaining or losing material. The difference between the energy of the food taken and that of the excreta and the energy given off by the body as heat and muscular work, is the balance of energy, and, if correctly measured, should equal the energy of the body material gained or lost. With such apparatus it is possible to learn what effect different conditions of nourishment will have on the human body. In one experiment, for instance, the subject might be kept quite at rest, and in the next do a certain amount of muscular or mental work with the same diet as before, then by comparing the results of the two, the use which the body makes of its food under the different conditions could be determined; or the diet may be slightly changed in the one experiment, and the effect of this on the balance of matter or energy, observed. Such methods and apparatus are very costly in time and money, but the results are proportionately more valuable than those from simpler experiments."

Fuel Values of Nutrients. - In experiments performed by Professor Atwater and others, and in the appended tables, the value of food as a source of energy is stated in heat units called calories. A calorie is the amount of heat required to raise the temperature of one kilogram of water from zero to one degree centigrade. This is about equivalent to 
raising one pound four degrees Fahrenheit. The fuel value of different foods may be computed in a definite manner. This is done by burning a given portion of a food (say one pound) in the apparatus known as the calorimeter. By this means may be determined the number of degrees the temperature of a given amount of water is raised during the process of burning.

The Best Dietary. - Inasmuch as all living substance contains nitrogen, it is evident that proteid food must form a part of the dietary; but proteid alone is not usable. We must take foods that will give us, as nearly as possible, the proportion of the different chemical elements as they are contained in protoplasm. We must have a mixed diet which may contain several different food materials.

A growing person must take in a little more food each day than is used up. In an ordinary day's work, a man uses up about two hundred and sixty grams of carbon and nineteen grams of nitrogen. This must be replaced in the correct proportion. More carbon or more nitrogen than needed, would simply mean that some of the organs of the body would have to work overtime to rid the body of the unused material. It has been found as a result of studies of Atwater and others, that a man who does muscular work requires about one quarter of a pound of proteid, the same amount of fat, and about one pound of carbohydrate to provide for the growth, waste, and repair of the body and the energy used up in one day. In addition to this, an ounce of salt and nearly one hundred ounces of water are used. The amount of food consumed varies with the age and occupation of the individual. A child of from five to six years needs only .5 of the food required by a man doing muscular work. A growing boy of highschool age, contrary to common belief, needs only between .7 and .8 of the food needed by an active man. People who lead a sedentary life need much less food than those doing hard work; the latter, on the other hand, need more food than a person who is only moderately active. By means of the table on the following page (modified from Atwater ${ }^{1}$ ), which shows the composition of some food materials, the nutritive and fuel value of the foods may be seen

${ }^{1}$ W. O. Atwater, Principles of Nutrition and Nutritive Value of Food. U.S. Dept. of Agriculture, 1902.

HUNTER'S BIOL. -21 
at a glance. The amount of refuse contained in foods (such as the bones of meat or fish, the exoskeleton of crustaceans and mollusks, the woody coverings of plant cells) is also shown in this table.

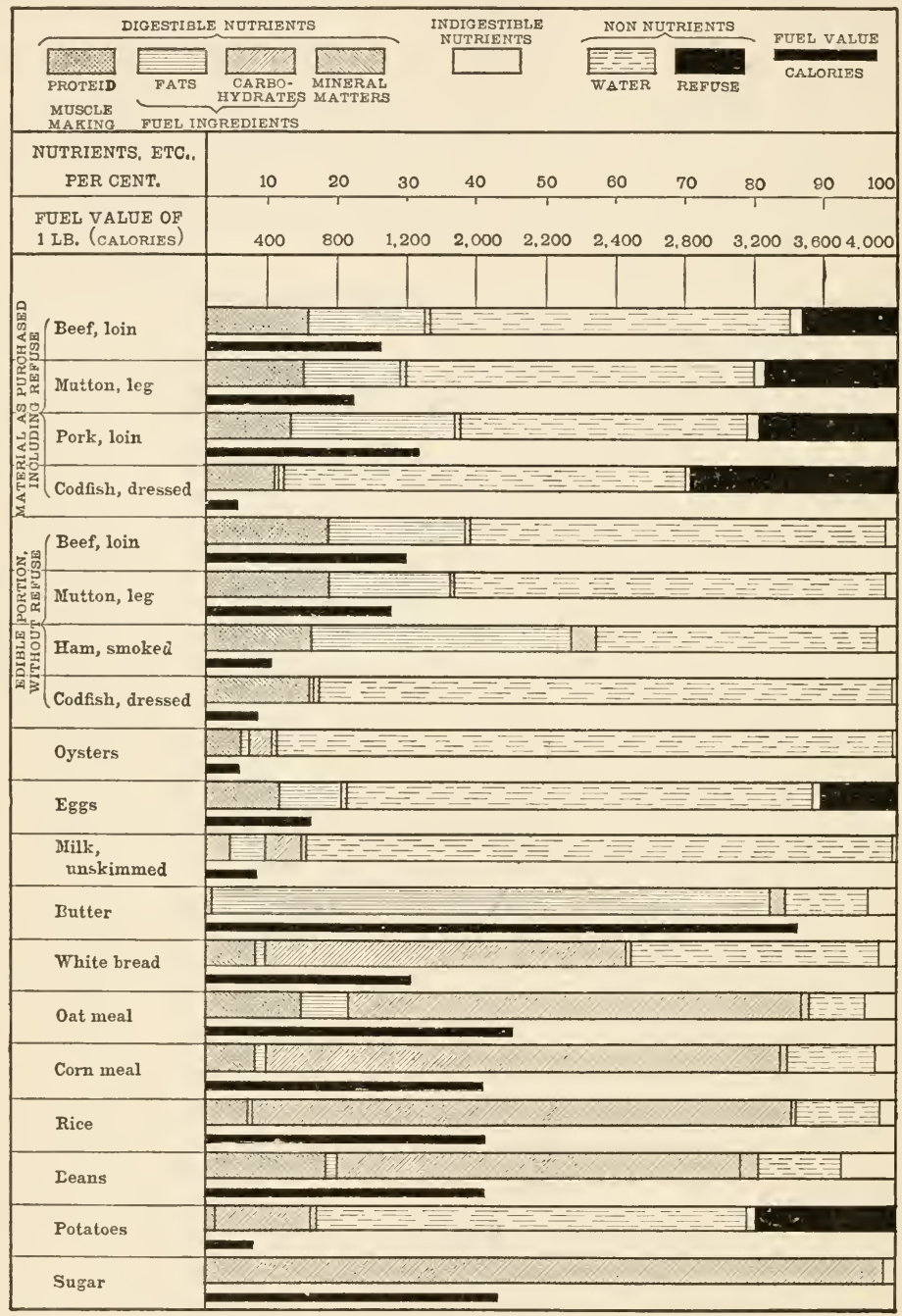

Table of food values. 
A Mixed Diet Best. - Knowing the proportion of the different food substances required by man, it will be an easy matter to determine from this table the best foods for use in a mixed diet. Meats contain too much nitrogen in proportion to the other substances. In milk, the proportion of proteids, carbohydrates, and fat is nearly right to make protoplasm; a considerable amount of mineral matter is also present. For these reasons, milk is extensively used as a food for children, as it combines food material for the forming of protoplasm with mineral matter for the building of bone. Some vegetables - for example, peas and beans - contain the nitrogenous material needed for protoplasm formation in considerable proportions, but in a less digestible form than is found in some other foods. Vegetarians are correct in theory when they state that a diet of vegetables may contain everything necessary to sustain life and build tissues. A mixed diet, however, has been found to be preferable. A purely vegetable diet contains much material, such as the cellulose which forms the walls of the plant cells, which is indigestible. Because of the small amount of proteid usually present in vegetables, a larger bulk of food material is taken; thus the organs of excretion are given increased work. The Japanese army ration consists almost entirely of rice. A recent report by their surgeon general intimates that the diminutive stature of the Japanese may, in some part at least, be due to this diet. Starch or sugar alone would be an unwholesome diet, because of the lack of nitrogen and overabundance of carbon.

Food Economy. - The American people are far less economical in their purchase of food than most other people. Nearly one half of the total income of the average working man is spent on food. Not only does he spend a large amount on food but he wastes money in purchasing the wrong kinds of food. The table on the following page (modified from At.water), ${ }^{1}$ shows how economy may be exercised in the purchase of foods.

Adulterations in Foods. - Many foods which are artificially marufactured have been adulterated to such an extent as to be almost unfit food or even harmful. One of the commonest adulterations is the substitution of grape sugar (glucose) for cane sugar. Most cheap candy is so made. Flour and other cereal foods are frequently adulterated with some cheap

${ }^{1}$ W. O. Atwater, Principles of Nutrition and Nutritive Value of Food. U.S. Dept. of Agriculture, 1902. 


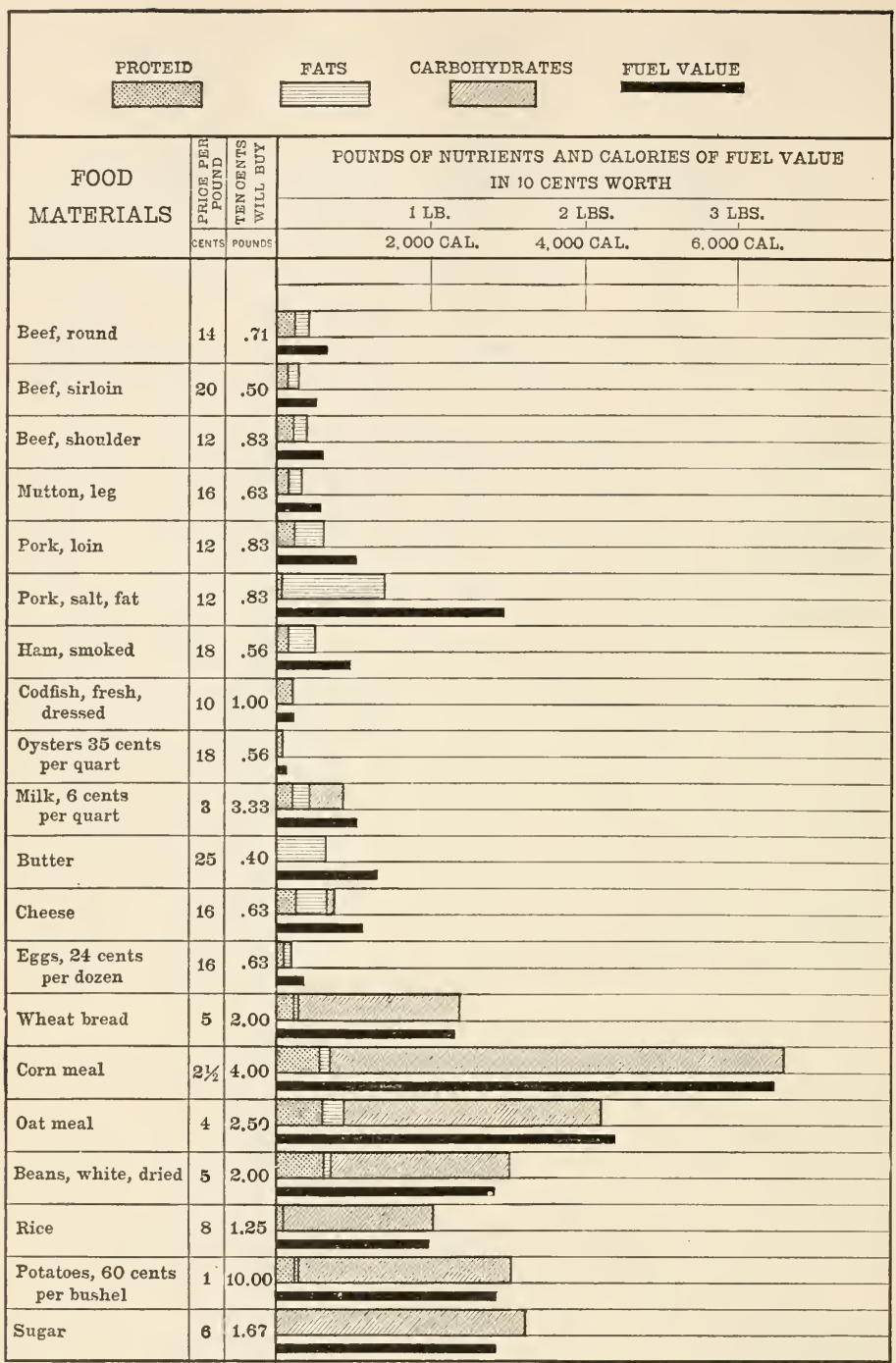

Table showing the cost of nutrients.

substitute; the list of adulterated articles is almost inexhaustible. Purefood laws have been passed by Congress, which strike at this evil. 
IMPURE WATER. - One danger far greater than the above-mentioned comes from drinking impure water. This subject has already been discussed under Bacteria, where it was seen that the spread of typhoid fever in particular is due to a contaminated water supply. As citizens we must aid all legislation that will safeguard the water used by our towns and cities. Boiling water for ten minutes or longer will render it safe from all organic impurities.

Food Waste in the Kitchen. - Much loss occurs in the improper cooking of foods. Meats especially, when overdone, lose much of their flavor and are far less easily digested than when they are cooked rare. The chief reasons for cooking meats are that the muscle fibers may be loosened and softened, and that the bacteria or other parasites in the meat may be killed by the heat. The common method of frying makes foods less digestible. Stewing is an economical as well as healthful method. A good way to prepare meat, either for stew or soup, is to place the meat, in small pieces, in cold water, and allow it to simmer for several hours. Rapid boiling toughens the muscle fibers by the too rapid coagulation of the albuminous matter in them, just as the white of egg becomes solid when heated. Broiling and roasting are excellent methods of cooking meat. In order to prevent the loss of the nutrients in roasting, it is well to baste the meat frequently; thus a crust is formed on the outer surface of the meat, which prevents the escape of the juices from the inside.

Vegetables are cooked in order that the cells containing starch grains may be burst open, thus allowing the starch to be more easily attacked by the digestive fluids. Inasmuch as water may dissolve out nutrients from vegetable tissues, it is best to boil them rapidly in a small amount of water. This gives less time for the solvent action to take place. Vegetables should be cooked with the outer skin left on when it is possible.

Stimulants. - We have learned that food is anything that supplies building material or releases energy in the body; but some materials used by man, presumably as food, do not come under this head. Such are tea and coffee. When taken in moderate quantities, they produce a temporary increase in the vital activity of the person taking them. This is said to be a stimulation; and material taken into the digestive tract, producing this, is called a stimulant. In moderation, tea and coffee appear to be harmless. Some people, however, cannot use either without ill effects. It is the habit formed of relying upon the stimulus given by tea or coffee, that makes them a danger to man. In large amounts, they are undoubtedly injurious because of a substance, called caffeine, contained in them. 
Alcohol. - The question of the use of alcohol has been of late years a matter of absorbing interest and importance among physiologists. Dr. Atwater performed a series of very careful experiments by means of the respiration calorimeter, to ascertain if alcohol is of use to the body as food. ${ }^{1}$ In these experiments, the subjects were given, instead of their daily allotment of carbohydrates and fats, enough alcohol to supply the same amount of energy that these foods would have given. The amount was calculated to be about two and one half ounces per day, about as much as would be contained in a bottle of light wine. ${ }^{2}$ This alcohol was administered in small doses six times during the day. Professor Atwater's results may be summed up briefly as follows:-

1. The alcohol administered was almost all oxidized in the body.

2. The potential energy in the alcohol was transformed into heat or muscular work.

3. The body did about as well with the rations including alcohol as it did without it.

The committee of fifty eminent men appointed to report on the physiological aspects of the drink problem, reported that a large number of scientific men state that they are in the habit of taking alcoholic liquor in small quantities, and many report that they do not feel harm thereby. A number of scientists seem to agree that, within limits, alcohol may be a kind of food, although a very poor food. The following statements support this view:-

"The conclusion to which all the evidence points is that alcohol is a food, and in certain circumstances, such as febrile conditions, it may be a very useful food; but in health, when other kinds of food are abundant, it is unnecessary, and as it interferes with oxidation, it is an inconvenient kind of food."-T. Lauder-Brunton, A Text-book of Pharmacology, Therapeutics and Materia Medica (London, 1887), page 768.

"If oxidized even to a small extent, and the evidence, as indicated, points to the oxidation of by far the larger proportion of it, ninety five per cent alcohol must be regarded in the scientific sense as a food. . . .

${ }^{1}$ Alcohol is made up of carbon, oxygen, and hydrogen. It is very easily oxidized, but it cannot, as is shown by the chemical formula, be of use to the body in tissue building because of its lack of nitrogen.

${ }^{2}$ Alcoholic beverages contain the following proportions of alcohol: beer, from 2 to 5 per cent; wine, from 10 to 20 per cent; liquors, from 30 to 70 per cent. Patent medicines frequently contain as high as 60 per cent alcohol. 
While, therefore, it must be classed technically as a food, it is in many respects an unsuitable food, and its place can be taken with great advantage by other substances." - Kendrick, Physiology (Glasgow, 1889), Vol. II, page 19.

"Alcohol is thus, within narrow limits, a food. . . . It is, moreover, a very uneconomical food. Much more nutriment would have been obtained from the barley or curds from which it was made. The value of alcohol within narrow limits is not as a food, but as a stimulant, not only to digestion, but to the heart and brain."-Halliburton, Text-book of Chemical and Pathological Physiology, 1891, page 600.

"According to Dupré, one grain of alcohol oxidized in the body evolves 7134 units of heat, while the same amount of lean beef gives off only 1482 units of heat. It has been estimated that 9.5 ounces of lean beef (equal to about 2 ounces of alcohol) will supply the force necessary to maintain the circulation and respiration for one day. That is, four ounces of strong spirit will suffice for this purpose. These considerations warrant the statement that, in a certain sense, alcohol is a food, i.e. that it is capable of being used for the purpose of the organism." - H. C. Wood, Therapeutics.

"Alcohol in small doses is of great use in conditions of temporary want or where food is taken in insufficient quantity. When alcohol is taken regularly, more especially in large doses, it affects the nervous system and undermines the physical and corporal faculties, partly by the action of the impurities which it may contain, such as fusel oil, which has a poisonous effect on the nervous system; pertly by its direct effects, such as catarrh and inflammation of the digestive organs, which it produces; and lastly by its effects on the normal metabolism." - Landois \& Sterling, Textbook on Human Physiology (London, 1891), page 437.

On the other hand, we know that although alcohol may technically be considered as a food, it is a very unsatisfactory food. In large doses, it is, undoubtedly, poisonous. A commonly accepted definition of a poison is that it is any substance which, when taken into the body, tends to cause serious detriment to health or the death of the organism.

That alcohol may do this is well known by scientists. The following quotations show that a large number of very eminent professors and physicians have this belief.

"From an exhaustive definition we shall have to class every substance as a poison which, on becoming mixed with the blood, causes a disturbance in the function of any organ. That alcohol is such a poison cannot be doubted. . . Very appropriately has the English language named the 
disturbance caused by alcoholic beverages intoxication, which, by derivation, means poisoning." - Dr. Adolph Fick, Professor of Physiology, Würzburg, Germany.

"Ethyl alcohol, even when diluted as in wine, beer, and cider, is a poison which changes pathologically the tissues of the body and leads to fatty degeneration. Of course I am not speaking here of the smallest doses. However, the latter (for example, half a liter of beer or a glass of wine) are also poisonous, because they injure the brain by producing paralysis and derangement of function; that is clearly demonstrated by the experiments of Kraepelin, Smith, Fürer, Aschaffenburg, etc. The same have never been controverted. The most moderate drinking of alcohol is quite useless for the individual, but by means of example and fashion produces an incalculable social injury and misery to the masses, since all cannot remain moderate, and the entirely moderate remains at last the exception." - Dr. August Forel, Professor of Psychiatry in the University of Zurich.

"All the alcohols are poisons." - Dujardin-Beaumetz and Audige.

"Is alcohol a poison? I reply, Yes. It answers to the description of a poison. It possesses an inherent deleterious property which, when introduced into the system, is capable of destroying life, and it has its place with arsenic, belladonna, prussic acid, opium, etc."一Dr. Willard PARKer, late Professor of Surgery in the College of Physicians and Surgeons, New York; Consulting Physician to Bellevue, Mount Sinai, Roosevelt, and the New York hospitals.

"It [alcohol] leads to degeneration $c_{2}^{s}$ the tissues; it damages the health; it injures the intellect. Short of drunkenness, that is, in those effects of it which stop short of drunkenness, I should say from my experience that alcohol is the most destructive agent we are aware of in this country." Sir William Gull, M.D., F.R.S., Consulting Physician to Guy's Hospital, London.

"We know that alcohol is mostly oxidized in our body. . . A Alcohol is, therefore, without doubt, a source of living energy in our body, but it does not follow from this that it is also a nutriment. To justify this assumption, proof must be furnished that the living energy set free by its oxidation is utilized for the purpose of a normal function. It is not enough that potential energy is transformed into living energy; the transformation must take place at the right time and place, and at definite points in definite elements of the tissues. These elements are not adapted to be fed with every sort of oxidizable material. We do not know whether alcohol can furnish to the muscles and nerves a source of energy for the performance of their functions.... In general, alcohol has only paralyzing properties, etc." - G. Bunge, Lehrbuch der Physiologischen und Pathologischen Chemie (Leipsic, 1894), page 124.

"Alcohol, also, when not taken in too large quantities, may be oxidized in the body, and furnish a not inconsiderable amount of energy. It is, 
however, a matter of controversy at present, whether alcohol in small doses can be considered a true foodstuff capable of serving as a direct source of energy, and of replacing a corresponding amount of fats and carbohydrates in the daily diet." - William H. Howell, American Textbook of Physiology (Philadelpnia, 1896), page 297.

"The nutritive value of alcohol has been the subject of considerable discussion and not a few experiments. Some of these tend to show that in moderate non-poisonous doses it acts as a non-proteid food in diminishing the oxidation of proteid, doubtless by becoming itself oxidized. Its ac'ion, however, in this respect, is relatively small, and, indeed, a certain proportion of the alcohol ingested is exhaled with the air of respiration.

"Moreover, in large doses it [alcohol] may act in a contrary manner, increasing the waste of tissue proteid. It cannot, in fact, be doubted that any small production of energy resulting from its oxidation is more than counterbalanced by its deleterious influence as a drug upon the tissue elements, and especially upon those of the nervous system." - E. A. Schaefer, A Text-book of Physiology (1898), page 882.

The Use of Tobacco. - A well-known authority defines a nar-. cotic as a substance "which directly induces sleep, blunts the senses, and, in large amounts, produces complete insensibility" Tobacco, opium, chloral, and cocaine are examples of narcotics. Tobacco owes its narcotic influence to a strong poison known as nicotine. In experiments with jellyfish and other lowly organized animals, the author has found as small a per cent as one part of nicotine to one hundred thousand parts of sea water to be sufficient to profoundly affect an animal placed within it. Nicotine in a pure form is so powerful a poison that two or three drops would be sufficient to cause the death of a man by its action upon the nervous system, especially the nerves controlling the beating of the heart. This action is well known among boys training for athletic contest. The heart is affected, boys become "short winded" as a result of the action on the heart. It has been demonstrated that tobacco has, too, an important effect on muscular development. The stunted appearance of the young smoker is well known. 


\section{DIGESTION AND ABSORPTION}

Purpose of Digestion. - We have learned that starch and proteid food of plants are formed in the leaves. A plant, however, is unable to make use of the food in this condition. Before it can

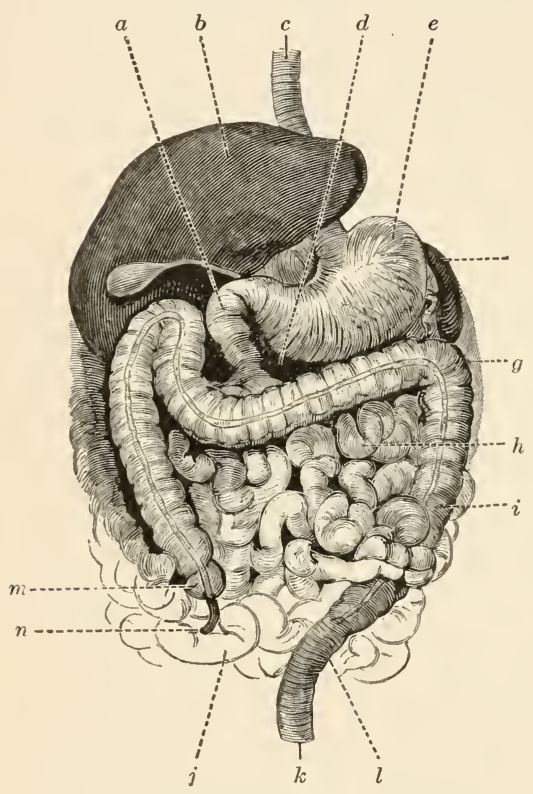

Picture of the organs of digestion; $a$, intestine, leading out of the pylorus; $b$, liver; $c$, esophagus; $d$, pancreas; $e$, stomach; $f$, spleen; $g, i, j, k, m, n$, parts of large intestine; $h, l$, small intestine. From Johonnot and Bouton. be used it is changed into a soluble form, such as grape sugar. In this state it can be passed from cell to cell by the process of osmosis, and can be used to build new cells or to release energy. The same condition exists in animals. In order that food may be of use to man, it must be changed into a state that will allow of its passage in a soluble form through the walls of the alimentary canal or food tube. Digestion consists in the changing of foods from an insoluble to a soluble form, so that they may pass through the walls of the alimentary canal and become part of the blood.

Alimentary Canal. - In all vertebrate animals, including man, food is normally taken in the mouth and passed through a food tube during the process of digestion. This tube is composed of different portions, named, respectively, as we pass from the mouth, posteriorly, the gullet, stomach, small and large intestine, and rectum. 
Glands. - In addition to the alimentary canal proper, we find a number of digestive glands, varying in size and position, connected with the canal. A gland is a collection of cells which takes up materials from the blood and pours out the secretion as a fluid; such cells, together with the blood vessels and nerves passing to them, are held in place by a web of connective tissue.

It is the substances formed by these glands that cause the digestion of food. The substances secreted by the cells of the glands and poured out into the food tube act upon insoluble foods so as to change them to a soluble form.

Structure. - The entire inner surface of the food tube is covered with a soft lining of mucous membrane. This is always moist because certain cells, called mucous cells, empty out their contents into the food tube, thus lubricating its inner surface. When a large number of cells which have the power to secrete or form fluids are collected together, the surface of the food tube may become indented; the little depression thus formed is a simple gland. If such a tube is greatly branched, with one common duct or tube connecting it with the inside surface of the food tube, it is then called a compound gland. If we think of a very sour pickle or a delicious bit of candy, our mouth waters. This is caused by the action of certain nerves upon some of the gland cells in the mouth (salivaric glands); this results in the setting free of a fluid we aall saliva. In case of stage fright, the

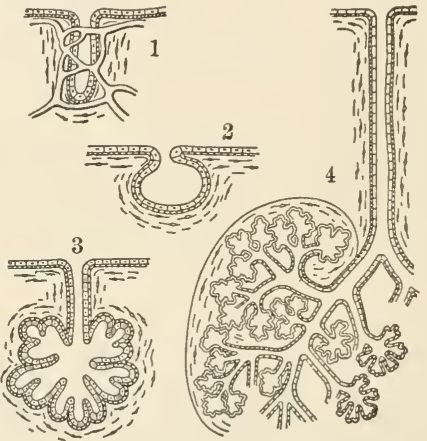

Structure of glands; 1, simple pit, surrounded by capillariss; 2 , flaskshaped gland, with short duct; 3,4 , more complex glands, with longer ducts. secretion of saliva is prevented by the action of the nervous system, and the mouth becomes dry.

Comparison of the Alimentary Canal of a Frog with that of MAN. ${ }^{1}$ - (Material - frogs preserved in alcohol or four per cent formol.) Notice the shape and size of the mouth when closed and when opened. Look for teeth. Feel with your finger the upper and lower jaws in the roof $\mathrm{o}^{-1}$ the mouth. The prominent teeth on the roof of the mouth are known as the vomerine teeth. Notice the mucous membrane lining in the interior of the mouth. With a pencil or tweezers, find the baglike opening of the gullet through which food passes to the stomach. Do not

' For more detailed work, see Hunter and Valentine, Manual, pp. 174-177. 
confuse this with the much smaller glottis, a longitudinal slit opening into the windpipe. Other paired openings are found in the mouth, those leading to the anterior nares or external nostril openings and those leading to the ear, the Eustachian tubes. Make a drawing of the open mouth of a frog, showing these points.

Buccal Cavity in Man. - In man, the mouth, or buccal cavity, is lined with mucous membrane. Mucous membrane, because it is thinner than the skin, allows the blood to show through, thus giving the characteristic red color of the lips and inner mouth. The roof of the mouth is formed by a plate of bone called the hard palate. This separates the nose cavity from that of the mouth proper. Behind the hard palate the cavities are separated by the soft palate. The part of the mouth cavity back of the soft palate is called the pharynx. From the pharynx lead off the gullet and windpipe, the latter placed ventral to the former. The lower part of the buccal cavity is almost filled by a muscular tongue. Examination of its surface with a looking glass shows it to be almost covered in places by tiny projections called papillce. These papillæ contain organs known as taste buds, the sensory endings of which determine the taste of substances. The tongue is also used in moving food about in the mouth, in starting it on its way

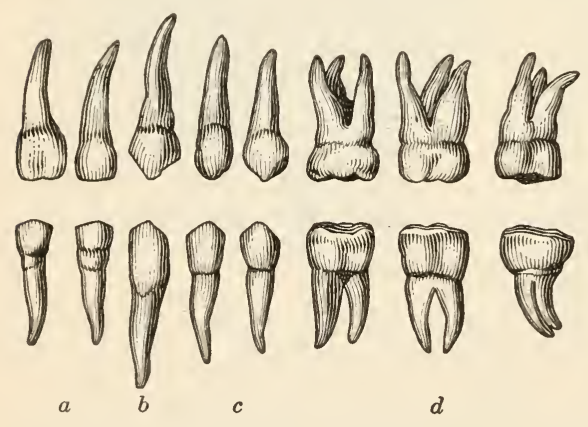

Teeth; $a$, incisors; $b$, canine; $c$, premolars; $d$, molars. to the gullet, while it plays an important part, as we know, in speaking.

The Teeth. - Plainly the teeth of a frog are not used for cutting or grinding up food; they point inward, a significant fact which shows them to be used for holding. The teeth of man are divided, according to their functions, into four groups. In the center of both the upper and lower jaw in front are found eight teeth with chisel-like edges; these are the incisors, or cutting teeth. Next is found a single tooth on each side (four in all); these have rather sharp points; they are the canines; look for them in a cat or dog. 
Then come two teeth on each side, called premolars. Lastly, the flat-topped molars, or grinding teeth. Food is caught between irregular projections on the surface of the molars and crushed to a pulpy mass.

Laboratory Exercise. - Procure from the dentist examples of each kind of teeth. Identify and draw in your notebook one of each of the four classes.

Dental Formula of Man. - It is possible, as we have seen, to classify mammals partially on the basis of the kind and number of teeth they possess. The number of these teeth may be graphically shown by means of what is called a dental formula. In a dental formula, the teeth of the upper jaw (the right and left sides separately) form the numerator of the fraction; those of the lower jaw form the denominator. This dental formula of man is graphically shown as follows:-

$$
\begin{aligned}
\text { incisors } & =\frac{2+2}{2+2} ; & \text { canines } & =\frac{1+1}{1+1} ; \\
\text { premolars } & =\frac{2+2}{2+2} ; & \text { molars } & =\frac{3+3}{3+3} ;
\end{aligned}
$$

Man differs from other vertebrate animals in that when young the child has a set of teeth which later fall out and are replaced by the thirty-two teeth known as the permanent set.

The first set, known as the milk teeth, consists of twenty teeth arranged as follows:-

$$
\text { - incisors }=\frac{2+2}{2+2} ; \quad \text { canines }=\frac{1+1}{1+1} ; \quad \text { molars }=\frac{2+2}{2+2} ; \quad \text { total, } 20 .
$$

The permanent teeth appear to push out the milk teeth; this is indeed the case, as the beginnings of the permanent teeth are found very early in life under the milk teeth. The so-called wisdom teeth (four molars) do not appear until the eighteenth to the twenty-first year of life.

Internal Structure of a Tooth. - If a tooth is cut lengthwise, it is found to be hollow; this cavity, called the pulp cavity, corresponds to the cavity containing marrow in bones. In life it contains living material the blood vessels, nerves, and cells which build up the bony part of the tooth. The bulk of the hard part of the tooth consists of a limy material called dentine. Outside of this is a very hard substance called enamel; this substance, the hardest in all the body, is thickest on the exposed surface or crown of the tooth. What is the use of this hard layer? Why is it so placed? Each tooth is held in its place in the jawbone by a thin layer of bony substance called cement.

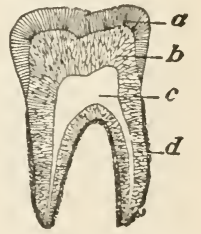

Section of a tooth; $a$, enamel; $b$, dentine; $c$. pulp cavity containing blood vessels and nerves; $d$, cement. 
Salivary Glands. - Besides the cells in the mouth which secrete mucus, other collections of gland cells form a substance called saliva. There are three pairs of the salivary glands. They are named according to their position, the parotid (under the ear), the submaxillary (under the jawbone), and the sublingual (under the tongue).

Home Exercise. - Chew paraffin or india rubber and collect saliva in a test tube. Answer the following questions. What is its color? Does any sediment appear after standing? Test with litmus paper for its chemical reaction. Partly fill three test tubes, one with water, one with saliva, one with saliva plus weak acetic acid. Place in each a small piece of cracker. Leave the three overnight in a warm place (about $98^{\circ}$ Fahrenheit). Next morning test the contents of the tubes for starch and for grape sugar. In which tube has some starch been changed to grape sugar? Chew a piece of cracker slowly. Notice any change in taste of cracker. How do you account for this?

Digestion of Starch. - The digestion of starch to grape sugar is caused by the presence in the saliva of an enzyme, or digestive ferment. You will remember that starch in the growing corn grain was changed to grape sugar by an enzyme, called diastase. Here the same action is caused by an enzyme called ptyalin. This ferment, as we see, acts only in an alkaline medium at about the temperature of the body.

Openings from Buccal Cavity. - The mouth cavity of man, as that of a frog, has four paired openings leading from it, - two into the nostril (the postcrior nares), and two to the ear (the Eustachian tubes, named after their discoverer, an Italian doctor). Three single openings also exist, - one to the outside (the mouth), another to the lungs, and a third, the gullet.

In man, the windpipe is easily felt. It is a cartilaginous tube, the upper part forming the voice box, or larynx (Adam's apple); directly dorsal to this is the gullet. Food, in order to reach the gullet from the mouth cavity, must pass over the glottis, the opening into the trachea. In the frog, the glottis is normally a closed slit. In man, it is proportionately much wider. When food is in the course of being swallowed, the upper part of the larynx, called the epiglottis, forms a trap door over the opening. When the epiglottis is not closed, and food "goes down the wrong way," we choke and the food is expelled by coughing.

The Gullet, or Esophagus. - In man this part of the food tube is much longer proportionately than in the frog. Like the rest of the food tube it is lined by soft and moist mucous membrane. The wall is made up of two sets of muscles, - the inside ones running around the tube; the outer band of muscle taking a longitudinal course. After food leaves the mouth 
cavity, it gets beyond our direct control; the muscles of the gullet, stimulated to activity by the presence of food in the tube, push the food down to the stomach by a series of contractions.

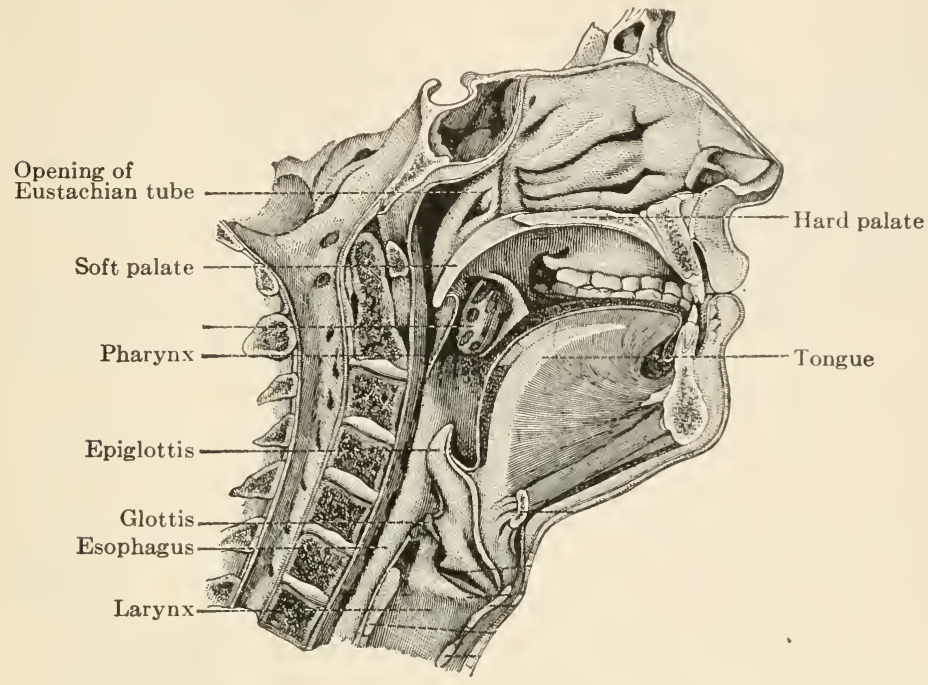

Vertical section of the head and neck.

Demonstration. - Cut away the throat muscles of a frog so as to expose the windpipe, or trachea; under this is a soft tube much wider in extent, the gullet.

Stomach of Frog. - Make a median cut through the muscles on the ventral side of the abdomen of a frog; then make incisions at right angles to this, just below the fore legs and immediately in front of the hind legs. Fold back the outer skin and the muscles and pin them into place at the dorsal side of the body. Notice the thin glistening membrane lining the cavity inside the body. This is called the peritoneum. The peritoneum forms a fold on the dorsal side of the body cavity (called the mesentery), and in this incloses all the organs of digestion, etc., so that they hang from the dorsal side when the animal is in natural position. The peritoneum and mesentery are present in man.

The stomach may easily be found after lifting up the dark red, threelobed liver. Note the position and size of the stomach. This will vary considerably according to the amount of food inside.

Stomach of Man. - In man, the stomach has, in general, the same position as in the frog. This difference, however, exists: The gullet passes directly through a muscular partition, the diaphragm, which is lacking in the frog. The diaphragm separates 


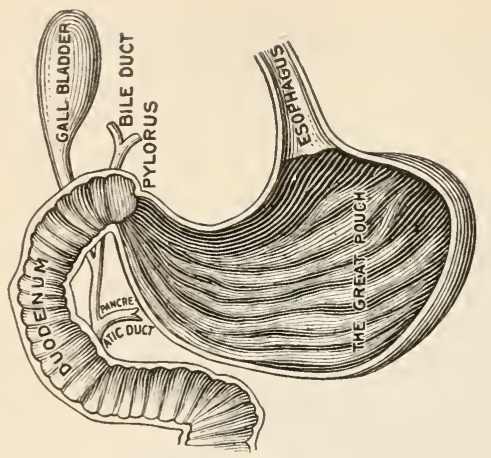

Inside of the stomach and intestine, showing the folds of the mucous membrane. the heart and lungs from the other organs of the body cavity. The stomach is a pear-shaped organ capable of holding about three pints. The end opposite to the gullet, which empties into the small intestine, is provided with a valve called the pylorus.

Demonstration - Open the stomach of the frog; remove its contents by carefully washing. The stomach wall is seen to be thrown into folds internally.

Gastric Glands. - Between these folds, in the stomach of man as well as in the frog, are located a number of tiny pits. These form the mouths of the gastric glands, which pour into the stomach a secretion known as the gastric juice. The gastric glands are little tubes, the lining of which secretes the fluid. This fluid is largely water. It is slightly acid in its chemical reaction. (It contains about .2 per cent free hydrochloric acid.) It also contains a very important enzyme called pepsin, and another less important one called rennin.

The action of gastric juice upon proteids may be determined by the following experiment. Number five test tubes, 1 to 5 inclusive.

In No. 1 place minced white of egg + water.

In No. 2 place minced white of egg +.2 per cent hydrochloric acid.

In No. 3 place minced white of egg +.2 per cent hydrochloric acid and pepsin.

Treat No. 4 and No. 5 as No. 3.

Place Nos. 1, 2, and 3 in a water bath (or in a pail of water over a radiator or register) where the temperature will stand at about $98 \frac{1}{2}^{\circ}$ Fahrenheit for several hours.

Place No. 4 in the ice box or surround with ice for three hours. Place No. 5 in boiling water for half an hour, then place with Nos. 1, 2, and 3 .

Note all changes that have taken place in the different tubes.

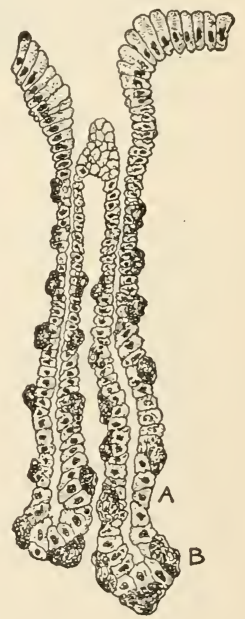

A peptic gland, from the stomach, very much magnified. $A$, central or chief cells, which make pepsin; $B$, border cells, which make acid. From Miller's Histology. 
Test the contents of the different tubes for peptone with the biuret test. (See below.) ${ }^{1}$

Action of Gastric Juice. - Most proteid substances are insoluble in water. They belong to the class of substances known as "colloids" - substances that do not easily pass through a membrane by osmosis. Protein is changed by the pepsin of the gastric fluid to a substance readily soluble. After protein is digested it is known as a peptone. Digestion of proteid results in a change of a colloid substance to one which will diffuse readily through a membrane, or a crystalloid. Peptones are crystalloid substances.

Gastric juice acts most perfectly at the temperature of the normal body. The enzyme pepsin will not act in an alkaline medium; boiling or freezing prevents its action as well. A slightly acid medium is necessary for proteid digestion in the stomach.

The other enzyme of gastric juice, called rennin, curdles or coagulates the proteid found in milk; after the milk is curdled, then the enzyme, pepsin, is able to act upon it and change it to a soluble crystalloid substance.

The hydrochloric acid found in the gastric juice acts upon lime and some other salts taken into the stomach with food.

EXPERIMENT. - Add, drop by drop, very dilute hydrochloric acid to a test tube containing limewater. Notice the change that takes place. By this means lime is changed from an insoluble to a soluble form and can be absorbed into the blood, to be later used in the building of bone.

Movement of Walls of Stomach. - The stomach walls, provided with three layers of muscle which run in an oblique, circular, and longitudinal direction (taken from the inside outward), are well fitted for the constant churning of the food in that organ. Here, as elsewhere in the digestive tract, the muscles are involuntary, muscular action being under the control of the so-called sympathetic nervous system. Food material in the stomach makes several complete circuits during the process of digestion in that organ. While this is taking place, the gastric juice acts upon proteins, softening them, while the constant churning movement tends to separate the bits of food into finer particles. Finally, some of the partly digested food is allowed to pass in small amounts through the pyloric valve, into the small intestines. This is done by the expansion of the ringlike muscles of the pylorus.

1 The food test for proteid already given (nitric acid followed by ammonium hydrate) is known as the xanthoproteic.

Another test is made in the following manner: Place in a test tube containing proteid some concentrated caustic soda solution. To this add, drop by drop, a little weak copper sulphate solution. Note the resulting color (violet). Heat the material and the color deepens.

If the proteid has been digested to peptone the above test will show a rose pink. This test, known as the biuret test, is used for the detection of peptones.

HUNTER'S BIOL. -22 
Absorption in Stomach. - Fluids leave the stomach more rapidly than do solids, milk, for example, taking about two hours to digest, while a meal of meat and vegetables will not leave the stomach for three to four hours. It is not thought that any great amount of absorption of digested food occurs through the wall of the stomach. As soon as food reaches the small intestine, however, sugars and peptones are slowly absorbed, and pass into the blood.

The Intestine and Glands connected with it. Laboratory Work on the Frog. ${ }^{1}$ - The liver is the most prominent structure found in the body cavity. Note its position, its red color, the number of lobes into which it is divided. If the liver be pushed to one side, the small intestine is found to occupy part of the remaining space in the body cavity. Between the stomach and a coil of the small intestine lies a pinkish gland, the pancreas. The duct or tube which carries its secretion empties, together with the bile duct from the liver, into the small intestine, a short distance posterior to where the latter leaves the stomach. Find the greenish gall bladder which holds the secretion of the liver, the bile. Try to trace the course of the bile duct to the small intestine. Notice the abrupt change in the diameter of the food tube near its posterior end where it forms the large intestine; the latter empties into a space called the cloaca. This forms a common outlet for the food tube, kidneys, and reproductive organs.

Position and Structure of the Pancreas. - In man, the pancreas occupies the same relative position that it does in the frog. The gland is a rather diffuse structure; its duct empties in a common opening with the bile duct, a short distance below the pylorus. In internal structure, the pancreas resembles the salivary glands. The fluid, as we shall see, has some functions possessed by the saliva.

The following experiments may be performed to illustrate the process of digestion by pancreatic fluid. The several enzymes of pancreatic fluid are sold in a powdered form as a substance called pancreatin. ${ }^{2}$ An artificial pancreatic fluid may be prepared by adding to some pancreatin enough water to dissolve it. To show saponification of fats add ten volumes of $\mathbf{1 . 5}$ per cent sodium carbonate.

Experiments to show the Properties of Pancreatic Fluid. - Prepare (1) test tube containing starch and artificial pancreatic fluid; (2) test tube containing proteid and artificial pancreatic fluid; (3) test tube containing oil and artificial pancreatic fluid + ten volumes of 1.5 per cent sodium carbonate; (4) test tube containing oil and water. Place tubes 1 and 2 in a pan containing warm water. Leave at a temperature of $98^{\circ}$ Fahrenheit, if possible, for twelve hours. Then test No. 1 with Fehling's solution; No. 2 for peptone with the biuret test. Test the contents of tube No. 1 or No. 2 with red litmus paper. What reaction do you obtain? Shake up No. 3 and No. 4 an equal number of times; compare the color and appearance of the two tubes one minute after shaking. Note that the milky condition existing

1 In the female frog it will be necessary to remove the ovary, filled with tiny black and white eggs, and the oviducts, twisted tubes through which the eggs are passed to the outside of the body, before working on the rest of the digestive tract.

2 This substance must be bought from a reliable firm, as it is frequently adulterated. 
in No. 3 after shaking continues for a longer period than the same condition in No. 4. Examine, under the compound microscope, a drop of the fluid taken from tube No. 3. Notice the fluid appears to contain thousands of tiny droplets of fat which float in the water surrounding them. Such a mass of finely separated particles of oil and water is called an emulsion.

Functions of Pancreatic Fluid. - From these experiments we see that pancreatic fluid is alkaline in its reaction. It has the power, by means of an enzyme called amolypsin, to change starches to sugars. A second enzyme, called trypsin, changes proteids to peptones. Oils and fats, with the aid of a third enzyme (lipase) are emulsified and in part changed to soap. It is estimated that half an ounce of soap is formed daily in the small intestine by this means. In such a form fats are enabled to pass through

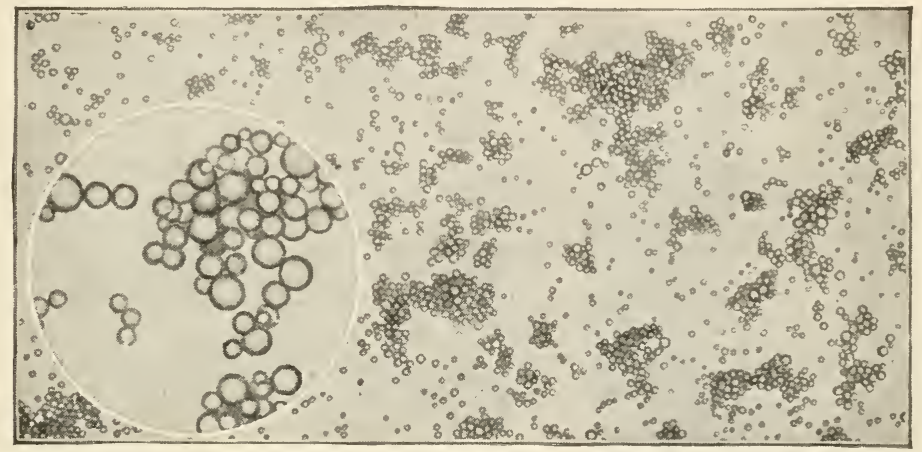

Appearance of milk under the microscope, showing the natural grouping of the fat globules.

In the circle a single group is highly magnified. Milk is one form of an emulsion.

(S. M. Babcock, Wis. Bul. No. 61.)

the walls of the intestine. This is, then, a form of digestion. The pancreatic fluid is thus seen to play a very important part in digestion, as it acts upon all three nutrients, starches, proteids, and fats.

LIVER. - The liver is the largest gland in the body. In man, it hangs just below the diaphragm, a little to the right side of the body. During life, its color is deep red. It is divided into three lobes, between two of which is found the gall bladder, a thin-walled sac which holds the bile, a secretion of the liver. Bile is a strongly alkaline fluid of greenish color. It reaches the intestine through a common opening with the pancreatic fluid. Almost one quart of bile is passed daily into the digestive canal.

Functions of Bile. - The action of bile on foods is not very well known. It does have slight action in emulsifying fats. It is slightly antiseptic, and is thus valuable in preventing fermentation within the intestine. Its greatest importance, however, is the peculiar faculty it has of aiding the passage of fats through the walls of the intestine. 
Experiment. - Place filter paper within each of two funnels. In one funnel, wet the filter paper with water. In the second, wet the paper with ox gall dissolved in water (equivalent to bile). Place olive oil in each funnel. Through which filter does the olive oil pass with greater rapidity?

Foriation of Glycogen. - Another important function of the liver (which may be taken up in connection with the circulation of the blood) is the formation within it of a material called glycogen or animal sugar. The liver is supplied by blood from two sources. The greater amount of blood received by the liver comes directly from the walls of the stomach and intestine to this organ. This blood is very rich in food materials, and from it the cells of the liver take out sugars to form glycogen. Glycogen is stored in the liver until such a time as a food is needed that can be quickly oxidized;

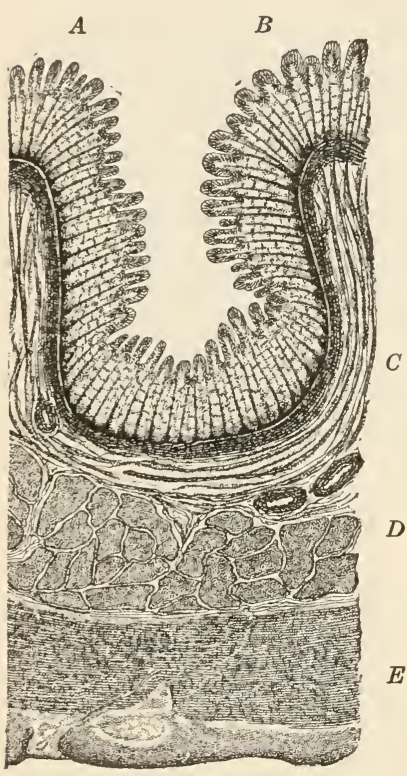

A much magnified section through the wall of the small intestine (after Benda). $A, B$, transverse folds of intestine covered with the fingerlike villi; note the very great absorbing surface thus gained; $C$, connective tissue; $D, E$, circular and longitudinally running muscle fibers. then the glycogen is carried off by the blood to the tissue which requires it and there used for this purpose.

\section{The Absorption of Digested Food} into the Blood. - The object of digestion is to change foods from an insoluble to a soluble form. This has been seen in the study of the action of the various digestive fluids in the body, each of which is seen to aid in dissolving solid foods, changing them to a fluid, and, in case of the bile, actually assisting them to pass through the wall of the intestine by osmosis. A very small amount of digested food may be absorbed by the blood in the $E$ blood vessels of the walls of the stomach. Most of the absorption, however, takes place through the walls of the small intestine. Let us examine this structure somewhat closely to see how it is adapted to absorb liquid food.

Structure of the Small Intestine. The small intestine in man is a slender tube nearly twenty feet in length and about one inch in diameter. Its walls contain muscles which, by a series of slow waves of contraction, force 
the fluid food gradually toward the posterior end of the tube. If the chief function of the small intestine is that of absorption, we must look for adaptations which increase the absorbing surface of the tube. This is gained in part by the inner surface of the tube being thrown into transverse folds which not only retard the rapidity with which food passes down the intestine, but also give more absorbing surface. But far more important for absorption are millions of little projections which cover the inner surface of the small intestine. So numerous are these projections that the whole surface presents a velvety appearance. Collectivcly, these structures are called the villi (singular villus). They form the chief organs of absorption in the intestine, several thousand being distributed over every square inch of surface. Between the villi are found the openings of many small tubelike glands, the intestinal glands. These glands manufacture a digestive fluid, the function of which is believed to be somewhat like that of the pancreatic fluid.

Internal Structure of a Villus. - The internal structure of a villus is best seen in a longitudinal section. We find the outer wall made up of a thin layer of cells, the epithelial layer. It is the duty of these cells to absorb, by osmosis, the semifluid food from within the intestine. Sugars and peptones are passed through the cells to a number of tiny capillaries or blood vessels found immediately under the epithelial layer. From here they pass (through what is known as the portal circulation) into the liver, where, as we have seen, sugar is taken from the blood and stored as glycogen.

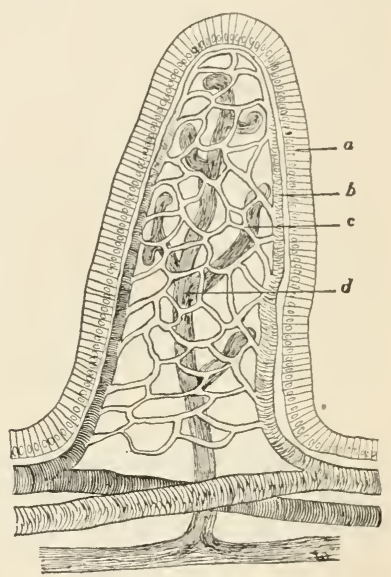

Diagram of a longitudinal section through a villus; $a$, epithelium which takes up food and transports it to the tubes within; $b$, an artery; $c$, capillaries; $d, a$ lacteal.

Course of Food after Absorption. - From the liver, this food within the blood is sent to the heart, from there pumped to the lungs, from there it returns to the heart and is pumped to the tissues of the body, where as nitrogenous food it may build protoplasm or, if carbohydrate, may be used to furnish energy. A large amount of water and some salts are absorbed through the walls of the stomach and intestine as food passes on its course. The fats, in the form of an emulsion, are also taken up through the cells lining the villi and pass, not into the blood vessels, but into a space which occupies part of the interior of the villus. Each of 
these spaces leads into a system of thin-walled vessels which, because of their milky appearance after their absorption of fats, are collectively called the lacteals (Lat. lac $=$ milk).

Mesenteric Glands. - The entire digestive tract hangs in the body cavity within a double fold of the. mesentery or membrane which lines the body cavity. In this double fold are found, besides the organs of the digestive tract, blood vessels leading to and from them, nerves, connective tissue, and fat, numerous small collections of gland cells called the mesenteric glands. These glands receive the fatty contents of the lacteals and, in some way, change this fat so that it may become part of the blood. Eventually, the fats reach the blood through the thoracic duct of the lymphatic system (which we shall study later). Fats reach the blood, then, without passing through the liver with the other foods absorbed by the villi.

Large Intestine. - The large intestine has somewhat the same structure as the small intestine except that the diameter is much greater. It also contains no villi nor transverse folds on its inner surface. Considerable absorption of food, however, takes place through its walls as the food mass is slowly pushed along by the muscles within its walls.

Vermiform Appendix. - At the point where the small intestine rvidens to form the large intestine a baglike pouch is formed. From one side ot this pouch is given off a small tube about four inches long, closed at the lower end. 'This tube, the function of which in man is unknown, is called the vermiform appendix. It has come to have unpleasant notoriety in late years, as the site of serious inflammation. It often becomes necessary to remove the appendix in order to prevent this inflammation spreading to the surrounding tissues. In some of the lower vertebrates (for example, fishes), the vermiform appendix is extremely large, and appears to be used as an organ of digestion and absorption. In man it has become reduced in size (perhaps through disuse) so that it is a mere vestige of what it is in lower vertebrates.

Hygienic Habits of Eating; the Causes and Prevention of Dyspepsia. - From the contents of the foregoing chapter it is evident that the object of the process of digestion is to break up solid food so that it may be absorbed to form part of the blood. Any habits we may form of thoroughly chewing our food will evidently aid in this process. A lump of white of egg will not be digested by pepsin in the experiment just performed; minced egg, on the other hand, is quickly changed to a peptone. Undoubtedly much of the 
distress known as dyspepsia is due to too hasty meals with consequent lack of proper mastication of food. Another cause is overeating. It is a good rule to go away from the table feeling hungry. Eating too much overtaxes the digestive organs and prevents their working to the best advantage. Still another cause of dyspepsia is eating when in a fatigued condition. It is always a good plan to rest a short time before eating, especially after any hard manual work. Eating between meals is also condemned by physicians because it calls the blood to the digestive organs at a time when it should be in other parts of the body.

Effect of Alcohol on Digestion. - It is a well-known fact that alcohol extracts water from tissues with which it is in contact. This fact works much harm to the interior surface of the food tube, especially the walls of the stomach, which in the case of a hard drinker are likely to become irritated and much toughened. In small amounts alcohol is believed to stimulate the secretion of the salivaric and gastric glands, and thus it seems to aid in digestion. It is doubtful, however, if this aid is real.

The following results of experiments on dogs, published in the American Journal of Physiology, Vol. I, Professor Chittenden gives as "strictly comparable," because " they were carried out in succession on the same day":-

\begin{tabular}{|c|c|c|}
\hline Number of Experiment. & zolb. meat with water. & $\frac{1}{10}$ lb. meat with dilute alcohol. \\
\hline 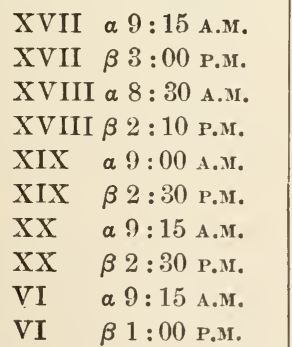 & $\begin{array}{l}\text { Digested in } 3 \text { hours. } \\
\text { Digested in } 2: 30 \text { hours. } \\
\text { Digested in } 2: 30 \text { hours. } \\
\text { Digested in } 2: 15 \text { hours. } \\
\text { Digested in } 3: 15 \text { hours. }\end{array}$ & $\begin{array}{l}\text { Digested in } 3: 15 \text { hours. } \\
\text { Digested in } 3: 00 \text { hours. } \\
\text { Digested in } 3: 00 \text { hours. } \\
\text { Digested in } 2: 45 \text { hours. } \\
\text { Digested in } 3: 45 \text { hours. }\end{array}$ \\
\hline Average & $2: 42$ hours. & $3: 09$ hours. \\
\hline
\end{tabular}




\section{THE BLOOD}

Function of the Blood. - We have seen in the preceding chapter that the chief function of the digestive tract is to change foods to such form that they can be absorbed through the walls of the food tube. The food, after it has passed through the intestine

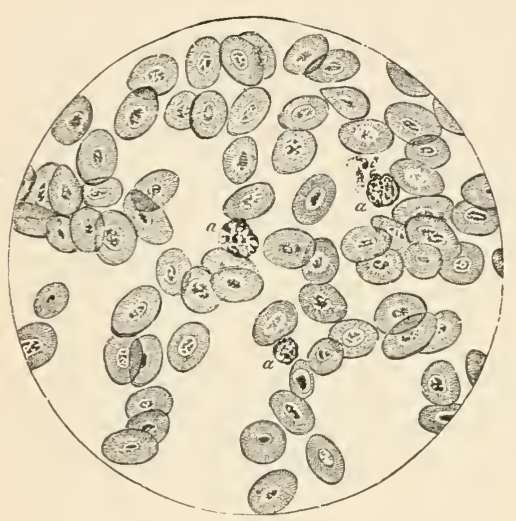

Nucleated blood cells of a frog, as seen under the compound microscope; $a$, colorless corpuscles. walls, ultimately reaches the blood and becomes, as we shall see, a part of this tissue. By means of a system of closed tubes, this fluid tissue circulates to all parts of the body, depositing its burden of food at the places where it is most needed and where it will be used, either in the repair or building of tissues or in the release of energy.

Laboratory Exercise. - Examine a prepared slide of the blood of a frog. Note that three constituents are found: (1) Ovoid cells, each containing a nucleus. What color do these bodies have? They are called the red corpuscles. (2) Other colorless corpuscles of irregular form may be seen. What can you say of the number of colorless corpuscles as compared with the red corpuscles? Notice that the colorless corpuscles have the power to change their shape. They are said to be amoboid. Like the amœba, they also have the power to take up particles of food and other materials and ingest them. (3) The colorless fluid in which the corpuscles float is known as the plasma.

Composition of Plasma. - The plasma of blood (when chemically examined in man) is found to be largely (about 90 per cent) water. It also contains a considerable amount of proteid, some sugar, fat, and mineral material. It is, then, the medium which holds the fluid food (or at least part of it) that has been absorbed from the food within the intestine. When the blood returns from the tis- 
sues where the food is oxidized, the plasma brings back with it to the lungs the carbon dioxide liberated from the tissues of the body where oxidation has taken place. Blood returning from the tissues of the body has from 45 to 50 cubic centimeters of carbon dioxide to every 100 cubic centimeters. (See Respiration, page 3S0.) Some waste products, to be spoken of later, are also found in the plasma.

Demonstration. - Get some fresh beef blood. Let it stand overnight in a jar. In the morning it will be found to have separated into two parts, a dark red clot and a thin straw-colored liquid, called serum. Serum is found to be made up of about 90 per cent water, 8 to 9 per cent proteid, and from 1 to 2 per cent sugars, fats, and mineral matter. In these respects it rather closely resembles the fluid food that is absorbed from the intestines.

Clotting of Blood. - Pour another jar of fresh becf blood into a pan and briskly whip it with a bundle of little rods (or with an egg beater). A stringy substance will be found to stick to the rods. This, if washed carefully, is seen to be almost colorless. Test with nitric acid and ammonia. Note the deep orange color. It is a proteid substance called fibrin.

Blood plasma, then, is made up of serum, a fluid portion, and fibrin, which, although in a fluid state in the blood vessels within the body, coagulates when removed from the body.

It is this coagulation which aids in the formation of a blood clot. A clot is simply a mass of fibrin with a large number of corpuscles tangled within. The clotting of blood is of great physiological importance, for otherwise we might bleed to death from the smallest wound.

In blood within the circulatory system of the body the fibrin is held in a fluid state called fibrinogen. It is believed that an enzyme, acting upon this fibrinogen, causes the change to take place in the blood.

The Red Blood Corpuscle; its Structure and Functions. - In the blood of the frog we have seen that the red corpuscle is a true cell of disklike form. The red corpuscle of man, however, lacks a nucleus. Its form is that of a biconcave disk. So small and so numerous are these

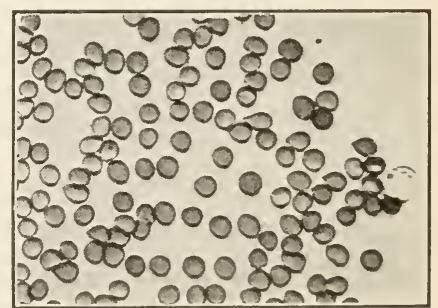

Human blood as seen under the compound microscope: at the extreme right is a colorless corpuscle. corpuscles that over five million are found in a drop of normal blood. 
The color, which is found to be a dirty yellow when separate corpuscles are viewed under the microscope, is due to a proteid material called haemoglobin. Haemoglobin, which constitutes about 35 per cent of the corpuscle, contains a large amount of iron. It has the power of uniting very readily with oxygen whenever that gas is abundant, and after having absorbed it, of giving it up to the surrounding media, when oxygen is there present in smaller amounts than in the corpuscle. This function of carrying oxygen is the one important function of the red corpuscles. The taking up of oxygen is accompanied by a change in color of the mass of corpuscles from a dull red to a bright scarlet.

Length of Life of Red Corpuscles. - It is difficult to say just how long the red corpuscles live in the body. We know, however, that large numbers are destroyed every day.

The coloring matter of the bile, and possibly other body excretions, is due to the color obtained from the worn-out blood corpuscles. To make up for the loss of the red corpuscles, new ones are manufactured in the red marrow of bone. The red marrow cells are in a continual state of division, forming new red corpuscles which at first are nucleated cells. These later lose their nuclei and become disk-shaped.

The Colorless Corpuscle; Structure and Functions. - A colorless corpuscle is a cell irregular in outline, the shape of which is constantly changing. These corpuscles are somewhat larger than the red corpuscles but less numerous, there being about one colorless corpuscle to every three hundred red ones. They seem to have the power of movement, for they are found not only inside blood vessels, but outside the blood tubes, showing that they have worked their way between the cells that form the walls of the blood vessels.

A Russian zoölogist, Metchnikoff, after studying a number of simple animals, such as medusæ and sponges, found that in such animals some of the cells lining the inside of the food cavity take up or enguif minute bits of food. Later, this food is changed into the protoplasm of the cell. Metchnikoff believed that the colorless corpuscles of the blood have somewhat the same function. This he later proved to be true. Like the amœba, 
they feed by engulfing their prey. This fact has a very important bearing on the relation of colorless corpuscles to certain diseases caused by bacteria within the bocly. If, for example, a cut becomes infected by bacteria, inflammation may set in. The bacteria form a poison known as a toxin, which causes this inflammation in their immediate neighborhood. Colorless corpuscles at once surround the spot and attack the bacteria. If the bacteria are few in number, they are quickly eaten by the colorless corpuscles, which are known as phagocytes. If bacteria are present in great

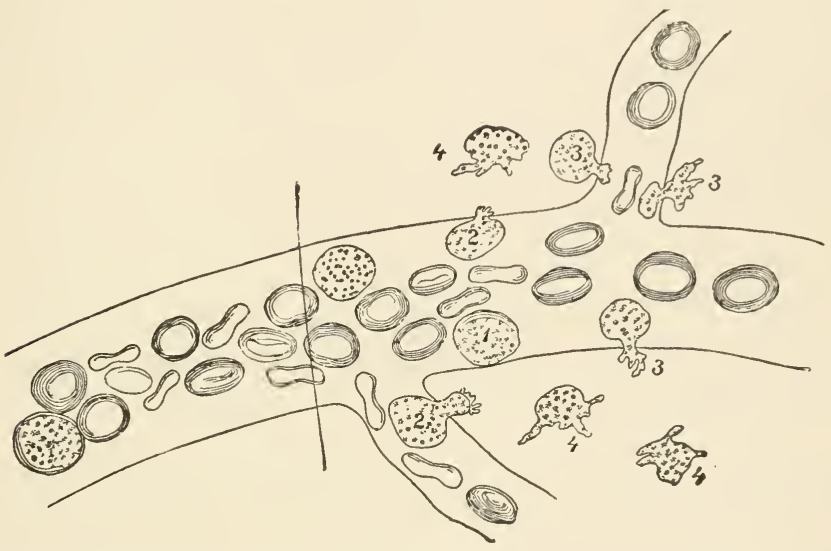

Diagram showing how colorless corpuscles pass between the cells that form the walls of the capillaries; $1,2,3,4$, different stages. Hall.

quantities, they may prevail and kill the phagocytes by poisoning them. The dead bodies of the rhagocytes thus killed are seen in the pus, or matter which accumulates in infected wounds. In such an event, we must come to the aid of the colorless corpuscle by washing the wound with some antiseptic, as weak carbolic acid or hydrogen peroxide.

Number and Manufacture of Colorless Corpuscles. - The number of colorless corpuscles, although normally about 17,000 to a drop of blood, may vary, especially in certain diseases. They are formed in large numbers within the lymph glands (collections of cells which are found here and there along the course of the lymph vessels). The spleen, a gland, and the marrow of bone are also believed to manufacture colorless corpuscles. 
The Amount of Blood and its Distribution. - Protoplasm of the body, as we know, is composed largely of water. The blood forms, by weight, about one thirteenth of the body. Its distribution varies somewhat according to the position assumed by the body, and the amount of undigested food in the stomach and intestines. Normally, about one half of the blood of the body is found in or near the organs lying in the body cavity, about one fourth in the muscles, and the rest in the heart, lungs, large arteries, and veins.

Blood Temperature. - The temperature of blood in the human body is normally about $98.5^{\circ}$ Fahrenheit, although the temperature drops almost two degrees after we have gone to sleep at night. It is highest about 5 P.M. and lowest about 4 A.M. Any considerable variation in the temperature of the blood means death. In fevers, the temperature of the body sometimes rises to $107^{\circ}$; but unless this temperature is soon reduced, death follows. Any considerable drop in temperature below the normal also would mean death. Bodily temperature, as we know, results from the oxidation of food; within the cells of the tissues in all parts of the body, but especially those of the muscles.

Cold-blooded Animals. - In lowei animals which are called cold blooded, the blood has no fixed temperature, but varies with the temperature of the medium in which the animal lives. Frogs, in the summer, may sit for hours in water with a temperature of almost $100^{\circ}$. In winter, they often endure freezing so that the blood and lymph within the spaces under the loose skin are frozen into ice crystals. Such frogs, if thawed out carefully, will live. This change in body temperature is evidently an adaptation to the mode of life.

Necessity of Good Food, Fresh Air, and Sleep. - Inasmuch as the fluid part of the blood receives its nourishment directly from the foods which are taken into the body, it follows that if food materials contain an ill-balanced proportion of nutrients, the blood and the body may suffer. Proteid must be taken into the blood at all times, for without it, no protoplasm can be formed. More carbohydrates and fats are needed in winter. Why? The red corpuscles, having the important function of carrying oxygen, must be kept in healthy condition. To do this, plenty of fresh air is 
essential. Sleep also seems to be a necessary factor in the health of the red corpuscle. Many are familiar with the pale face which comes from sleeplessness and overwork in poorly ventilated rooms. Moderate exercise is another important factor. The disease called anæmia, which means a lack of red corpuscles in the blood, is too often brought about by sedentary habits and lack of sleep and air. Tonics containing iron are given in such cases so as to supply the lacking element to the hæmoglobin of the red corpuscle. 


\section{CIRCULATION}

The Organs of Circulation in the Frog. - In a frog that has been recently killed the organs of circulation may be made out in part. It is best, however, to have a specimen in which the blood vessels have been injected with some semifluid mass (made of gelatine or starch colored with carmine

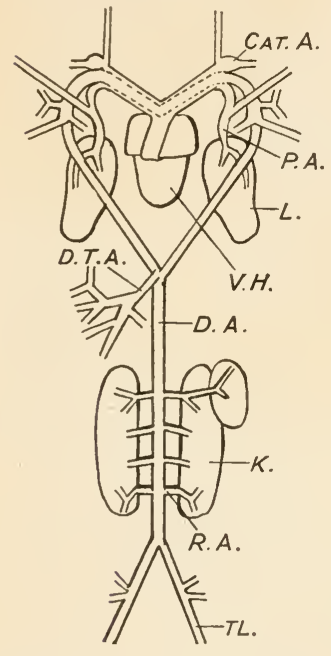

Arterial system of the frog; Cat. A., carotid artery; D. A., dorsal aorta; D.T.A., artery to digestive tract; $I L .$, iliac artery; $L$., lungs; $K$., kidney; $P . A$., pulmonary artery; R.A., renal artery; V.H., ventricle of heart. (After Parker and Haswell.) or other bright coloring material). Two specimens should be used to demonstrate the organs of circulation, one for the veins, the other for the arteries. In a specimen killed by chloroforming find the nearly triangular-shaped heart. It is seen to be composed of two distinct parts, a light-colored area, the ventricle, and a broader portion, which is darker in color. This latter area is made up of the two auricles. Compare the two areas of the heart in position. The auricles, according to their position, are called respectively the right and left auricles.

The arterial system of the frog may be said to include all blood vessels which carry blood away from the heart. The heart is only imperfectly divided into a right and a left heart, there being only one ventricle, with an imperfect partition wall extending in an anterior-posterior direction. Blood leaves the heart to pass to the lungs by a vessel (shown in the diagram), known as the pulmo-cutaneous trunk, because it carries blood to the skin and lungs. Over the ventral surface of the heart is found a large common trunk, the conus. This divides into two branches while still over the heart, and then each branch splits into three large arteries, the carotid, systemic, and pulmo-cutaneous appearing from the midline as we go outwards. Trace the course of the carotid artery; it supplies the head and neck with arterial blood. The systemic arteries are the most important in the body. Trace one backward to where it unites with its neighbor on the opposite side of the body to form the dorsal aorta, the great main trunk supplying the organs of the body cavity and the muscles of the body and legs. Find the branches passing to the stomach, intestine, liver, and other organs held in the mesentery. Farther back, arteries may be found that pass to the kidneys and genital organs. The aorta divides to form two large trunks, the iliac arteries, that supply the muscles of the hind legs. Make a drawing to show the principal arteries and their connection with the heart of the frog.

The system of blood vessels which return blood from the various organs of the body to the heart is known collectively as the venous system or veins 
In the frog some of these blood vessels are somewhat difficult to find; otners may easily be seen. One which collects blood from the skin and muscles near the ventral surface of the body, but chiefly from the hind legs, is called the abdominal vein. It may be seen near the surface, on the ventral midline of the body, as we open the frog from the ventral side. This vein turns inward at a point nearly between the fore limbs, divides into two branches, and enters the liver. Just before it reaches the liver, another vein, bringing blood from the digestive tract, joins with it. The rest of the blood from the hind legs has to pass through what is known as the renal portal system of circulation, the veins of which send the blood through the kidney, and thence, by a large single vein (the postcaval vein) to a thin-walled sac on the dorsal side of the heart. This sac, known as the sinus venosus, receives the blood from the veins and empties it into the heart. Immediately before reaching the sinus, the blood from the liver (the so-called portal circulation) joins with the postcaval vein. It is seen in the portal circulation that part of the blood of the body passes through the liver before reaching the heart. Blood from the head region is returned to the heart by two large precaval veins. The blood from the fore limbs also takes this course.

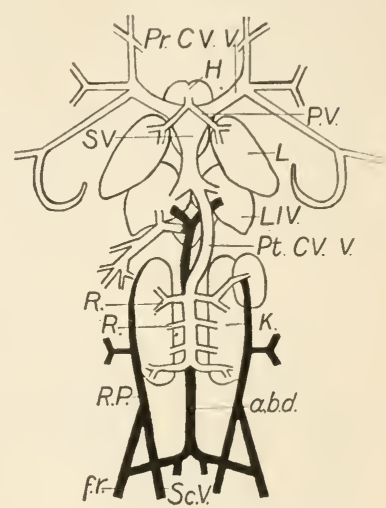

Venous system of the frog; $a . b . d$. , abdominal vein; f.r., femoral vein; $H$, heart; $L$, lungs; $K$, kidney; $L I V$., liver; $P . V$., pulmonary vein; $\operatorname{Pr} . C V . V$., precaval vein; $R$., $R$., renal veins; $S V$, sinus venosus; $S c . V$., sciatic veins. (After Parker and Haswell.)

Circulation of the Blood in Man. - As in the frog and other vertebrate animals, the organs of circulation are the heart and blood vessels. These blood vessels are called arteries when they carry blood away from the heart, veins when they bring blood back to the heart, and capillaries when they connect the arteries with the veins. Except in the spleen, where the blood capillaries are open, blood flowing between and around the cells, the organs of circulation form a system of closed tubes through which the blood flows in a continuous stream.

The Heart; Position, Size, Protection. - The heart is a coneshaped muscular organ about the size of a man's fist. It is located immediately above the diaphragm, and lies so that the muscular apex, which points downward, moves in beating or contracting against the fifth and sixth ribs, just a little to the left of the midline of the body. This fact gives rise to the notion that the heart is on the left side of the body. The heart is surrounded by a loose 
membranous bag called the pericardium. The inner lining of the pericardium secretes a fluid in which the heart lies. This fluid prevents any friction which otherwise might arise from the constant movement of the heart against the surrounding tissues. When, for any reason, the pericardial fluid is not secreted, inflammation arises in that region.

Internal Structure of Heart. - If we should cut open the heart of an ox, down the midline, we could divide it into two parts, each

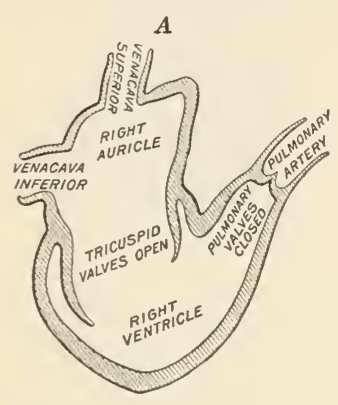
of which would have no internal connection with the other. Each side of the heart is found to be distinct and to be made up of a thin-walled portion with a rather large internal cavity, the auricle, and a smaller portion with heavy muscular walls, the ventricle. The auricles occupy the base of the cone-shaped heart; the ventricles, the apex. The auricle of the right side communicates with the ventricle of that side. In the same manner

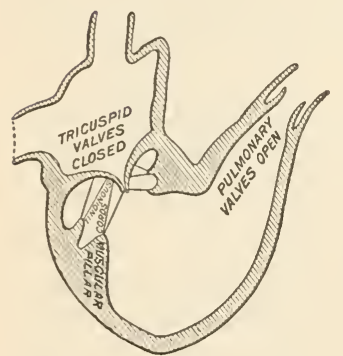

Diagrams illustrating the forcepump action of the valves of the heart; $A$, during the filling of the right ventricle; $B$, during the contraction of the ventricle. the auricle of the left side is connected with the ventricle on the left side. Communication between auricles and ventricles is guarded by little flaps of muscle called valves. The auricles receive blood from the veins. The ventricles pump the blood into the arteries. From each ventricle, large arteries leave the heart; that of the left side is called the aorta. Through the aorta, blood passes to all parts of the body. On the right side, the pulmonary artery carries blood to the lungs. The openings to these arteries are guarded by three halfmoon-shaped flaps, which open so as to allow blood to pass away from the ventricle, but not to go back into it when the muscles relax. The heart is constructed on the same plan as a pump, the valves preventing the reflux of blood into the auricle after it is forced out of the ventricle. 
The Heart in Action. - In a quiet room, the pulsation of the heart may be distinctly heard. A long sound, luub, is followed by a short one, dûb. The first sound is caused by the contraction of the muscles of the heart; the latter sound by the closing of the valves in the heart. The action of the heart is somewhat like that occurring when we squeeze water through a rubber bulb. Blood enters the auricles from the veins because the muscles of that part of the heart relax; this allows the space within the auricles to fill. Almost immediately the muscles of the ventricles relax, thus allowing blood to pass into the chambers within the ventricles. Then, after a short pause, during which time the muscles of the heart are resting, a wave of muscular contraction begins in the auricles and ends in the ventricles, with a sudden forceful contraction which forces the blood out into the arteries. This contraction of the heart is known as a systole. The extension of the muscles, to allow the auricles and ventricles to fill, is called a diastole. Blood is kept on its course by the valves, which act in the same manner as do the valves in a pump, thus forcing the blood to pass into the arteries upon the contraction of ventricle walls.

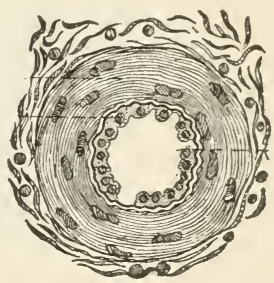

Transverse section of an artery, showing muscular walls.

The Work of the Heart. - The work performed by the heart is consideraible. The two ventricles, at each pulsation, expel about a cup and a half of blood into the arteries of the body. The average rate of the heart beat is about seventy to the minute, so that the work of the ventricles, in a single day, is estimated to release enough energy to lift 193 tons one foot from the ground. The heart is estimated to do as much work in a single day as a moderately heavy man would perform in climbing a mountain 3600 feet in height.

Demonstration. The Circulation of Blood in a Frog's Foot. - Bore a half inch hole in one end of a shingle. Wrap a live frog in wet flannel or absorbent cotton, and bind it, by means of elastic bands, upon the board so that the web of the frot is stretched in a horizontal position over the hole. Keep the web of the foot wet. Cover it with a large coverslip. Place it on the stage of a compound microscope, focus with low and then with the high power. A network of blood vessels will be seen which may be partially obscured by numerous pigment cells (dark-colored cells of irregular shape). The blood vessels may easily be recognized by the fluid contents, the ovoid corpuscles floating in the transparent plasma. Note that in some of the blood tubes the blood moves in regular spurts. These are the arteries. 
Trace the artery until it breaks out into very tiny tubes, the capillaries. Notice that in the capillaries the diameter of the tube is little more than that of a red corpuscle. Follow the capillaries until they come together to form a vein. What difference in the movement of the blood do you notice in the veins?

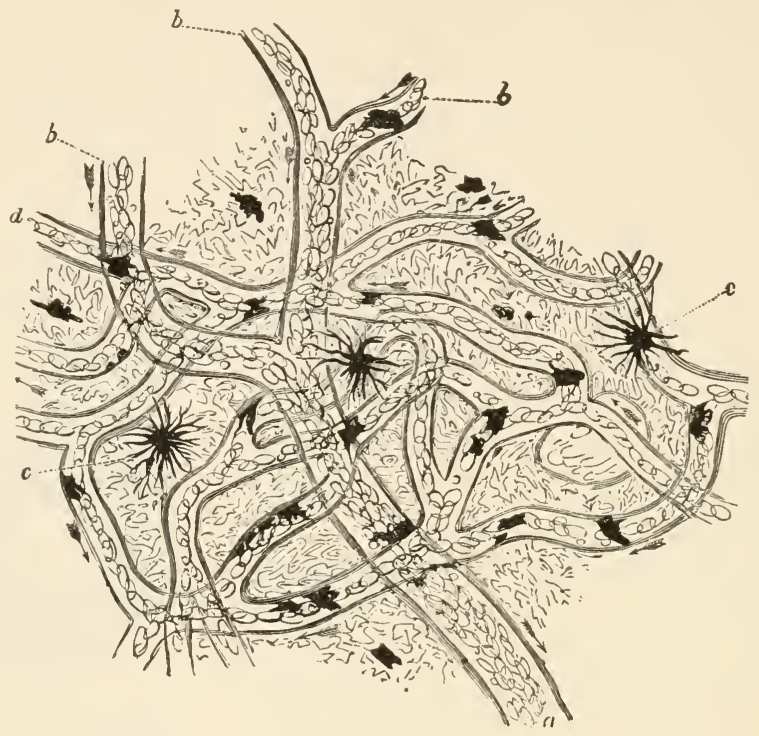

Capillary circulation in the web of a frog's foot, as seen under the compound microscope; $a, b$, small veins; $d$, capillaries in which the oval corpuscles are seen to follow one another in single series; $c$, pigment cells in the skin.

Structure of the Arteries. - A distinct difference in structure exists between the arteries and the veins in the human body. The arteries, because of the greater strain received from the blood which is pumped from the heart, have thicker muscular walls, and, in addition, are very elastic.

Cause of the Pulse. - The pulse, which can easily be detected by pressing the large artery in the wrist or the small one in front of and above the external ear, is caused by the gushing of blood through the arteries after each pulsation of the heart. In the earthworm, we found that certain parts of the blood vessels take up the work of pumping the blood. These vessels which connect the dorsal with the ventral blood vessels are called hearts. Each is a single muscular tube. The fish has such a heart. In the higher vertebrates the heart is more complex, being composed of two such muscu- 
lar tubes, side by side, each having two chambers (auricle and ventricle). As the large arteries pass away from the heart, the diameter of each individual artery becomes smaller. At the very end of their course, these arteries are so small as to be almost microscopic in size. They are very numerous. There are so many that if they were placed together, side by side, their united diameter would be much greater than the diameter of the large artery (aorta) which passes blood from the left side of the heart. This fact is of very great importance, for the force of the blood as it gushes through the arteries becomes very much less when it reaches the smaller vessels. This gushing movement is quite lost when the capillaries are reached. First, because there is so much more space for the blood to fill; secondly, there is considerable friction caused by the very tiny diameter of the capillaries.

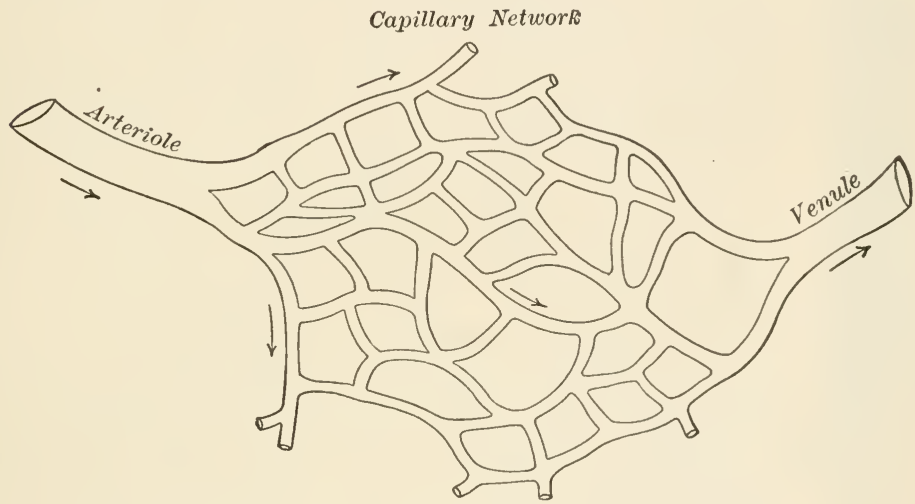

Capillary network, showing change from arterial to venous blood.

Capillaries. - The capillaries form a network of minute tubes everywhere in the body, but especially near the surface and in the lungs. It is through their walls that the food and oxygen pass to the tissues, and carbon dioxide is given up to the plasma. They form the connection that completes the system of circulation of blood in the body.

Function and Structure of the Veins. - If the arteries are pipes which supply fluid food to the tissues, then the veins may be likened to drain pipes which carry away waste material from the tissues. Extremely numerous in the extremities and in the muscles and among other tissues of the body, they, like the branches of a 
tree, become larger and unite with each other as they approach the heart. The blood supply from the body enters the right heart (auricle) by two large vessels, called, respectively, because of their position, the inferior and superior vence cave.

If the wall of a vein is carefully examined, it will be found to be not so thick or so tough as an artery wall. When empty, a vein collapses; the wall of an artery holds its position. If you hold your hand downward for a little time and then examine it,

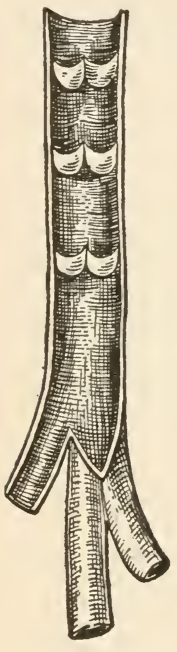

Valves in a vein. you will find that the veins, which are relatively much nearer the surface than are the arteries, appear to be very much knotted. This appearance is due to the presence of tiny valves inside the veins. These valves open in the direction of the blood current, but would close if the direction of the blood flow should be reversed (as in case a deep cut severed a vein). As the pressure of blood in the veins is much less than in the arteries, these valves thus aid in keeping the flow of blood in the veins toward the heart.

The Course of the Blood in the Body. - Although the two sides of the heart are separate and distinct from each other, yet every drop of blood that passes through the left heart likewise passes through the right heart. There are two distinct systems of circulation in the body. The pulmonary circulation takes the blood through the right auricle and ventricle, to the lungs, and passes it back to the left auricle. This is a relatively short circulation, the blood receiving in the lungs its supply of oxygen, and there giving up some of its carbon dioxide. The greater circulation is known as the systemic circulation; in this system, the blood leaves the left ventricle through the great dorsal aorta. A large part of the blood passes directly to the muscles; some of it goes to the nervous system, kidneys, skin, and other organs of the body. It gives up its supply of food and oxygen in these tissues, receives the waste products of oxidation while passing through the capillaries, and returns to the right auricle through the venæ cavæ. It 
requires from twenty to thirty seconds only for the blood to make the complete circulation from the ventricle back again to the starting point. This means that the entire volume of blood in the human body passes three or four thousand times a day through the various organs of the body. ${ }^{1}$

Portal Circulation. - Some of the blood, on its return to the heart, passes by an indirect path through the spleen, pancreas, and other organs of the body cavity, to the liver. Here the vein which carries the blood (called the portal vein) breaks up into capillaries around the cells of the liver. We have already learned that the liver is a great storehouse of animal sugar called glycogen. This glycogen is a food that may be easily oxidized to release energy, and is stored for that purpose. The sugar that becomes glycogen is carried to the liver directly from the walls of the stomach and intestine, where it has been absorbed from the food there contained. From

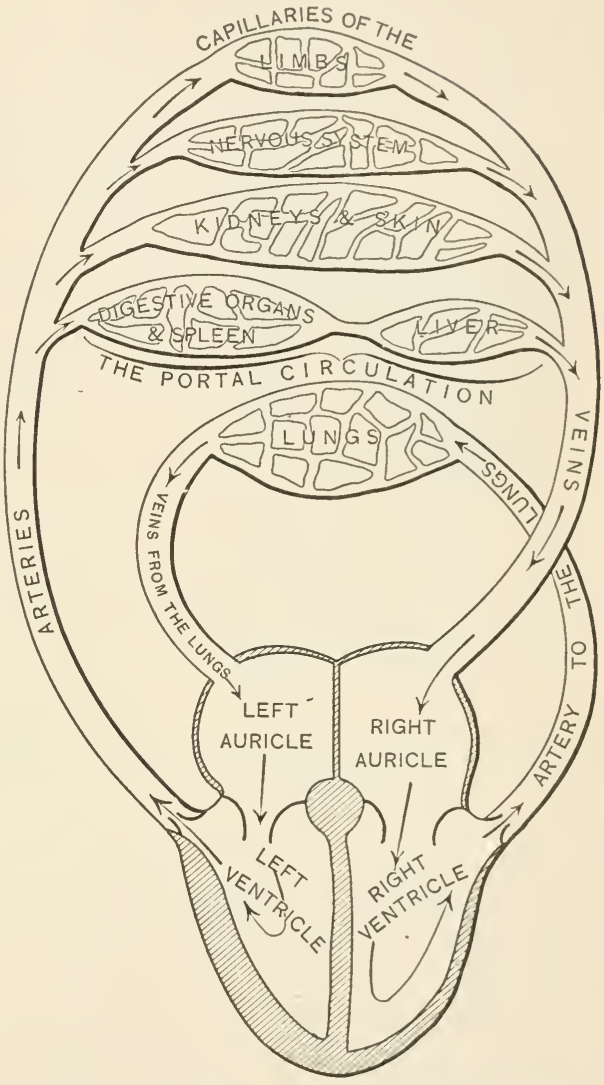

Diagram of the course of the blood in the circulation. the liver, blood passes directly to the right auricle. The portal system, as it is called, is the only part of the circulation where the blood passes through two sets of capillaries.

Changes in Blood within the Body. - We have already seen that blood loses much of the carbon dioxide it has taken from the tissues, 1 See Hough and Sedgwick, The Human Mechanism, page 136. 
replacing it with oxygen. This is accompanied by a change of color from purple (in blood which is poor in oxygen) to that of bright red (in richly oxygenated blood). Other changes take place in other parts of the body. In the muscles the blood gives up food and oxygen, receiving carbon dioxide in return. In the liver, the blood gives up its sugar. In glands, it gives up materials used by the gland cells in their manufacture of secretions. In the kidneys, it loses water and nitrogenous wastes (urea). In the skin, it also loses some waste materials and water.

Function of Lymph. - Different tissues and organs of the body are traversed by a network of tubes which carry the blood. Inside

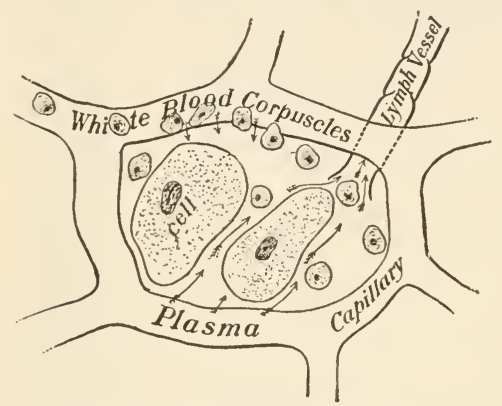

Diagram showing how food reaches the cells from the capillaries. these tubes is the blood proper, consisting of a fluid plasma, the colorless corpuscles, and the red corpuscles. Outside the blood tubes, in spaces between the cells which form tissues, is found another fluid very much like plasma of the blood in chemical composition. This is the lymph. It is, in fact, a fluid food in which some colorless amœboid corpuscles are found. Blood gives much of its food material to the lymph. This it does by passing it through the walls of the capillaries. The food is in turn given up to the tissue cells which are bathed by the lymph.

Some of the amœboid corpuscles from the blood make their way between the cells forming the walls of the capillaries. Lymph, then, is practically blood-plasma plus some colorless corpuscles. It acts as the medium of exchange between the blood proper and the cells in the tissues of the body. It not only gives food to the cells of the body but also takes away waste materials, which are ultimately passed out of the body by means of the skin and kidneys.

LyMph Vessels. - The lymph is collected from the various tissues of the body by means of a number of very thin-walled tubes, which are at first very tiny, but after repeated connection with other tubes ultimately 
unite to form large ducts. These lymph ducts are provided, like the veins, with valves. The pressure of the blood within the blood vessels forces continually more plasma into the lymph; thus a slow current is maintained from the lymph spaces toward the veins. On its course the lymph passes through many collections of gland cells, the lymph glands. In these glands some impurities appear to be removed and colorless corpuscles made. The lymph ultimately passes into a large tube, the thoracic duct, which flows upward near the ventral side of the spinal column, and empties into the large subclavian vein in the left side of the neck. Another smaller lymph duct enters the right subelavian vein.

The Lacteals. - We have already found that part of the digested food (chiefly carbohydrates, peptones, salts, and water) is absorbed directly into the blood through the walls of the villi and carried to the liver. Some of the food, however, especially fats, makes its way into the spaces in the central part of the villi, and from there into other loose spaces between the tissues, known as the lacteals. The lacteals form the most direct course for the fats to reach the

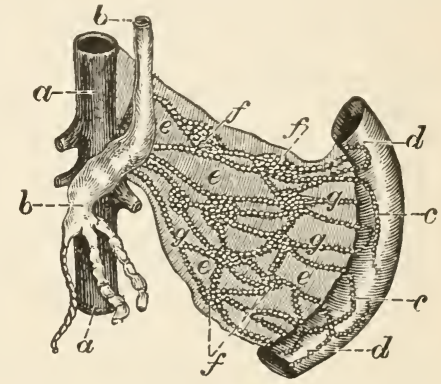

Lacteal system of mammal ; $a$, descending aorta, or principal artery; $b$, thoracic duct; $c$, origin of lacteal vessels; $g$, in the walls of the intestine, $d ; e$, mesentery, or membrane attaching the intestine to walls of the body; $f$, lacteal, or mesenteric, glands.

blood. The lacteals and lymph vessels have in part the same course. It will be thus seen that lymph at different parts of its course would have a very different composition.

The Nervous Control gf the Heart and Blood Vessels. - Although the muscles of the heart contract and relax without our being able to stop them or force them to go faster, yet in cases of sudden fright or after a sudden blow, the heart may stop beating for a short interval. This shows that the heart is under the control of the nervous system. Two sets of nerve fibers, both of which are connected with the central nervous system, pass to the heart. One set of fibers accelerates, the other slows or inhibits, the heart beat. The arteries and veins are also under the control of the sympathetic nervous system. This allows of a change in the diameter of the blood vessels. Thus, blushing is due to a sudden rush of blood to the surface of the body, caused by an expansion of the blood vessels at the surface. The blood vessels of the body are always full of blood. This results from an automatic regulation of the diameter of the blood tubes by a part of the nervous system called the vasomotor nerves. These.nerves act upon the muscles in the walls of the blood vessels. In this way, each vessel adapts itself to the amount of blood in it at a given time. After a hearty meal, 
a large supply of blood is needed in the walls of the stomach and intestines. At this time, the arteries going to this region are dilated so as to receive an extra supply. When the brain performs hard work, blood is supplied in the same manner to that region. Hence, one should not study or do mental work immediately after a hearty meal, for blood will be drawn away to the brain, leaving the digestive tract with an insufficient supply. Indigestion may follow as a result.

The Effect of Exercise on the Circulation. - It is a fact familiar to all that the heart beats more violently and quickly when we are doing hard work than when we are resting. Count your own pulse when sitting quietly, and then again after some brisk exercise in the gymnasium. Exercise in moderation is of undoubted value, because it sends the increased amount of blood to such parts of the body where increased oxidation has been taking place as the result of the exercise. Exercise also affects the diameter of the blood vessels because the sympathetic nervous system at this time causes the muscular walls of the arteries to relax. Exercise should not be attempted immediately after eating. This causes a withdrawal of blood from the walls of glands of the digestive tract to the muscles of the body.

Treatment of Cuts and Bruises. - Blood which oozes slowly from a cut will usually stop flowing by the natural means of the formation of a clot. A cut or bruise should, however, be washed in a weak solution of carbolic acid or some other antiseptic in order to prevent bacteria from obtaining a foothold on the exposed flesh. If blood, issuing from a wound, is bright red in color and gushes in distinct pulsations, then we know that an artery has been severed. To prevent the flow of blood, a tight bandage must be tied between the cut and the heart. A handkerchief with a knot placed over the artery may stop bleeding if the cut is on one of the limbs. If this does not serve, then insert a stick in the handkerchief and twist it so as to make the pressure around the limb still greater. Thus we may close the artery until the doctor is called, who may sew up the injured blood vessel.

The Effect of Alcohol on the Circulation. - Alcoholic drinks affect the very delicate adjustment of the nervous centers controlling the blood vessels and heart. Even very dilute alcohol acts upon the muscles of the tiny blood vessels, consequently, more blood is allowed to enter them, and, as the small vessels are usually near the surface of the body, the habitual redness seen in the face of hard drinkers is the ultimate result. 
"The first effect of diluted alcohol is to make the heart beat faster. This fills the small vessels near the surface. A feeling of warmth is produced which causes the drinker to feel that he was warmed by the drink. This feeling, however, soon passes away, and is succeeded by one of chilliness. The body temperature, at first raised by the rather rapid oxidation of the alcohol, is soon lowered by the increased radiation from the surface.

"Alcohol in the stomach is rapidly absorbed and passes into the blood stream. There the strong affinity of alcohol for oxygen, which leads them to enter very rapidly into chemical combination, causes the alcohol to appropriate the oxygen of the red corpuscles of the blood, which, as we have seen, are the great oxygen carriers in the body. This tends to impoverish the blood and render it less valuable to the tissues.

"The immediate stimulation to the heart's action soon passes away and, like other muscles, the muscles of the heart lose power and contract with less force after having been excited by alcohol."- MACY, Physiology.

Alcohol, when brought to act directly on heart muscle, lessens the force of the beat. It may even cause changes in the tissues, which eventually result in the breaking of the walls of a blood vessel or the plugging of a vessel with a blood clot. This condition may cause the disease known as apoplexy.

Effects of Tobacco upon the Circulation. - "The frequent use of cigars or cigarettes by the young seriously affects the quality of the blood. The red blood corpuscles are not fully developed and charged with their normal supply of life-giving oxygen. This causes paleness of the skin, often noticed in the face of the young smoker. Palpitation of the heart is also a common result, followed by permanent weakness, so that the whole system is enfeebled, and mental vigor is impaired as well as physical strength." MaCY, Physiology. 


\section{MUSCLES}

Muscles and Movement. - We are all aware that motion in any of the higher animals is caused by the action of the muscles. These contract and expand, thus giving the required amount of

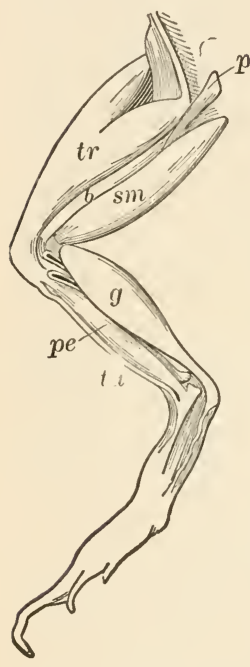

Muscles of the left leg of the frog; $b, \mathrm{M}$. biceps; $g$, M. gastrocnemius; $s m, \mathrm{MI}$. semimembranosus; $t r$, M. triceps. movement. In man and the other vertebrate animals the muscles are fastened to bones, which, acting as levers, give wide range of motion. Study of the muscles in the leg of a frog will help us to a better understanding of the subject.

Study of the Muscles of a Frog. - (Material preserved in 70 per cent alcohol or 4 per cent formol is best for this purpose.) Remove the skin from the leg of a frog by stripping it downward as you would take off a glove. Notice the yellowish-white muscles which form the "meat" of the frog's leg. Notice that they are more or less separated into bundles each of which tapers at the end. Look for dark-colored blood vessels and tiny white nerves which lead into the bundle of muscles. The wide part of the muscle is called the belly. The glistening white part which attaches the muscle to the bone is called the tendon. Notice the large muscle forming the calf of the leg (the gastrocnemius). Try to make out what movements are performed by means of this muscle. (Pull it and note the resulting movements.)

Arrangement of Voluntary Muscles in the Human Body. - Muscles are usually placed in pairs; one, called the extensor, serves to straighten the joint; the other, the flexor, bends the joint. Try to find examples of flexor and extensor muscles in the leg of the frog. Locate, by means of feeling the muscles when expanded and contracted, the extensors and flexors in your own arm. This paired arrangement of muscles is of obvious importance, a flexor muscle balancing the action of an extensor on the other side of the joint. The end of the muscle that has the wider movement in a contraction is called the insertion; the part that 
moves least is the origin. Muscles are named biceps or triceps (two-headed or three-headed, depending on the number of tendons found at the origin): the gastrocnemius, already referred to, is a biceps muscle; the large muscle forming the front part of the thigh is a triceps muscle.

Microscopic Structure of Voluntary Muscle. - With a sharp pair of seissors cut through the belly of a muscle at right angles to the long axis; examination will show that it is composed of a number of bundles of fibers. These fibers are held together by a sheath of connective tissue called the perimysium (Lat. $=$ around the muscle). Each of these bundles may be separated into smaller ones. If we continue this so as to separate into the smallest possible bits that can be seen with the naked eye, and then examine such a tiny portion under the compound microscope, it will present some-

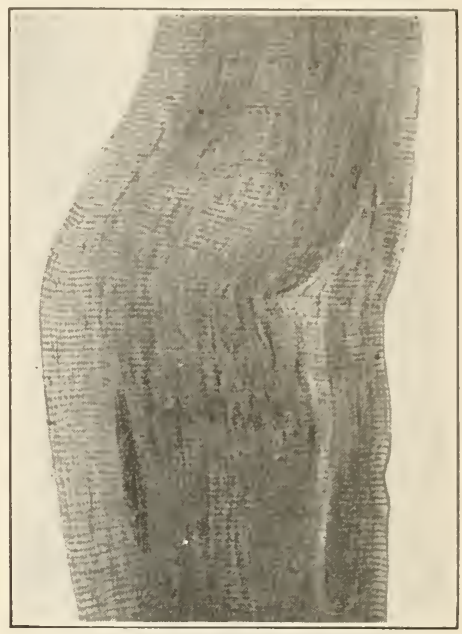

A bit of voluntary muscle fiber, showing the cross striations as seen under the microscope.

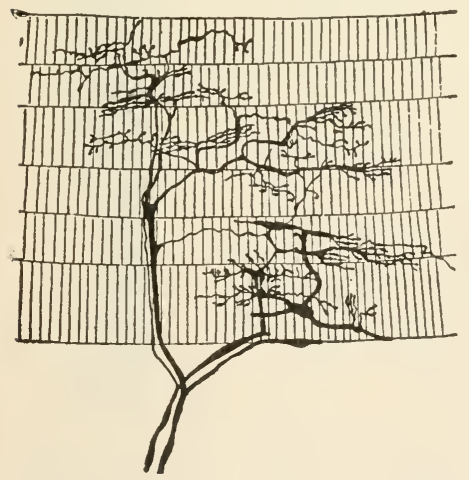

Motor nerve endings in striated muscle fibers as seen under the microscope.

what the appearance of the figure. The muscle is seen to be made up of a number of tiny threads which lie side by side, held together by the perimysium. Each thread consists of several muscle fibers, each of which is inclosed in a tiny sheath. A single fiber under the compound microscope appears to have alternate light and dark bands rumning at right angles to its long axis. This gives the bundle of fibers a striped appearance. Nuclei are seen here and there, showing that the muscle is made up of cells. Such is the structure of muscle fibers which are under the control of the will, the roluntary muscles as they are called. If it were possible to prepare muscle fibers in such a manner as to trace the path of the nerves in these fibers, such nerves would be seen to end in little 


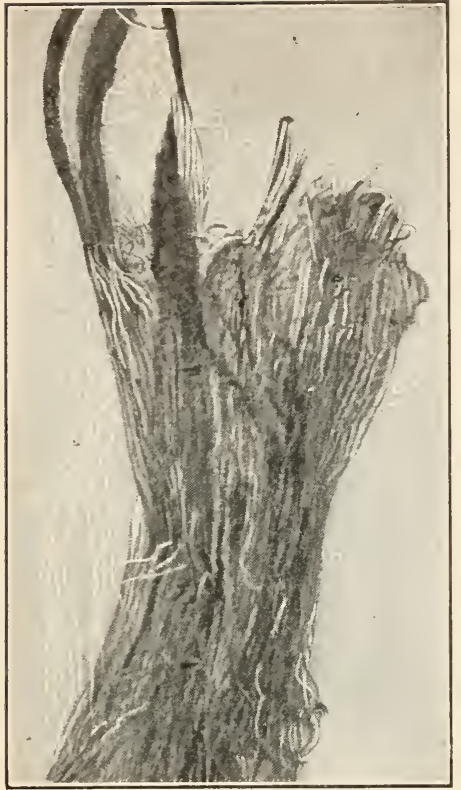

A bundle of involuntary muscle fibers, as seen under the microscope.

knobs or plates on the muscle cells; thus, the action of every muscle fiber, perhaps every cell, is under the control of the nervous system.

Structure of Involuntary MusCLE. - Muscles in which the movement is not controlled by the will are called involuntary. The most apparent difference between voluntary and involuntary muscle fibers (such as those found in the wall of the stomach and intestines of man) is that the latter do not show the cross striation characteristic of the former. The involuntary fibers are supplied with blood vessels and nerves. The latter, however, come from what is known as the sympathetic nervous system. Of this we shall learn more later. Fibers from the sympathetic system go to most organs in the body cavity of man - the heart, the food tube and different glands connected with it; and to the muscles of the blood vessels. The act of breathing and the heart-beat are examples of an automatic muscular action where nervous control comes largely from the sympathetic system. The churning movements of the stomach and intestines are examples of muscular action entirely beyond control of the will.

Structure of Heart Muscle. - Heart muscle differs slightly in appearance from both voluntary and involuntary muscle fibers. The cross striation is seen here as in voluntary muscle. The outline of the individual cells can be made out in heart muscle. (See diagram.)

Rate of Muscular Contraction. - A wave of muscular contraction moves rather slowly in an involuntary muscle; a little more rapidly in heart muscle; and most rapidly of all in voluntary muscle fibers.

Muscle Tissue and its Uses. - As we have seen in the frog, muscles evidently form a large part of

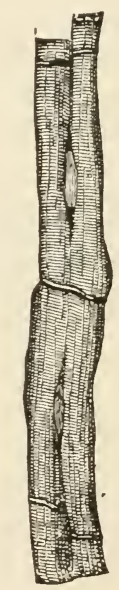

Striated muscular fibers, from the heart of man, divided by transverse septa into separate nucleated portions, much magnified 
the body. In man, nearly half the body weight is muscle. Nearly every muscle in the human body is attached to a bone either at one or at both ends. Movement is performed by means of the muscles, leverage being obtained by means of their attachment to the bones. Movement is, indeed, the chief function of muscles. In the human body there are over five hundred muscles, varying from the size of a pinhead to a band almost two feet in length. Every movement of the body, be it merely a change of expression or change in the pitch of the voice, directly results from contraction or expansion of a muscle. Nuscles also give form to the body, and are useful in protecting the delicate organs and large blood vessels within them.

Standing. - Certain muscles of the body attached to bones are used in standing. These are muscles of the legs, trunk, and neck. Certain joints must be kept rigid by the pull of flexor and extensor muscles attached to them; coöperation of muscles with the central nervous system, especially the balancing organ in the ear, must also be had.

WaLKing and RUNNing. - Walking is more difficult than standing. Two sets of muscles are always used, one set being extended while the other set is contracted. Walking may be considered as a series of falls in a forward direction, equilibrium being maintained by putting forward one foot; the swinging motion of the arms and swaying of the body aids in keeping this equilibrium. Running differs from walking in the fact that, when walking, one foot is always on the ground, while in running, a brief period exists when both feet are off the ground.

Work done by Muscles. - The heart is an excellent example of an organ which does muscular work. The constant pulsation of the heart during one day releases energy sufficient to raise one pound 434,112

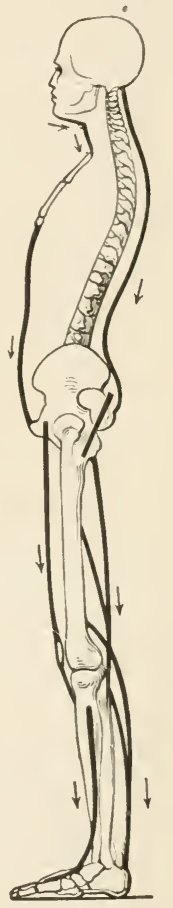

Diagram of some of the muscles which tend to keep the body erect. feet from the earth's surface. During this period the heart is estimated to rest about one third of the time between the pulsations. Thus, it is evident that muscles may liberate a vast amount of energy; in order to do this, food material, which is brought by the blood to the muscles, must be oxidized. As we 
have seen in the frog, muscles are well supplied with blood vessels: under the compound microscope, these blood vessels are observed to break up into tiny capillaries so that the fibers are literally bathed in blood and lymph. The protoplasm of the muscles takes up oxygen from the blood; this oxygen unites with the material of which the muscle is formed or with food which is brought there by the blood; as a result of the oxidation, carbon dioxide is given up and carried off by the lymph; nitrogenous wastes (such as urea) are also removed in the lymph.

How Bodily Heat is Produced. - When coal is burned, heat is given off; this heat is a form of energy. Food and tissues, when oxidized, also give off heat. When muscles are exercised, oxidation takes place more rapidly, and more heat is thus produced. From one sixth to one third of the energy produced by oxidation of muscles results in work; two thirds to five sixths of it is given off in the form of heat. It is evident that the high body temperature is thus directly due to the oxidation of foods or tissues. The heat thus produced in muscles is largely dissipated to other parts of the body by means of the blood.

When an extra amount of heat is released in the body, the blood is allowed to go to the skin, and heat is there set free: An increased amount of blood sent to the skin favors perspiration by increasing the rate of evaporation; this leads to an increased loss of heat from the body.

Necessity of Food and Fresh Air for Muscles. - From the facts given above, it is evident that muscles need food and a supply of oxygen in order to perform their work. Muscle, although a large per cent is made up of water, contains proteid as its principal solid ingredient. (This may be proved by testing a bit of frog muscle with nitric acid and ammonia.) In order to build up new muscle to replace the cells which are worn out or used up, proteid food is a necessity. Sugars, which are energy-releasing foods, can be utilized in moderate amounts.

Fresh air is a necessity because all muscular energy is released as a result of oxidation. In order to perform muscular work, fresh air containing a large per cent of oxygen is necessary. It is essential to the health of every one, even a sedentary person, that a 
good supply of oxygen be provided, especially during the rest periods at night; this is the time that much of the carbon dioxide formed in the tissues during the day, when hard work is done, is eliminated.

Rest and Exercise. - It has been discovered that the feeling of muscular fatigue, the feeling of utter weariness which one often has after prolonged muscular exertion, is probably due to the presence of waste matters in the muscle and blood. These wastes are chiefly the products of oxidation, - carbon dioxide and urea.

Exercise in moderation is directly a benefit to the muscle. Each time a muscle does work, part of it is oxidized. The very process of oxidation gives the muscle an opportunity to assimilate new proteid food; this results directly in the building of new muscle cells or the repairing of the wasted ones.

The amount and kind of exercise taken depends largely on the situation of the individual. A strong girl or boy, brought up in the country with fresh air in abundance, and an opportunity to do manual labor out of doors, has great advantage over a city child. Exercise in a gymnasium is not nearly of so much benefit as outof-door work and play; this is because the supply of oxygen, even in the best-ventilated room, may soon be at least partially used up and carbon dioxide take its place in the air. The best results are obtained by working the greatest number of muscles during a given period of time.

When we become moderately warm, after exercise, a tepid bath followed by a cold plunge and a rub down brings the blood to the surface of the body; a feeling of warmth then results after the sudden cooling of the skin by the cold water.

The Relation of Alcohol to Muscular Work. - Records, compiled from a number of reliable sources, seem to show that alcohol has a very decided effect upon the ability of a man to perform muscular work. Not only does it affect the man as to the amount of work, but as to the quality of the work that can be performed in a given period of time. The following extracts show plainly the relation of alcohol, even in moderate quantities, to the capacity for muscular work and to the performance of work that requires great accuracy and training of the eye and muscles. 
Experiments have been made, both in the British and American armies, testing the ability of soldiers to make long, forced marches, some regiments having been supplied with a liquor ration and others without it.

"There are experiments which show that men may do an increased amount of work for a very short time under the influence of alcohol; but such increase is accomplished, as the above experiments show, only at the expense of energy or tissue which is needed for bearing sustained labor or exposure. Thus, in some experiments upon British regiments, the regiment which had liquor took the lead at the start, but was far behind at the finish." Hewes, High School Physiology.

"The sirdar, Sir Herbert Kitchener, and General Gatacre, in their advances up the Nile, have strictly forbidden the supply of alcoholic liquors to any of the troops under their command. We learn that they took this step on two grounds. First, on the ground that from long experience they were convinced that the physical condition of the troops would, under these conditions, be enormously improved, and the men would have much greater staying power, while their dash, determination, and steadiness would also be increased. The second ground appears to have been that the mental and moral stamina of the troops would be preserved in a far greater degree than could possibly be the case if alcohol were served out. The result has been that the health, spirits, and conduct of the troops have been the admiration of all those who have had any dealings with them, and this experiment on a large scale has been an unqualified success." J. Sims Woodhead, M.D., Professor of Pathology in the University of Cambridge, England.

"The attention of the civilized world has been called to the conspicuous fact of the accuracy of the firing of the gunners on our battle ships in the recent war with Spain. The contrast between the firing of the men of our navy and that of Spain was due in part, no doubt, to the custom that prevails on the ships of the latter, where daily rations of grog are given at all times, and when an action is going on or anticipated, double rations of grog are furnished to the men; while since 1862, when that custom was 
abolished by our government, no rations of liquor are allowed at any time on board our ships." - Hewes, High School Physiology. "The custom just alluded to as followed by Spain is true of all the navies of the world but ours. Yet Great Britain has abandoned the double rations of grog when a fight is on, and then no liquor is allowed; but in place of it supplies of water and oatmeal are arranged all over the ship to satisfy the thirst resulting from the heat, exertion, and smoke inseparable from a naval combat." - The Journal of the American Medical Association, January, 1899, p. 174.

It is a well-known fact that all athletes who go into training for any events give up, for the time at least, all alcoholic drinks and tobacco.

It is said that a desire to excel in athletic sport has led clubs of students at some of the German universities to give up their " morning drinking bout." They have learned that beer drinking stands in the way of their best physical development and the highest degree of athletic success. "For years sports have been in great favor. Some of these, such as contests between boatmen or between cyclists, require considerable energy and power of endurance. Evidently, if alcohol increased strength, these competitors would provide themselves with it and use it freely. But this is not the case. No true sportsman, either before or during the contest, touches a glass of spirits, experience having taught the harm he would thereby do himself." - DE Bienfait, of Liège.

Effect of Alcohol and Other Stimulants and Narcotics upon Muscular Action. - "The most serious effects of the excessive use of alcoholic drinks, tobacco, opium, chloral, and other narcotic drugs are felt by the nervous system and will be most fully treated when we come to the special study of that part of the human organism. But it is well to notice here how those substances influence the organs of motion.

"No one who has ever seen a drunken man in the stage preceding that of stupor can have failed to observe the uncertainty of his muscular movements: the shaking hand, the staggering gait, the thick, indistinct utterance. These effects are due to what is called the excessive use of alcoholic drinks, and no one HUNTER'S BIOL. -24 
doubts that in large quantities they act injuriously upon the system. Alcohol deranges the action of the muscles by its influence upon the nervous system, causing defective regulation of the supply of nervous force to the several muscles. As to whether it is possible to use alcohol in small amounts without impairing the perfection and vigor of muscular action, there is one very significant fact: that men in training for severe muscular exertion in athletic contests are strictly forbidden the use of alcohol in any form and in any quantity, whether or not they have been previously accustomed to such indulgence. As the rules for such training are the result of long and wide experience and most careful study, it is safe to conclude that alcohol at least does not promote strength, endurance, or precision of muscular movement." - Macr, Physiology.

Effect of Tobacco on Muscles. - The stunting effect of tobacco on the growth and development of the muscles is well known. Every teacher of gymnastics knows this; hence tobacco is not allowed to the athlete. Another reason why the man in training is not allowed tobacco, is because of its paralyzing effect upon the nerve cells controlling the movement of muscles, this diminishing or inhibiting the nervous energy which a man uses in the exercise of his muscles.

"Tobacco and other narcotics also affect muscular activity through their effect upon the nerves. All narcotics have as their natural, characteristic influence the paralyzing of some of the nerve centers. As medicines they may give relief from pain and so act beneficently under skillful application. Tobacco has a special effect upon the nerve centers regulating the action of the muscles of the heart, making that action irregular and less vigorous. This is particularly true of the young, and it is not very uncommon for boys addicted to excessive cigarette smoking to develop serious disease of the heart, or even to die suddenly from 'heart failure." - MACY, Physiology. 


\section{THE SKELETON}

General Structure and Uses of the Skeleton. - First, bones form a framework to which muscles are attached; thus they are used as levers for purposes of movement. Second, they give protection to delicate organs; they form a case around the brain, and spinal cord; as ribs they protect the organs in the body cavity. Third, they give rigidity and form to the body.

Laboratory Work on the Skeleton of a Frog; Comparison with the Skeleton of Man. - For this purpose, clean skeletons of the frog (these may be prepared by careful students) and a prepared skeleton of man may be used. This exercise may be made of increased value by using skeletons of several different vertebrates, for example, a bony fish, frog, snake, bird, dog or cat, and

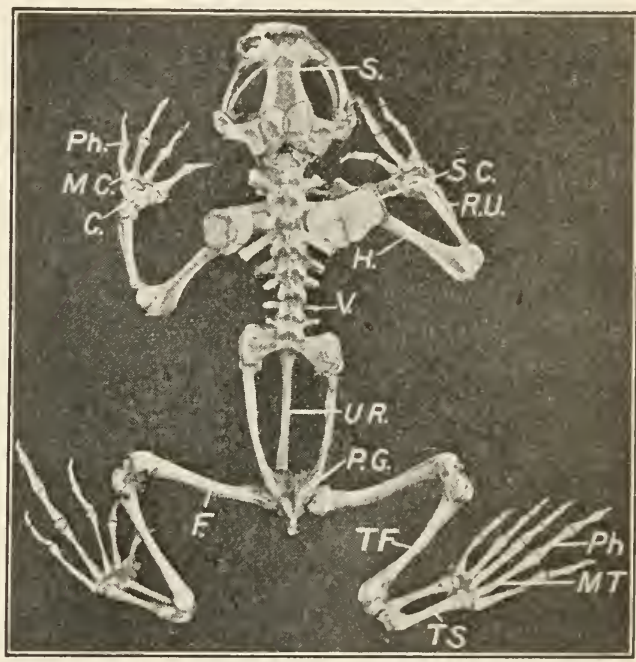

Skeleton of the frog; S., skull; $S C$., scapula; $R . U$., radio ulna; $H$., humerus; $P h$. , phalanges ; $M C$., metacarpals; $C$., carpals; $V$., vertebral column; UR., urostyle; P.G., pelvic girdle; $F$., femur; $T F$., tibia and fibula; $T S$., tarsals; $M T$., metatarsals. man. The different regions may be identified and homologies and analogies drawn between different bones and organs in the various skeletons.

The skeleton of vertebrate animals consists of two distinct regions: a vertebral column or backbone which, with the skull, forms the axial skeleton; and the parts attached to this main axis, the appendicular skeleton (the appendages). All skeletons of vertebrates have the same general regions, the size and shape of the bones in these regions differing somewhat in each kind of animal.

In the axial skeleton of the frog, as well as in man, the vertebral column is made up of a number of bones of irregular shape, which fit more or less closely into each other. These bones are called vertebra. Notice that the 


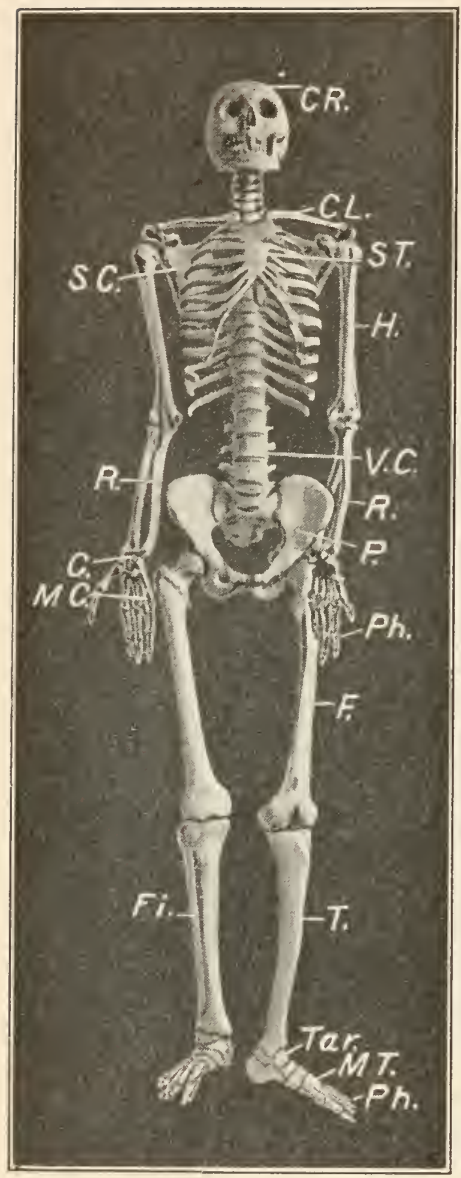

Skeleton of man; $C R$., cranium; $C L$., clavicle; $S T$., sternum; $S C$., scapula; $H$., humerus; V.C., vertebral column; $R$., radius and ulna; $P$., pelvic girdle; $C$., carpals; $M C$., metacarpals; $P h$., phalanges; $F$., femur; $F i$., fibula; $T$. tibia; Tar., tarsals; $M T$., metatarsals. vertebræ possess long processes to which muscles of the back are attached. Compare the vertebral column of the frog and man in the following respects : Is there a distinct neck region? Are ribs present? Are the ribs attached to the vertebræ? How many vertebræ in man bear ribs? In man a flat bone to which certain of the ribs are attached is found on the ventral midline of the skeleton. This bone, called the sternum, is so small in the frog that you will not be able to see it. Are all the ribs in man attached to the breastbone or sternum? How many ribs are free from the breastbone? Notice, in the frog, the peculiar long bone at the posterior end of the spinal column; this bone is called the urostyle. No homologous bone is found in man. Look at the vertebral column of man; notice that it is shaped somewhat like the letter S. The bodies of the vertebræ, piled one upon the other, form a column of enough strength to support the whole body. The double curve of the vertebral column combines elasticity with strength.

Structure of a Vertebra in Man.Observe a single vertebra of man; it will be found, in a general way, to consist of two regions, a solid rounded portion called the centrum or body, and a bony arch from which are given off the processes referred to above. Within this arch (called the neural arch) is found the spinal column or nerve cord. Thus, the vertebræ form a wonderful protection for this most delicate of all organs; and, with the bony covering of the skull, protect the central nervous system.

\section{Adaptations in the Vertebral} Column. - The vertebral column in man is made up of many separate pieces of bone: thirty-three in a child; twenty-six in the adult, several bones in the region of the pelvis later growing together. Each vertebra presents the general form of a body or centrum of bone and a bony arch with seven projections; in this arch runs 
the spinal cord. The surface of the centrum and those parts of the vertebræ each of which fits into its next neighbor are covered with pads of cartilage. Two of the processes in each vertebra project forward and two backward; these form articulations or joints with the neighboring vertebræ. Of the other processes, one projects dorsally and two project laterally; these give attachment to the muscles of the back. The two vertebræ directly beneath the head are modified so as to permit the skull to rest in the upper one; this articulates freely with the second vertebra, thus permitting of the nodding and turning movements of the head. Besides these individual adaptations, the vertebral column, as a whole, is peculiarly adapted to protect the brain from jar; this is seen in the double bend of the vertebral column and the pads of cartilage between the individual vertebræ. The whole column of vertebræ joined each to the other supports the weight of the body. The largest vertebræ at the base are joined to the huge pelvic bones for the better support of the body above. That part of the

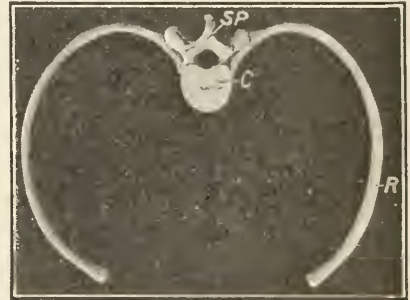

Vertebra, showing attachment of ribs; $C$., centrum; $R$., ribs; $S P$. spinous process.

vertebral column of man which bears the ribs is known as the thoracic region. The ribs, twelve in number, are long bones which combine lightness with strength; joined by elastic cartilage to the sternum in front and to the vertebræ behind, they form a wonderful protection to the organs in the thoracic cavity and yet allow free movement in breathing. That part of the skeleton to which the bones of the anterior and posterior appendages are attached are respectively known as the pectoral girdle (from which hangs the arm) and the pelvic girdle (which joins the leg bones to the axial skeleton).

The Appendages. - The bones of the appendages attached to the pectoral and pelvic girdles are adapted peculiarly to locomotion and support; for this purpose the bones are long and strong, hinged by very flexible joints. The latter are especially free in the hand to allow for grasping. In the leg, where weight must be 
supported as well as carried, the bones are bound more firmly to the axial skeleton. The bones of the foot are so arranged that a springy arch is formed which aids greatly in locomotion.

Pelvic Girdle and Leg. Laboratory Exercise.-The lower end of the vertebral column in man, as in the frog, is united with a number of broad bones which together form the pelvic girdle. Notice the difference in the shape and position of the pelvic girdle in the frog and in man. In man, the pelvic bones support the organs of the body cavity; this is a peculiar adaptation to the upright position of man. Compare the bones of the hind leg of the frog with those of the human skeleton. Beginning with the large bones next the pelvic girdle, these bones are: the thigh bone, or femur; the shank bones, or tibia and fibula (the tibia and fibula are united into one bone in the frog; the tibia is the larger bone in man; it is on the side of the big toe); the ankle bones, or tarsals; foot bones, or metatarsals; and the bones of the toe, phalanges, so-called from the arrangement which is somewhat like a Greek phalanx of soldiers. Compare the relative size, shape, and number of the bones of the foot and ankle in the frog and in man. Can you explain the differences which occur as an adaptation to the life which the animal leads?

Bones of the Pectoral Girdle and Arm. - Compare the attachment of the fore limb of the frog with that of man. The bones which attach the fore limb to the axial skeleton collectively form the pectoral girdle. Find in the frog the flat shoulder blade (not quite homologous with the shoulder blade or scapula of man). The collar bone or clavicle is not plainly seen in the frog; note its position in the human skeleton. (See page 372.) Now compare the bones of the fore limb of a frog and in man. The large stout bone of the upper arm is the humerus; the two bones of the forearm (united in the frog) are the ulna and radius; the latter is on the thumb side of the arm. The bones of the wrist are known as carpals; those of the palm of the hand, metacarpals; those of the fingers, the phalanges.

Notice how the fore limb of a frog is shortened. The thumb is almost completely lost. Is this an adaptation to the frog's mode of life? Give reasons.

Comparison of the Skull of the Frog with that of Man. - Notice the difference in the general shape of the head and the lack of a neck in the frog. In man, two groups of bones make up the skull, the bones of the face and those of the brain case or cranium. In the frog, this distinction is not so easily seen. Notice the upper and lower jawbones in man. Do they bear teeth? Do you find corresponding bones that bear teeth in the frog? Are both jaws moved in talking or chewing? Notice how much larger, relatively, the cranium in man is than that of the frog. Notice in man that the bones of the cranium are dovetailed together, such joints being known as sutures.

The Human Skull. - In man, the cranium is a box made up of eight bones. This is adapted to protect the delicate brain. Of the eight bones, four are paired: the two parietals, which form a large part of the crown of the head, and the temporals, which inclose the ear cavities. Of the four single bones, two are easily found; the frontal, forming the forehead and upper part of the eye sockets, and the occipital, covering the base of the brain. In the occipital bone is a large opening, through which, in life, the spinal cord 
passes. Part of the base of the cranium is formed by the sphenotd and ethmoid bones. Part of the former bone extends upward between the frontal and temporal bones. The skull shows wonderful adaptations for its varied functions. The brain case is compactly built, its arched roof giving strength. The eye and inner ear are protected in sockets of bone. The lower jaw works upon a hinge, and furnishes attachment for strong muscles which move the jaw. Try to add other adaptations to this list.

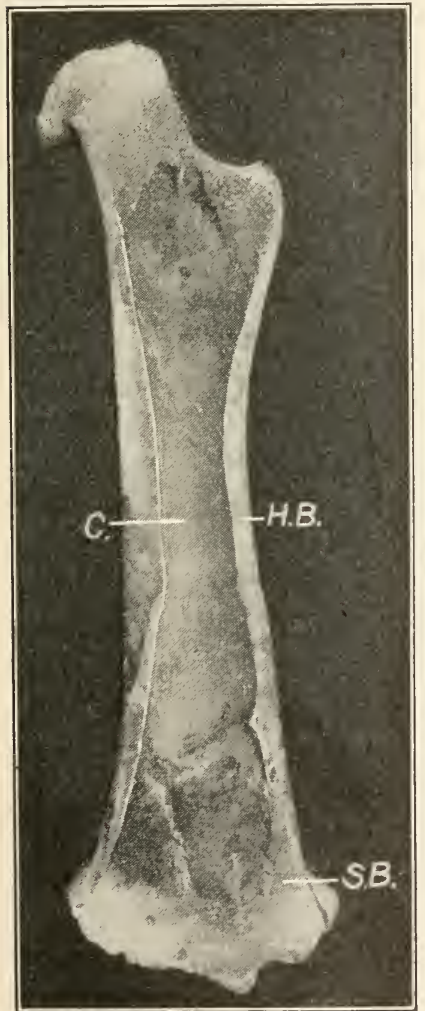

Long bone; $C$., internal cavity; H.B., hard bone; S.B., spongy bone.

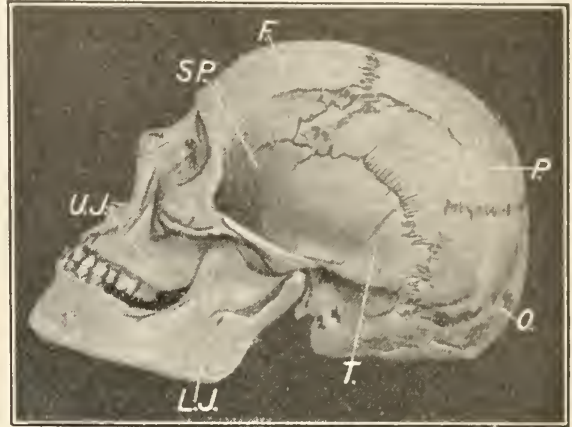

The skull; $F$., frontal bone; $P$., parietal bone; $T$., temporal bone ; $S P$., sphenoid bone; $O$., occipital bone; U.J., superior maxillary (upper jaw) bone ; L.J., inferior maxillary (lower jaw) bone.

Internal Structure of a Long Bone. Laboratory Exercise. - A better understanding may be gained of the internal structure of the long bone from observations made, for example, on a long leg bone of a sheep (obtained fresh from the butcher). In such a bone, notice the rounded ends; these are covered during life by a layer of gristle (cartilage). Notice also the roughened projections (called processes) which serve for the attachment of muscles. What parts of the bone are provided with such projections? In a bone cut lengthwise, notice that the outer surface is covered with a thin layer of connective tissue; this is called the periosteum. The periostcum permits of the entrance into the bone of blood ressels and nerves. It also forms bone from its inner surface. In cases of injury, the bone inside the periosteum may be removed by a surgeon. New bony tissue will then be rebuilt by the periosteum. Notice also the difference between the end of the bone and the middle part or shaft. The entire outer layer is compact; the inner, spongy in structure. Where is the most compact mass of the bone? The 
most spongy area? Find the marrow which partially fills the central cavity. What is its color? Blood vessels and nerves pass into the marrow through small openings in the compact bone. Try to find a rather large opening (near one end) through which the artery passes into the bone. Draw in your notebook a bone cut lengthwise, and label all the parts in the drawing.

A long bone of the human body shows the same general characteristics as above described. The surface of the bone is covered with periosteum or connective tissue. Under the periosteum is found a layer of hard, compact bone. This covers a layer of spongy bony tissue under the heads or ends of the bone. The ends of the bone are covered with pads of cartilage. The internal cavity is filled with yellow marrow, the cells of which contain considerable fat.

Home Experiment. - Rub some marrow on a piece of paper. Hold the paper to the light. What substance is present?

Structure of a Flat Bone. Laboratory Exercise. - Compare the long bone with a flat one, for example, a rib. The following differences in structure will be noted. The outer wall is hard bone as in the leg bone. The entire interior, however, is made up of spongy tissue, its spaces being more or less completely filled with red marrow. We thus find that in all long bones, where strength must be combined with lightness, the bone is hollow. For example, in birds, most of the large bones contain air spaces; the weight of the bird is thus decreased, a peculiar adaptation for flight. In a flat bone, lightness and strength are obtained by having a layer of solid bone outside the soft spongy material.

Substances present in Bone. Home Experiment. - Burn a bone in a hot fire. This removes the animal material. Now test with hydrochloric acid. What happens? Leave another bone for several days in 10 to 20 per cent hydrochloric acid solution. The mineral matter is thus removed. After the bone has been taken from the acid, it may be bent or twisted into knots without breaking.

The bone-making cells make bony tissue largely from lime. This is easily shown by the above experiments. Some other mineral matters are left behind after testing for lime, common table salt and silica being the most abundant. These materials are, of course, taken into the body with food.

Growth of the Skeleton. - In some of the lower animals studied, for example the limy sponge, we found certain cells of the animal take up lime from the water or food taken into the body and lay this down as a secretion in the form of spicules. In somewhat the same manner certain cells undertake the work of skeleton formation in man. Water, milk, and other foods furnish the mineral matter necessary. The result is that the skeleton grows 
continually, both from the inside and the outside surface of bone. Early in life, when the skeleton grows rapidly, the living part of bone exceeds the mineral matter in it. Bones of young people are frequently quite soft and flexible. Very early in life, almost all bones are formed of a tissue called cartilage.

Microscopic Structure of Bone.-Gristle, the common name for cartilage, is seen under the microscope to be made up of living cells surrounded by a clear, tough material, the latter formed by the action of the cells embedded in it. Formation of bone takes place in much the same way. In a piece of bone examined under the microscope are found hundreds of little irregular spaces. From these spaces radiate many tiny canals. These spaces, during the life of the animal, were occupied by bone-forming cells, irregular processes from which passed out into the canals. Later, limy mat-

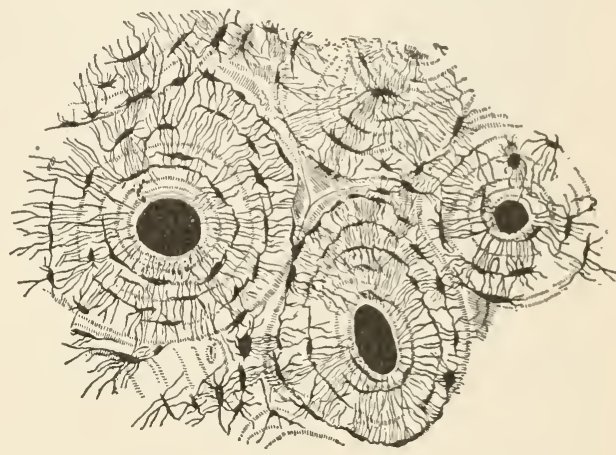

Bone, as seen under the microscope. ter was deposited around certain of the cells. Thus true bone was formed.

Hygiene of the Skeleton; Differences ix Structure of the Skeleton of a Child and AN Adult. - During childhood, because of the small amount of mineral matter and consequent lack of rigidity in bone, we must exercise some care in the treatment of the skeleton. A round-shouldered condition, brought on by sitting in an incorrect position, may cause a prominent deformity of the skeleton. Children are frequently allowed to walk before the leg bones are capable of supporting the weight of the body, thus causing bow-leggedness. Seats at school which force a child to take an incorrect attitude when at rest are frequently the means of permanently deforming the vertebral column. Later in life, when the activity of the bone-forming cells ceases, more mineral matter is present than animal matter. A broken bone is thus much more serious at this time than in a young person.

\section{JoINTS}

Movement in the Hind Leg of the Frog. - In the hind leg of the frog previously studied, cut through the muscles of the thigh to the bone; make out exactly how and where the muscles of the thigh are attached to the 
bone; move the leg in as many different directions as possible; notice that it may be flexed or bent; that it may be extended to its original position; that it may be rotated; that it may be moved to and from the midline of the body; that, with the knee held stiff, the whole limb may be made to describe the arc of a circle.

These same movements are possible in the leg of a man. This movement between bones is obtained by means of joints. If, in the frog, we care-

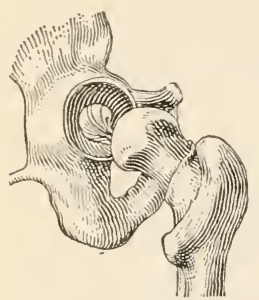

Ball and socket joint. fully separate the muscles of the thigh to the bone, we find that they are attached to the bone by white, glistening tendons. Careful examination shows that the bones themselves are held together by very tough white bands or cords; these are the ligaments. We find, too, that one end of the large thigh bone fits into a socket in the hip bone or pelvic arch. It is thus easy to see how such free movement is obtained in the leg.

Ball and Socket Joint. - Such a joint as just described is called a ball and socket joint. In man the movement of the leg is obtained in exactly the way described for the hind leg of the frog. The two best examples of a ball and socket joint are found between the long bone in the arm and the shoulder, and between the bones of the hip and the long bone of the leg.

Hinge Joints. - The second kind of joint, in the leg of the frog, is found between the thigh and the shank. Notice that movement here occurs freely in only two directions, backward and forward; hence this is called a hinge joint. In man the best examples of a hinge joint are found in the knee and elbow; others are in the fingers and toes.

Gliding JoInts. - Another form of joint, best seen in the skeleton of man, is a sliding or gliding joint. Here the range of movement is slight. Gliding joints are found between the vertebræ or bones of the vertebral column (backbone).

Pivot Joints. - Another rather unusual joint is the pivot joint. This is best seen between the skull of man and the topmost bone of the vertebral column. The skull is held in place by means of two small knobs which project downward and rest in cavities in the bone directly beneath them.

Levers in the Body. - It is evident that movement of a joint is caused by muscles which act in coöperation with the bones to which they are attached; the latter

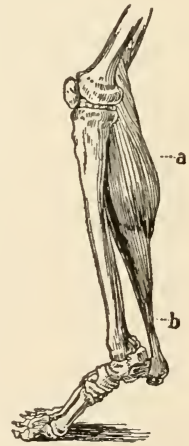

Hinge joint, showing muscle $(a)$ and its $t \in n d o n$ (b). form true levers. A lever is a structure by which either greater work power or greater range of motion is obtained. In this apparatus, the lever works 
against a fixed point, the fulcrum, in order to raise a certain weight. A seesaw is a lever; here the fulcrum is in the middle, the weight is at one end, and the power to lift the weight is applied at the other end. There are three classes of levers, named according to the position of the fulcrum.

In the first class, the fulcrum lies between the weight and the power; the seesaw is an example of this. The best example in the human body, of a lever of the first class, is seen when the head nods. Here the fulcrum is the vertebra known as the atlas; the power is the muscles of the neck attached to the back of the skull and to the spine; the weight is the front part of the head. When one keeps the head erect, this lever is used; the nodding head when one is sleeping shows this plainly.

A lever of the second class has the fulcrum at one end, and the weight between it and the power; when we rise on our toes, we use this kind of lever. Try to explain this by referring to a skeleton of a frog or of man.

In a lever of the third class, the fulcrum is at one end, with the power between it and the weight. This is the kind of lever seen most frequently in the human body. The flexing (drawing up) of the lower leg or the forearm is an example of the use of this kind of lever. In such a lever, a wide range of movement is obtained.

Sprains. - A sudden strain or twisting in the region of a joint may result in the pulling out or tearing of the ligaments or tendons of that joint. Such an injury may be recognized by the sudden swelling in that region, followed by great pain. A cure of the sprain is effected only by nature's own remedy, complete rest. For immediate relief hot water applications, followed by arnica or some liniment, are best; a tight bandage should be applied at once and a doctor called as soon as possible.

Dislocations. - The bones of a joint may be accidentally forced apart. Such a separation is called a dislocation and is known by the intense pain which follows any attempt to move the joint. There is often considerable swelling of the affected part; the bone may even protrude. A physician should be called at once so that the bone may be slipped into place again. Hot or cold water applied to the joint and rest in a comfortable position should be given until the doctor comes.

Fractures. - A break or fracture usually occurs in one of the long bones of the body. The clavicle or collar bone (easily felt in the front part of the shoulder below the neck), because of its exposed position, is most frequently broken. The immediate treatment for fracture is rest in a comfortable position; cold water applications may relieve the pain. Send for a doctor at once. To heal a fracture, it is necessary to bring the two broken ends of the bone together, and hold them so that they will grow together or knit; for this purpose splints are often employed. 


\section{RESPIRATION}

Necessity for Respiration. - We have seen that plants and animals need oxygen in order that the life processes may go on. Food is oxidized to release energy, just as coal is burned to give heat to run an engine. As a draft of air is required to make a fire under the boiler, so, in the human body, oxygen must be given so that

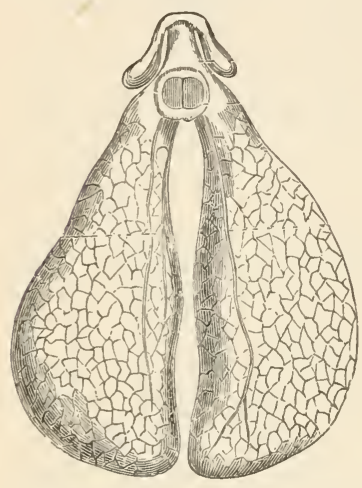

Lungs of a frog; baglike extensions of the windpipe. foods or tissues may be oxidized to release energy used in growth. Blood, in its circulation to all parts of the body, is the medium which conveys the oxygen to that place in the body where it will be used. But where does the blood get this supply of oxygen? We have alluded, in Circulation, to the fact that the lungs are the organs which give oxygen to the blood and take from it carbon dioxide. Let us examine the organs used by the frog in breathing, and see if this matter becomes any plainer.

Study of the Organs of Respiration in the Frog; Comparison with Man. Notice the pumping movement in the throat as a frog breathes. The frog swallows air. Does this method differ from breathing in man? How and where are the nostril holes (nares) placed? How is this of advantage to the animal? Do you notice any movement of the nares in breathing? Use a preserved frog for the following exercise: Open the mouth of the frog, and find the openings in the roof of the mouth, leading from the anterior nares. Find a vertical slit in the floor of the throat. This is the glottis or opening to the windpipe. If the muscles be carefully removed from the ventral surface of the body just beneath the arms, and a careful incision made, the windpipe may be seen. Notice that it branches into two smaller tubes, each of which leads to a lung. These tubes are the bronchi. The lungs are two spongy bags, the walls of which are filled with tiny blood vessels. Inflate the lungs by inserting a blowpipe in the glottis and blowing into it. Are the lungs elastic?

The Organs of Respiration in Man. - The course of air passing from the outside of the lungs in man is much the same as in the 
frog. Air passes through the nares, the glottis, and into the windpipe. This cartilaginous tube, the top of which may easily be felt as the Adam's apple of the throat, divides into two bronchi. The bronchi within the lungs break up into a great number of smaller tubes, the bronchial tubes, which divide somewhat like the small branches of a tree. This branching increases the surface of the air tubes within the lungs. The bronchial tubes, indeed all the air passages, are lined with ciliated cells. The cilia of these cells are constantly in motion, beat-

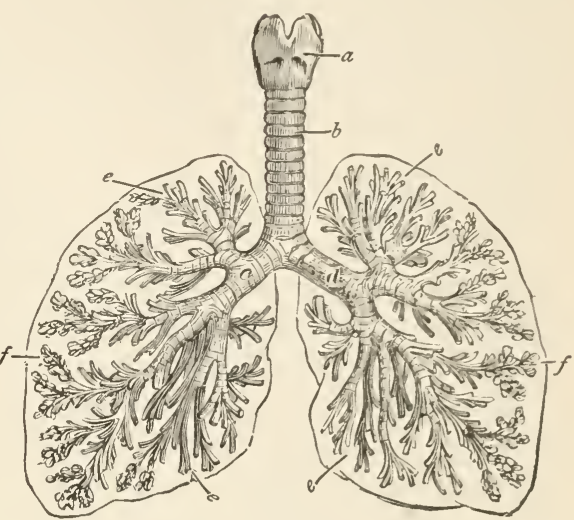

Air passages in the human lungs; $a$, larynx; $b$, traehea (or windpipe); $c, d$, bronchi; $e$, bronchial tubes; $f$, eluster of air cells. ing with a quick stroke toward the outer end of the tube, that is,

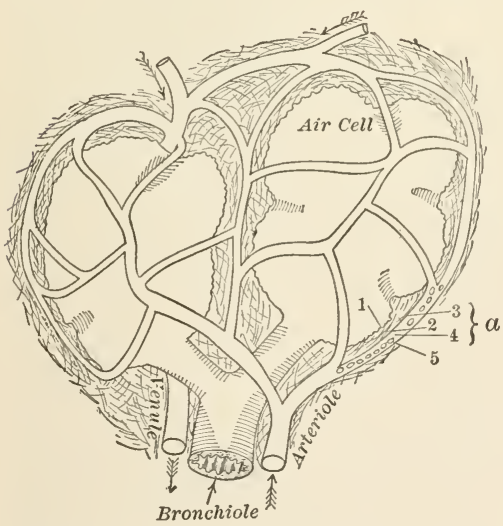

Diagram of two air cells, showing the capillary network which covers them, and at $a$ the structures which intervene between the air and the blood are indicated; 1 , mucous membrane of the air cell; 2, submucous meshwork; 3, wall of capillary: 4, plasma in capillary; 5 , red blood corpuscle. toward the mouth. Hence "if any foreign material should get into the windpipe or bronchial tubes, it will be expelled by the action of the cilia. It is by means of cilia that phlegm is raised from the throat. Such action is of great importance as it prevents the filling of the air passages with foreign matter. The bronchi end in very minute air s.cs called alveoli; these are little pouches having elastic walls. It is into these pouches that air is taken when we inspire or take a deep breath. Thus we see the lung of man gets a very 
great increase in wall area by having a large number of tiny sacs instead of one large one as in the frog. In the walls of the alveoli are numerous capillaries, the ends of arteries which pass from the heart into the lung. It is through the thin walls of the alveoli that an interchange of gases takes place which results in the blood giving up part of its load of carbon dioxide, and taking up oxygen in its place.

The Pleura. - The lungs are covered with a thin elastic membrane, the pleura. This forms a bag in which the lungs are hung. Between the walls of the bag and the lungs is a space filled with lymph. By this means, the lungs are prevented from rubbing against the walls of the chest.

Breathing. - In every full breath there are two distinct movements; inspiration (taking air in) and expiration (forcing air out). Thus this action differs considerably from "breathing" movements of the frog. The frog pumps air into its lungs by raising and lowering the floor of the mouth and then shutting the flaps or valves in the anterior nares. It is actually a process of swallowing. In man the act of inspiration is partly under the control of the will. We are able to take a long breath, or a short breath, though we cannot stop breathing. An inspiration is produced by the contraction of the muscles between the ribs together with the contraction

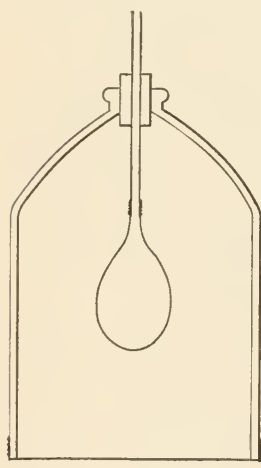

Apparatus to illustrate the action of the diaphragm in respiration. of the diaphragm, a muscular wall just below the heart and lungs (not found in the frog); this results in pulling down the diaphragm and pulling upward and outward of the ribs, thus making the space within the chest cavity larger. The lungs, which lie within this cavity, are filled by the air rushing into the larger space thus made. An expiration is simpler than an inspiration for it requires no muscular effort; the muscles relax, the breastbone and ribs sink into place, while the diaphragm returns to its original position.

A piece of apparatus which illustrates to a degree the mechanics of breathing may be made as follows: Attach a string to the middle of a piece of sheet rubber. Tie the rubber over the large end of 
a bell jar. Pass a glass tube through a rubber stopper. Fasten a small toy balloon to the lower end of the tube. Close the small end of the jar with the stopper. Adjust the tube so that the balloon shall hang free in the jar. If now the rubber sheet is pulled down by means of the string, the air pressure in the jar is reduced and the toy balloon within expands, owing to the air pressure down the tube. When the rubber is allowed to go back to its former position, the balloon collapses.

Coughing, Sighing, And Sneezing. - Coughing is a sudden strong $e x$ piration, with the glottis (or top of the windpipe) closed. A sigh is a quick inspiration followed by a quiet expiration. A sneeze is a sharp expiration, the air passing through the nose because the passage to the mouth is closed by the descent of the soft palate.

Rate of Breathing and Amount of Air Breathed.-During quiet breathing, the rate of inspiration is from fifteen to eighteen times per minute; this rate largely depends on the amount of physical work performed. About thirty cubic inches of air are taken in and expelled during the ordinary quiet respiration. The air so breathed is called tidal air. In a "long breath," we take in about 100 cubic inches in addition to the tidal air. This is called complemental air. By means of a forced expiration, it is possible to expel from 75 to 100 cubic inches more than tidal air; this air is called reserve air. What remains in the lungs, amounting to about 100 cubic inches, is called the residual air. (See diagram, page 384.) The value of deep breathing is seen by a glance at the diagram. It is only by this means that we clear the lungs of the reserve air with its accompanying load of carbon dioxide.

The actual amount of oxygen used in the body during the course of a day is nearly 25 ounces; this being almost entirely used in oxidizing the food materials taken into the body during the 24 hours.

Respiration under Nervous Control. - The muscular movements which cause an inspiration are partly under the control of the will, but in part the movement is beyond our control. The nerve centers which govern inspiration are part of the sympathetic nervous system of which we shall learn later. That the sympathetic nervous system controls respiratory movements is seen, for example, in the involuntary short breath taken by the bather who plunges into cold water. Anything of an irritating nature in the trachea or larynx will cause a sudden expiration or cough. When a boy runs, the quickened respiration is due to the fact that oxygen is used up rapidly and a larger quantity of carbon dioxide is formed. These facts, together with the presence of certain other poisonous materials in the lung cells, stimulate the nervous center which has controi of respiration to greater activity, and quickened inspiration follows.

Experiments to determine Changes undergone by Air in the Lungs. - 1. Breathe on the bulb of a thermometer and record any changes 2. Breathe gently on any polished glass cr metal surface. Note what happens. 
3. Take a moderate breath, and force air (tidal air) through limewater. Notice what occurs.

4. Force the last part of a deep expiration (reserve air) through limewater. Note result. What is one reason for deep breathing?

Changes in Air in the Lungs. - Air is much warmer after leaving the lungs than before it enters them. Expired air contains a considerable amount of moisture, which it has taken up in the air

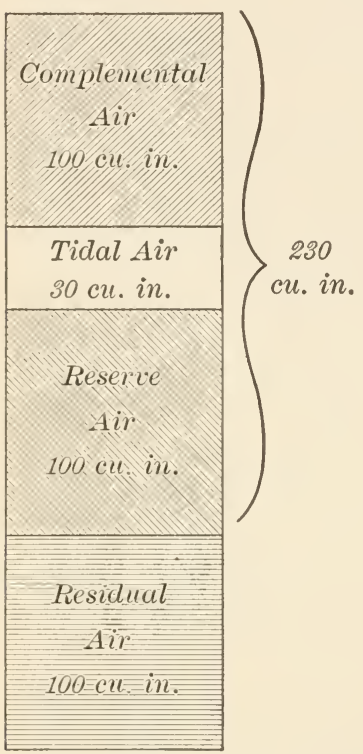

Diagram showing the relative amounts of tidal, complemental, reserve, and residual air. The brace shows the average lung capacity for the adult man. sacs of the lungs. The presence of carbon dioxide may easily be detected in expired air. Air such as we breathe out of doors, contains, by volume:-

Nitrogen . . . . . . 79.00

Oxygen . . . . . . 20.90

Carbon dioxide . . . . . .04

Air expired from the lungs, contains:-

Nitrogen • • • • • • • 79

Oxygen . . . . . . 16

Carbon dioxide . . . . . $4+$

In other words, there is a loss of between four and five per cent oxygen, and nearly a corresponding gain in carbon dioxide, in expired air. There are also some other organic substances present. The volume of carbon dioxide given off is always a little less than the amount of oxygen taken in. This seems to show that some oxygen unites with some of the chemical elements in the body.

Loss From the Lungs. - A man expires about 540 cubic inches of air per minute; this would make a total of something over 770,000 cubic inches in twenty-four hours. Of this air, about 4 per cent is carbon dioxide, the amount varying with the amount and kind of work performed. There would be at least 31,000 cubic inches of carbon dioxide expired in twentyfour hours; this amount weighs nearly thirty ounces. The amount of water evaporated by the lungs in twenty-four hours is estimated at half a pint, so the lungs are a source of actual loss in body weight. 
Changes in the Blood within the Lungs. - Blood, after leaving the lungs, is much brighter red than just before entering them. The change in (olor is due to a taking up of oxygen by the hamoglobin of the red rorpuscle. Changes taking place in blood are obviously the reverse of those which take place in air in the lungs. Blood in the capillaries within the lungs gains from four to five per cent of oxygen which the air loses. At the same time blood loses the four per cent of carbon dioxide which the air gains. The water given off is mostly lost from the blood.

Tissue Respiration. - It has been found, in the case of very simple animals, such as the amœba, that when oxidation takes place in a cell, work or release of heat results from this oxidation. The oxygen taken into the lungs is not used there, but is carried by the blood to such parts of the body as need oxygen to oxidize food materials either in the performance of work or the maintenance of the body temperature. The quantity of oxygen used by the body is nearly dependent on the amount of work

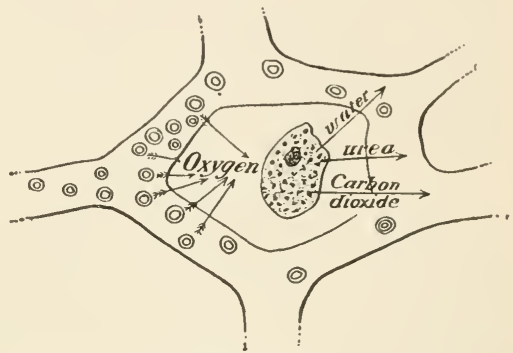

Diagram to show the respiration of cells. performed. From twenty to twenty-five ounces is taken in and used by the body every day. Oxygen is constantly taken from the blood by tissues in a state of rest. This oxygen is used up when the body is at work. This is proved by the fact that in a given time a man, when working, gives off more carbon dioxide than the oxygen he has taken in during that time.

"Alcohol interferes with the Respiration of the Cells.-Alcohol is quickly absorbed from the stomach and intestine and as quickly disappears. After it is taken, little or no alcohol, or any substance like alcohol, or any substance containing so little oxygen as alcohol, can be found in any waste of the body. Hence the inference is that it must be oxidized, although the exact point and the manner of its oxidation may not be known. But the evidence for its oxidation is the same as that for the oxidation of sugar.

HUNTER'S BIOL. -25 
"Every ounce of alcohol requires nearly two ounces of oxygen to oxidize it fully. Taking twenty-five ounces of oxygen gas as the amount used in a day, there will be only one ounce used in an hour. So to oxidize an ounce of alcohol takes an amount of oxygen equal to the whole supply of the body for two hours. Three or four drinks of whisky contain this ounce of alcohol. If this amount is drunk, there will soon be a lessened action and a narcotic effect throughout the body, due mainly to the lack of oxygen. A noticeable degree of uncertain action is called intoxication.

"Using alcohol in the body is like burning kerosene in a coal stove. By taking great care a little kerosene can be made to give out some heat from the stove, but the operation is dangerous. Some people seem to oxidize alcohol within the body with but little harm; but they run great risks of doing themselves harm, and the result is not nearly so good as if they had used proper food.

"Poisons produced by Alcohol. - When too little oxygen enters the draft of the stove, the wood is burned imperfectly, and there are clouds of smoke and irritating gases. So, if oxygen goes to the alcohol and too little reaches the cells, instead of carbonic acid gas, and water, and urea being formed, there are other products, some of which are exceedingly poisonous and which the kidneys handle with difficulty. The poisons retained in the circulation never fail to produce their poisonous effects, as shown by headaches, clouded brain, pain, and weakness of the body. The word intoxication means, 'in a state of poisoning.' These poisons gradually accumulate as the alcohol takes oxygen from the cells. The worst effects come last, when the brain is too benumbed to judge fairly of their harm. It is not true that alcohol in a small amount is beneficial. A little is too much, if it takes oxygen which would otherwise be available to oxidize wholesome food.

" Effects of Tobacco. - Tobacco smoke contains the same kind of poisons as the tobacco, with other irritating substances added. It is usually sucked into the mouth and at once blown out again, but cigarette smoke is commonly drawn into the lungs and afterwards blown out through the nose. It is irritating to the throat, 
causing a cough and rendering it more liable to inflammation. If inhaled into the bronchi, it produces still greater irritation, and the vaporized nicotine is more readily absorbed as the smoke is inhaled the more deeply. Cigarettes contain the same poisons as other forms of tobacco, and often contain other poisons which are added to flavor them." - Overton, Applied Physiology.

Need of Ventilation. - During the course of a day the lungs have lost to the surrounding air nearly two pounds of carbon dioxide. This means that about three fifths of a cubic foot is given off from each person during an hour. When we are confined for some time in a room, it becomes necessary to get rid of this carbon dioxide. This can be done only by means of proper ventilation. Other materials are passed off from the lungs, with carbon dioxide. It is the presence of these wastes in combination with carbon dioxide that makes breathed air particularly unwholesome. It has been determined that as little as one per cent carbon dioxide is injurious in expired air, although a much greater percentage than this may be safely breathed if the carbon dioxide is introduced into fresh air. The presence of impurities in the air of a room may easily be determined by its odor. The "close" smell of a poorly ventilated room is due to organic impurities given off with the carbon dioxide. This, fortunately, gives us an index by which we may prevent poisoning. Air containing 8 parts of carbon dioxide to 10,000 parts of air is bad; while from 12 to 14 parts in 10,000 makes a very dangerous amount. Among the factors which take oxygen from the air in a closed room and produce carbon dioxide, are burning gas or oil lamps, stoves, the presence of a number of people, etc.

Proper Ventilation. - Ventilation consists in the removal of air that has been used, and the introduction of a fresh supply to take its place. If we remember that warm air is lighter than cold air, and carbon dioxide is heavier than air, we can see that ventilation outlets should be on the level of the floor. The inlets should be near the top of the room, especially in houses heated by any method of direct radiation, such as steam or hot water. A good method of ventilation for the home is obtained by placing a board two or three inches high between the lower sash and the frame of a. window.

Sweeping and Dusting. - It is very easy to demonstrate the amount of dust in the air by following the course of a beam of light in a darkened room. We have already proved that spores of mold and yeast exist in the air. That bacteria are also present 
can be proved by exposing a sterilized gelatin plate to the air in a schoolroom for a few moments. ${ }^{1}$

Many of the bacteria present in the air are active in causing diseases of the respiratory tract, such as diphtheria, membranous croup, and tuberculosis. Other diseases, as colds, bronchitis, (inflammation of the bronchial tubes), and pneumonia (inflammation of the tiny air sacs of the lungs), are probably caused by bacteria.

Dust, with its load of bacteria, will settle on any horizontal surface in a room not used for three or four hours. Dusting and sweeping should always be done with a damp cloth or broom, otherwise the bacteria are simply stirred up and sent into the air again. The proper watering of streets before they are swept is also an important factor in health.

Ventilation of Sleeping Rooms. - Sleeping in close rooms is the cause of much illness. Beds ought to be placed so that a constant supply of fresh air is given without a direct draft. This may often be managed with the use of screens. Bedroom windows should be thrown open in the morning to allow free entrance of the sun and air, bedclothes washed frequently, sheets and pillow covers often changed. Bedroom furniture should be simple, and but little drapery allowed.

Hygienic Habits of Breathing. - Every one ought to accustom himself upon going into the open air to inspire slowly and deeply to the full capacity of the lungs. A slow expiration should follow. Take care to force the air out. Breathe through the nose, thus warming the air you inspire before it enters the lungs and chills the blood. Repeat this exercise several times every day. You will thus prevent certain of the air sacs which are not often used, from becoming hardened and permanently closed.

The Relation of Tight Clothing to Correct Breathing. - It is impossible to breathe correctly unless the clothing is worn loosely over the chest and abdomen. Tight corsets and tight belts prevent the walls of the chest and the abdomen from pushing outward and

1 Expose two sterilized dishes containing culture media; one in a room being swept with a damp broom and the other in a room which is being swept in the usual manner. Note the formation of colonies of bacteria in each dish. In which dish does the most growth take place? 
interfere with the drawing of air into the lungs. They may also result in permanent distortion of parts of the skeleton directly under the pressure. Other organs of the body cavity, as the stomach and intestines, may be forced downward, out of place, and in consequence do not perform their work properly.

Relation of Exercise. - We have already seen that exercise results in the need of greater food supply, and hence a more rapid pumping of blood from the heart. With this, comes need of more oxygen to allow the oxidations which supply the greater energy used. Hence deeper breathing during time of exercise is a prime necessity in order to increase the absorbing surface of the lungs.

Suffocation and Artificial Respiration.-Suffocation results from the shutting off of the supply of oxygen from the lungs. It may be brought about by an obstruction in the windpipe, by a lack of oxygen in the air, by inhaling some other gas in quantity, or by drowning. A severe electric shock may paralyze the nervous centers which control respiration, thus causing a kind of suffocation. In all the above cases, death may be prevented by recourse, in time, to artificial respiration. To accomplish this place the patient on his back with the head lower than the body; grasp the arms near the elbows and draw them upward and outward until they are stretched above the head, on a line with the body. By this means, the chest cavity is enlarged and an inspiration produced. To produce an expiration, carry the arms downward, and press them against the chest, thus forcing the air out of the lungs. This exercise, regularly repeated every few seconds, if necessary for hours, has been the source of saving many lives.

Effect of Alcohol and Tobacco on Respiration. - It has been shown that alcohol tends to congest the membranes of the organs of respiration. This it does by relaxing the membranes of the throat and lungs.

"Those who have injured themselves with alcohol show less power of resistance against influences unfavorable to health, and are carried off by diseases which other people of the same age pass through safely, especially in cases of inflammation of the lungs." - Birch-Hirsch feld.

"The action of alcohol upon the muscular walls of the arteries, which has been already more than once referred to, is especially important in the capillaries of the lungs. When they are dilated by the paralyzing effect of alcohol, their expansion reduces the 
size of the air cells in the lungs and leaves less room for the air which the lungs need, so that less oxygen is supplied to the blood. When the capillaries are often or continuously distended in this way, their walls are likely to become permanently thickened, and the interchange of gases which normally takes place there, by which carbon dioxide passes from the blood while the purifying oxygen is taken into the blood, is impeded. Serious disease even may result, such as a peculiar and quickly fatal form of consumption found only among drinkers of alcoholic fluids.

"The throat, bronchial tubes, and lungs of a tobacco smoker are all liable to irritation by the poisonous smoke, and chronic inflammation is often caused. The nicotine of tobacco is a deadly poison, and in cigarettes there are often other poisons equally dangerous to health." - MACY, Physiology.

"Dr. Legendre, a Paris physician, has recently published, for public distribution, a leaflet in which he says: 'Alcohol is a frequent cause of consumption by its power of weakening the lungs. Every year we see patients who attend the hospital for alcoholism come back after a period to be treated for consumption." " - London Lancet.

"An American medical writer (Journal of American Medical Association) points out the reason why the use of alcohol makes one liable to consumption. He mentions the use of alcohol among various other things which cause the natural vital resistance of the healthy body to be impaired. Among those other things mentioned with alcohol, which produce this impairment of vital resistance, are: 'Living in overcrowded, ill-ventilated houses, on damp soils, or insufficient clothing and outdoor exercise.' " Hall, Elementary Physiology.

Tobacco has a somewhat similar effect, besides causing a constant irritation of the diseased surfaces. 


\section{EXCRETION}

Organs of Excretion. - All the life processes which take place in a living thing result ultimately in the formation of organic wastes within the body. This is the direct outcome of the processes we call oxidation. In the one-celled animals we find the outer layer of the body used to excrete or discharge waste materials. In some invertebrates, coiled tubes called nephridia are found, for the purpose of throwing off nitrogenous waste. In the vertebrate animals, the skin and kidneys perform this function, hence they are called the organs of excretion.

Laboratory Work on the Urino-genital System of the Frog. - The organs of excretion and those of reproduction are closely connected in the frog, and are best studied together. In a male frog from which the digestive tract has been carefully removed, the kidneys may be found closely attached at the dorsal side of the body cavity. They are red-brown in color. How many are there? What is their general shape? The ovoid bodies, lying directly on the kidneys, are the spermaries. Notice the yellowish fingerlike bodies just anterior to the spermaries. These are the so-called fatty bodies; their function is not exactly known, though it is believed that they contain a reserve supply of food. Look along the outer edge of each kidney for tiny white tubes, the ureters, which connect each kidney with the cloaca. Just ventral to the cloaca is the urinary bladder, a large thin-walled biparted sac; this is also connected with the cloaca. (The bladder is frequently found in a collapsed condition. It is easy to cut it away unintentionally).

Draw the urino-genital system of the male frog (twice natural size), showing as many parts as you can.

In the female frog, a large part of the body cavity, especially at the breeding season, may be filled by the ovary; this contains a great number of black and white eggs, which may easily be seen through its very delicate walls. On each side of the body cavity, posterior to the ovary, are found two long and much-twisted tubes, the oviducts. In these tubes, the eggs receive a jellylike coat which protects them after they are laid. The oviducts are connected with the cloaca. The position of the kidneys, ureters, and bladder is practically the same as in the male frog.

Draw (twice natural size) the urino-genital system of the female frog, showing the ovary and oviduct on one side removed. Label all the parts shown.

Laboratory Work on the Kidney. - An idea of the internal structure of the kidney of man may be gained by examination of a sheep's kidney. Get the butcher to leave the mass of fat around the kidney. Of 'what use might this fat be? Notice, after removing the fat, that the kidney appears to be 
closely wrapped in a thin coat of connective tissue; this is called the capsule. Remove the kidney from this capsule. Notice its color and shape. The

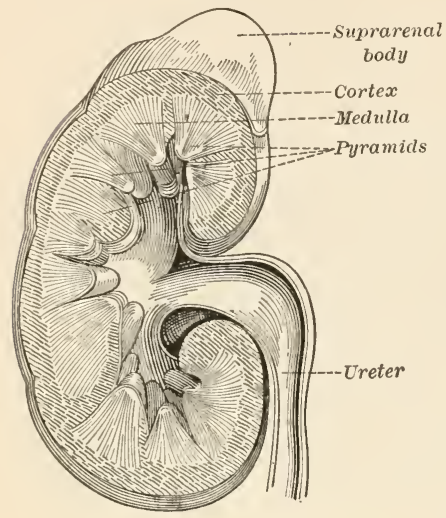

Longitudinal section of kidney. depression called the hilum is deeper than the corresponding region in the kidney bean. The hollow tube passing out from this region is called the ureter. Blood vessels also enter and leave the kidney at the hilum. Cut the kidney lengthwise into halves. Try to find the following regions: (1) The outer or cortical region; note its color; (2) The inner or medullary layer; this layer is provided with little projections; these are the pyramids of Malpighi, so called after their discoverer, Narcello Nalpighi, a celebrated Italian physiologist; (3) the cavity or pelvis of the kidney. At the summit of each pyramid is a small opening through which escapes into the pelvis the secretion formed in the little tubules which make up the substance of the kidney. Draw a sheep's kidney, cut lengthwise, showing all the above points.

The Human Kidney. - The description given above will apply almost exactly to the kidney of man except for the size. The human kidney is about four inches long, two and one half inches wide, and one inch in thickness. Its color is dark red. If you examine the structure of the medulla and cortex (see above) under the compound microscope, you will find these regions to be composed of a vast number of tiny branched and twisted tubules. The outer end of these tubules open into the pelvis; the inner end, in the cortex, forms a tiny closed sac. In each sac, the outer wall of the tube has grown inward and carried with it a very tiny artery. This artery breaks up into a mass of capillaries. These capillaries, in turn, unite to form a small vein as they leave the little sac. Each of these sacs with its contained blood vessels is called a glomerulus.

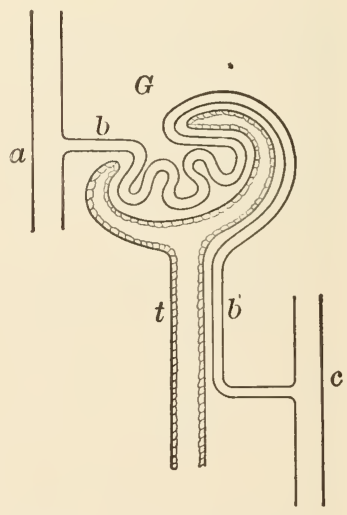

Diagram of kidney circulation, showing a glomerulus and tubule; $a$, artery bringing blood to part; $b$, capillary bringing blood to glomerulus; $b^{\prime}$, vessel continuing with blood to tubule; $c$, vein ; $t$, tubule ; $G$, glomerulus. 
Wastes given off by the Blood in the Kidney. - In the glomerulus the blood loses by osmosis, through the very thin walls of the capillaries, first, a considerable amount of water (amounting to nearly three pints daily); second, a nitrogenous waste material known as urea; third, salts and other waste organic substances, uric acid among them.

These waste products, together with the water containing them, are known as urine. The total amount of nitrogenous waste leaving the body each day is about twenty grams; this is nearly all accounted for in the urea passed off by the kidney, as urine is secreted in the kidney. It is passed through the ureter to the urinary bladder; from this reservoir it is passed out of the body, through a tube called the urethra. After the blood has passed through the glomeruli of the kidney it is purer than in any other place in the body, because, before coming to the kidney, the blood lost a large part of its burden of carbon dioxide in the lungs. After leaving the kidney it has lost much of its nitrogenous waste. So dependent is the body upon the excretion of its poisonous material that, in cases where the kidneys do not do their work properly, death may ensue within a few hours.

Effect on the Kidneys. - It is said that alcohol is one of the greatest causes of disease in the kidneys. The forms of disease known as "fatty degeneration of the kidney" and "Bright's disease" are both frequently due to this cause. The kidneys are the most important organs for the removal of nitrogenous waste.

Alcohol unites more easily with oxygen than most other food materials, hence it takes away oxygen that would otherwise be used in oxidizing these foods. Imperfect oxidation of foods causes the development and retention of poisons in the blood which it becomes the work of the kidneys to remove. If the kidneys become overworked, disease will occur. Such disease is likely to make itself felt as rheumatism or gout, both of which are believed to be due to waste products (poisons) in the blood.

"Influence of Alcohol upon Excretion. - If the waste substances constantly formed in the body are not promptly removed, they tend to poison the system. When the organism is at a high level of health, the breaking down of tissue by oxidation, which produces waste, goes on rapidly and vigorously. When this is retarded, as we have seen it to be when alcohol is introduced into 
the circulation and uses up the oxygen which should be applied to the oxidation of food, then the weight may increase, but it is by the retention of poisonous matter which ought to be removed. No other one cause creates so much disease of the kidneys as does the use of alcohol. Imperfect oxidation of food develops poisons which the kidneys are overtaxed to remove. This may be caused by eating too much, or by eating unwholesome food, or too much of certain kinds of food, as sugar especially; or it may be caused by alcohol. 'Fatty degeneration of the kidneys' is a frequent result of the use of alcoholic drinks. The cells of the tissues become so altered, also, that they fail to act normally by removing only the poisonous substances, and they allow the valuable elements in the blood to be drained off with the waste. This is seen in the serious disease called 'Bright's disease' in which the albumin which is necessary to health is excreted by the kidneys." - MACY, Physiology.

The Effects of Alcohol upon the Kidneys. - Dr. McMichael, in the Dietetic and Hygienic Gazette, says, "Alcohol produces disease of the liver and of the kidneys because these glands are most concerned in the throwing out of any poison, and are always, until they are deranged in structure, engaged in removing it from the body." He further says that the disease almost universally caused in the liver by alcohol, is one in which the connective tissue framework of the liver increases, taking the place of the liver cells, until the liver is no longer able to perform its function.

The kidneys may undergo a change similar to that of the liver when alcohol is used, even in moderate amounts, for a long period.

\section{The Skin}

Structure of the Skin. - In man, the skin is composed of two layers, an outer layer called the epidermis, and an inner layer called the dermis. The outer part of the epidermis is composed of flattened dead cells. It is part of this layer that peels off after sunburn, or that separates from the inner part of the epidermis when a water blister is formed. The epidermis frequently forms callous places which are called into existence by much use of the 
exposed part, and thus form pads for special protection. Such thickening of the outer layer is well seen in the pads on the feet of a $d o g$ or cat. The inner cells of the epidermis are provided with more or less pigment or coloring matter. It is to the varying quantity of this pigment that the "light or dark" complexion is due. The inmost layer of the epidermis is made up of small cells which are constantly dividing to form new cells to take the place of those in the outer layer which are lost.

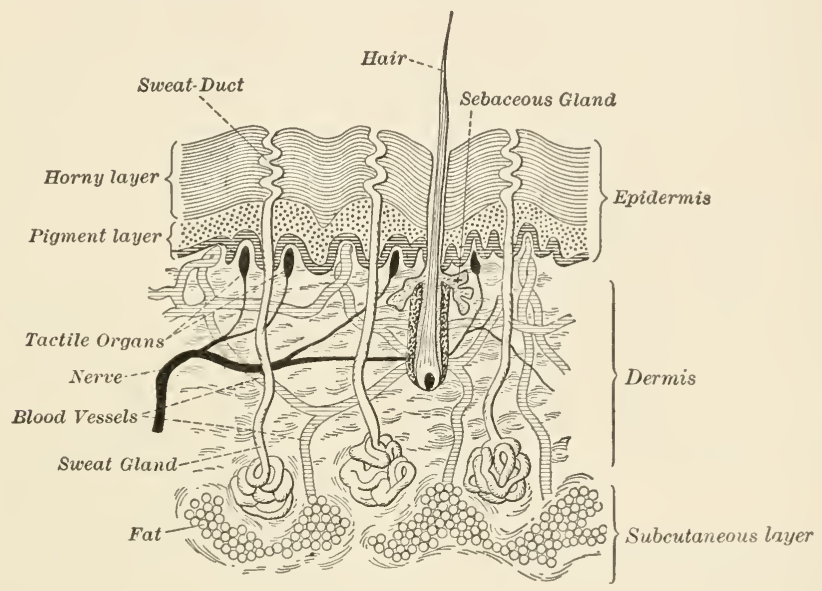

Diagram of section of the skin

The dermis is largely composed of connective tissue filled with a network of blood vessels and nerves. This layer contains the sweat glands, some of the most important glands in the body. Other organs connected with the nervous system and called the tactile corpuscles, cause this part of the skin to be sensitive to touch.

Nails. - Nails are a development from the horny layer of the epidermis. Except at the tip, the nail lies directly on the dermis, and gets its pink color from the blood beneath it. Nails grow from a layer of living cells at their roots, part of the inner layer of the epidermis.

Hairs. - A hair is also an outgrowth of the horny layer, although it is formed in a deep pit or depression in the dermis; this pit is 
called the hair follicle. A hair is formed by the rapid multiplication of the cells covering a little projection of the epidermis at the bottom of the pit. Scattered through the dermis, but always connected with the hair follicles, are tiny oil-secreting glands, the sebaceous glands. The function of the sebaceous gland is to keep the hair and surface of the skin soft. The scales of fishes and snakes, the feathers of birds, and the hoofs and horns of cattle, are all examples of outgrowth from the epidermis. They may then be considered as modifications of hair or nails.

Structure and Use of Sweat Glands. - Examine the surface of your skin with a lens. Notice the surface is thrown into little ridges. In these ridges may be found a large number of very tiny pits; these are the pores or openings of the sweat-secreting glands. From each opening a little tube penetrates deep within the epidermis; there, coiling around upon itself several times, it forms the sweat gland. Close around this coiled tube are found many capillaries. From the blood in these capillaries, cells lining the wall of the gland tube take water, and with it a little carbon dioxide, urea, and some salts (table salt among others). This forms the excretion known as sweat. It has been estimated that there are over two million five hundred thousand sweat glands in the skin of an average-sized person. A combined secretion from these glands amounts normally to a little over a pint during twenty-four hours. The amount secreted varies greatly. At all times, a small amount of sweat is given off, but this is evaporated or is absorbed by the underwear; as it passes off unnoticed it is called insensible perspiration. In hot weather or after hard manual labor the amount of perspiration is greatly increased.

Home or Laboratory Experiment. - Take your temperature by inserting a clinical thermometer in the mouth just under the tongue immediately before and immediately after some hard manual labor. Note the difference in temperature if any.

Relation of Bodily Heat to Work Performed. - The bodily temperature of a man engaged in manual labor will be found to be but little higher than his temperature when at rest. When a man works, he releases energy by oxidizing food material or tissue in the body. Thus we know from our previous experiments that 
heat is released. Muscles, nearly one half the weight of the body, release about five sixths of their energy as heat. At all times, they are giving up some heat. How is it, then, that the bodily temperature does not differ greatly at such times?

Regulation of Heat of the Body. - The temperature of the body is largely regulated by means of the activity of the sweat glands. If a large amount of perspiration is produced, it takes a correspondingly large amount of heat to evaporate it. Thus it is that when we perspire, we are cooler afterward. The object of increased perspiration, then, is to remove heat from the body. In hot weather, the blood vessels of the skin are dilated; in cold weather, they are made smaller by the action of the nervous system.

With a large amount of blood present in the skin, perspiration is increased; with a small amount, it is diminished. Hence, we have in the skin an automatic regulator of bodily temperature. Bodily temperature is also helped to be kept at a constant level, because the amount of heat produced in the body is, to some extent, regulated by the temperature outside of the body. Cold air stimulates the body to produce more heat. A high temperature outside the body retards its heat production.

Sweat Glands under Nervous Control. - The sweat glands, like the other glands in the body, are under the control of the sympathetic nervous system. Frequently the nerves dilate the blood vessels of the skin, thus helping the sweat glands to secrete, by giving them more blood.

"Thus regulation is carried out by the nervous system determining, on the one hand, the loss by governing the supply of blood to the skin and the action of the sweat glands; and on the other, the production by diminishing or increasing the oxidation of the tissues." - Foster and Shore, Physiology. ${ }^{1}$

Comparison with Cold-Blooded Animals. - We have seen the bodily temperature of a frog remain nearly that of the surrounding medium. Fishes, all amphibious animals, and reptiles are alike in this respect. This

1 "Some warm-blooded animals, as bears, hibernate, that is, sleep all through the winter and take no food. They feed well in the warm weather, and are quite fat at the close of autumn, when they seek some sheltered place to winter in. This shelter and their warm, furry coats make the loss of heat very little; the animal, except for its breathing and the beat of its heart, hardly ever moves during the winter, and even those necessary movements are reduced to the fewest possible, the breathing and heart beat being much slower than during the summer. With return of warm weather the creature wakes up again, but is then lean and weak, having burnt up its fat and part of its muscles during its winter sleep." - MARTIN, The Human Body. 
change in the bodily temperature is due to the absence of regulation by the nervous system. A sort of regulation is exerted, however, by outside forces, for the cold in winter causes the cold-blooded animals to become inactive. Warm weather, on the other hand, stimulates them to greater activity and to increased oxidation. This is naturally followed by a rise in bodily temperature.

\section{Importance of Cleanliness and Proper Clothing. - The skin as} an organ of excretion is of importance. It is of even greater importance as a regulator of bodily temperature. The mouths of the sweat glands must not be allowed to become clogged with dirt. The skin of the entire body should, if possible, be bathed daily. For those who can stand it, a cold sponge bath is best. Soap should be used daily on parts exposed to dirt. Exercise in the open air is important to all who desire a good complexion. The body should be kept at an even temperature by the use of proper underclothing. Wool, a poor conductor of heat, should be used in winter, and cotton, which allows of a free escape of heat, in summer.

Cuts, Bruises, and Burns. - In case the skin is badly broken, some antiseptic solution (weak carbolic acid or mercuric chloride tablets) can be obtained at any drug store, and should be kept in the house. N.B. These are strong poisons and should be used with great care according to exact directions. This solution may be applied at once. Thus bacteria will be prevented from obtaining entrance to the wound and causing inflammation.

"A burn or scald should be covered at once with a paste of baking soda, which tends to lessen the pain by keeping out the air and reducing the inflammation. A mixture of linseed oil and lime water, known as carron oil, is a good remedy to keep on hand for burns." - PEABody, Physiology.

"The Bodily Heat as affected by Alcohol. - The paralyzing effect of the use of alcoholic drinks, upon the muscles in the walls of the minute blood vesseis, has been mentioned in connection with the muscles, the circulation, and respiration. It should be referred to also in connection with the subject of this chapter.

"Because alcohol is quickly oxidized, and because heat is produced in the process, it was long believed to be of value in maintaining the heat of the body. A different view now prevails 
as the result of much observation and experiment. Travelers in Arctic regions and others exposed to intense cold agree that those who use no alcohol whatever are far better able to resist the cold than are those who indulge in it. Physiologists show by careful experiments that though the temperature of the body rises during digestion of food, it is lowered for some hours when alcohol is taken. The flush which is felt upon the skin after a drink of wine or spirits is due in part to an increase of heat in the body, but also to the paralyzing effect of the alcohol upon the capillary walls, allowing them to dilate, and so permitting more of the warm blood of the interior of the body to reach the surface. There it is cooled by radiation, and the general temperature is lowered." MaCY, Physiology.

Effect of Alcohol. - Alcohol lowers the temperature of the body by dilating the blood vessels of the skin. It does this by means of its influence on the nervous system. It is, therefore, a mistake to drink alcoholic beverages when one is extremely cold, because by means of this more bodily heat is allowed to escape.

"Alcohol and Heat. - The amount of heat in the body depends upon the balance between its production and its loss. The rapid destruction of alcohol, in all probability, yields heat too rapidly to be utilized by the body. The most constant effect of taking alcohol is to dilate the arteries of the skin, so that an extra a mount of heat is lost. More heat is always lost than is produced. Alcohol lessens the power of the body to endure cold. On a cold day when the arteries of the skin are contracted so that there is but little blood to warm its nerves, alcohol may send the blood to these nerves and produce an agreeable sense of warmth, but in reality this feeling of warmth is due only to the heat which is passing off from the interior of the body." - Overton, Applied Physiology. 


\section{THE NERVOUS SYSTEM}

General Functions of the Nervous System. - We have seen that, in the simplest of animals, one cell performs the functions necessary to its existence. In the more complex animals, where groups of cells form tissues, each having a different function, a nervous system is developed. The functions of the nervous system are: (1) the providing of the man with sensation, by means of which he gets in touch with the world about him; (2) the giving to the human being a will, a provision for thought; (3) the connection of organs in different parts of the body so that they act as a united and harmonious whole. Coöperation in word and deed is the end attained. We are all familiar with examples of the coöperation of organs. You see food; the thought comes that it is good to eat; you reach out, take it, raise it to the mouth; the jaws move in response to your will; the food is chewed and swallowed; while digestion and absorption of the food are taking place, the nervous system is still in control. The nervous system also regulates pumping of blood over the body, respiration, secretion of glands, and, indeed, every bodily function.

Divisions of the Nervous System. - The control of a number of activities for the attainment of a definite end is the function of the nervous system in the lowest as well as the highest of animals. In the vertebrate animals, the nervous system consists of two divisions. One includes the brain, spinal cord, the cranial and spinal nerves, which together make up the cerebro-spinal nervous system. The other division is called the sympathetic nervous system. The activities of the body are controlled frorı nerve centers by means of fibers which extend to all parts of the body, there ending in the muscles. The brain and spinal cord are examples of such centers, since they are largely made up of nerve cells. Small collections of nerve cells, called ganglia, are found in other parts of the body. These nerve centers are connected, to a greater or less degree, with the surface of the body by the nerves which 


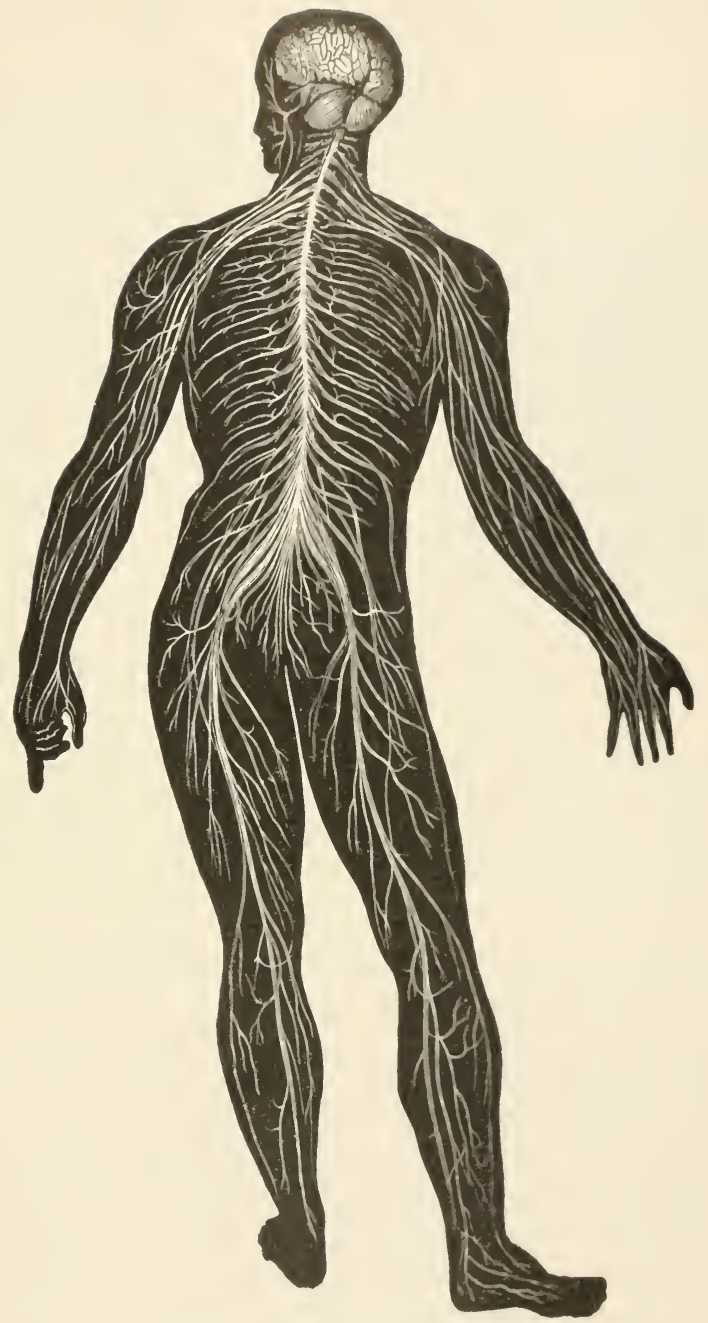

The central cerebro-spinal nervous system. 
serve as pathways between the end organs of touch, sight, taste, etc., and the centers in the brain or spinal cord. Thus sensation is obtained.

Nerve Cells and Fibers. - A nerve cell, like most other cells in the body, is a mass of protoplasm containing a nucleus. The body of the nerve cell is

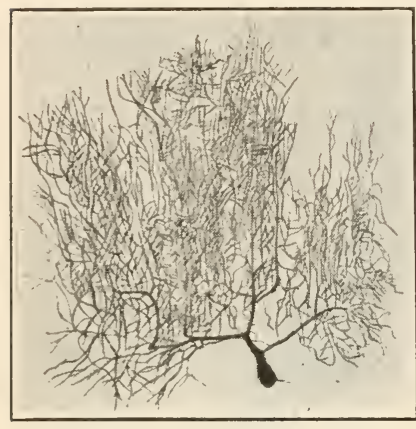

A nerve cell from the brain of a monkey, showing a great number of dendrites. usually rather irregular in shape, and distinguished from most other cells by possessing several delicate, branched protoplasmic projections called dendrites. (See figure.) One of these processes, the axis cylinder process, is much longer than the others and ends in a muscle or organ of sensation. The axis cylinder process forms the pathway over which nervous impulses travel to and from the nerve centers.

Nerves consist of bundles of such tiny axis cylinder processes, bound together by connective tissue. As a nerve ganglia is a center of activity in the nervous system, so a nerve cell is a center of activity which may send an impulse over this thin strand of protoplasm, the axis cylinder process, prolonged into a nerve fiber many hundreds of thousands of times the length of the cell. Some nerve cells in the human body, although visible only under the compound microscope, give rise to axis cylinder processes several feet in length. Because some nerve fibers originate in organs that receive sensations and send those sensations to the central nervous system, they are called sensory nerves. Other axis cylinder processes originate in the central nervous system and pass outward as nerve fibers; such nerves produce movement of muscles and are called motor nerves.

The Cerebro-spinal Nervous System of the Frog.-For this exercise use frogs that have been preserved in alcohol. Those previously used for other work on the anatomy of the frog will do perfectly well.

With a sharp knife or scalpel, cut away the skin from the top of the head and along the back. Cut carefully through the top of the cartilaginous skull. The brain will then be exposed, lying in a bony cavity surrounded by a watery fluid, the function of which is to protect the delicate brain from shock. Notice the white elongated hemispheres of the forebrain or cerebrum. The two anterior projections of the cerebrum are called the olfactory lobes. It is by means of the olfactory lobes that odors are perceived. Posterior to the cerebrum and connected with it is the midbrain. The dorsal side is enlarged to form a pair of optic lobes. How do the optic lobes compare in size with the cerebrum? Insert the blunt end of a scalpel, and turn the optic lobes slightly so as to find the optic nerves. Notice that they cross each other, the one from the right optic lobe going to the left eyeball, the one 
from the left optic lobe to the right eyeball. This erossing of the optic nerves is found in man The region just under and behind the optic lobes is the hindbrain; it consists of the cerebellum (seen as a little ridge posterior to the optic lobes) and the medulla (the hindmost part of the brain). Notice the nerves leaving it laterálly. By carefully removing the bone surrounding the spinal cord, you may be able to see some of the spinal nerves and the cord itself. Make a drawing of the brain of the frog, naming all the parts. Now turn the frog over. After removing all the organs from the body cavity, trace the course of some of the white spinal nerves. There are ten in all. They leave the spinal cord by two branches known as the dorsal and ventral roots. These roots unite under a series of yellowish white patches (ganglionic glands). The dorsal roots enter collections of nerve cells known as the spinal ganglia. Connected with that part of the central nervous system just described is the sympathetic nervous system. Part of this may, in favorable specimens, be found as a row of nerves and ganglia lying along each side of the spinal cord in the body cavity. The sympathetic nervous system supplies all the organs of the body cavity, and is connected with the spinal and cranial (brain) nerves. In man the sympathetic nervous system has practically the same position and function as it has in the frog. It has the control of the organs of digestion, circulation, respiration, excretion, and reproduction, the so-called vegetative functions.

Functions of the Parts of the Central Nervous System of THe Frog. - From careful study of living frogs, birds, and some mammals we have learned much of what we know of the functions of the parts of the central nervous system in man.

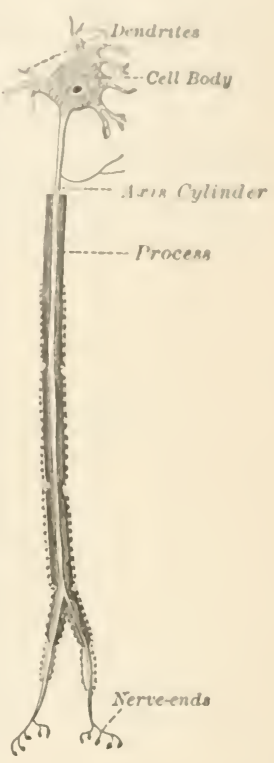

Diagram of a neuron or nerve unit.

It has been found that if the entire brain of a frog is destroyed and separated from the spinal cord, "the frog will continue to live but with a very peculiarly modified activity." It does not appear to breathe nor does it swallow. It will not move or croak, but if acid be placed upon the skin so as to irritate it, the legs make movements to push away and to clean off the irritating substance. The spinal cord is thus shown to be a center for defensive movements. If the forebrain be separated from the rest of the nervous system, the frog seems to act a little differently from the normal animal. It jumps when touched and swims when plaeed in water. It will croak when stroked or swallow if food be placed in its mouth, But it manifests no hunger or fear, and is in every sense a mathine which will perform certain actions after certain stimulations. Its movements ar. automatic. If now we watch the movements of a frog which has the brain uninjured in any way, we find that the frog acts spontancously. It tries to escape when caught. It feels hungry and secks food. It is capable of voluntary action It acts like a normal individual. 
The Brain of Man. - In man, as in the frog, the central nervous system consists of a brain and spinal cord inclosed in a bony case with the nerves leaving. it. From the brain, twelve pairs of nerves are given off; thirty-one more leave the spinal cord. Along the course of some of these nerves are found ganglia. The brain has three divisions. The cerebrum makes up the largest part. In this respect it differs from the cerebrum of the frog and other vertebrates. It is divided into two lobes, the hemispheres, which are connected with each other by a broad band of nerve fibers. The

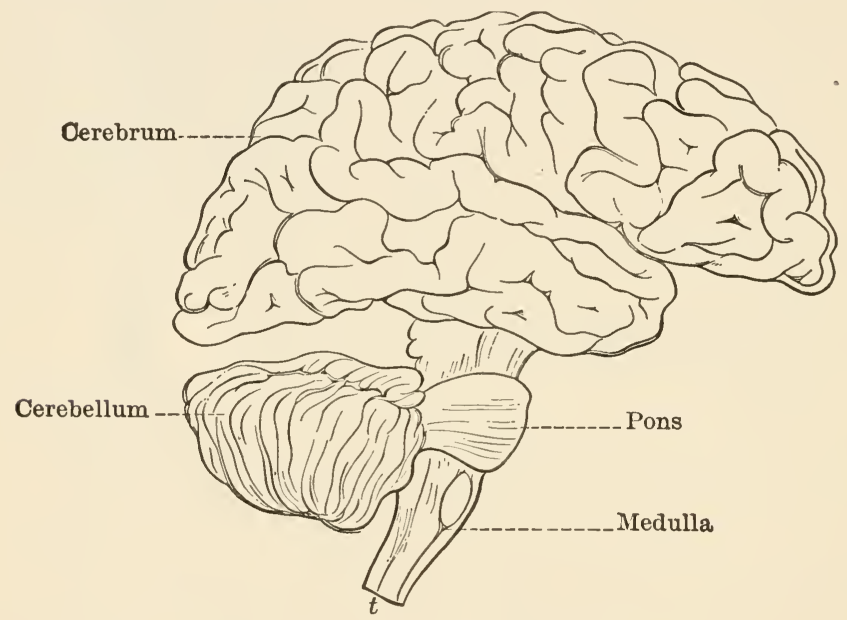

The brain, with parts separated to show each clearly.

outer surface of the cerebrum is thrown into folds or convolutions. The outer layer, seen in section, is gray in color, made up of nerve cells and supporting material (the neuroglia, a kind of connective tissue). The inner part (white in color) is composed largely of fibers which pass to other parts of the brain and down into the spinal cord. (In man, the midbrain is covered by the cerebrum, and need not be considered in this description.) Under the cerebrum, and dorsal to it, lies the little brain, or cerebellum, a part of the hindbrain. This part consists of nerve cells and fibers. The two sides of the cerebellum are connected by a band of nerve 
fibers which run around into the lower hindbrain or medulla. This band of fibers is called the pons. The medulla is, in structure, part of the spinal cord, and is made up largely of fibers running longitudinally. Just above the pons, these fibers are collected into two bundles which separate and pass up, one to each hemisphere of the cerebrum. The bundles are called the crura cerebri.

Sensory and Motor Nerve Fibers. - Nerves which are connected with the central nervous system may be made up of fibers bearing

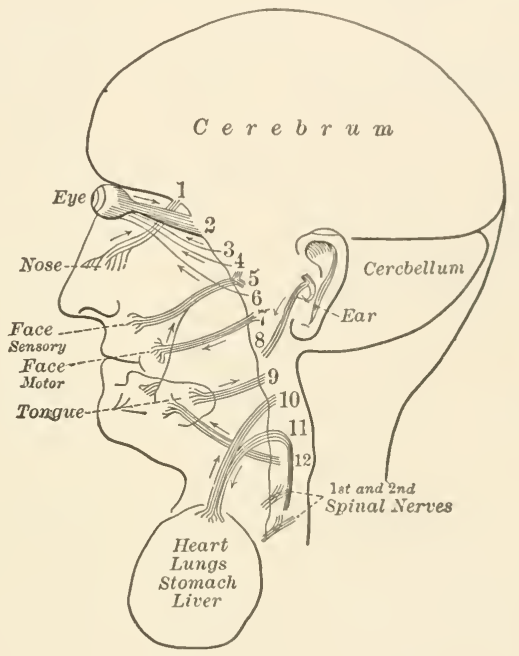

Diagram of the distribution of the cranial nerves.

sensations from the skin or sense organs to the central nervous system, the sensory fibers, or of other fibers which carry impulses from the central nervous system to the outside, the motor fibers. Some nerves are made up of both kinds of fibers, in which case they are called mixed nerves.

Distribution of Cranial (Brain) Nerves in Frog and Man. - In the frog, the cranial nerves agree in function with the first ten nerves, or cranial nerves, of man. There are two additional cranial nerves, however, found in man. These nerves are distributed as shown in the table on the following page. 


\begin{tabular}{|c|c|c|c|}
\hline $\begin{array}{l}\text { No. of } \\
\text { Nerve }\end{array}$ & FroG & $\begin{array}{l}\text { KIND OF NeRvé } \\
\text { OR COMPOSI- } \\
\text { TION OF NERVE }\end{array}$ & MaN \\
\hline I & Olfactory - to nose & Sensory & Olfactory - to nose \\
\hline II & Optic - to eye & Sensory & Optic - to eye \\
\hline III IV VI & To muscles of eye & Motor & To muscles of eye \\
\hline V & $\begin{array}{l}\text { To tongue, skin, mus- } \\
\text { cles of jaw }\end{array}$ & Mixed & $\begin{array}{l}\text { To tongue, skin, muscles } \\
\text { of jaw }\end{array}$ \\
\hline VII & To muscles of face & Motor & $\begin{array}{l}\text { To muscles of face and } \\
\text { scalp }\end{array}$ \\
\hline VIII & Auditory — to ear & Sensory & Auditory - to ear \\
\hline IX & To tongue and pharynx & Mixed & $\begin{array}{l}\text { To sense organs of } \\
\text { tongue, muscles and } \\
\text { throat }\end{array}$ \\
\hline $\mathrm{X}$ & $\begin{array}{l}\text { Vagus - to lungs, air } \\
\text { passages, heart, blood } \\
\text { vessels, digestive tract, } \\
\text { reproductive organs }\end{array}$ & Mixed & $\begin{array}{l}\text { To organs of respira- } \\
\text { tion, digestion, etc., } \\
\text { movement of same. } \\
\text { Sensations of pain, } \\
\text { hunger, etc. }\end{array}$ \\
\hline $\mathrm{XI}$ & & Motor & To muscles of shoulder \\
\hline XII & & Motor & To muscles of tongue \\
\hline
\end{tabular}

The Sympathetic Nervous System. - The sympathetic nervous system consists of a series of ganglia connected with each other and with the central nervous system through some of the spinal and cranial nerves, especially the vagus (tenth cranial). The sympathetic system, both in the frog and man, controls the muscles of the digestive tract and blood vessels, the secretion of gland cells and all functions which have to do with life processes in the body.

Functions of the Cerebrum. - In general, the functions of the different parts of the brain in man agree with those functions we have already observed in the frog. The cerebrum has to do with conscious activity, that is, thought. It presides over what we call our thoughts, our will, and our sensations. Each part of the area of the outer layer of the cerebrum is given over to some one of the different functions of speech, hearing, sight, touch, movements of bodily parts. The movement of the smallest part of the body has its definite localized center in the cerebrum. Experiments have been performed on monkeys, 
and these, together with observations made on persons who hal lost the power of movement of certain parts of the hody, and who, after death, were found to have had diseases localized in certain parts of the cerebrum, have given to us our knowledge on this sul)ject.

Reflex Actions, their Meaning. - If through disease or for ot her reasons the cerebrum does not function, no will power is exerted, no intelligent acts performed, and no incoming impulses are received as sensations. All acts performed in such a state are known as reflex actions. An example of a reflex may be obtained by crossing the legs and hitting the knee a sharp blow. The leg, below the knee, will fly up as a result of reflex stimulation. The involuntary brushing of a fly from the face or the attempt to move away from the source of annoyance when tickled

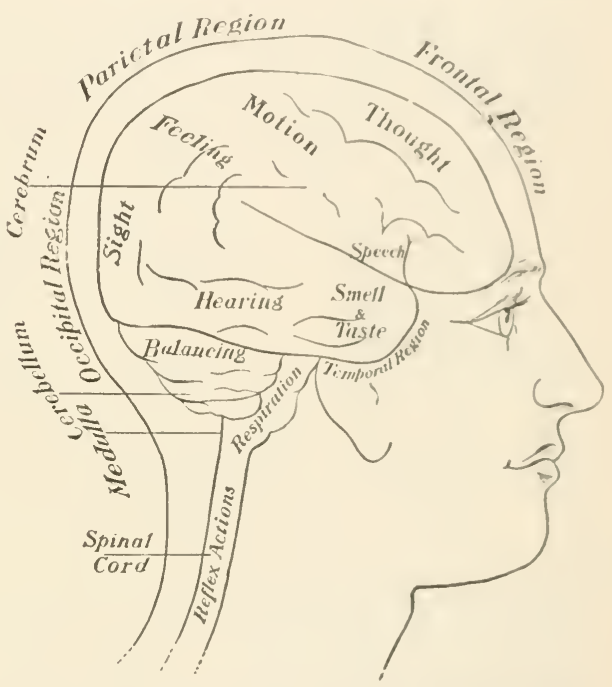

Regions of the head and action of the different parts of the brain.

with a feather, are other examples. In a reflex act, a person does not think before acting. The nervous impulse comes from the outside to cells that are not in the cerebrum. The mesige is short-circuited back to the surface by motor nerves, without wer having reached the thinking centers. The nerve cells which take charge of such acts are located in the cerebellum or spinal cord. But some reflex acts may be controlled in part hy the will. We need not, for instance, brush away a fly, although we camnot stop the churning of the stomach or the process of hreathing, yet sudden fright may cause us to take a certain shary or long hreath or 
may cause nausea or even vomiting. The glands of the stomach will not secrete unless a proper stimulation has been given to

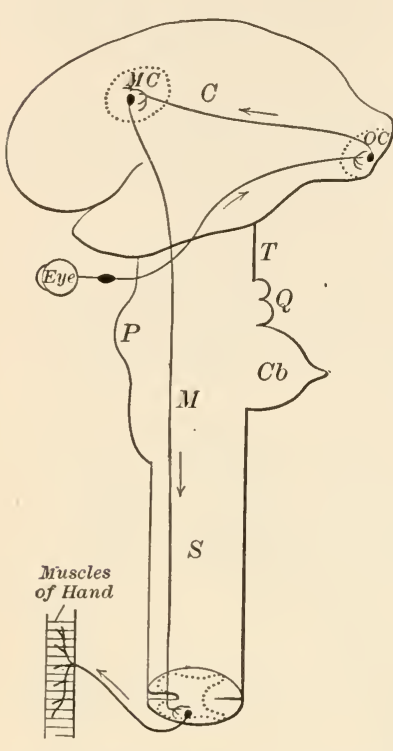

Diagram of the path of a nervous impulse which results in the hand reaching to seize an object seen with the eye; $C$, cerebrum; $C b$, cerebellum; $M$, medulla oblongata; $M C$, motor center in brain; $O C$, optic center in brain; $P$, pons Varolii; $Q$, corpora quadrigemina; $S$, spinal cord; $T$, optic thalami. them by food entering the stomach. When food reaches the gland, the message is sent from the nerve endings in the gland, to the reflex nervous center. The gland begins to secrete its fluid on the receipt of a return message from that center. Each set of glands in the digestive tract acts in a similar manner, and thus digestive fluid is poured out, and digestion is accomplished.

Automatic Acts. - Some acts, however, are learned by conscious thought, as writing, walking, running, or swimming. Later in life, however, these activities become automatic. The actual performance of the action is then taken up by the cerebellum, medulla, and spinal ganglia. Thus the thinking portion of the brain is relieved of part of its work.

Habit Formation. - The training of the different areas in the cerebrum to do their work well is the object of education. When we learned to write, we exerted conscious effort in order to make the letters. Now the act of forming the letters is done without thought. By training, the act has become automatic. In the beginning, a process may take much thought and many trials before we are able to complete it. After a little practice, the same process may become almost automatic. We have formed a habit. Habits are really aequired reflex actions. They are the result of nature's method of training. The conscious part of the brain has trained the cerebellum or spinal cord to do certain things that, at first, were taken charge of by the cerebrum. 
Importance of forming Right Habits. Danger of Strong Drink. - Among the habits early to be acquired are the habits of studying properly, of concentrating the mind, of learning self-('ontrol, and above all, the habit of contentment. Ciet the most out of the world about you. Remember that the immediate effect in the study of some subjects in school may not he great, but the cultivation of certain methods of thinking may be of the greatest importance later in life.

"The hall to be endured hereafter, of which theology tells, is no worse than the hell we make for ourselves in this world by habitually fashioning our characters in the wrong way. Could the young but realize how soon they will become mere walking bundles of habits, they would give more heed to their conduct while in the plastic state. We are spinning our own fates, good or evil, and never to be undone. Every smallest stroke of

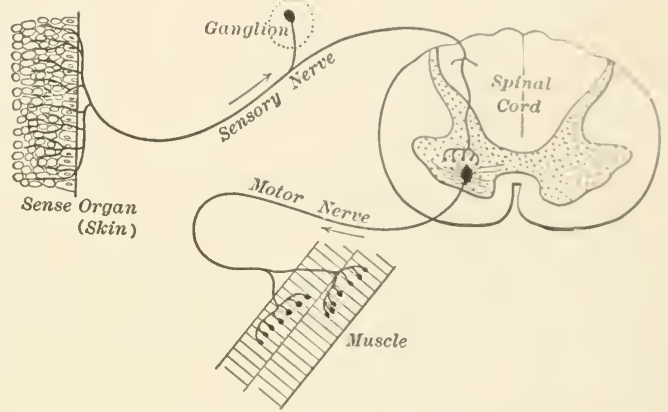

Diagram of the path of a simple nervous reflex action.

virtue or of vice leaves its never-so-little scar. The drunken Rip Van Winkle, in Jefferson's play, excuses himself for every fresh dereliction by saying, 'I won't count this time!' Well! he may not count it, and a kind Heaven may not count it; but it is being counted none the less. Down among his nerve cells and fibers the molecules are counting it, registering and storing it up to be used against him when the next temptation romes. Nothing we erer do is, in strict scientific literalness, wiped out. Of course this has its good side as well as its bad one. As we become perminent drunkards by so many separate drinks, so we become saints in the moral, and authorities in the practical and scientific, spheres by so many separate acts and hours of work. Let no youth have any anxiety about the upshot of his education, whatever the line 
of it may be. If he keep faithfully busy each hour of the working day, he may safely leave the final result to itself. He can with perfect certainty count on waking up some fine morning, to find himself one of the competent ones of his generation, in whatever pursuit he may have singled out." - JAMEs, Psychology.

Necessity of Food, Fresh Air, and Rest. - The nerve cells, like all other cells in the body, are continually wasting away and being rebuilt. Oxidation of food material is more rapid when we do mental work. The cells of the brain, like muscle cells, are not only capable of fatigue, but show this in changes of form and of contents. Food brought to them in the blood, plenty of fresh air, especially when engaged in active brain work, and rest at proper times, are essential in keeping the nervous system in condition. One of the best methods of resting the brain cells is a change of occupation. Tennis, golf, baseball, and other outdoor sports combine muscular exercise with brain activity of a different sort from that of business or school work.

Necessity of Sleep. - Sleep is an essential factor in the health of the brain, especially for growing children. Most brain cells attain their growth early in life. Changes occur, however, until some time after the school age. Ten hours of sleep should be allowed for a child, and at least eight hours for an adult. At this time, only, do the brain cells have opportunity to rest and store food and energy for their working period.

Effects of Alcohol. - Alcohol has the effect of temporarily paralyzing the nerve centers. The first effect is that of exhilaration. This, however, is a false feeling, the alcohol having paralyzed the sense of fatigue. A man may do more work for a time under the influence of this false feeling of exhilaration, but it is of short duration and is invariably followed by a period of depression and inertia. In this latter state, a man will do less work than before. He frequently takes more alcohol to renew the feeling of buoyancy, and in this way the alcohol habit may be formed. In larger quantities, alcohol has the effect of completely paralyzing the nerve centers. This is seen in the case of a man "dead drunk." He falls in a stupor because all of the centers governing speech, sight, locomotion, etc., have been temporarily paralyzed. If a 
man takes a very large amount of alcohol, even the nerve center: governing respiration and circulation may become poisoned, and the victim may die.

Influence of Alcohol on the Nervous System. - The exict action of alcohol upon the human nervous system at every stage of the above-mentioned process has not as yet been completely accounted for.

It is agreed that in large or continued amounts alcohol has a narcotic effect; that it first dulls or paralyzes the nerve centers which control our judgment, and later acts upon the so-called motor centers, those which control our muscular activities.

The reason then that a man in the first stages of intoxication talks rapidly and sometimes wittily, is because the centers of judgment are paralyzed. This frees the speech centers from control exercised by our judgment with the resultant rapid and free flow of speech.

In small amounts alcohol is believed by some physiologists to have always this same narcotic effect, while other physiologists think that alcohol does stimulate the brain centers, especially the higher centers, to increased activity. Many scientific and professional men use alcohol in small amounts for this stimulation and report no seeming harm from the indulgence. Others, and by far the larger number, agree that this stimulation from alcohol is only apparent and that even in the smallest amounts alcohol has a narcotic effect. One of the most serious effects of alcohol is the lowered resistance of the body to disease. It has been proved that a much larger proportion of hard drinkers die from infectious or contagious diseases than from special diseased conditions due to the direct action of alcohol on the organs of the body. This lowered resistance is shown in increased liability to contract disease and increased severity of the disease.

But many cases of illness are directly due to the action of alcohol on the tissues. "Such chronic diseased condition" arise from the gradual poisoning of the system by the continued use of beverages containing alcohol. Even though we admit that alcohol in a definite small amount is, in some cases at least, fully oxidized in the body, like other carbo- 
hydrates, and so supplies energy as food, we must never forget that different constitutions may be differently affected, and conditions as to climate, temperament, and habits of life may cause variations in its influence upon health and character. We can never know perfectly the nature of all the innumerable strains of hereditary tendency which unite to make an individual what he is. Some one of these may have impressed upon the nerve cells an instability, a weakness, a peculiar susceptibility to the influence of alcohol, so that the first taste may arouse the insatiable craving which leads to dipsomania. In another case, the inherited weakness may render the child of an inebriate an epileptic, an imbecile, or a consumptive. We can never foresee just how the transmitted nervous weakness will manifest itself, but as a rule the descendants of those whose systems are poisoned by alcohol are enfeebled in body or mind or both.

"But suppose a man to have derived from his ancestors a sound constitution and to have become addicted to the moderate use of alcohol; the insidious nature of the dangerous substance may gradually lead him to consume, insensibly perhaps, only a little more than the cells can oxidize. Without realizing it, he may slowly poison his system. The primary effect is upon the brain; there is congestion and overexcitement of the nerve cells there conditions which gradually extend to the nerve cells of the spinal cord; inflammation sets in, and there follows fibrous degeneration of the tissues, substituting an inferior form for the specialized tissues which do the work of the organs in various parts of the body. Paralysis may result, or epilepsy, or dyspepsia from lack of the due amount of nervous influence upon the digestive organs, or any one of a thousand forms of disorder, some of which have been mentioned in preceding chapters. Though a man may never drink to intoxication, and never realize that he is using alcohol to excess, he may nevertheless become seriously diseased in consequence of his moderate indulgence, or what he believes to be such, while wondering why he is not well and strong. Still less does he consider the legacy of evil which he may be laying up for his children.

"Life insurance companies have gathered an immense body 
of statistics respecting human life, with sole reference to their bearing upon the business of insurance, and it is well known that life insurance companies regard policies upon the lives of drinking men - even 'moderate drinkers' - as involving 'extra risk.' Their figures have convinced them that the man who uses no alcoholic beverages is likely to live longer than one who does." MaCY, Physiology.

"Alcohol a Cause of Mental Disorders. - If you look round and try to find out the primary causes of disease and poverty and crime and misery, you are over and over again thrown back on the use of alcohol. One cannot read the newspapers and reports of judges without seeing that alcohol accounts for a very large proportion of what is evil in our daily life. It is sapping the foundation of our national life, and if we could do away with all the disease and poverty and crime caused by alcohol, the questions which confront us would be solved very easily.

"The Influence of Alcohol ur on the Morals. - The most highly specialized characteristics are fir it impaired, and thus the spiritual faculty, if I may so term it, first becomes blunted by the use of alcohol. Following this in rapid succession there is blunting of the moral sense; a slight, though distinctly perceptible, interference with the intellectual faculties, which leads to what we might call blurring of the reasoning power; then follows a distinct diminution in the power of rapidity and accuracy of perception. At none of these stages would a man admit that he was under the influence of alcohol; but these powers are just as assuredly under its influence as are the muscles which can no longer act coördinately to enable a man to walk straight." - Profrssok G. Sims Woodhead.

The Influence of Alcohol. - "Alcohol acts primarily on the nerve cells, changing their granular matter, breaking up their nutrition, and changing their dynamic force. This action is followed by contraction of the dendrites, swelling and atrophy of these fibers, also shrinking of cell walls, as in fatigue, and coalecing and disappearance of the granular matter of protoplasm." Journal of the American Medical Association, November, 1898.

"Alcohol does not affect all the spinal cells equally, and in the 
early stages the changes are rather indefinite, a greater sharpness of contour being the most obvious. In the cerebrum the cells appear as mere shadows, both substances disappearing, whilst the nuclei are also altered." - London Lancet, October 31, 1896, p. 1245.

"Just why the alcohol should select a set of nerves on which to act at one time and a different set at another does not at once appear, but it is a well-authenticated fact that it has a selective power. Most likely the explanation lies in the chemical or electrical condition of the white substance at the time of action, or it may be attributable to the different chemical constituents of the liquor used." - Dr. Wilkins, in the New York Medical Journal, September 22, 1894.

"Professor Kraepelin of Heidelberg tried a number of experiments on individuals, with the object of seeing whether a small quantity of alcohol hindered the nervous transmission of intelligence to the brain. Flags were raised at a given distance, and the exact time was noted when the various men experimented upon observed the raising of the flag. The result proved that the watchers who had been given a small quantity of alcohol, though they felt that they had seen the flag rise sooner than those who had received no alcohol, actually took longer." - HALL, Elementary Physiology.

Professor Woodhead says, "After careful examination of the whole question, physiologists - and among physiologists I include those who maintain alcohol may be useful, as well as those who hold that it is harmful - have come to the conclusion that the principal action of alcohol is to blunt sensation, and to remove what we may call the power of inhibition by blunting the higher centers of the brain."

Professor David Starr Jordan in the Popular Science Monthly, February, 1898, said: "The healthy mind stands in clear and normal relations with Nature. It feels pain as pain. It feels action as pleasure. The drug which conceals pain or gives false pleasure when pleasure does not exist forces a lie upon the nervous system. The drug which disposes to reverie rather than to work, which makes us feel well when we are not well, destroys the sanity 
of life. All stimulants, narcotics, tonics, which affect the nervous system in whatever way, reduce the truthfulness of sensation, thought, and action. Toward insanity all such influences lead; and their effect, slight though it be, is of the same nature as mania. The man who would see clearly, think truthfully, and act effectively must avoid them all. Emergency aside, he cannot safely force upon his nervous system even the smallest falsehood."

Dr. Hammond said: "The more purely intellectual qualities of the mind rarely escape being involved in the general disturbance [caused by alcohol]. The power of application, of appreciating the bearing of facts, of drawing distinctions, of exercising the judgment aright, and even of comprehension, are all more or less impaired. The memory is among the first faculties to suffer.

The will is always lessened in force and activity. The ability to determine between two or more alternatives, to resolve to act when action is necessary, no longer exists in full power, and the individual becomes vacillating, uncertain, the prey to his various passions, and to the influence of vicious counsels."

"Helmholtz told us in his autobiography that if he took wine while occupied with a mathematical or scientific problem, his thinking powers were interfered with, and he had to wait for the alcoholic effects to work off before his inspiration returned." -Dr. Adolph Rupp, New York Medical Journal, July 9, 1898.

"Finally we have still to declare that alcohol hinders the action of the highest mental faculties. A remark made by Helmholtz at the celebration of his seventieth birthday is very interesting in this connection. He spoke of the ideas flashing up from the depths of the unknown soul, that lies at the foundation of every truly creative intellectual production, and closed his account of their origin with these words: "The smallest quantity of an alcoholic beverage seemed to frighten these ideas away.'"-Dr. G. Sims Woodhead, Professor of Pathology, Cambridge University. England.

W. Boyd Dawkins says: "I cannot drink beer when I am using my brain, and do not take it when I have any thing to think about." - Quoted by Dr. M. L. Holbroor, Journal Medical T'mperance Association, January, 1898, p. 21. 
"Some people imagine that after the use of alcohol they can do things more quickly, that they are brisker and sharper, but exact measurement shows that they are slower and less accurate. Men believe that they are wiser and brighter, but their sayings are more automatic and apt to be profane. To quote Dr. Lauder Brunton, of Oxford University, England, 'It produces progressive paralysis of the judgment,' and this begins with the first glass. Men say and do, even after a single glass of drink, what they would not say or do without it, and therefore it clearly affects the brain and diminishes self-control." - AdolPH Fick, Professor of Physiology, Würzburg, Germany.

Professor von Bunge (Text-book of Physiological and Pathological Chemistry) of Switzerland, says that: "The stimulating action which alcohol appears to exert on the brain functions is only a paralytic action. The cerebral functions which are first interfered with are the power of clear judgment and reason. No man ever became witty by aid of spirituous drinks. The lively gesticulations and useless exertions of intoxicated people are due to paralysis, - the restraining influences, which prevent a sober man from uselessly expending his strength, being removed."

"The capital argument against alcohol, that which must sventually condemn its use, is this, that it takes away all the reserved control, the power of mastership, and therefore offends against the splendid pride in himself or herself, which is fundamental in every man or woman worth anything." - DR. JoHN JoHnson, quoting Walt Whitman.

The Drink Habit. - The harmful effects of alcohol (aside from the purely physiological effect upon the tissues and organs of the body) are most terribly seen in the formation of the alcohol habit. The first effect of drinking alcoholic liquors is that of exhilaration. After the feeling of exhilaration is gone, for this is a temporary state, the subject feels depressed and less able to work than before he took the drink. To overcome this feeling, he takes another drink. The result is that before long he finds a habit formed from which he cannot escape. With body and mind weakened, he attempts to break off the habit. But his will, too, has suffered from over indulgence. He has become a victim of the drink habit ! 
Self-indulgence, be it in gratification of such a simple denire as that for candy or the more harmful inclulgence in folnacer or alcoholic beverages is dangerous - not only in its immediate offects on the tissues and organs, but in its more far-rear.hing efferts on habit formation.

The Moral, Social, and Economic Effect of Alcoholic Poisoning.In the struggle for existence, it is evident that the man whose intellect is the quickest and keenest, whose judgment is most soumul, is the man who is most likely to succeed. The fraralyzing effert of alcohol upon the nerve centers must place the drinker at a disadvantage. In a hundred ways, the drinker sooner or later feels the handicap that the habit of drink has imposed upon him. Many corporations, notably several of our greatest railroads (the New York Central Railroad among them), refuse to employ any but abstainers in positions of trust. Few persons know the number of railway accidents due to the uncertain eye of some encineer who mistook his signal, or the hazy inactivity of the hrain of some train dispatcher who, because of drink, forgot to send the telegram that was to hold the train from wreck.

In business and in the professions, the story is the same. The abstainer wins out over the drinking man.

Not alone in activities of life, but in the length of life has the $a b$ stainer the advantage. Figures presented by life insurance companies show that the nondrinkers have a considerably greater chance of long life than do drinking men. So decided are these figures that several companies have lower premiums for the nondrinkers than for the drinkers who insure with them.

"Other Narcotics in Common Use. - Narcoties are very widely used by the human family for the relief which they give from pain or fatigue, or for the direct pleasurable sensations which they impart. All are deadly poisons when taken in sufficient quantities. Those most common (after alcohol) are toluceo and opium. "It has already been shown that tobaceo maty affect unfavorably" many parts of the system, and is especially injurious to the young. It stimulates in small quantities and narotizes in larger ones, working its effects directly upon the nervous system. Nicoline is a powerful poison found in tobacco. It affects the nerve cells, HUNTER'S BIOL. -27 
injures the brain, and leads especially to weakness of the heart by interfering with its supply of nervous force. Many cases of cancer of mouth and throat are believed to have resulted from tobacco smoking.

"Opium, for its benumbing influence upon the nerves, is used by large numbers of persons, especially in Oriental lands. Its continued use deranges all the digestive processes, disorders the brain, and weakens and degrades the character. Like alcohol, it produces an intolerable craving for itself, and the strongest minds are not proof against the deadly appetite.

"Self-control versus Appetite. - Man is a bundle of appetites. Every organ, every cell even, craves its appropriate stimulus. Animals under natural conditions gratify the appetites as they arise only to that extent which is healthful for the whole body. Man alone, whose highly developed brain is overlord to the rest of his system, permits an unwholesome indulgence of appetite to interfere with this general well-being. Alcohol, opium, and their like are far from being the only substances whose excessive use injures the organism and degrades character. Children are often allowed to indulge a natural fondness for sweets to an extent which is ruinous to digestion; for sugar, which is a useful and necessary food in suitable quantities, in larger ones acts injuriously upon the system. Boys pampered with dainties from infancy logically infer that a fancy for cigars or beer may be similarly gratified. Appetite for even the most wholesome food may be in excess of bodily needs, and the practice of gluttony is certain to derange nutrition.

"A child should be early taught that because he "likes' a certain article of food he should not therefore continue to eat it after natural hunger is satisfied, or at times when he does not need food; while to persist.in eating or drinking that which experience, or the advice of those competent to judge, has taught him to be harmful, should be regarded as unworthy a rational being.

"These are but illustrations of the manifold forms of intemperance which work untold harm to the physical and moral natures. There seems no possibility of improvement to our race except as the young are led to recognize the manliness and dignity of controlling one's appetites." - MACY, Physiology. 


\section{THE SENSES}

Touch. - In animals having a hard outside covering, such as certain worms, insects, and crustaceans, minute hairs, which are sensitive to touch, are found growing out from the body covering. At the base of these hairs are found nerve cells which send a nerve fiber inward to the central nervous system.

Organs of Touch. - In man, the nervous mechanism which governs touch, is located in the folds of the dermis or in the skin. Special nerve endings, called the tactile corpuscles, are there found. They are inclosed in a sheath, or capsule, of connective tissue.

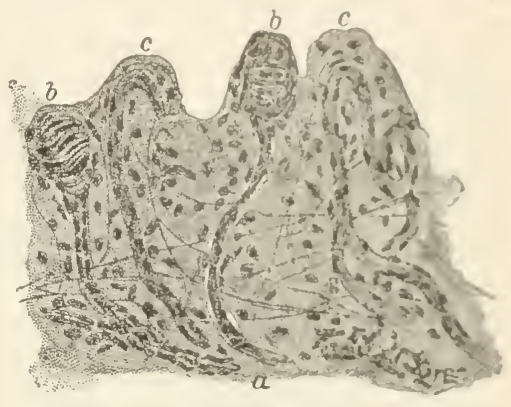

Nerves in the skin: $a$, nerve fiber: $b$, (actile papillx, containing a tactile mrpuscle : $c$, papills containing blood vessels. (After Benda.)

Inside is a complicated nerve ending, and nerve fibers are sent inward to the central nervous system. The number of tactile corpuscles present in a given area of the skin determines the aceuracy and ease with which objects may be known by touch.

If you test the different parts of the body, as the back of the hand, the neck, the skin of the arm, of the back, or the tip of the tongue, with a pair of open dividers, a vast difference in the accuracy with which the two proints may be distinguished is noticed. On the tip of the tongue, the two proints need only be separated by $\frac{1}{24}$ of an inch to be sis distinguished. In the small of the back, a distance of two inches maly be reached hefore the dividers feel like two points.

Temperature, Pressure, Pain. - The feeling of temperature. pressure, and pain, the latter only in part, are determined by organs in the skin. Physiologists believe, however, that these organs atre distinct from the apparatus which distinguishes touch.

Taste Organs. - The surface of the tongue is folded into a number of little projections known as papillie. These may he more 
easily found on your own tongue if a drop of vinegar is placed on its broad surface. In the folds, between these projections on the

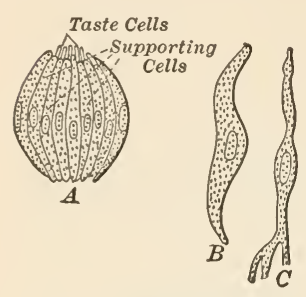

$A$, isolated taste bud, from whose upper free end project the ends of the taste cells; $B$, supporting or protecting cell; $C$, sensory cell. top and back part of the tongue, are located the organs of taste. These organs are called taste buds.

Each taste bud consists of a collection of spindleshaped nerve cells, each cell tipped at its outer end with a hairlike projection. These cells send inward fibers which ultimately reach the brain. The sensory cells are surrounded by a number of protecting cells which are arranged in layers about them. Thus the organ in longitudinal section looks somewhat like an onion cut lengthwise.

How we Taste. - Four kinds of substances may be distinguished by the sense of taste. These are sweet, sour, bitter, and salt. Certain taste cells located near the back of the tongue are stimulated only by a bitter taste. Sweet substances are perceived by cells near the tip of the tongue. A substance must be dissolved in fluid in order to be tasted. Many things which we believe we taste, are in reality perceived by the sense of smell. Such are spicy sauces and flavors of meats and vegetables. This

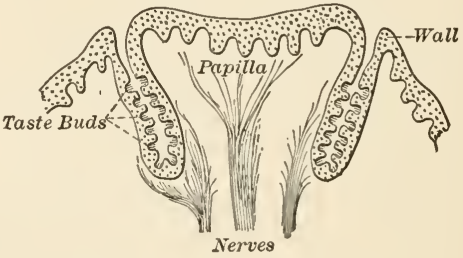

Section of circumvallate papilla. may easily be proved by holding the nose and chewing, with closed eyes, several different substances, such as an apple, an onion, and a raw potato.

Smell. - The sense of smell is located in the membrane lining the upper part of the nose. Here are found a large number of rod-shaped cells which are connected with the forebrain by means of the olfactory nerve. In order to perceive odors, it is necessary to have them diffused in the air; hence we sniff or draw in more air over the olfactory cells so as to bring more odoriferous particles to them and thus to distinguish the odor.

"Effects of Alcohol upon Taste and Smell. - The habitual use of drinks containing alcohol, of tobacco, and of very strongly 
flavored foods is found to dull the sense of taste, and hy aldenherl, at

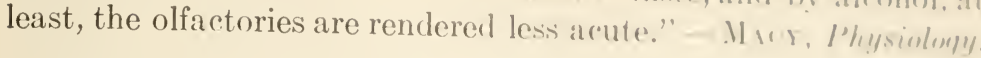

The Organ of Hearing. - The organ of hearing is the car. In a fith, frog, or reptile, the outer ear, so prominent in man, is entircly lacking. The outer ear consists of a funnel-like organ composed largely of cartilage which is of use in collecting sound waves. This part of the ear inclusen the anditory canal which is elosed at the inner end by a tightly stretched membranc. the tympanic membrane. We have seen the tympanic mombrane of the frog on the outer surface of the head. The function of the tympanic membrane is to. receive sound waves, for all sound is eaused by vibrations in the air, these vibrations being transmitted, by the means of a complicated apparatus found in the middle ear, to the real organ of hearing located in the inner ear.

Middle EAR.-The middle ear in man is a cavity inclosed by the temporal bone, and separated from

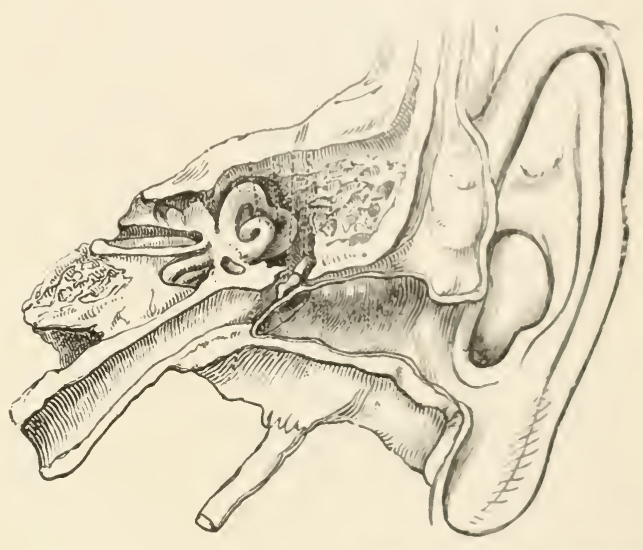

Section of ear, showing auditory canal. middle ear, internal ear, and Eustachian tube.

the outer ear by the tympanic membrane. A little tube called the Eustachian tube connects the inner ear with the mouth cavity. By allowing air to enter from the mouth, the air pressure is equalized on the ear drum. For this reason, we open the mouth at the time of a heary concussion and thus prevent the rupture of the delicate tympanic membrane. Placred directly against the tympanic membrane and connecting it with another me-mbrane, separating the middle from the inner ear, is a chain of three tiny bones, the smallest bones of the body. The outermost is called the hummer; the next the incus or anvil; the third the stirrup. All three bumes are so ealled from their resemblances in shape to the articles for which they are named. These bones are held in place hy very small mustes which are delicately adjusted so as to tighten or relax the membranes guarding the middle and inner ear.

The INNer EAR. - The inner ear is one of the most complicated. as well as one of the most delicate, organs of the body. Dewp within the tum- 
poral bone there are found two parts, one of which is called, collectively, the semicircular canal region, the other the cochlea or organ of hearing. Both of these organs consist of membranous bags lying in a fluid which partially fills the bony cavity which incloses them. These membranous structures themselves also contain a fluid. The semicircular canals are connected with the cochlea on one side, and are separated from the middle ear only by a membrane and the fluid which surrounds them. There are three semicircular canals, delicate membranous bags lying in a watery fluid and surrounded by bone.

It has been discovered by experimenting with fish in which the semicircular canal region forms the chief part of the ear, that it has to do with the equilibrium or balancing of the body. We gain our knowledge of our position and movements in space by means of the semicircular canals.

That part of the ear which receives sound waves is known as the cochlea, or snail shell, because of its shape. This very complicated organ is lined with sensory cells provided with cilia. The cavity of the cochlea is filled with a fluid; this fluid presses against the membrane and separates the inner from the middle car. It is believed that somewhat as a stone thrown into water causes ripples to emanate from the spot where it strikes, so sound waves, transmitted by the bones of the middle ear to the membrane guarding the entrance to the inner ear, are transmitted by means of the fluid filling the cavity to the sensory cells of the cochlea (collectively known as the organ of Corti) and thence to the brain by means of the auditory nerve.

The Character of Sound. - When vibrations which are received by the ear follow each other at regular intervals, the sound is said to be musical. If the vibrations come irregularly, we call the sound a noise. If the vibrations come slowly, the pitch of the sound is low; if they come rapidly, the pitch is high. The ear is able to perceive as low as thirty vibrations per second and as high as almost thirty thousand. The ear can be trained to recognize sounds which are unnoticed in untrained ears.

CARE of the EAR. - Some of the cells lining the cavity of the outer ear secrete a bitter substance called wax. This wax, which aids in keeping the canal of the outer ear moist, also aids in keeping foreign matters, especially living insects, out of the ear. In removing wax or dirt no sharp pointed instrument should be used. Inflammation of the ear should be treated by a doctor, as at such times pus may gather in the inner ear in sufficient quantity to rupture the tympanic membrane. In serious cases, the bone around the inner ear may become diseased and the brain affected. The ear should be protected against sudden loud sounds, such sounds tending to break the tympanic membrane. When the ear is sensitive to cold or dampness, a small wad of cotton may be inserted when going out of doors. This should always be removed upon entering the house.

The Eye. - The eye or organ of vision is an almost spherical body which fits into a socket of bone, the orbit. What might be the function of this 
bony socket? A stalklike structure, the optic neres, connects the fye with the brain. Free movement is obtained by means of six little mu ele w wh h are attached to the outer coat, the eyeball, and to the bony suckit around the eye. ${ }^{1}$ Notice the living frog. Compare the movements of your own eye with those of the frog. Note any differencest in position of the we of the frog and of that of man, and try to acrount for these differences. I now for adaptations for the protection of your eye. Among such adiputations are the position, structure of the lids, and the lashes. The littir are ueful in protecting the eye from foreign substances. As we have secn, the awo outer lids are not always found in lower vertebrate animals. In some vertebrates, however, as in the bird, lizard, frog, and some lower mammals, we find a third or winking eyelid. In man this eyelid is reduced to a small fleshy fold seen in the inner angle of the eye. Glands which secrete a salty, watery fluid are present. This fluid keeps the eye moist, and prevents friction between the eyeball and its coverings. A small duct, which can be found in the inner corner of the eye, carries off all waste secretion into the nose. During a cold, when this passage is stopped up, the tears overflow. Other glands which secrete an oil prevent tears, under normal circumstances, from flowing out of the eyes.

Internal Structure. ${ }^{2}$ - The human eyeball, if cut in a longitudinal median section, from the front backwards, will show the following structures:-

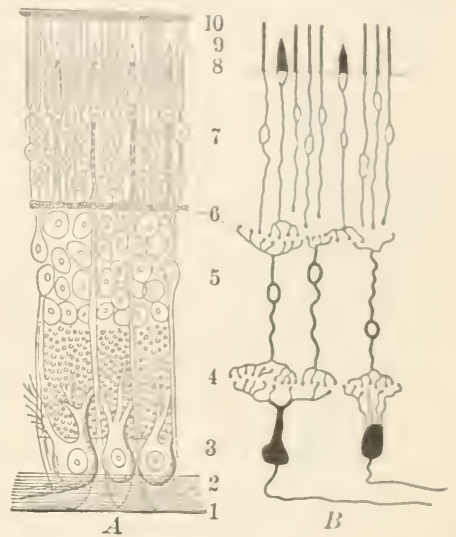

Section of the retina; .1 , diagram of the structure of the retina as seen with the compound microscope; $B$, the ent ntwl nervous elements of the retuna nas demenstrated by the (iolgi methexl: 1 . internal limiting membrane; 2 , nerve-filuer lnser; 3 , nerve-cell or ganglion-cell layer: 4 , inner molecular liyer, 5 , inner granular layer; 6, outer molecular layer: 7 , outer granular layer: 8 , exterwal boniting membrane; $?$, rod-and-eme layer : 10, pigment-cell layer.

The wall of the eyeball is made up of three coats. In nuter tough white coat, of connective tissue, is callerl the scle rotic coal; this coat is lacking in the exposed part of the cyelall. hut may he seen by lifting the eyelid. Under the sclerutic coat, in iront, the eye bulges outward a little. Here the outer cont is replacel his

${ }^{1}$ Use for the following work a living frog.

2 For laboratory work on the eye of the sheep or the human eye, we fluter atul Valentine, Manual, pages 189-192. 
a transparent tough layer called the cornea. A second coat, the choroid, is supplied with blood vessels and cells which bear pigments. It is this coat which we see through the cornea as the colored part of the eye (the iris). In the center of the iris is a small circular hole (the pupil). The iris is under the control of muscles, and may be adjusted to varying amounts of light, the hole becoming larger in dim light, and smaller in bright light. Watch the pupil of

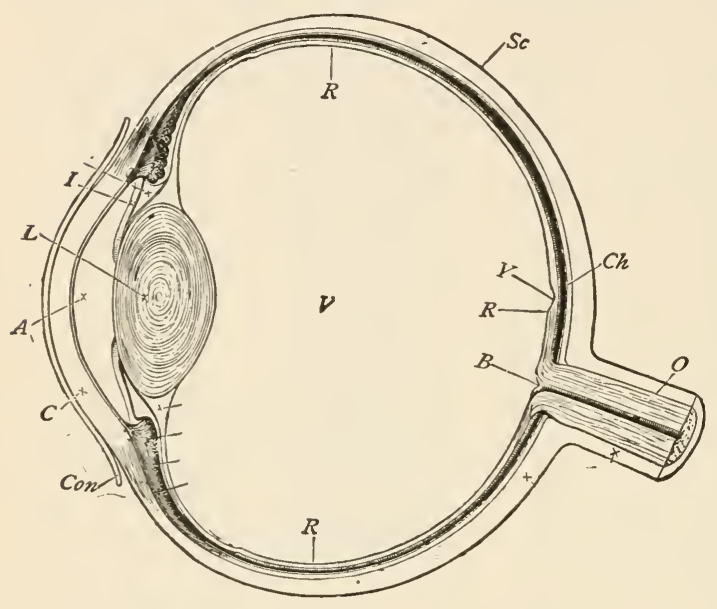

Longitudinal section through the eye; $S c$, sclerotic coat; $C h$, choroid; $O$, optic nerve ; $C$, cornea; $I$, iris; $B$, blind spot; con, conjunctiva; $R$, retina; $Y$, yellow spot; $L$, lens; $A$, anterior chamber, filled with aqueous humor; $V$, posterior chamber, filled with vitreous humor. a cat's eye, in changing the animal from a dark to a light room. The inmost layer of the eye is called the retina. This is, perhaps, the most delicatelayer in the entire body. Despite the fact that the retina is less than $\frac{1}{80}$ of an inch in thickness, there are no less than eight layers of cells in its composition. The optic nerve enters the eye from behind and spreads out over the surface of the retina. Its finest fibers end in elongated rodlike and conelike cells. The retina is dark purple in color, this color being caused by a layer of cells next to the choroid coat. This accounts for the black appearance of the pupil of the eye, when we look through the pupil into the darkened space within the eyeball. The retina acts as the sensitized plate in the camera, for on it are received the impressions which are transformed and sent to the brain as sensations of sight. The eye, like the camera, has a lens. This lens is formed of transparent, elastic material. It is found directly behind the iris and is attached to the choroid coat by 
means of delicate ligaments. In front of the lens is a small catvity filled with a watery fluid, the aqueous humor, while behind it is the main cavity of the eye, filled with a transparent, almost jelly-like, vitrcous humor. The lens itself is elastic. This circumstance permits of a change of form and, in consequence, a change of focus upons the retina of the lens. By means of this change in form, or "accommodation," we are able to distinguish between near and distant objects.

Defects in the Eye. - In some eyes, the lens is in focus for near objects, but is not easily focused upon distant objects; such an eye is said to be nearsighted. Other eyes which do not focus clearly on objects near at hand are said to be far-sighted. Still another eye defect is astigmatism, which causes

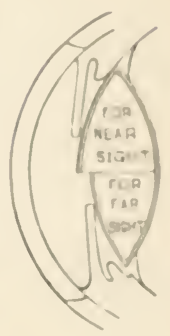

Jiagram showing how the lens ehanges its form. images of lines in a certain direction to be indistinct, while images of lines transverse to the former are distinct. Many nervous troubles, especially headaches, may be due to eye st rain.

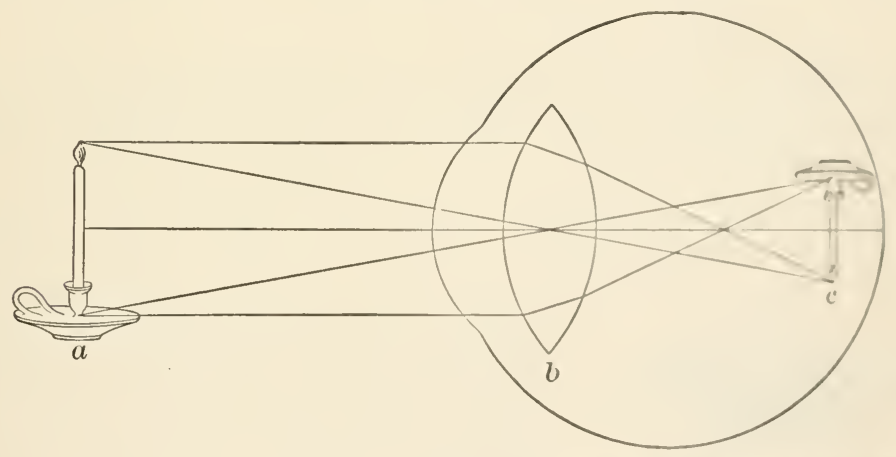

Diagram to show how an image is formed in the eye; $a$, object ; $b$, lens; $c$, image upen retina.

How we See. - Suppose an ohject he held in front of the eye: rays of light pass from every part of the ohject and are brought to a focus on the retina by means of the transparent lens. You can form an object in the same manner hy using a reading glase, a box with a hole in one end, and a piece of white paper. Notice 
that the image is inverted. The same is true of the image on the retina. By means of this image thrown on the sensory layer, the rod and cone cells of the retina are stimulated and the image is transmitted to the forebrain. We must remember that the optic nerve crosses under the brain so that images formed in the right eye are received by the left half of the forebrain, and vice versa.

"Effects of Drinks containing Alcohol upon the Eye. - Through its influence upon the nerves and the muscles, the continued and too free use of alcohol renders the eye unsteady and its adjustment uncertain; the small blood vessels become dilated, and the eyes are blood-shot and often inflamed. The optic nerve is frequently affected, causing dimness of vision, and specific diseases of parts of the eye may result, such as cataract and disorders of the retina. The confirmed inebriate is the victim of diseased conditions in which the sight becomes untrustworthy. He sees horrible visions, frightful, venomous creatures appear to threaten him, and he is haunted by specters. Under his imaginary suffering he may become a raving maniac, and repeated attacks of the disease are likely to prove fatal." - MACY, Physiology.

The Blind Spot. - Although the eye is an accurate organ for sight, yet one part of the retina is not provided with sensory cells. This area, called the blind spot, marks the point within the eye where the optic nerve enters and spreads out in a very thin layer over the surface of the retina.

How the Voice is Produced. - The voice box, or larynx, is well known to every boy as his "Adam's apple." It consists of a box of movable cartilages,

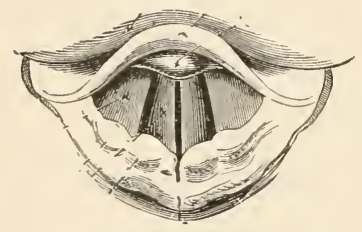

Vocal cords. joined in such a way to each other and to muscles so that by contraction of certain muscles, the form of the larynx is changed. Within the larynx are stretched two narrow pads of elastic tissue called the vocal cords. It is by the vibration of these cords that the sounds of the voice are produced. The vocal cords project into the larynx so that only a narrow slit is formed between the larynx and the mouth cavity. This slit is the glottis. When the vocal cords are drawn into position for speech, they vibrate, the vibration being caused by a current of air driven against them. This current of air is caused by movement of the lips, cheeks, palate, and tongue. The stronger the air current, the louder the voice. 
Pitch and Range of the Voice. - The piteh of the voice depends upon the length of the vocal cords and, hence, on the size of the larymx low this reason, a boy's voice changes from a high to a lower pitch during the period of rapid growth. The range of voice is about three octives. This means a difference in the vibration of the vocal cords from cighty-eight tince per second, in a low note, to nearly eight hundred, in the highest note. The range and actual pitch of the voice is controlled by the muscles of the larynx attached to the sides of the voice box. When the tension of the oord is increased by stretching them, a higher tone results from the tighter stretching of the cord.

Speech. - Articulation or speech is caused by the interruption, for a very short period of time, of the air current as it passes over the vocill cerrels or as air passes between the almost elosed lips. Vowels are really mu-imil tones produced in the larynx. Semivowels, especially the $n, m$, and $n !$ sounds, are produced by a tone which emanates from the voice box, but with the soft palate lowered. The air current is forced out, partly through the nose. The resonance of air in the nose cavity gives them a characteristic sound. Consonants are produced in part by the action of the tongue in connection with different positions of the lips while the air is forced out of the mouth. Practice before a mirror, and observe the shape assumed by the lips when you make the following sounds: $p, t, g, s, f, c h$. Record the movement in each case.

"Alcohol and Tobacco as affecting the Vocal Organs. - As the perfect control of the voice depends upon the healthy condition of all the muscles connected with the vocal apparatus, and upon the accurate adjustment of nervous force to their varying needs, anything which affects those muscles or the nerves affects also the voice. Alcohol and tobacco do affect both. The mucous membrane of the larynx is often much inflamed by tobacco smoking, and especially by the use of cigarettes. The inflammation may extend through the Eustachian tubes, impairing the hearing, and into the bronchial tubes, causing an annoying cough. A disease known as 'smoker's sore throat' may result. Alcoholic beverages irritate the throat and are often forbidden to those cultivating the voice for singing." - MACr, Physiology.

\section{Reference Books}

Some valuable suggestions for laboratory work in human physiology may be obtained from Eddy, Experimental Physiology and Anatomy, American Book Company, and Peabody, Laboratory Exercises in Anatomy and Physiolongy, Henry Hule and Company. Of the briefer texts the best are Lidly, T'crl-book of Physioling, 
American Book Company, Hall, Elementary Physiology, American Book Company, and Foster and Shores, Physiology for Beginners, The Macmillan Company. For the teacher, Foster, A Text-book of Physiology, The Macmillan Company, is invaluable. Verworn, General Physiology, The Macmillan Company, gives the broad basis to physiology teaching which is needed in a general course such as planned in the preceding pages.

The numerous Farmers' Bulletins of the U.S. Department of Agriculture treating of foods are readable and easy of comprehension. Much valuable reference reading on foods may thus be obtained free of charge. The following bulletins have proved of value to the writer for class work: Numbers $34,74,85,93,121$, and 128 . Other publications of the Department of Agriculture have been referred to in the preceding pages. 


\section{APPENDIX}

\section{LABORATORY EQUipMENT}

THE following articles comprise a simple equipment for a laboratory class of ten. The equipment for larger classes is proportionately less in price. The following articles may be obtained from any reliable dealer in laboratory supplies, such as the Bausch and Lomb Optical Company of Rochester, N.Y.

1 balance, Harvard trip style, with weights on carrier.

1 set gram weights, $1 \mathrm{mg}$. to $100 \mathrm{~g}$.

1 bell jar, about $365 \mathrm{~mm}$. high by $165 \mathrm{~mm}$. in diameter.

10 wide mouth (salt mouth) bottles, with corks to fit.

1025 c.c. dropping bottles for iodine, etc.

25250 c.c. glass-stoppered bottles for stock solutions. 100 test tubes, assorted sizes.

1 test tube rack.

5 test tube brushes.

2 graduated cylinders, one to 100 c.c., one to 500 c.c.

1 package filter paper $300 \mathrm{~mm}$. in diameter.

4 flasks, Erlenmeyer form, 800 c.c. capacity.

2 glass funnels, one 50 , one $150 \mathrm{~mm}$. in diameter.

10 Petri dishes, $100 \mathrm{~mm}$. in diameter, $10 \mathrm{~mm}$. in depth.

10 stender dishes $30 \mathrm{~mm}$. by $50 \mathrm{~mm}$.

10 pairs scissors.

10 pairs forceps.

20 needles in handles.

10 scalpels.

10 feet glass tubing, soft, sizes 2, 3, 4, 5, 6, assorted.

1 oblong aquarium jar, 10 liters capacity.

12 mason jars, pints.

12 mason jars, quarts. 
2 specimen jars, glass tops, of about 1 liter capacity.

1 alcohol lamp.

10 hand magnifers, vulcanite or tripod form.

2 compound demonstration microscopes or 1 more expensive compound microscope.

1 gross slides.

100 cover slips No 2.

1 razor, for cutting sections.

1 mortar and pestle.

300 insect pins, Klaeger, 3 sizes assorted.

10 bulb pipettes.

1 box rubber bands, assorted sizes.

10 feet rubber tubing to fit glass tubing, sizes 3,5 .

1 support stand with rings.

2 books test paper, red and blue.

1 chemical thermometer graduated to $100^{\circ} \mathrm{C}$.

15 agate ware or tin trays about $350 \mathrm{~mm}$. long by 100 wiae. 10 Syracuse watch glasses.

1 spool fine copper wire.

1 gal. 95 per cent alcohol. (Do not use denatured alcohol.)

1 liter formol.

$1 \mathrm{oz}$. iodine cryst.

$1 \mathrm{oz}$. iodide of potassium.

$6 \mathrm{oz}$. nitric acid.

$6 \mathrm{oz}$. ammonium hydrate.

$6 \mathrm{oz}$. benzole or xylol.

6 oz. chloroform.

$\frac{1}{2}$ lb. copper sulphate.

$\frac{1}{2}$ lb. sodium hydroxide.

$\frac{1}{2} \mathrm{lb}$. rochelle salts.

$6 \mathrm{oz}$. glycerine.

The materials for Pasteur's solution and Sach's nutrient solution can best be obtained from a druggist at the time needed and in very small and accurately measured quantities. 


\section{N D EX}

Illustrations are indicated by page numerals in bold-faced type.

Absorption, by root hairs, 86 ;

course of food after, 341 ;

in intestine, 342 ;

in stomach, 338;

into blood, 340 ;

organs of (villi), 341.

Accessory fruit, $\mathbf{5 1 .}$

"Accommodation" in human eye, 425.

Achene, 51, 54.

Acid, hydrochloric, 336 ; reaction in root hairs, 93 ; test for, (note) 93 .

Acorn, 54.

Adaptation to environment, 142.

Adaptations, for perching, 293;

for seed dispersal, 58 ;

in birds, 293, 296;

in moths and butterflies, 239;

in skull, 375;

in turtle, 286;

in vertebral column, 372 .

Agassiz, Louis, quoted, 12.

Aggressive resemblance, defined, 232; in mantis, 232.

Air, in germination, 79; in starch making, 131.

Albumen, test for, 22.

Alcohol, a poison, 327;

as a food, 326;

Atwater's experiments with, 326; cause of mental disorders, 413 ;

chemical formula of, 326 ;

effect on bodily heat, 398 ;

effect on circulation, 360 ;

effect on digestion, 343 ;

effect on the eye, 426;

effect on the heart, 361;

effect on the kidney, 393;

effect on muscle, 369 .
Alcohol, effect on the nervous system, 411;

effect on nerve cells, 413 ;

effect on the respiratory organs, 389 ;

effect on the rocal organs, 427 ;

oxidation of, 385 .

Alcohol poisoning, 413;

moral effect of, 417 .

Algæe, blue-green, 173 ;

brown, 174 ;

chlorophyll in, 173 ;

economic importance of, 173;

green, 174;

red, 173.

Alimentary canal, comparison of, in frog and man, 331;

in $\operatorname{man}, \mathbf{3 3 0}$.

Alligator, 290.

Alligators and crocodiles, 290.

Alternation of generations in forns, 155 ;

in mosses, 158.

Alveoli, function of, 381 .

Ambulacræ, 203.

Ambulacral grooves, 203.

Amœba, 182;

asexual reproduction in, 182, 183;

changes during division, 182;

locomotion in, 18:;

oxilation in, 182 ;

structure of, 182.

Amphibia, characteristics of, 280; classification of, 285 ;

examples of, 284.

Ampulla, 204.

Angiosperms, defined, 151.

Annual rings, 108.

Annulus, 153.

Anther, 31. 
Antheridium, in fern, 154, 155;

in liverworts, 159 ;

in moss, 158.

Ants, life history of, 253;

talking of, 254 .

Ants' nest, artificial, 252, (note) 253.

Aphids, 247;

life history of, 248 .

Aphids and ants, 249.

Appendages, in crayfish, 217;

in frog, 371,374 ;

in man, 372,374 .

Apple, study of, 51 .

Apple and blossoms, 51.

Archegonium, in fern, 154, 155;

in liverwort, 159;

in moss, 158.

Arteries, structure of, 353, 354.

Arthropoda, 227.

Ascent of sap, causes of, 113 .

Ascospores, 166.

Ascus (plu. asci), 166.

Asexual reproduction in coral, 201; in fern, 155 ;

in hydroids, 199;

in mold, 160;

in moss, 158;

in paramœcium, 181.

Astigmatism, 426.

Asymmetry, 223, 263.

Auricle, 352.

Automatic acts, 408 .

Bacteria, diseases caused by, 170; habitat of, 168;

in fermentation, 169;

method of study, 169;

relation to nitrogen, 94 ;

size and form, 169.

Bacteroids forming in root cells, 94 .

Bark, uses of, 109.

Barnacles, 225, 226.

Bast fibers, 109.

Bean, study of, 66 .

Bee, attractions offered by flower to,

38. See Bumblebee and Honeybee.

Beer making, 168.
Beetles, economic importance of, 245;

life history of, 245 ;

sexual dimorphism in, 246;

structure of, 244 ;

useful to man, 246.

Berry, 52, 53.

Bile, 339.

Biology defined, 11.

Birds, adaptations in, 293, 296;

bills of, 295, 296;

care of young, 298;

classification of, 302,306 ;

extermination of, 300 ;

feather of, 292, 293;

flight of, 292;

food of, 299;

harmful to man, 298;

high temperature in, 295;

migrations of, 301 ;

nervous system of, 297 ;

nesting habit of, 297;

nests of, 297, 298;

protection of, 292 ;

relationship between reptiles and

305 ;

skeleton of, 294, 295;

tail of, 293.

Birds of prey, 304 .

Bison, 315.

Biuret test, (note) 337.

Bladderwort, 139.

Blade of leaf, section through, 24.

Blastula, formation of, 192.

Blood, amount of, 348;

changes of, in body, 357 ;

clotting of, 345 ;

corpuscles in, $\mathbf{3 4 4}, \mathbf{3 4 5}, \mathbf{3 4 7}$;

course of, 356,357 ;

distribution of, 348 ;

function of, 344 ;

hæmoglobin in, 346;

Metchnikoff on, 346;

phagocytes in, 347 ;

plasma in, 344;

relation of food, air, and sleep to, 348 ;

temperature of, in cold-blooded animals, 348;

temperature of, in man, 348 . 
Blood cell, 189.

Blood serum, 345 .

Boa constrictor, skull of, 289.

Bodily heat, effect of alcohol on, 398; how produced, 348;

regulation of, 397 ;

relation to work, 396 .

Body, a machine, 317.

Bone, structure of, 375,376 ; fracture of, 379 ;

microscopic structure of, 377 ; substances present in, 376 .

Bone-making cell, 189.

Botany defined, 11.

Brain, action of parts of, 407 ;

effect of alcohol upon, 410;

of frog, 402;

of man, 404, 407 ;

necessity of food, rest, and fresh air to, 410;

necessity of sleep to, 410 .

Breathing, hygienic habits of, 388; mechanics of, 382 ;

rate of, in man, 383 ;

relation of exercise to, 389 ;

relation of tight clothing to, 388 .

Bruises, treatment of, 360 .

Bryophytes, 151, 156.

Buccal cavity, in frog, 331 ; in $\operatorname{man}, 332$;

openings from, 334 .

Bud, defined, 100;

effect of, on shape of tree, 102;

lateral, 102;

opening of, 101, 105;

protection of, 105;

structure of, 100, 101;

terminal, 102.

Budding, 116;

in yeast, 166.

Budding hydra, 195.

Bugs, characteristics of, 246 ; economic importance of, 247.

Bulb, 119.

Bumblebee, 37, 39, 249.

Burns, treatment of, 398 .

Calorimeter, Atwater's, 320. Calyptra, 157.

$$
\text { HUNTER'S BIOL. }-28
$$

Calyx, 31.

Cambium, 109.

Cap of mushroom, 162.

Capillaries, changes in bleod in, 355 passige of forel through walle of, 355,358 ; position of, 355 .

Capsule, 54 ;

of moss, 157.

Carbohydrates, 21, 318.

Carbon, 17.

Carbon dioxicle, in photosyntheis, 131; test for, 18 .

Carnivora, economic importance of, 314 ;

examples of, 312 ;

skuil of, 313.

Carp, anatomy of, 273.

Carpel, 31.

Cecropia moth, 237.

Cell, animal, 27;

as a unit, 183;

defined, 25;

example of plant (ye^st), 166;

parts of, 25, 26;

sizes and shapes of, 27.

Centiped, poisonous, 257.

Cephalopods, '267.

Cephalothorax, 215.

Cercariæ, 213.

Cerebrum, function of, 406;

position of, 405 .

Chelipeds, 215, 220 .

Chemical element, defined, 15.

Chemistry, defined, 15 .

Chestnut, 55 .

Chimney swift, nest of, 298.

Chlorophyll bodies in photosynthesis. 130.

Chloroplasts, 130 .

Chromosumes, 25.

Cicada, life history of, 247.

Cigarettes, poisons in, 357.

Cilia, on parameceium, 180

Circulation, effeet of alenhol on, 360; effect of exercise ons. 360).

in frog, 350,351 ;

in frog's foot, $353,354$. 
Circulation in man, portal, 357;

pulmonary, 356, 357;

systemic, $356,357$.

Clam, economic importance of, 264 ;

"long," 264;

"round," 264.

Classification of plants, 150.

Cleistogamous flower, 42.

Clitellum, 208, 211.

Club moss, 156.

Cluster cup, 165.

Cnidoblasts, 196.

Cocoon, 237.

Cœlenterates, alternation of generations in, 199;

classification of, 202;

division of labor in, 197;

meaning of, 195 ;

organs of offense in, 196.

Coleoptera, 244.

Colloids, 337.

Combustion defined, 16.

Communal life, of ants, 253;

of bee, 250 ;

of bumblebee, 249 .

Comparison, between earthworm and hydra, 210 ;

between skeleton of child and of adult, 377;

between skeleton of man and of frog, 371 ;

between starch making and milling, 131.

Composite head of flower, 48 .

Composition of water, 18.

Conjugation, defined, 161;

in mold, 161;

in paramœcium, 181;

in Spirogyra, 176.

Connective tissue cells, 189.

Coral, asexual reproduction in, 201; cup, 201;

economic importance of, 201;

formation of, 201;

madreporic, 201.

Coral reefs, 202.

Corky layer, use of (Exp.), 110.

Corn, production of, 62, 63.

Corolla, 31.
Corolla in cross-pollination, 39.

Corpuscles, colorless, 346, 347; red, 345, 346;

tractile, 395, 419.

Cotton, distribution of, 64 .

Cotton-boll weevil, 245.

Cotyledons, 66;

as foliage leaves, 70 ;

food in, 67.

Crab, asymmetry in hermit, 223;

edible blue, 222 ;

fiddler, 223;

hermit, 223;

metamorphosis of, 223 ;

spider, 224;

symbiosis between sea anemone

and, 224 .

Crane, sandbill, 305.

Crayfish, 215, 218;

activities of, 215 ;

circulation in, 218;

development of, 219 ;

digestion in, 219;

excretion in, 219;

habitat of, 215 ;

mouth parts of, 217;

nervous system of, 219 ;

protective coloration of, 215 .

Crinoid, 207.

Crustaceans, classes of, 225 ;

compared with insects, 227 ;

degenerate, 225, 226;

habitat of, 224 ;

parasitic, 225;

structures common to all, 226.

Cryptogams, 151.

Crystalloid, 337.

Cuts, treatment of, 360 .

Cyclops, 225.

Cyme, 47.

Cytoplasm, 26.

Damsel fly, 244.

Deer, Virginia, $\mathbf{3 1 5}$.

Degenerate crustaceans, 225, 226

Deliquescent trunk, 102.

Delirium tremens, 411.

Dendrites, 402.

Desert conditions, 143, 145, 147. 
Development, of earthworm, 211; of frog, 280; of mosquito, 242.

Diastase, action on starch (Exp.), 73.

Diastole, 353.

Diatoms, 177.

Dichogamy, 46.

Dicotyledons, defined, 75 ; fibrovascular bundle of, 109; parts of stem of, 105, 108.

Diet, mixed dietary the best, 321, 323.

Digestion, defined, 330;

in corn cotyledon, 75 ;

in stem, 112;

of starch, 334 ;

organs of, in man, 330 ;

purpose of, 330 .

Dimorphism in flowers, 46 ;

sexual, 235, 236, 246.

Diœcious flowers, 45.

Dipsomania, 411.

Diptera, 240.

Disk flowers, 49.

Dislocations, 379.

Division of labor, in Pandorina, 187; in the hive, 250;

in Volvox, 187.

Dragon fly, 243.

Drawing, 13.

Drink habit, 416.

Drupe, 53.

Eagle, golden, 304.

Ear, care of, 422 ;

in $\operatorname{man}, 421$;

inner, 421, 422;

middle, 421;

structure of, 421.

Earthworm, 208;

bilateral symmetry in, 208;

blood course of, 210;

body cavity, 210 ;

comparison between hydra and, 210 ;

Darwin on, 210;

development of, 211 ;

digestive tract, 209, 210;

feeding habits, 209.
Earthworm, locomotion, 209;

nephridia, 209, 210;

reactions of, 2(0)9;

regeneration in, 211;

respiration in, 211.

Eating, hygienic habits of. 342.

Economic importance, of hugs, 217 of flies, 242 ;

of mollusks, 268;

of toards, 2S3.

Economic value of fruits, 62 ;

of leaves, 141 ;

of lobsters, 222;

of trees, 117.

Ectoderm, 193.

Ectoplasm, 182.

Egg, segmentation of, 192.

Egg cell, in ferns, 154;

in flowers, 34 ;

in moss, 158 .

Elements, chemical, 15.

Elytra, 244.

Embryo, 67; arrangement of, 71.

Emulsion, effect of pancreatic fluid upon, 339;

how produced, 339 ;

milk an, 339.

Endoderm, 193.

Endoplasm, 182.

Energy, sun a souree of, 128.

Entomostraca, 225.

Enzyme, amolypsin, 339;

diastase, 73 ;

lipase, 339;

pepsin, 336;

ptyalin, 334;

rennin, 337;

trypsin, 339.

Epidermis, 129, 130;

human skin, 394, 395.

Epithelial cells, 189.

Equisetun, 156.

Eustachian tulxe, in frog. 279.

Exeretion, organs of, 391.

Excurrent trunk, 102.

Experiment, 1:.

Eye, of insects, 230 ;

blind spot, 426 . 
Eye, defects in, 425;

focusing, 425 ;

internal structure of, 423,424 ;

longitudinal section, 424;

section of retina, 423 .

Factors, determining form of plant, 146 ;

determining growth of seeds, 77 .

Fats, in bean, 67 .

Feather, development of, 293;

structure of, 293.

Fehling's solution, formula for, 21 .

Fermentation, a chemical process, 167 ;

bacteria in, 169 ;

by yeast, 166 .

Ferments, digestive. See Enzyme.

Fern, economic importance of, 156 ; life history of, 154 ;

parts of, 152 .

Fertilization, defined, 34;

in fern, 154;

in moss, 158 ;

of flowers, 33,34 .

Fibrin, 345.

Fibrinogen, 345.

Fibrovascular bundle, defined, 88; in dicotyledonous stem, 109; in monocotyledonous stem, 106, 107.

Fiddler crab, 223.

Filament, $\mathbf{3 1}$.

Fisheries map, 276.

Fishes, appendages of, 271;

body of, 271;

bony, 278;

breathing in, 272 ;

circulation in, 274 ;

classification of, 277 ;

digestive system in, 273;

economic value of, 275 ;

egg-laying habits of, 275 ;

elasmobranch, 277;

ganoid, 277;

gills in, 272 ;

gill rakers in, 273 ;

lateral line in, 274 ;

lung, 278.
Fishes, nervous system of, 274;

senses of, 271;

skeleton of, 274 ;

swim bladder in, 273;

teeth in, 272.

Fission, defined, 169;

in paramœcium, 181;

of a cell, 26.

Flagellates, 185.

Flower, fertilization of, 33,35 ;

imperfect, 45 ;

irregular (sweet pea), 36 ;

parts of, 31 ;

relation to fruit, 66 .

Flower envelope, 31.

Flower scar, 104.

Follicle, 53.

Food, adulterations in, 323;

carbohydrates, 318 ;

defined, 20 ;

economy, 323;

hydrocarbons, 318 ;

inorganic, 319;

need of, 317 ;

of birds, 299;

proteid, 317;

storage in roots, 95 ;

value of mushrooms, 163;

value of nutritive, 322 ;

waste, 325 .

Forestry, 116.

Fowls, 303.

Frog, appendages of, 279;

development of, 280 ;

eggs of, 281;

eye of, 279 ;

habitat of green, 279 ;

life history of, 280 ;

protective resemblance in, 279 ;

skin of, 279 ;

stages of tadpole life, 282.

Frond, 153.

Fruit, defined, 50;

dehiscent, 53;

distinct from seed, 55;

use of, 66 .

Fruits, dry, 53;

economic value of, 62 ;

explosive, 60. 
Fruits, fleshy, 51; indehiscent, 54 .

Functions, common to all animals 189 ;

of cotyledons, 69,70 ;

of endosperm in corn (Exp.), 73;

of parts of a plant, 24.

Fungi, economic importance of, 159; parasitic, 164;

poison, 163 ;

sac, 166 ;

shelf, 163.

Funiculus in pea pod, 50 .

Gall bladder, 330, 339.

Gamete, defined, 155.

Gametophyte, defined, 155;

of fern, 155;

of moss, 158 .

Gases in living things, 19.

Gastrie glands, 336 .

Gastric juice, acid in, 337 ; action of, 336, 337 .

Gastric mill of crayfish, 219.

Gastropods, 265.

Gastrula, formation of, 192.

Gemmæ, 159.

Germinating seeds, expansive force of, 78.

Germination, 69.

Giant spider crab of Japan, 224.

Girdle, pectoral, 295, 374; pelvic, 295, 371, 372, 374 .

Glands, defined, 331; digestive, 334 , 336, 338, 339, 341 ; gastric, 336 ;

intestinal, 341 ; mesenteric, 342;

nectar, 38;

peptic, 336;

salivary, 334 ;

sebaceous, 395;

structure of, $\mathbf{3 3 1}$;

sweat, 395, 396.

Glucose. See Grape sugar.

Glycogen, use of, 340 ;

where formed, 340 .

Grafting, 116.

Grain, 55.
Grape sugar, test fır, 21.

Grasshripper, blood making in, 229, economic importance of, 230;

eyes of, 230;

food t:king in, 229;

life history of, 230 ;

mouth parts of, 229;

muscular activity of, 229;

nervous system of, 230;

relatives of, 230

Guard cells, 129, 130, 136.

Gymnosperms, 151 .

Habit, drink, 416;

formation of, 40s;

importance of forming good, 409

Hair, follicle, 395 ;

growth of, 395 .

Hairs, as protection for leaves, $13 \mathrm{~S}$

Halophytes, 145.

Hare, wood, 308 .

Hay infusion, animals in, 179;

plants in, 179 ;

preparation of, 179 .

Head, regions of, 407

Heart, in action, 353 ;

internal structure of, $\mathbf{3 5 2}$;

nervous control of, 359 ;

position of, 351 ;

protection of, 351 ;

size of, 351 ;

work of, 353,365 .

Heart muscle, 364 .

Heart wood, 114.

Hemiptera, 246.

Hermit erab, 223.

Hibernation, of animals, (note) 397; of butterflies, 235

Hilum, 66 .

Homology, of parts of flower, 56 .

Honeybee, 250, 251;

food of, 252

Hooks, in seed dispersal, 59.

Horse, geologic history of, 315 ;

Osborn on, 316

Horsetail form, 156

House fly, a pest, 241 :

economic importance of, 242;

home experiments with, 241 . 
House fly, life history of, 241.

Humus, 92.

Hydra, development of, 198;

food taking in, 197;

reproduction in, 195, 197;

structure of, 196, 197.

Hydrocarbons, 318; tests for, 21.

Hydroid colony, 199.

Hydrophytes, 144.

Hymenoptera, 248.

Hypha, 160, 162.

Hypocotyl, arched, 68.

Ichneumons, 254.

Indian corn, 62.

Inflorescence, 47 .

Inorganic matter, action of root hairs on, 93 ;

in living things, 19;

needed for plant growth, 94 ;

relation to organic, 28.

Insectivorous plants, 139, 140.

Instruments, 14, 429.

Intestine, absorption in, 341, 342;

structure of, 340, 342;

glands of, 341 .

Involucre, 48.

Joints, as levers, 378 ;

ball and socket, 378 ;

dislocation of, 379 ;

gliding, 378;

hinge, 378;

movement by means of, 378 ;

pivot, 378.

Keel, 36.

Key fruit, $\mathbf{5 5}$.

Kidney, circulation in, 392;

effect of alcohol on, 393 ;

section of, 392;

sheep's, 391;

wastes given off in, 393 .

Knots, 104, 115.

Laboratory essentials, 13, 429 .

Lacteal system, 359.

Lacteals, 342, 359.
Laminated layer of shell, 260.

Leaf, compound, 124;

cross section of, 130 ;

dicotyledonous, 124 ;

functions of, 132;

monocotyledonous, 124;

heliotropism in, 125;

modifications of, 124, 137, 138;

photosynthesis in, 133;

respiration in, 137;

structure of, 132;

transpiration in, 134;

venation of, 125 .

Leaf scar or trace, 103.

Leaflike stems, 121.

Leaves, arrangement of, 126;

as food, 141;

effect of light on, 125.

Leech, 212.

Legume, 50, 53.

Lenticels, 104.

Lepidoptera, 232.

Lichens, 172; symbiosis in, 173.

Lingual ribbon, 266.

Liver, 330, 339.

Liver fluke, 213.

Liverworts, 159.

Lizards, examples of, 287, 288.

Lobster, development of, 220; economic importance of, 222; molting of, 221;

North American, 216, 220.

Locules, 33.

Lungs, changes in air in, 384; changes of blood in, 385;

human, 381;

loss from, 384;

of frog, 380.

Lymph, composition of, 358;

function of, 358 ; glands of, 359.

Lymph vessels, 358.

Macronucleus, 181.

Madreporic plate, 204.

Malaria, cause of, 185 .

Malacostraca, 225.

Mammals, adaptations in, 312 . 
Mammals, carnivorous, 312; characteristics of, 310 ;

examples of, 311 ;

hoofed, 314;

orders of, 311.

Man, a mammal, 316.

Man's place in nature, 316 .

Mantle, section of, 260.

Manubrium, 198.

Marsupials, 311.

Matter, defined, 11; forms of, 15. See Inorganic and Organic.

May fly, 244.

Medullary rays, 108, 114.

Medusa, development of, 199; structure of, 198.

Mesenteries, 201.

Mesoderm, 193.

Mesoglea, 193.

Mesophytes, 145, 146.

Metamorphosis, defined, 227; in butterfly, 233;

in crab, 223;

in frog, 280 ;

in moth, 236, 237;

in toad, 283.

Micronucleus, 181.

Micropyle, 66; in ovule, 34 .

Mildews, 166.

Milk teeth, dental formula, 333 .

Milkweed fruit, $\mathbf{7 7}$.

Mimicry, 235.

Mold, growth of, 160 .

Mollusca, characteristics of, 259 .

Mollusks, 259;

boring and harmful, 266, 269;

classification of, 26 :

cross section of, 260 ;

economic importance of, 268 ;

habitat of, 268.

Monarch butterfly, life history of,

233 ; senses of, 233.

Monocotyledons, 75, 107.

Morphology, defined, 12.

Mosquito, development of, 242; relation of, to disease, 243 .
Moss, economic value of, 159;

life history of, 157 ; parts of, 157 .

Moth, adaptations in, 239;

cecropia, 237;

life history of, 236, 237;

harmful larvie of, 238.

Moths and butterflies, ('omparmer, 23?

Motor nerves, in striated muscle fiber, 363.

Muscle eells, 189.

Muscles, and movement, 362;

blood supply to, 36.4 ;

contraction rate of, 364 ;

effect of tobareco on, 370;

extensor, 362 ;

flexor, 362 ;

in leg of frog, 362 ;

necessity of food and fresh air for. 366 ;

relation of alcohol to, 367 ;

rest and exercise of, 367 ;

strueture of involuntary, 364;

structure of voluntary, 363;

uses of, in standing, 365 ;

uses of, in walking, 365;

work done by, 36.5 .

Mushroom, parts of, 162

Mushrooms, food value of, 163;

poisonous, 163 .

Mussel, 261;

circulation of blood in, 262;

circulation of water over gills of, 261 ;

early development of, 263;

food getting in, 262;

locomotion in, 262;

nervous system of, 263;

shell of, 259, 260;

strueture of, 261.

Mycelium, 162.

Myriapods, 258.

Narcotics, 329, 417. Fee Alcohol and

Tobaceo.

Nectar, defined, 38.

Neetar glands, 39.

Nectar guides, 39.

Nectaries, 39. 
Nephridia, 209, 210.

Nerve cell, 189.

Nerve fiber, 402.

Nerve unit, 403.

Nerves, cranial, 405;

motor, 402, 405;

sensory, 402, 405;

vasomotor, 359.

Nervous system, central functions of, in frog, 403;

cerebro-spinal in frog, 402;

cerebro-spinal in man, 401;

divisions of, 400 ;

general functions of, 400 ; sympathetic, 406.

Neuroptera, 243.

Nicotine, a deadly poison, 329 .

Nictitating membrane, 279.

Nitrogen, 18;

amount of, in air (Exp.), 19;

needed for plant growth, 94 .

Nitrogen-fixing bacteria, 94 .

Nomenclature, botanical, 150.

Notebook, use of, 13.

Nucleolus, 26.

Nucleus, 25;

in ovule, 33,34 ;

in Spirogyra, 175;

in yeast, 166.

Nut, 54.

Nutrients, cost of, 324;

defined, 20 ;

fuel value of, 320 ;

uses of, 319 .

Octopus, 268.

One-celled plants and animals, 183.

Opossum, Virginia, 311.

Organ, defined, 24.

Organic matter, classified, 19;

relation to inorganic, 28 .

Organism, defined, 24.

Osmometer, potato, 90.

Osmosis, defined, 89;

importance of, 90;

in root hair, 89.

Osmotic pressure, 90.

Ostrich, African, 302.

Ovary, 31,33 ; parts of, 32 .
Ovule, development of, 34;

fertilization of, 33 .

Oxidation, defined, 16;

heat the result of, 17;

in a match, 16;

in amœba, 182;

in human body, 80;

slow (Exp.), 17.

Oxygen, given off by green leaves,

132 ;

preparation of, 16;

properties of, 16.

Oyster drill, shell bored by, 266.

Oysters, artificial breeding of, 263;

asymmetry in shell of, 263 ;

economic importance of, 264;

typhoid bacillus in raw, 264.

Palisade layer, 130.

Palmate venation, 123.

Pancreas, 330, 339.

Papilionaceous corolla, 36.

Pappus, 59.

Paramœcium, locomotion in, 180;

reproduction in, 181;

response to stimuli, 180;

study of, 179.

Parapodia, 211.

Pasteur's solution, formula for, 167.

Pearls and pearl formation, 269.

Pectoral girdle, in birds, 295;

in frogs, 374;

in man, 374 .

Pelvic girdle, in birds, 295;

in frogs, 371, 374;

in man, $372,374$.

Perching, adaptations for, 293.

Pericardium, use of, 352.

Pericarp, defined, 50.

Perithecium, 165.

Pepo, 52.

Peptone, defined, 337.

Petiole, 125.

Petal, 31, 38.

Phanerogams, 151.

Phœbe, nest of, 297.

Photosynthesis, chemical action in. 133; compared with milling, 131 . 
Photosynthesis, illustrated, 131;

oxygen and water the waste products of, 132, 134;

rapidity of, 134 .

Physics, defined, 15.

Physiology, defined, 12; importance of osmosis in, 90.

Pine seedlings, 76.

Pinna, 153.

Pistil, 31.

Pistillate flower of corn, $\mathbf{7 1 .}$

Pitcher plant, 140.

Placenta, in ovary, 33; in pea pod, 50 .

Plant, a living, 23.

Plant societies, 146.

Plasma, composition of, 344 ; function of, 344.

Pleura, 382.

Pleurococcus, 177; formation of zoöspores, 177.

Plumule, 67.

Pocket garden, $\mathbf{8 2}$.

Pod, study of, 50 .

Polar limit of trees, 147.

Pollen, 31, 32; amount of, 43 ; protection of, 46 .

Pollen grain, 32; germination of, 32 .

Pollen tube, 32.

Pollination by bird, 40 ;

by insect, $36,39,42,43$;

by water, 45 ;

by wind, 43 ;

Darwin on, 35;

defined, 35;

self, 42 .

Polycotyledons, defined, 75; embryo of, 75 .

Polymorphism, 235.

Pome, 52.

Pork worm, 214.

Primates, 316.

Prismatic layer of shell, 259, 260.

Proboscis, 232.

Proglottids, 213.

Protective resemblance, in dead-leaf butterfly, 239.
Protective resemblaner, defined, 231 ; in katydid, 231 ;

in luna moth, 240;

in underwing moth, 240;

in walking stick, 231

Proteid formation in plant, 133.

Proteids, in seeds, 67; tests for, 22.

Prothallus, 154 ; growth of, 154.

Protonema, 157.

Protoplasm, chemical composition of 28 ;

defined, 26;

properties of, 29 ;

structure of, 27.

Protozoa, and Metazoa, 188;

habitat of, 184;

relation of, to discase, 185;

skeleton building of, 184;

use of, as food, 184.

Pulse, cause of, 354 .

Pupa, formation of, 234.

Ptarmigan, 303, 304.

Pteridophytes, 152.

Pyloric cæca, 273.

Rabbit, adaptations in, 308;

circulation in, 310 ;

nervous system of, 310 ;

organs of digestion in, 310 ;

skeleton of, 309;

teeth in, 308, 309.

Raceme, 47.

Radial canal, 198.

Radial symmetry, 203.

Radiolarian, skeleton of, 183.

Rat, 310.

Rattlesnake, 288.

Ray flower, 48.

Red Algæ, 173.

Redia, 213.

Reduced leaves, 138.

Reflex actions, 407, 409

Regeneration in carthworm, 211

Reproduction, asexual, 152; zygosporic, 161 ; sexual, 151

Reptilia, claracteristics of, 287. 
Reptilia, classification of, 291 .

Respiration, artificial, 389;

in leaves. 137 ;

necessity for, 380 ;

organs of, in frog, $\mathbf{3 8 0}$;

organs of, in man, 381;

tissue, 385 ;

under nervous control, 38

Resurrection fern, 148.

Retina, 423.

Rhizome, 153.

Rib and vertebra, 373.

Rodents, 311; oeaver, 313;

rabbit, 311 ;

skull of, 309 .

Root, adventitious, 96;

air, 97;

downward pressure in (Exp.), 85; effect of moisture on (Exp.), 83; fine structure of, 87 ;

geotropism in, 83, 85;

growing point in, 85;

osmosis in, 89;

parasitic, 97 ;

passage of soil water within, 89 ;

water, 96 ;

cap, 86 ;

pressure, 113;

hairs, 86, 88, 93

system, 82 .

Rootstock, 118;

in ferns, 153.

Rusts, 164, 165.

Sac, embryo, 34.

Salamander, spotted, 284.

Salt, importance of, 319 .

Samara, 55.

Sand dollar, 207.

Sap, ascent of, 113.

Saprophyte, defined, 159.

Saprophytic fungi. See Mold and Mushroom.

Scallop, 265.

Science and Matter, 11.

Scutes, 289.

Sea anemone, 200.

Sea cucumber, 207.
Sea lily, 207.

Sea lion, 314.

Sea urchin, 206, 207.

Seed dispersal, 57.

Seeds, winged, 60.

Selective planting, 81.

Self-control versus appetite, 418.

Self-pollination, 42 ; prevention of, 45 .

Semicircular canals, functions of, in birds, 293.

Senses, hearing, 421;

sight, 423, 425 ;

smell, 420;

taste, 419 ;

temperature, 419 ;

touch, 419.

Sensitive leaves, 128.

Sepal, 31.

Seta, 209.

Sexual reproduction, in amœba, 183;

in fern, 154;

in mold, 161;

in moss, 158;

in paramœcium, 181.

Ship worm, timber bored by, 269 .

Shrimp, 221, 222.

Silkworms, American, 237.

Silicle, 54 .

Silique, 54 .

Skeleton, growth of, 376 ;

hygiene of, 377 ;

in adult and child, 377 ;

in frog and man, 371;

of $\operatorname{dog}, 309$;

structure of, 371 ;

uses of, 371.

Skin, an organ of excretion, 391, 396; an organ of sensation, 395, 419; glands in, 395 ;

importance of cleanliness, 398;

importance of proper clothing, 398 ;

layers in, 394, 395;

structure of, 395.

Skull, bones in man, 375 ;

in man and frog, 374;

of $\operatorname{dog}, 313$.

Sleep movements, 127.

Snakes, adaptation in, 289. 
Snakes, feeding habits of, 289; locomotion in, 289; poisonous, 290.

Snails, activities of, 265;

breathing in, 267;

developinent of, 267 ;

European, 266;

feeding habits of, 266 ;

forest, 266 ;

lingual ribbon, 266;

senses of, 267 ;

variability in shell of, 265, 266 .

Soils, composition of, 91 ;

favorable to evaporation, 91 ;

organic matter in, 92;

water in (Exp.), 91;

weathering of, 92 .

Sorus, 153.

Sound, character of, 422 .

Sparrow, English, 301; white-throated, 303.

Speech, formation of sounds, 427 .

Spermatophytes, defined, 151.

Sperm cell, in flower, 32;

of fern, 155 ;

of hydra, 197;

of moss, 158;

rôle in fertilization of egg, 33 .

Spider, care of eggs and young, 258; structure of, 256.

Spider crab, 224.

Spider's web, forms of, 256,257 ; use of, 256.

Spike, 48.

Spines, in seed dispersal, 58 .

Spiracle, 229.

Spirogyra, formation of zygospore, 176 ; structure of, 175.

Sponge, glassy, 193;

development of, 192;

horny fiber, 193;

limy, 191;

relation to environment, 193 ;

simple, 191.

Sponges, classification of, 193.

Sporangium, in fern, 153;

in mold, 160;

in moss, 157.
Spore, defined, 152;

in fern, 153.

in mold, 152, 180;

in moss, 157 .

Spore formation in yeast, 167.

Spore print, 162

Sporidia, 165

Sporophyte, of fern, 155; of moss, 157

Sprains, 379 .

Squid, 267.

Stamen, 31, 38; diadelphous, 36 .

Staminate flower, of corn, $\mathbf{7 1}$; of squash, 45 .

Standard, 36 .

Stareh, non-osmosis of, 112 .

Starch grains, 67

Starch test, 21

Starfish, development of, 206 ;

food of, 205 ;

method of loconotion, 204;

nervous system, 204 ;

organs of breathing, 205;

regeneration in, 206;

skeleton of, 203

Stem, compared with rout, 98; dicotyledonous, 105, 108;

digestion in, 112;

effect of gravity on, 85;

effect of light on, 98;

forn of food in, 112;

heliotropism of 99 ;

monocotyledonous, 106, 105;

passage of fluid in, 110, 111;

position of buds on, 102.

Stigma, 31, 33, 38;

of wind-pollinated flower, 44

Stimulant, alefined, 325.

Stimuli, response to, in paranerium. 180.

Stipe, 162

Stipule, 123, 124

Stoma, 129, 136: in trancpiration, 136

Stomach, glands of, 336 ;

movement of walls of, 337;

of frog, 336 ;

of man, 336

Storage in steus, 118 
Striated muscle, 363, 364.

Strophiole, 66.

Struggle for existence, 61.

Style, 31, 33.

Suffocation, 389.

Sugar, osmosis of, 112.

Sundew, 140.

Swarming, 252.

Sweat glands, structure of, 395,396 ; use of, 396 ; under nervous control, 397.

Sweeping and dusting, 387.

Symbiosis, in lichens, 173; between crab and sea anemone, 224.

Symmetry, in flower, 41.

Sympathetic system, 337.

Systematic botany, 150 .

Systole, 353.

Tactile corpuscle or organ, 395, 419.

Taste buds, 420 .

Teeth, dental formula, 333;

in frog, 331;

in man, 332;

internal structure of, 333.

Teleutospore, 165.

Temperature, in germination, 80 .

Tendrils, 120.

Tern, common, 306.

Testa, 66.

Tetanus, 171.

Thallophytes, 151, 159.

Thallus, 142.

Tissue, defined, 25; cells, 189.

Tissues and organs, 188.

Toad, economic value of, 283; field work on, 283;

horned, 288; tadpoles, 283.

Tobacco, effect of, on circulation, 361 ;

effect on muscles, 370 ;

relation to respiration, 386,389 ;

use of, 329 .

Tortoise, box, 287.

Tracheæ, 229; structure of, 381.
Transpiration, efrect of, within stem (Exp.), 137; experiment showing, 134; regulation of, 136 ; water lost by (Exp.), 135.

Trichina, 213, 214.

Trimorphic flower, 46.

Tube feet, 203.

Tuber, 118, 119

Tubercles, in infected lungs, 171; on roots of a legume, $\mathbf{9 5}$.

Tuberculosis, 171.

Tumble weed, 60 .

Turtle, mud, 286; painted, 286; spotted, 286.

Turtles, adaptations in, 286.

Tussock moth, 238.

Tympanic membrane in frog, 279.

Typhoid, 160, 170.

Ungulates, even-toed, 315;

hoofed, 314;

odd-toed, 315 .

Univalve, 265.

Umbel, 48.

Upper limbs, in frog, 371, 374; in $\operatorname{man}, 372,374$.

Urea, 393.

Uredospore, 165.

Urine, 393.

Uriniferous tubules, 392.

Urino-genital system of frog, 391.

Vacuole, contractile, 180, 181, 182.

Vacuole, food, 180.

Valves, in human heart, 352; in human veins, 356 .

Vegetation, in temperate zones, 149; of cold regions, 147 ; of tropics, 148.

Veins, valves in, $\mathbf{3 5 6}$; function of, 355 ; structure of, 355 .

Venation, palmate, 123; parallel, 124; pinnate, 125.

Ventilation, in sleeping rooms, 388 ; need of, 387 ; proper, 387. 
Ventricle, 352.

Venus's flower basket, 193.

Venus's flytrap, 139.

Vermiform appendix, 342.

Vernation, 105.

Vertebra, structure of, in man, 372 373.

Vertebral column, adaptations in, 372 .

Villus (plu. villi), function of, 341 ; structure of, 341.

Vocal cords, 426.

Voice, how produced, 426; pitch and range of, 427 .

Volvox, colony of, 187.

Waders, 304.

Walking, 365.

Walking stick, 231.

Warning coloration, 234.

Wasp, digger, 249; solitary, 249, 250.

Wasp nest, 251.

Wastes, in human body, 393.

Water, amount lost through kidney, 393 ;

amount lost through lungs, 384 ;

effect on dry seeds, 78;

impure, 325;

in germination, 78;

in living things, 19.
Water supply, effect of, on plants, 143.

Wax, in the (ar, 42.2 .

Wheat, production of, 63.

Winding stair, use of, 257.

Wings, 36.

Wood, ceonomic value of, 117 ; method of cutting, 115;

structure of, 114.

Work, daily, of heart, 353;

effect of alcohol on inuscular, 367 ;

muscular, :365.

Worms, classification of, 214;

flat, 212;

sand, 211;

round, 214;

segmented, 211;

tape, 213;

unsegmented, 212.

Xerophytes, 144.

Yeast, spore formation in, 167 ;

growth of, 166 ;

economic value of, 166

Zoölogy, defined, 11.

Zoöspores, formation of, 177.

Zygospore, in Spirogyra, 176;

in mold, 161. 


\section{H E M I S T R I E S}

By F. W. CLARKE, Chief Chemist of the United States Geological Survey, and L. M. DENNIS, Professor of Inorganic and Analytical Chemistry, Cornell University

Elementary Chemistry . \$I.IO

Laboratory Manual . . \$०.50

7 HESE two books are designed to form a course in

1 chemistry which is sufficient for the needs of secondary schools. The TEXT-BOOK is divided into two parts, devoted respectively to inorganic and organic chemistry. Diagrams and figures are scattered at intervals throughout the text in illustration and explanation of some particular experiment or principle. The appendix contains tables of metric measures with English equivalents.

9 Theory and practice, thought and application, are logically kept together, and each generalization is made to follow the evidence upon which it rests. The application of the science to human affairs, its utility in modern life, is also given its proper place. A reasonable number of experiments are included for the use of teachers by whom an organized laboratory is unobtainable. Nearly all of these experiments are of the simplest character, and can be performed with home-made apparatus.

- The LABORATORY MANUAL contains 127 experiments, among which are a few of a quantitative character. Full consideration has been given to the entrance requirements of the various colleges. The left hand pages contain the experiments, while the right hand pages are left blank, to include the notes taken by the student in his work. In order to aid and stimulate the development of the pupil's powers of observation, questions have been introduced under each experiment. The directions for making and handling the apparatus, and for performing the experiments, are simple and clear, and are illustrated by diagrams accurately drawn to scale.

\section{A M E R I CA N BOOK COMPANY}




\section{HOADLEY'S NEW PHYSICS}

By GEORGE A. HOADLEY, C. E., Se. D., Pretewer of Physics, Swarthmore College.

Elements of Phrsics (Text-bouk)

Laboratory Handbook .

7 HIS text-book is straightforward and concise. It teth

1 only what everyone should know, and it covers all coi. lege entrance requirements in phrsics. The fundamental principles are presented in a logical order. 'The topics have been selected with the greatest carc. The treatment is clear and simple, practical and interesting. The intimate relation between everyday life and applied physics is made plainly evident.

- The problems also are practical; they deal with real events in both time and place, based upon things that have happened, rather than upon imaginary cases. Importane physical laws are verified by well-arranged demonstrations.

9 The numerical answers to the problems given at the close of the book make it easy for the student to verify the accurac! of his solutions. Many of the illustrations are entirely rew to works on physics or are from the photographs of real ap plications.

- The book meets the requirements of the New Yorh and other State Education Departments, and the recommendations of the National Education Association, those of the Cullege Entrance Examination Board, and those of a number of Associations of Teachers of Physics.

- The Laboratory Handbook contains sixt!-two experiments, selected with care, and eminently practical. The directions are simple and clear, the apparatus required no: elaborate. Throughout, the student is trained to profit from his observations, to exercise his ingenuity, and to depend upun himself.

\section{A MERICAN BOOK COMPAN}




\section{E D D Y'S PHYS I O L G Y C O U R E}

By WALTER H. EDDY, Chairman of Department of Biology, High School of Commerce, New York City.

Text-Book of General Physiology . . . . . . . \$1.20

Experimental Physiology and Anatomy . . . . . . . . . . .

HIS course, consisting of text-book and experimental 1 work, places the study of physiology where it properly belongs - in the laboratory. It is therefore suited for use in the most modern schools and by the most progressive teachers. Although intended especially to supply all the material required by the New York State syllabus, its topical arrangement and division of subject matter adapt it equally to schools in other localities.

- The laboratory manual contains simple practical exercises which afford information of much value supplementing the pupil's daily experience. The directions for performing the work are ample and easily grasped.

- The text supplements the laboratory exercises, and enables the pupil to complete and round out the information he has gained by experiment. At the same time it aids the teacher in directing the experimental inductions and gives unity to the work.

- Both text and manual treat physiology as a study of function in living forms and as a part of the training in biologic science and not as an isolated subject. The physiological processes are presented as activities common to all living matter, and much space is given to the comparative study of function in the animal forms other than man. The teaching of recent biological progress is recognized in the prominence given to the cell and protoplasm as the structural and physiological units.

\section{A M ERICAN BOOK COMPANY}






